DOC.20040915.0011

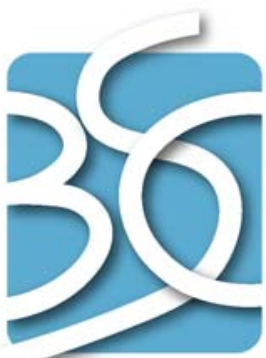

BECHTEL SAIC COMPANYLC

QA: QA

MDL-NBS-GS-000004 REV 01

September 2004

NOTICE OF OPEN CHANGED DOCUMENTS - THIS DOCUMENT IS IMPACTED BY THE LISTED CHANGE DOCUMENTS AND CANNOT BE USED WITHOUT THEM.

1) ACN-001, DATED 02/14/2005

\title{
Rock Properties Model
}

Prepared for:

U.S. Department of Energy

Office of Civilian Radioactive Waste Management

Office of Repository Development

1551 Hillshire Drive

Las Vegas, Nevada 89134-6321

Prepared by:

Bechtel SAIC Company, LLC

1180 Town Center Drive

Las Vegas, Nevada 89144

Under Contract Number

DE-AC28-01RW12101 


\section{DISCLAIMER}

This report was prepared as an account of work sponsored by an agency of the United States Government. Neither the United States Government nor any agency thereof, nor any of their employees, nor any of their contractors, subcontractors or their employees, makes any warranty, express or implied, or assumes any legal liability or responsibility for the accuracy, completeness, or any third party's use or the results of such use of any information, apparatus, product, or process disclosed, or represents that its use would not infringe privately owned rights. Reference herein to any specific commercial product, process, or service by trade name, trademark, manufacturer, or otherwise, does not necessarily constitute or imply its endorsement, recommendation, or favoring by the United States Government or any agency thereof or its contractors or subcontractors. The views and opinions of authors expressed herein do not necessarily state or reflect those of the United States Government or any agency thereof. 
Rock Properties Model

MDL-NBS-GS-000004 REV 01

September 2004 


\section{OCRWM}

\section{Model Signature Page/Change History}

Page iii

1. Total Pages: 296

2. Type of Mathematical Model

$\bigotimes$ Process Model

Abstraction Model

System Model

Describe Intended Use of Model

The intended use of the Rock Properties Model is to provide a three-dimensional (3-D) representation of selected rock properties.

The rock property representations that are developed are porosity, bulk density, hydraulic conductivity, and thermal conductivity.

3. Title

Rock Properties Model (RPM3.1)

4. DI (including Rev. No., if applicable):

MDL-NBS-GS-000004 REV 01

\begin{tabular}{|l|l|}
\hline 5. Total Appendices & $\begin{array}{l}\text { 6. No. of Pages in Each Appendix } \\
9\end{array}$ \\
A-10, B-18, C-6, D-6, E-40, F-20, G-20, H-4, I-16
\end{tabular}

\begin{tabular}{|c|c|c|c|}
\hline & Printed Name & Signature & Date \\
\hline 7. Originator & Clinton Lum & & 9. \\
\hline $\begin{array}{l}\text { 8. Independent Technical } \\
\text { Reviewer }\end{array}$ & Robert W. Andrews & & \\
\hline 9. Checker & Alexander Sanchez & & \\
\hline 10. QER & Judy Gebhart & & \\
\hline 11. Responsible Manager/Lead & Clinton Lum & & 9.1 \\
\hline 12. Responsible Manager & Ming Zhu & & \\
\hline
\end{tabular}

13. Remarks

Change History

\begin{tabular}{|c|c|}
\hline \multicolumn{2}{|r|}{ Change History } \\
\hline 14. Revision No. & 15. Description of Change \\
\hline 00 & Initial issue. \\
\hline $00 / 01$ & $\begin{array}{l}\text { ICN } 01 \text { incorporates DOE comments and editorial changes. Changes are designated by a } \\
\text { change bar in the right margin. }\end{array}$ \\
\hline $00 / 02$ & $\begin{array}{l}\text { The Rock Properties Model Analysis Model Report is being updated to record data } \\
\text { qualification and verification activities. } \\
\text { References deleted: } \\
\qquad \begin{array}{l}\text { AP-3.10Q, Rev 1, ICN 0; } \\
\text { QAP-2-0, Rev } 4 \\
\text { SNL QAIP 20-2 Rev 01 } \\
\text { AP-SI.1Q Rev. 1, ICN 0 }\end{array}\end{array}$ \\
\hline
\end{tabular}




\begin{tabular}{|c|c|}
\hline $00 / 03$ & $\begin{array}{l}\text { The purpose of this ICN is to record changes in data input status due to data qualification and } \\
\text { verification activities. The DTN MO9911INPUTRPM.000 was replaced by the qualified } \\
\text { DTN: MO0109HYMXPROP.001. This action resolves TBV-3732. } \\
\text { DTN: MO9910POROCALC.000 was replaced with the qualified DTNs } \\
\text { MO0010CPORGLOG.002 and MO0010CPORGLOG.003. This action resolves TBV-3681. } \\
\text { In Table 9, p. } 32 \text { the reference to the technical product output for GFM } 3.0 \text { was a typographical } \\
\text { error which has been corrected to DTN: MO9804MWDGFM03.001. Use of DTN: } \\
\text { LA9910DB831321.001 has been changed to corroborative. As described in Section 4.1.4, the } \\
\text { primary data used to represent zeolite abundances are obtained from the "soft" indicators of } \\
\text { mineralogic alteration. This action resolves TBV-3682. The changes made as a result of the } \\
\text { qualification process did not affect the technical product output of this document (Rev } 00 \text { ICN } \\
\text { 03). } \\
\text { Section 8.4 and Attachments ll, lll, IV, and V of this technical product contains the } \\
\text { documentation of single use software routines or macros that were qualified under procedure } \\
\text { AP-SI.1Q, Software Management, prior to release of Revision } 3 \text { of said procedure. As the } \\
\text { scope of this ICN did not involve a change to the routine codes, and they have not been used to } \\
\text { develop additional quality affecting information in this technical product, these single use } \\
\text { software routines or macros will remain documented herein, in accordance with AP-SI.1Q } \\
\text { prior to release of Revision } 3 . \\
\text { The changes made are marked in the right margin of the document with change bars. } \\
\text { Administrative changes were made to the positioning of the graphics, however, no graphics } \\
\text { were altered. Changes were made to: } \\
\text { Section 1, p. } 17 \\
\text { Section 2, p. } 20 \\
\text { Section 3, p. } 21 \\
\text { Section 4, pp. } 25 \text { to } 28 \\
\text { Section 5, pp. } 29 \text { to } 31 \\
\text { Section 7, p. } 142 \\
\text { Section 8, pp. } 143 \text { to } 147 \\
\text { Attachment II, pp. II-1, -36 }\end{array}$ \\
\hline $01 / 00$ & $\begin{array}{l}\text { The document has been completely revised following the Regulatory Integration Team } \\
\text { guidance and to conform to procedural requirements of AP-SIII.10Q, Models and AP-3.15Q, } \\
\text { Managing Technical Product Inputs, and updates to the Q-List. } \\
\text { Changes to this version are too extensive to be indicated by change bars. Entire model } \\
\text { documentation was revised. Side bars are not used because the changes were too extensive to } \\
\text { use Step 5.8f)1) per AP-SIII.10Q, REV 02, ICN 06. }\end{array}$ \\
\hline
\end{tabular}




\section{CONTENTS}

Page

ACRONYMS AND ABBREVIATIONS ...................................................................... xvii

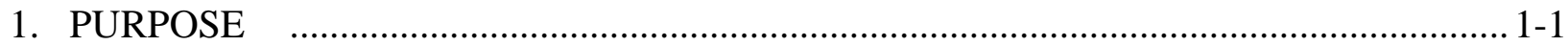

2. QUALITY ASSURANCE ........................................................................... 2-1

3. USE OF SOFTWARE ......................................................................................... 3-1

3.1 SOFTWARE TRACKED BY CONFIGURATION MANAGEMENT ...................... 3-1

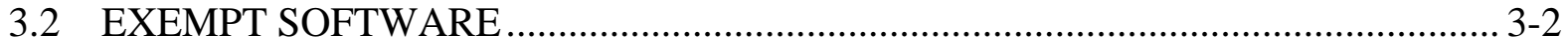

4. INPUTS

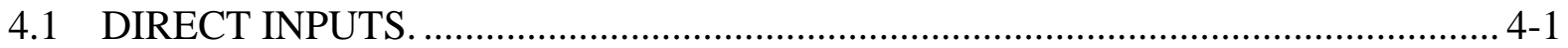

4.1.1 Laboratory Core Porosity Data ................................................................ 4-1

4.1.2 Calculated Petrophysical Porosity Data.......................................................... 4-2

4.1.3 Laboratory Measured Secondary Property Data............................................ 4-2

4.1.4 X-Ray Diffraction Indicators of Mineral Alteration..................................... 4-3

4.1.5 Petrophysical Indicators of Hydrous-Phase Mineral Alteration ........................ 4-4

4.1.6 Observed (Measured) Lithostratigraphic Contacts ........................................ 4-4

4.1.7 Modeled Lithostratigraphic Contacts....................................................... 4-4

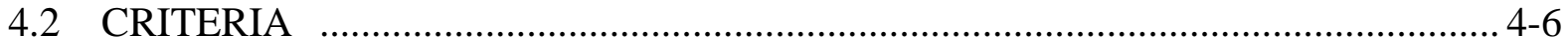

4.3 CODES, STANDARDS, AND REGULATIONS .............................................. 4-7

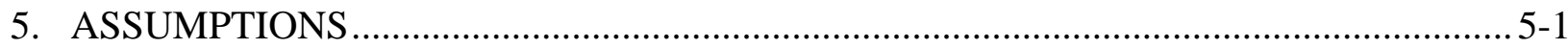

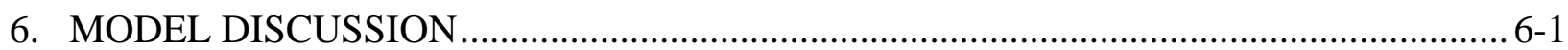

6.1 INTRODUCTION AND ROCK PROPERTIES MODEL OVERVIEW .................. 6-1

6.2 CHANGES BETWEEN MODEL VERSIONS ...................................................... 6-4

6.2.1 Changes in Model Unit Subdivisions and Modeled Region............................ 6-4

6.2.2 Adjustment of Model Unit Contacts to Reflect Mineralogy............................. 6-4

6.2.3 Revised Petrophysical Data .................................................................. 6-5

6.2.4 Revised Approach to Identifying Hydrous-Phase Mineral Alteration.............. 6-6

6.3 PHILOSOPHICAL AND CONCEPTUAL MODELING FRAMEWORK................. 6-6

6.3.1 Modeling Philosophy and Conceptual Approach .......................................... 6-6

6.3.1.1 Capturing Heterogeneity ............................................................... 6-7

6.3.1.2 Heterogeneity Versus Uncertainty ............................................ 6-7

6.3.1.3 Geostatistical Methods ............................................................ 6-8

6.3.1.4 Evaluating the Consequences of Heterogeneity and Uncertainty ................................................................................. 6-9

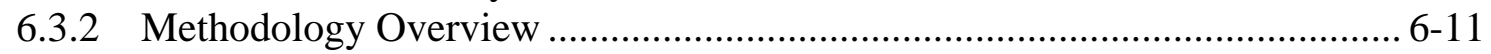

6.4 DEVELOPMENT OF THE MODELS ................................................................ 6-12

6.4.1 Model Domain ................................................................................... 6-12

6.4.2 Separate Modeling of Distinctive, Aggregate Geologic Units ..................... 6-12

6.4.3 Available Data and Preliminary Processing …......................................... 6-12 


\section{CONTENTS (Continued)}

Page

6.4.3.1 Data Compilation, Resampling, and Generation of Derived Quantities $6-13$

6.4.3.2 Stratigraphic Coordinate Conversion ........................................ 6-18

6.4.4 Statistical and Spatial Description of Porosity.....

6.4.4.1 PTn Model Unit......................................................................... 6-21

6.4.4.2 TSw Model Unit................................................................... 6-22

6.4.4.3 CHn Model Unit........................................................................ 6-27

6.4.4.4 Tcp Model Unit ..................................................................... 6-28

6.4.5 Statistical Description of Secondary Material Properties ............................... 6-30

6.4.5.1 Matrix Saturated Hydraulic Conductivity .................................... 6-30

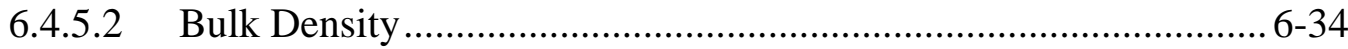

6.4.5.3 Thermal Conductivity.............................................................. 6-36

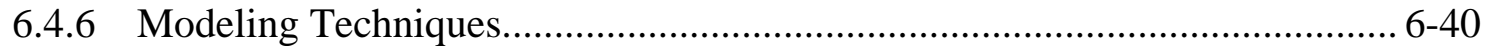

6.4.6.1 Discretization of the Model Domain ............................................. 6-40

6.4.6.2 Sequential Gaussian Simulation of Porosity ................................ 6-41

6.4.6.3 Indicator Kriging Using Uncertain Data ..................................... 6-44

6.4.6.4 Coregionalization Modeling of Derivative Properties ................... 6-46

6.4.7 Modeling of Hydrous-Phase Mineral Alteration ........................................... 6-47

6.4.7.1 Calibrating Soft Indicators of Hydrous-Phase Mineral

Alteration............................................................................. 6-47

6.4.7.2 Indicator Kriging of Hydrous-Phase Mineral Alteration .............. 6-49

6.4.8 Postprocessing of Simulated Models ......................................................... 6-50

6.4.8.1 Incorporation of Specific Attributes into Simulated Models ......... 6-50

6.4.8.2 Uncertainty Modeling...............................................................6-53

6.4.8.3 “Expected-Value Modeling” ......................................................6-53

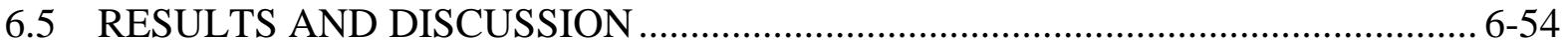

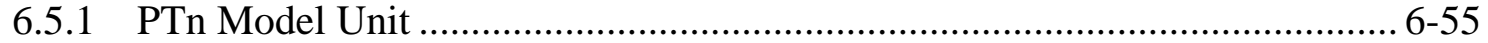

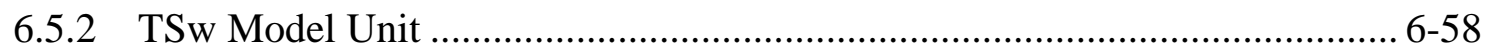

6.5.3 CHn Model Unit ..................................................................................... 6-66

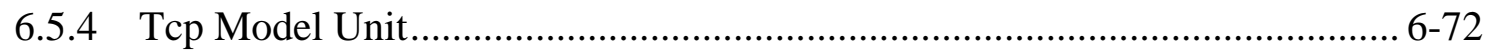

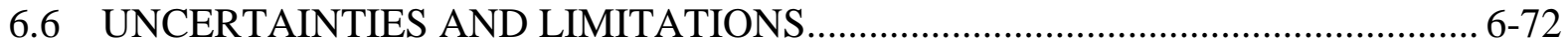

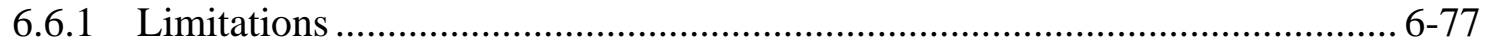

6.6.1.1 Errors and Biases in Sample Data ............................................. 6-77

6.6.1.2 Porosity as a Surrogate ....................................................... 6-78

6.6.1.3 Underestimation of Porosity and Hydraulic Conductivity in the TSw Model Unit ................................................................... 6-79

6.6.1.4 Use of Major Stratigraphic Units as Modeling Units.................... 6-80

6.6.1.5 Faulting, Erosion, and the Stratigraphic Coordinate System ......... 6-81

6.6.2 Stochastic Uncertainty Assessment ................................................... 6-82

6.6.2.1 Expectations versus Individual Outcomes ................................ 6-82

6.6.2.2 Summary Uncertainty Models..................................................6-83

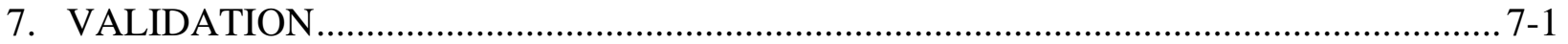

7.1 CONFIDENCE BUILDING DURING MODEL DEVELOPMENT .......................... 7-1 


\section{CONTENTS (Continued)}

Page

7.2 CONFIDENCE BUILDING AFTER MODEL DEVELOPMENT TO SUPPORT THE SCIENTIFIC BASIS OF THE MODEL …………......................... 7-4

7.2.1 Validation: Matrix Porosity ……………………........................................... 7-4

7.2.2 Validation: Lithophysal Porosity ........................................................... 7-5

7.2.3 Validation: Bulk Density ........................................................................... 7-9

7.3 MODEL VALIDATION SUMMARY AND CONCLUSIONS .............................. 7-10

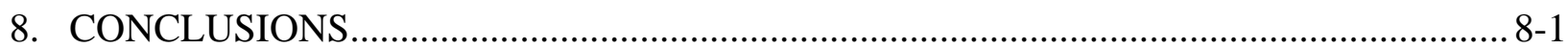

8.1 SUMMARY OF MODEL ACTIVITIES AND DESCRIPTIVE RESULTS ................ 8-1

8.2 UNCERTAINTY AND RESTRICTIONS …………....................................... 8-2

8.3 CONCLUSIONS FOR YMRP CRITERIA …………............................................. 8-3

9 INPUTS AND REFERENCES .............................................................................. 9-1

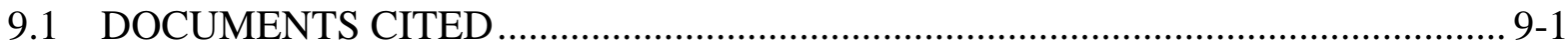

9.2 CODES, STANDARDS, REGULATIONS, AND PROCEDURES …………............ 9-6

9.3 SOURCE DATA, LISTED BY DATA TRACKING NUMBER …………................. 9-7

9.4 OUTPUT DATA, LISTED BY DATA TRACKING NUMBER ……………............. 9-9

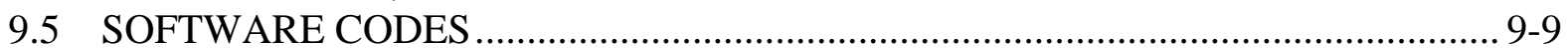

APPENDIX A - SIGMA PLOT TRANSFORM "STRATC4”........................................... A-1

APPENDIX B - GSLIB ROUTINE “TRANS” ............................................................

APPENDIX C - VALIDATION OF UNCERT PROGRAM "VARIO”................................ -1

APPENDIX D - VALIDATION OF UNCERT PROGRAM "VARIOFIT”........................ D-1

APPENDIX E - DATA QUALIFICATION REPORT: CUTTINGS MINERALOGY DATA.......................................................................

APPENDIX F - SELECTED MINERALOGIC-ABUNDANCE DATA FROM DATA SETS TO BE QUALIFIED ......................................................F-1

APPENDIX G - SELECTED QUALIFIED MINERALOGIC-ABUNDANCE

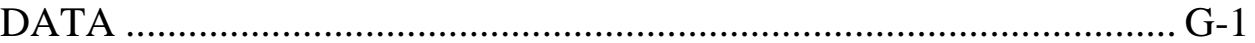

APPENDIX H - SOURCE DATA TRACKING NUMBERS FOR

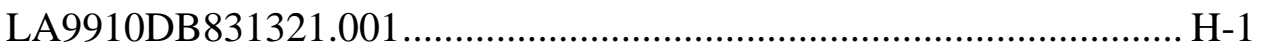

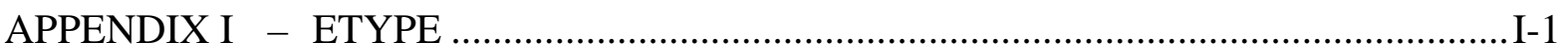


INTENTIONALLY LEFT BLANK 


\section{FIGURES}

1-1. Index Map Showing the Location of the Geologic Framework Model, the Rock Properties Model (this report), and the Mineralogic Model........................................... 1-2

6.3-1. Conceptual Representation of a Monte Carlo Process ................................................... 6-10

6.4-1. Drill Holes Used in Modeling the PTn Model Unit .................................................... 6-14

6.4-2. Drill Holes Used in Modeling the TSw Model Unit .................................................... 6-15

6.4-3. Drill Holes Used in Modeling the CHn Model Unit ...................................................... 6-16

6.4-4. Drill Holes Used in Modeling the Tcp Model Unit...................................................... 6-17

6.4-5. Conceptual Illustration of the Construction and Use of Stratigraphic Coordinates .... 6-19

6.4-6. Histogram and Cumulative Distribution Function of Matrix Porosity in the PTn Model Unit.

6.4-7. Experimental and Fitted Model Variograms of Matrix Porosity in the PTn Model Unit................................................................................................... 6-22

6.4-8. Histograms and Cumulative Distribution Functions .................................................. 6-23

6.4-9. Comparison of Different Types of Porosity Data for Drill Hole USW SD-7 ............. 6-24

6.4-10. Crossplots of Core Porosity.................................................................................. 6-25

6.4-11. Experimental and Fitted Model Variograms for Porosity in the TSw Model Unit..... 6-26

6.4-12. Histogram and Cumulative Distribution Function of Matrix Porosity in the CHn

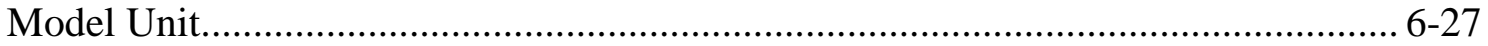

6.4-13. Experimental and Fitted Model Variograms for Matrix Porosity in the CHn Model Unit

6.4-14. Histogram and Cumulative Distribution Function of Matrix Porosity in the Tcp Model Unit.

6.4-15. Experimental and Fitted Model Variograms for Matrix Porosity in the Tcp Model Unit

6.4-16. All Measured Core Samples ............................................................................. 6-30

6.4-17. Unaltered Core Samples .................................................................................... 6-31

6.4-18. Altered Core Samples............................................................................................... 6-32

6.4-19. Scatterplots of Matrix Saturated Hydraulic Conductivity Versus Matrix Porosity..... 6-33

6.4-20. Matrix Saturated Hydraulic Conductivity Histograms and Cumulative Distribution Functions .......................................................................................... 6-34

6.4-21. Bulk Density Relationship.............................................................................. 6-35

6.4-22. Bulk Density Histograms ………………………................................................ 6-36

6.4-23. Thermal Conductivities from Non-Zeolitic Rock Samples......................................... 6-37

6.4-24. Histograms and Cumulative Distribution Functions .................................................. 6-38

6.4-25. Histogram and Cumulative Distribution Function for Thermal Conductivity Systematically Predicted from Lithophysal Porosity Values in Drill Holes USW SD-7, SD-9, and SD-12 Using the Regression Relationship from 6.4-23(b) .............. 6-39

6.4-26. Downhole Variation in Predicted Thermal Conductivity Values Based on Systematically Measured Lithophysal Porosity Data for Drill Holes ....

6.4-27. Conceptual Probability Density Functions Representing the Uncertainty Associated With Various Unsampled Locations 6-42

6.4-28. Graphical Representation of the Quantile-Preserving Normal-Score Transform Process Using Cumulative Distribution Functions. 


\section{FIGURES (Continued)}

Page

6.4-29. Scatterplot of Core Versus Petrophysically Derived Bound-Water Content for 354 Depth-Matched Pairs of Samples

6.4-30. Scatterplot of Total Hydrous-Phase Mineral Content Versus Adjusted Bound-Water Content for 334 Depth-Matched Paired Samples

6.4-31. Indicator Variogram and Fitted Model Computed for Alteration in the CHn Model Units

6.4-32. Indicator Variogram and Fitted Model Computed for Alteration in the Tcp Model Unit

6.4-33. Logic Diagram for Postprocessing Porosity and Hydraulic Conductivity Simulations to Recognize Vitrophyre Rock Type.

6.4-34. Logic Diagram for Postprocessing Porosity and Alteration Indicator Simulations to Recognize Hydraulic Conductivity Dependence on Alteration State

6.5-1. Perspective Diagrams Showing E-Type Model Matrix Porosity in the PTn Model Unit in Both Stratigraphic and Real-World Coordinates

6.5-2. Cross-Sectional Views Showing E-Type Heterogeneity in Matrix Porosity in the PTn Model Unit in Stratigraphic Coordinates.

6.5-3. Cross-Sectional View Showing E-Type Heterogeneity of Bulk Density in the PTn Model Unit in Stratigraphic Coordinates.

6.5-4. Cross-Sectional Views Showing E-Type Heterogeneity in Matrix Saturated Hydraulic Conductivity in the PTn Model Unit in Stratigraphic Coordinates............. 6-58

6.5-5. Perspective Diagrams Showing E-Type Model Matrix Porosity in the TSw Model Unit in Both Stratigraphic and Real-World Coordinates

6.5-6. Cross-Sectional Views Showing E-Type Heterogeneity of Matrix Porosity in the TSw Model Unit in Stratigraphic Coordinates.

6.5-7. Perspective Diagrams Showing E-Type Model Lithophysal Porosity in the TSw Model Unit in Both Stratigraphic and Real-World Coordinates

6.5-8. Cross-Sectional Views Showing E-Type Heterogeneity of Lithophysal Porosity in theTSw Model Unit in Stratigraphic Coordinates

6.5-9. Cross-Sectional Views Showing E-Type Heterogeneity of Bulk Density in the TSw Model Unit in Stratigraphic Coordinates 6-64

6.5-10. Cross-Sectional Views Showing E-Type Heterogeneity of Thermal Conductivity in the TSw Model Unit in Stratigraphic Coordinates.

6.5-11. Cross-Sectional Views Showing E-Type Heterogeneity of Matrix Saturated Hydraulic Conductivity in the TSw Model Unit in Stratigraphic Coordinates ........... 6-66

6.5-12. Perspective Diagrams Showing E-Type Model Matrix Porosity in the $\mathrm{CHn}$ Model Unit in Both Stratigraphic and Real-World Coordinates

6.5-13. Cross-Sectional Views Showing E-Type Heterogeneity of Matrix Porosity in the $\mathrm{CHn}$ Model Unit in Stratigraphic Coordinates

6.5-14. Cross-Sectional Views Showing E-Type Heterogeneity of Bulk Density in the CHn Model Unit in Stratigraphic Coordinates

6.5-15. Block and Cross-Sectional Views Showing E-Type Heterogeneity of Matrix Saturated Hydraulic Conductivity in the CHn Model Unit in Stratigraphic Coordinates 


\section{FIGURES (Continued)}

6.5-16. Perspective Diagrams Showing E-Type Model Matrix Porosity in the Tcp Model Unit in Both Stratigraphic and Real-World Coordinates

6.5-17. Cross-Sectional Views Showing E-Type Heterogeneity of Matrix Porosity in the Tcp Model Unit in Stratigraphic Coordinates

6.5-18. Cross-Sectional Views Showing E-Type Heterogeneity of Bulk Density in the Tcp Model Unit in Stratigraphic Coordinates

6.5-19. Block Diagram and Cross-Sectional Views Showing E-Type Heterogeneity of Matrix Saturated Hydraulic Conductivity in the Tcp Model unit in Stratigraphic Coordinates

6.6-1. Uncertainty Model Showing E-Type Standard Deviation of Matrix Porosity in the PTn Model Unit

6.6-2. Uncertainty Model Showing E-Type Standard Deviation of Matrix Porosity in the TSw Model Unit....

6.6-3. Uncertainty Model Showing E-Type Standard Deviation of Lithophysal Porosity in the TSw Model Unit.

6.6-4. Uncertainty Model Showing E-Type Standard Deviation of Matrix Porosity in the CHn Model Unit.

6.6-5. Uncertainty Model Showing E-Type Standard Deviation of Matrix Porosity in the Tcp Model Unit

7-1. $\quad$ ECRB Lithophysal Porosity Versus Stationing.

7-2. Calculated Porosity of Lithophysal Cavities Calculated By Tape, Angular, and Panel Map Measurements in the Tptpll Exposed Along the ECRB Cross-Drift

7-3. Scatterplot of Bulk Density as a Function of Matrix Porosity for Corroborating and Input Data

A-1 Printed Spreadsheet Cells from Sigma Plot File Containing the Test Case Data and Output

B-1. Crossplot of the Transformed Variable as a Function of the Input Variable Indicating a One-to-One Monotonically Increasing, but Nonlinear, Relationship

B-2. Histograms and Cumulative Distribution Functions for (a) Input StandardNormal Distribution and (b) Transformed Distribution Where $\mathrm{N}=35,088$ (both figures)

B-3. (a) Histogram and Cumulative Distribution Function for the Target Reference Distribution; Compare with Figure B-2 (b) where $N=510$. (b) Comparison of cumulative distribution functions for the transformed [Figure B-2(b)] and target distributions [Figure B-3(a)]

C-1. Locations of Sample Values for the Test Case Data Set.

C-2. "Ordered" Computation of Squared Differences between Sequential Values Implemented in the "Manual” Calculation Using Excel 97. 


\section{FIGURES (Continued)}

Page

D-1. $\quad$ Reproduced Screen Image of an Arbitrary Nested Variogram Model Generated Using the UNCERT Program, Variofit ………………………………………...... D-2

D-2. Comparison of Model Variograms Generated by Program Variofit and by an Independent Computation Using Sigmaplot ............................................................ D-2 


\section{TABLES}

Page

3-1. Software Tracked by Configuration Management........................................................... 3-1

3-2. Software Routines ........................................................................................

4-1. Source of Input Laboratory Core Porosity Data ………………………………............... 4-1

4-2. $\quad$ Source of Input Petrophysical Porosity Data ................................................................ 4-2

4-3. Source of Input Secondary Property Data ................................................................. 4-3

4-4. $\quad$ Source of Input X-ray Diffraction Mineralogy Data .................................................... 4-3

4-5. Source of Input Petrophysical Data Used for Identification of Mineral Alteration....... 4-4

4-6. $\quad$ Source of Input Observed Lithostratigraphic Contacts.................................................. 4-4

4-7. Source of Input Projected Lithostratigraphic Contacts and Isochore Information ........ 4-6

6.1-1. Correlation Chart for Model Stratigraphy ………................................................... 6-2

6.3-1. Scientific Notebooks for Rock Properties Models....................................................... 6-12

6.4-1. Unit-Specific Scaling Constants for Nominal Model Unit Thickness.......................... 6-20

6.4-2. Statistical Summary of Porosity Data Used in Modeling ............................................. 6-21

6.4-3. Variogram Parameters for Spatial Continuity Model of Porosity in the PTn Model Unit ....................................................................................................... 6-22

6.4-4. Variogram Parameters for Spatial Continuity Model of Porosity in the TSw Model Unit.

6.4-5. Variogram Parameters for Spatial Continuity Model of Porosity in the CHn Model Unit.

6.4-6. Variogram Parameters for Spatial Continuity Model of Porosity in the Tcp Model Unit

6.4-7. Statistical Summary of Matrix Saturated Hydraulic Conductivity Measurements...... 6-31

6.4-8. Statistical Summary of Measured Thermal Conductivity Data from Non-Zeolitic Rock Samples.

6.4-9. Statistical Comparison of Measured and Predicted Thermal Conductivity Data for the TSw Model Unit

6.4-10. Geostatistical Modeling Grid Specification Parameters Corresponding to the Southwest Corner of the Grid

6.4-11. Prior Probability of Altered vs. Unaltered Rocks as a Function of Bound-Water Content

6.4-12. Variogram Parameters for Spatial Continuity Model, Alteration in the CHn and Tcp Model Units 6-50

7-1. Matrix Porosity and Bulk Density Data Supporting Model Validation........................... 7-4

7-2. $\quad$ Lithophysal Porosity Data Supporting Model Validation ................................................. 7-5

B-1. Comparative Statistics for Input, Transformed, and Reference Distributions ...............B-15

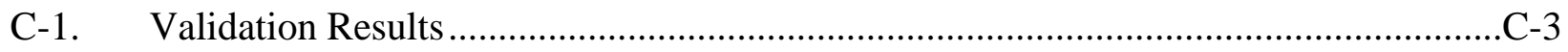




\section{TABLES (Continued)}

Page

E-1. Source DTNs of MO0101XRDDRILC.001 [DIRS 169517] and their Relevant

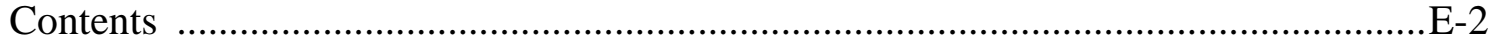

E-2. Sample Extraction from DTN: MO0101XRDDRILC.001 [DIRS 169517], SEP Table S01025_003, Illustrating the Data Type and Structure.

E-3. List of Boreholes in DTN: MO0101XRDDRILC.001 [DIRS 169517], Material Type Analyzed, and Qualification Status of the Material..........................................E-6

E-4. Comparison for Equivalence of J-12 Analyzed Samples Included in Data Packages

E-5. Comparison for Equivalence of UE-25 p\#1 Analyzed Samples Included in Data Packages

E-6. Comparison for Equivalence of USW H-3 Analyzed Samples Included in Data Packages E-10

E-7. Comparison for Equivalence of USW H-4 Analyzed Samples Included in Data Packages

E-8. Comparison for Equivalence of USW H-5 Analyzed Samples Included in Data Packages

E-9. Comparison for Equivalence of USW WT-1 Analyzed Samples Included in Data Packages .....

E-10. Comparison for Equivalence of USW WT-2 Analyzed Samples Included in Data Packages

E-11. Summary of Records for Sample Collection and XRD Analysis .............................E-17

E-12. Published Sources on XRD Mineralogy for Unqualified Data Sets ..........................E-17

E-13. Lithostratigraphic Unit Descriptions and Abbreviations ............................................19

E-14. Mineral-Abundance Ranges, UE-25 p\#1 and UE-25 UZ\#16 (Weight Percent)..........E-21

E-15. Ranges of Mineral Content in the Tptpmn of p\#1, UZ\#16, SD-12, and G-4 (Weight Percent)

E-16. Mineral-Abundance Ranges, UE-25 p\#1 and USW G-1 (Weight Percent).................E-24

E-17. Mineral-Abundance Ranges, USW H-3 and USW GU-3 (Weight Percent) ...............E-26

E-18. Ranges of Mineral Content in the Tptpln of H-4, SD-12, UZ\#16, and G-4 (Weight Percent)

E-19. Mineral-Abundance Ranges, USW H-4, USW SD-12, and UE-25 UZ\#16 (Weight Percent)

E-20. Ranges of Mineral Content in the Tpc_un of H-5, UZ\#16, and GU-3 (Weight Percent)

E-21. Mineral-Abundance Ranges, USW H-5, UE-25 UZ\#16, and USW GU-3 (Weight Percent)

E-22. Mineral-Abundance Ranges, USW WT-1, UE-25 UZ\#16, and USW GU-3 (Weight Percent)

E-23. Mineral-Abundance Ranges, USW WT-2, USW SD-12, and UE-25 UZ\#16 (Weight Percent) E-36

F-1. Selected Mineralogic-Abundance Data for Drill Hole UE-25 p\#1 (Weight Percent) F-1 


\section{TABLES (Continued)}

Page

F-2. Selected Mineralogic-Abundance Data for Drill Hole USW H-3 (Weight

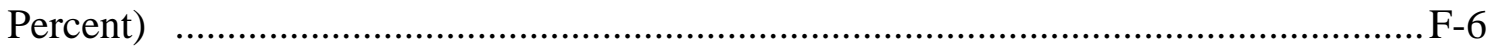

F-3. $\quad$ Selected Mineralogic-Abundance Data for Drill Hole USW H-4 (Weight

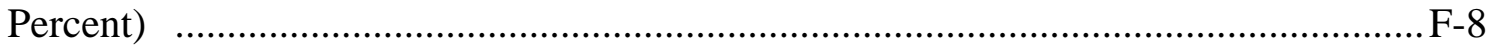

F-4. Selected Mineralogic-Abundance Data for Drill Hole USW H-5 (Weight Percent)

F-5. Selected Mineralogic-Abundance Data for Drill Hole USW WT-1 (Weight Percent)

F-6. Selected Mineralogic-Abundance Data for Drill Hole USW WT-2 (Weight Percent)

G-1. Selected Mineralogic-Abundance Data for Drill Hole UE-25 UZ\#16 (Weight Percent) G-1

G-2. Selected Mineralogic-Abundance Data for Drill Hole USW G-1 (Weight Percent) G-7

G-3. Selected Mineralogic-Abundance Data for Drill Hole USW GU-3 (Weight Percent) G-11

G-4. Selected Mineral-Abundance Data for Drill Hole USW G-4 (Weight Percent)......... G-14

G-5. Selected Mineral-Abundance Data for Drill Hole USW SD-12 (Weight Percent) .... G-15 


\section{INTENTIONALLY LEFT BLANK}




\section{ACRONYMS AND ABBREVIATIONS}

3-D three-dimensional

2-D two-dimensional

DIRS Document Input Reference System

DTN data tracking number

E-type $\quad$ expected-value type (model)

ECRB Enhanced Characterization of the Repository Block

ESF Exploratory Studies Facility

GFM Geologic Framework Model

ICN interim change notice

ISM integrated site model

$K_{s} \quad$ saturated hydraulic conductivity

LANL Los Alamos National Laboratory

M-type median type (model)

OCRWM Office of Civilian Radioactive Waste Management

OD oven dried

QA quality assurance

$\mathrm{RH} \quad$ relative humidity (oven-dried)

RPM Rock Properties Model

SNL Sandia National Laboratories

SZ saturated zone

TBV to be verified

TWP technical work plan

USGS U.S. Geological Society

UZ unsaturated zone

VWC volumetric water content

XRD X-ray diffraction

YMP Yucca Mountain Site Characterization Project 
INTENTIONALLY LEFT BLANK 


\section{PURPOSE}

The purpose of this model report is to document the Rock Properties Model version 3.1 with regard to input data, model methods, assumptions, uncertainties and limitations of model results, and qualification status of the model. The report also documents the differences between the current and previous versions and validation of the model.

The rock properties model provides mean matrix and lithophysae porosity, and the cross-correlated mean bulk density as direct input to the Saturated Zone Flow and Transport Model Abstraction, MDL-NBS-HS-000021, REV 02 (BSC 2004 [DIRS 170042]). The constraints, caveats, and limitations associated with this model are discussed in Section 6.6 and 8.2. Model validation accomplished by corroboration with data not cited as direct input is discussed in Section 7.

The revision of this model report was performed as part of activities being conducted under the Technical Work Plan for: The Integrated Site Model, Revision 05 (BSC 2004 [DIRS 169635]). The purpose of this revision is to bring the report up to current procedural requirements and address the Regulatory Integration Team evaluation comments. The work plan describes the scope, objectives, tasks, methodology, and procedures for this process.

The steps for developing the model consist of the following:

1. Conversion of the input data (laboratory measured porosity data, x-ray diffraction mineralogy, petrophysical calculations of bound water, and petrophysical calculations of porosity) for each borehole into stratigraphic coordinates

2. Re-sampling and merging of data sets

3. Development of geostatistical simulations of porosity

4. Generation of derivative property models via linear co-regionalization with porosity

5. Postprocessing of the simulated models to impart desired secondary geologic attributes and to create summary and uncertainty models.

The rock properties model is one of the three models developed as part of the integrated site model work scope. The integrated site model provides a consistent volumetric portrayal of the rock layers, rock properties, and mineralogy of the Yucca Mountain site and consists of three components:

- Geologic framework model

- Rock properties model, which is the subject of this model report

- Mineralogic model.

Figure 1-1 shows the geographic boundaries of the rock properties model and other component models of the integrated site model. 
The specific report that uses the rock properties product output parameters is the Saturated Zone Flow and Transport Model Abstraction MDL-NBS-HS-000021, REV 02 (BSC 2004 [DIRS 170042]). The report uses the mean matrix and lithophysae porosity, and the cross-correlated mean bulk density values from the rock properties model report as direct input.

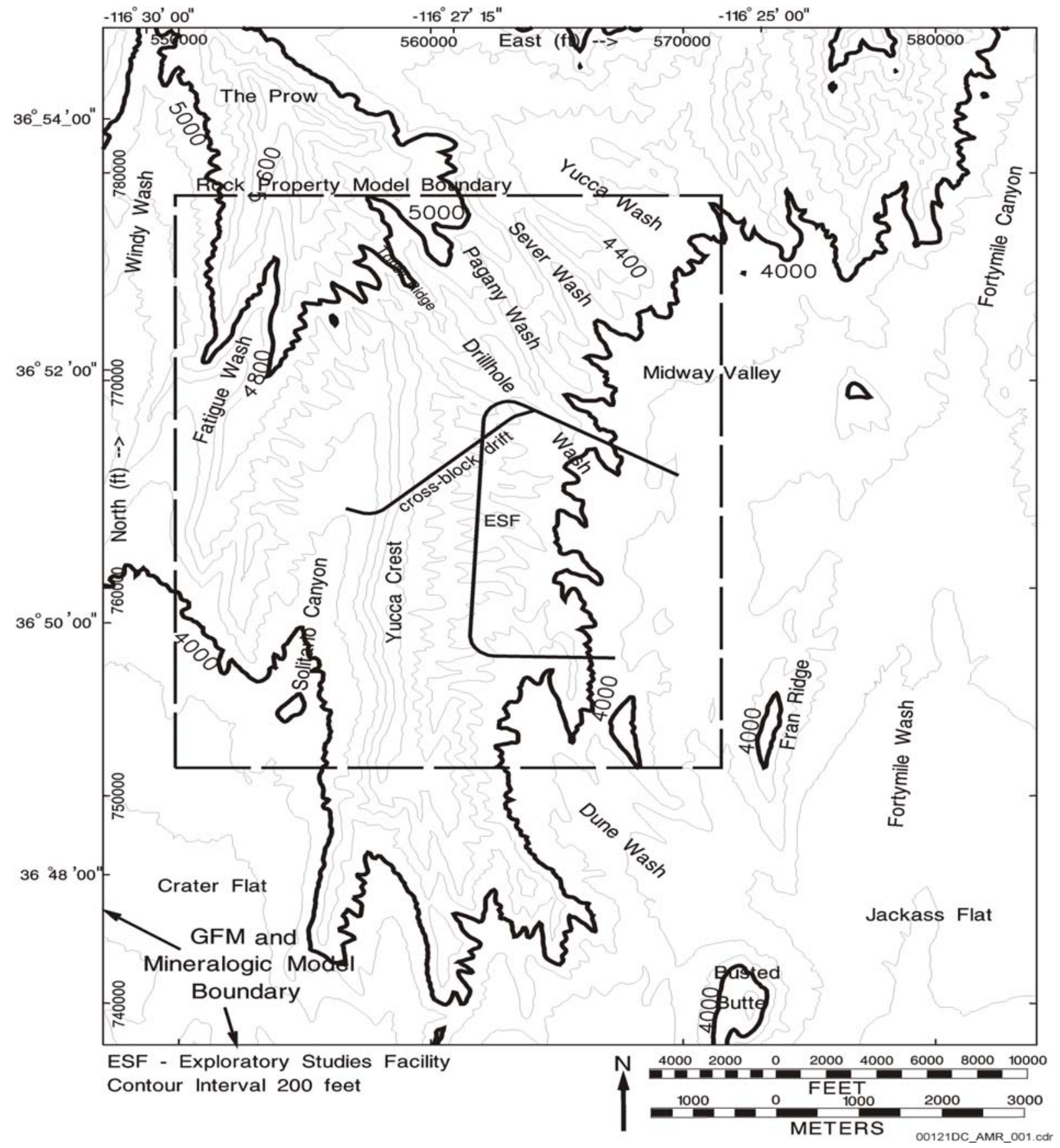

Source: Rautman, C. and McKenna, S. 1998 [DIRS 107442], Section 2 and MDL-NBS-GS-000002, REV 00 ICN 02, Figure 1.

Figure 1-1. Index Map Showing the Location of the Geologic Framework Model, the Rock Properties Model (this report), and the Mineralogic Model 


\section{QUALITY ASSURANCE}

Development of this model report and the supporting modeling activities have been determined to be subject to the Yucca Mountains Site Characterization Project's (YMP) quality assurance (QA) program, as indicated in the Technical Work Plan for: The Integrated Site Model, TWP-NBS-GS-000003 REV 05 (BSC 2004 [DIRS 169635], Section 8.1, Work Package (WP) ARTM01). Approved QA procedures identified in the Technical Work Plan (TWP) (BSC 2004 [DIRS 169635] have been used to conduct and document the activities described in this model report. The TWP also identifies the methods used to control the electronic management of data (BSC 2004 [DIRS 169635]), Section 8.4 WP ARTM01) during the model documentation activities.

This Model Report provides representations of selected rock properties: matrix and lithophysae porosity and bulk density that are used as inputs to models that are subsequently used as input to Total System Performance Assessment that is used to evaluate compliance with the postclosure performance objectives prescribed in 10 CFR 63.113 [DIRS 156605]. This model report evaluates some properties of the Lower Natural Barrier and Upper Natural Barrier, that are classified in the Q-List (BSC 2004 [DIRS 168361]) as Safety Category "SC" because they are important to waste isolation, as defined in AP-2.22Q, Classification Analysis and Maintenance of the Q-List. The report contributes to the analysis and modeling data used to support performance assessment; the conclusions do not directly impact engineered features important to safety, as defined in AP-2.22Q Classification Analysis and Maintenance of the Q-List. 


\section{INTENTIONALLY LEFT BLANK}




\section{USE OF SOFTWARE}

\subsection{SOFTWARE TRACKED BY CONFIGURATION MANAGEMENT}

The Rock Properties Model was constructed principally using geostatistical algorithms that are part of the public domain geostatistical subroutine library, GSLIB (Deutsch and Journel 1992 [DIRS 100567] and 1998 [DIRS 102895]). The major modeling codes subject to configuration management are listed in Table 3-1, together with a brief description of their functionality. These computer software packages were obtained from configuration management at the time of model development, and are judged appropriate for use in this type of modeling activity. The software was used within the range of validation.

The GSLIB software was selected for use as it provides the geostatistical algorithms needed to provide the volumetric representation of the selected rock properties. Earthvision was used only to produce "geologic" or real-world coordinate visualizations of the volumetric representation of the selected rock properties. MATCHUP and MATCH were selected for use as they permitted the generation of a single file of depth-matched values from two input files. There are no limitations on the output caused by the selected software.

The software listed in Section 3.1 and 3.2 is provided for information only and to document their completeness and traceability. When the product output was developed the software was qualified according to the controlling procedure at the time AP-SI.1Q Software Configuration Management. After the development of the product output the software GSLIB 2.0MIK3 DV2.0, MATCHUP 12/05/98, and MATCH 12/05/98 were retired.

Table 3-1. Software Tracked by Configuration Management

\begin{tabular}{|c|c|c|c|c|}
\hline Code Name & Version & STN Number & $\begin{array}{c}\text { Platform/Operating } \\
\text { System }\end{array}$ & Brief Description \\
\hline GSLIB & $\begin{array}{l}\text { 1.4SGSI } \\
\text { MV1.40 }\end{array}$ & $\begin{array}{c}\text { 10110- } \\
\text { 1.4MSGSIMV1.40-00 } \\
\text { [DIRS 113569] } \\
\text { Deutsch and Journel, } \\
\text { 1998 [DIRS 102895], } \\
\text { Section V } 7.2 \\
\end{array}$ & HP 9000/ HP-UX 10.20 & $\begin{array}{l}\text { Generates conditional or } \\
\text { unconditional Gaussian } \\
\text { simulations of a continuous } \\
\text { variable; optional } \\
\text { normal-score forward and } \\
\text { back transformation (from the } \\
\text { software library, GSLIB) }\end{array}$ \\
\hline GSLIB & $\begin{array}{l}\text { 2.0MIK3 } \\
\text { DV2.0 }\end{array}$ & $\begin{array}{c}\text { 10122-2.0MIK3D } \\
\text { V2.0-00 } \\
\text { [DIRS 113587] } \\
\text { Deutsch and Journel, } \\
\text { 1998 [DIRS 102895], } \\
\text { Section IV 5 }\end{array}$ & PC/Windows NT V. 4.0 & $\begin{array}{l}\text { Conducts indicator kriging of } \\
\text { continuous or discrete } \\
\text { variables using either hard or } \\
\text { soft data or both (from the } \\
\text { software library, GSLIB) }\end{array}$ \\
\hline GSLIB & $\begin{array}{c}\text { 14MNS } \\
\text { COREV1 } \\
.201\end{array}$ & $\begin{array}{c}\text { 10109-1.4MNSCORE } \\
\text { V1.201-00 } \\
\text { [DIRS 113595] } \\
\text { Deutsch and Journel, } \\
\text { 1998 [DIRS 102895], } \\
\text { Section VI 2.5 } \\
\end{array}$ & HP 9000/ HP-UX 10.20 & $\begin{array}{l}\text { Transforms a distribution of } \\
\text { values to standard-normal } \\
\text { form while preserving quantile } \\
\text { relationships (from the } \\
\text { software library, GSLIB) }\end{array}$ \\
\hline
\end{tabular}


Table 3-1. Software Tracked by Configuration Management (Continued)

\begin{tabular}{|c|c|c|c|l|}
\hline Code Name & Version & STN Number & $\begin{array}{c}\text { Platform/Operating } \\
\text { System }\end{array}$ & \multicolumn{1}{|c|}{ Brief Description } \\
\hline EARTHVISION & 4.0 & $\begin{array}{c}30035.1 \text { V4.0 } \\
\text { [DIRS 113625] }\end{array}$ & $\begin{array}{c}\text { SGI INDIGO R4000/IRIX } \\
6.4\end{array}$ & $\begin{array}{l}\text { 3-D earth science modeling } \\
\text { package; used only to } \\
\text { produce visualizations (report } \\
\text { figures; e.g., Figure 63.5-18) } \\
\text { of the Integrated Site Model } \\
\text { 3.0/ and Rock Properties } \\
\text { Model 3.0 for this report }\end{array}$ \\
\hline ETYPE & 2.01 & $\begin{array}{c}10731-2.01-00 \\
\text { [DIRS 159417] }\end{array}$ & MS 2000 Server & $\begin{array}{l}\text { Reads a set of simulation } \\
\text { output (GSLIB format) files } \\
\text { and creates summary E-type } \\
\text { model; optional uncertainty } \\
\text { output as standard deviation } \\
\text { of simulations. Use is of this } \\
\text { code is documented in } \\
\text { Appendix I. }\end{array}$ \\
\hline MATCHUP & $12 / 05 / 98$ & $\begin{array}{c}\text { 10196-12/05/98-00 } \\
\text { [DIRS 113660] }\end{array}$ & PC/Windows NT V. 4.0 & $\begin{array}{l}\text { Software routine that creates } \\
\text { a single file of depth-matched } \\
\text { values from two columnar } \\
\text { input files }\end{array}$ \\
\hline MATCH & $12 / 05 / 98$ & $\begin{array}{c}\text { 10195-12/05/98-00 } \\
\text { [DIRS 113664] }\end{array}$ & PC/Windows NT V. 4.0 & $\begin{array}{l}\text { Modification of software } \\
\text { routine MATCHUP for one } \\
\text { GSLIB format file }\end{array}$ \\
\hline
\end{tabular}

A number of additional "software routines" were developed as part of the rock properties modeling process. These routines are listed in Table 3-2 and they are documented for quality assurance purposes in the scientific notebooks associated with this activity (Table 6.3-1); the use of scientific notebooks is explained in Section 6.3.2. Exceptions to this practice are included as appendices to this report (noted in tables that follow). With the exception of STRATC4 (which is a macro-type software routine), all software routines listed in Table 3-2 run as Microsoft Fortran PowerStation Version 4.0 and have been compiled and executed on Intel-type personal computers under the Microsoft Windows NT Version 4.0 operating system.

\subsection{EXEMPT SOFTWARE}

Various exempt software products were also used during the course of this modeling activity to assist in organizing, managing, manipulating, comparing, and displaying data and information and computing standard statistical measures. This includes commercial off-the-shelf software and other industry-standard software. These software packages were used to perform support activities and were not used as the controlled source of information for the analysis, as defined in AP-SI.1Q. They were not required to be qualified under these procedures. 
Table 3-2. Software Routines

\begin{tabular}{|c|c|c|c|}
\hline Routine Name & Version & Reference & Brief Description \\
\hline \multicolumn{4}{|c|}{ Acquired Software } \\
\hline TRANS & $\begin{array}{l}\text { GSLIB V1.4 Module } \\
\text { TRANS V1.3 } \\
\text { [DIRS 114225] }\end{array}$ & Appendix B & $\begin{array}{l}\text { Transforms an input distribution to match the } \\
\text { histogram of a target distribution (both in GSLIB } \\
\text { format) while preserving the quantile relationships } \\
\text { (from the software library, GSLIB) }\end{array}$ \\
\hline BICALIB & $\begin{array}{l}\text { GSLIB V1.4 Module } \\
\text { BICALIB V2.0 } \\
\text { [DIRS 114227] }\end{array}$ & $\begin{array}{l}\text { Rautman and } \\
\text { McKenna } 1998 \\
\text { [DIRS 107442], } \\
\text { p. } 1143\end{array}$ & $\begin{array}{l}\text { Calibrates soft data (GSLIB format) for use as prior } \\
\text { cdf values from matched hard-soft data pairs (from } \\
\text { the software library, GSLIB) }\end{array}$ \\
\hline BACKTR - & $\begin{array}{l}\text { GSLIB V1.4 } \\
\text { MBACKTRV1.2. } \\
\text { V1.2. [DIRS 113642] }\end{array}$ & $\begin{array}{l}\text { Rautman and } \\
\text { McKenna } 1998 \\
\text { [DIRS 107442], } \\
\text { p. } 1127 \\
\end{array}$ & $\begin{array}{l}\text { Transforms a standard-normal distribution (GSLIB } \\
\text { format) to match a reference histogram (from the } \\
\text { software library, GSLIB; inverse of program NSCORE } \\
\text { [Table 1]) }\end{array}$ \\
\hline \multicolumn{4}{|c|}{ Developed Software } \\
\hline BUD & $\begin{array}{c}6 / 25 / 98 \\
{[D I R S ~ 113651]}\end{array}$ & $\begin{array}{l}\text { Rautman and } \\
\text { McKenna } 1998 \\
\text { [DIRS 107442], } \\
\text { p. } 1013 \\
\end{array}$ & $\begin{array}{l}\text { Reads a "log-analysis standard" '.las' file and extracts } \\
\text { specified well log traces }\end{array}$ \\
\hline TWOFOOT & $\begin{array}{c}6 / 25 / 98 \\
{[D I R S ~ 113653]}\end{array}$ & $\begin{array}{l}\text { Rautman and } \\
\text { McKenna 1998 } \\
\text { [DIRS 107442], } \\
\text { p. } 1020 \\
\end{array}$ & $\begin{array}{l}\text { Reads an ASCII file of well log data and resamples it } \\
\text { on a user-specified spacing, averaging values over } \\
\text { two-foot intervals }\end{array}$ \\
\hline COREGPC & $\begin{array}{c}5 / 22 / 99 \\
{[D I R S ~ 113671]}\end{array}$ & $\begin{array}{l}\text { Rautman } 1999 \\
\text { [DIRS } 109035] \\
\quad \text { p. } 307\end{array}$ & $\begin{array}{l}\text { Postprocesses a porosity simulation (GSLIB format) } \\
\text { in standard-normal format and an unconditional } \\
\text { simulation with the same spatial correlation structure, } \\
\text { and generates a co-regionalized simulation of a } \\
\text { secondary property given a correlation coefficient } \\
\text { between the two variables }\end{array}$ \\
\hline ZEOLITE5 & $\begin{array}{c}9 / 10 / 98 \\
{[\text { DIRS 113682] }}\end{array}$ & $\begin{array}{l}\text { Rautman and } \\
\text { McKenna } 1998 \\
\text { [DIRS } 107442] \\
\text { p. } 1266\end{array}$ & $\begin{array}{l}\text { Postprocesses a set of simulated Ks values } \\
\text { (GSLIB format) together with an indicator model of } \\
\text { "zeolite" alteration that is used as a template to insert } \\
\text { random Gaussian Ks values at altered grid notes; } \\
\text { appropriate only for altered units }\end{array}$ \\
\hline VITROPHYRE & $\begin{array}{c}9 / 10 / 98 \\
{[\text { DIRS 113694] }}\end{array}$ & $\begin{array}{l}\text { Rautman and } \\
\text { McKenna } 1998 \\
\text { [DIRS 107442], } \\
\text { p. } 1274\end{array}$ & $\begin{array}{l}\text { Postprocesses a set of simulated Ks values } \\
\text { (GSLIB format) together with the corresponding } \\
\text { porosity simulation and substitutes uniform random } \\
\text { Ks values at grid nodes where the simulated porosity } \\
\text { value is less than } 0.05 \text {; appropriate only for TSw } \\
\text { model unit. }\end{array}$ \\
\hline COORDS & $\begin{array}{c}\text { 12/17/98 } \\
\text { [DIRS } 113704]\end{array}$ & $\begin{array}{l}\text { Rautman and } \\
\text { McKenna } 1998 \\
\text { [DIRS 107442], } \\
\text { p. } 1287\end{array}$ & $\begin{array}{l}\text { Adds Nevada state plane }(x, y, z) \text { coordinates to a } \\
\text { GSLIB-format output file given a grid specification } \\
\text { and a corresponding structure contour file of top } \\
\text { elevations and thicknesses }\end{array}$ \\
\hline STRATC4 & $\begin{array}{c}4 \\
\text { [DIRS 113708] }\end{array}$ & Appendix A & $\begin{array}{l}\text { Computes unit-specific stratigraphic coordinates } \\
\text { using Equation 6.4-2 from Section 6.4.3.2 using a } \\
\text { SIGMA PLOT transform (macro). }\end{array}$ \\
\hline
\end{tabular}

NOTE: Formal version numbers were not used for software routines under SNL QAIP 19-1 [DIRS 129329]; instead, the date that the documentation associated with the routine was entered into the referenced scientific notebook is shown. 
Microsoft Excel 95 and/or Excel 97 were used to compile and organize rock properties measurements by drill hole and depth, and later by modeling unit prior to writing the final ASCII text files used as input to the modeling algorithms. Standard cell-based arithmetic operations of Excel were used on a temporary basis to check for and identify duplicate sample data (by depth), but the results of these calculations did not change any measurement values, and the columns involved were deleted prior to writing the final ASCII text input files. Standard cell-based arithmetic operations were also used to construct two new variables in selected data files related to hydrous-phase mineral alteration. One variable represents the total hydrous mineral phase content, and was constructed simply as the sum of the four relevant mineral fractions described in Section 6.4.3.1. The other variable is an indicator variable constructed using the logic of Equation 6.4-1, also described in Section 6.4.3.1. These computations are immediately verifiable by visual inspection. Cell-based arithmetic was also used to adjust the core bound-water contents for parity with the petrophysically based bound-water contents, as described in Section 6.4.7.1. This computation also is immediately verifiable by visual inspection.

SIGMA PLOT, versions 2.0 and 5.0, was used to compile and organize rock properties measurements and to generate graphic displays of drill hole data for determining that the selection and organization of the drill hole data was conducted properly. SIGMA PLOT arithmetic spreadsheet operations were also used to create the bound-water content variable described in Sections 6.4.3.1 and 6.4.7.1 as the simple difference between two original variables. This calculation is immediately verifiable by visual inspection. SIGMA PLOT was also used to generate various statistical measures, including histograms, cumulative distribution functions, crossplots, and linear regressions of selected data sets.

EVS, version 3.75, was used to generate selected graphic visualizations (report figures, including block diagrams and cross-sectional views: e.g., Figures 6.5-1 [top half] and 6.5-2) of the completed rock properties models in stratigraphic coordinates only. The geostatistical and other modeling capabilities of EVS were not used for this analysis.

VARIO, versions 1.16 and 1.20, from the geostatistical package UNCERT, was used to compute standard 3-D experimental variograms using the input data files. Proper operation of this software was verified by visual inspection of the results and by a simple manual verification documented in Appendix C.

VARIOFIT, version 1.20, from the geostatistical package, UNCERT, was used to fit standard variogram models to the experimental variograms produced with VARIO. Proper operation of this software was verified by visual inspection of the results and by a simple manual verification documented in Appendix D.

HISTPLT, version 1.2, from the geostatistical software library GSLIB (Deutsch and Journel 1992 [DIRS 100567]), was used to generate histograms and summary statistics for various data sets, including quality checks of completed simulations and other models. Proper operation of this software was verified by visual inspection of the results and by comparison of results with similar values produced by other software (especially SIGMA PLOT, above). 
GAM3, version 1.2, from the geostatistical software library GSLIB (Deutsch and Journel 1992 [DIRS 100567]), was used to generate exhaustive 3-D variogram data for plotting as a quality checks of completed simulations and other models. Proper operation of this software was verified by visual inspection of the results. 


\section{INTENTIONALLY LEFT BLANK}




\section{INPUTS}

\subsection{DIRECT INPUTS}

There are seven different classes of data used as input to rock properties modeling. Four of these categories (Sections 4.1.1 through 4.1.4) involve actual measurements of rock material properties, either in the laboratory or by calculation from geophysical measurements obtained in the field. A fifth class of property (Section 4.1.5) is also derived from in situ geophysical measurements; it is sufficiently different in nature and used for a different purpose, therefore it is discussed separately. The remaining two classes of input data (Sections 4.1.6 and 4.1.7) consist of the stratigraphic contacts bounding the four rock properties modeling units. The sixth class consists of actually observed (measured) contacts. The seventh class involves interpreted or modeled contacts, used in cases where a given drill hole did not go deep enough to penetrate a unit completely. These seven types of data are described in the paragraphs that follow. Data tracking numbers (DTNs) associated with each type of data are provided in tables in the relevant section. The description provided for the seven classes of data constitutes the justification for their selection as appropriate inputs. Each discussion documents data attributes that were the basis for their selection as direct inputs.

\subsubsection{Laboratory Core Porosity Data}

Laboratory measurements of porosity have been obtained for core samples taken from boreholes within both the repository block and immediately adjoining areas. The measurement process is described by Flint (1998 [DIRS 100033], pp. 11 to 17). DTNs associated with the laboratory-measured core porosity values used in the rock properties model are presented in Table 4-1.

Table 4-1. Source of Input Laboratory Core Porosity Data

\begin{tabular}{|l|l|}
\hline \multicolumn{1}{|c|}{ Data Source Description } & \multicolumn{1}{c|}{ Reference } \\
\hline RH core porosity data & DTN: MO0109HYMXPROP.001 [DIRS155989] \\
\hline RH porosity, SD-6 & DTN: GS980808312242.014 [DIRS 106748] \\
\hline RH porosity, WT-24 & DTN: GS980708312242.010 [DIRS 106752] \\
\hline
\end{tabular}

DIRS=Document Input Reference System; DTN=data tracking number; $\mathrm{RH}=$ relative humidity

Flint reports two porosity values for each sample: one obtained after drying the sample in a relative humidity oven at elevated humidity levels $\left(60^{\circ} \mathrm{C}\right.$ and 65 percent relative humidity), and the other after drying in a $105^{\circ} \mathrm{C}$ oven (oven-dried) and ambient, but very low relative humidity (Flint 1998 [DIRS 100033], pp. 11 to 17, Table 7). The distinction is important, as Flint has demonstrated that matrix saturated hydraulic conductivity is better correlated with the relative humidity porosity values (Flint 1998 [DIRS 100033], pp. 17 and 32 to 33, Figure 12). Because part of the intent of this rock properties modeling exercise is to model spatial variability in the hydraulic conductivity of the site, the relative humidity core porosity values were used exclusively as input to the geostatistical modeling of porosity. 


\subsubsection{Calculated Petrophysical Porosity Data}

Borehole petrophysical logs have been converted to quantitative estimates of porosity in Combined Porosity from Geophysical Logs (CRWMS M\&O 1999 [DIRS 109022], pp. 5-1 to 5-2). These data provide substantial information regarding spatial heterogeneity across the entire site area (Figure 1-1), particularly for regions remote from the repository block for which no core samples exist. Use of data from these regions outside the immediate rock properties model boundaries is important in identifying long-range spatial correlation patterns that reduce uncertainty within the modeled area. The DTNs associated with the calculated petrophysical porosity data are presented in Table 4-2.

Table 4-2. Source of Input Petrophysical Porosity Data

\begin{tabular}{|l|l|}
\hline \multicolumn{1}{|c|}{ Data Source Description } & \multicolumn{1}{c|}{ Reference } \\
\hline POREF, VWC & DTNs: MO0010CPORGLOG.002 [DIRS 155229], \\
& MO0010CPORGLOG.003 [DIRS 155959] \\
\hline
\end{tabular}

DIRS=Document Input Reference System; DTN-data tracking number; POREF= Effective Porosity or RH Porosity; VWC=volumetric water content

Combined Porosity from Geophysical Logs generated two different porosity values using petrophysics (CRWMS M\&O 1999 [DIRS 109022], p. 5-1). These values are identified in the files as effective porosity (POREF), which corresponds approximately to the relative humidity laboratory core measurements, and total porosity (POROTOT), corresponding approximately to the $105^{\circ} \mathrm{C}$ oven-dried samples. The data files in Table 4-2 also include a calculated petrophysical value, VWC, representing the volumetric water content, derived from neutron logging (CRWMS M\&O 1999 [DIRS 109022], p. 5-2). Values of VWC have been substituted for POREF in certain geologic intervals and under certain circumstances that are described in Section 6. The method of calculating porosity and volumetric water content followed standard industry practice (CRWMS M\&O 1999 [DIRS 109022], Section 5).

\subsubsection{Laboratory Measured Secondary Property Data}

A second class of laboratory measurements performed on core samples consists of "secondary" material properties that generally are of greater interest in design or performance assessment modeling than simple porosity (completed models are referred to in Section 6 as "derivative" properties). Laboratory values of bulk density, matrix saturated hydraulic conductivity $\left(K_{\mathrm{s}}\right)$ (Flint 1998 [DIRS 100033], pp. 11 to 17), thermal conductivity, and additional measurements of porosity (specifically those correlated with the secondary properties) were also measured for selected samples, in addition to the "primary" porosity data of Section 4.1.1. This measurement of multiple properties on the same physical specimen allows identification of statistically valid cross-variable correlations. Such correlations thus permit modeling the spatial variability of these secondary or derivative properties in regions where no actual measurements of these properties exist. DTNs associated with the secondary laboratory property data are presented in Table 4-3. 
Table 4-3. Source of Input Secondary Property Data

\begin{tabular}{|c|c|}
\hline Data Source Description & Reference \\
\hline Porosity, bulk density, $K_{s}$ data & DTN: MO0109HYMXPROP.001 [DIRS 155989] \\
\hline Porosity, thermal conductivity samples & DTN: SNL01A05059301.007 [DIRS 108980] \\
\hline Thermal conductivity, NRG- holes & DTN: SNL01A05059301.005 [DIRS 109002] \\
\hline
\end{tabular}

\subsubsection{X-Ray Diffraction Indicators of Mineral Alteration}

The identification and modeling of "hydrous-phase mineral alteration" (see Section 6.2.4) as it affects matrix $K_{s}$ is complicated by a general scarcity of both mineralogic and hydraulic conductivity data across the entire Yucca Mountain site area. As described in more detail (Section 6.2.4), the approach is to use both direct (x-ray diffraction analyses [XRD]) and indirect (petrophysical data) in combination to model this type of alteration. Quantitative XRD mineralogic data (as mineral fractions of several zeolite minerals and smectite clays) are used as input to the alteration modeling portion of the rock properties modeling effort. The mineralogic data are both converted to hard (certain) indicators of mineral alteration and used to calibrate petrophysical data (Section 4.1.5) as soft (uncertain) indicators. Generation of both types of indicators is described in Section 6.4.7. The DTN associated with the XRD mineralogic analyses is presented in Table $4-4$.

In Technical Work Plan for: The Integrated Site Model, TWP-NBS-GS-000003 REV 05 (BSC 2004 [DIRS 169635]) there was no plan to qualify the XRD mineral abundance data cited by the rock properties model. However, because the qualification report prepared for the mineralogic model also qualifies the XRD mineral abundance data for the rock properties model it was included in this report. The qualification report was prepared in accordance with the plan contained in the Technical Work Plan for: The Integrated Site Model, TWP-NBS-GS-000003, Rev 05 (BSC 2004 [DIRS 169635]), Appendix A. Documentation of the qualification of unqualified mineral alteration data are discussed and documented in Appendices E, F, and G. Information listing the sources and related qualification activities for DTN: LA9910DB831321.001 [DIRS 113568] are provided in Appendix H. The documentation provided by Appendices E through $\mathrm{H}$ qualifies all of the XRD mineral abundance data cited as direct input by the rock properties model.

Table 4-4. Source of Input X-ray Diffraction Mineralogy Data

\begin{tabular}{|l|c|}
\hline \multicolumn{1}{|c|}{ Data Source Description } & Reference \\
\hline Zeolite mineral contents & DTN: LA9910DB831321.001 [DIRS 113568] \\
\hline
\end{tabular}




\subsubsection{Petrophysical Indicators of Hydrous-Phase Mineral Alteration}

The use of both direct and indirect indicators to model hydrous-phase mineral alteration as it affects the magnitude and spatial distribution of matrix $K_{s}$ was noted in Section 4.1.4. Petrophysically derived data, specifically the POROTOT and POREF calculated porosity values described in Section 4.1.2, are used to generate soft indicators of mineral alteration. Soft indicators are data that provide indirect indications of hydrous phase mineral alteration such as porosity and hydraulic conductivity. The use and calibration of soft indicators is documented in Section 6.4.7. The DTNs associated with the petrophysical porosity data used to create the petrophysical indicators of hydrous-phase mineral alteration are presented in Table 4-5. The mechanics of generating and calibrating those indicators is presented in Section 6.4.7.

Table 4-5. Source of Input Petrophysical Data Used for Identification of Mineral Alteration

\begin{tabular}{|l|l|}
\hline \multicolumn{1}{|c|}{ Data Source Description } & \multicolumn{1}{c|}{ Reference } \\
\hline POREF, POROTOT, VWC & $\begin{array}{l}\text { DTNS: MO0010CPORGLOG.002 [DIRS 155229], } \\
\text { MO0010CPORGLOG.003 [DIRS 155959] }\end{array}$ \\
\hline
\end{tabular}

DIRS=Document Input Reference System; DTN=data tracking number; POREF=Effective Porosity; POROTOT=Total Porosity; VWC=volumetric water content

\subsubsection{Observed (Measured) Lithostratigraphic Contacts}

Rock properties modeling has been conducted within stratigraphic coordinates, which represent the relative vertical position of each measured property value within a model unit. This stratigraphic coordinate conversion requires depth values for both the upper and lower contact of each aggregate model unit in each borehole, as described in Section 6.3.2. Typically, the required depth values were physically observed, either in core, in geophysical logs, or in downhole video records. DTNs associated with the observed lithostratigraphic contact data are presented in Table 4-6.

Table 4-6. Source of Input Observed Lithostratigraphic Contacts

\begin{tabular}{|l|l|}
\hline \multicolumn{1}{|c|}{ Data Source Description } & \multicolumn{1}{c|}{ Reference } \\
\hline Contacts for Geologic Framework Model 3.0 & DTN: MO0004QGFMPICK.000 [DIRS 152554] \\
\hline Contacts for USW SD-6 & DTN: SNF40060298001.001 [DIRS 107372] \\
\hline Contacts for USW WT-24 & DTN: SNF40060198001.001 [DIRS 107239] \\
\hline
\end{tabular}

DIRS=Document Input Reference System; DTN=data tracking number

\subsubsection{Modeled Lithostratigraphic Contacts}

The vast majority of model-unit contacts required for the stratigraphic coordinate conversion are taken directly from a tabulation of observed contacts (Table 4-6). However, a small number of contacts were projected using Geologic Framework Model version 3.0 (DTN: MO9804MWDGMFM03.001 [DIRS 109050]) or Geologic Framework Model version 3.1 (DTN: MO9901MWDGFM31.000 [DIRS 103769]) because the drill hole did not fully penetrate the model unit. This situation most frequently involves projecting the depth of the lower contact of a given modeling unit where the borehole bottomed within that unit. A few upper contacts had to be projected where the top of a particular model unit had been eroded at the borehole location. The stratigraphic coordinate 
conversion is also complicated for boreholes that intercept a fault. In this case, it has been necessary to use modeled isochore information to reconstruct the missing portion of the stratigraphic section and infer the "unfaulted depths" based on unit-thickness trends obtained using the Geologic Framework Model. These instances are documented in the scientific notebooks associated with this modeling activity (Rautman, C. and McKenna, S. 1998 [DIRS 107442] and Rautman, C. 1999 [DIRS 109035]. DTNs associated with the geologic framework models used to extract the projected lithostratigraphic contacts are presented in Table 4-7. Note that Rock Properties Model version 3.1 (DTN: MO9901MWDGFM31.000 [DIRS 103769]) was created simply by inserting the new drill hole data for holes SD-6 and WT-24 into the data set from rock properties model version 3.0 (created using projected contacts from Geologic Framework Model Version 3.0 (DTN: MO9804MWDGFM3.001 [DIRS 109050]) and regenerating the model.

Use of projected stratigraphic contacts for boreholes, where the observed contacts were not available, is justified because this is one of the specific purposes of the GFM as described in Section 1 of the report (BSC 2004, [DIRS 170029]). The primary difference between the Geologic Framework Model version 3.0 and version 3.1 is the inclusion of lithostratigraphic contact data from boreholes USW SD-6 and USW WT-24 (BSC 2004 [DIRS 170029] Section 6.3.3). The principle changes from Geologic Framework Model version 3.1 to version 2000 are to correct the thickness of the RHH model layer, and an anomalous flexure in the extreme northern edge of the model (BSC 2004 [DIRS 170029] Section 6.3.4). Neither of these changes impacts the rock properties model. This is because the RHH is not a model layer that is used by the rock properties model, and the extreme northern edge of the geologic framework model exceeds the boundary of the rock properties model, as shown on Figure 4. Therefore, this impact assessment will focus on the changes in predicted stratigraphic contacts between Geologic Framework Model version 3.0 and version 3.1 due to the inclusion of boreholes USW SD-6 and USW WT-24.

Figures 6.4-1 through 6.4-4 shows that changes caused by the inclusion of borehole USW SD-6 are constrained by the surrounding nearest boreholes: USW H-5, USW H-6, USW SD-12, and USW UZ-6. All four of these surrounding boreholes penetrate the tops of the PTn, TSw, CHn, and Tcp layers' model layers. These surrounding boreholes already constrain the stratigraphic tops of the model layers. Therefore, the inclusion or exclusion of USW SD-6 contact data would have a minimal impact on the predicted tops for the rock properties model layers. The base of the lowest model layer, Tcp (equivalent to the top of the Tcb layer), is not penetrated by borehole USW SD-6. However, the base of the Tcp layer is observed in the nearby surrounding boreholes: USW H-5, USW H-6, USW SD-12, and USW H-3 (DTN: MO0004QGFMPICK.000 [DIRS 152554]). Therefore, changes in predicted contacts caused by the inclusion of borehole USW SD-6 will be minimal between version 3.0 and 3.1 of the geologic framework model because of the close proximity of surrounding boreholes that already constrain the model layers.

Similarly, for borehole USW WT-24 model layer, tops and bottoms are constrained by the surrounding nearest boreholes: USW G-2, USW WT-18, and USW UZ-14, as shown by Figures 6.4-1 through 6.4-4. USW WT-24 partially penetrates or ends within model layer CHn. The surrounding three boreholes penetrate to the top of model layer Tcp. Therefore, again the surrounding boreholes provide control or constrain the location of the model layers. Therefore, changes in the predicted stratigraphic contacts caused by inclusion of borehole USW WT-24 will 
be minimal between version 3.0 and 3.1 of the geologic framework model due to the close proximity of surrounding boreholes that constrain the model layers.

In addition, as shown by Figure 6.4-5 the rock properties model is constructed in stratigraphic coordinates. Therefore, all borehole data and results are located relative to their position in the model layer as shown by Equation 2. Therefore, changes caused by the difference between the use of the Geologic Framework Model versions 3.0, as compared to version 3.1, for predicted contacts would only result in the shifting of the projected properties when modeled in stratigraphic coordinates. Examination of the results of the model layer representations of the parameters, as shown by Figures 6.5-16, 6.5-17, and 6.5-18, do not indicate that any discontinuities exist in the parameter representations.

Therefore, based on the evaluation of existing boreholes that surround USW SD-6 and USW WT-24, and the lack of observed discontinuities in the property representations, there is no significant impact to the rock properties model caused by the use of the Geologic Framework Model 3.0 and 3.1 instead of the current version of the Geologic Framework Model 2000 (DTN: MO0012MWDGFM02.002 [DIRS 153777]).

Table 4-7. Source of Input Projected Lithostratigraphic Contacts and Isochore Information

\begin{tabular}{|c|c|}
\hline Data Source Description & Reference \\
\hline Geologic Framework Model 3.0 & DTN: MO9804MWDGFM03.001 [DIRS 109050] \\
\hline Geologic Framework Model 3.1 & DTN: MO9901MWDGFM31.000 [DIRS 103769] \\
\hline Geologic Framework Model 2000 & DTN: MO0012MWDGFM02.002 [DIRS 153777] \\
\hline \multicolumn{2}{|c|}{ DIRS=Document Input Reference System; DTN=data tracking number } \\
\hline \multicolumn{2}{|c|}{$\begin{array}{l}\text { The Geologic Framework Model } 2000 \text { DTN: DTN: MO0012MWDGFM02.002 } \\
\text { [DIRS 153777] is not cited as direct input but listed for completeness and } \\
\text { traceability. }\end{array}$} \\
\hline
\end{tabular}

\subsection{CRITERIA}

The acceptance criteria that will be used by the Nuclear Regulatory Commission (NRC) to determine whether the technical requirements have been met are identified in the Yucca Mountain Review Plan, Final Report (YMRP; NRC 2003 [DIRS 163274]). An evaluation of the acceptance criteria against the information in this model report determined that criteria other than those documented in the TWP should be addressed. The identification of the technical users and their specific use of the product output, rather than the intended use of the product output, was basis for this re-examination of the acceptance criteria. The result of this re-examination was the identification of Acceptance Criteria not listed in the TWP.

\subsection{3, Radionuclide Transport in the Saturated Zone}

\section{Acceptance Criterion 1: System Description and Model Integration Are Adequate.}

Subcriterion (2): The description of the aspects of hydrology, geology, geochemistry, design features, physical phenomena, and couplings, that may affect radionuclide transport in the saturated zone, is adequate. For example, the description includes changes in transport properties in the saturated zone, from water-rock interaction. Conditions and assumptions in the 
abstraction of radionuclide transport in the saturated zone are readily identified, and consistent with the body of data presented in the description;

\section{Acceptance Criterion 2: Data Are Sufficient for Model Justification.}

Subcriterion (3): Data on the geology, hydrology, and geochemistry of the saturated zone, including the influence of structural features, fracture distributions, fracture properties, and stratigraphy, used in the total system performance assessment abstraction, are based on appropriate techniques. These techniques may include laboratory experiments, site-specific field measurements, natural analogue research, and process-level modeling studies. As appropriate, sensitivity or uncertainty analyses used to support the U.S. Department of Energy total system performance assessment abstraction are adequate to determine the possible need for additional data.

\subsection{CODES, STANDARDS, AND REGULATIONS}

No specific formally established codes, standards, or regulations have been identified as applying to this modeling activity other than those previously cited in this report. 


\section{INTENTIONALLY LEFT BLANK}




\section{ASSUMPTIONS}

The principal assumption involved in constructing the rock properties models involves the use of "porosity-as-a-surrogate" for modeling the spatial variability of other, "secondary" material properties that are typically of greater interest in performance modeling than porosity itself, but which are less sampled when compared to porosity at Yucca Mountain. This concept of using abundant porosity data as a surrogate for other properties is not new. Rautman and McKenna (1997 [DIRS 100643], p. 13) list a sampling of published references using the porosity-as-a-surrogate technique. For Rock Properties Model version 3.0, porosity has been used to model the spatial distributions of bulk density, saturated hydraulic conductivity, and thermal conductivity (MO9804MWDGFM03.001 1998 [DIRS 109050]).

The concept of porosity as a surrogate is based on empirically observed correlations of porosity with a secondary properties. A consequence of undersampling is that the spatial variability of the undersampled variable cannot be described confidently on a stand-alone basis, let alone such that the joint spatial continuity patterns of the two (or more) variables can be reproduced simultaneously. It is important to understand that modeling the spatial distribution of several material properties without considering the inter-variable correlations can lead to highly unrealistic input to physical-process modeling codes, which in turn can lead to highly unreasonable estimates of performance parameters. Sampling randomly from separate (univariate) probability density functions may easily produce such un-physical combinations as a low porosity-high thermal conductivity-high hydraulic conductivity tuff. The severity of neglecting cross-variable correlations in modeling spatially variable domains increases as physical-process modeling captures multiple coupled processes.

Using porosity as a surrogate for various other materials in modeling, Yucca Mountain is supported by consideration of the physics involved in the site-specific rock units being modeled. For example, for a given rock type, increasing the volume of pore space must decrease the bulk density of the rock mass. The part of the rock that "isn't there” is available to hold fluids, but it contributes nothing to the total mass contained within a unit volume: the definition of bulk density. Again for a given rock type, the conduction of heat energy through the material is directly related to the density (or, inversely to the pore space) of the material. All else being equal, a higher porosity-lower density tuff will conduct heat less readily, leading to a lower thermal conductivity value. Note here that it is the total amount of void space in a rock that affects thermal conductivity, not simply the amount of pore space that is conducting water within the unsaturated zone (UZ). This fact has important implications to modeling of whole-rock thermal conductivity in the presence of large-diameter (up to 1 meter) lithophysal cavities.

As another example, although hydraulic conductivity is not generally well correlated with porosity across many classes of soils and/or rock materials, the empirical observation at Yucca Mountain is that this correlation is quite strong within limited groupings of rock types. Specifically, both welded and nonwelded lithologies appear to be associated with a continuum of saturated hydraulic conductivity values (see Section 6.4.5.1). Evidently, unless affected by some additional physical process (such as zeolitic or other similar alteration), there is a strong relationship between the progressive, overall reduction in porosity and the progressive reduction in the average diameter of the passages between interconnected pores (which is what exerts principal control on the flow of water through the existing pore space) across this continuum of 
nonwelded to densely welded materials. Conversely, a genetic process that changes the diameter and/or geometry of the pore throats (e.g., zeolitization), while not commensurately filling in the total quantity of void space, can reduce the hydraulic conductivity of the rock by orders of magnitude while leaving the porosity essentially unchanged. In fact, both these cases are observed and modeled at Yucca Mountain.

This assumption does not require confirmation. 


\section{MODEL DISCUSSION}

\subsection{INTRODUCTION AND ROCK PROPERTIES MODEL OVERVIEW}

Yucca Mountain is located in the southwestern Nevada volcanic field and consists of faulted and tilted blocks composed of layered sequences of ash-flow, ash-fall, and bedded tuffs of Miocene age (Sawyer et al. 1994 [DIRS 100075], pp. 1304 to 1318).

The rock properties model (RPM) is a 3-D, discretized numerical representation of spatial variability and heterogeneity of a number of fundamental bulk and hydrologic material properties for the majority of the rocks within the UZ at Yucca Mountain. The model divides the model volume into four internally lithologically similar model units. In descending stratigraphic order these are (1) the Paintbrush nonwelded (PTn) model unit, (2) the Topopah Spring welded (TSw) model unit, (3) the Calico Hills nonwelded (CHn) model unit, and (4) the Prow Pass Tuff (Tcp). The Tiva Canyon Tuff was not modeled for two primary reasons, which are discussed in detail in Rautman and McKenna (1997 [DIRS 100643], p. 10). First, such a model is not needed because the Tiva Canyon Tuff is highly fractured, so that matrix properties are subordinate to the role of fractures in hydrologic flow. Second, because most boreholes are located in ravines eroded into the Tiva, few boreholes penetrate a meaningful stratigraphic section of the Tiva Canyon Tuff and data are accordingly sparse. The Bullfrog Tuff underlies the Prow Pass Tuff and was not modeled, as the amount of borehole rock property data is significantly less when compared to the four overlying model layers. This can be verified by examining Table 7 from Flint (1988 [DIRS 100033]). Table 6.1-1 presents a correlation of the RPM model units with other project stratigraphies. For all four model units, the modeled material properties are:

- Matrix porosity

- Whole-rock bulk density

- Matrix saturated hydraulic conductivity.

For the TSw model unit, additional material properties are:

- Lithophysal porosity:

- Whole-rock thermal conductivity. 
Table 6.1-1. Correlation Chart for Model Stratigraphy

\begin{tabular}{|c|c|c|c|c|c|}
\hline \multicolumn{4}{|c|}{ Stratigraphic Unit ${ }^{1}$} & Abbreviation $^{1}$ & $\begin{array}{l}\text { Rock Properties } \\
\text { Model Unit }\end{array}$ \\
\hline 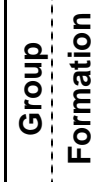 & 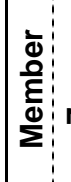 & 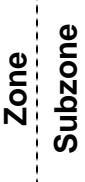 & & & \\
\hline \multicolumn{4}{|c|}{ Alluvium and Colluvium } & Qal, QC & \multirow{6}{*}{ Not Modeled } \\
\hline \multicolumn{4}{|c|}{ Timber Mountain Group } & :Tm & \\
\hline \multicolumn{4}{|c|}{ Paintbrush Group. } & T. & \\
\hline \multicolumn{4}{|c|}{ Tiva Canyon Tuff } & Tpc. & \\
\hline \multicolumn{4}{|c|}{ Crystal-Rich Member } & Tpcr & \\
\hline \multicolumn{4}{|c|}{ Crystal-Poor Member } & Tpcp & \\
\hline \multicolumn{4}{|c|}{$\begin{array}{l}\text { Vitric zone } \\
\end{array}$} & Tpcpv & \\
\hline & & \multicolumn{2}{|c|}{ Densely welded subzone } & Tpcpv3 & \\
\hline & \multicolumn{3}{|c|}{ Moderately welded subzone } & Tpcpv2 & \\
\hline & & \multicolumn{2}{|c|}{ Nonwelded subzone } & Tpcpv1 & \multirow{6}{*}{ PTn } \\
\hline & \multicolumn{3}{|c|}{ Pre-Tiva Canyon bedded tuff } & Tpbt4 & \\
\hline \multicolumn{4}{|c|}{ Yucca Mountain tuff } & Tpy... & \\
\hline \multicolumn{4}{|c|}{ Pre-Yucca Mountain bedded tuff } & $\begin{array}{l}\text { Tpbt3 } \\
\end{array}$ & \\
\hline \multicolumn{4}{|c|}{ Pah Canyon Tuff } & Tpp. & \\
\hline \multicolumn{4}{|c|}{ Pre-Pah Canyon bedded tuff } & $\begin{array}{ll}\text { Tpbt2 } \\
\end{array}$ & \\
\hline \multicolumn{4}{|c|}{ Topopah Spring Tuff } & Tpt & \\
\hline \multicolumn{4}{|c|}{ Crystal-Rich Member } & Tptr & \\
\hline \multicolumn{4}{|c|}{ Vitric zone } & Iptrv. & \\
\hline & & \multicolumn{2}{|c|}{ Nonwelded subzone } & Tptrv3 & \\
\hline & & \multicolumn{2}{|c|}{ Moderately welded subzone } & Tptrv2 & \\
\hline & & \multicolumn{2}{|c|}{ Densely welded subzone } & Tptrv1 & \\
\hline & \multicolumn{3}{|c|}{ Nonlithophysal zone } & Tptm & \\
\hline & \multicolumn{3}{|c|}{ Lithophysal zone } & Tptrl & \\
\hline & Crys & stal-Pc & oor Member & Tptp. & \\
\hline & & Upper & lithophysal zone & Tptpul & \\
\hline & & Middle & nonlithophysal zone & Tptpmn & \\
\hline & & Lower & lithophysal zone & Tptpll & $15 W$ \\
\hline & & Lower & nonlithophysal zone & Tptpln & \\
\hline & & Vitric $z$ & zone. & Tptpv & \\
\hline & & $\mathrm{De}$ & nsely welded subzone & Tpcpv3 & \\
\hline & & & derately welded subzone & Tpcpv2 & \\
\hline & : & & nwelded subzone & Tpcpv1 & \\
\hline & Pre- & -Topo & pah Spring bedded tuff & $\begin{array}{l}\text { Tpbt1 } \\
\end{array}$ & \\
\hline & lico! & Hills F & ormation & $\mathrm{Ta}$ & $\mathrm{CHn}$ \\
\hline & Bed & Ided ty & & (Tacbt) & \\
\hline Crate & Flat & Group & & :Tc & \\
\hline & DW Pa & ass Tu & & Tcp & $T r n$ \\
\hline & Pre- & -Prow & Pass bedded tuff & $\begin{array}{l}\text { (Tcbbt) } \\
\end{array}$ & 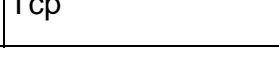 \\
\hline
\end{tabular}


Table 6.1-1. Correlation Chart for Model Stratigraphy (Continued)

\begin{tabular}{|c|c|c|c|c|}
\hline \multicolumn{3}{|c|}{ Stratigraphic Unit ${ }^{1}$} & Abbreviation $^{1}$ & $\begin{array}{l}\text { Rock Properties } \\
\text { Model Unit }\end{array}$ \\
\hline 음 & 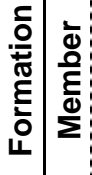 & 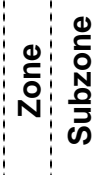 & & \\
\hline \multicolumn{3}{|c|}{ Bullfrog Tuff } & $\mathrm{Tcb}$ & \multirow{4}{*}{ Not Modeled } \\
\hline & \multicolumn{2}{|c|}{ Pre-Bullfrog Tuff bedded tuff } & (Tcbbt) & \\
\hline \multicolumn{3}{|c|}{ Tram Tuff } & Tct & \\
\hline & $\mathrm{Bec}$ & dded th & (Tctbt) & \\
\hline
\end{tabular}

Source: DTN: MO9510RIB00002.004 [DIRS 103801]

NOTE: ${ }^{1}$ Shaded areas represent "header" lines for subdivided units.

Lithophysal porosity and the two whole-rock properties in the above list are intended to represent the effect of the large (up to 1 meter in diameter) lithophysal cavities that are a very prominent feature of certain intervals within the Topopah Spring Tuff and the potential horizon. The rock properties model is tied geometrically to the bounding surfaces of model units within Geologic Framework Model (GFM) 3.1 (MO990MWDGFM31.000 [DIRS 103769]).

There are three fundamentally different types of models included within the RPM. First, a suite of 50 simulated property models (or realizations) have been generated for each material property using Monte Carlo-style geostatistical conditional simulation techniques. The number of simulated property models generated is a balance between the number of times the material property will be sampled to generate each representation, and the computational resources needed to generate the models. These models reproduce both the measured data values and the full range of spatial heterogeneity and spatial continuity exhibited by those data. At locations other than those of the measured values, material properties are generated (simulated) randomly from the local conditional probability density functions, and the variability of these values is interpreted to represent the uncertainty associated with predictions of material properties at these unsampled locations. The second types of models included in the RPM are summary expectation ("E-type") models for each rock property. These E-type models are computed as the node-by-node mathematical expectation (average) across the 50 simulated realizations, and they represent the property values most likely to be encountered at each discretized location. The third type of model included in the RPM is also a summary-type model, and these are computed as the node-by-node standard deviations of the 50 individual simulated property models. This third type of model is intended to provide users with a first-pass estimate of geologic uncertainty throughout the repository site, where "geologic uncertainty" consists of that uncertainty that results from less-than-exhaustive site characterization.

The two primary data sources used to model the spatial variability of rock properties at Yucca Mountain are laboratory-measured core samples and down-hole measured petrophysical property values. Porosity is the primary variable for which spatial variability and heterogeneity have been modeled directly from measured values. The other material properties are derivative properties that have been generated from the simulated porosity models using the geostatistical technique known as linear coregionalization. Additional information has been incorporated from x-ray 
diffraction (XRD) measurements of (principally) zeolite mineral content. This form of rock alteration is considered to be an important control on the variability of matrix saturated hydraulic conductivity. Correlation between XRD alteration mineralogy and down-hole petrophysical measurements has been used to extend modeling of this type of alteration into regions from which no mineralogical samples have been obtained.

The rock properties models are intended principally for use as input to numerical physical-process modeling, such as of ground-water flow and/or radionuclide transport. In anticipation of such use on a site scale, the models are discretized uniformly in the horizontal plane on a $200 \mathrm{~m}$ by $200 \mathrm{~m}$ ( $656.2 \mathrm{ft}$ by $656.2 \mathrm{ft}$ ) grid. Vertical discretization is unit-dependent at a nominal $2 \mathrm{~m}$ (approximately $7 \mathrm{ft}$ ) spacing in the PTn model unit and $5 \mathrm{~m}$ (approximately $16 \mathrm{ft}$ ) spacing elsewhere. The rock property models can be regenerated at virtually any desired level of discretization to meet the needs of downstream model users.

\subsection{CHANGES BETWEEN MODEL VERSIONS}

Four significant changes in modeling methodology and data from those used in RPM 2 (Rautman and McKenna 1997 [DIRS 100643] page 8; note that RPM 2 is the first numbered rock properties model) have been implemented for the current version of the rock properties model (RPM 3.1). These changes are described briefly in this section. Expanded discussions are presented as appropriate in Section 4.1 and 6.4.

\subsubsection{Changes in Model Unit Subdivisions and Modeled Region}

The first major change in the rock properties models (RPM) 3.1 is that the combined Calico Hills-Prow Pass model unit of RPM 2 (Rautman and McKenna 1997 [DIRS 100643]) has been subdivided into two new modeling units along the formation boundary at the top of the Prow Pass Tuff (Table 6.1-1). This revised subdivision scheme was adopted because the area of rock properties modeling for RPM 3.1 is smaller than that for RPM 2. The smaller model area is a consequence of increased focus on the immediate repository area by the YMP site-scale UZ hydrologic model. This decrease in the modeled volume resulted in an improved spatial distribution of boreholes within the remaining area and decreased the need to aggregate data in search of statistical mass, as that term was described by Rautman and McKenna (1997 [DIRS 100643], pp. 10 to 11).

\subsubsection{Adjustment of Model Unit Contacts to Reflect Mineralogy}

A second change is the adjustment of contacts between the welded interior core of the Topopah Spring Tuff (model unit TSw) and the respectively overlying and underlying PTn and CHn nonwelded units. For RPM 3.1, these contacts were moved outward one lithostratigraphic interval, with the result that the breaks are now between the Tptrv3-Tptrv2 and the Tptpv2-Tptpv1 lithostratigraphic units (Table 6.1-1). The rationale for this contact adjustment is that the revised boundaries better separate rocks with the potential to have been altered to zeolite minerals from high-temperature-crystallized rocks that almost never undergo such alteration. The spatial distribution of one derivative property, matrix saturated hydraulic conductivity, is strongly affected by the presence or absence of zeolitic minerals; thus a more accurate 
representation of this particular transition is the objective. Note that such modeling of alteration has been conducted only for the CHn and Tcp model units.

\subsubsection{Revised Petrophysical Data}

The third and most significant, but perhaps least obvious change between the rock properties models of RPM 2 and 3.1, is that all of the petrophysically based porosity data have been recalculated by CRWMS M\&O (1999 [DIRS 109022], pp. 5-1 to 5-2) following identification of a number of problems with the earlier data sets (see Rautman and McKenna 1997 [DIRS 100643], pp. 138 to 139). Specifically, the original petrophysical porosity data for RPM 2 involved two different calculation methods described by Nelson (1996 [DIRS 101270], pp. 17 to 23 and CRWMS M\&O 1996 [DIRS 100632], pp. 26 to 29), with the result that some spatial variability appeared to represent only the source of the calculated values (see discussion in Rautman and McKenna 1997 [DIRS 100643], pp. 26 to 29 and 49 to 51). A separate issue involved the absolute magnitude of some of the porosity values calculated by Nelson (1996 [DIRS 101270]; the data values themselves are contained in GS960708312132.002 (1996 [DIRS 113584]) within selected stratigraphic intervals, principally the densely welded vitric subzones (Tptrv1, Tptpv3) of the Topopah Spring Tuff. As a consequence, it was unclear if some portion of the inferred spatial heterogeneity was related simply to the mathematical calculations and not to physical geology.

The RPM 3.1, (CRWMS M\&O 1999 [DIRS 109022], pp. 4-1 to 4-25) re-examined all of the underlying petrophysical logs, and processed the necessary fundamental petrophysical traces through a common data-reduction algorithm to calculate porosity. Specifically, use of the “balanced-water approach” using resistivity logs (CRWMS M\&O 1996 [DIRS 100632], p. 28) to calculate water saturation and volumetric water content was abandoned. Instead, porosity was calculated directly from the downhole density logs (separately above and below the water table), with volumetric water content derived directly from calibrated neutron logs (CRWMS M\&O 1999 [DIRS 109022], pp. 4-13 to 4-25 and pp. 5-1 to 5-2). This recalculation and common processing history eliminate one (nongeologic) source of apparent variability.

Recalculation of the petrophysical porosity data involved not only a common data-reduction algorithm, but also calibration of the input bulk density trace against a set of internal standards (CRWMS M\&O 1999 [DIRS 109022], pp. 3-1 to 3-2 and 4-2 to 4-5). Bulk density is the principal petrophysical measurement used in the porosity calculation. The internal standards are provided by four distinctive lithostratigraphic units, at least one of which is present in virtually each of the site boreholes. These units are the crystal-rich densely welded vitric (Tptrv1) and nonlithophysal (Tptrn) lithostratigraphic units, and the crystal-poor middle nonlithophysal (Tptpmn) and densely welded vitric (Tptpv3) units. Based on evidence from recovered drill core that these four intervals are of relatively uniform material, a set of density-correction factors was developed for each borehole (CRWMS M\&O 1999 [DIRS 109022], pp. 4-2 to 4-5, Table 3). The relatively uniform character of the four intervals in terms of density is shown in Figure 6.4-9. The density logs throughout each borehole were then adjusted proportionately (by individual logging run if appropriate) so that the average value in these distinctive zones indicated the correct bulk density. 


\subsubsection{Revised Approach to Identifying Hydrous-Phase Mineral Alteration}

The term "hydrous-phase mineral alteration" is used in this report to indicate changes in initial (volcanic) mineral compositions that collectively act to reduce the matrix hydraulic conductivity of laboratory specimens (and in situ rocks) compared with equivalent unaltered rocks of approximately the same porosity (Rautman and McKenna 1997 [DIRS 100643], pp. 35 to 40, Figures 25 and 26 and Table 8; Flint 1998 [DIRS 100033], pp. 31 to 33 and Figure 12). Such rocks typically exhibit mineralogical alteration either to zeolite minerals, principally but not exclusively clinoptilolite and mordenite, or to expandable-layer clay minerals ("smectite" or montmorillonite; Flint 1998 [DIRS 100033], p. 33). Within the two rock properties modeling units of principal interest ( $\mathrm{CHn}$ and Tcp), hydrous-phase mineral alteration translates fairly precisely to zeolitic alteration. However, this distinction is maintained with respect to petrophysically based indicators of reduced $K_{s}$ to emphasize that this approach is unable to distinguish zeolites and montmorillonitic clays in the downhole environment.

A fourth change in rock properties modeling procedure involves the approach used to identify the spatial distribution of hydrous-phase mineral alteration, which affects the coregionalization of hydraulic conductivity with porosity in the lower two (CHn, Tcp) of the four properties modeling units. For version 2 of the rock properties models, each grid node was identified as either likely or unlikely to exhibit such alteration based on a spatial continuity model identified through petrophysical measurements (see Rautman and McKenna 1997 [DIRS 100643], pp. 43 to 44 and 57 to 59). For version 3, altered grid nodes were modeled as a weighted combination of both hard (X-Ray Diffraction Indicators of Mineral Alteration, Section 4.1.4) and soft (Petrophysical Indicators of Hydrous-Phase Mineral Alteration, Section 4.1.5) data. Generation and use of the combined alteration data set is described in see Section 6.4.7.

\subsection{PHILOSOPHICAL AND CONCEPTUAL MODELING FRAMEWORK}

This section is intended to provide a relatively high-level conceptual description of the geostatistical modeling approach, including a brief discussion of how stochastic material-property models such as these fit into the overall performance modeling of the Yucca Mountain site. The methodology has been described in some detail by Rautman and McKenna (1997 [DIRS 100643], pp. 6 to 69). Additional information regarding geostatistical modeling techniques in general may be found by following the references cited in the Rautman and McKenna document (1997 [DIRS 100643]).

\subsubsection{Modeling Philosophy and Conceptual Approach}

Licensing of the Yucca Mountain site as a geologic disposal site for nuclear waste will require quantitative predictions of waste-isolation performance of both the rocks that form Yucca Mountain and the engineered barrier system for an extended period of time into the future. These predictions will require the use of numerical modeling techniques in an effort to capture critical aspects of highly complex physical processes; for example, the flow of ground-water and the transport of radionuclide contaminants under both unsaturated and saturated conditions. Modeling the performance of the site will be influenced both by present-day conditions and by future conditions that must account for perturbation of ambient conditions by the thermal pulse related to the presence of heat-generating radioactive materials and potential changes in climate. 
A fundamental principle involved in the numerical representation of real-world physical processes is that the relevant material properties of the modeled domain must be known at all positions within that domain. However, in contrast to this requirement for an "exhaustive" spatial description, the process of describing or characterizing a site invariably consists of collecting observations of properties or state variables at a limited number of locations, the exact positions of which are frequently determined by less-than-optimal external factors. This is particularly true for the 3-D characterization of a geologic site, such as Yucca Mountain. Because descriptive characterization is limited both by access (particularly to the subsurface) and by the availability of resources, that description is necessarily incomplete. Therefore, the exhaustive description of a geologic site for purposes of numerical modeling requires the prior assumption of some type of conceptual model for the site, which is then implemented to assign the necessary properties and other variables at every relevant point in space.

\subsubsection{Capturing Heterogeneity}

A slightly refined, but still quite simplified, conceptual model for the site makes use of the fact that, at Yucca Mountain (as in many other geologic environments), the lithologic deposits were produced by relatively widespread but temporally variable geologic processes. In particular, the volcanic activity responsible for the formation of Yucca Mountain was episodic in nature, with thick, widespread ash deposits produced by near-instantaneous (geologically speaking) eruptions separated by thin inter-eruption deposits that probably represent much longer intervals of time. If the time represented by a progressively accumulating geologic deposit is considered to be frozen and preserved in the vertical dimension, then the resulting conceptual model is one of successive subhorizontal layers, that may be broken and tilted, or folded and otherwise moved about at some later time.

The GFM component of the ISM is such a layered representation of Yucca Mountain. However, without further refinement, a layered rock-properties model corresponding precisely to the GFM still relies upon the prior assumption that, within each originally subhorizontal layer, the material properties of interest are essentially uniform and homogeneous. Geologic studies of the volcanogenic rocks at Yucca Mountain and of similar deposits elsewhere in the world indicate that the geologic processes responsible for deposition of these materials vary both temporally and areally. For example, variations in cooling rates caused by local conditions affect the material properties in the resultant rocks. This spatial variation of process has produced spatial heterogeneity of material properties in all three dimensions. Yet despite the existence of vertical and lateral heterogeneity, the spatial distribution of material properties within geologic layers is not simply "random." Knowledge of property values at one location imposes limits on the values of those properties likely to exist at "nearby" locations. Therefore, an alternative conceptual model of "filling-in" a geologic framework with values randomly assigned from some inferred univariate distribution without regard for other nearby values (spatial correlation) is an unnecessary oversimplification (and potentially an unwarranted distortion) of the real world.

\subsubsection{Heterogeneity Versus Uncertainty}

In contrast to heterogeneity, which is an objective feature of the real world, uncertainty is a knowledge-based concept. Distinguishing properly between uncertainty (as a state of imperfect 
information resulting from less-than-complete observation) and spatial heterogeneity (as a state of being, unaffected by the availability or lack of information) becomes critically important in the application of predictive engineering methods to the geologic environment. Natural earth materials are heterogeneous to a far greater degree than most materials of conventional engineering interest. Heterogeneity in rock properties affects the actual operation of physical processes, even though there is only one, unique heterogeneous reality. The impact of that heterogeneity on the numerical approximation (modeling) of those physical processes is only compounded by geologic uncertainty. Incomplete information must be accounted for in predictive modeling, as must the effects of material properties that are different in different locations. A key attribute, therefore, of the rock properties modeling activities, has been the description and quantification of the effects of geologic uncertainty on the physical description of the Yucca Mountain site.

\subsubsection{Geostatistical Methods}

The current approach to modeling rock properties as part of the ISM strikes a balance between the inherent simplification of a hollow-shell GFM and the near-infinite degree of complexity that is the real world. Selected major lithostratigraphic horizons are used as the constraining (framework) boundaries for a statistically based description of the measured rock material properties that have been sampled within those boundaries. Geostatistical methods have been used to create the exhaustive material property descriptions comprising the rock properties model. Geostatistical methods in general are one of a variety of methods for distributing isolated measurements of different attributes in space, and thus for modeling spatial heterogeneity. A fundamental principle underlying all geostatistical techniques is the quantification and use of some measure of spatial correlation, which may be defined informally as the degree to which samples "close" to one another resemble each other more than do samples "far" away from each other, where "close" and "far" are defined from the data values. Furthermore, unlike many other methods for predicting the material property attributes of a large volume from direct observation of a relatively minuscule fraction of that volume, geostatistical methods offer a quantitative and more-or-less rigorous approach to the issues of knowledge-based uncertainty discussed in Section 6.3.1.2.

Within the purview of geostatistical methods are two broad classes of algorithms for predicting attributes at unsampled locations constrained by some limited set of actual measurements: estimation and simulation. Geostatistical estimation is focused on the prediction of the attribute values most likely to be encountered at a given spatial position, and may be thought of as modeling the expected value of a variable of interest. Geostatistical estimation is most frequently described using the term, kriging, and it is simply a weighted-average interpolation method using some neighborhood of near-by relevant data. A common thread connecting all estimation methodologies (including nongeostatistical ones) is that they are interpolation techniques directed toward producing a model in which the estimated values grade progressively and generally smooth away from the data locations and away from one another.

The other broad class of geostatistical methods comprises a variety of simulation algorithms. In contrast with estimation, geostatistical simulation places principal emphasis on reproducing the input data values and the overall statistical character (including the spatial correlation characteristics) exhibited by the data ensemble, the total collection of input values. Models 
produced by geostatistical simulation typically do not grade smoothly between measured data values, but rather are more highly variable at the same time that they represent the broad heterogeneity structure of the measurements. These techniques are conceptually equivalent to the Monte Carlo simulation process frequently employed in engineering analyses. In common with other Monte Carlo simulation approaches, the emphasis is less on the specific predicted values, which are in effect simply the products of a random number generator with certain "desirable" properties, and much more on evaluation of the space of uncertainty associated with some performance measure computed to represent the behavior of the modeled system.

\subsubsection{Evaluating the Consequences of Heterogeneity and Uncertainty}

A schematic diagram of the geostatistical process for combining statistical description with the Monte Carlo generation of multiple replicate models, which are then evaluated for performance consequences are presented in Figure 6.3-1 (see also Rautman and McKenna 1997 [DIRS 100643], Figure 6). The logic is straightforward Monte Carlo, except that the need to capture both heterogeneity and spatial correlation jointly causes the geostatistical simulation process to consist of drawing entire "intact" property models (rather than single property values) from a conceptual distribution of alternative "realities."

As shown by the upper row of panels in Figure 6.3-1, the individual measured values of a material property are combined with the overall statistical character of the complete data set (the data ensemble) and with the spatial correlation patterns exhibited by the data to produce replicate "exhaustive" models (center part of Figure 6.3-1) showing the distribution of that material property in space. Each replicate model reproduces the measured data at the data locations, and the overall variability of all the values in the model reproduces the histogram of the measurements. Additionally, the spatial correlation structure of the model, evaluated as a whole, approximates the spatial correlation among the input measurements. Completing the Monte Carlo methodology, each of these individual realizations (property models) may then be processed through some relevant transfer function or consequence analysis (for example, a radionuclide-transport computer code), and the likelihood of various acceptable versus unacceptable performance responses evaluated. This final step is represented in the lower portion of Figure 6.3-1. 


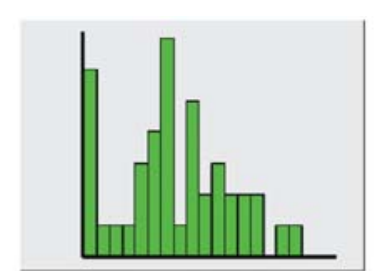

Statistical Character
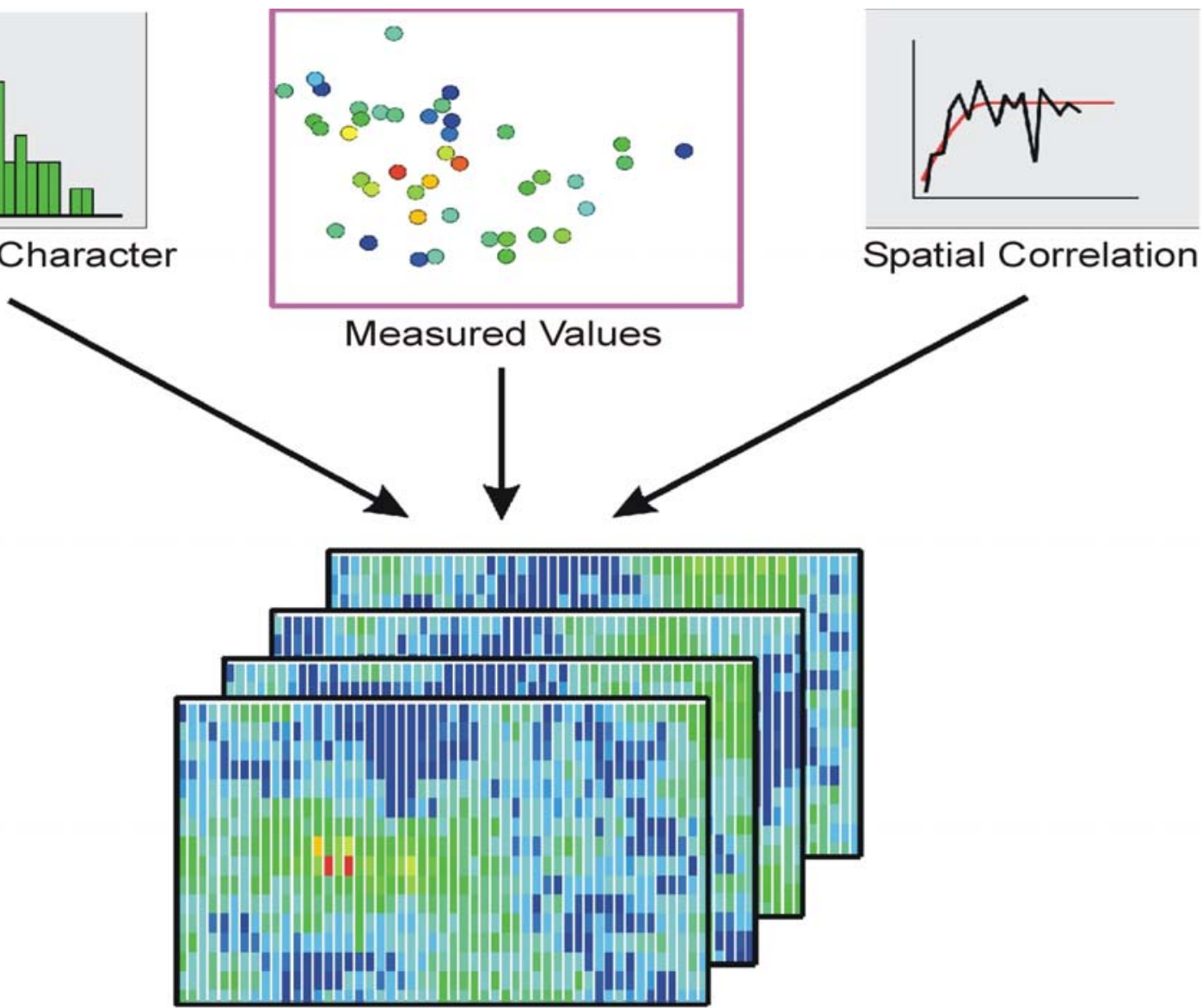

Replicate Stochastic Simulations

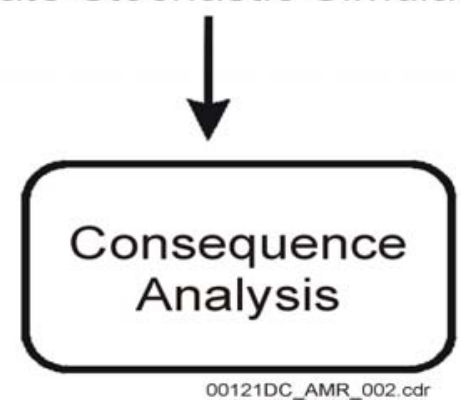

NOTE: Conceptual representation of a Monte Carlo process incorporating geostatistical simulation techniques as the basis for assessing the impact of geologic uncertainty on a performance measure relevant to licensing of a geologic repository. A "consequence analysis" is any postsimulation mechanism for computing a measure of performance across the suite of replicate stochastic simulations (from Rautman and McKenna, 1997 [DIRS 100643], Figure 6)

Figure 6.3-1. Conceptual Representation of a Monte Carlo Process 


\subsubsection{Methodology Overview}

Construction of the 3-D rock properties models has been guided by the philosophically separate but related concepts of heterogeneity and uncertainty described in the preceding section. The models make maximum use of "deterministic" genetic processes to constrain the modeling of measured property values away from the physical locations of those measurements. The effort to capture genetic processes as they relate to material properties has led to the separation of the geologic column of interest into several discrete geologic units, each of which is internally more "homogeneous" in some identifiable manner than subdivisions based on other criteria.

An interpretation that the material properties of the rocks are controlled principally by the original genetic geologic processes and that much of the postdepositional alteration that has produced second-order variability in properties occurred before tectonic tilting and faulting indicates that the influence of such deformation should be discounted in the modeling process. A concept has been adopted of using a stratigraphic coordinate system during the modeling process, as distinct from a real-world coordinate system that describes the present-day location of points within the several geologic units. Both the measured data and the geostatistical models are described in stratigraphic coordinates throughout the modeling exercise. Models are back-transformed into real-world coordinates upon completion.

Because measurements of most material properties of direct interest for use in performance calculations are quite limited in number and spatial distribution, the concept of porosity-as-a-surrogate is adopted in order to use relatively abundant and widely distributed (in three dimensions) porosity data as a first approximation of the geologic heterogeneity of the site. The conceptual assumption (Section 5) is that the spatial variation and trends in many different properties should be roughly the same, as the entire ensemble of material properties is related to the geologic processes responsible for formation of these rocks.

Sequential gaussian simulation techniques are used to generate the discretized, exhaustive, primary porosity models, conditioned to both laboratory core and downhole petrophysical measurements in an effort to integrate virtually all available data from the entire Yucca Mountain site. Conditional simulation methods produce models that effectively reproduce both the conditioning measurements and the overall (geo)statistical character of those measurements. A technique known as linear coregionalization is then used to produce similarly exhaustive models of selected derivative material properties. For certain material properties, additional postprocessing of these derivative models is required to induce desired geologic attributes in the final models. For example, an indicator-kriged model of hydrous-phase mineral alteration is used to constrain the derivative models of saturated hydraulic conductivity for two units where the presence of this type of alteration is known.

The modeling process has been documented using a scientific notebook procedure (SNL QAIP 20-2, Rev. 02 [DIRS 109474]). Details of the modeling process, including expansion of topics discussed only in abbreviated or illustrative form in this report, may be found in the scientific notebooks listed in Table 6.3-1. 
Table 6.3-1. Scientific Notebooks for Rock Properties Models

\begin{tabular}{|l|l|l|}
\hline \multicolumn{1}{|c|}{ Scientific Notebooks } & \multicolumn{1}{|c|}{ Title } & \multicolumn{1}{c|}{ Reference } \\
\hline SNL-SCI-006 & $\begin{array}{l}\text { Scientific Notebook, Geostatistical Modeling of } \\
\text { Porosity and Derivative Properties (FY 1998) }\end{array}$ & $\begin{array}{l}\text { Rautman and McKenna 1998 } \\
\text { [DIRS 107442] }\end{array}$ \\
\hline SNL-SCI-011 & $\begin{array}{l}\text { Scientific Notebook, Geostatistical Modeling of } \\
\text { Porosity and Derivative Properties (FY 1999) }\end{array}$ & Rautman 1999 [DIRS 109035] \\
\hline
\end{tabular}

\subsection{DEVELOPMENT OF THE MODELS}

\subsubsection{Model Domain}

The location of the 3-D rock properties model is shown in relationship to the general Yucca Mountain area and to the Exploratory Studies Facility (ESF) in Figure 1-1. The modeled region extends from west to east from the vicinity of Fatigue Wash to the middle of Midway Valley, and from north to south from central Yucca Wash to the middle portion of Dune Wash. The model domain for the rock properties model is closely tied to the location of the YMP UZ site-scale model numerical process-model grid.

\subsubsection{Separate Modeling of Distinctive, Aggregate Geologic Units}

Rock properties models have been created for four distinctly different aggregate geologic units: the upper Paintbrush nonwelded interval, the welded portion of the Topopah Spring Tuff, the Calico Hills nonwelded interval, and the Prow Pass Tuff. The relationship of these four aggregate modeling units to the detailed lithostratigraphic subdivision of Yucca Mountain and to other modeling units involved in the GFM and the mineralogical model of Yucca Mountain is shown in Table 6.1-1.

Note that the aggregate geologic units selected for separate rock properties modeling efforts do not coincide in general with the breaks between genetic "packages" of rock, which at Yucca Mountain are typically collections of virtually coeval pyroclastic flow deposits associated with a major volcanic event such as a caldera-collapse sequence. However, as documented by Rautman and McKenna (1997 [DIRS 100643], pp. 6 to 11, Figures 3 and 4), the available measurements of material properties indicate that the modeling units defined here are more homogeneous (consistent) internally than are the major genetic packages.

\subsubsection{Available Data and Preliminary Processing}

The data used in modeling the spatial variability of material properties in the rock properties model were obtained from a number of sources, as described in Section 4, including both laboratory measurements of core samples (Sections 4.1.1 and 4.1.3) and down-hole petrophysical measurements (Sections 4.1.2 and 4.1.5) of in situ rocks. Only surface-based drill holes have been used in constructing the rock properties model, as the large areal extent of the model and the requirement that the vertical positions of all data be expressed in stratigraphic coordinates effectively precludes the use of samples from the underground workings of the ESF. The locations of the various drill holes used in modeling each separate geologic unit are shown in Figures 6.4-1 through 6.4-4. Note that although there is major consistency of the drill hole 
coverage from unit to unit, the suite of holes that contain data relevant to any particular model unit is unique. Data tracking numbers associated with all data values are tabulated in Section 4.

\subsubsection{Data Compilation, Resampling, and Generation of Derived Quantities}

Compilation of porosity, secondary property data, and mineralogical analyses into initial working files, even though from a large number of sources, is relatively straightforward. Laboratory core data were used essentially as-is. Relevant petrophysical variables were extracted from much more massive source files, containing all extant downhole geophysical data, using software routine BUD (see Table 3-2). Core and petrophysical porosity data were compiled on an individual drill hole basis in spreadsheets using the graphics package Sigma Plot (Section 3.2), prior to being combined on a by-unit basis in Excel.

Because the petrophysical data were recorded in the field on 0.5-ft depth spacings (some older holes were recorded on only $1 \mathrm{ft}$ spacings), it was determined that direct use of all available petrophysical values would statistically overwhelm the available core porosity measurements (collected on a nominal $3 \mathrm{ft}$ spacing) available for an equivalent length of drill hole. Therefore, to maintain approximate parity of statistical mass across the two different types of porosity data, the petrophysical values were resampled to a $3 \mathrm{ft}$ depth spacing as well. In keeping with the practice of Rautman and McKenna (1997 [DIRS 100643], pp. 29 to 30, Figure 14) in developing RPM2, the resampling algorithm also calculated a simple average of the adjoining measurements within plus and minus $1 \mathrm{ft}$ of the nominal $3 \mathrm{ft}$ depth value. This averaging process is necessary to deal with missing values present in the original petrophysical data (generally related to unacceptable borehole conditions). The averaging process is standard practice for smoothing or aliasing the petrophysical data. Both resampling and computation of the desired two-foot average values was accomplished using software routine TWOFOOT (see Table 3-2).

Relevant mineralogical analyses (hydrous-mineral phase “altered” mineral fractions of smectite, clinoptilolite, mordenite, and chabazite) were extracted from the source data files (Section 4.1.4) using the data manipulation capabilities of Excel. A new variable, total hydrous-phase mineral content, was created as the sum of these individual mineral fractions. A hydrous-mineral phase alteration-indicator variable, $I$, was also constructed for the mineralogical data set by the logical statement:

$$
I=\left\{\begin{array}{l}
1 \leftarrow \sum(\text { Altered Minerals }) \geq 5 \text { - percent } \\
0 \leftarrow \text { Otherwise }
\end{array}\right.
$$




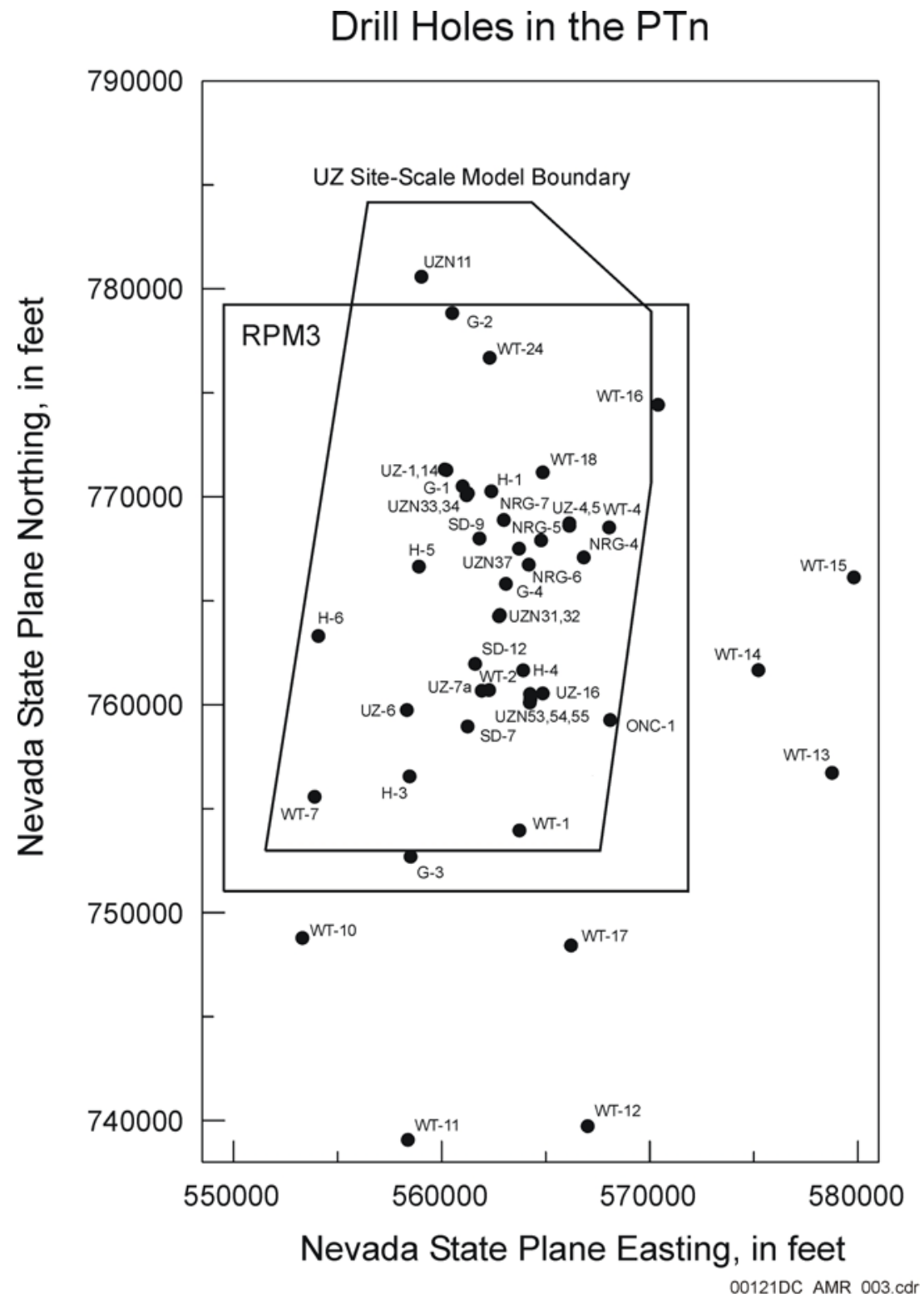

Source: Rautman, C. and McKenna, S. 1998 [DIRS 107442] Section 2.

NOTE: Some holes may include only partial penetrations of the unit.

Figure 6.4-1. Drill Holes Used in Modeling the PTn Model Unit 


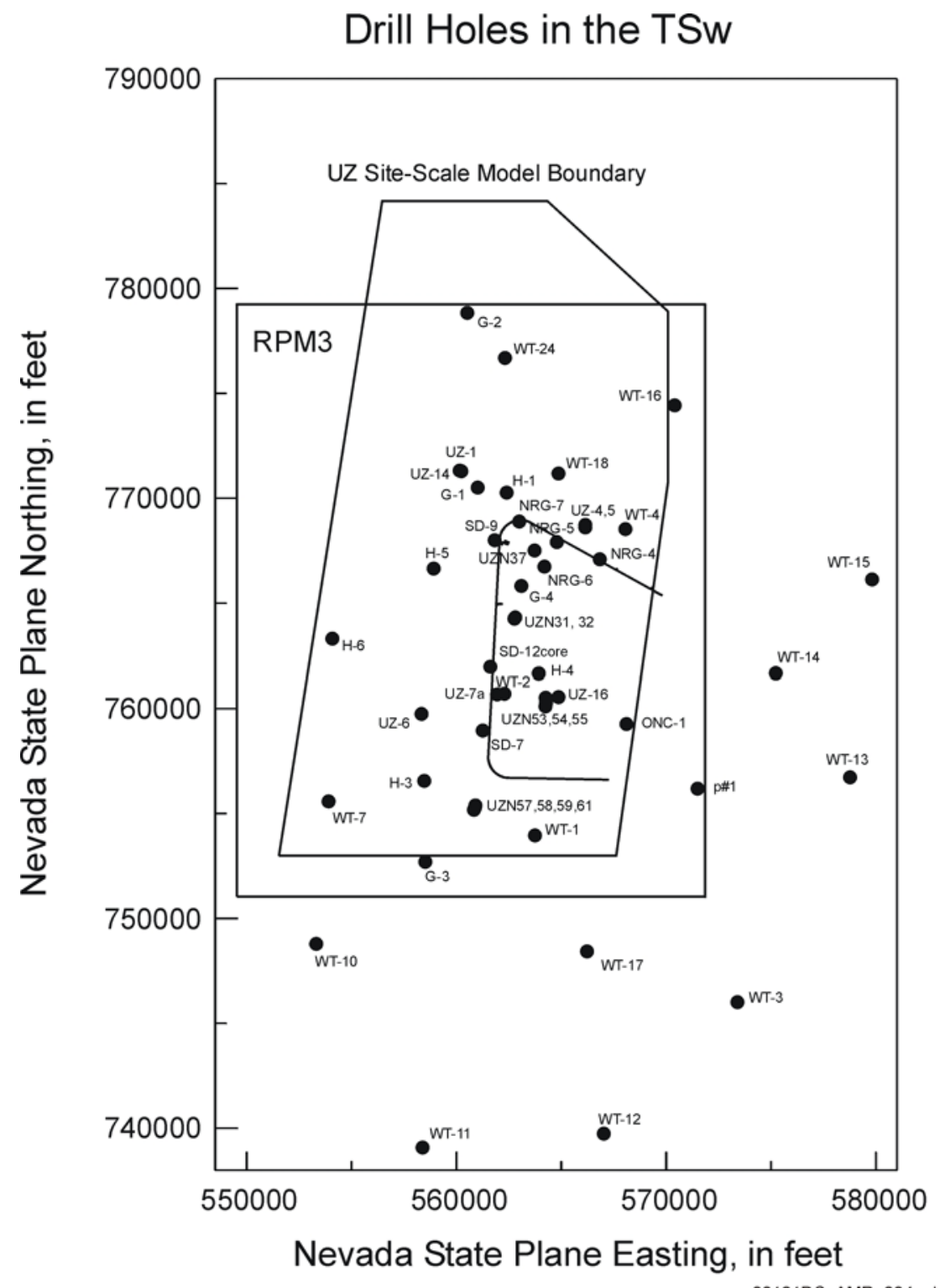

Source: Rautman, C. and McKenna, S. 1998 [DIRS 107442] Section 2. NOTE: Some holes may include only partial penetrations of the unit.

Figure 6.4-2. Drill Holes Used in Modeling the TSw Model Unit 


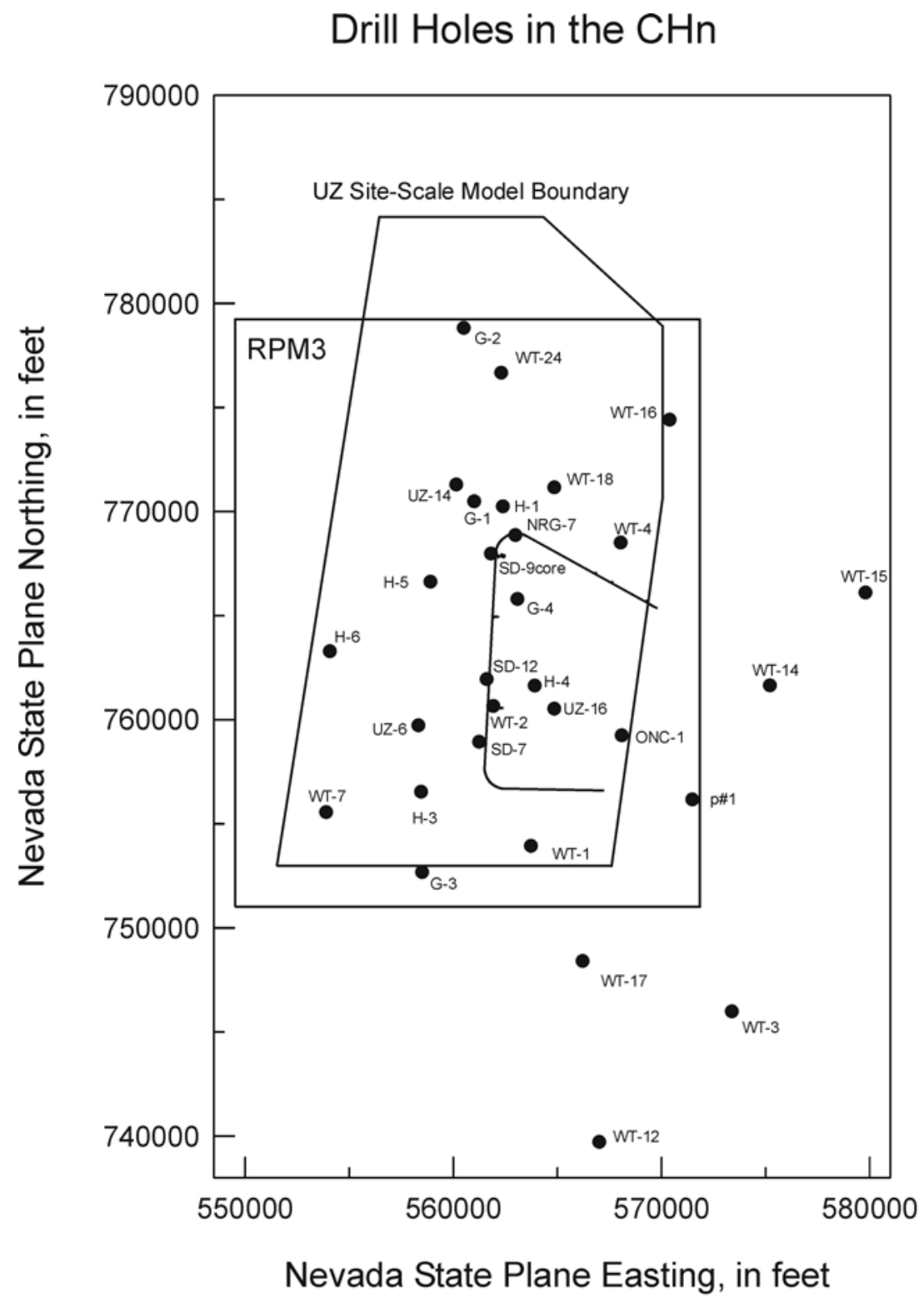

00121DC_AMR_005.cdr

Source: Rautman, C. and McKenna, S. 1998 [DIRS 107442] Section 2.

NOTE: Some holes may include only partial penetrations of the unit.

Figure 6.4-3. Drill Holes Used in Modeling the CHn Model Unit 


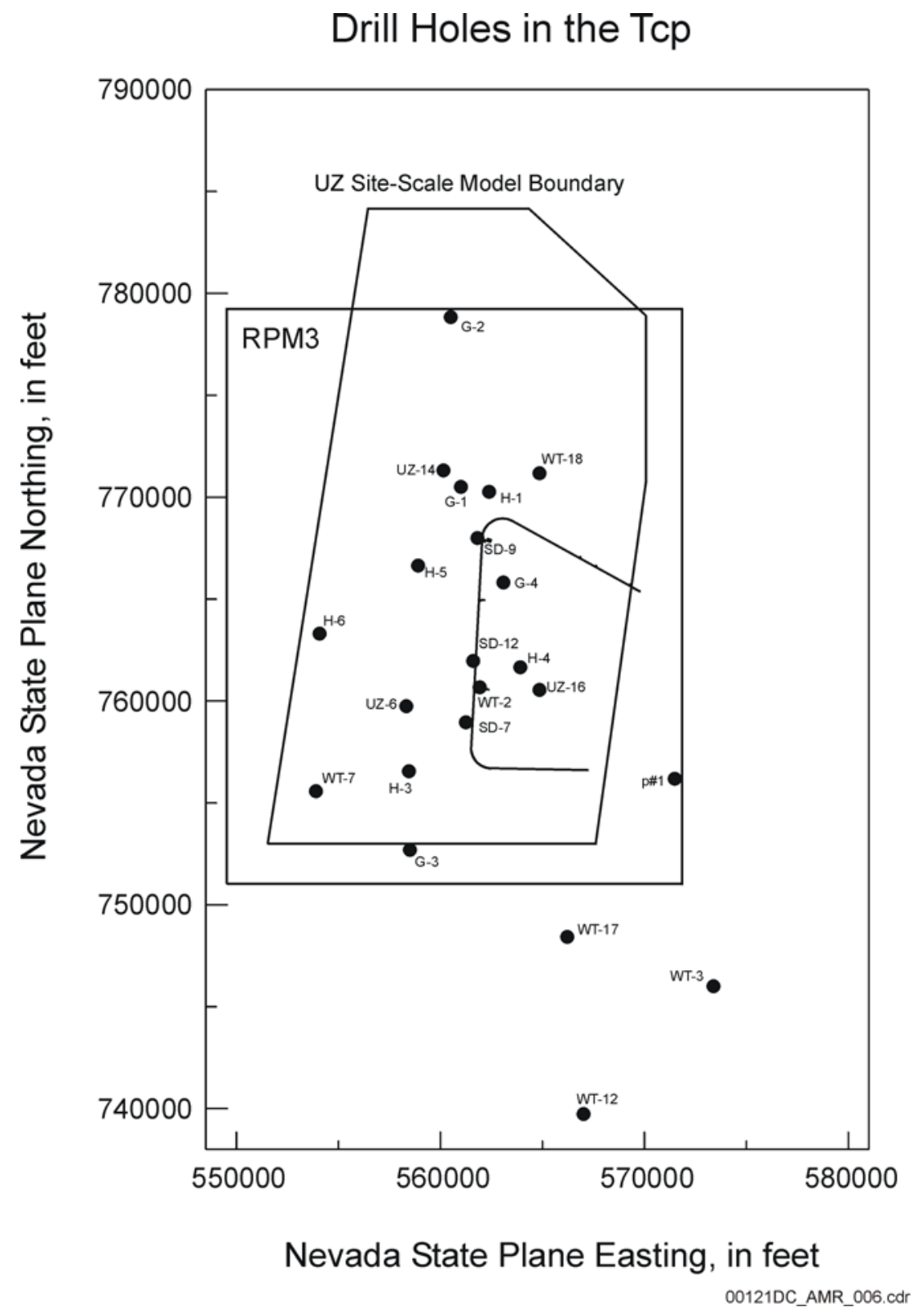

Source: Rautman, C. and McKenna, S. 1998 [DIRS 107442] Section 2.

NOTE: Some holes may include only partial penetrations of the unit.

Figure 6.4-4. Drill Holes Used in Modeling the Tcp Model Unit 
In preparation for calibrating the soft indicators of hydrous-phase mineral alteration (Section 6.2.4), additional variables were created for both the core and petrophysical data sets. These variables, referred to as "bound-water", were calculated simply as the arithmetic difference between the OD and RH porosity values (for core; Section 4.1.1) or between the POROTOT and POREF porosity values (for petrophysics; Section 4.1.5). Further manipulation and use of the bound-water variables is discussed below in Section 6.4.7.1.

\subsubsection{Stratigraphic Coordinate Conversion}

Each major lithologic interval selected for modeling has been modeled in a stratigraphic coordinate system that reflects the original, prefaulting depositional continuity of these ash-flow and air-fall tuffaceous deposits (Figure 6.4-5). Stratigraphic coordinates use the same east-west and north-south coordinates (Nevada state plane coordinate system, defined in feet) as the drill hole from which the relevant data were obtained. However, the vertical coordinate of a sample is represented as the relative fractional position of that sample within the thickness of the entire unit at that horizontal location. The stratigraphic coordinate concept effectively removes the effect both of depositional thinning away from the source volcanic vent(s) and of postdepositional tilting and deformation, and it thus positions samples from equivalent portions of the overall unit at the same nominal internal position within a rectangular volume.

As shown schematically in part (a) of Figure 6.4-5, regions of varying material properties are presumed to have been emplaced or otherwise formed by various alteration processes in an essentially stratiform manner. At Yucca Mountain, the volumetrically dominant rocks were formed by deposition by pyroclastic flows to form thick ash-flow sheets that thin laterally away from their source. Thus, there is a tendency for regions of similar material properties that were formed under similar pressure-temperature conditions to occupy roughly the same relative vertical position within a unit. Later faulting as part of Basin and Range tectonism disrupted the originally continuous volcanic rocks and tilted the rock units, with their contained material properties, toward the east, as indicated in part (b) of the figure. Modeling of those rock properties is illustrated in part (c) of Figure 6.4-5. The vertical locations of drill hole samples are specified within the stratigraphic coordinate system as a fractional distance where the base of the unit is assigned a distance of zero and the top of the unit is assigned a distance of one. Stratigraphic coordinates are thus dimensionless.

As suggested by the mesh of intersecting dotted lines in the right-hand portion of Figure 6.4 -5, a regular rectangular modeling grid is defined within each stratigraphic coordinate system. Because the various material property zones have been stretched or compressed vertically so that the overall stratigraphic thickness of the unit is constant, defining the modeling grid within this framework generally positions nodes with similar materials on a stratigraphically "horizontal" plane. This repositioning of similar materials in similar relative locations greatly simplifies the search for data in the neighborhood of an unsampled location, as shown conceptually by the search ellipse in part (c) of Figure 6.4-5. Although it is possible to rotate the principal direction of the search ellipse to match the overall tectonic dip of the unit (see part [b] of the figure), it is virtually impossible to modify the search strategy to account for vertical displacement of the material property zones by discrete faults. 


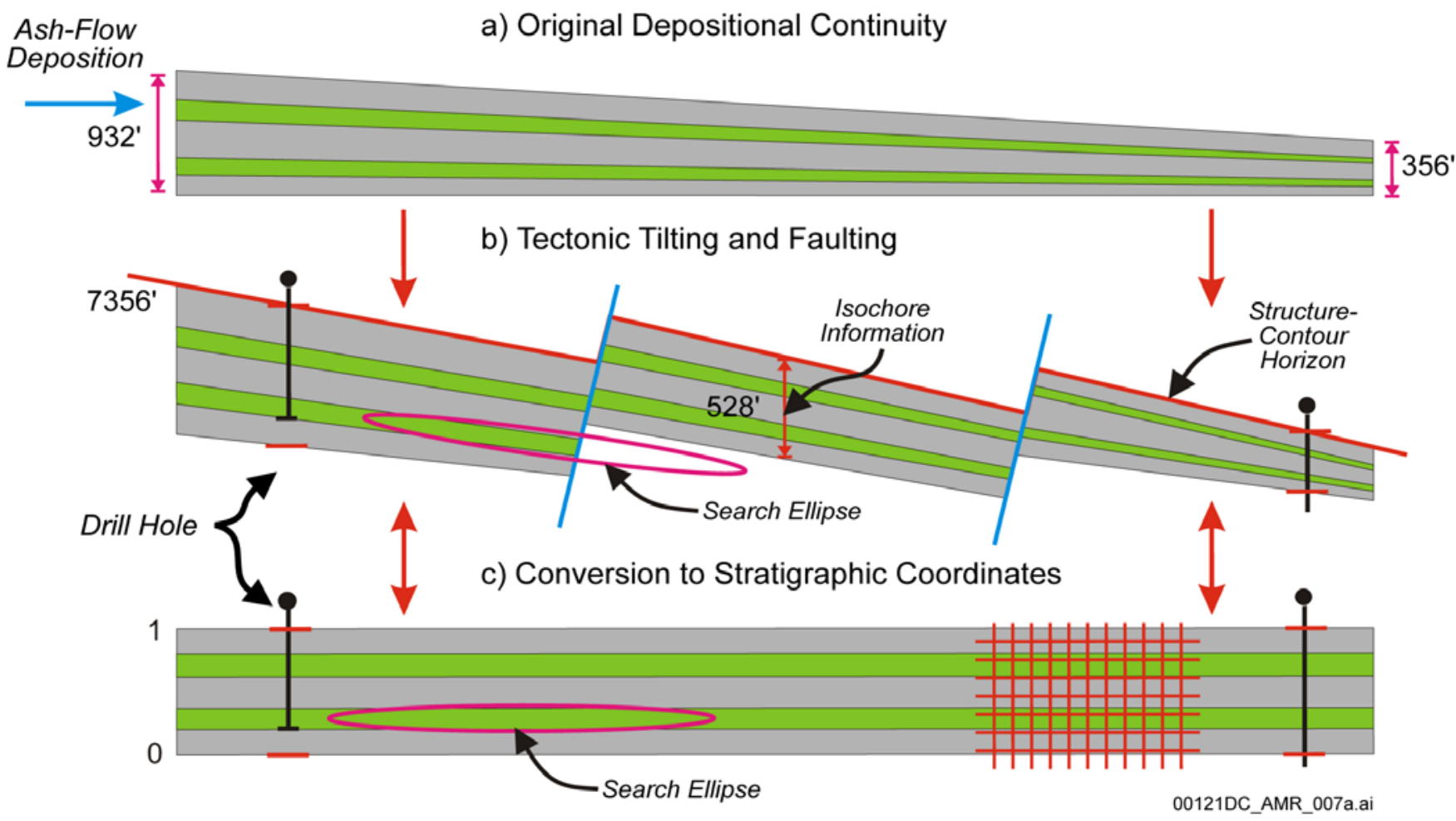

Source: For Illustration Purposes Only

NOTE: (a) Rock unit is formed by areally extensive volcanic (or sedimentary) processes. Zones of differing rock properties (shaded colors) are formed in a stratiform manner. (b) Tectonic deformation tilts and disrupts original stratiform continuity by faulting. (c) Modeling unit is returned to an approximation of original continuity in a rectangular coordinate system in which all vertical distances are measured as a fractional position measured from the top or bottom of the rock unit.

Figure 6.4-5. Conceptual Illustration of the Construction and Use of Stratigraphic Coordinates

At the end of a modeling exercise, the transformation process between parts (b) and (c) in Figure 6.4-5 is reversed by assigning each grid node a computed vertical position derived from knowledge of the structure contour model for the top of each unit and the spatially varying thickness of each unit (software routine coordinates, Table 3-2). These values are obtained from the independently developed 3-D GFM (e.g., GFM 3.0 [DIRS 109050]).

In practice, implementation of the stratigraphic-coordinate concept is slightly more complicated than the idealized example of Figure 6.4-5. First, sample locations are typically specified in terms of their depth within a specific drill hole (the drilling process measures all locations from the collar of the hole regardless of the physical elevation of the hole and its contained samples). Thus, the measured depths were converted to stratigraphic depths initially, and only to stratigraphic elevations at the time of modeling. Second, for reasons involving principally numerical precision within the computer programs that implement the actual rock properties modeling algorithm(s), the fractional stratigraphic positions indicated in Figure 6.4-5 are multiplied by unit-specific scaling constant to obtain values that approximate the nominal thickness of the different units in the real world. Additionally, unlike the 2-D example shown in Figure 6.4-5, actual modeling of rock properties was conducted in full 3-D space. 
Finally, the issue arises regarding how to treat samples from a drill hole that fails to penetrate the entire thickness of the geologic unit in question (represented by the drill hole on the left-hand side of Figure 6.4-5). Clearly it is inappropriate to assign a stratigraphic elevation of zero to a sample obtained from the very bottom of the hole itself, as the materials at this elevation in general are not representative of materials at the base of the unit here or elsewhere. Yet, without drilling deeper, the distance between the foot of the hole and the true base of the unit is unknown. Such situations have been reconciled by inferring the base of the unit in question from the GFM (e.g., GFM 3.0 [DIRS 109050]) and adjusting the fractional position accordingly. The presumption is that the base of the unit projected using the framework model is a reasonable approximation of the unknown true position at that location. This is a reasonable modeling assumption given that the GFM provides a 3-D representation of the geology surrounding the geologic repository (BSC 2004, [DIRS 170029] Section 1). Similar reconstructions are required in the case where erosion has removed the top of a particular modeling unit at a drill hole location or if part of a unit is missing from a drill hole because of faulting.

The equation for calculating stratigraphic depth (StratDepth) is:

$$
\text { StratDepth }=\frac{\text { SampleDepth }- \text { UnitTop }}{\text { UnitBottom }- \text { UnitTop }} . \text { NominalThickness, }
$$

where SampleDepth is the depth of the relevant sample measurement in a given drill hole, UnitTop and UnitBottom are the measured or projected depths to the top and bottom contacts of that model unit at the drill hole location used to determine the thickness of the unit, and NominalThickness is the appropriate unit-specific scaling constant from Table 6.4-1. Conversion of drill hole depths to stratigraphic depths was accomplished using the transform capabilities of SIGMA PLOT (STRATC4.XFM; Table 6.4-1; Appendix B). Stratigraphic elevation is calculated simply as NominalThickness-StratDepth, and was calculated using the mathematical capabilities of EXCEL prior to writing final ASCII text files of the data values.

Table 6.4-1. Unit-Specific Scaling Constants for Nominal Model Unit Thickness

\begin{tabular}{|c|c|}
\hline Model Unit & Nominal Thickness \\
\hline PTn & 200 \\
\hline TSw & 1000 \\
\hline CHn & 400 \\
\hline Tcp & 400 \\
\hline
\end{tabular}

Source: SN9910T0501399.001 [DIRS 129717]. 


\subsubsection{Statistical and Spatial Description of Porosity}

Porosity is the primary material property used to generate the material properties models contained in RPM3. Even the models of derivative properties such as hydraulic conductivity are based ultimately on porosity. This section presents the statistical description (the ensemble characteristics; Sections 6.3.1.3 and 6.3.1.4) of the underlying porosity measurements that have been used to condition the stochastic models of each modeling unit. This presentation consists principally of histograms for the various model units and a summary of their descriptive statistics (Table 6.4-2). Experimental variograms calculated using the measured values and a fitted model for each unit are presented to represent the spatial continuity patterns expressed in the data. Finally, because of the unique geologic nature of the TSw model unit, two different types of porosity (matrix and lithophysal) are presented and justified.

Table 6.4-2. Statistical Summary of Porosity Data Used in Modeling

\begin{tabular}{|c|c|c|c|c|c|}
\hline \multirow{2}{*}{} & \multirow{2}{*}{ PTn } & \multicolumn{2}{|c|}{ TSw } & \multirow{2}{*}{ Tcp } \\
\cline { 3 - 4 } & 0.342 & Matrix & Lithophysal & CHn & 0.229 \\
\hline Mean & 0.122 & 0.146 & 0.254 & 0.090 \\
\hline Std.Dev. & 0.122 & 0.061 & 0.076 & 0.075 & 0.001 \\
\hline Minimum & 0.001 & 0.001 & 0.001 & 0.001 & 0.494 \\
\hline Maximum & 0.750 & 0.519 & 0.551 & 0.511 & 2603 \\
\hline $\mathrm{N}$ & 2,300 & 11,052 & 11,796 & 2711 & 0 \\
\hline
\end{tabular}

Source: SN0004T0501399.003 [DIRS 155045], folder 3dm_input.

NOTE: All values are porosity as a fraction (equivalent to $\mathrm{m} 3 / \mathrm{m} 3$ ), except number of values $(\mathrm{N})$.

\subsubsection{PTn Model Unit}

Porosity Data-Porosity data obtained from the upper Paintbrush nonwelded model unit are portrayed in histogram format in Figure 6.4-6. A statistical summary of these data is given in Table 6.4-2.

Matrix Porosity in the PTn Model Unit

(POREF, RH)

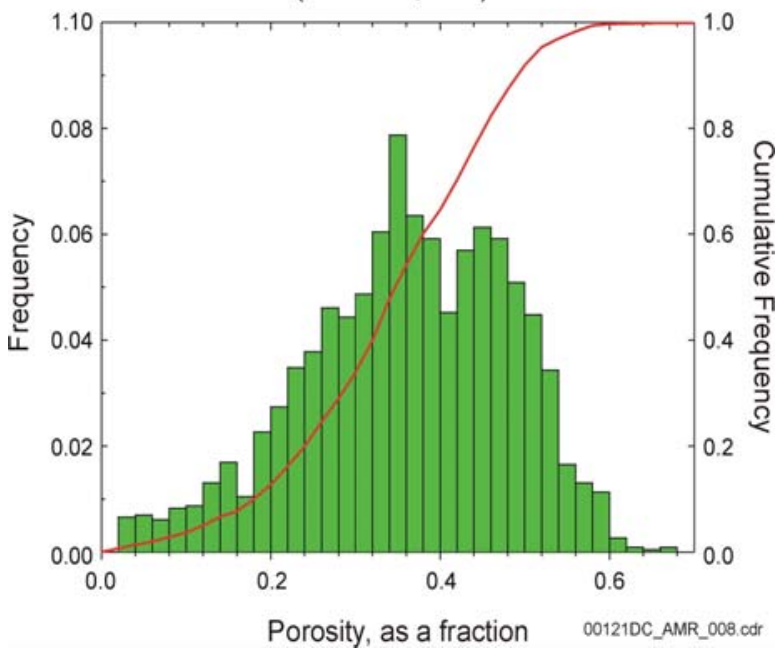

Source: SN9910T0501399.001 [DIRS 129717].

Figure 6.4-6. Histogram and Cumulative Distribution Function of Matrix Porosity in the PTn Model Unit 
Spatial Continuity Data-Modeled variograms for porosity in the PTn model unit are presented in Figure 6.4-7. Parameters of the fitted variogram model are presented in Table 6.4 -3. Details of the variogram modeling exercise for the PTn model unit may be found in the scientific notebook (Rautman and McKenna 1998 [DIRS 107442], pp. 361 to 368).
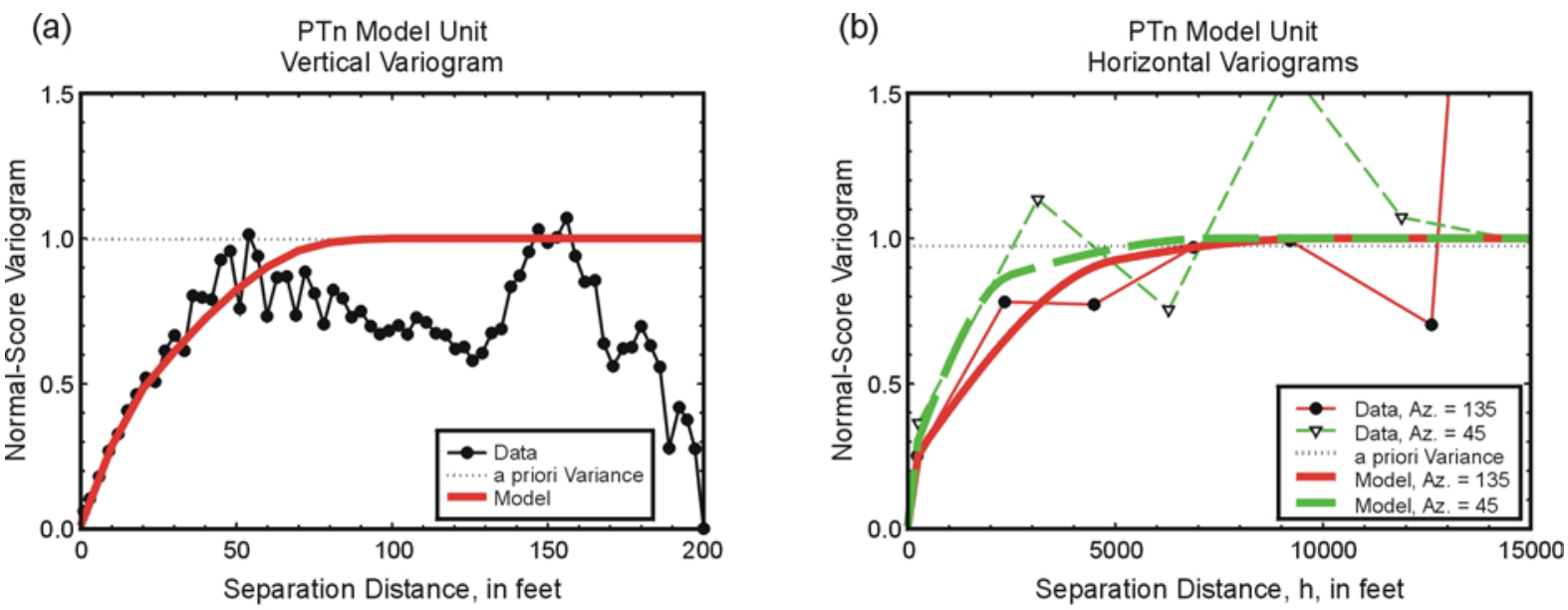

00121DC_AMR_009a.cdr

Source: SN9910T0501399.001 [DIRS 129717].

NOTE: (a) stratigraphic vertical and (b) stratigraphic horizontal directions.

Figure 6.4-7. Experimental and Fitted Model Variograms of Matrix Porosity in the PTn Model Unit

Table 6.4-3. Variogram Parameters for Spatial Continuity Model of Porosity in the PTn Model Unit

\begin{tabular}{|c|c|c|c|c|c|c|c|c|c|c|}
\hline \multirow[b]{2}{*}{ Nest No. } & \multirow[b]{2}{*}{ Model Type } & \multicolumn{3}{|c|}{ Range (ft) } & \multirow[b]{2}{*}{ Sill } & \multicolumn{3}{|c|}{$\begin{array}{c}\text { Rotation Angle } \\
\text { (degrees) }\end{array}$} & \multicolumn{2}{|c|}{$\begin{array}{c}\text { Anisotropy } \\
\text { Ratio }^{1}\end{array}$} \\
\hline & & $\begin{array}{c}\text { Maximum } \\
\text { (horizontal) }\end{array}$ & $\begin{array}{c}\text { Inter- } \\
\text { mediate }\end{array}$ & $\begin{array}{l}\text { Minimum } \\
\text { (vertical) }\end{array}$ & & 1 & 2 & 3 & 1 & 2 \\
\hline-- & Nugget & -- & -- & -- & 0.01 & -- & -- & -- & -- & -- \\
\hline 1 & Spherical & 300 & 50 & 20 & 0.20 & 135 & 135 & 135 & 0.167 & 0.067 \\
\hline 2 & Spherical & 5,000 & 2,500 & 80 & 0.55 & 135 & 135 & 135 & 0.500 & 0.016 \\
\hline 3 & Spherical & 10,000 & 7,500 & 100 & 0.24 & 135 & 135 & 135 & 0.750 & 0.010 \\
\hline
\end{tabular}

Source: SN9910T0501399.001 [DIRS 129717], and Rautman, C. and McKenna, S. 1998 [DIRS 107442], Section 5.

NOTE: Rotation angles 1-3 and anisotropy ratios 1-2 are keyed to input requirements of the SGSIM computer code, as documented in Deutsch and Journel 1992 [DIRS 100567], pp. 22 to 29 and 167.

\subsubsection{TSw Model Unit}

Porosity Data-Porosity values obtained from the Topopah Spring welded (TSw) model unit are presented graphically in histogram format in Figure 6.4-8; the corresponding statistical summary of these data is presented in Table 6.4-2. Examination of the raw porosity data indicates that there are two different porosity values of interest in modeling rock material properties: matrix and lithophysal. Lithophysal porosity, as that term is used in this report, is taken to mean the porosity of volumes of rock many tens of centimeters in diameter, such that the porosity effect of large (decimeter scale and larger) lithophysal cavities is included. In contrast, the term matrix 
porosity is used in this report to refer to the porosity approximately equivalent to that measured for laboratory core samples, in which the size of the matrix pores is small enough that water is held in them by capillarity under slightly unsaturated (negative pressure) conditions. The difference between the two types of porosity measurements is not trivial, as illustrated in Figure 6.4-9, a comparative down-hole plot of matrix and lithophysal porosity data from drill hole SD-7. Lithophysal porosity is indicated by the dark solid curve, whereas the matrix porosity values measured for core samples are indicated by the filled-circle symbols. Note the marked divergence of the porosity values indicated by these two sets of data in two vertical locations within the drill hole. In general, these zones of divergence correspond to the two lithophysal zones (upper and lower) defined by Buesch et al. (1996 [DIRS 100106]). However, the correspondence is not at all exact, and the petrophysical POREF (= lithophysal) porosity curve from downhole geophysics indicates that substantial lithophysal cavity development may extend significantly above and below the limits of the formally named lithophysal zones (Figure 6.4-9). A scatterplot of these lithophysal porosity values versus the depth-equivalent core relative humidity porosity for the formally named lithophysal-zone intervals only is presented in Figure 6.4-10, part (a). The region of marked divergence from the $45^{\circ}$ one-to-one correspondence line represents high lithophysal porosities matched on a nearest-sample basis to the lower core porosity values.

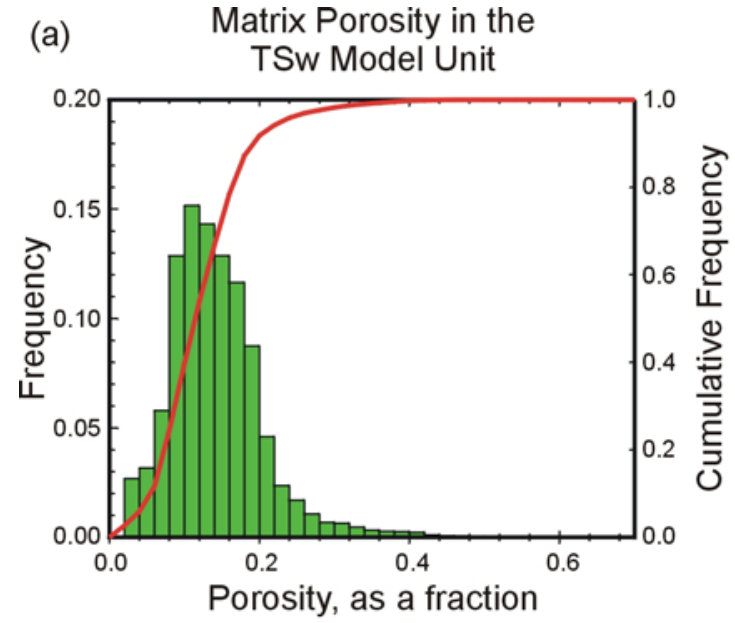

Source: SN9910T0501399.001 [DIRS 129717].

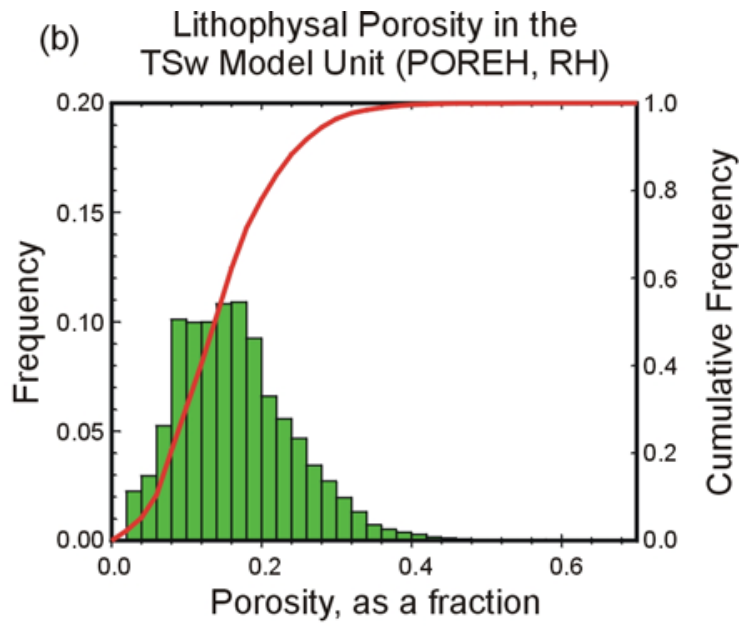

00121DC_AMR_011a.cdr

NOTE: (a) matrix porosity; (b) lithophysal porosity in the TSw model unit.

Figure 6.4-8. Histograms and Cumulative Distribution Functions 

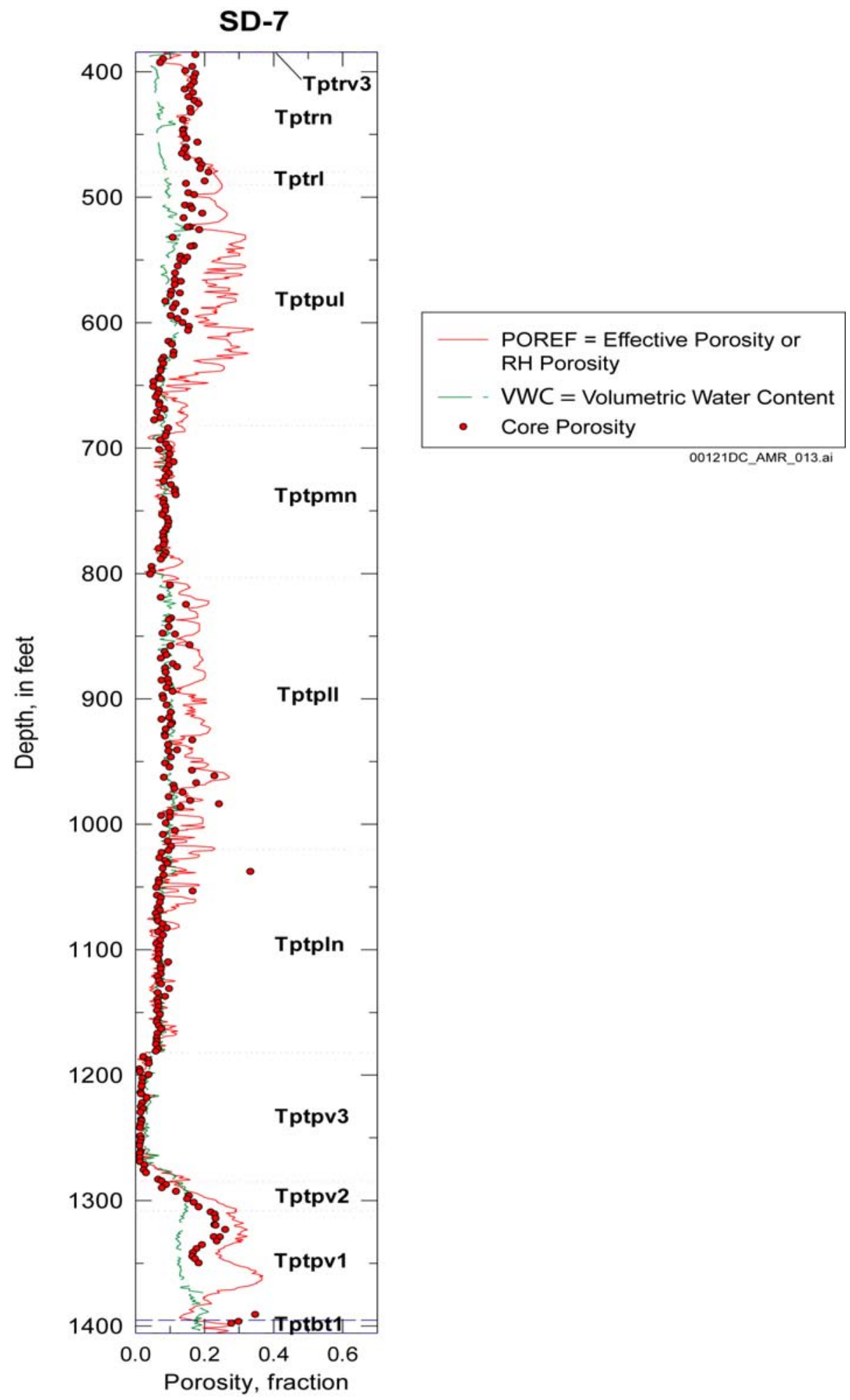
(a) Formal Lithophysal Zones Only

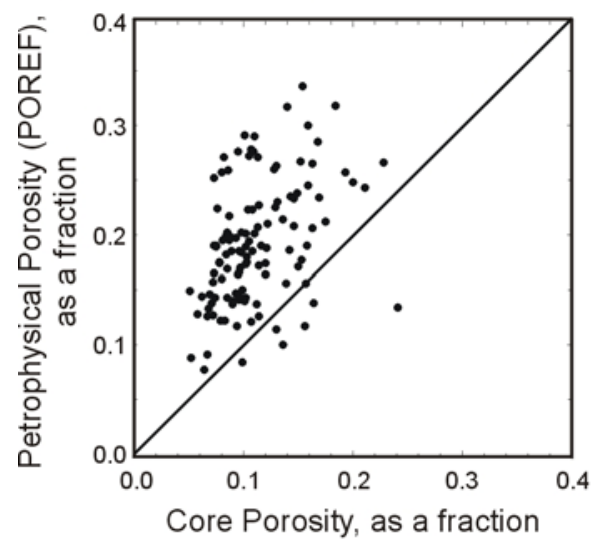

(b) Formal Lithophysal Zones Only

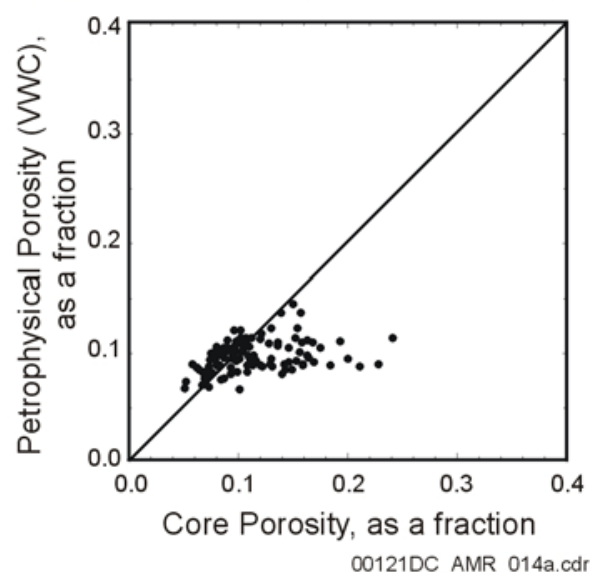

Source: SN9910T0501399.001 [DIRS 129717].

NOTE: (a) petrophysical POREF porosity vs. core relative humidity porosity; (b) petrophysical VWC vs. core relative humidity porosity for formally defined lithophysal intervals in drill hole SD-7. Line indicates one-to-one correspondence

Figure 6.4-10. Crossplots of Core Porosity

Note also the third set of data plotted in Figure 6.4-9; this curve is identified as volumetric water content (equivalent to the amount of water-filled porosity) and is shown by the dashed line without symbols. This third curve is observed essentially to overlie the true matrix (= core) porosity data throughout much of the drill hole. In locations where the water-filled porosity trace does not closely match the core values, it is always observed to indicate markedly lower values than the solid lithophysal porosity curve. The near-equivalence of core and VWC values is demonstrated in part (b) of Figure 6.4-10. The small set of mismatched pairs may be identified in Figure 6.4-9 as representing the interval between approximately 480 and 550 feet.

Because many drill holes lack core data from which to obtain matrix porosity for modeling purposes, the practice has been adopted (for those noncored holes only) of using volumetric water content as a surrogate for matrix porosity. Outside these lithophysae-bearing intervals, matrix porosity is set equal to POREF porosity, whereas within these intervals of curve separation, matrix porosity is set equal to the VWC values.

It is clear that this practice is merely a simple heuristic device, and that use of the volumetric water content as representing water-filled porosity unquestionably will underestimate the actual matrix porosity within the UZ for the simple reason that all the available matrix pore space in the $\mathrm{UZ}$ is not water filled (any large lithophysal cavities also will not be water filled). However, the approach is a reasonable approximation for several reasons. (1) Water saturation throughout much of the Topopah Spring Tuff is rather high, typically greater than about 80 percent. (2) The VWC values in zones of significant lithophysal cavity development are much closer to the true matrix porosity than are the lithophysal porosity values, which can be observed from Figures 6.4-9 and 6.4-10 to be as much as double the matrix (core) porosity values for drill hole USW SD-7. And finally, (3) because one of the purposes of modeling the spatial heterogeneity of porosity is to model the variability of saturated hydraulic conductivity using porosity as a surrogate, the volumetric water content representing the water-filled porosity (at any in situ 
saturation) most likely represents essentially all the pore space that is available for the transmission of water under unsaturated conditions.

Note that it is possible to significantly underestimate the whole-rock saturated hydraulic conductivity of the Topopah Spring welded interval under true saturated conditions in this manner, because the effect of lithophysal cavities on the whole-rock permeability is neglected. However, such underestimation is likely to be a nonissue, as this relatively high stratigraphic interval almost invariably is present in the UZ throughout the entire modeled region. Additionally, under true saturated conditions, most ground-water flow through the TSw model unit would be through fractures (and lithophysae), and not through the matrix.

Spatial Continuity Data-Modeled variograms for both matrix and lithophysal porosity in the TSw model unit are presented in Figure 6.4-11. Parameters for both fitted variogram models are presented in Table 6.4-4. Details of the variogram modeling exercise may be found in the scientific notebook (Rautman and McKenna 1998 [DIRS 100643], pp. 437 to 444 and 459 to 464$)$.
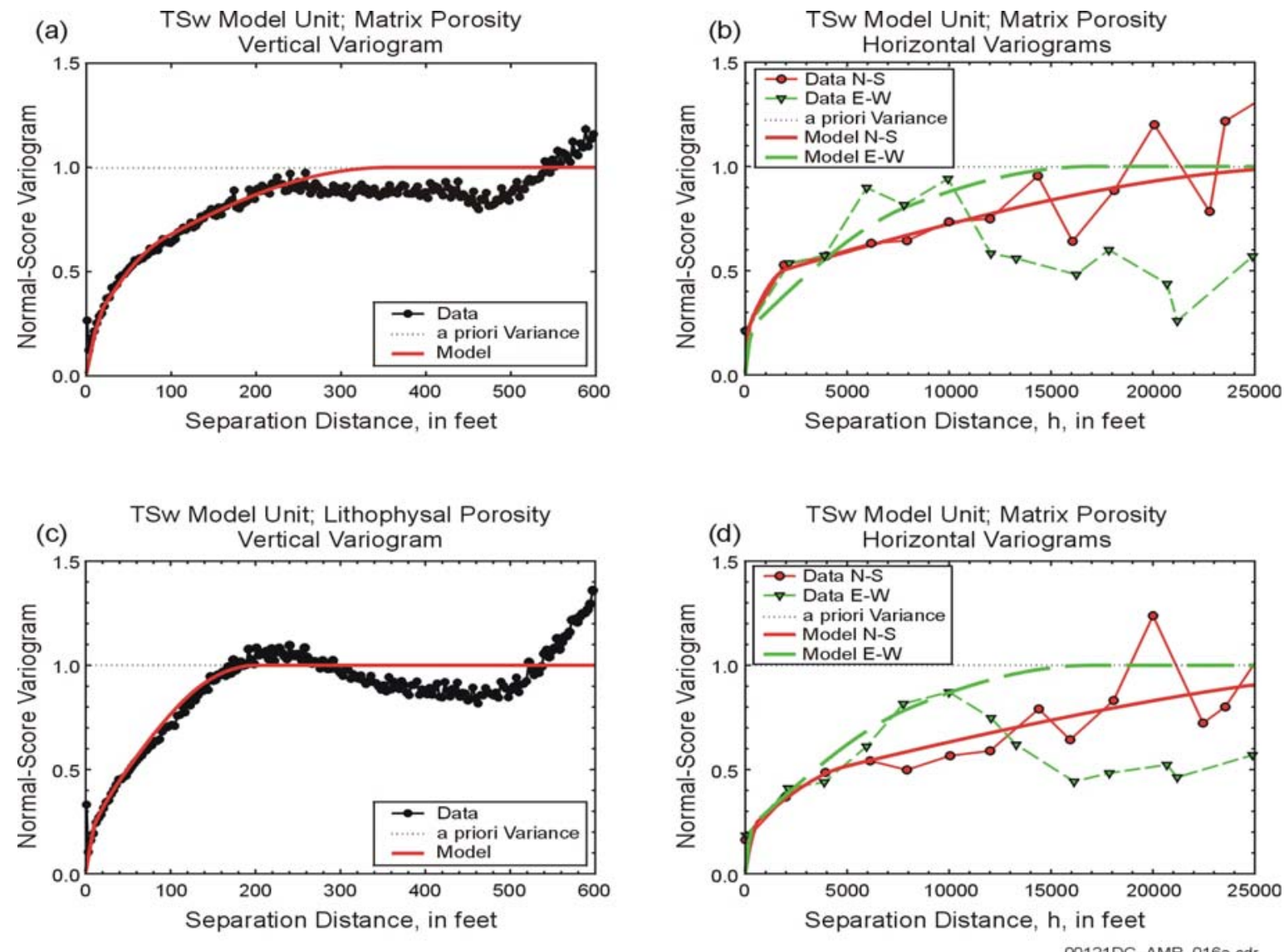

Source: SN9910T0501399.001 [DIRS 129717].

NOTE: (a) matrix porosity, stratigraphic vertical and (b) stratigraphic horizontal. (c) Lithophysal porosity, stratigraphic vertical and (d) stratigraphic horizontal.

Figure 6.4-11. Experimental and Fitted Model Variograms for Porosity in the TSw Model Unit 
Table 6.4-4. Variogram Parameters for Spatial Continuity Model of Porosity in the TSw Model Unit

\begin{tabular}{|c|c|c|c|c|c|c|c|c|c|c|}
\hline \multirow[b]{2}{*}{ Nest No. } & \multirow[b]{2}{*}{ Model Type } & \multicolumn{3}{|c|}{ Range (ft) } & \multirow[b]{2}{*}{ Sill } & \multicolumn{3}{|c|}{$\begin{array}{c}\text { Rotation Angle } \\
\text { (degrees) }\end{array}$} & \multicolumn{2}{|c|}{$\begin{array}{l}\text { Anisotropy } \\
\text { Ratio }^{1}\end{array}$} \\
\hline & & $\begin{array}{l}\text { Maximum } \\
\text { (horizontal) }\end{array}$ & $\begin{array}{c}\text { Inter- } \\
\text { mediate }\end{array}$ & $\begin{array}{l}\text { Minimum } \\
\text { (vertical) }\end{array}$ & & 1 & 2 & 3 & 1 & 2 \\
\hline \multicolumn{11}{|c|}{ TSw Model Unit, Matrix Porosity } \\
\hline -- & Nugget & -- & -- & -- & 0.01 & -- & -- & -- & -- & -- \\
\hline 1 & Spherical & 250 & 250 & 20 & 0.19 & 0 & 0 & 0 & 1.000 & 0.080 \\
\hline 2 & Spherical & 2,000 & 6,500 & 90 & 0.25 & 0 & 0 & 0 & 3.250 & 0.045 \\
\hline 3 & Spherical & 29,000 & 12,500 & 350 & 0.55 & 0 & 0 & 0 & 0.431 & 0.012 \\
\hline \multicolumn{11}{|c|}{ TSW Model Unit, Lithophysal Porosity } \\
\hline-- & Nugget & -- & -- & -- & 0.01 & -- & -- & -- & -- & -- \\
\hline 1 & Spherical & 600 & 400 & 15 & 0.19 & 0 & 0 & 0 & 0.667 & 0.025 \\
\hline 2 & Spherical & 5,000 & 8,000 & 175 & 0.20 & 0 & 0 & 0 & 1.600 & 0.035 \\
\hline 3 & Spherical & 38,000 & 17,000 & 200 & 0.60 & 0 & 0 & 0 & 0.447 & 0.006 \\
\hline
\end{tabular}

Source: SN9910T0501399.001 [DIRS 129717] and Rautman, C. and McKenna, S. 1998 [DIRS 107442], Section 6.

NOTE: Rotation angles 1-3 and anisotropy ratios 1-2 are keyed to input requirements of the SGSIM computer code, as documented in Deutsch and Journel 1992 [100567], pp. 22 to 29 and 167.

\subsubsection{CHn Model Unit}

Porosity Data-Porosity values obtained from the Calico Hills nonwelded (CHn) model unit are presented graphically in Figure 6.4-12; the corresponding statistical summary of these data is presented in Table 6.4-2.

Matrix Porosity for the $\mathrm{CHn}$ Model Unit (POREF)

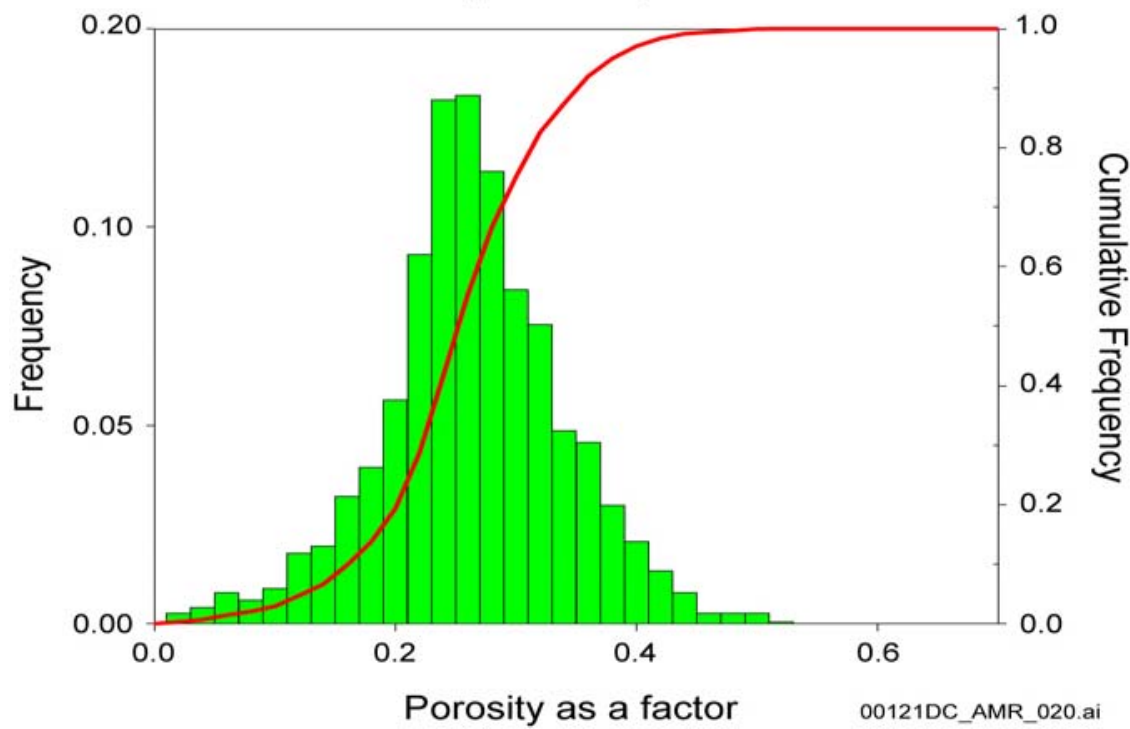

Source: SN9910T0501399.001 [DIRS 129717].

Figure 6.4-12. Histogram and Cumulative Distribution Function of Matrix Porosity in the CHn Model Unit 
Spatial Continuity Data-A modeled variogram for matrix porosity in the CHn model unit is presented in Figure 6.4-13. Parameters of the fitted variogram model are presented in Table 6.4-5. Details of the variogram modeling exercise may be found in the scientific notebook (Rautman and McKenna 1998 [DIRS 107442], pp. 534 to 556).
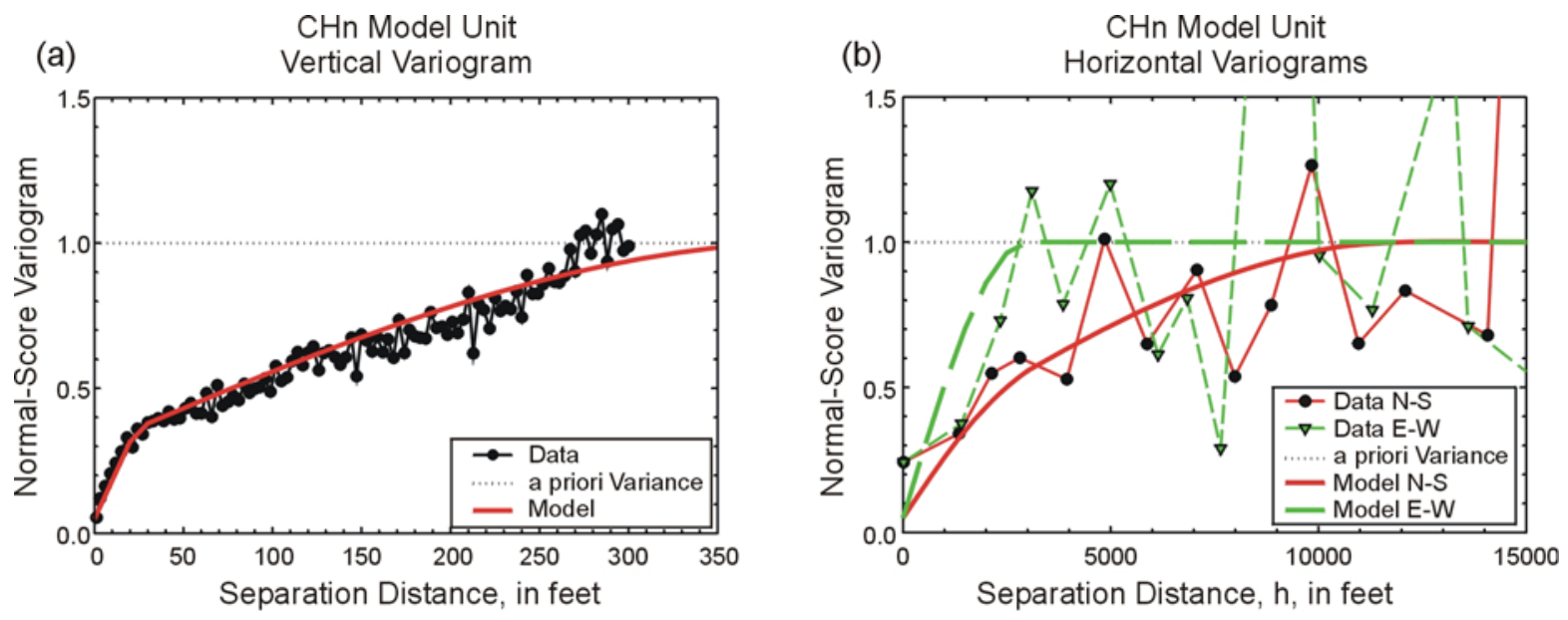

00121DC_AMR_021a.cdr

Source: SN9910T0501399.001 [DIRS 129717].

NOTE: (a) stratigraphic vertical; (b) stratigraphic horizontal.

Figure 6.4-13. Experimental and Fitted Model Variograms for Matrix Porosity in the CHn Model Unit

Table 6.4-5. Variogram Parameters for Spatial Continuity Model of Porosity in the CHn Model Unit

\begin{tabular}{|c|c|c|c|c|c|c|c|c|c|c|}
\hline \multirow[b]{2}{*}{ Nest No. } & \multirow[b]{2}{*}{ Model Type } & \multicolumn{3}{|c|}{ Range (ft) } & \multirow[b]{2}{*}{ Sill } & \multicolumn{3}{|c|}{$\begin{array}{l}\text { Rotation Angle } \\
\text { (degrees) }^{1}\end{array}$} & \multicolumn{2}{|c|}{$\begin{array}{c}\text { Anisotropy } \\
\text { Ratio }^{1}\end{array}$} \\
\hline & & $\begin{array}{c}\text { Maximum } \\
\text { (horizontal) }\end{array}$ & $\begin{array}{c}\text { Inter- } \\
\text { mediate }\end{array}$ & $\begin{array}{l}\text { Minimum } \\
\text { (vertical) }\end{array}$ & & 1 & 2 & 3 & 1 & 2 \\
\hline-- & Nugget & -- & -- & -- & 0.05 & -- & -- & -- & -- & -- \\
\hline 1 & Spherical & 3,000 & 3,000 & 30 & 0.25 & & & & 1.000 & 0.010 \\
\hline 2 & Spherical & 12,000 & 5,000 & 400 & 0.70 & & & & 0.417 & 0.033 \\
\hline
\end{tabular}

Source: SN9910T0501399.001 [DIRS 129717] and Rautman, C. and McKenna, S. 1998 [DIRS 107442], Section 7.

NOTE: Rotation angles 1-3 and anisotropy ratios 1-2 are keyed to input requirements of the SGSIM computer code, as documented in Deutsch and Journel 1992 [DIRS 100567], pp. 22 to 29 and 167.

\subsubsection{Tcp Model Unit}

Porosity Data-Porosity values obtained from the Prow Pass Tuff (Tcp) model unit are presented graphically in histogram format in Figure 6.4-14 the corresponding statistical summary of these data is presented in Table 6.4-2. 


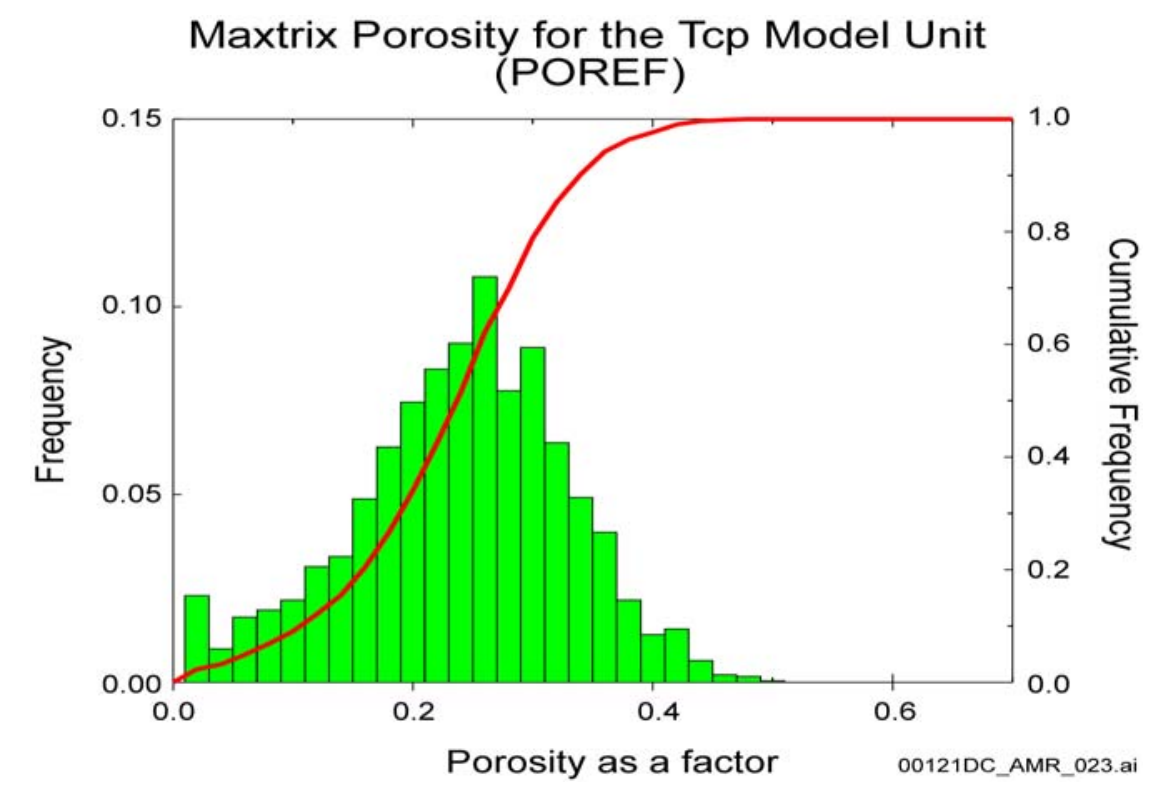

Source: SN9910T0501399.001 [DIRS 129717].

Figure 6.4-14. Histogram and Cumulative Distribution Function of Matrix Porosity in the Tcp Model Unit

Spatial Continuity Data-A modeled variogram for matrix porosity in the Tcp model unit is presented in Figure 6.4-15. Parameters of the fitted variogram model for porosity in the Tcp model unit are presented in Table 6.4-6. Details of the variogram modeling exercise may be found in the scientific notebook (Rautman and McKenna 1998, [DIRS 107442] pp. 704 to 726).
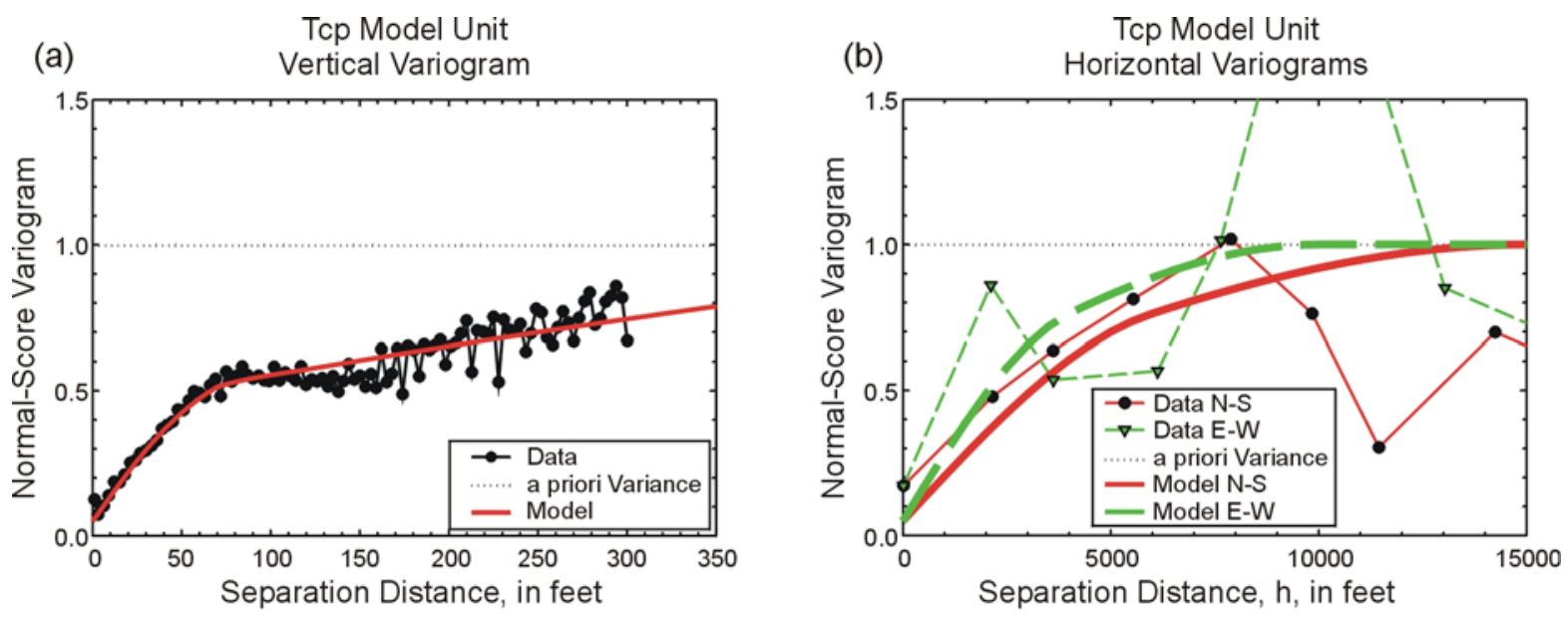

00121DC_AMR_024a.cdr

Source: SN9910T0501399.001 [DIRS 129717].

NOTE: (a) stratigraphic vertical; (b) stratigraphic horizontal.

Figure 6.4-15. Experimental and Fitted Model Variograms for Matrix Porosity in the Tcp Model Unit 
Table 6.4-6 Variogram Parameters for Spatial Continuity Model of Porosity in the Tcp Model Unit

\begin{tabular}{|c|c|c|c|c|c|c|c|c|c|c|}
\hline \multirow[b]{2}{*}{ Nest No. } & \multirow[b]{2}{*}{ Model Type } & \multicolumn{3}{|c|}{ Range (ft) } & \multirow[b]{2}{*}{ Sill } & \multicolumn{3}{|c|}{$\begin{array}{c}\text { Rotation Angle } \\
\text { (degrees) }\end{array}$} & \multicolumn{2}{|c|}{$\begin{array}{l}\text { Anisotropy } \\
\text { Ratio }\end{array}$} \\
\hline & & $\begin{array}{c}\text { Maximum } \\
\text { (horizontal) }\end{array}$ & $\begin{array}{c}\text { Inter- } \\
\text { mediate }\end{array}$ & $\begin{array}{l}\text { Minimum } \\
\text { (vertical) }\end{array}$ & & 1 & 2 & 3 & 1 & 2 \\
\hline-- & Nugget & -- & -- & -- & 0.05 & -- & -- & -- & -- & -- \\
\hline 1 & Spherical & 6,000 & 4,000 & 80 & 0.40 & & & & 0.667 & 0.013 \\
\hline 2 & Spherical & 15,000 & 10,000 & 800 & 0.55 & & & & 0.667 & 0.053 \\
\hline
\end{tabular}

Source: SN9910T0501399.001 [DIRS 129717] and Rautman, C. and McKenna, S. 1998 [DIRS 107442], Section 8.

NOTE: Rotation angles 1-3 and anisotropy ratios 1-2 are keyed to input requirements of the SGSIM computer code, as documented in Deutsch and Journel 1992 [DIRS 100567], pp. 22 to 29 and 167.

\subsubsection{Statistical Description of Secondary Material Properties}

The secondary, or derivative, material properties considered in this analysis are matrix saturated hydraulic conductivity, bulk density, and thermal conductivity (Section 4.1.3). In general, there are insufficient individual measurements of these material properties to determine their spatial continuity patterns independently of porosity. Accordingly, they have been modeled under the presumption that each variable is coregionalized with porosity. This section contains the basic statistical description of each derivative material property, including the correlation of that property with corresponding porosity measurements, which is used in the coregionalization process.

\subsubsection{Matrix Saturated Hydraulic Conductivity}

The histogram of all available laboratory measurements of matrix saturated hydraulic conductivity is presented in Figure 6.4-16(a). A scatterplot of these same data against the corresponding laboratory porosity values is shown in part (b) of the figure, and a statistical summary of the data is presented in Table 6.4-7.

(a) All Measured core samples, Ksat Values all units

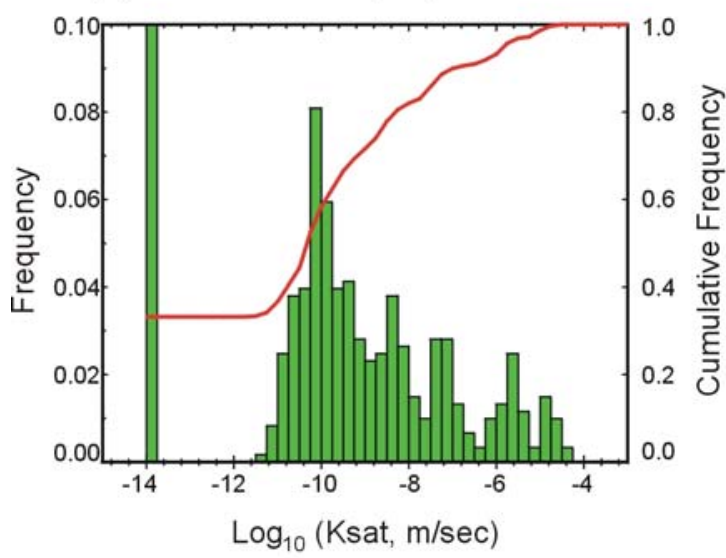

Source: SN9910T0501399.001 [DIRS 129717].

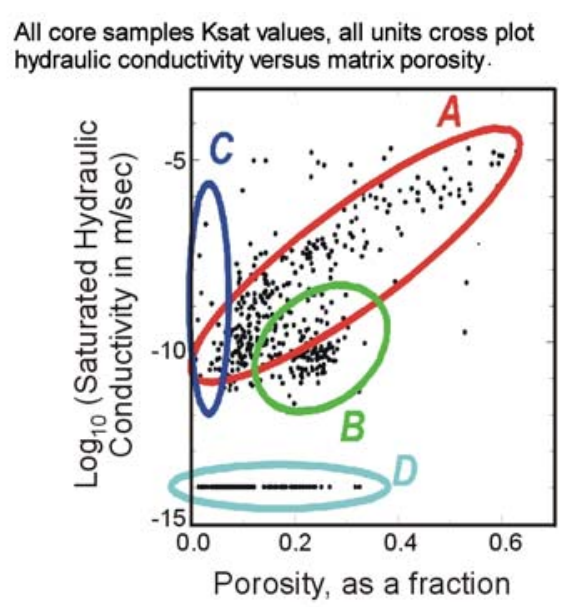

00121DC_AMR_111a.cdr

NOTE: (a) Histogram of laboratory-measured matrix saturated hydraulic conductivity from core samples; and (b) crossplot of hydraulic conductivity versus matrix porosity for the same samples.

Figure 6.4-16. All Measured Core Samples 
Table 6.4-7. Statistical Summary of Matrix Saturated Hydraulic Conductivity Measurements

\begin{tabular}{|c|c|c|c|}
\hline & All Data & Unaltered & Altered \\
\hline Mean & -8.9553 & -8.6536 & -9.6805 \\
\hline Std.Dev. & 1.7317 & 1.7248 & 1.5269 \\
\hline Minimum & -11.7086 & -11.3360 & -11.7086 \\
\hline Maximum & -4.6866 & -4.6955 & -4.6866 \\
\hline $\mathrm{N}$ & 405 & 286 & 119 \\
\hline
\end{tabular}

Source: SN9910T0501399.001 [DIRS 129717], folder 3dm_input.

NOTE: All values in $\log _{10} \mathrm{~m} / \mathrm{sec}$ except number of samples $(\mathrm{N})$; "no-flow" samples omitted.

Figure 6.4-16(a) is distinctively multi-modal, and Figure 6.4-16(b) indicates four subpopulations that can be identified in the matrix hydraulic conductivity data set. Essentially, cluster A consists of samples for which the delta-porosity, computed simply as the arithmetic difference between the OD and relative humidity laboratory-measured porosity values, is less than 5 percent (0.05). Cluster A corresponds to a continuum of hydraulic conductivity values that are rather strongly correlated to porosity, as presented separately in Figure 6.4-17. Rautman and McKenna (1997 [DIRS 100643], pp. 37 to 40) present an expanded discussion of identifying hydrousphase mineral alteration in core samples through the use of delta-porosity values.

(a) Unaltered core samples, Ksat, all units

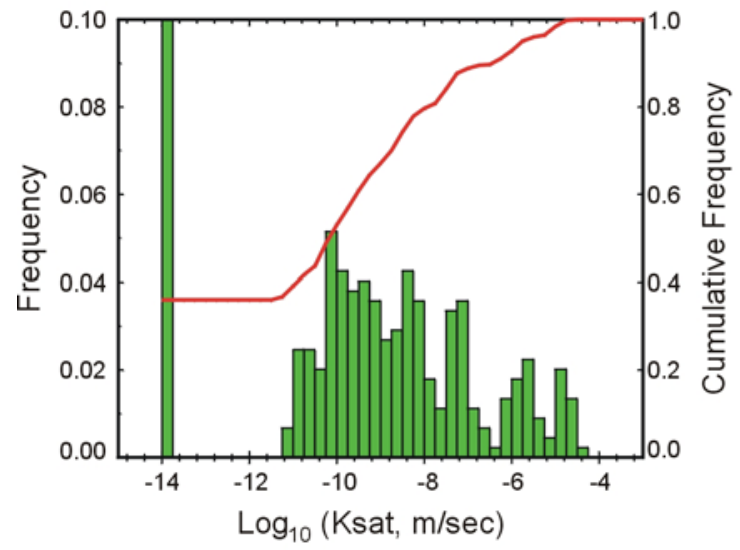

(b) Unaltered core samples Ksat, all units. Cross plot hydraulic conductivity (unaltered Ksat) versus matrix.

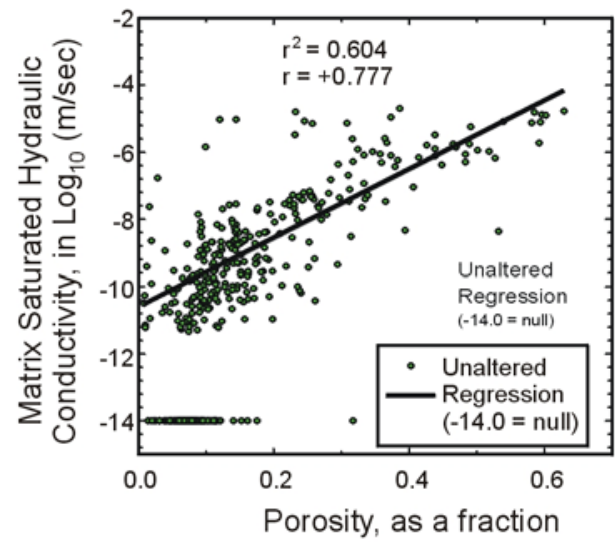

00121DC_AMR_026b.cdr

Source: SN9910T0501399.001 [DIRS 129717].

NOTE: Conductivity of nonflowing samples set to $10^{-14} \mathrm{~m} / \mathrm{sec}$ for plotting only. (a) Histogram of laboratory-measured matrix saturated hydraulic conductivity from unaltered core samples (identified by delta-porosity); and (b) crossplot of hydraulic conductivity versus matrix porosity for the same samples. Conductivity of nonflowing samples set to $10^{-14} \mathrm{~m} / \mathrm{sec}$ for plotting only

Figure 6.4-17. Unaltered Core Samples 
(a) Altered core sample, Ksat, all units

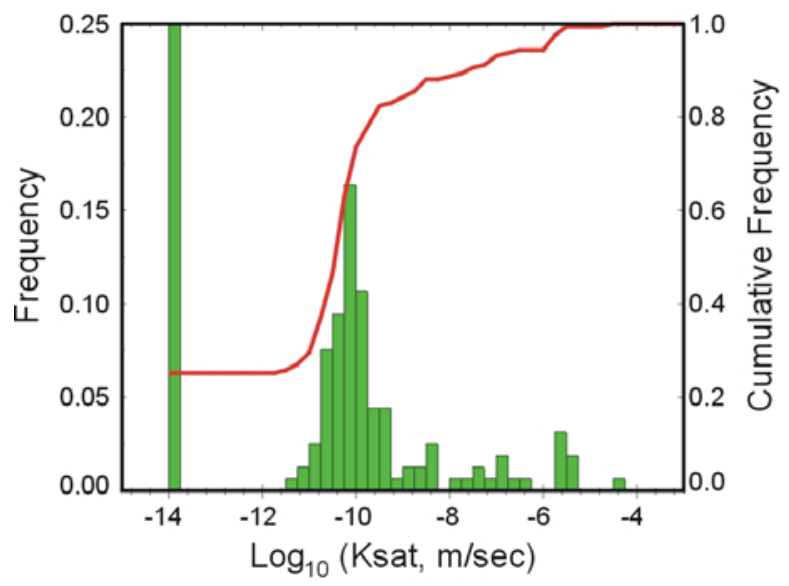

(b) Altered core samples, all units cross plot of hydraulic conductivity versus matrix porosity.

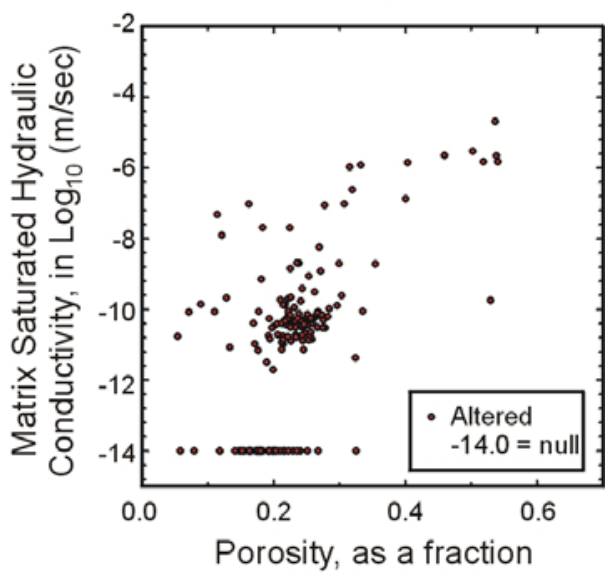

00121DC AMR 028b.cdr

Source: SN9910T0501399.001 [DIRS 129717].

NOTE: (a) Histogram of laboratory-measured matrix saturated hydraulic conductivity from altered core samples (identified by delta-porosity) and (b) crossplot of hydraulic conductivity vs. matrix porosity for the same samples. Conductivity of nonflowing samples set to $10^{-14} \mathrm{~m} / \mathrm{sec}$ for plotting only

Figure 6.4-18. Altered Core Samples

Cluster B in Figure 6.4-16(b) contains samples for which the delta-porosity between the OD and relative humidity porosity measurements is greater than 5 percent. These are samples that exhibit significant hydrous-phase mineral alteration, as evidenced by the removal of moderately large quantities of water during drying at $105^{\circ} \mathrm{C}$. This subpopulation is plotted separately in Figure 6.4-18, and it appears largely indistinguishable from a normally distributed (gaussian) population if the small group of samples with conductivities greater than $10^{-6} \mathrm{~m} / \mathrm{sec}$ are

discounted as potentially misclassified samples. These samples may be misclassified because hydrous-phase mineral alteration causes development of the secondary mineral phases thatoccluded the matrix flow pathways. Therefore if affected by hydrous phase mineral alteration these samples are unlikely to have hydraulic conductivity values greater than $10^{-6}$ $\mathrm{m} / \mathrm{sec}$.

Cluster C of Figure 6.4-16(b) is represents a small subset of the entire population of matrix hydraulic conductivity measurements for which the corresponding porosity measurement is very low, and for which there appears to be no particular correlation of porosity with conductivity. These samples are almost exclusively from two vitrophyric lithostratigraphic units: Tptrv1 and Tptpv3, Figure 6.4-19(a) and (c). Experimentation indicates that almost the identical subset of samples can be extracted from the complete hydraulic conductivity data set simply as those samples whose measured porosity is less than 5 percent (0.05). These samples are presented in Figure 6.4-19(b) and (d). Flint (1998 [DIRS 100033], p. 38) interpreted the relatively uniform-random distribution of these "matrix" hydraulic conductivities as caused by microfracturing within these densely welded rock types. 


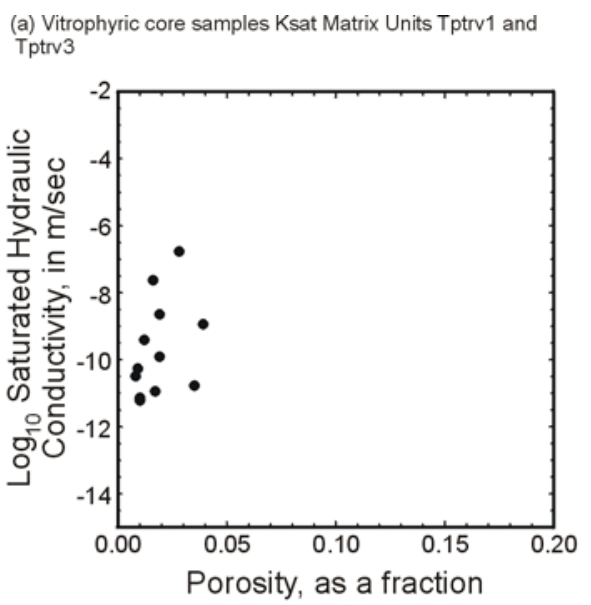
(c) Vitrophyric core samples Ksat Matrix Units Tptrv1 and
Tptrv3

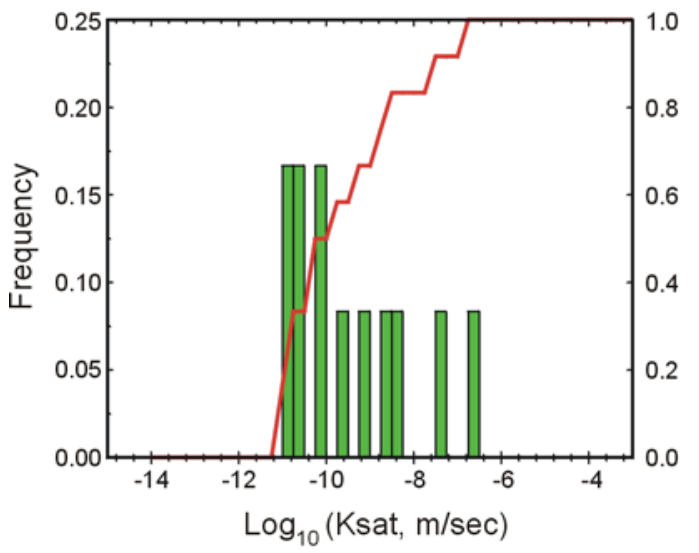

(b) Vitrophyric core samples matrix porosity less than

0.05

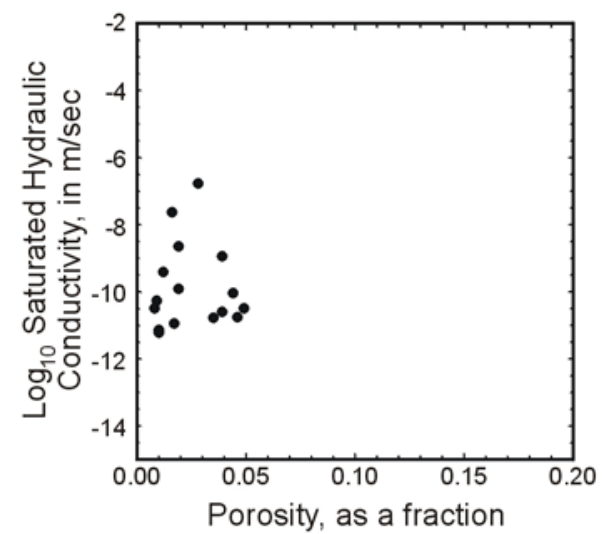

(d) Vitrophyric core samples Ksat matrix porosity less than 0.05

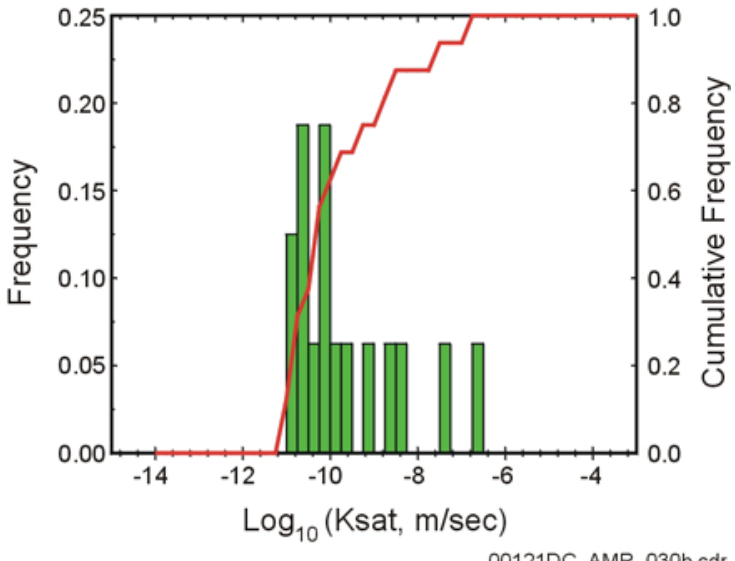

Source: SN9910T0501399.001 [DIRS 129717]

NOTE: (a) core samples from vitrophyric lithostratigraphic units Tptrv1 and Tptpv3 and (b) core samples with matrix porosity less than 0.05 . (c) and (d) histograms and cumulative distribution functions for samples presented in parts (a) and (b), respectively; no-flow samples omitted

Figure 6.4-19. Scatterplots of Matrix Saturated Hydraulic Conductivity Versus Matrix Porosity

Cluster D of Figure 6.4-16(b) represents those core samples for which the matrix saturated hydraulic conductivity was below the sensitivity limit of the laboratory permeameter. Note that these null values have been ignored in all statistical calculations for this modeling exercise. As shown in Figure 6.4-16, the saturated hydraulic conductivity of these "no-flow" samples have been arbitrarily set equal to $10^{-14} \mathrm{~m} / \mathrm{sec}$ for plotting purposes, both here and elsewhere in this report.

In contrast to the discussion of Figures 6.4-17 and 6.4-18, which involves more or less global characteristics of the measured matrix saturated hydraulic conductivity measurements from Yucca Mountain, a broader objective of this modeling exercise is to reproduce the material property characteristics appropriate for individual model units. The ability to discriminate and identify the hydraulic conductivity characteristics of specific vitrophyric rock units essentially by 
looking solely at their porosity characteristics (e.g., Figure 6.4-17 and discussion) is one example. Other relevant matrix hydraulic conductivity characteristics for purposes of this report are the by-unit statistical distributions of values. These target histograms for the individually simulated models of the four modeling units are presented in Figure 6.4-20 (a) through (d).
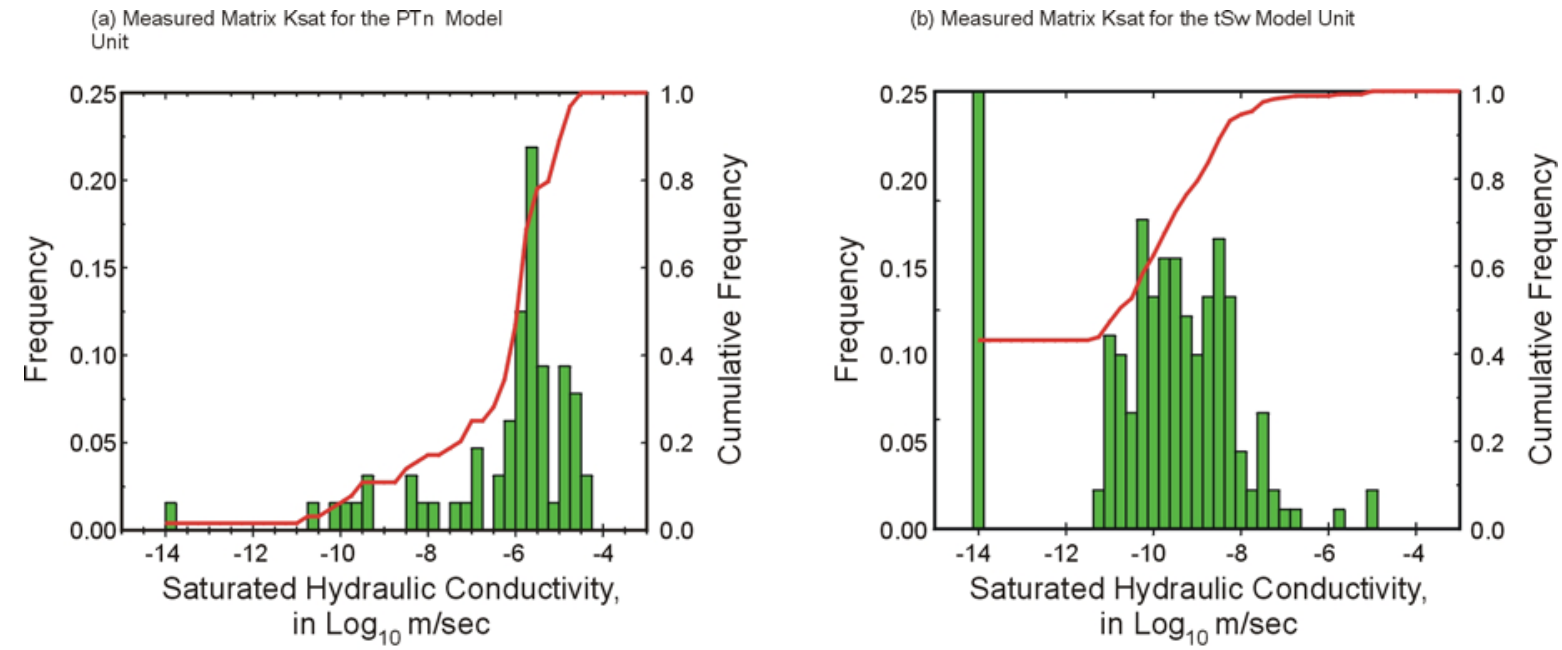

(c) Measured Matrix Ksat for the $\mathrm{CHn}$ Model Unit

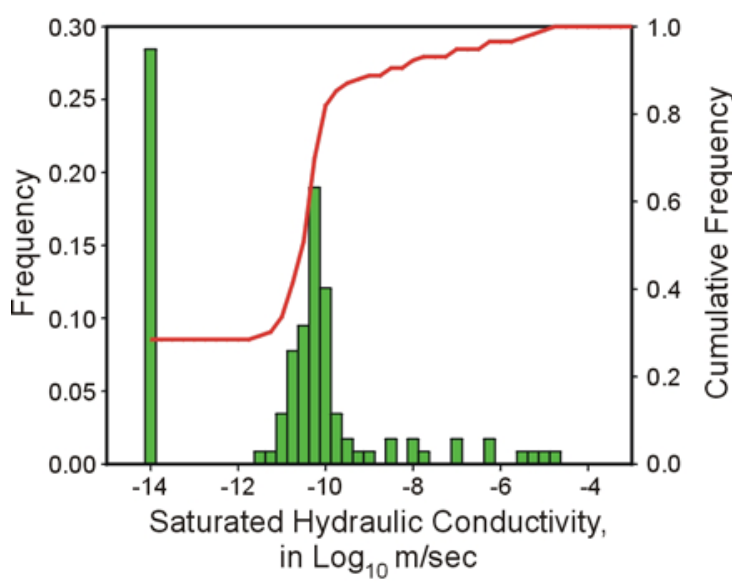

(d) Measured Matrix Ksat for the Tcp Model Unit

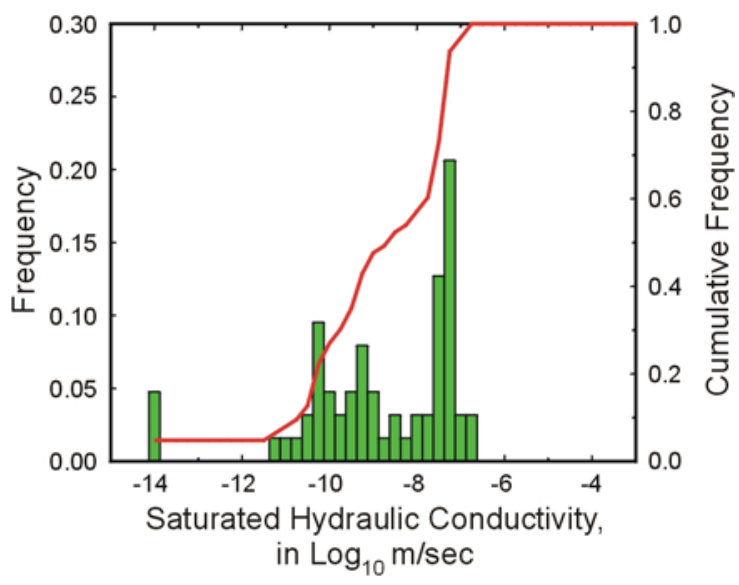

00121DC_AMR 034b.cdr

Source: SN9910T0501399.001 [DIRS 129717].

NOTE: (a) PTn; (b) TSw; (c) CHn; (d) Tcp Model Units.

Figure 6.4-20. Matrix Saturated Hydraulic Conductivity Histograms and Cumulative Distribution Functions

\subsubsection{Bulk Density}

A histogram of more than 3,000 relative-humidity-oven-dried bulk density values from all four model units is presented in Figure 6.4-21(a). The composite histogram is distinctly multimodal, as might be expected from aggregation of densely welded tuffs with a collection of non- to partially welded ash-flow tuffs and nonwelded air-fall tuffaceous debris. 

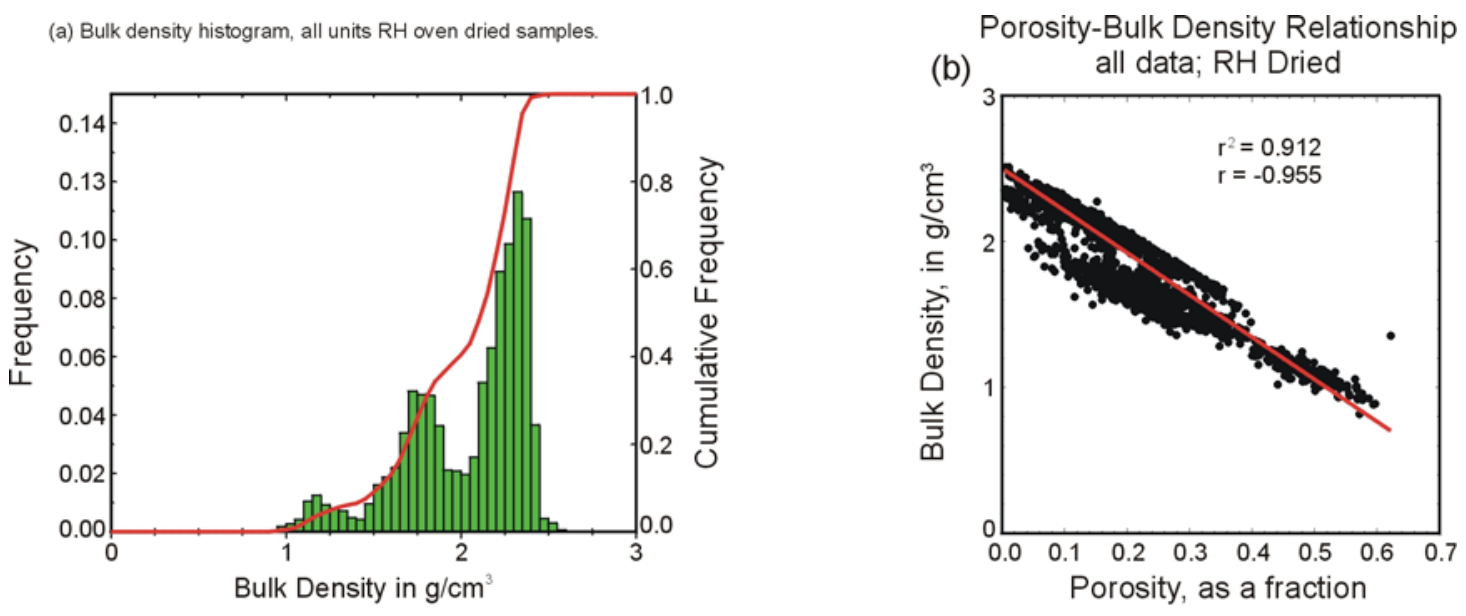

00121DC_AMR_038b.cdr

Source: 6.4-21(a) SN9910T0501399.001 [DIRS 129717] and 6.4-21(b) SN0004T0501399.002 [DIRS 155046].

NOTE: (a) histogram and cumulative distribution function of Relative-Humidity Oven-Dried bulk density values from all four modeling units; (b) scatterplot of bulk density as a function of matrix porosity for the same data.

Figure 6.4-21. Bulk Density Relationship

Despite the compositing of a group of diverse lithologies (and mineralogies) for Figure 6.4-21(a), the bulk density data appear to belong to a relatively consistent family of values. A scatter diagram showing the relationship between the bulk density values and relative humidity dried porosity (equivalent to relative humidity-oven-dried porosity) is presented in Figure 6.4-21(b). Although there is some segregation of the cloud of data points into two overlapping subpopulations (which can be demonstrated to relate to hydrous-phase mineral alteration), the coefficient of determination $\left(\mathrm{r}^{2}\right)$ value is a very strong 0.912 , indicating only slightly less than one-to-one correspondence. Given the generally low importance of bulk density in most performance assessment analyses, it has not been determined to be of sufficient importance to analyze altered and unaltered bulk densities separately. Unit-specific histograms that serve as the target distributions for the coregionalized bulk density models are presented in Figure 6.4-22 Model unit genesis is reflected clearly in the four parts of the figure: high-density densely welded tuffs in the TSw model unit (part (b)), low-density nonwelded and pumiceous rich materials in the PTn unit (part (a)), and intermediate-density nonwelded to only partially welded tuffaceous materials in the CHn and Tcp model units (parts (c) and (d)). 
(a)

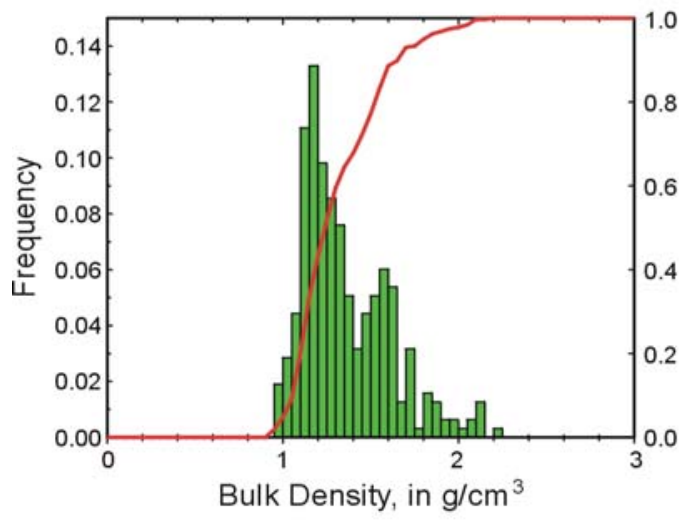

(c)

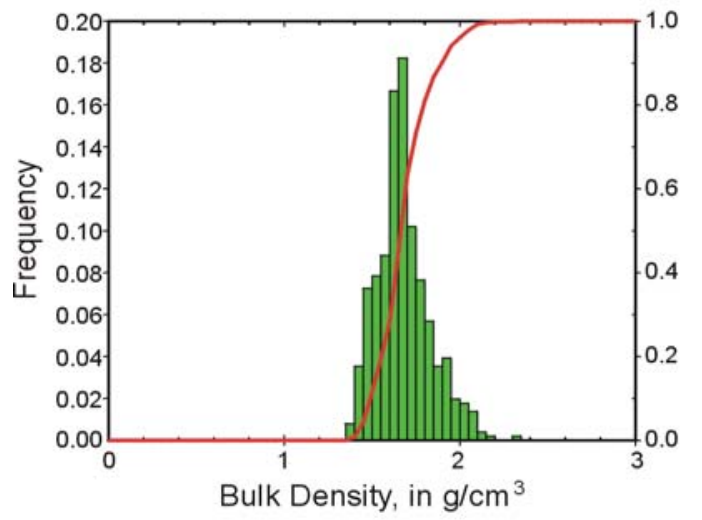

RH Bulk Density for the TSw Model Unit

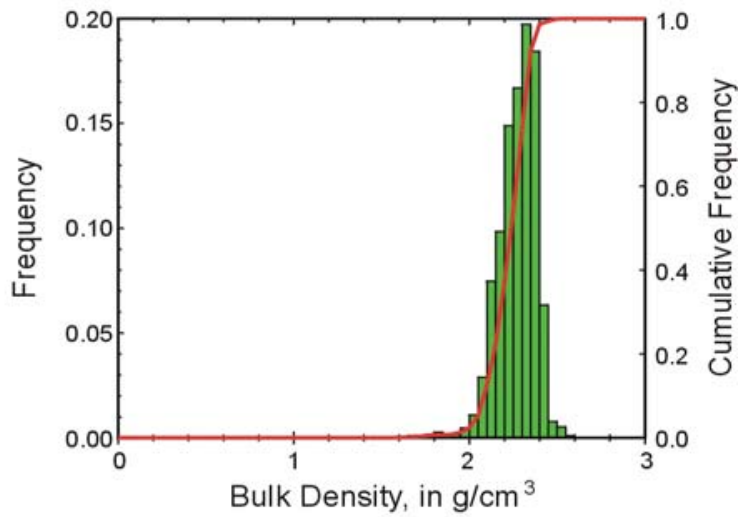

(d)

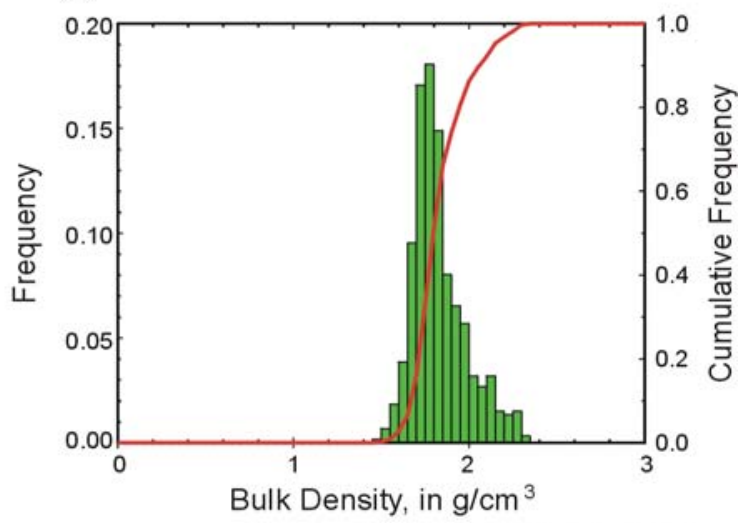

00121DC_AMR_040b.cdr

Source: SN9910T0501399.001 [DIRS 129717].

NOTE: (a) the PTn, (b) TSw, (c) CHn, and (d) Tcp Model Units.

Figure 6.4-22. Bulk Density Histograms

\subsubsection{Thermal Conductivity}

Thermal conductivity and porosity data have been obtained from a modest number of samples collected from the PTn and TSw model units. Figure 6.4-23(a) presents a histogram and cumulative distribution function for these thermal conductivity values measured at $70^{\circ} \mathrm{C}$ and under $105^{\circ} \mathrm{C}$-dried saturation conditions (note that thermal conductivity is a function of both absolute temperature and saturation state). The crossplot of these same values in Figure 6.4-23(b) clearly indicates an inverse relationship of thermal conductivity with porosity. A statistical summary of these available thermal conductivity data is presented in Table 6.4-8.

There are two significant difficulties in using the existing thermal conductivity data, which is derived from laboratory testing on matrix-sized specimens. First, the in situ bulk density of the Topopah Spring welded unit is most directly related to the lithophysal porosity of this unit, not to the matrix porosity. Open cavities too large to be measured as part of the matrix porosity laboratory procedure (or its petrophysical equivalent) will significantly reduce the whole rock 
bulk density, leading to lower effective thermal conductivity. Previous discussion of porosity data from the TSw model unit (Section 6.4.4.2) indicates that the lithophysal porosity values can be greater by a factor of two compared with the depth-equivalent matrix porosity values. Use of this factor-of-two porosity difference applied to the regression relationship shown in Figure 6.4-23(b) would lead to overprediction errors of roughly 30 to 50 percent for thermal conductivity, depending on the actual porosity level considered. Given that the thermal conductivity models will be coregionalized using lithophysal porosity in an effort to model the in situ thermal conductivity of the rock mass, the phrase whole-rock thermal conductivity will be used in this report.

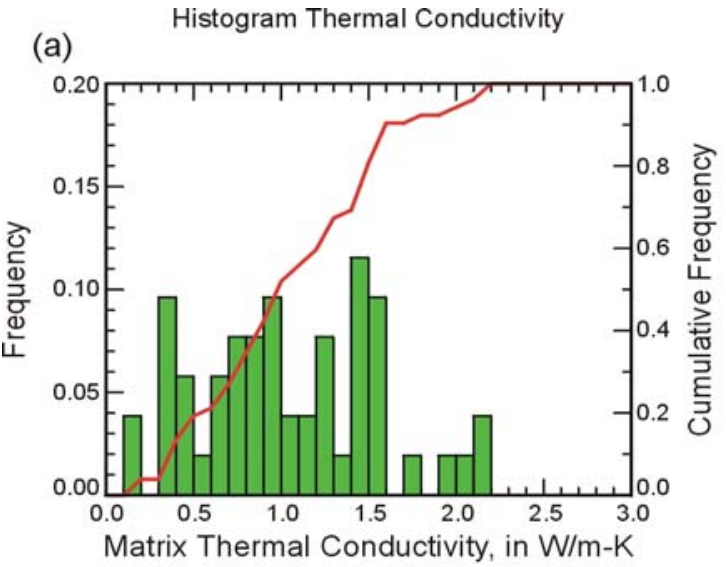

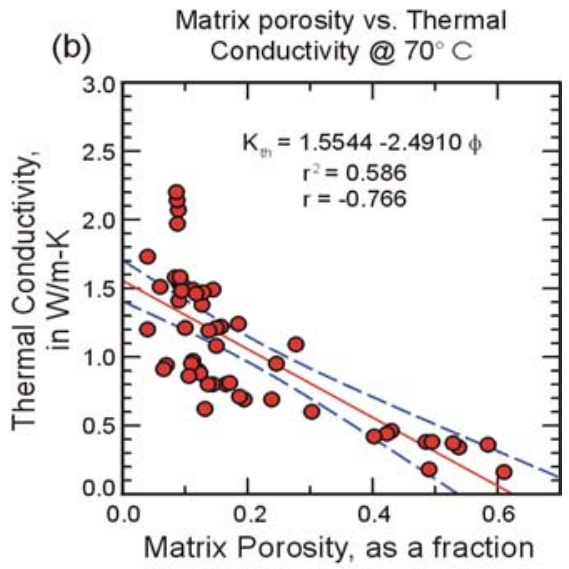

00121DC AMR 044b.cdr

Source: SN9910T0501399.001 [DIRS 129717].

NOTE: All thermal conductivities measured at $70^{\circ} \mathrm{C}$ and $105^{\circ} \mathrm{C}$-dried conditions. Solid line in (b) is regression fit (used in Section 6.4.5.3); dashed lines are 95-percent confidence limits. (a) histogram and cumulative distribution function for measured thermal conductivity data. (b) scatterplot of thermal conductivity as a function of matrix porosity.

Figure 6.4-23. Thermal Conductivities from Non-Zeolitic Rock Samples

Table 6.4-8. Statistical Summary of Measured Thermal Conductivity Data from Non-Zeolitic Rock Samples

\begin{tabular}{|c|c|c|c|}
\hline & \multicolumn{2}{|c|}{$\begin{array}{l}\text { Thermal Conductivity }(\mathrm{W} / \mathrm{m}-\mathrm{K}) \text { at } \\
70^{\circ} \mathrm{C} \text { and } 105^{\circ} \mathrm{C} \text { dry }\end{array}$} & \multirow[b]{2}{*}{ Porosity $\left(105^{\circ} \mathrm{C}\right)$} \\
\hline & All Data & TSw Only & \\
\hline Mean & 1.054 & 1.241 & 0.197 \\
\hline Std.Dev. & 0.516 & 0.427 & 0.156 \\
\hline Minimum & 0.160 & 0.620 & 0.040 \\
\hline Maximum & 2.200 & 2.200 & 0.610 \\
\hline $\mathrm{N}$ & 52 & 35 & 54 \\
\hline
\end{tabular}

Source: SN9910T0501399.001 [DIRS 129717], folder 3dm_input.

NOTE: All values in Watts per meter-Kelvin $(\mathrm{W} / \mathrm{m}-\mathrm{k})$ except $\mathrm{N}=$ number of samples. 
A second, and rather severe difficulty with the available thermal conductivity data is that the density of sampling is not great (a maximum of 52 samples; see Table 6.4-8), and furthermore, those samples are highly biased both spatially and toward low-porosity materials, as follows: (1) Two of four drill holes that were sampled for thermal conductivity specimens, although located within the extended site area, are actually located some distance from the region transected by the main part of the ESF (NRG-4, NRG-5; see Figure 5). (2) The sampling vertically within a drill hole is not systematic, and in fact, the vertical distribution of samples cannot be considered particularly "representative" of the entire Topopah Spring welded model unit. (3) The only samples that represent the higher porosity values (needed to model the effect of lithophysal cavities on heat conduction) are taken from the PTn model unit, and thus represent nonwelded tuffs rather than the lithophysal portion of welded materials.

With respect to the several biases known to exist in the thermal conductivity data, consider Figure 6.4-24 (a), which is a histogram of the 54 porosity values measured on the thermal conductivity test specimens (Table 6.4-8). Comparison of this figure with the histogram of all lithophysal porosity values measured from the TSw model unit (part (b) of the figure) clearly indicates the extent of the sampling bias. First, Figure 6.4-24(a) is clearly bimodal, representing as it does, samples from both welded and nonwelded rock types. If the group of samples with porosities higher than about 40 percent (presumably representing nonwelded tuffs) is discounted, the mode corresponding to the welded Topopah Spring samples is strongly skewed toward lower porosity values. For example, the approximate modal value in Figure 6.4-24(a) is 8 to 10 percent, whereas the modal value for the TSw model unit as a whole (Figure 6.4-24(b)) is 18 to 20 percent for lithophysal porosity.
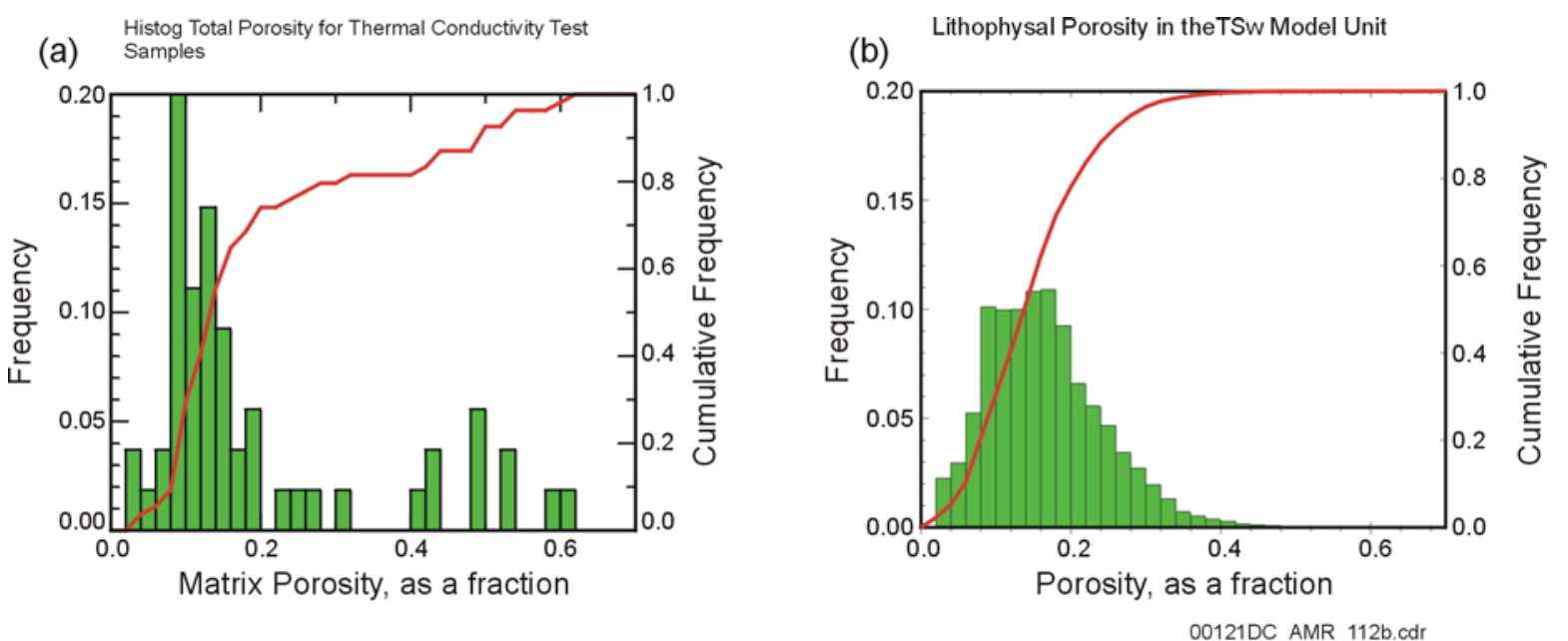

Source: SN9910T0501399.001 [DIRS 129717].

NOTE: (a) total porosity measured for thermal conductivity test specimens; (b) lithophysal porosity from the TSw model unit (repeated from Figure 6.4-23[b]).

Figure 6.4-24. Histograms and Cumulative Distribution Functions

These sampling biases have been reduced in the following manner. First, the regression relationship presented in the scatterplot of Figure 6.4-23(b) is assumed to be a valid predictor of thermal conductivity across the range of porosity values appropriate for the TSw model unit. A 
systematic prediction of the nominal thermal conductivity of the TSw model unit is then generated using the systematically sampled (nominal $3 \mathrm{ft}$ spacing) porosity data available for three drill holes located along the ESF main drift (SD-7, SD-9, and SD-12; Figure 6.4-26). These three sets of predicted values are then aggregated and the appropriate statistical quantities and histogram are computed (Figure 6.4-25; Table 6.4-9). The histogram of Figure 6.4-25 will be used as the target distribution for the coregionalized models. Note that although the mean thermal conductivity for both the 35 measured samples of the Topopah Spring welded unit and the systematically predicted thermal conductivity of the TSw model unit as a whole (Table 6.4-9) are remarkably similar at $1.2 \mathrm{~W} / \mathrm{m}-\mathrm{K}$ (rounded), the local thermal conductivity of major intervals within the unit differ markedly from one another (Figure 6.4-26).

Predicted Thermal Conductivity.

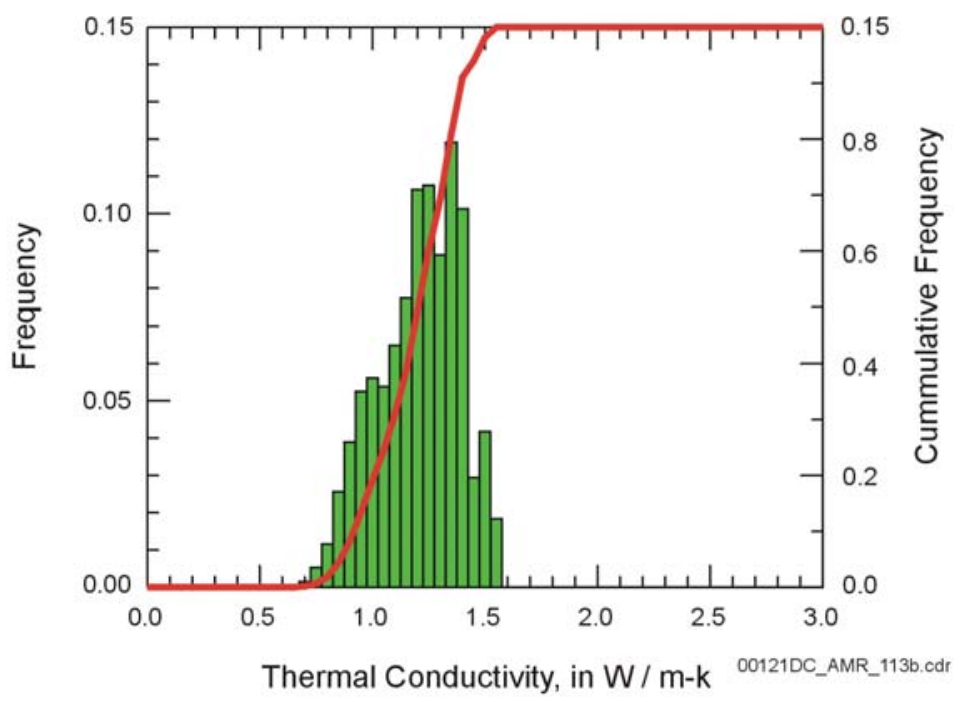

Source: SN9910T0501399.001 [DIRS 129717].

Figure 6.4-25. Histogram and Cumulative Distribution Function for Thermal Conductivity Systematically Predicted from Lithophysal Porosity Values in Drill Holes USW SD-7, SD-9, and SD-12 Using the Regression Relationship from Figure 6.4-23(b)

Table 6.4-9. Statistical Comparison of Measured and Predicted Thermal Conductivity Data for the TSw Model Unit

\begin{tabular}{|c|c|c|}
\hline & $\begin{array}{c}\text { Measured Thermal } \\
\text { Conductivity } @ \mathbf{7 0}^{\circ} \mathbf{C}\end{array}$ & $\begin{array}{c}\text { Predicted Thermal } \\
\text { Conductivity @ 70 } \mathbf{C}\end{array}$ \\
\hline Mean & 1.241 & 1.183 \\
\hline Std.Dev. & $0.427^{1}$ & $0.182^{2}$ \\
\hline Minimum & 0.620 & 0.676 \\
\hline Maximum & 2.200 & 1.550 \\
\hline $\mathrm{N}$ & 35 & 6063 \\
\hline
\end{tabular}

Source: SN9910T0501399.001 [DIRS 129717], folder 3dm_input.

NOTES: Units are Watts/meter-Kelvin (W/m-K) except for number of values $(\mathrm{N})$.

${ }^{1}$ Also includes effect of measurement errors and lithologic variability.

${ }^{2}$ Includes effect of lithologic variability only.

(see text for discussion of prediction methodology) 
(a)

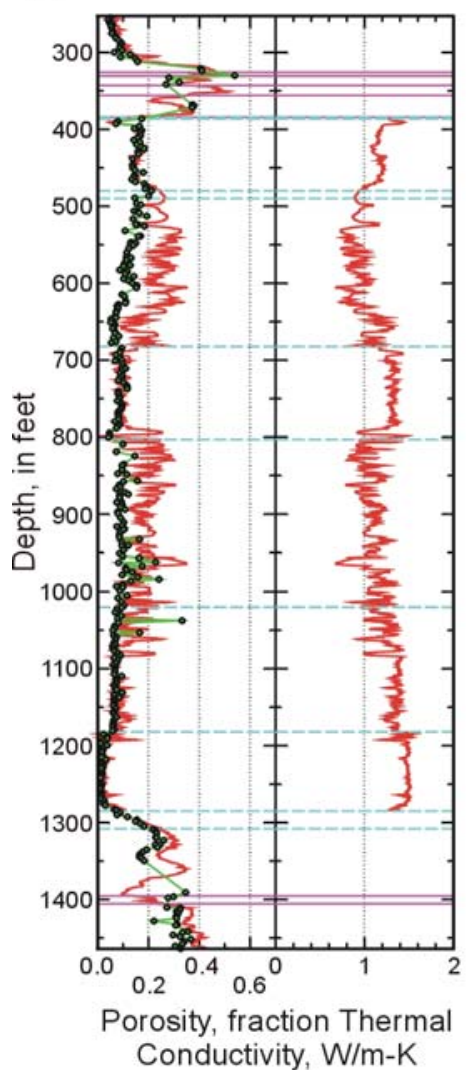

(b)

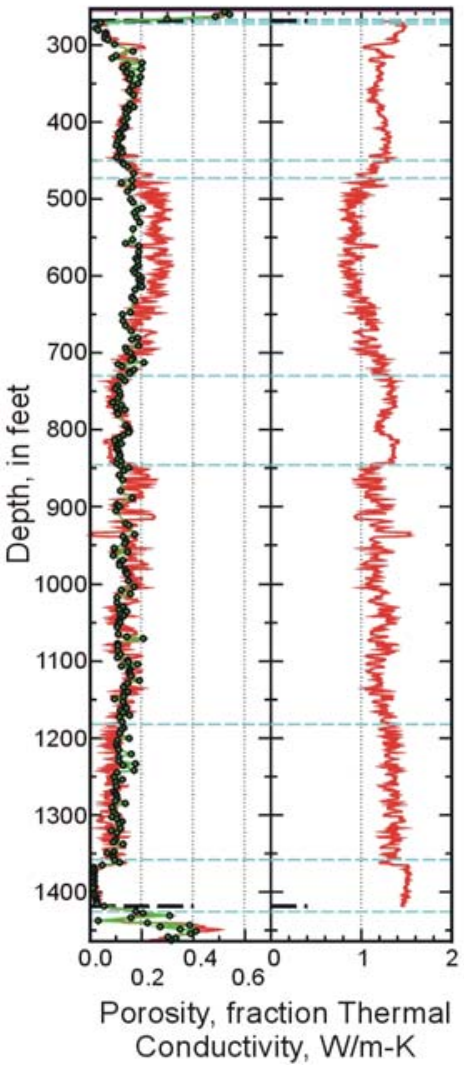

(c)

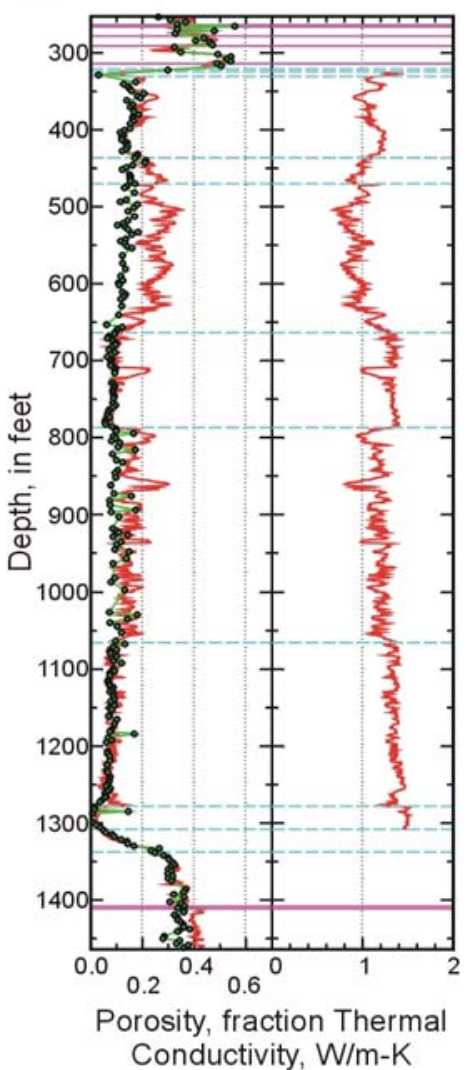

00121DC AMR 046acdr

Source: SN9910T0501399.001 [DIRS 129717].

NOTE: Thermal conductivity key: predicted thermal conductivity at $70^{\circ} \mathrm{C}$ and $105^{\circ} \mathrm{C}$-dried conditions. Porosity key: dark line-lithophysal porosity from petrophysical logs; light grey line with symbols—matrix porosity from core samples. (a) USW SD-7, (b) SD-9; (c) SD-12.

Figure 6.4-26. Downhole Variation in Predicted Thermal Conductivity Values Based on Systematically Measured Lithophysal Porosity Data for Drill Holes

\subsubsection{Modeling Techniques}

This section contains a summarized, yet, logically accurate description of the geostatistical modeling techniques used to produce the rock properties models, including reference to the various computer codes (Table 3-1) and software routines (Table 3-2) used to generate the actual models. Sequential gaussian simulation is used to generate the primary porosity models, whereas linear coregionalization is used to generate the derivative models of secondary properties. Indicator kriging is used to produce the model of hydrous-phase mineral alteration that constrains the distribution of the derivative models of saturated hydraulic conductivity in two of the model units.

\subsubsection{Discretization of the Model Domain}

Details of the grid defined for all geostatistical modeling are presented in Table 6.4-10 The horizontal discretization of $200 \mathrm{~m}$ by $200 \mathrm{~m}$ is tied directly to the horizontal resolution of the UZ 
site-scale flow model across its entire areal extent. Vertical resolution of the geostatistical grid is also tied to the UZ zone flow model, particularly within the general repository volume. Additionally, the total number of grid nodes in the resulting suite of models was computationally tractable.

Table 6.4-10. Geostatistical Modeling Grid Specification Parameters Corresponding to the Southwest Corner of the Grid

\begin{tabular}{|c|c|c|c|c|c|}
\hline \multicolumn{2}{|c|}{ Grid Dimension } & $\begin{array}{c}\text { Midpoint } \\
(\mathrm{ft} / \mathrm{m})\end{array}$ & $\begin{array}{c}\text { Spacing } \\
(\mathrm{ft} / \mathrm{m})\end{array}$ & $\begin{array}{l}\text { No. of } \\
\text { Nodes }\end{array}$ & $\begin{array}{c}\text { Total } \\
\text { Nodes }\end{array}$ \\
\hline \multicolumn{2}{|l|}{$\begin{array}{l}\text { Model X } \\
\text { (Easting) }\end{array}$} & $\begin{array}{l}549,895.6 \\
167,600.0 \\
\end{array}$ & $\begin{array}{l}656.2 \\
200.0 \\
\end{array}$ & 34 & -- \\
\hline \multicolumn{2}{|l|}{$\begin{array}{l}\text { Model Y } \\
\text { (Northing) }\end{array}$} & $\begin{array}{l}751,349.0 \\
229,000.0 \\
\end{array}$ & $\begin{array}{l}656.2 \\
200.0 \\
\end{array}$ & 43 & -- \\
\hline \multirow{4}{*}{$\begin{array}{l}\text { Model Z } \\
\text { (Stratigraphic } \\
\text { Vertical) }\end{array}$} & PTn & $\begin{array}{l}3.3333 \\
1.0159 \\
\end{array}$ & $\begin{array}{l}6.667 \\
2.032 \\
\end{array}$ & 30 & 43,860 \\
\hline & TSw & $\begin{array}{l}8.2025 \\
2.5000 \\
\end{array}$ & $\begin{array}{c}16.405 \\
5.000 \\
\end{array}$ & 61 & 89,182 \\
\hline & $\mathrm{CHn}$ & $\begin{array}{l}8.4444 \\
2.5399 \\
\end{array}$ & $\begin{array}{c}16.666 \\
5.080 \\
\end{array}$ & 24 & 35,088 \\
\hline & Tсp & $\begin{array}{l}8.4444 \\
2.5399\end{array}$ & $\begin{array}{c}16.666 \\
5.080\end{array}$ & 24 & 35,088 \\
\hline
\end{tabular}

Source: Rautman (1999 [DIRS 109035]) Section 2, page 16.

\subsubsection{Sequential Gaussian Simulation of Porosity}

Geostatistical simulation comprises a large class of modeling techniques that can produce very complex, and presumably therefore highly realistic numerical representations of spatially variable properties. Simulation may be thought of as "expanding" the actual information available in a stochastic manner that is also compatible with additional information derived from the data ensemble and the spatial context of those data. The process builds on the geologic intuition that unsampled locations nearby a known value will "tend" to resemble that value, whereas unsampled locations at increasing distances from a known measurement tend progressively to resemble that datum less and less. This intuition will be observed statistically across a suite of several equiprobable simulations.

The philosophical framework of simulation is simple. Using concepts of random variables, one develops a model of the probability density function ( $p d f$ ) for a material property of interest at all locations in space. By transforming the measured data to their respective positions on the probability density function and using simple kriging (Deutsch and Journel 1992 [DIRS 100567], pp. 62 and 137), the desired pdfs can be made conditional to a set of measured values. Alternative realizations are simply generated by sampling from these pdfs. The variance of individual, location-specific, $p d f s$ will vary with the amount of geologic uncertainty. Near conditioning data (Figure 6.4-27), the $p d f$ associated with an unsampled location will be relatively narrow. Where less information is known, such as away from data or in the vicinity of conflicting measurements, the $p d f$ will be relatively broad (Figure 6.4-27[a-b]), leading to generation of a wide range of likely values across a suite of realizations. Because the underlying kriging algorithm used to derive the $p d f s$ is an exact interpolator, the $p d f$ degenerates to a spike with probability $=1$ at a measured location (Figure 6.4-27(d)). 
(a)

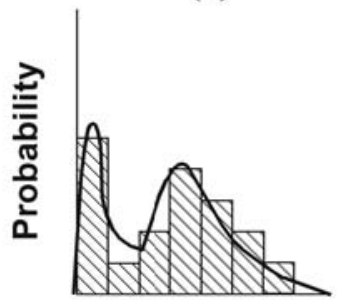

(b)

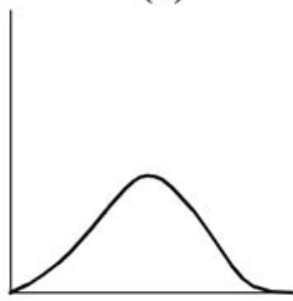

(c)

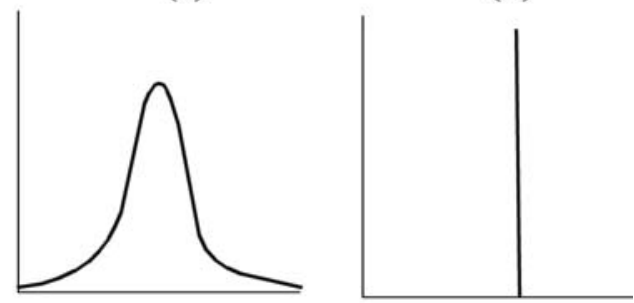

Property Value

00121DC_AMR_115.cdr

Source: For Illustrative Purposes Only.

NOTE: (a) beyond the range of spatial correlation: pdf is virtually identical to the univariate histogram; essentially all that is known about the unsampled location is what is known about the population as a whole. (b) far away from a sample, but within the range of spatial correlation: pdf is broad, indicating considerable uncertainty; distribution begins to focus on expected value. (c) nearby a sample value: $p d f$ is narrower indicating less uncertainty. (d) immediately adjacent to a sample value: pdf is nearly a spike value corresponding to the adjacent sample datum.

Figure 6.4-27. Conceptual Probability Density Functions Representing the Uncertainty Associated With Various Unsampled Locations

Simulations may be conditional or unconditional. Conditional simulations are numerically anchored to a specific set of real-world data, and they exhibit three properties that adds to their usefulness in evaluating the effects of geologic uncertainty on physical process models. Specifically, conditional simulations:

1. Reproduce the known data values at the same locations within the model as represented by the real-world samples

2. Reproduce the full range of measurement variability, as represented by histogram and univariate descriptive statistics of the known data values

3. Reproduce the bivariate statistics, or two-point spatial correlation structure, of the input data.

Unconditional simulations are similar, except that they are not conditioned to any particular spatially anchored data, and thus item 1 does not apply. As simulations with these three characteristics cannot be distinguished statistically from the ensemble of data used in their construction nor from each other, they serve as alternative, equally likely stochastic realizations of an incompletely sampled and measured reality shown conceptually in Figure 6.3-1.

Simulations may be developed using parametric or nonparametric techniques for mechanically inducing the desired univariate (item 2 above) and bivariate (item 3) statistical properties. Parametric techniques rely upon the predictive power of well-understood multivariate probability functions, almost invariably the multivariate gaussian. A number of algorithms have been developed that implement gaussian-related simulation (e.g., references in Deutsch and Journel 1992 [DIRS 100567]). 
The sequential gaussian simulation program SGSIM (Table 3-1; see also Deutsch and Journel 1992 [DIRS 100567], pp. 123 to 125 and 164 to 167) was used to generate 50 replicate models of porosity at all unsampled locations for each of the four model units, conditioned to the observed porosity data from the several drill holes. The sequential modeling process is relatively straightforward and is implemented as follows:

1. All data values are converted to positions on a univariate standard-normal $(\mathrm{m}=0, \mathrm{~s} 2=1)$ distribution using the graphical normal-score transform (Figure 6.4-28), implemented in program NSCORE (Table 3-1; see also Deutsch and Journel 1992 [DIRS 100567], pp. 138 and 209 to 211). This transformation does nothing to the spatial correlation structure because the relative positions of all values with respect to each other are preserved (i.e., the transform is quantile-preserving).

2. The spatial correlation structure is identified using the normal-score transformed values and modeled using standard variography.

3. The transformed measured data are mapped into the model volume; samples located (only fortuitously) at a node in the stratigraphic-coordinate grid are assigned to that node and the node is not simulated.

4. A sequential random path is defined that will visit each unsampled node once and only once.

5. At each node along this path, a search is conducted for nearby data and any previously simulated grid nodes. The search parameters (anisotropic radii; number of data to use) are user specified.

6. The (user-specified) $\mathrm{N}$ closest data are identified and weighted by their "geological distance" (in contrast to simply their Euclidean distance), as defined in the stratigraphic coordinate system according to the mathematical formulation of the spatial continuity model (variogram). Because the normal-score transformed values are effectively relative positions on a cumulative distribution function, the resultant value is also effectively a relative position on the same cumulative distribution function.

7. A value (in normal-score space) is drawn at random from the conditional probability distribution defined in step 6 and this value is assigned to represent the porosity at that point. The simulation process then moves to the next unsampled location along the random path defined in step 4 and the process is repeated beginning with step 5 .

8. After all originally unsampled grid nodes have been simulated using the logic of steps 5 through 7, the resulting spatial array of normal-score values are back-transformed to the original porosity space using the inverse of the normal score transform of step 1 (software routine BACKTR, Table 3-2), and the simulation process is complete. 
(a)

(b)

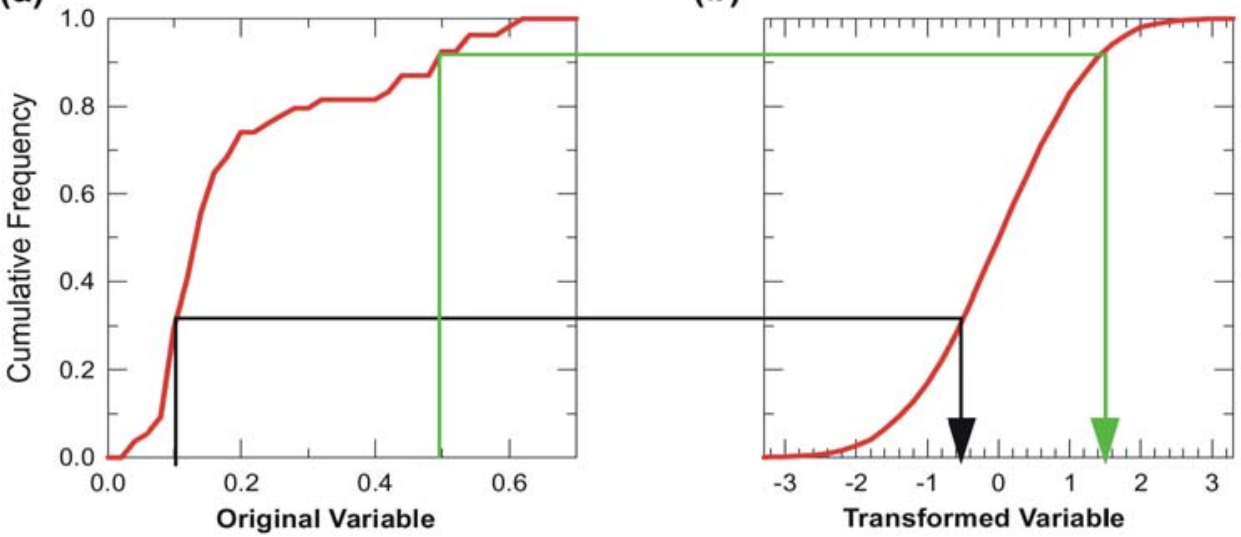

00121DC_AMR_116.cdr

Source: SN9910T0501399.001 [DIRS 129717].

NOTE: A population with virtually any univariate distribution (a) can be transformed to any other univariate distribution (b) (here standard gaussian) in a manner represented by the arrows such that the quantile relationships among the data are preserved. The reverse transformation is also possible in the same manner.

Figure 6.4-28. Graphical Representation of the Quantile-Preserving Normal-Score Transform Process Using Cumulative Distribution Functions

Because porosity values are drawn at random for each unsampled grid node, the values obtained in different simulation runs will be different. Indeed, the weighting scheme used to develop the conditional expectation in each independent simulation will be different as well in that the same path through the 3-D grid is not used in successive simulations. Additionally, because the data-search process considers previously simulated grid nodes as well as measured data (non-varying), the nearby values used to estimate the conditional expectation will also vary among simulation runs. At grid locations that are well constrained by consistently measured data, the variability of the simulated values across a suite of simulations will be small, as described by the spatial continuity model. However, at grid locations far from any conditioning measured data, or at grid nodes that are in the vicinity of conflicting measurements, the spread of porosity values that will be generated by the simulation algorithm across different computer runs will be quite broad, approaching the univariate variance of the data when considered without regard for spatial position. Uncertainty, measured by variability across the suite of simulations is small where much is known about the rock mass and progressively greater at longer distances from actual sampled values.

\subsubsection{Indicator Kriging Using Uncertain Data}

The indicator methodology is most easily understood through the following definition of an indicator transformation of a spatially distributed variable, $Z$ :

$$
I_{(x)}=\left\{\begin{array}{l}
1 \leftarrow Z_{(x)} \leq Z * \\
0 \leftarrow \text { Otherwise }
\end{array}\right.
$$

where $I\left({ }_{x}\right)$ is the indicator-transformed variable at spatial location $x, Z\left(_{x}\right)$ is the original variable also at location $x$, and $Z^{*}$ is a particular threshold value of interest. In other words, the original 
variable is replaced by the value 1 at all locations where it is less than or equal to the threshold and by the value 0 at all locations where it is greater.

All of this presumes that there is precise knowledge of the original variable of interest, $Z\left({ }_{x}\right)$. Should knowledge of $Z$ be less than 100 percent certain, however, it is possible to restate Equation 6.4-3 to account for the "soft" probability, $p$, that $Z$ less than or equal to $Z *$. Thus:

$$
I_{(x)}=\left\{\begin{array}{l}
p \leftarrow Z_{(x)} \leq Z * \\
1-p \leftarrow \text { Otherwise }
\end{array}\right.
$$

Note that it is perfectly legitimate to mix hard and soft indicators in the same analysis, and thus the methodology is suitable for combining the relatively definitive XRD indicators of hydrous-phase mineral alteration with the less certain but spatially more abundant petrophysical indicators (Sections 4.1.4 and 4.1.5, respectively). It remains to calibrate the appropriate value(s) of $p$, given the petrophysical estimates of bound-water content; this calibration effort is described below in Section 6.4.7.1.

Implementation of indicator kriging process (Program IK3D, Table 3-1; see also Deutsch and Journel 1998 [DIRS 102895], pp. 103 to 106) is straightforward enough in concept.

1. Hard XRD measurements of hydrous-phase mineral content are converted to a set of ones and zeros with respect to some threshold concentration judged relevant.

2. Soft petrophysical measurements of hydrous-phase mineral content are converted to a set of values ranging between zero and one in accordance with the calibration exercise (using program, BICALIB, Deutsch and Journel 1998 [DIRS 102895], pp. 235 to 236).

3. The spatial continuity structure of the composite hard and soft data set is determined through standard variography.

4. The transformed measured data are mapped into the model coordinate system.

5. At each desired grid location a search is conducted for nearby indicator data, $I\left({ }_{x}\right)$ (either hard or soft).

6. The nearest $N$ values identified by the search are then weighted according to their relative geologic distances, as computed from the variogram model. The weighted average is assigned as the appropriate indicator value at that location, and the estimation process moves to the next grid node. Steps 5 and 6 are iterated until the grid is complete.

7. All grid nodes with a modeled probability of $p$ less than 0.5 may be considered unaltered, and that those with $p$ greater than 0.5 may be deemed altered. 
Note that implicit in Equations 6.4-3 and 6.4-4 is probabilistic interpretation that $p$ is the likelihood of $Z\left({ }_{x}\right)$ being less than the threshold, $Z^{*}$. If one is dealing with a binary classification in which the rock present at location $\mathrm{x}$ is either altered versus unaltered, it is a logical conclusion that:

\subsubsection{Coregionalization Modeling of Derivative Properties}

There are two frequently used methods that have been used to incorporate cross-variable correlations of material properties into rock properties models in the presence of undersampling of one variable. First, one may assume a coefficient of determination $\left(\mathrm{r}^{2}\right)$ equal to one and simply apply the empirically determined regression equation to predict the secondary (undersampled) variable. A second method is to model a randomly distributed error ("noise") about the regression line. However, neither of these two alternatives is particularly satisfying. In many instances, $r^{2}=1.0$ implies a substantially stronger relationship than exists in fact. In the second case, a cross-plot of the two resulting variables reproduces the desired cross-variable relationship, but any spatial correlation exhibited in nature by the secondary variable is effectively destroyed by the addition of spatially uncorrelated noise. Cokriging and cosimulation (Journel and Huijbregts 1978 [DIRS 102898], pp. 324 to 326; Deutsch and Journel 1992 [DIRS 100567], pp. 121 to 123) are well-established algorithms for producing models that reproduce both the observed correlation between two variables and the observed spatial correlation structure of each. However, with the degree of undersampling of the secondary variable, such as is the case at Yucca Mountain, there are insufficient data from which to infer the necessary auto-correlation and cross-correlation relationships.

A practical alternative mechanism to cokriging or cosimulation in the presence of undersampling involves the assumption of a linear model of coregionalization (Journel and Huijbregts 1978, pp.171 to 175 and 516 to 517; Luster 1985 [DIRS 102904]; Altman et al. 1996 [DIRS 100591], pp. 54 to 59), which effectively states that the spatial continuity of the secondary variable, and of the joint (cross-variable) correlation structure, is presumed to be approximately identical to that of the primary variable. Although the mathematical relationships involved in the derivation are tedious (e.g. Rautman and McKenna 1997 [DIRS 100643], pp. 63 to 66, and references therein), it can be shown that it is possible to generate a pair of cross-correlated simulations as a weighted linear combination of two independent standard-normal spatially correlated simulations where the weighting factor is effectively the cross-variable correlation coefficient, $r$. This translates to in practical terms, is to take a conditional porosity simulation in standard-normal form, such as is generated in step 7 of Section 6.4.6.2, and combine it (software routine COREGPC, Table 3-2) with an identically generated but independent unconditional simulation (these are paired in this activity by run number), also in standard-normal form, using $r$ and as the appropriate weighting coefficients. The resulting linear combination is also essentially in standard normal form, and it can be back-transformed to match the desired distribution of the target secondary variable (software routine TRANS, Table 3-2). If appropriate, the back transformed coregionalized property simulation is post-processed further to impart additional relevant characteristics as described below in Section 6.4.8. 


\subsubsection{Modeling of Hydrous-Phase Mineral Alteration}

Volcanic glass within the lower two modeling units (CHn and Tcp) has been variably altered to (dominantly) zeolite minerals throughout a major portion of the model area. These altered rocks exhibit markedly reduced saturated hydraulic conductivity by comparison with unaltered materials of approximately the same porosity. The rock properties modeling effort included not only the XRD mineralogic data (described in Section 4.1.4), which provide virtually 100-percent certain identification of hydrous-phase mineral alteration, but also less accurate but more abundant and widely distributed petrophysical indicators of such alteration (Section 4.1.5).

\subsubsection{Calibrating Soft Indicators of Hydrous-Phase Mineral Alteration}

Because the petrophysical data available provide a less than 100 percent certain identification of hydrous-phase alteration, it is necessary to calibrate these values to account for the added uncertainty. The calibration effort involved 334 samples from the CHn and Tcp model units for which depth-matched pairs (generated using software routine MATCHUP, Table 3-1) of both XRD mineral analyses and petrophysical bound-water contents could be obtained. Petrophysical bound-water content was calculated simply as the difference between the POROTOT and POREF log traces (see also Section 4.1.5). Core bound-water content was calculated as the difference between the OD and relative humidity porosity values (Section 4.1.1), and is initially identical to the delta-porosity value described in Section 6.4.5.1. Comparison of depth-matched core and petrophysical bound-water data (software routine MATCH, Table 3-1) indicate that the laboratory core measurement process gave a bound-water content of approximately twice that indicated by the down-hole petrophysical measurements; see Figure 6.4-29. Although a precise explanation for the discrepant measurements is uncertain, the empirical relationship can be used to adjust the core measurements to provide a common basis with the petrophysical values. Adjusted values for core bound water content have been used in the calibration work that follows.

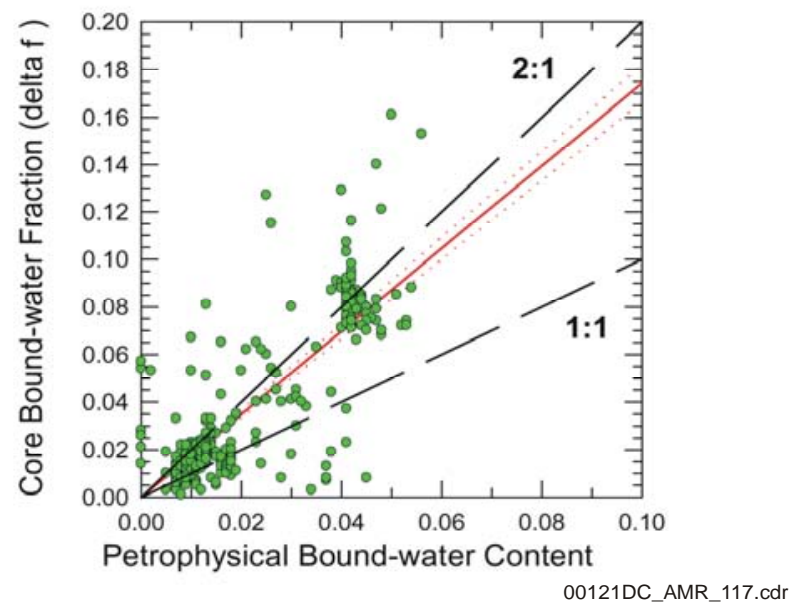

Source: SN9910T0501399.001 [DIRS 129717].

NOTE: Regression line (solid, with 95-percent confidence limits, dotted) has been forced through the origin and has a slope of 1.74; unconstrained regression has $r^{2}=0.67$ ( $r$-squared for a constrained line is not meaningful)

Figure 6.4-29. Scatterplot of Core Versus Petrophysically Derived Bound-Water Content for 354 Depth-Matched Pairs of Samples 
A scatterplot shown in Figure 6.4-30 represents the total hydrous-phase mineral content vs. adjusted bound-water content. In general, an increase in adjusted bound-water content corresponds directly to an increase in the total hydrous minerals. The calibration consists of cross-tabulating (software routine BICALIB, Table 3-2) the number of pairs in each of the categories:

- Hydrous-phase mineral content:

- Greater than 5 percent

- Less than or equal to 5 percent.

- Adjusted bound-water content:

- Less than or equal to 0.03

- Greater than 0.03 to less than 0.04

- Greater than 0.04 to less than 0.05

- Greater than 0.05 .

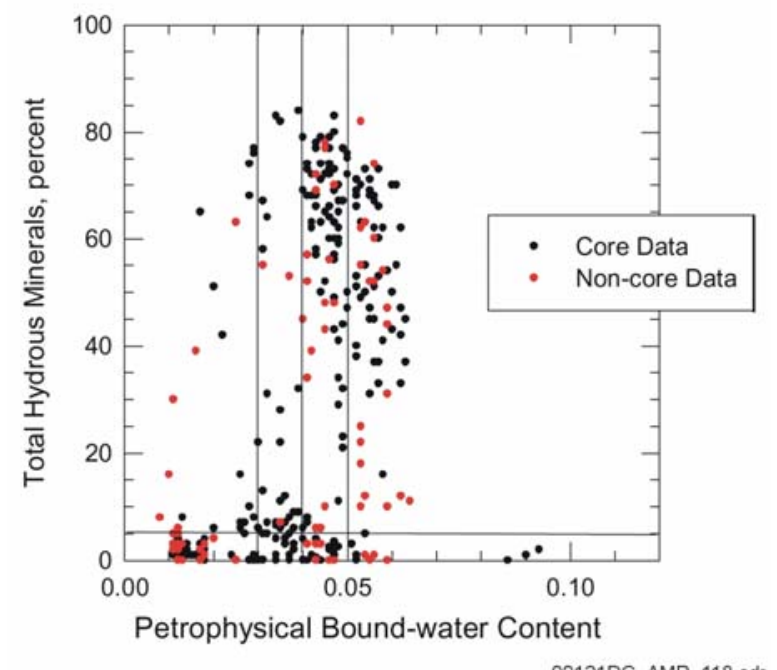

Source: SN9910T0501399.001 [DIRS 129717].

NOTE: Interior lines correspond to the various threshold values used in Table 6.4-19.

Figure 6.4-30. Scatterplot of Total Hydrous-Phase Mineral Content Versus Adjusted Bound-Water Content for 334 Depth-Matched Paired Samples

The cross-tabulated counts of soft-value pairs were converted to a decimal proportion (software routine BICALIB), and these values were taken as the prior probability of obtaining the specified total hydrous-phase mineral content given a specified adjusted bound-water content. These soft, prior-probability values are presented in Table 6.4-19. In contrast, XRD hydrous-phase mineral contents were coded as hard probability values of zero or one. 
Table 6.4-11. Prior Probability of Altered vs. Unaltered Rocks as a Function of Bound-Water Content

\begin{tabular}{|c|c|c|c|c|}
\hline \multirow{2}{*}{ Hydrous-Phase Mineral Content } & \multicolumn{4}{|c|}{ Bound-Water Content, Cumulative Prior Probability } \\
\cline { 2 - 5 } & $\mathbf{2 0 . 0 3}$ & $\mathbf{0 . 0 3 - 0 . 0 4}$ & $\mathbf{0 . 0 4 - \mathbf { 0 . 0 5 }}$ & $>\mathbf{0 . 0 5}$ \\
\hline$<5$ percent & 0.2474 & 0.6122 & .7778 & 0.8625 \\
\hline$>5$ percent & 0.7526 & 0.3878 & 0.2222 & 0.1375 \\
\hline
\end{tabular}

Source: SN9910T0501399.001 [DIRS 129717], Rautman, C. and McKenna, S. 1998 [DIRS 107442], Section 9, and Rautman, C. 1999 [DIRS 109035], Section 9.

\subsubsection{Indicator Kriging of Hydrous-Phase Mineral Alteration}

Both hard and soft indicators of hydrous-phase mineral alteration were combined and supplied as input to an indicator kriging exercise (Program 1K3D, Deutsch and Journel 1998 [DIRS 102895], pp. 103 to 106). Indicator kriging (Section 6.4.6.3) is a variant of ordinary kriging, in which the variable of interest is estimated as a weighted linear combination (average) of the available observed values within some local neighborhood of influence. In common with ordinary kriging, the weights applied to the observed values are calculated in accordance with the spatial continuity model developed from the combined indicator data set. Necessarily, alteration in the CHn and Tcp model units was modeled separately, even though the two units were combined for purposes of estimating the prior probability values discussed above.

CHn Model Unit-The variogram model for hydrous-phase mineral alteration indicators in the CHn model unit is presented in Figure 6.4-31, and the parameters of the fitted variogram model are in Table 6.4-12. Details of the variogram modeling exercise may be found in the scientific notebook (Rautman and McKenna 1998 [DIRS 100643], pp. 663 to 695).
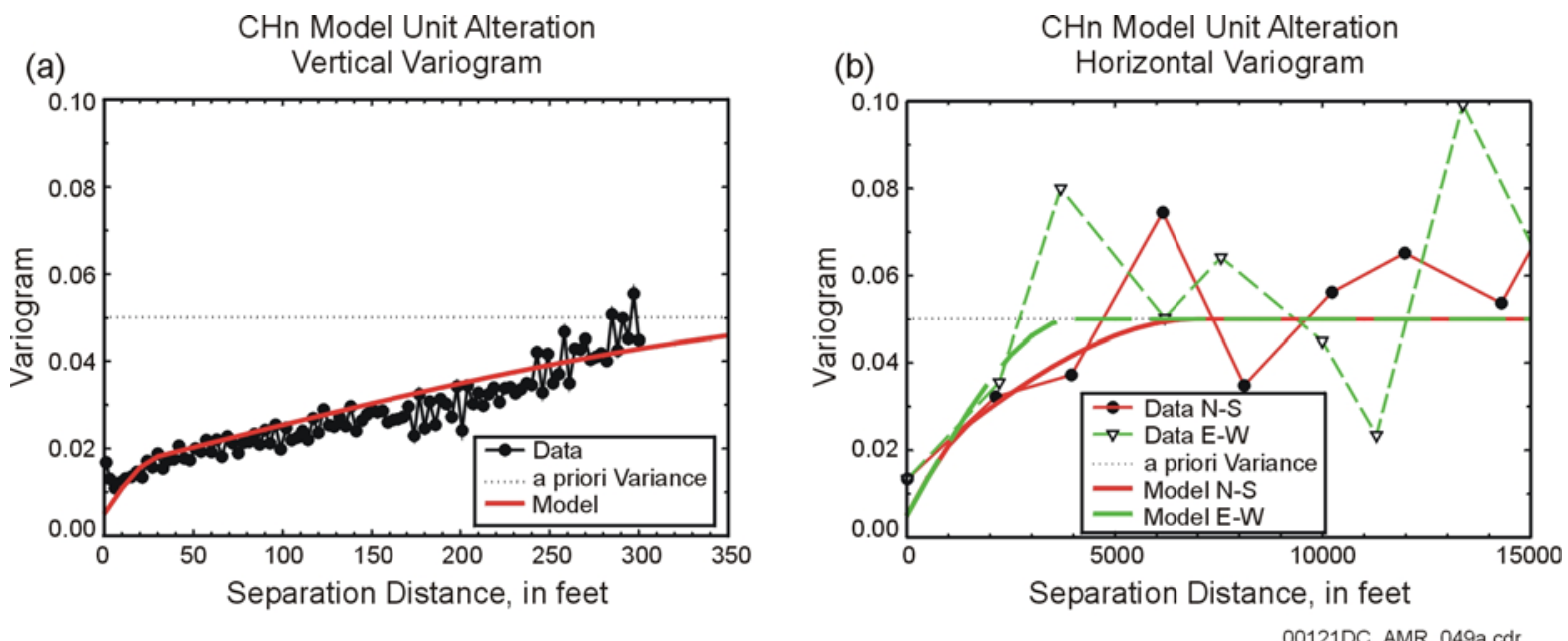

Source: SN9910T0501399.001 [DIRS 129717].

NOTE: (a) stratigraphically vertical; (b) stratigraphically horizontal directions.

Figure 6.4-31. Indicator Variogram and Fitted Model Computed for Alteration in the $\mathrm{CHn}$ Model Units 
Table 6.4-12. Variogram Parameters for Spatial Continuity Model, Alteration in the CHn and Tcp Model Units

\begin{tabular}{|c|c|c|c|c|c|c|c|c|c|c|}
\hline \multirow[b]{2}{*}{$\begin{array}{c}\text { Nest } \\
\text { No. }\end{array}$} & \multirow[b]{2}{*}{$\begin{array}{l}\text { Model } \\
\text { Type }\end{array}$} & \multicolumn{3}{|c|}{ Range (ft) } & \multirow[b]{2}{*}{ Sill } & \multicolumn{3}{|c|}{$\begin{array}{c}\text { Rotation } \\
\text { Angle } \\
\text { (degrees) }\end{array}$} & \multicolumn{2}{|c|}{$\begin{array}{c}\text { Anisotropy } \\
\text { Ratio }\end{array}$} \\
\hline & & $\begin{array}{c}\text { Maximum } \\
\text { (horizontal) }\end{array}$ & $\begin{array}{c}\text { Inter- } \\
\text { mediate }\end{array}$ & $\begin{array}{c}\text { Minimum } \\
\text { (vertical) }\end{array}$ & & 1 & 2 & 3 & 1 & 2 \\
\hline \multicolumn{11}{|c|}{ CHn Model Unit } \\
\hline-- & Nugget & -- & -- & -- & 0.005 & -- & -- & -- & -- & -- \\
\hline 1 & Spherical & 4000 & 1500 & 30 & 0.010 & 0 & 0 & 0 & 0.3750 & 0.0075 \\
\hline 2 & Spherical & 7000 & 4000 & 500 & 0.035 & 0 & 0 & 0 & 0.5714 & 0.0714 \\
\hline \multicolumn{11}{|c|}{ Tcp Model Unit } \\
\hline-- & Nugget & -- & -- & -- & 0.010 & -- & -- & -- & -- & -- \\
\hline 1 & Spherical & 2500 & 2500 & 150 & 0.025 & 0 & 0 & 0 & 1 & 0.060 \\
\hline 2 & Spherical & 15000 & 15000 & 150 & 0.058 & 0 & 0 & 0 & 1 & 0.010 \\
\hline
\end{tabular}

Source: SN9910T0501399.001 [DIRS 129717] and Rautman, C. and McKenna S. 1998 [DIRS 107442], Section 9 , page 827 to 831 .

(a)

Tcp Mixed Alteration Verticle Variogram

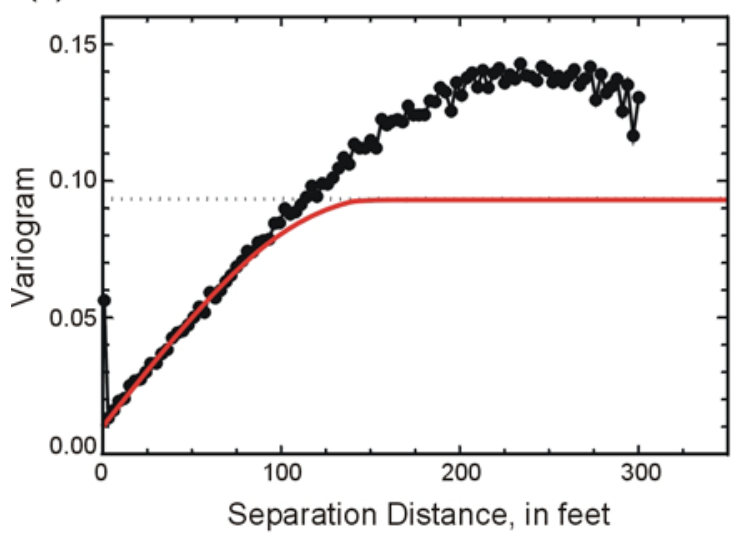

(b)

Tcp Mixed Alteration Horizontal Variogram (Isotopic)

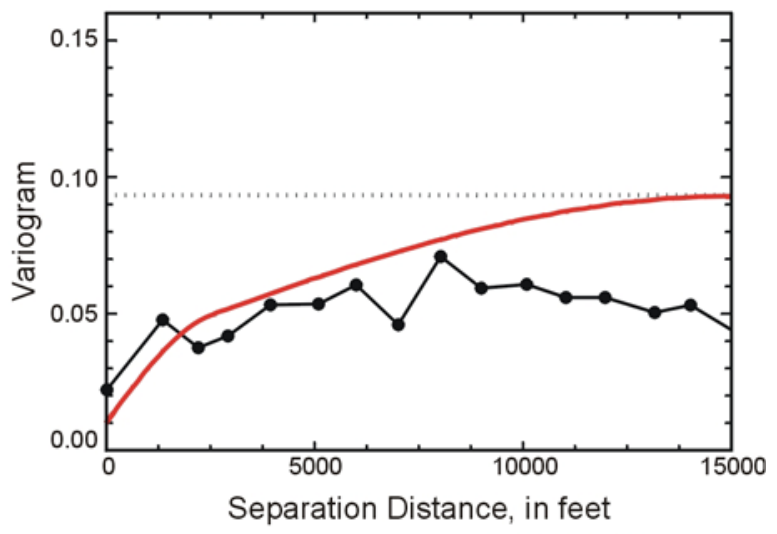

00121DC_AMR_051b.cdr

Source: SN9910T0501399.001 [DIRS 129717.]

NOTE: (a) stratigraphically vertical; (b) both stratigraphically horizontal directions (isotropic).

Figure 6.4-32. Indicator Variogram and Fitted Model Computed for Alteration in the Tcp Model Unit

Tcp Model Unit-The variogram model for hydrous-phase mineral alteration indicators in the Tcp model unit is presented in Figure 6.4-32. The parameters of the fitted variogram model are given in Table 6.4-12. Details of the variogram modeling exercise may be found in the scientific notebook (Rautman and McKenna 1998 [DIRS 107442], pp. 772 to 786).

\subsubsection{Postprocessing of Simulated Models}

\subsubsection{Incorporation of Specific Attributes into Simulated Models}

The actual rocks at Yucca Mountain are the composite result of numerous geologic processes that overlap in both space and time. Consequently, rock properties modeling involves more than 
the simple generation of a set of porosity values. This is particularly true for the models of derivative material properties that have been generated by coregionalization with porosity. This section presents the techniques used to incorporate two specific types of secondary geologic attributes into raw simulated property models.

Vitrophyres-The widely variable hydraulic conductivity values associates with densely welded vitrophyric core samples of uniformly low porosity from the Topopah Spring Tuff (lithostratigraphic units Tptrv1 and Tptpv3) have been described by Flint (1998 [DIRS 100033], p. 38) as resulting from microfractures present within these glassy, brittle rocks. Additional consideration of these samples (Flint 1998 [DIRS 100033], Figure 12) suggests that vitrophyric samples may independently be identified by their uniformly very low porosity (less than approximately 0.05; see Section 6.4.5.1, Figure 6.4-19). Accordingly, the simulated models of saturated hydraulic conductivity for the TSw model unit (only) were postprocessed (software routine VITROPHYRE, Table 3-2) such that if the corresponding porosity value was less than 0.05 (simulations paired by run number), the coregionalized hydraulic conductivity value was discarded. Under the assumption that such low-porosity grid nodes represent vitrophyre or other essentially nonporous brittle materials, a value of Ks was generated by random sampling from a uniform population with a range of $10^{-14}$ to $10^{-6} \mathrm{~m} / \mathrm{sec}$ as derived from the histogram of Figure 6.4-19. A conceptual representation of the logic underlying the modeling of vitrophyric rocks is presented in Figure 6.4-33.

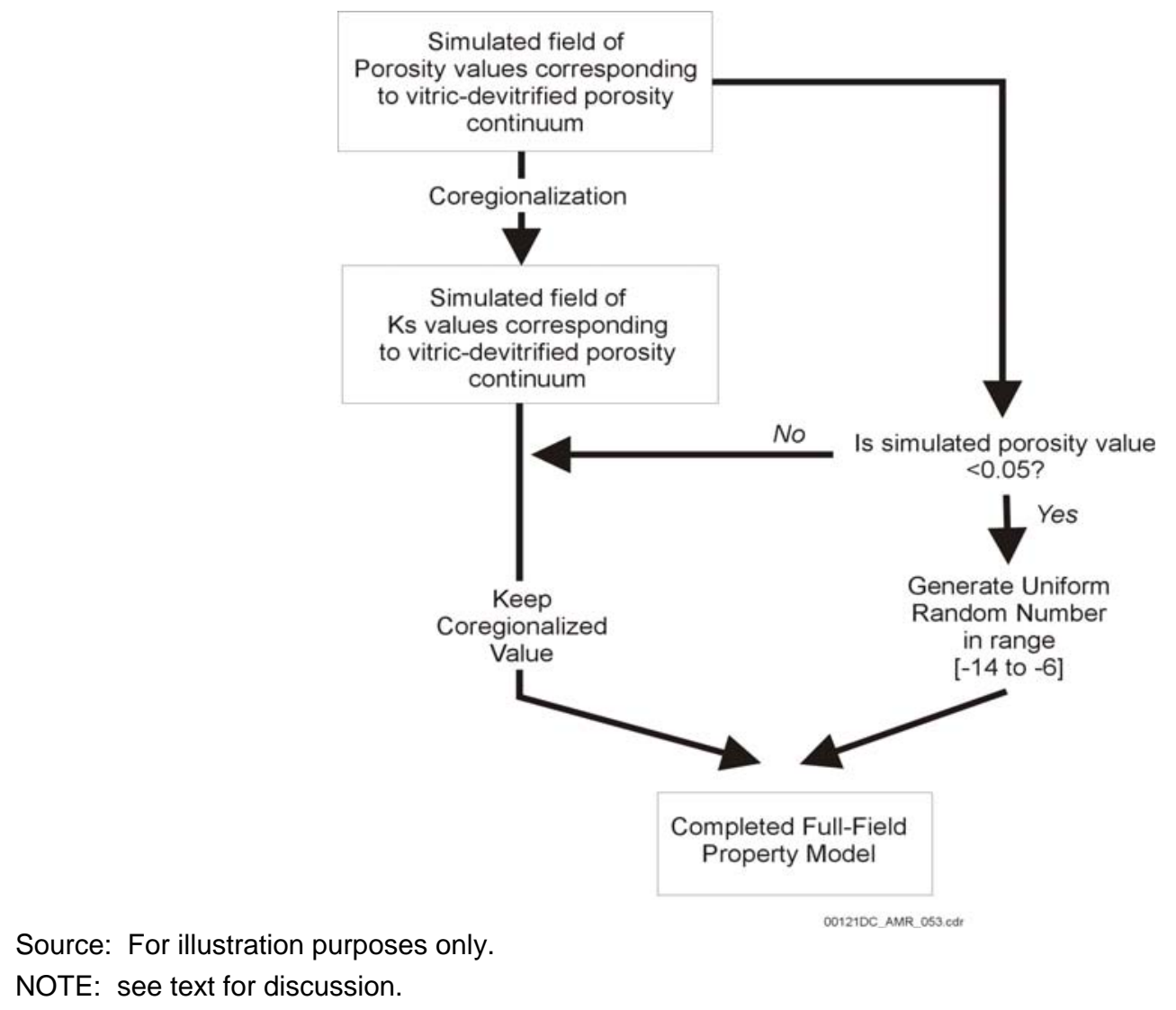

Figure 6.4-33. Logic Diagram for Postprocessing Porosity and Hydraulic Conductivity Simulations to Recognize Vitrophyre Rock Type 
Hydrous-Phase Mineral Alteration-Hydrous-phase mineral alteration is inferred to represent a secondary alteration process that affected vitric tuffaceous materials at some particular time after formation of the original rock mass, although generally before tectonic faulting and tilting. Consequently, there appears to be little or no direct correlation of saturated hydraulic conductivity with matrix porosity for altered (zeolitized) samples, see Section 6.4.5.1, Figure 6.4-18). Recall also from Figure 6.4-18 that the histogram of altered hydraulic conductivity values appears virtually indistinguishable from a gaussian population, given the relatively small sample size.

This modeling philosophy has been implemented for the rock properties model by postprocessing (software routine ZEOLITE5, Table 3-2) the initial coregionalized hydraulic conductivity models (for both the CHn and Tcp model units) grid node by grid node together with a corresponding indicator kriging model (Section 6.4.7.2) indicating the probability of significant hydrous-phase mineral alteration. If the grid node under consideration was considered unaltered (palt $<0.50$ ), the coregionalized $K_{s}$ value was retained, and the processing moved to the next grid node. If the node was considered altered (palt $>0.50$ ), then the coregionalized $K_{s}$ value was discarded in favor of a normally distributed random value sampled from a population with the appropriate mean and variance. A schematic diagram of this postprocessing procedure is presented in Figure 6.4-34.

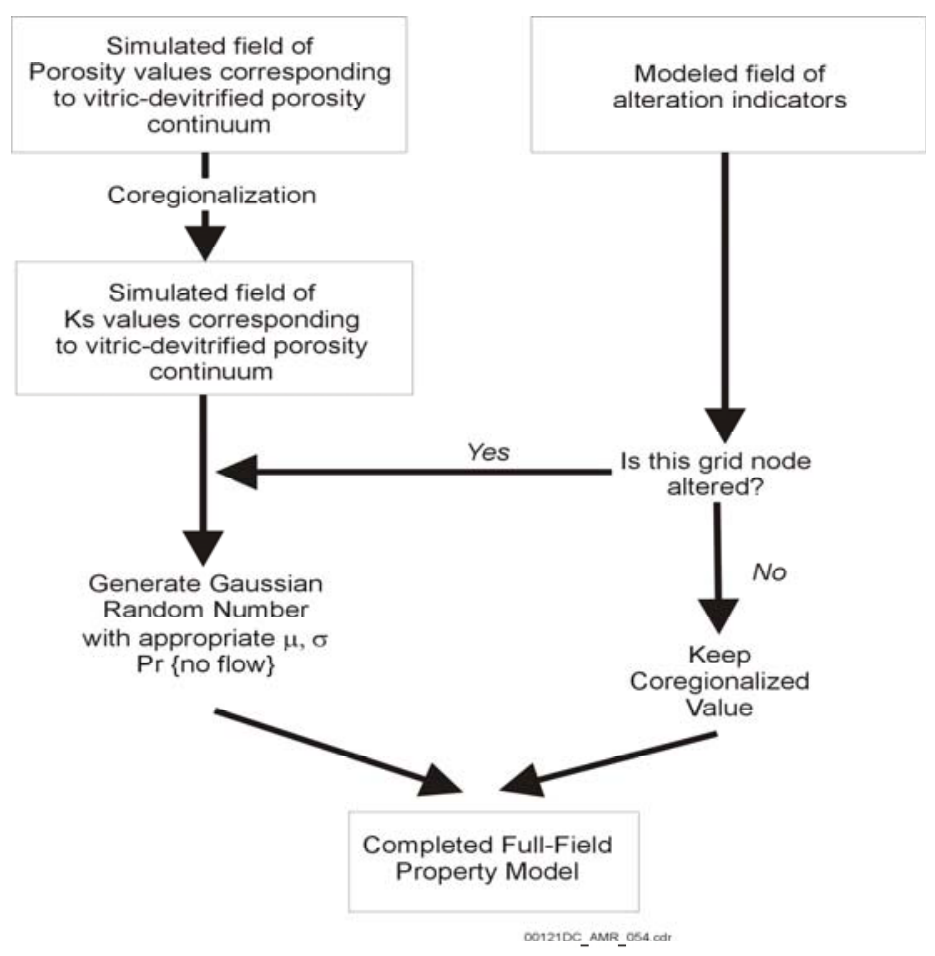

Source: For illustration purposes only.

NOTE: see text for discussion.

Figure 6.4-34. Logic Diagram for Postprocessing Porosity and Alteration Indicator Simulations to Recognize Hydraulic Conductivity Dependence on Alteration State 


\subsubsection{Uncertainty Modeling}

Geostatistical generation of the material property models is essentially complete at this point. As part of the current modeling exercise, 50 replicate, statistically indistinguishable models of porosity for each model unit (one set each for matrix and lithophysal porosity in the TSw model unit) and 50 replicate models for each one of the derivative properties (bulk density, matrix saturated hydraulic conductivity, and-for the TSw model unit-thermal conductivity as well) have been generated. Each of the replicate simulations honors the measured porosity data at sample locations (subject to the discretization limits), exhibits the full range of variability captured by the histogram of the relevant property, exhibits the appropriate range of spatial correlation (variogram), and (for the derivative properties) exhibits the appropriate correlation coefficient with porosity. In effect, there is nothing objective about any one simulated (or coregionalized) model to prefer it over any other model of that suite. Indeed, the only meaningful distinguishing feature within a suite of replicate models is the arbitrarily selected random number seed, which initiated the simulation process.

Because there are few, if any, objective differences to distinguish the members of each suite of simulated property models, it thus logically follows that the variability among members of a suite represents an empirical estimate of the geologic uncertainty associated with each material property. Geologic uncertainty is defined in this context as that which results from less-than-exhaustive sampling or other measurement. The difficulty arises, however, as how best to represent this space of uncertainty in a simple and concise manner.

An uncertainty model has been generated (software routine ETYPE; Table 3-2) for each material property-modeling unit combination by computing the node-by-node standard deviations of each set of 50 replicate simulated models. This process produces uncertainty models that are themselves spatially heterogeneous. By theory and in practice, variability among simulations-and uncertainty as defined by the standard deviation-is small in close proximity to measured sample values. Variability among simulations-and uncertainty as defined by the standard deviation - is small in close proximity to measured sample values. Variability among simulations and uncertainty is high at great distances from measured data, or in the vicinity of conflicting measured values. Note that there is no particular reason other than general reader familiarity for selecting the standard deviation as the measure of uncertainty. Values such as the total range of the modeled property or the interquartile range could easily be computed during this postprocessing step.

With respect to alternative uncertainty models, it is also important to remember that the best measure of geologic uncertainty for the potential nuclear-waste repository at Yucca Mountain is the impact of that uncertainty on some relevant measure of repository system performance. Potential examples of such global performance measures might be particle-tracking transport times or cumulative radionuclide release rates, as suggested by the consequence analysis step shown in the conceptual diagram of Figure 6.3-1. Development of these types of comprehensive uncertainty assessments is beyond the scope of the rock properties modeling effort.

\subsubsection{3 “Expected-Value Modeling”}

The postprocessing step used to generate the standard-deviation uncertainty model for each rock property-modeling unit combination described in Section 6.4.8.2 is easily adapted to produce 
some type of summary statistical measure associated with the "central-tendency" of the simulation process. In effect, the geostatistical simulation process develops a 3-D array of spatially correlated probability density functions, one distribution for each of the discretizing grid nodes within a model unit. Continuing with the probability density function analogy, certain rock property values are more likely to exist at a given location than other values. Note, however, that "more likely to exist" can be defined in more than one manner.

A set of summary "expected-value models" has been generated (software routine ETYPE; Table 3-2) for each suite of simulated models by calculating the arithmetic mean of the 50 replicate simulated values generated at each grid node. Journel (1983 [DIRS 102897], pp. 459 to 461; see also Deutsch and Journel 1992 [DIRS 102895], pp. 76 and 225) defined this conditional expectation representation of central tendency as the "E-type estimate". Note that computing the median ("M-type estimate", Journel 1983 [DIRS 102897], p. 460) of the 50 replicate simulated values would be an equally legitimate measure of "expectation", although one that is more computationally intensive.

Because of the logistical difficulty of presenting the full simulated results for 50 models times 19 unique material-property/model-unit combinations, the results of this geostatistical modeling exercise described in Section 6.5 that follows are presented in terms of the E-type estimate. It is important to remember, however, that the three characteristic properties of simulated models described as desirable in the first paragraph of Section 6.4.6.2 no longer necessarily apply to these summary models. Compare, for example, the statistical nature of the simulated and summary models from ISM2, as discussed by Rautman and McKenna (1997 [DIRS 100643], e.g., pp. 99 to 104), and in abbreviated form for ISM3 as presented in the discussion of model validation in Section 6.7.

The first characteristic, that involving reproduction of the measured (porosity) values at the locations of actual measurement, is maintained. However, the ensemble of modeled E-type values no longer represents the full range of univariate variability of the measurement ensemble (the second characteristic). Additionally, the two-point spatial correlation character (variogram) of the E-type model no longer reproduces that of the underlying measurements (the third characteristic). Specifically, because of averaging across the replicate simulations, the E-type model typically grades relatively smoothly and continuously from one (exactly reproduced) measured value to the next (in three dimensions). Thus the apparent spatial continuity of the E-type model typically is much greater than that observed for the data themselves. This is the so-called smoothing effect that is typical of virtually all interpolation (in contrast to simulation) algorithms, including kriging, nearest-neighbor estimation, and inverse-distance-to-a-power weighting.

\subsection{RESULTS AND DISCUSSION}

The "real" results of the rock properties modeling exercise consist of the numerical model files containing the replicate Monte Carlo simulated models and the associated summary E-type and uncertainty model files for each of the four modeling units and each of the modeled properties. Because of the impracticality of presenting and discussing each of these simulated and summary models individually, the results presented in this section are illustrative and focus on gross heterogeneity features as revealed by the summary E-type models. Each model unit and each 
modeled material property within that model unit is discussed in turn. Discussion of the replicate individual simulated models is generally restricted to the section on Model Validation. Again, because of the impracticality of "validating" each and every replicate simulation, the discussion in this section will be illustrative.

Because of technical limitations involving plotting the individual drill holes on some model views, refer to Figures 6.4-1 though 6.4-4 for information regarding the spatial distribution of input measurements. Note that the distribution of available drill hole information is unit-specific. Also note that although the color-scale legend on each figure generally represents the full range of the modeled property present in the underlying numerical file, it is only fortuitous if the highest (or lowest) value is actually shown in the particular model view.

\subsubsection{PTn Model Unit}

Heterogeneity of matrix porosity within the PTn model unit is shown in Figure 6.5-1 in both stratigraphic and real-world coordinates. As indicated by the projection arrows connecting the two halves of the figure, the vertically exaggerated rectangular volume in stratigraphic coordinates is back transformed to real-world coordinates, such that the material property values assume their correct relative positions within the tilted and faulted strata of Yucca Mountain, shown with no vertical exaggeration. Cross-sectional views of porosity heterogeneity are presented in Figure 6.5-2.

Porosity values within the PTn model unit are generally high, varying principally from about 30 to more than 60 percent $(0.30$ to 0.60$)$. Porosity values appear relatively continuous over distances of 5,000 to 10,000 feet, as expected from the input range of spatial continuity. Porosity trends are prominently anisotropic from northwest to southeast, also as expected from the variogram model (top surface of the block diagram of Figure 6.5-1).

Bulk density (Figure 6.5-3) varies spatially approximately inversely with porosity, as expected from the strong $(r=-0.912)$ negative correlation coefficient. Bulk density values vary from less than $1.0 \mathrm{~g} / \mathrm{cm}^{3}$ to nearly $2.0 \mathrm{~g} / \mathrm{cm}^{3}$. Densities are generally low across the modeled area. Prominent regions of higher density are associated with drill hole $\mathrm{H}-6$, shown on the southernmost east-west cross section, and particularly with drill hole G-2 near the northern boundary of the modeled region at the intersection of the north-south and northernmost east-west cross sections. At the G-2 locality, density exceeds $1.9 \mathrm{~g} / \mathrm{cm}^{3}$ at two horizons, presumably corresponding to the Pah Canyon and Yucca Mountain Tuffs, which are described as moderately welded in this part of the model area.

Heterogeneity in matrix saturated hydraulic conductivity values is shown in Figure 6.5-4. Hydraulic conductivity values are generally between $10^{-5}$ and $10^{-7} \mathrm{~m} / \mathrm{sec}$ (note that in this and following similar figures, hydraulic conductivity values are shown in $\log _{10}$ units; i.e., $10^{7} \mathrm{~m} / \mathrm{sec}=-7.000$ ). Lower conductivities on the order of $10^{-8} \mathrm{~m} / \mathrm{sec}$ are modeled in the vicinities of drill hole H-6 (not visible in Figure 6.5-4) and G-2, coincident with the lower matrix porosities in these regions from which the hydraulic conductivity values are coregionalized. 


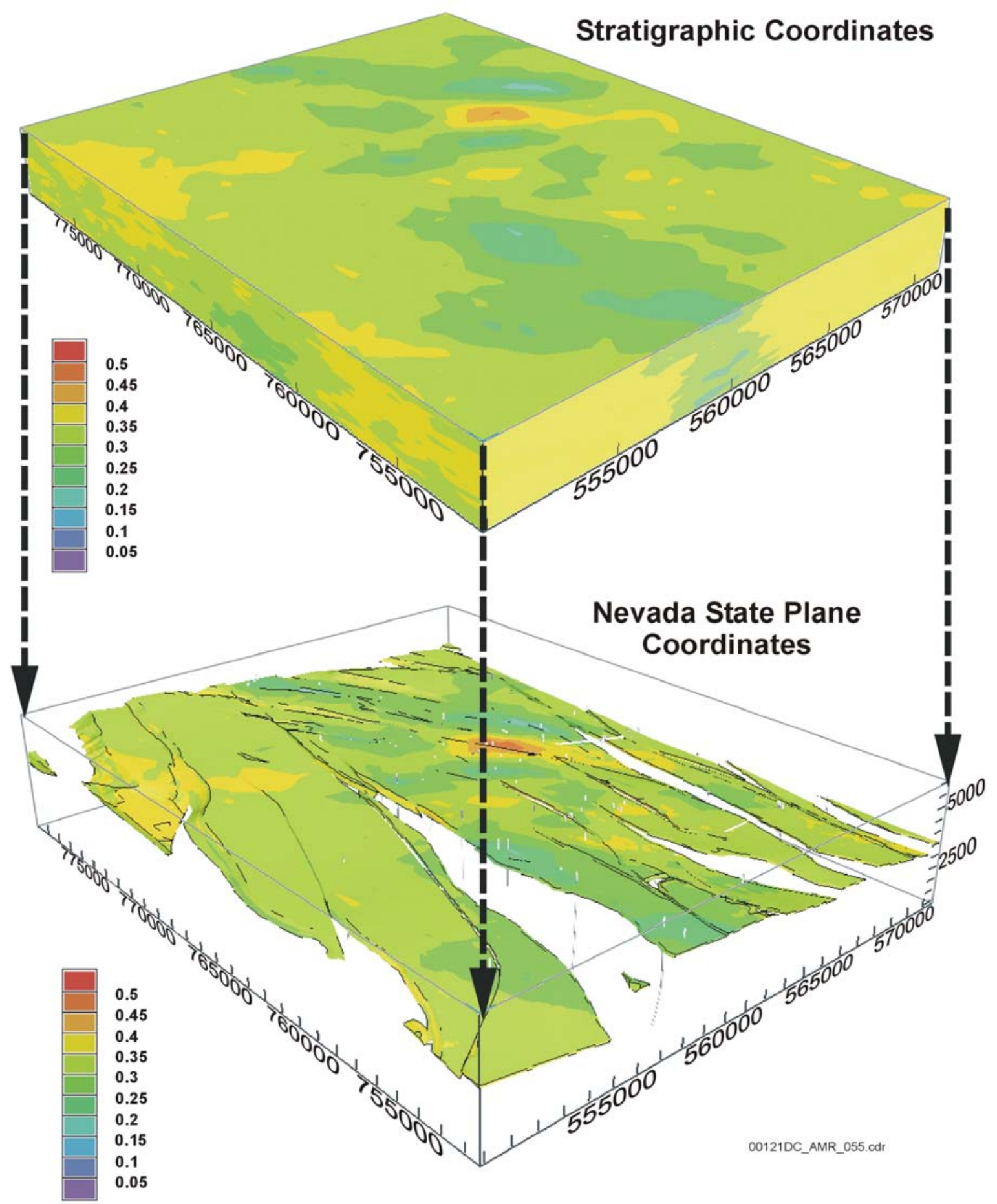

Source: SN9910T0501399.001 [DIRS 129717] Stratigraphic Coordinates, and MO9910MWDISMRP.002 [DIRS 145731] Nevada State Plane Coordinates figure shown for illustration purposes only.

NOTE: Light-grey objects in real-world-coordinate view are drill holes and workings of the ESF. Easting and northing values are Nevada state plane coordinates in feet.

Figure 6.5-1. Perspective Diagrams Showing E-Type Model Matrix Porosity in the PTn Model Unit in Both Stratigraphic and Real-World Coordinates 


\section{PTn E-type porosity}

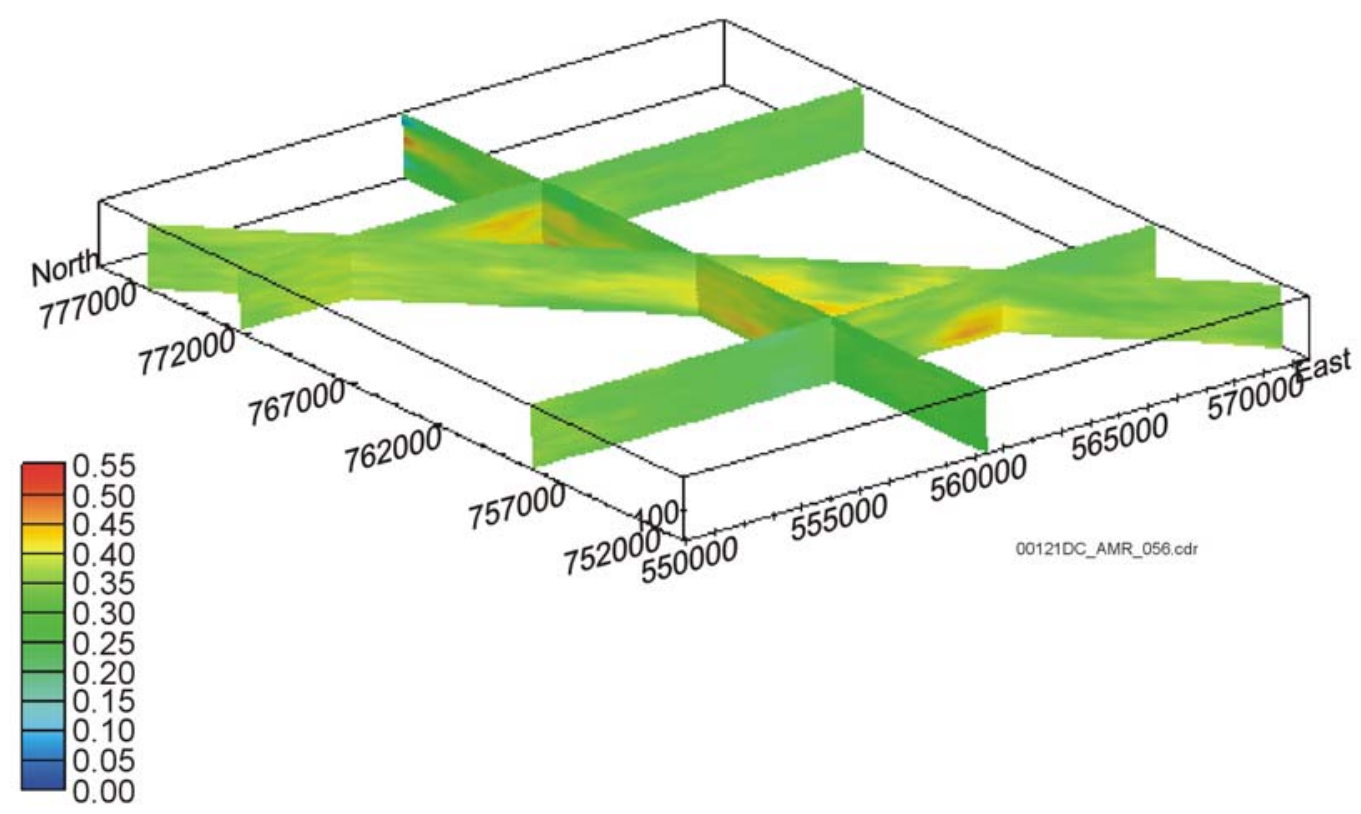

Source: SN9910T0501399.001 [DIRS 129717].

NOTE: Vertical exaggeration 10x.

Figure 6.5-2. Cross-Sectional Views Showing E-Type Heterogeneity in Matrix Porosity in the PTn Model Unit in Stratigraphic Coordinates

\section{PTn E-type Bulk Density}

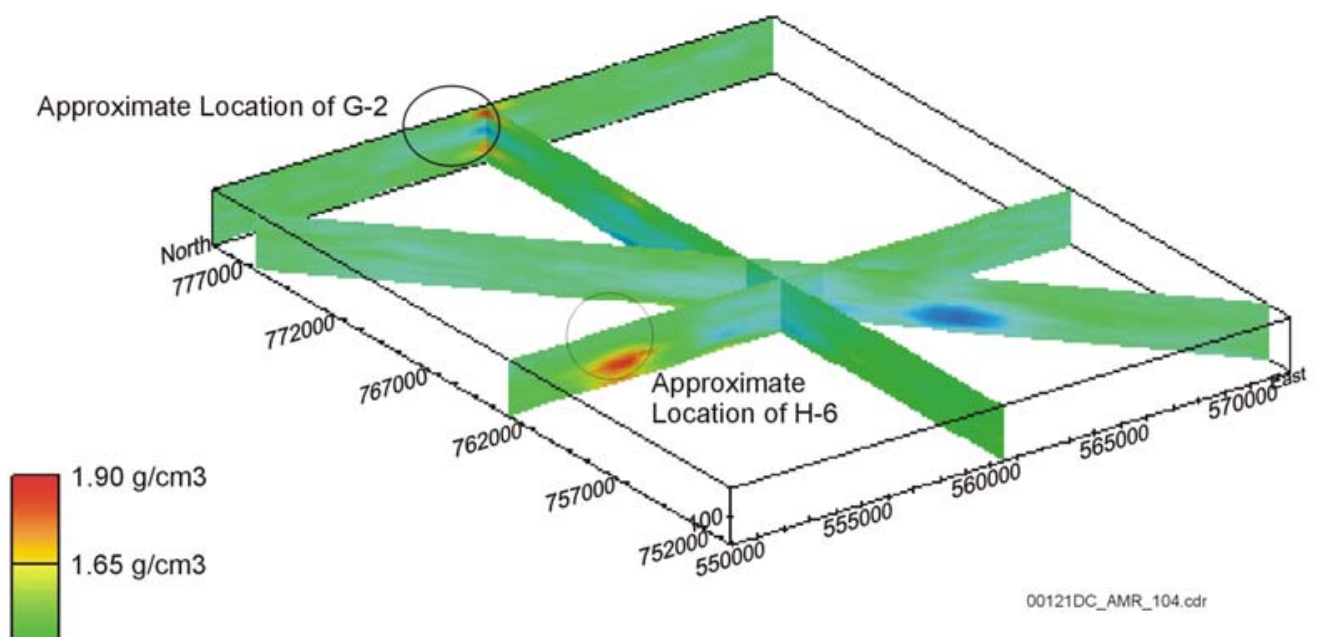

$1.40 \mathrm{~g} / \mathrm{cm} 3$

$1.15 \mathrm{~g} / \mathrm{cm} 3$

$0.90 \mathrm{~g} / \mathrm{cm} 3$

Source: SN9910T0501399.001 [DIRS 129717].

NOTE: Vertical exaggeration 10x.

Figure 6.5-3. Cross-Sectional View Showing E-Type Heterogeneity of Bulk Density in the PTn Model Unit in Stratigraphic Coordinates 


\section{PTn E-type Ksat}

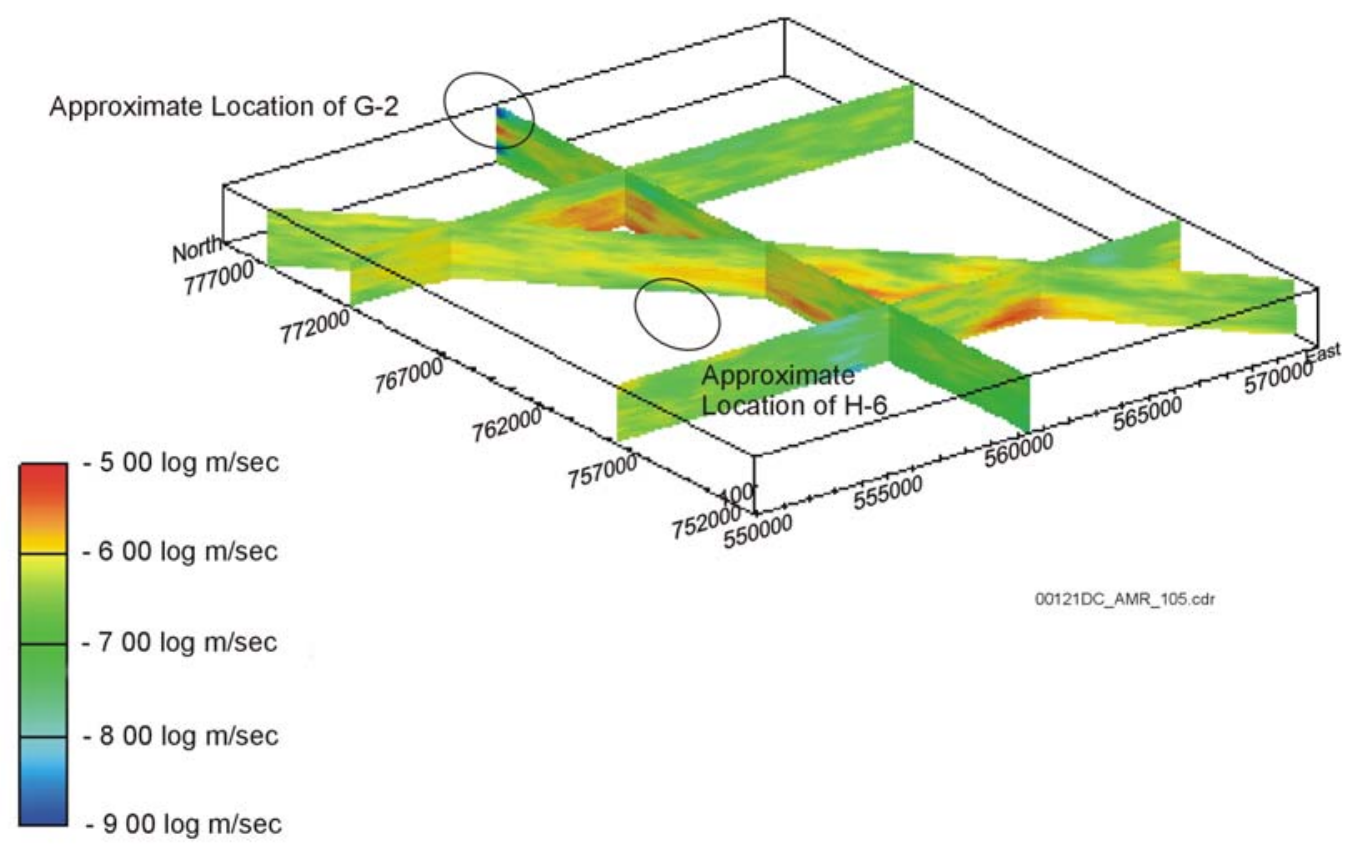

Source: SN9910T0501399.001 [DIRS 129717].

NOTE: Vertical exaggeration 10x.

Figure 6.5-4. Cross-Sectional Views Showing E-Type Heterogeneity in Matrix Saturated Hydraulic Conductivity in the PTn Model Unit in Stratigraphic Coordinates

\subsubsection{TSw Model Unit}

Heterogeneity of material properties within the TSw model unit is presented in Figures 6.5-5 to 6.5-11. Note that matrix porosity, as indicated in Figure 6.5-5 and 6.5-6, is very low, mostly less than 10 to 15 percent, and relatively constant in magnitude across the entire modeled region. This minimal variability is consistent with the definition of this unit as densely welded tuff. However, the front face of the block diagram, shown in stratigraphic coordinates in Figure 6.5-5, and the cross-section views of Figure 6.5-6 indicate that increased matrix porosity is associated with the major lithophysae-bearing intervals within the unit, and most particularly with what in the GFM would be the vapor-phase corroded crystal-rich nonlithophysal interval near the top of the unit.

The heterogeneity of lithophysal porosity, in contrast to the matrix porosity, is shown in Figure 6.5-7 as perspective views, and in Figure 6.5-8 in cross-sectional view. Although even lithophysal porosity is generally low compared to the porosity of a nonwelded welded tuff, such as the PTn model unit, maximum porosity values within the lithophysal intervals locally exceed 30 to 35 percent $(0.30$ to 0.35$)$. Figure $6.5-8$ clearly indicates two such intervals of high porosity, corresponding approximately to the upper and lower lithostratigraphic units (Tptpul and Tptpll), separated by a low-porosity (on the order of 10 percent) interval equivalent to the middle nonlithophysal lithostratigraphic unit (Tptpmn). Note however, that there is a fairly large amount of lateral heterogeneity within each of the elevated porosity intervals. It is the measured 
porosity data themselves, as propagated away from drill hole locations by the spatial continuity model, that produce both the apparent layering and the variations within those layers. There are no detailed lithostratigraphic (or other) subunits explicitly modeled within the TSw model unit. All property heterogeneity in the rock properties model are functions strictly of the measured material properties.

Bulk density heterogeneity, which is coregionalized from lithophysal porosity, is illustrated in Figure 6.5-9. Density values are typically above $2.0 \mathrm{~g} / \mathrm{cm}^{3}$ throughout most of the relatively lithophysae-free region. Bulk density is particularly high (approaching $2.5 \mathrm{~g} / \mathrm{cm}^{3}$ ) in the lower parts of the TSw model unit, as indicated by the red colors on the figure. A prominent high density interval is associated with the lower vitrophyre in the central part of the modeled region (approximately corresponding to lithostratigraphic unit Tptpv3). However, bulk-rock density values associated with the upper lithophysal horizon in particular may be as low as 1.5 to $1.8 \mathrm{~g} / \mathrm{cm}^{3}$. The alternation of lithophysal and nonlithophysal intervals are particularly clearly visualized through the bulk density model.

Thermal conductivity is also coregionalized from lithophysal porosity, in an effort to predict the thermal conductivity of volumes of rock influenced by the presence of lithophysal cavities one decimeter or larger in diameter. Figure 6.5-10 presents the E-type model of spatial heterogeneity in thermal conductivity. High values of thermal conductivity (greater than approximately 1.3 to $1.4 \mathrm{~W} / \mathrm{m}-\mathrm{K}$ and shown in yellow and orange tones) are associated with the lower portion of the TSw model unit, and with the presumed low-lithophysae "middle nonlithophysal" lithostratigraphic unit (Tptpmn). Particularly high thermal conductivity values, approaching $1.5 \mathrm{~W} / \mathrm{m}-\mathrm{K}$, are present at the very base of the TSw unit, presumably associated with the densely welded vitric lithostratigraphic unit. In contrast, the most lithophysal portions of the unit, which contain lithophysal cavities up to a meter in diameter, appear to be characterized by bulk-rock thermal conductivities less than $1.0 \mathrm{~W} / \mathrm{m}-\mathrm{K}$ (blue and blue-green colors in Figure 6.5-10). 


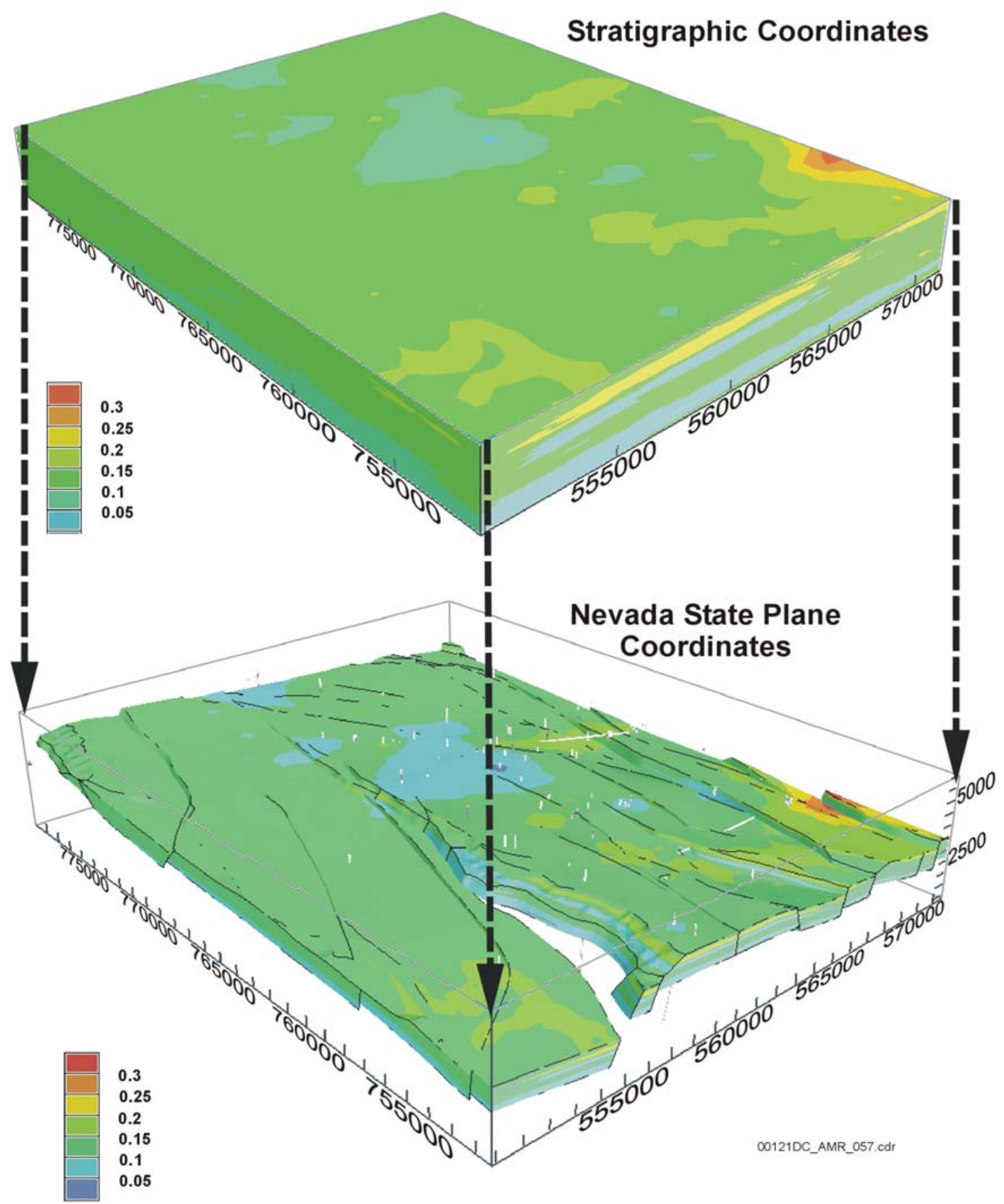

Source: SN9910T0501399.001 [DIRS 129717] Stratigraphic Coordinates, and MO9910MWDISMRP.002 [DIRS 145731] Nevada State Plane Coordinates figure shown for illustration purposes only.

NOTE: Light-grey objects in real-world-coordinate view are drill holes and workings of the ESF. Easting and northing values are Nevada state plane coordinates in feet. Note compressed porosity scale compared with Figure 6.5-7.

Figure 6.5-5. Perspective Diagrams Showing E-Type Model Matrix Porosity in the TSw Model Unit in Both Stratigraphic and Real-World Coordinates 


\section{TSw E-type Matrix Porosity}

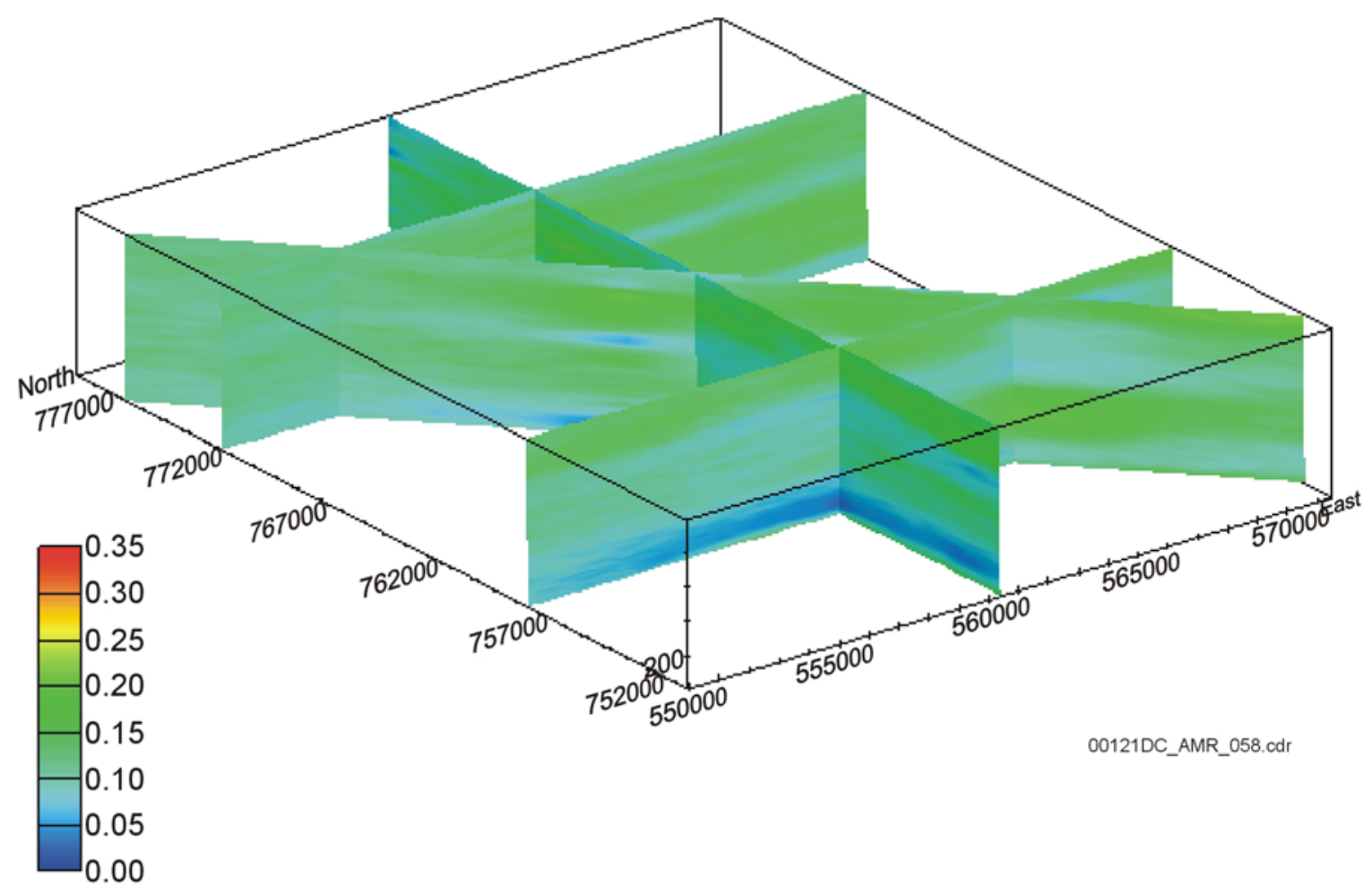

Source: SN9910T0501399.001 [DIRS 129717].

NOTE: Vertical exaggeration 10x.

Figure 6.5-6. Cross-Sectional Views Showing E-Type Heterogeneity of Matrix Porosity in the TSw Model Unit in Stratigraphic Coordinates 


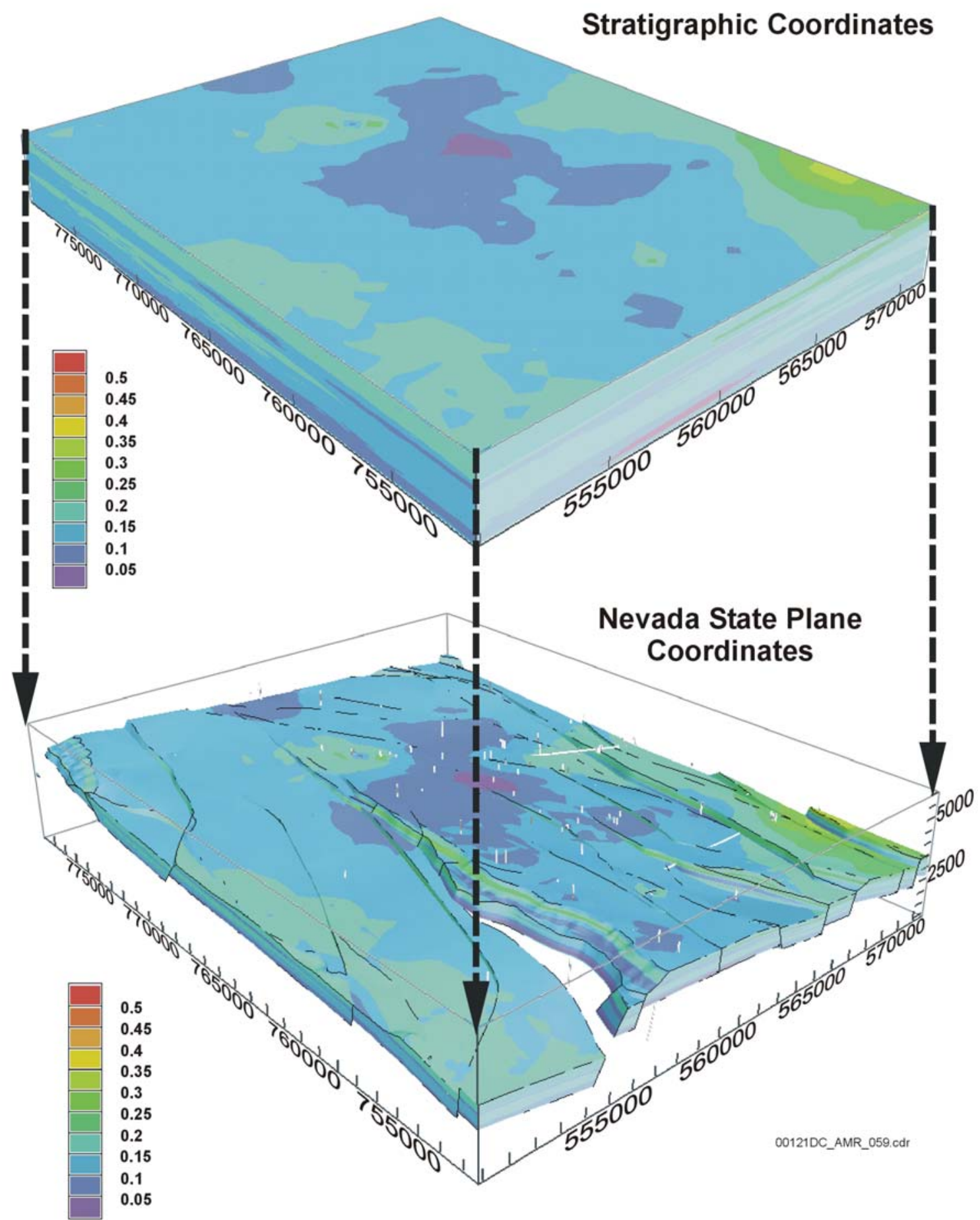

Source: SN9910T0501399.001 [DIRS 129717] Stratigraphic Coordinates, and MO9910MWDISMRP.002 [DIRS 145731] Nevada State Plane Coordinates figure shown for illustration purposes only.

NOTE: Light-grey objects in real-world-coordinate view are drill holes and workings of the ESF. Easting and northing values are Nevada state plane coordinates in feet. Note expanded porosity scale compared with Figure 6.5-5.

Figure 6.5-7. Perspective Diagrams Showing E-Type Model Lithophysal Porosity in the TSw Model Unit in Both Stratigraphic and Real-World Coordinates 


\section{TSw E-type Lithophysal Porosity}

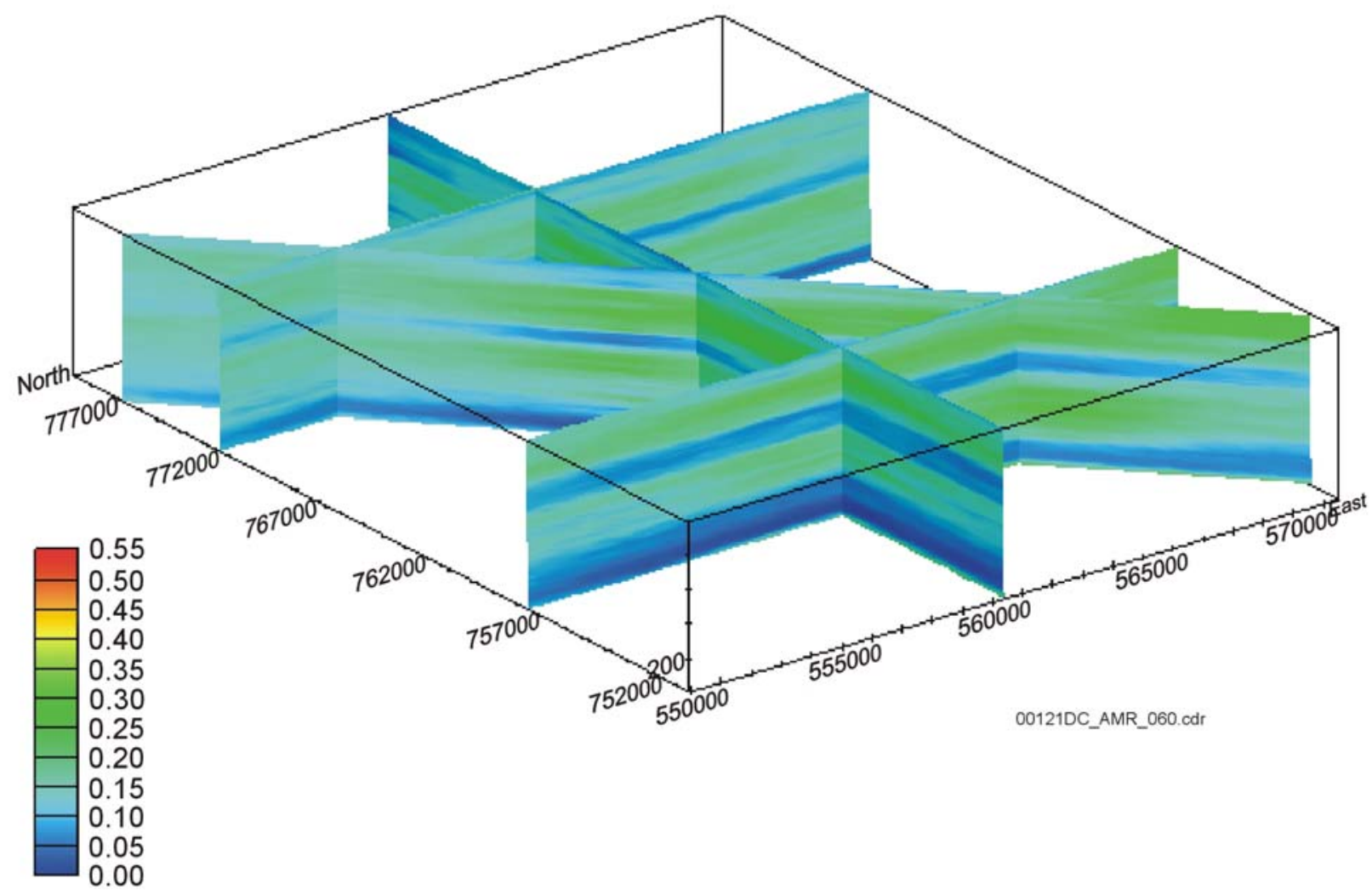

Source: SN9910T0501399.001 [DIRS 129717].

NOTE: Vertical exaggeration $5 x$.

Figure 6.5-8. Cross-Sectional Views Showing E-Type Heterogeneity of Lithophysal Porosity in theTSw Model Unit in Stratigraphic Coordinates 


\section{TSw E-type Bulk Density}

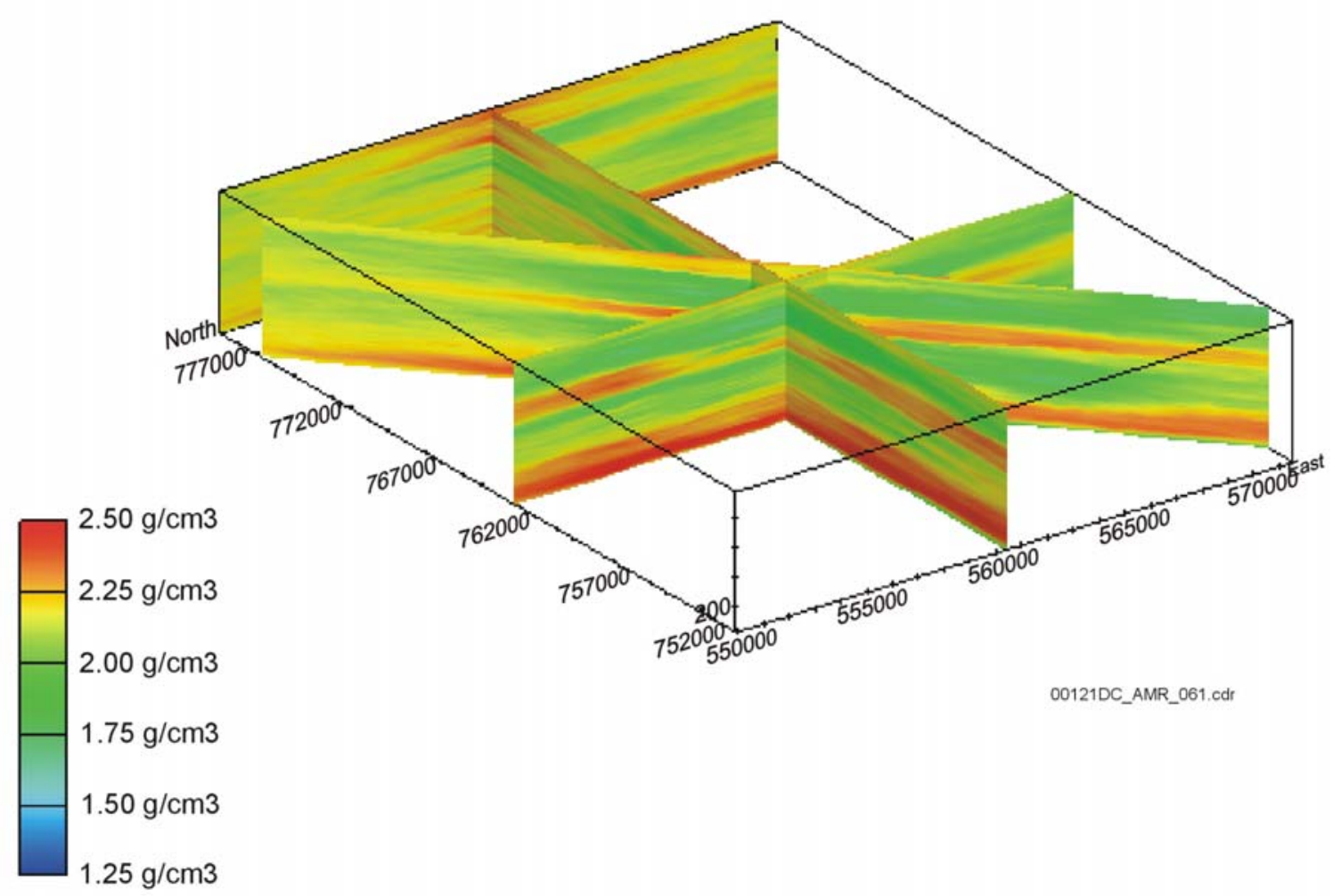

Source: SN9910T0501399.001 [DIRS 129717].

NOTE: Vertical exaggeration $5 x$.

Figure 6.5-9. Cross-Sectional Views Showing E-Type Heterogeneity of Bulk Density in the TSw Model Unit in Stratigraphic Coordinates 


\section{TSw E-type Thermal Conductivity}

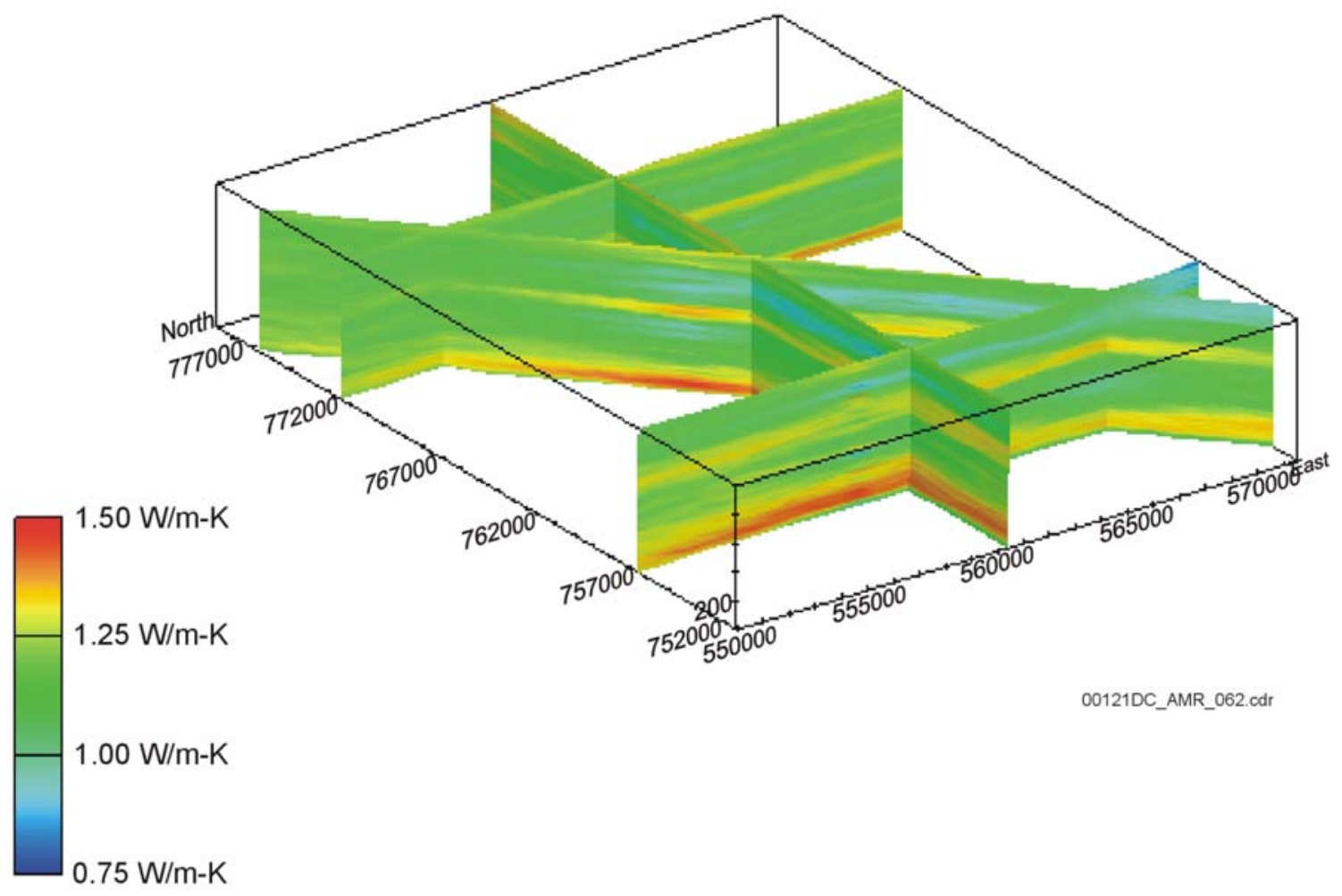

Source: SN9910T0501399.001 [DIRS 129717].

NOTE: Vertical exaggeration $5 x$.

Figure 6.5-10. Cross-Sectional Views Showing E-Type Heterogeneity of Thermal Conductivity in the TSw Model Unit in Stratigraphic Coordinates 
TSw E-type Ksat

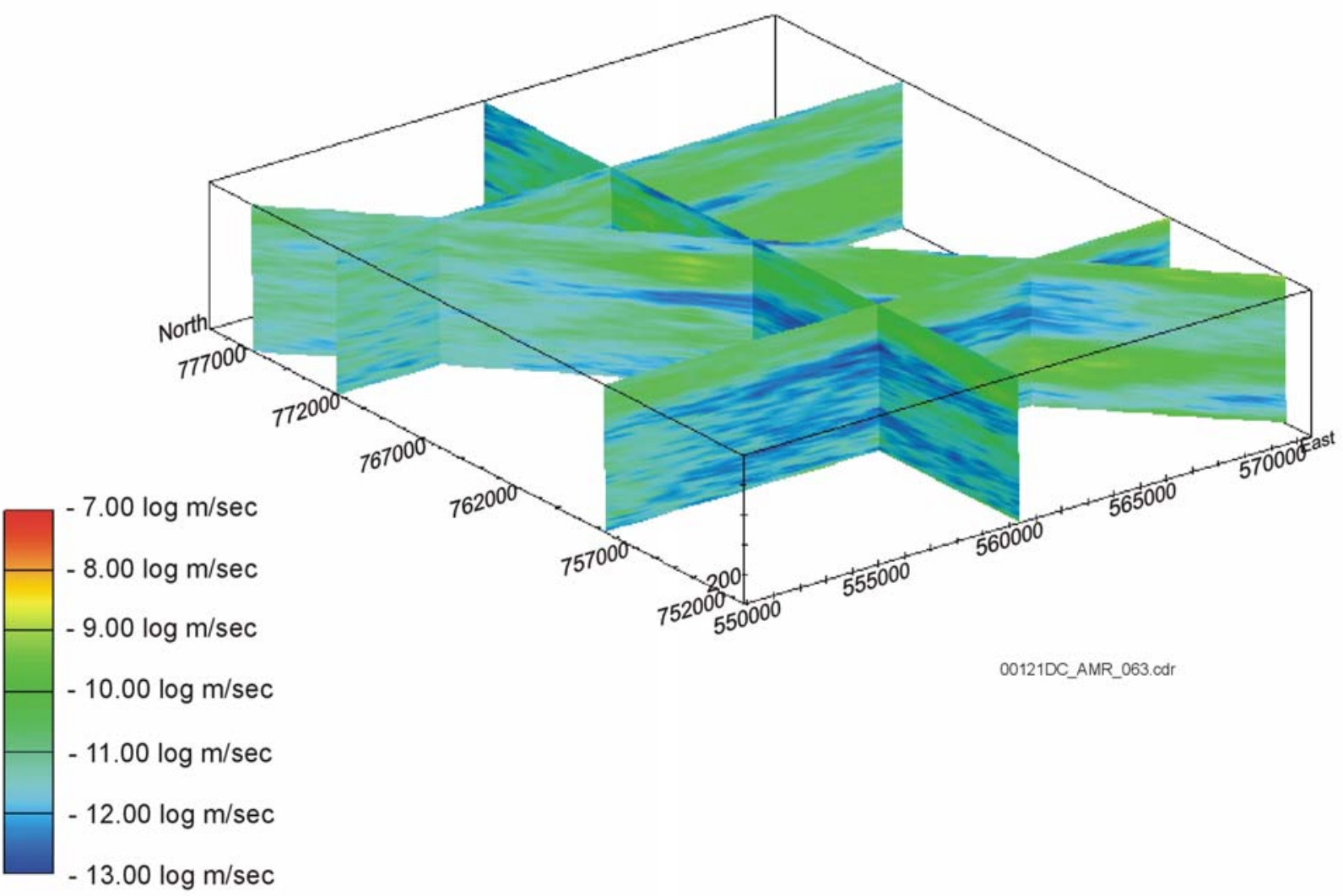

Source: SN9910T0501399.001 [DIRS 129717].

NOTE: Vertical exaggeration $5 x$.

Figure 6.5-11. Cross-Sectional Views Showing E-Type Heterogeneity of Matrix Saturated Hydraulic Conductivity in the TSw Model Unit in Stratigraphic Coordinates

Heterogeneity in matrix saturated hydraulic conductivity is presented in Figure 6.5-11, and has been coregionalized from the matrix porosity model shown in Figures 6.5-5 and 6.5-6. Matrix conductivities are less than $10^{-11} \mathrm{~m} / \mathrm{sec}$ through much of the lower part of the model unit. As expected from the higher matrix porosity values associated with the lithophysae-bearing portions of the TSw model unit, matrix hydraulic conductivity values are markedly higher, $10^{-9}$ to $10^{-10} \mathrm{~m} / \mathrm{sec}$ (yellow to green tones), in these vapor-phase altered portions of the unit. Some of these higher conductivity values may also be associated with vapor-phase corrosion of the welded tuff within the crystal-rich nonlithophysal unit. Note, however, that "matrix" hydraulic conductivity does not include conductivity attributable to flow through lithophysal cavities or fractures under true saturated conditions.

\subsubsection{CHn Model Unit}

Variations in the matrix porosity of the CHn model unit are presented in Figures 6.5-12 and 6.5-13. Porosity values are generally high at 20 to 40 percent ( 0.20 to 0.40$)$ throughout the unit, particularly in contrast to the low porosity values typical of the overlying TSw model unit 
(0.10 to 0.15 ). Expanding the porosity color scale indicates that a mass of particularly high porosity occupies the central portion of the modeled volume. Porosity values locally approach 50 percent $(0.50)$ within this region.

Variations in bulk density in the CHn model unit are presented in Figure 6.5-14. Density values vary from more than $2.0 \mathrm{~g} / \mathrm{cm}^{3}$ to less than $1.3 \mathrm{~g} / \mathrm{cm}^{3}$, depending upon location, although the majority of this nonwelded unit exhibits limited variation in bulk density at 1.5 to $1.75 \mathrm{~g} / \mathrm{cm}^{3}$. Generally speaking, bulk density varies inversely with porosity, as anticipated from the coregionalization relationship.

Heterogeneity in matrix saturated hydraulic conductivity for the CHn model unit is illustrated in Figure 6.5-15. Although hydraulic conductivity is derived by coregionalization with matrix porosity, the relationship between the two material properties is not precisely straightforward because of the presence of hydrous-phase mineral alteration (predominantly zeolitic) within the unit. Matrix conductivities are typically $10^{-6}$ to $10^{-7} \mathrm{~m} / \mathrm{sec}$ (greens to reds) within the unaltered portion of the CHn, and typically less than $10^{-11} \mathrm{~m} / \mathrm{sec}$ elsewhere (blue). The block diagram in the upper part of Figure 6.5-15 clearly indicates that vitric (to potentially devitrified) materials are limited to the upper portion of the model unit, and more particularly to the southwestern portion of the modeled volume. The overall impression is of a wedge of vitric (unaltered) material tapering to a feather edge toward the northeast. Zeolitic (altered) rocks are shown in tones of blue underlying and replacing the green- through red-colored volume to the north. Recall that the saturated hydraulic conductivity of altered samples are essentially uncorrelated with matrix porosity. The lower portion of Figure 6.5-15 presents cross-sectional views of the hydraulic conductivity field within the model unit, and illustrates some of the complex interfingering relationships of altered and unaltered rock types. 


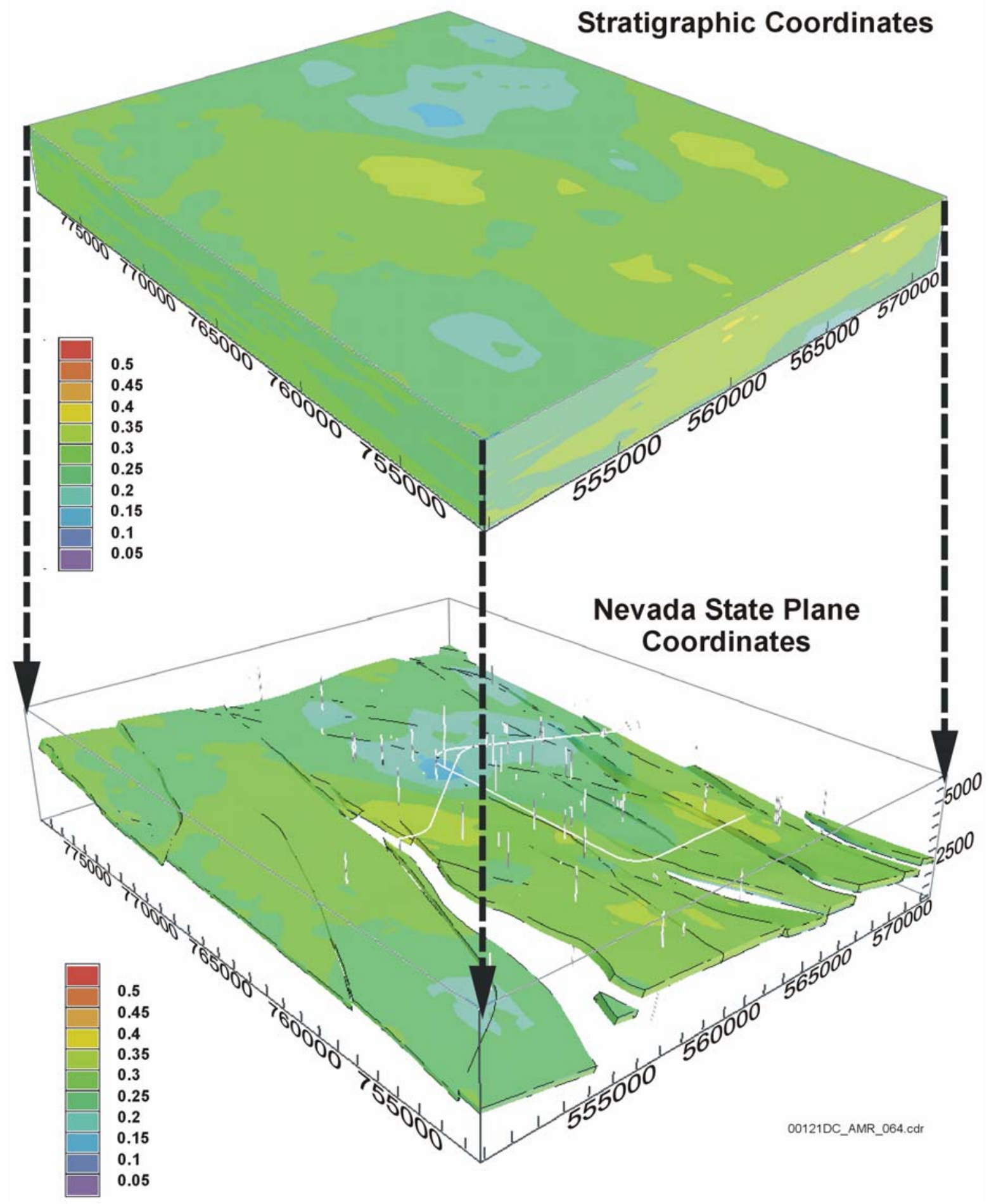

Source: SN9910T0501399.001 [DIRS 129717] Stratigraphic Coordinates, and MO9910MWDISMRP.002 [DIRS 145731] Nevada State Plane Coordinates figure shown for illustration purposes only.

NOTE: Light-grey objects in real-world-coordinate view are drill holes and workings of the ESF. Easting and northing values are Nevada state plane coordinates in feet.

Figure 6.5-12. Perspective Diagrams Showing E-Type Model Matrix Porosity in the $\mathrm{CHn}$ Model Unit in Both Stratigraphic and Real-World Coordinates 


\section{Chn E-type Porosity}

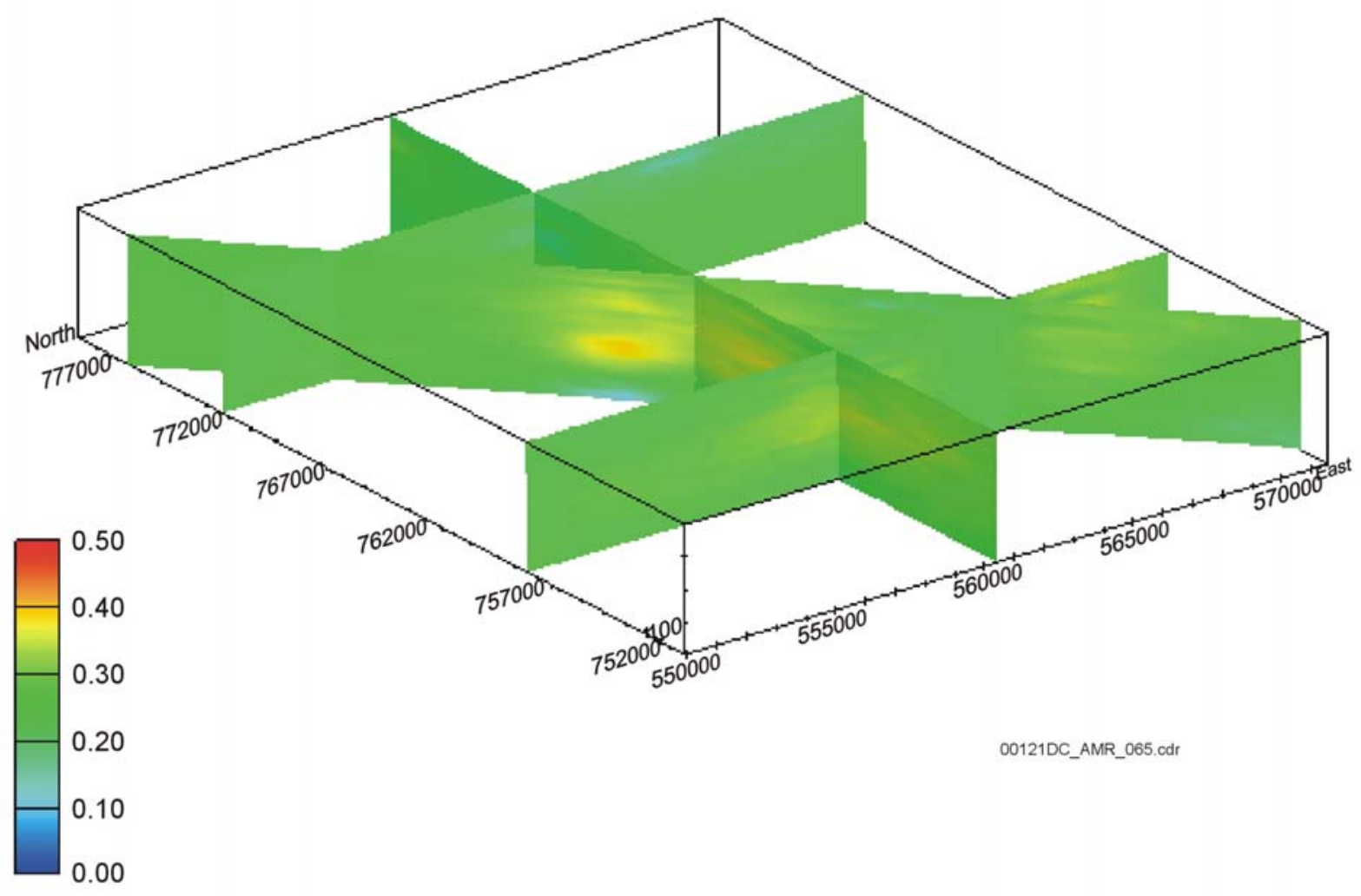

Source: SN9910T0501399.001 [DIRS 129717].

NOTE: Vertical exaggeration 10x.

Figure 6.5-13. Cross-Sectional Views Showing E-Type Heterogeneity of Matrix Porosity in the CHn Model Unit in Stratigraphic Coordinates 


\section{Chn E-type Bulk Density}

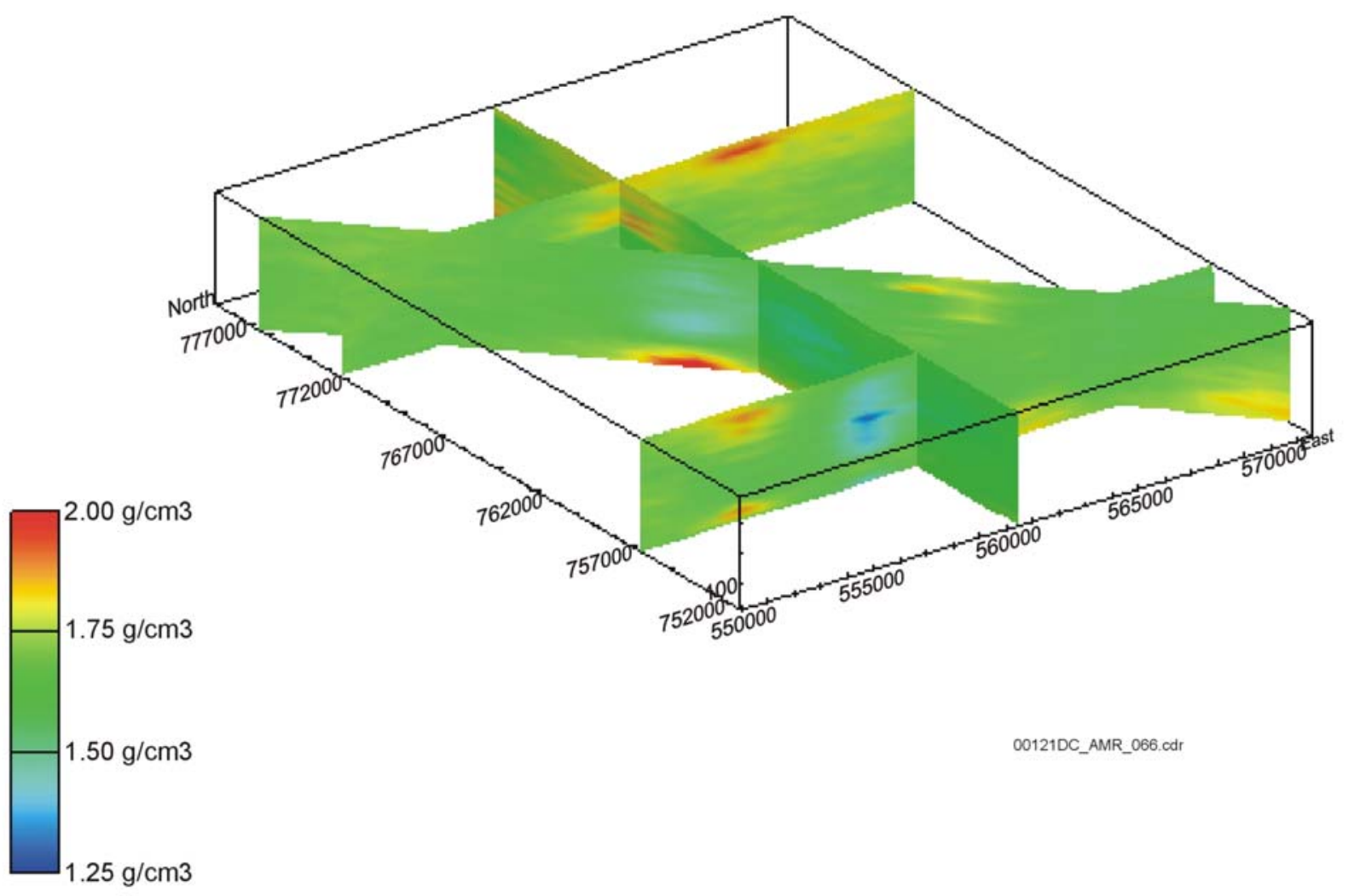

Source: SN9910T0501399.001 [DIRS 129717].

NOTE: Vertical exaggeration 10x.

Figure 6.5-14. Cross-Sectional Views Showing E-Type Heterogeneity of Bulk Density in the CHn Model Unit in Stratigraphic Coordinates 

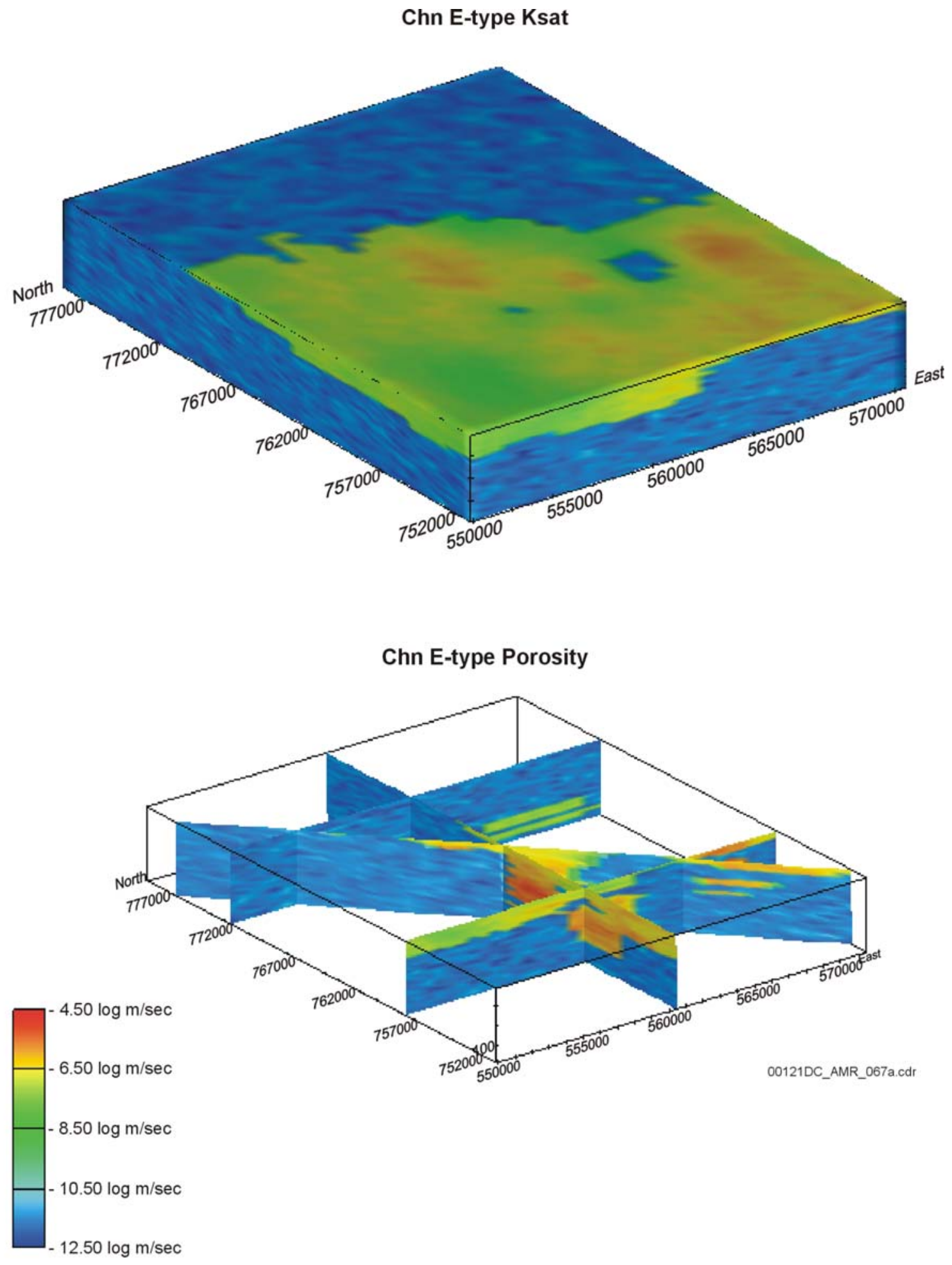

Source: SN9910T0501399.001 [DIRS 129717].

NOTE: Vertical exaggeration 10x.

Figure 6.5-15. Block and Cross-Sectional Views Showing E-Type Heterogeneity of Matrix Saturated Hydraulic Conductivity in the CHn Model Unit in Stratigraphic Coordinates 


\subsubsection{Tcp Model Unit}

Figures 6.5-16 and 6.5-17 present the spatial heterogeneity of matrix porosity within the Tcp model unit. Because the Prow Pass Tuff is mostly nonwelded, the porosity values are typically high, varying from 20 to nearly 40 percent across large volumes of the model. Lower porosity values, typically less than 15 percent (0.15), are present along the northern boundary of the modeled volume, and as a poorly defined lobate mass (indicated by the 0.15 porosity isoshell), which may correspond to the "moderately welded" portion of this unit, generally low within the central-eastern part of the region.

Variations in bulk density, shown in Figure 6.5-18, substantiate the variations in porosity described in the preceding paragraph. Densities well in excess of $2.1 \mathrm{~g} / \mathrm{cm}^{3}$ are prominently displayed along the northern boundary of the model in the vicinity of drill hole G-2. Higher densities on the order of $2.0 \mathrm{~g} / \mathrm{cm}^{3}$ are also visible in the east-central portion of the block, corresponding to the low porosity lobe. Elsewhere across the modeled volume, bulk densities are more typically between 1.75 and $2.0 \mathrm{~g} / \mathrm{cm}^{3}$ and are shown in green colors.

Heterogeneity in matrix saturated hydraulic conductivity is presented in Figure 6.5-19. In a manner similar to the overlying CHn model unit, a bimodal distribution of conductivity values, corresponding to altered and unaltered rock types, is quite prominent. Lower hydraulic conductivity values, typically less than $10^{-10} \mathrm{~m} / \mathrm{sec}$ are associated with regions affected by hydrous-phase mineral alteration. Markedly higher values of hydraulic conductivity, varying from $10^{-10}$ to $10^{-7} \mathrm{~m} / \mathrm{sec}$, are associated with the vitric-to-devitrified continuum of matrix porosity values in regions unaffected by alteration. The block diagram in the upper portion of Figure 6.4-19 indicates that the upper and lower margins of the Prow Pass Tuff are essentially completely altered. Reference to the cross-sectional views in the lower half of the figure indicates that the unaltered portions of the unit correspond to the devitrified interior core of the ash flow.

\subsection{UNCERTAINTIES AND LIMITATIONS}

Uncertainty, in the context of a stochastic modeling analysis, assumes a specific meaning as a descriptor of one's state of knowledge, in that a quantitative assessment of uncertainty is typically one of the explicit objectives of the analysis. This meaning is in contrast to another possible definition, which is expressed more precisely as involving limitation or doubt as to the accuracy or relevance of a result. This distinction is maintained in this report. This section first describes a number of limitations of both methodology and data that detract from the exactness or accuracy of the models generated by this analysis. The results of a stochastic uncertainty analysis are then presented, which rigorously quantifies the space of geologic uncertainty that results from less-than-completely "exhaustive” site characterization. 


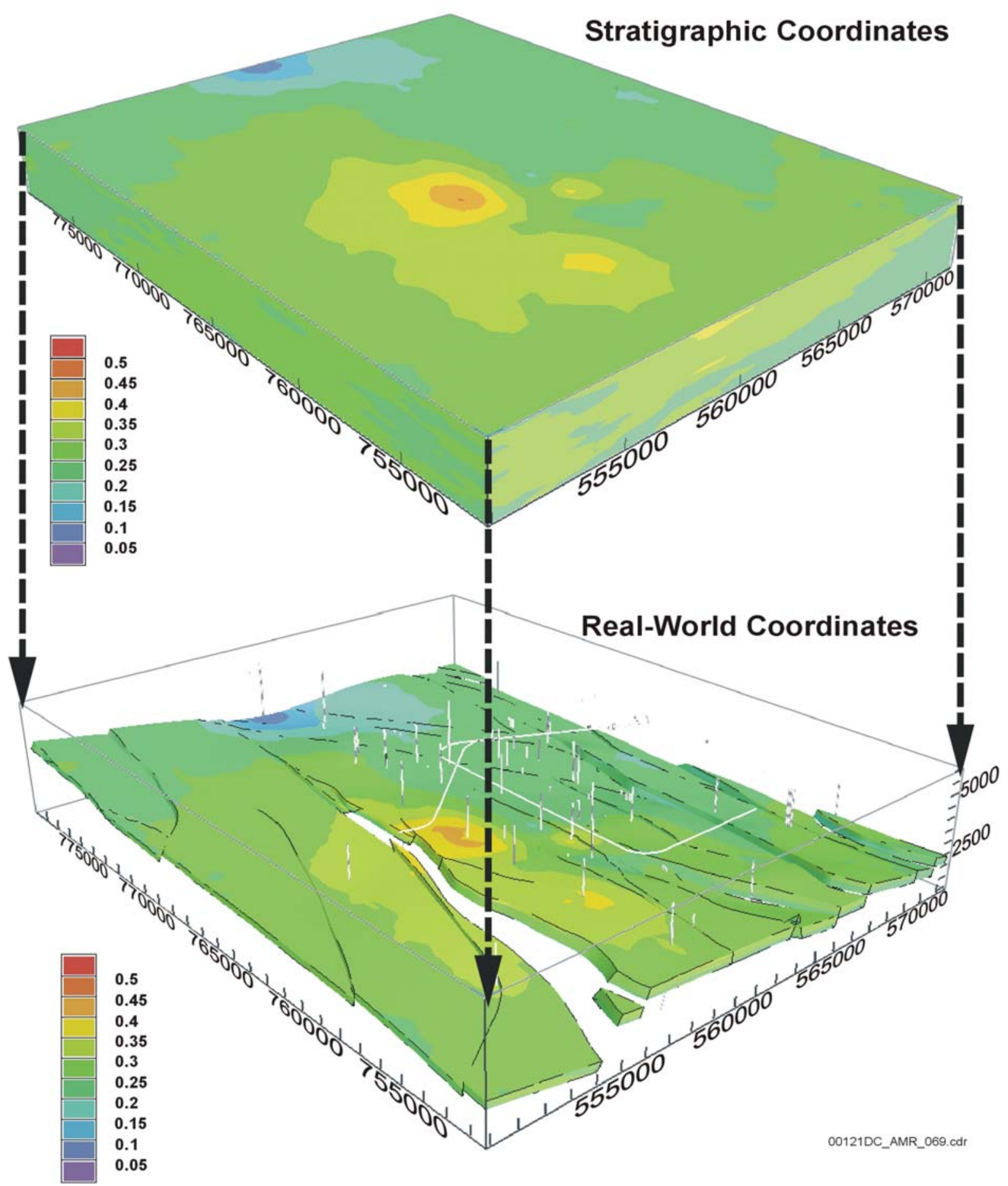

Source: SN9910T0501399.001 [DIRS 129717] Stratigraphic Coordinates, and MO9910MWDISMRP.002 [DIRS 145731] Nevada State Plane Coordinates figure shown for illustration purposes only.

NOTE: Light-grey objects in real-world-coordinate view are drill holes and workings of the ESF. Easting and northing values are Nevada state plane coordinates in feet.

Figure 6.5-16. Perspective Diagrams Showing E-Type Model Matrix Porosity in the Tcp Model Unit in Both Stratigraphic and Real-World Coordinates 

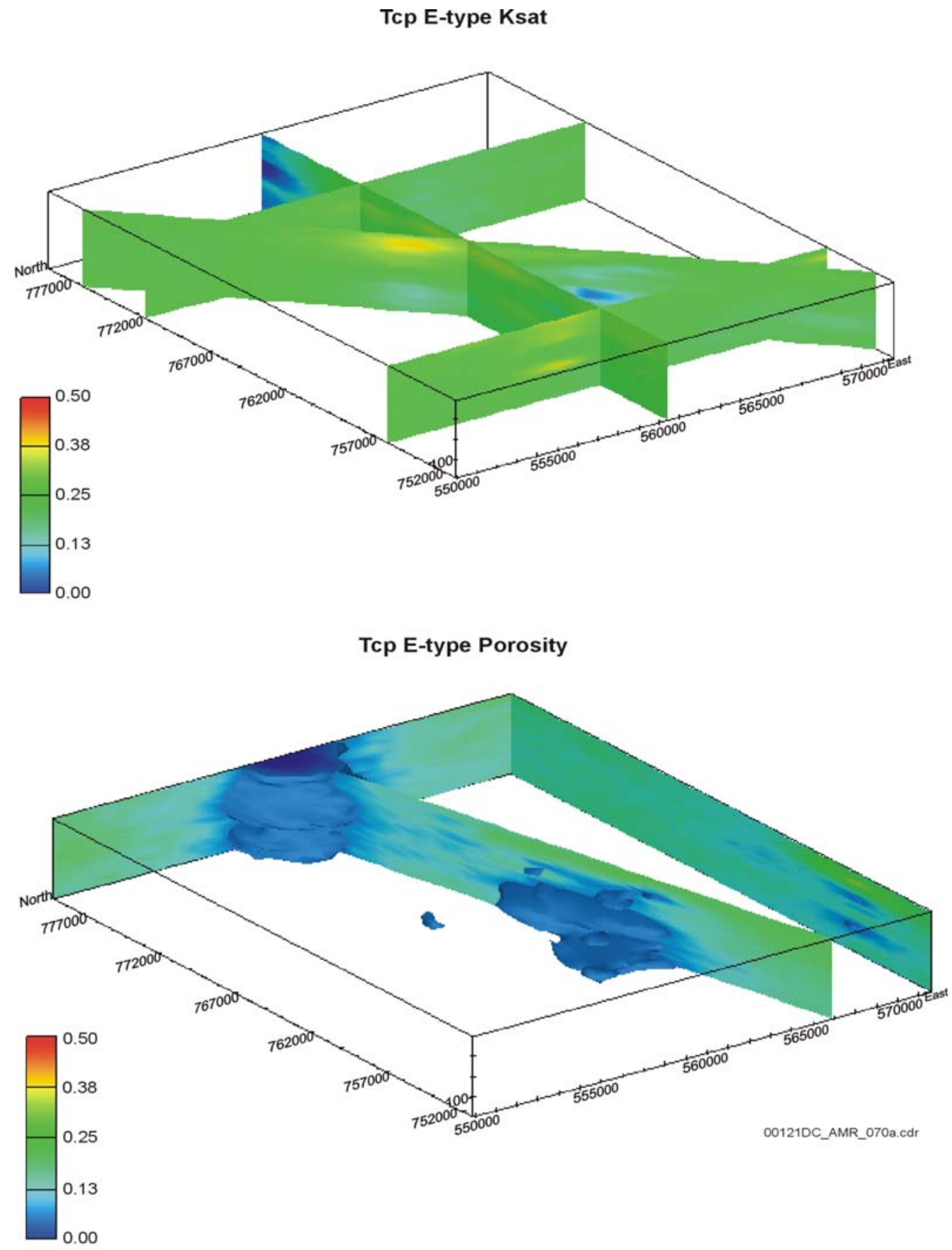

Source: SN9910T0501399.001 [DIRS 129717].

NOTE: Vertical exaggeration 10x. Note adjusted porosity scale in lower figure. Objects extending away from cross sections in lower figure are isoshells enclosing all regions of lowest porosity (less than approximately 0.15 ).

Figure 6.5-17. Cross-Sectional Views Showing E-Type Heterogeneity of Matrix Porosity in the Tcp Model Unit in Stratigraphic Coordinates 


\section{Tcp E-type Bulk Density}

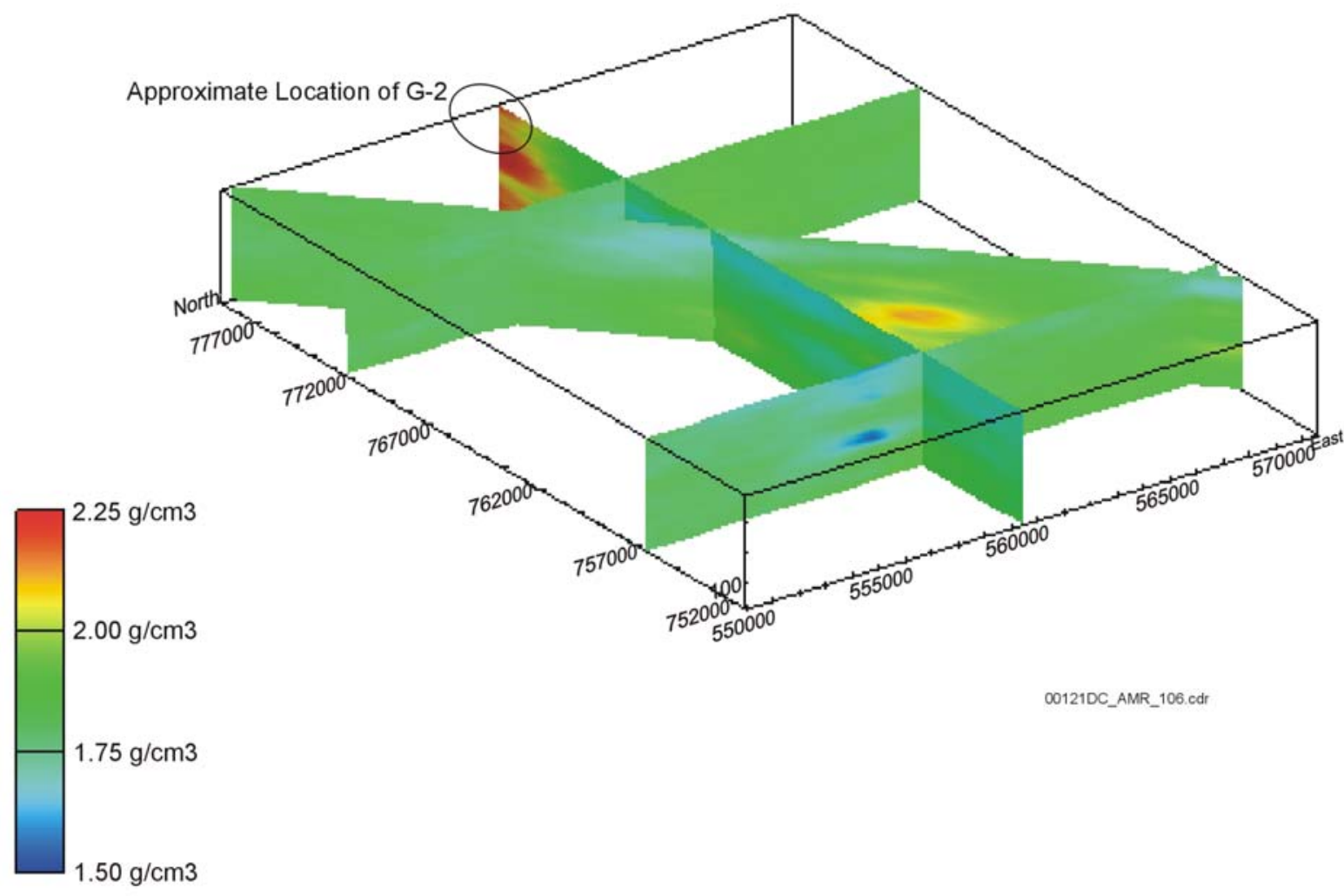

Source: SN9910T0501399.001 [DIRS 129717].

NOTE: Vertical exaggeration 10x.

Figure 6.5-18. Cross-Sectional Views Showing E-Type Heterogeneity of Bulk Density in the Tcp Model Unit in Stratigraphic Coordinates 


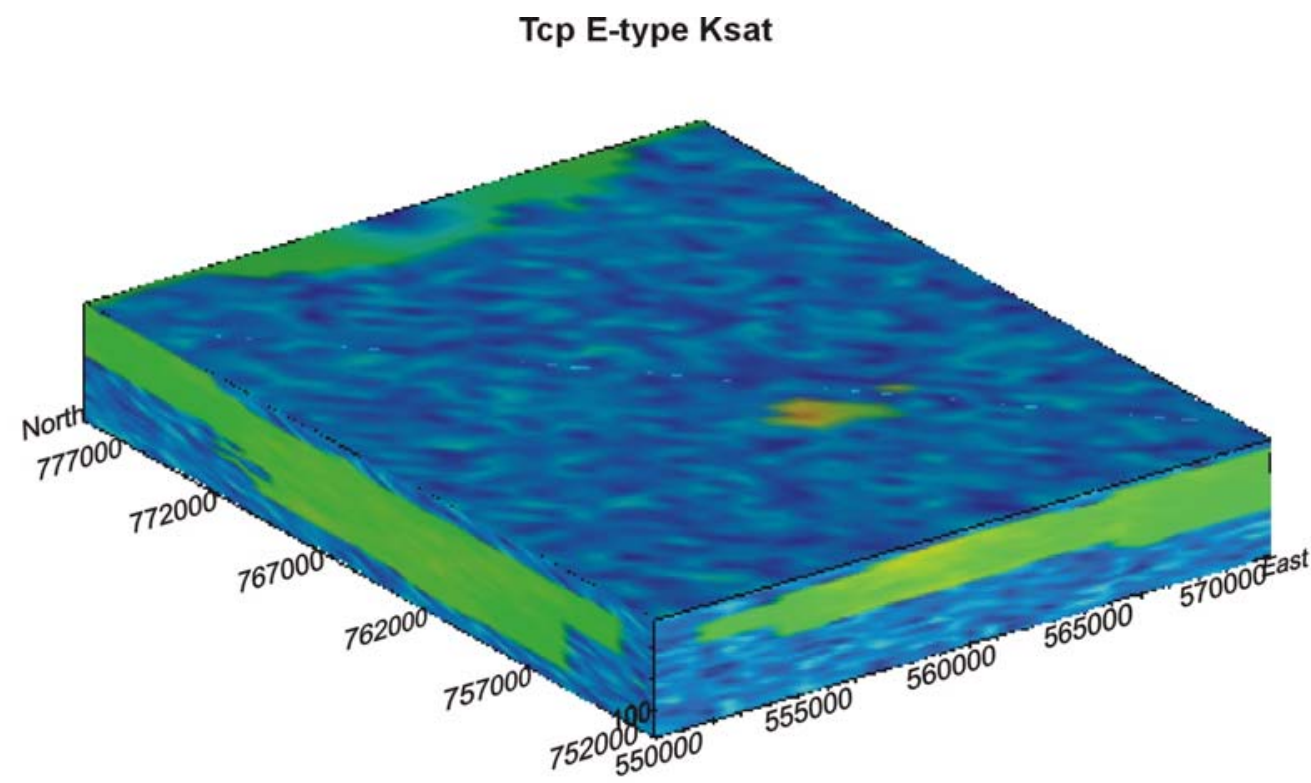

Tcp E-type Ksat

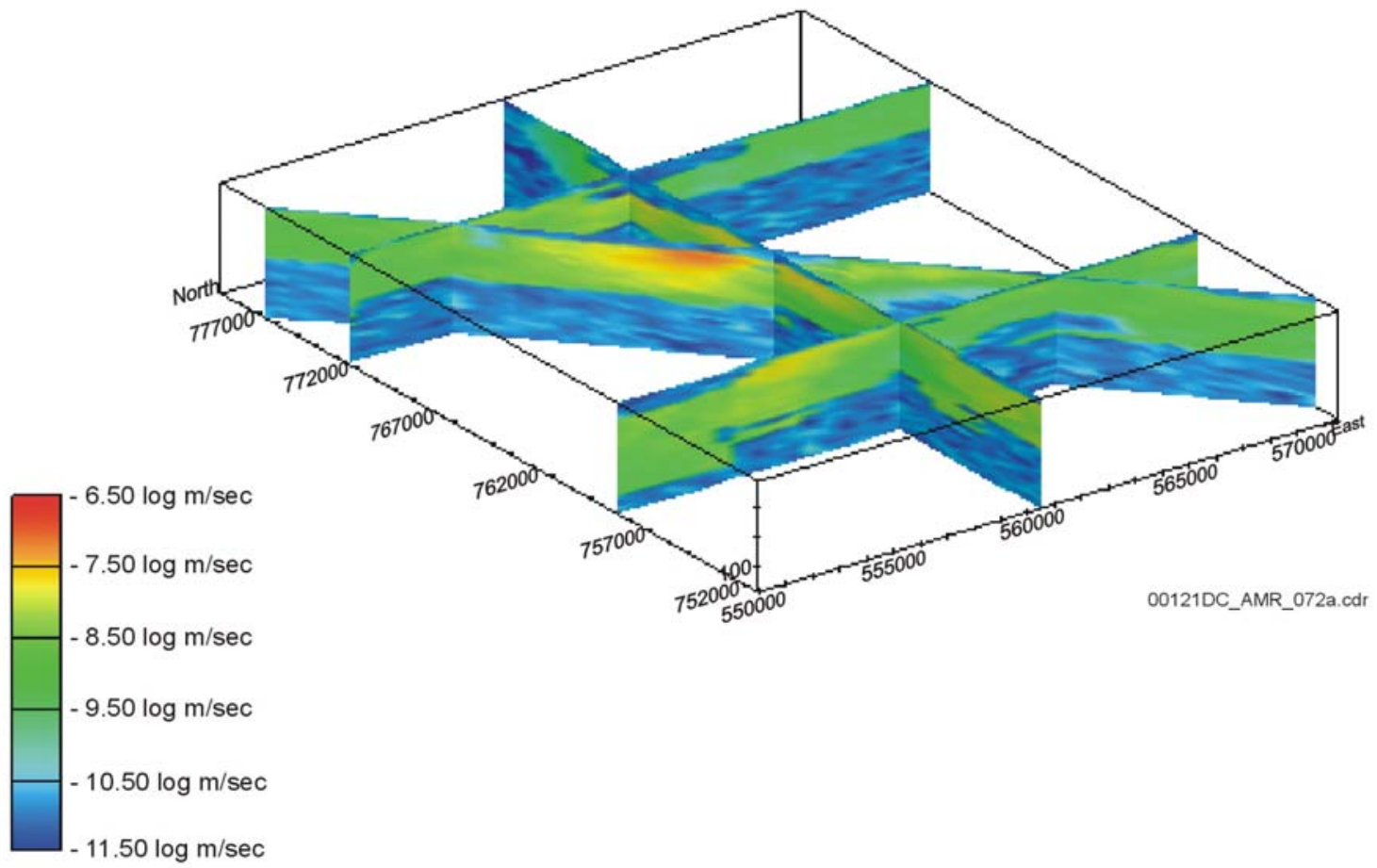

Source: SN9910T0501399.001 [DIRS 129717].

NOTE: Vertical exaggeration 10x.

Figure 6.5-19. Block Diagram and Cross-Sectional Views Showing E-Type Heterogeneity of Matrix Saturated Hydraulic Conductivity in the Tcp Model unit in Stratigraphic Coordinates 


\subsubsection{Limitations}

There are a number of factors affecting this analysis that may best be described as limitations of the data or of the modeling process itself. These limitations include errors and biases in the sample data used in the analysis, the methodological use of porosity as a surrogate for other material properties, the combination of numerous lithostratigraphic units into the four major modeling units, and the effect of geologic departures from the assumptions inherent in the use of the stratigraphic coordinate system.

\subsubsection{Errors and Biases in Sample Data}

Stochastic simulation is a statistical-probabilistic methodology, with reproduction of various target statistical measures an important part. As such, errors ("uncertainties") incorporated into the statistical description of the rock mass unquestionably will be propagated through the simulation process into the output models. These errors are of two principal types: measurement error and systematic bias.

Measurement error or analytical uncertainty in the input data is not addressed in these rock property models. Philosophically, the underlying assumption is that measurement uncertainty, such as would be captured by replicate measurements of a given material property on the same physical sample, is small compared to the lateral heterogeneity of the actual rock mass. It is also assumed that these measurement types of errors are essentially unbiased, such that some may be high whereas others may be correspondingly low. Statistically, this assumption may be stated that the errors are of mean zero with a small relative variance.

Systematic biases, on the other hand, represent a more severe challenge for rock properties modeling using a statistical-probabilistic approach. Two examples of systematic bias within the data sets used for this modeling activity are known, and have been compensated for to some extent during creation of the individual simulated models. These biases are discussed in the following paragraphs.

Measurement Sensitivity Limits-Measurement of the matrix saturated hydraulic conductivity values for core samples appears to have had a lower "detection" limit of roughly $10^{-12}$ to $10^{-11} \mathrm{~m} / \mathrm{sec}$. Samples whose hydraulic conductivity are lower than this lower limit are reported in the data set as "no flow". Omitting these samples entirely would lead to an unrealistically high set of modeled hydraulic conductivity values. On the other hand, substituting the no-flow samples with an arbitrary low value prior to the simulation process would tend to skew the results towards that arbitrary low conductivity. Therefore, as described in Section 6.4.5.1, the effect of these no-flow samples has been simulated explicitly during postprocessing by setting the appropriate fraction of values equal to the arbitrary value of $10^{-14}$ $\mathrm{m} / \mathrm{sec}$ at randomly selected grid nodes within each model unit. This "fix" to approximate the nonnegligible number of nonflowing laboratory samples assumes that there is no particular spatial correlation among these samples.

Preferential Sampling Bias-Another, more pronounced example of preferential bias in the target sample population involves the whole-rock thermal conductivity modeling. As described originally by Rautman and McKenna (1997 [DIRS 100643], pp. 40 to 43), the laboratory 
measurements of thermal conductivity are systematically biased by preferential sampling of more coherent, generally lower-porosity/higher thermal conductivity, core specimens. This bias was identified by differences in the histograms of porosity for those laboratory thermal-test specimens (Figure 6.4-24) versus the overall histogram of porosity for the Topopah Spring welded unit. An additional confounding influence with respect to thermal conductivity is the effect of larger-than-core-size lithophysal cavities on the thermal conductivity of the rock mass as a whole. To reduce the impact of this identified sampling bias for thermal conductivity an unbiased reference distribution was constructed (see Rautman and McKenna 1997 [DIRS 100643], pp. 40 to 43) of thermal conductivity values for simulation using a porosityweighted distribution of estimated thermal conductivities (Section 6.4.5.3), where the porosity values were obtained by relatively rigorous systematic sampling of the entire TSw model unit.

Similar sampling bias also affects matrix hydraulic conductivity determinations, in that laboratory testing is skewed slightly toward measurements of the more conductive samples (low permeability samples take longer to run) in certain drill holes. This bias was not addressed explicitly in this modeling work as the total number of laboratory hydraulic conductivity determinations is quite large (400-plus) compared to thermal conductivity ( $\sim 50$ total; 35 for the TSw model unit), and several drill holes (especially UZ-16, SD-9) were sampled on a quite systematic basis for the hydraulic property (compare, for example, the locations and measured values of hydraulic conductivity specimens sampled from SD-9 (Rautman and Engstrom 1996 [DIRS 100642], Figure 11) with the corresponding information for SD-7 (Rautman and Engstrom 1996 [DIRS 101008], Figure 9)).

\subsubsection{Porosity as a Surrogate}

A fundamental limitation of the rock properties modeling effort clearly is the use of porosity as a surrogate for derivative properties of more general interest to design and performance assessment analysts (Section 5). These derivative properties, such as matrix saturated hydraulic conductivity, are related to the principal modeled property only through a correlation coefficient, generally indicated as $r$. To the extent that the absolute value of $r$ is less than one (recall that $r=-1.0$ implies a perfect inverse relationship), this modeling of a surrogate thus increases the uncertainty in the secondary properties. Nevertheless, use of a nonzero correlation coefficient combined with incorporation of spatial correlation in the modeling of those secondary properties works to decrease uncertainty in those secondary properties. This is in contrast to modeling methodologies that discount either or both of these observable statistical characteristics. Knowing that a particular region exhibits high porosity values most likely translates to higher-than-average matrix permeability in the same region (a positive $r$-value). However, actual measured values of derivative properties are not reproduced within the simulated (coregionalized) models in the same manner that measured porosity values located at a grid node are reproduced by construction. Again, the real issue is whether the modeled uncertainty in material properties translates to unacceptable uncertainty in an objective performance measure when evaluated over a number of statistically indistinguishable simulated models (Figure 6.3-1). 
Another limitation induced by the modeling process into the rock properties models through the porosity-as-a-surrogate mechanism involves those hydraulic conductivity values that are not correlated with porosity. Flint (1998 [DIRS 100033], Figures 12(a) and (b)) describes a group of low-porosity samples that exhibit apparently random permeabilities with respect to their uniformly low porosity values, and Flint interprets these samples as exhibiting behavior consistent with the existence of microfractures, largely in vitrophyric rocks (lithostratigraphic units Tptrv1 and Tptpv3). The implication is that the permeability measured is not truly a matrix property, even though microfracture-related flow is measurable at the core scale. These erratic, out-of-porosity-character permeability values have been modeled as a random overprint imposed only on extremely low-porosity $(<0.05$ ) grid nodes (interpreted as representing vitrophyre). Because the entire sampled population of microfractured "vitrophyre-like" samples consists of a mere dozen or so individuals, it is simply impossible to determine if these values are spatially correlated in their own right. However, to the extent that the measured data truly represent vitrophyre as a rock type (geologically restricted to the upper (Tptrv1) and lower (Tptpv3) margins of the TSw unit), it is thus possible to generate microfractured permeability values at inappropriate spatial locations within the TSw model unit. This limitation is presumed to be relatively minor, as the restriction of generating these values to extremely low-porosity grid nodes (typically between five and seven percent of the TSw grid) suggests that such rocks might be susceptible to microfracturing even though they would not belong to the vitrophyre-type small-scale lithostratigraphic units (see also Flint 1998 [DIRS 100033], Figures 12(a) and (b)). Additionally, conditioning of the interior of the TSw model unit to porosity values substantially in excess of 0.05 produces models that are very unlikely to exhibit extremely low porosity values except near the margins where measured porosities of this magnitude are observed.

A similar limitation affects the modeling of altered hydraulic conductivity values within the CHn and Tcp model units. Although the style of hydrous-mineral-phase alteration responsible for these reduced matrix permeability values is clearly correlated spatially (Section 6.4.7.2), it is unclear whether the permeability values themselves within those altered regions are correlated. Adequate, spatially distributed measured $K_{s}$ data do not exist to provide an estimate of the spatial correlation structure of permeability itself in these materials. In any event, as there is no reliable relationship between porosity and matrix permeability for these altered specimens, it is unclear what would serve as a surrogate for modeling spatial continuity for these materials. Accordingly, the spatial distribution of altered permeability has been treated as random within the spatial envelope of altered rocks, and the affected grid nodes merely assigned values sampled from a normal population with the appropriate mean and variance. To the extent that altered permeabilities are, in fact, spatially correlated, this modeling approach increases uncertainty. Across the full suite of simulated models, however, the variability of rock properties (and presumably of process modeling results as well) is likely to be greater than had the properties been spatially correlated, thus allowing a quantitative evaluation of the consequences of that increased space of uncertainty.

\subsubsection{Underestimation of Porosity and Hydraulic Conductivity in the TSw Model Unit}

Another limitation related to the use of porosity as a surrogate for hydraulic conductivity affects modeling of parts of the TSw model unit. Recall from Section 6.4.4.2 that for noncored drill holes in this model unit, the available petrophysical data were able to provide only an estimate of lithophysal porosity, because the density logging tool is sensitive to the total amount of void 
space in the rock mass, including the influence of large lithophysal cavities. Accordingly, a surrogate for porosity-as-a-surrogate was adopted whereby the water-filled porosity data from the computed VWC trace were inserted into the matrix porosity data files for the named lithophysal zones only. Because matrix saturations, particularly in the crystal-rich lithophysal zone (Tptrl) and crystal-poor upper lithophysal zone (Tptpul) are less than one where these units are present above the static water level, substitution of the VWC data for matrix porosity underestimates the true matrix porosity (such as would be obtained from core) of the rock (see Figure 6.4-9). Coregionalization of matrix saturated hydraulic conductivity from porosity models conditioned to these lowered matrix porosity data produces models of $K_{s}$ that are systematically low in localized regions.

The impact of this limitation on the overall material property models is limited. First, the effect is limited almost exclusively to the upper lithophysal intervals (Tptrl and Tptpul), as matrix saturations within the crystal-poor lower lithophysal zone (Tptpll) are typically sufficiently high that there is little mismatch between measured core porosity values and the water-filled porosity (VWC) measurements (see Figure 6.4-9). Second, the matter becomes an issue only for areas populated by noncored drill holes. The immediate Yucca Mountain-ESF area is dominated by drill holes for which core samples were obtained (Figure 6.4-2). Close within the range of influence of these cored holes, the porosity (and hydraulic conductivity) models are strongly conditioned by the presence of laboratory measured matrix porosity data. Furthermore, examination of Figure 6.4-2 indicates that the principal holes lacking core, the WT- series, are located primarily in regions near the periphery or surrounding the volume modeled by the rock properties model. It is presumed that these regions are of less direct interest in the evaluation of the Yucca Mountain site. Third, the additional uncertainty caused by this substitution of VWC data for measured matrix porosity values has already been incorporated into the simulated models. For regions near the main part of the ESF where noncored drill holes (such as H-5, Figure 6.4-2) compete with cored holes (e.g., SD-9), any discordance between the laboratory measurements and the VWC substitute will result in the simulation algorithm generating a wider range of simulated values (in the appropriate stratigraphic interval) than would be the case in the absence of that discordance. The space of uncertainty, as measured across the suite of simulations (Figure 6.3-1), has been increased, which is a realistic reflection of the state of knowledge associated with the limitations imposed by the use of noncore drilling techniques: the matrix porosity is unknown.

\subsubsection{Use of Major Stratigraphic Units as Modeling Units}

A quite different, but potentially significant limitation of the approach used in development of the rock properties model is the use of composite major stratigraphic intervals and an internal stratigraphic coordinate system as the geometric basis for modeling. There are only four such model units; compare these to the virtual plethora of different lithostratigraphic units tabulated in Table 6.1-1. To the extent that the stratigraphic coordinate transformation for each of these major modeling units does not reposition equivalent parts of the model unit at the same stratigraphic position, the model simulates continuity (improperly) between rocks formed at significantly different pressure-temperature conditions. This will create an increase of uncertainty across the suite of replicate simulations as the simulation algorithm tries to resolve any inconsistency of the measured material properties in between drill hole locations. 
This limitation is probably of minimal effect within the major ash-flow units at Yucca Mountain, particularly for the Topopah Spring welded unit, which was effectively an instantaneous deposit of massive proportions. Although the rock unit thins southward away from its source, the same physical/chemical conditions responsible for the ultimate physical properties of the rock almost certainly varied with relative vertical position within the cooling rock mass. The same logical argument applies to a large extent to the Prow Pass Tuff modeling unit, and (to a lesser degree) to the multiple-cooling-unit Calico Hills nonwelded interval.

The PTn modeling interval contains two distinctly different, significant if only locally, developed pyroclastic-flow deposits (the Pah Canyon and Yucca Mountain Tuffs), separated by intervals of unrelated and even reworked volcanic materials. The decision to model a single PTn entity is based on two factors. First, in general, the properties of the rocks within the PTn unit are quite similar (almost all nonwelded tuffaceous materials, particularly within the region transected by the main part of the ESF), and especially in comparison with overlying and underlying materials. Second, the individual genetic units are typically very thin, leading not only to a vastly increased bookkeeping task for selecting and tracking sample data but-more importantly—to markedly reduced statistical mass relevant to any one unit. Ultimately the choice to represent the PTn model unit as a whole was a pragmatic determination, presumably suitable for modeling at the site scale.

\subsubsection{Faulting, Erosion, and the Stratigraphic Coordinate System}

Another limitation related to the use of a stratigraphic coordinate system is that the presence of erosional unconformities or within-unit faulting will work to confound the petrologic and material-property equivalence of rocks assigned the same stratigraphic (vertical) coordinates. Faults are known to affect several of the drill holes at Yucca Mountain, specifically WT-1, WT-11, ONC-1, and UZ-7a. Drill hole p\#1 is affected by erosion, and Moyer and Geslin (1995 [DIRS 101269], pp. 8 to 31) report progressive lateral truncation of inferred depositional units within the Calico Hills Formation and Prow Pass Tuff across the model area. The effects of fault displacements have been included in the computation of stratigraphic coordinates based on the best available information, and in all cases, this compensation involves the same separations and uncertainties as the GFM (GFM 3.0). The locations and extents of erosional complexities are probably less well constrained than the effects of faulting. However, in all cases, there should be no discontinuities between the adjustments to stratigraphic coordinates applied to the rock properties modeling effort and the representation of the GFM.

A factor working to offset uncertainties related to the stratigraphic coordinate transformation is that all of the properties modeling activities were conducted within that conceptual and mathematical framework. Specifically, the quantitative description of spatial correlation behavior (variograms) was conducted after conversion to stratigraphic coordinates. If undetected faulting or erosion worked to juxtapose samples of differing rock properties, the observed range of spatial correlation should be reduced, and this higher lateral variability would be reflected in the simulated property models. For a given set of conditioning data, a lesser degree of spatial correlation will also translate into more variability across the suite of realizations, and thus more uncertainty is (accurately) reflected in the suite of simulated models. 


\subsubsection{Stochastic Uncertainty Assessment}

The entire rock properties modeling effort has been designed as one method for quantifying the geologic uncertainty - that which results from less-than-exhaustive site characterization-in the material properties used in downstream design and performance assessment analyses. The stochastic simulation process is intended to generate an arbitrary number of individual rock property models, each one of which reproduces the measured site characterization data and exhibits the full range of heterogeneity and spatial continuity observed in those data. This uncertainty in material properties then must be propagated into uncertainty in some particular performance measure, through some relevant consequence analysis, as depicted in the conceptual representation of a Monte Carlo modeling process presented in Figure 6.3-1.

Because the emphasis in a geostatistical modeling analysis such as this one is on the joint characteristics of heterogeneity and spatial continuity, it logically follows that estimates of uncertainty are spatially variable as well. By theory and intuition, uncertainty as a statement of confidence is low in the immediate vicinity of observations, where the effect of conditioning the simulated models to measured property values leads to the construction of well-constrained probability density functions. At great distances from measured values, the probability density functions are less well constrained, which leads to the generation of more disparate values when considered across a suite of simulations. The space of uncertainty is greater. However, even at these locations, there is the constraint imposed by the statistical character of the data ensemble as a whole. At a minimum the unconditional probability density function is effectively equal to the histogram of all relevant measured values, in contrast to the uniform distribution of all physically possible values.

The influence of spatial correlation in the modeling process further works to reduce uncertainty, regardless of the presence or absence of observed information in the vicinity. Because the simulated models are built sequentially, inclusion of previously simulated grid nodes in the local search neighborhood used in constructing the probability density function means that low values are likely to be generated in the vicinity of other low values and high values are likely to be generated near other highs. Note, however, that this relationship is not absolute. Because the value at each simulated grid node is derived by random sampling from the relevant probability density function, there is a finite chance within any one realization at each node of generating an unusual value from the tails of the distribution. Because the properties at any unsampled location are, in fact, not known, it is possible that the true property value might be quite different from the expectation. Across multiple simulations, it is therefore possible to account quantitatively for the performance or design consequences of that uncertainty by propagating variations in input properties through numerical process models to describe uncertainty in performance measures (Figure 6.3-1).

\subsubsection{Expectations versus Individual Outcomes}

These comments regarding the representation of spatial uncertainty related to less-than-exhaustive site characterization apply to the individual stochastically simulated rock property models. In addition to these individual simulations or outcomes, summary type models have been created that correspond to the mathematical expectation of a probability distribution. These summary models were generated by computing the node-by-node arithmetic mean value 
of the suite of individual simulations (50 in the present case), and these are typically referred to as E-type models.

Note, however, that simply because a value is mathematically the "most likely" does not mean that value is the appropriate value to use for a particular purpose. In fact, the "expected" value may be a very unlikely value for any actual realization or outcome. The mathematical expectation of one-half where zero is "heads" and one is "tails" does not mean that the result of tossing a coin is "most likely" to be standing on edge. In similar manner, an expected porosity value of 0.20 at a particular grid location does not necessarily imply that 0.20 is the value of porosity that should be entered into a numerical flow-and-transport model at this location. It means that over a (large) number of individual simulated outcomes, the average simulated porosity at the location, individual values of which may have varied from 5 to 45 percent, was 0.20 . Those simulated values were discarded in the summary process.

The limitations of E-type models, which are in common with the shortcomings of most interpolation-type modeling algorithms in representing the real world, are fairly well known. For example, the range of variability is always reduced with respect to variability of the input data (the so-called smoothing effect). Modeled values outside the limits of the measured values generally are impossible, even though it is rather unlikely that physical sampling has actually encountered the absolute highest or lowest value present in the real world. Also, the apparent strength of spatial correlation is typically much greater (a consequence of smoothing). And finally, the consequences of applying a numerical physical-process algorithm to a smoothed input property field may be very different from the results of applying that same algorithm to one (or more) of the underlying more realistically varying individual "outcome" models. This effect may be particularly important in performance assessment analyses, for which the "expected" behavior of the physical system is of less interest than high-consequence/low probability events representing the tails of a probability density function. Also, the flow consequences of smoothly varying (i.e., continuous) material properties may be quite different than the consequences of a more heterogeneous property representation.

\subsubsection{Summary Uncertainty Models}

Uncertainty in rock material properties should be evaluated rigorously in terms of the consequences of that variability on a particular computed performance measure. However, the postprocessing step that produces the E-type models is easily adapted to generate models of spatially distributed variability across the suite of simulations. Such a spatially varying representation may be thought of as a first-order "uncertainty model."

This type of summary model has been generated for this modeling activity as the node-by-node standard deviations of the 50 individual simulated rock property models. There is no particular reason to prefer the standard deviation approach other than general user familiarity. It would also be possible to represent in one summary model the variability of individual stochastic simulations through use of the inter-quartile range or the tenth-to-ninetieth-percentile difference. In almost any such uncertainty model, the magnitude of the spatially varying uncertainty will decrease effectively to zero at sample locations and increase to some maximum value at great distances from conditioning samples or in close proximity to samples exhibiting conflicting 
values. In all cases, it is important to separate conceptually the difference between spatial heterogeneity and uncertainty.

PTn Model Unit-A block view of the PTn model unit in stratigraphic coordinates is presented in Figure 6.6-1 showing the uncertainty model of porosity for this unit. Uncertainty is generally low (shown in blue colors) in the immediate vicinity of drill holes containing conditioning measurements (Figure 6.4-1), and increases to higher values away from these locations. Uncertainty is spatially heterogeneous within the model as well. However, because most drill holes penetrate most of each unit, the general pattern of heterogeneity in uncertainty will be that exhibited on the top surface of the model unit.

TSw Model Unit-Block models presenting the uncertainty models of matrix and lithophysal porosity in the TSw model unit are presented in Figures 6.6-2 and 6.6-3, respectively. Uncertainty in the figures is calculated as the node-by-node standard deviation of the replicate simulated material property models. As anticipated, uncertainty is lowest in the vicinity of drill holes containing conditioning measurements (Figure 6.4-2), and it increases away from those drill hole locations. Note that there are slight differences in the uncertainty models for matrix and lithophysal porosity, even though drill hole coverage at this stratigraphic level is essentially identical. As is typical in many real-world data sets, the variance (standard deviation) is a function of the magnitude of the variable under consideration.

CHn Model Unit-The uncertainty model for matrix porosity in the CHn model unit is presented in Figure 6.6-4, again as the node-by-node standard deviation of the 50 replicate simulated models of this property. Low values of uncertainty are indicated by the shades of blue, and these regions are associated with the drill holes containing conditioning data that penetrate this model unit (Figure 6.4-3). Spatial heterogeneity of uncertainty can be seen on the front face of the block model. However, the dominant pattern of uncertainty will be vertically downward associated with the vertical drill holes.

Tcp Model Unit-A block view of uncertainty in matrix porosity for the Tcp model unit, as computed as the standard deviation of the replicate simulated models, is presented in Figure 6.6-5. Uncertainty is lowest in the immediate vicinity of the drill holes penetrating this unit (Figure 6.4-4), and increases away from these locations of conditioning data. It is interesting to note the marked increase in uncertainty within the Tcp model unit, in comparison with the uncertainty model for the CHn model unit presented previously in Figure 6.6-4. This increase is most noticeable in the northeast corner of the modeled volume (note also the increase in the maximum value of the standard deviation in these two figures, colored red on the color scale). The cause of this marked change in uncertainty is the loss of drill hole WT-16 from the Tcp data set (compare Figures 6.4-3 and 6.4-4, showing the drill hole locations). Additional increases in modeled uncertainty, particularly in the eastern portion of the area, in the Tcp model unit result from the loss of drill holes WT-14 and WT-15 (outside the modeled volume) and drill hole ONC-1 (within the volume). 


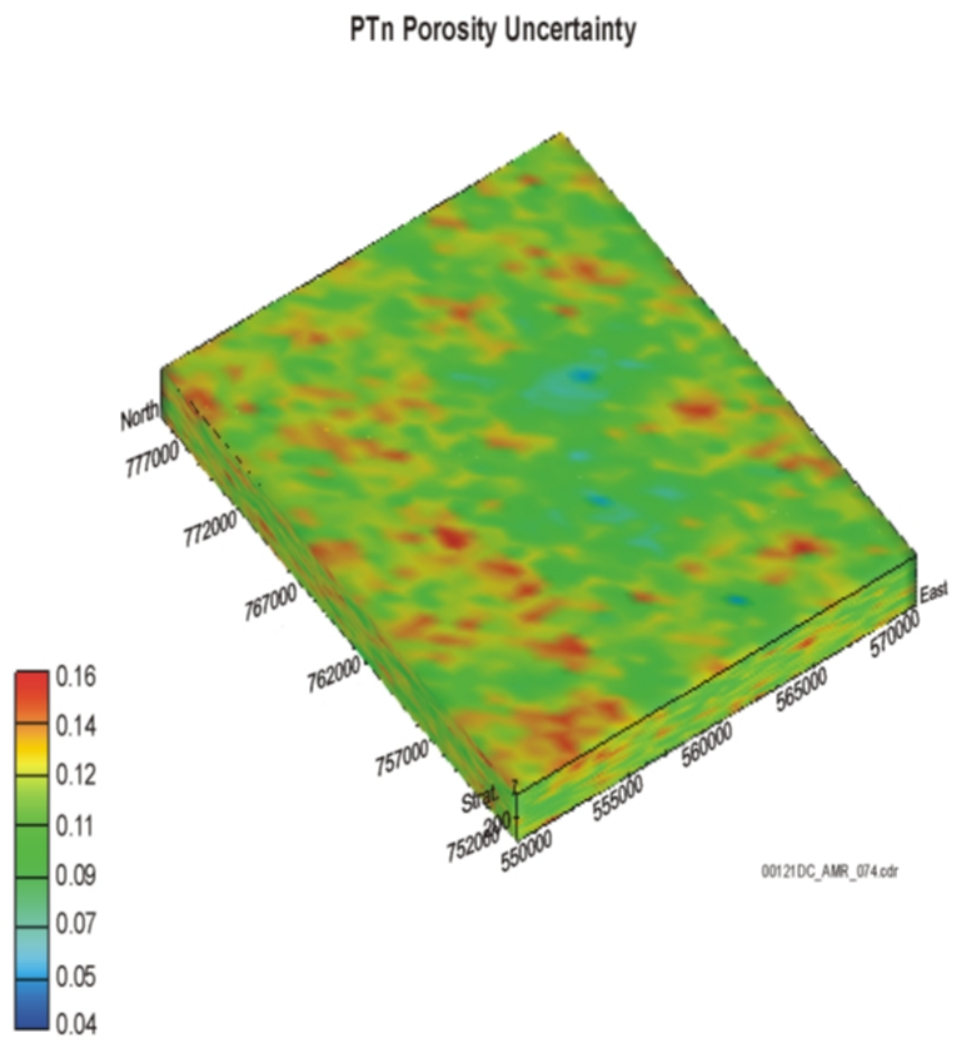

Source: SN9910T0501399.001 [DIRS 129717].

NOTE: Color scale is in porosity units as a fraction. Vertical exaggeration 10x.

Figure 6.6-1. Uncertainty Model Showing E-Type Standard Deviation of Matrix Porosity in the PTn Model Unit 


\section{TSw Matrix Porosity Uncertainty}

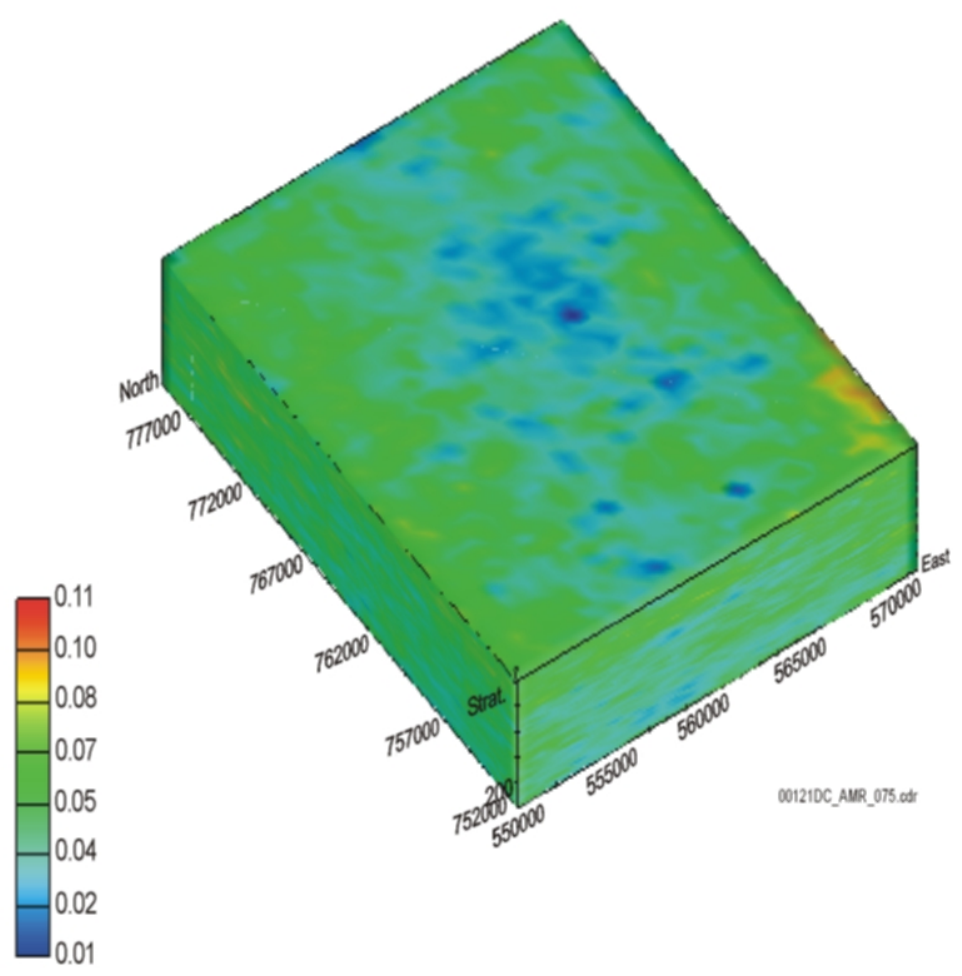

Source: SN9910T0501399.001 [DIRS 129717].

NOTE: Color scale is in porosity units as a fraction. Vertical exaggeration 10x.

Figure 6.6-2. Uncertainty Model Showing E-Type Standard Deviation of Matrix Porosity in the TSw Model Unit 


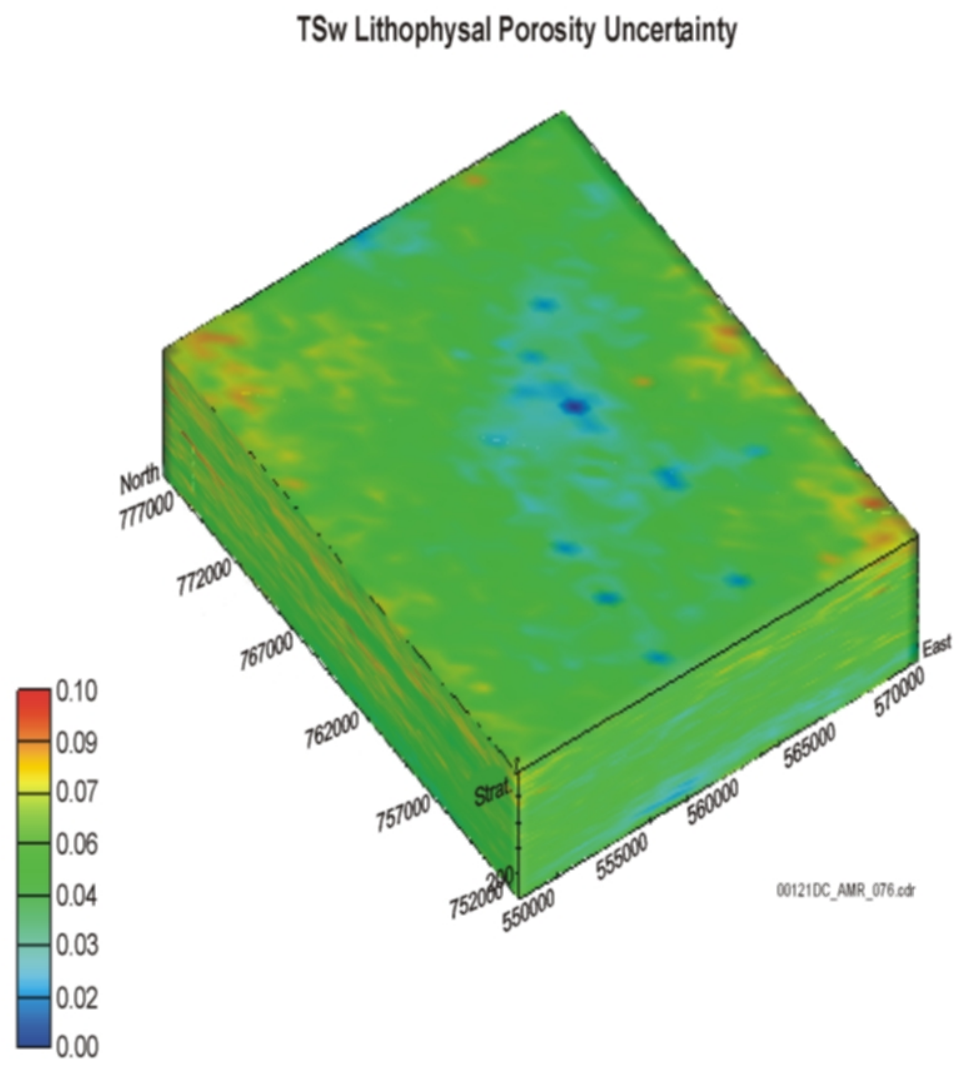

Source: SN9910T0501399.001 [DIRS 129717].

NOTE: Color scale is in porosity units as a fraction. Vertical exaggeration 10x.

Figure 6.6-3. Uncertainty Model Showing E-Type Standard Deviation of Lithophysal Porosity in the TSw Model Unit 


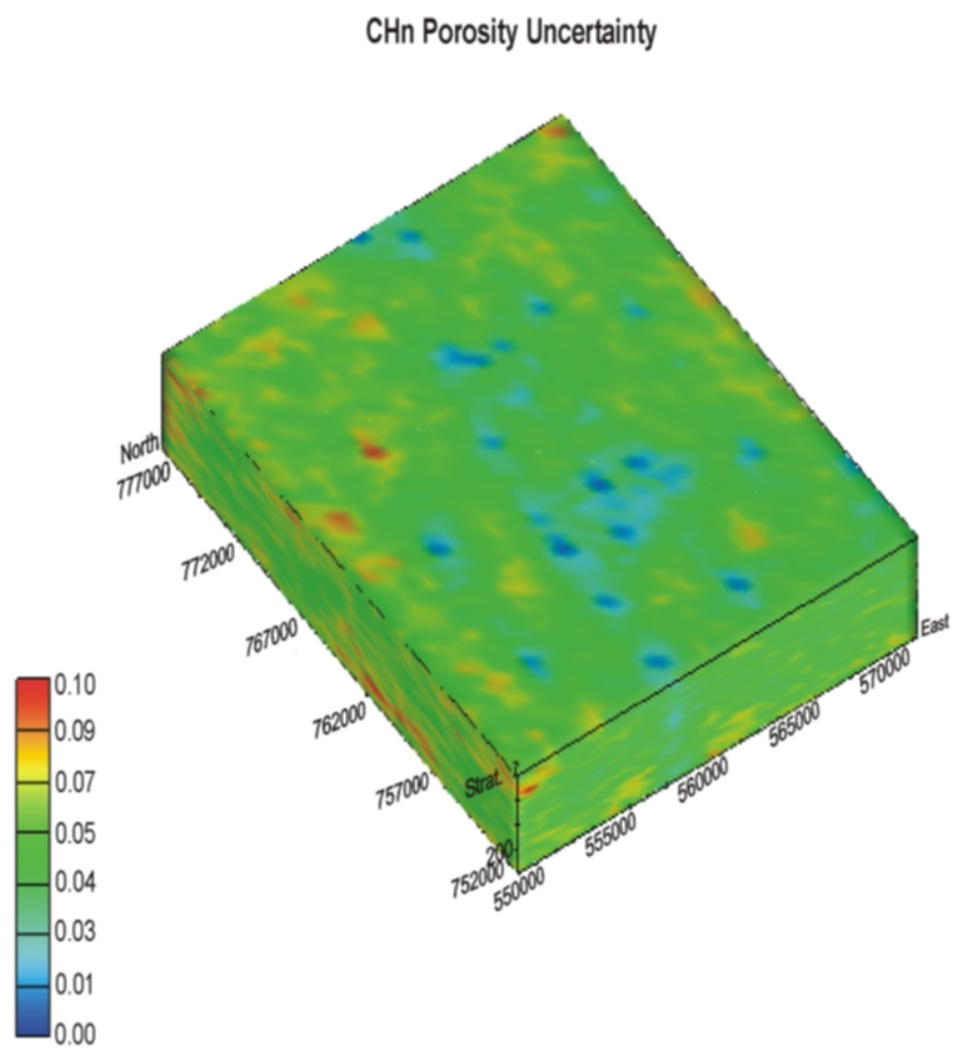

CO1210C_AUR_OTI. Cod

Source: SN9910T0501399.001 [DIRS 129717].

NOTE: Color scale is in porosity units as a fraction. Vertical exaggeration 10x.

Figure 6.6-4. Uncertainty Model Showing E-Type Standard Deviation of Matrix Porosity in the CHn Model Unit 


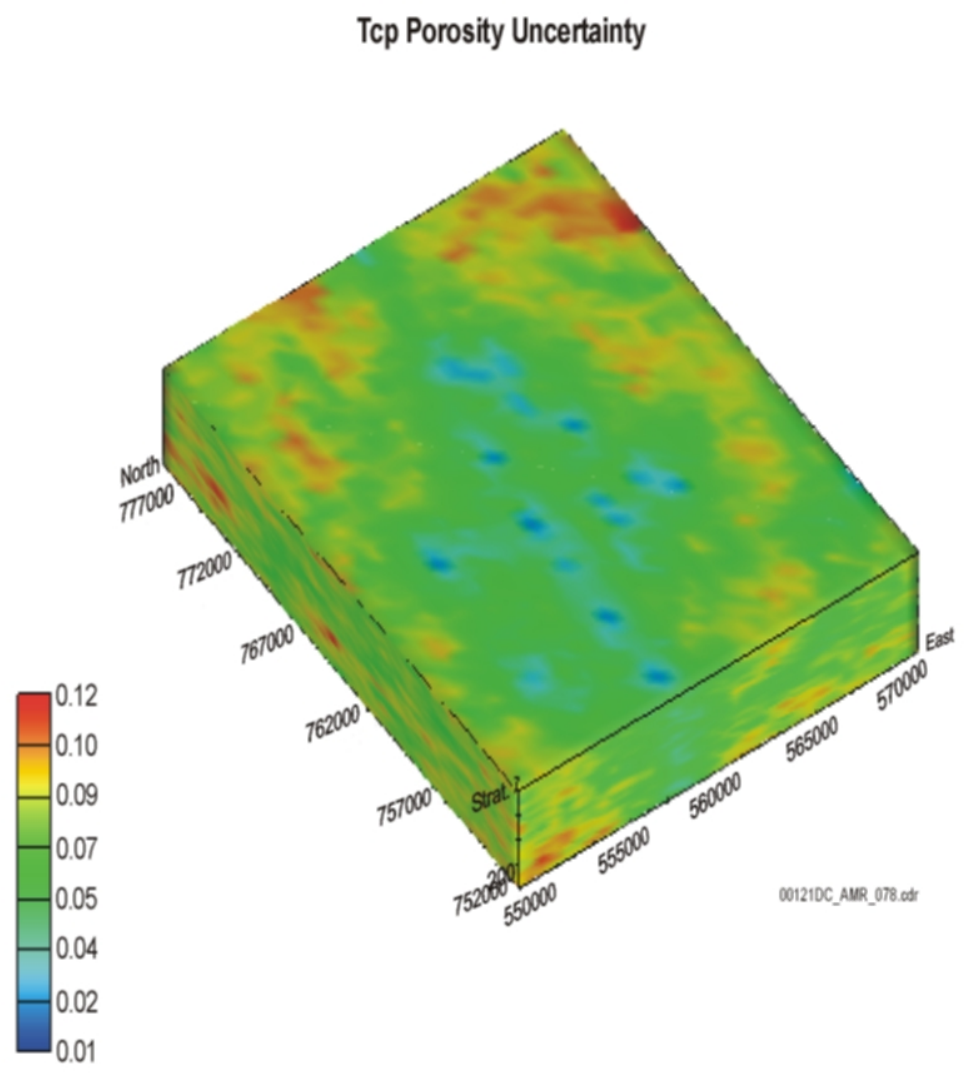

Source: SN9910T0501399.001 [DIRS 129717].

NOTE: Color scale is in porosity units as a fraction. Vertical exaggeration 10x.

Figure 6.6-5. Uncertainty Model Showing E-Type Standard Deviation of Matrix Porosity in the Tcp Model Unit 


\section{INTENTIONALLY LEFT BLANK}




\section{VALIDATION}

The purpose of this section is to validate the model by showing how the confidence building criteria were satisfied during and after model development. Section 7.1 explains how the model development process satisfies the criteria in the TWP (BSC 2004 [DIRS 169635] and AP-SIII.10Q. Section 7.2 provides a detailed discussion of the postdevelopment validation of the product output parameters: matrix and lithophysal porosity and bulk density. These validations were demonstrated with data not relied on as direct input in the construction of the model. These parameters are used by Saturated Zone Flow and Transport Model Abstraction, MDL-NBS-HS-000021, REV 02 (BSC 2004 [DIRS 170042]).

In contrast, the representations for thermal conductivity and hydraulic conductivity developed in this report are not used as direct input by project documents and will not be validated. Therefore, the representations of thermal conductivity and hydraulic conductivity developed in this report should not be cited as direct input in support of the Total System Performance Assessment for License Application (TSPA-LA). More recent representations of thermal conductivity and hydraulic conductivity are available and should be cited instead. For thermal conductivity the reader is referred to Thermal Conductivity of the Potential Repository Horizon Model Report, (BSC 2004, [DIRS 169854], Table 7-10 and Table 7-11) and Thermal Conductivity of the Non-Repository Lithostratigraphic Layers Model Report, (BSC 2004 [DIRS 170033], Table 6-13). Similarly, for hydraulic conductivity, the reader is referred to Analysis of Hydrologic Properties Data (BSC 2004 [DIRS 170038], Table 6-6).

The level of confidence required for the model validation activity for the rock property model has been determined from the guidelines in AP-2.27Q, Attachment 3, Levels of Model Importance, Validation, and Confidence to be Level I for the following reasons. Because the rock properties model does not provide any direct input to the total system performance model, its level of significance depends in part on its association with models that do provide direct input to the TSPA-LA. The rock properties model is associated with the Saturated Zone Flow and Transport Model Abstraction MDL-NBS-HS-000021, REV 01 (BSC 2003 [DIRS 167651]) which is a direct feed to the TSPA-LA. The Saturated Zone Flow and Transport Model Abstraction has been identified as Level II in Table 1 of AP-2.27Q. However, the Saturated Zone Flow and Transport Model Abstract is insensitive to the rock properties model parameters cited when compared to the models overal uncertainty. Citation of the rock properties model parameters are as mean values and used as deterministic or constant values. Accordingly validation Level I applies.

\subsection{CONFIDENCE BUILDING DURING MODEL DEVELOPMENT}

For Level I validation, Section 2.2.3 of TWP-NBS-GS-000003 REV 05 (BSC 2004 [DIRS 169635]) specifies the following steps for 'Confidence Building During Model Development'. The development of the model should be documented in accordance with the requirements of Section 5.3.2(b) of AP-SIII.10Q. Attachment 3 of AP-2.27Q also provides model validation guidance that is documented in the TWP (BSC 2004 [DIRS 169635] Section 2.2.3). 
The development of the rock properties model has been conducted according to these criteria, as follows:

1. Selection of input parameters and/or input data, and a discussion of how the selection process builds confidence in the model [AP-SIII.10 Q, 5.3.2(b) (1) and AP-2.27Q, Attachment 3 Level I (a)].

The seven classes of data used as inputs to the rock properties model have all been obtained from controlled sources (see Section 4.1, Tables 4-1 through 4-7). Each of the seven classes of data are described and discussed in Section 4.1. Each discussion documents the data attributes that were the basis for their selection as model inputs. All input data are qualified. Two data qualification activities were conducted for the XRD mineral abundance data. See Section 4.1.4, Steinborn 2002 [DIRS 160702]), and Appendix E through $\mathrm{H}$.

Porosity has been used as a surrogate parameter for parameters of interest. The basis for this is discussed in Section 5. More broadly the use of scientifically acceptable concepts to construct a rock property model which addresses heterogeneity and uncertainty in ways that make the model adequate for its intended purposes are discussed in detail in Sections 6.3 and 6.4.

For these reasons, the process for selecting input parameters meets the applicable criteria and, thus builds confidence in the model.

2. Description of calibration activities, and/or initial boundary condition runs, and/or run convergences, simulation conditions set up to span the range of intended use and avoid inconsistent outputs, and a discussion of how the activity or activities build confidence in the model. Inclusion of a discussion of impacts of any non-convergence runs [AP-SIII.10Q , 5.3.2(b)(2) and AP-2.27Q, Attachment 3 Level I (e)].

Calibration related activities for the rock properties model, including the extensive processing of data to prepare it to support calibration are discussed in detail in Section 6.4. Section 6.4 documents the spatial character and correlation of the input parameters modeled used to develop the model results. Section 6.4.1 and 6.4.2 discuss the model domain boundaries and subdivisions, respectively. Section 6.4.3 describes the basis for selecting the appropriate data and the processes used to process that data for use. Section 6.4.4 discusses porosity, and Section 6.4.5 discusses the secondary parameters matrix saturated hydraulic conductivity, bulk density, and thermal conductivity.

Discussion about nonconvergence runs is not relevant for this model report.

For these reasons, the process for selecting input parameters meets the applicable criteria and, thus builds confidence in the model.

3. Discussion of the impacts of uncertainties to the model results including how the model results represent the range of possible outcomes consistent with important 
uncertainties (AP-SIII.10 Q, 5.3.2(b)(3) and AP-2.27Q, Attachment 3 Level 1 (d) and $(f)$ ).

The impacts of model uncertainties and limitations on model results are provided in Section 6.6 and 8.2. The primary uncertainties are intrinsic to the input data or the modeling methodology. Measurement errors are shown in Section 6.6.1.1 and do not significantly affect the model results because they are small compared with the lateral heterogeneity of the rock mass. Known systematic biases in measured values do not significantly affect the model results because the biases are compensated for as described in Section 6.6.1.1. Methods and/or reasons that support a decrease in the possible uncertainties and limitations resulting from the use of porosity as a surrogate for other rock properties are discussed in Sections 6.6.1.2 and 6.6.1.3. Methods and/or reasons that support a decrease in the possible uncertainties and limitations resulting from the use of stratigraphic coordinates are discussed in Sections 6.6.1.4 and 6.6.1.5. Finally, as discussed in Section 6.6.2, uncertainty models are provided for use in calculations.

A summary discussion on uncertainties and their impact is given in Section 8.2. That section explains that the rock properties model is not intended to make locationspecific predictions of rock properties. Rather, it is intended to provide a suite of equally plausible, realistic models which collectively describe the space of uncertainty for the relevant material properties and which can be used in Monte Carlo-style flow and transport calculations.

For these reasons, the impacts of model uncertainties on model results and the range of possible outcomes consistent with important uncertainties have been adequately addressed to meet the applicable criteria and build confidence in the model.

4. Formulation of defensible assumptions and simplifications [AP-2.27Q, Attachment 3 Level I (b)].

The basic assumption for this model is the use of porosity as a surrogate to model the other rock properties of interest. Section 5 provides a defensible justification for this assumption. Accordingly, this criterion is met in a way that builds confidence in the model.

5. Consistency with physical principles, such as conservation of mass, energy, and momentum [AP-2.27Q , Attachment 3 Level I (c)].

Because the rock properties model is a static representational model, consistency with physical principles is expressed through the use of standard geostatistical methods rather than dynamic equations expressing mass; energy and momentum. The model is consistent with applicable geologic and geostatistical principles. These principles and their applicability are discussed in Sections 6.1 and 6.2. 


\subsection{CONFIDENCE BUILDING AFTER MODEL DEVELOPMENT TO SUPPORT THE SCIENTIFIC BASIS OF THE MODEL}

For confidence building after model development TWP-NBS-GS-000003 REV 05 (BSC 2004 [DIRS 169635]), Section 2.2.3 imposes the following requirements for model validation for matrix porosity, lithophysal porosity, and bulk density.

\subsubsection{Validation: Matrix Porosity}

The purpose of this section is to validate the model by corroborating the model output representation of matrix porosity with data not cited as direct input. The product output values for the mean matrix porosity values for the model layers are listed in Table 6.4-2 and provided by DTN: SN0004T0501399.003 [DIRS 155045]. The difference between matrix and lithophysal porosity are discussed in Section 6.4.4.2 and illustrated by Figure 6.4-9. The planned approach for validation is corroboration with data that were not used as direct input in the development of the product output of this report. The explicit criterion for successful validation is that the mean value calculated for the corroborating data set should fall within the range defined by the mean value and standard deviation for the model layers listed in Table 6.4-2.

The corroborative data used to validate the model are presented in Table 7-1. The matrix porosity and bulk density data were obtained from laboratory measurements on core samples. As shown in Table 6.1-1 the Tptpll zone is part of the TSw model layer. Therefore, the mean matrix porosity value calculated from DTN: SN0209L01A1202.001 [DIRS 163601] will be compared to the range for the TSw model layer in Table 6.4-2.

Table 7-1. Matrix Porosity and Bulk Density Data Supporting Model Validation

\begin{tabular}{|l|c|}
\hline \multicolumn{1}{|c|}{ Data Source Description } & \multicolumn{1}{c|}{ Reference } \\
\hline $\begin{array}{l}\text { Corroborative matrix porosity and bulk } \\
\text { density data }\end{array}$ & DTN: SN0209L01A1202.001 [DIRS 163601] \\
\hline
\end{tabular}

DIRS = Document Input Reference System; DTN=data tracking number.

The mean value obtained from DTN: SN0209L01A1202.001 [DIRS 163601] is 11.5 percent with a standard deviation of 2.7 percent. The range for the TSw model layer defined by the DTN: SN0004T0501399.003 [DIRS 155045] is based on the mean value of 12.2 percent and a standard deviation of 6.1 percent. Therefore, the validation range for the TSw model layer is 6.1 to 18.3 percent. The mean value of the corroborating data fall within the range specified by the validation criterion, therefore this validation is determined to be successful.

This validation is deemed to be adequate and accurate for the following reasons: First, regardless of the range of validation the corroborative and model mean values are very close, 11.5 percent compared to 12.2 percent, respectively. The range of analytical uncertainty for porosity is 1 percent porosity (or one porosity unit 0.01) (Brodsky, 2003 [DIRS 164584]). Therefore, the difference between the two calculated means is within the analytical uncertainty for the parameter. Second, this result is not unanticipated, as the matrix porosity values for the TSw layer (Tptprn to Tptpln) obtained by measurement on core samples or calculated from borehole geophysical data are very consistent. This is illustrated in Figure 6.4-9 that shows the overall consistency in matrix porosity values. Third, the mean values for matrix porosity are 
based on values directly measured from core samples (Table 3-2). These data are qualified and verified and are either supported by a records package or data qualification report that establishes that its adequate for its intended use.

Note that although this validation is only performed for the TSw model layer, it is appropriate to extend it as supporting the validation of the other model layers because all the data used in this corroboration are measured values of matrix porosity. For example, because all the data are measured values and the measurement of matrix porosity on core samples is relatively standardized, differences would most likely indicate differences in sampling. Although a similar corroborative validation could be performed for the other model layers, the known heterogeneity observed in the PTn and CHn layers makes it more appropriate to compare the corroborative data to the matrix porosity histogram distributions, Figures 6.4-6 and 6.4-12, respectively. Corroboration for the Tcp model layer could be performed based on the mean value provided in Table 6.4-10, or the histogram distribution provided by Figure 6.4-14.

\subsubsection{Validation: Lithophysal Porosity}

The purpose of this section is to validate the model by corroboration of model output representation of lithophysal porosity with data not cited as direct input. The product output values for mean porosity value for the TSw layer is listed in Table 6.4.2 and provided by DTN: SN0004T0501399.003 [DIRS 155045]. The planned approach for validation is corroboration with data that were not used as direct input in the development of the product output of this report. The explicit criterion for successful validation is that the mean value calculated for the corroborating data set should fall within the range defined by the mean value and standard deviation for the model layers listed in Table 6.4-2.

The independent corroborative lithophysal porosity data are collected from the ECRB and presented in Table 7-2. Two sets of ECRB data are available for comparison. The first is provided by Mongano et al., (1999, ACC: MOL.20000324.0614 [DIRS 149850], p. 77, Figure 13), and a second is from the Drift Degradation Analysis Report, ANL-EBS-MD-000027, REV 02 (BSC 2004 [DIRS 166107], Section 6.1.2, 6.1.4.2, and Attachment XV). The lithophysal data that are presented in the Drift Degradation Analysis Report are provided by the DTN: GS021008314224.002 [DIRS 161910].

Table 7-2. Lithophysal Porosity Data Supporting Model Validation

\begin{tabular}{|l|l|}
\hline \multicolumn{1}{|c|}{ Data Source Description } & Reference \\
\hline ECRB Lithophysal porosity data & ACC: MOL.20000324.0614 [DIRS 149850] \\
\hline ECRB Lithophysal porosity data & DTN: GS021008314224.002 [DIRS 161910] \\
\hline
\end{tabular}

ACC = Accession Number; ECRB = Enhanced Characterization of the Repository Block; DIRS = Document Input Reference System; DTN = data tracking number

Corroborating RPM lithophysal porosity data with data acquired from the ECRB is not straightforward. The following factors that complicate the comparison:

- Direct comparison ECRB and borehole data are not possible since the ECRB is oriented horizontally, and boreholes are oriented vertically. For the most part the boreholes transect and, therefore, sample the horizontal formation completely (example, 
DTN: GS000308314211.002 [DIRS 158000]) when logged by borehole geophysical tools. However, horizontal transects, such as the ECRB, are affected by repeated sections or truncations of the formation due to faulting (Mongano et al. 1999 [DIRS 149850], Table 1 and Figure 13). The table and figure document the contact between Tptpln-Tptpul is due to the Solitario Canyon fault at Station 25+85, while the contact between Tptpul-Tptrl is due to an unnamed fault at Station 26+57.5. These faults have truncated the true section of the formations, though the amount of missing section is not provided by the reference.

- The calculation of lithophysal porosity that is presented in this report is based on data collected from borehole geophysical tools. The data acquired from the ECRB are obtained by visual observation of the tunnel surfaces. Because the density and neutron borehole tools used to calculate lithophysal porosity are known to have a "depth of investigation" into the surrounding rock, they are by definition providing an mean value of the rocks petrophysical properties (Schlumberger, 1972 [DIRS 129068]). The effect of this averaging is difficult to assess without a means of calibration, and therefore difficult to assess. It should be considered when comparing these two types of data.

- The distribution of lithophysae is not homogeneous vertically or horizontally, in the Topopah Spring Tuff. Vertically, lithophysae abundance decreases with depth within each zone of the Topopah Spring Tuff. (This is illustrated in Figure 13 from Mongano et al., 1999 [DIRS 149850]). Laterally, lithophysae abundance decreases from the central region of the modeled area as illustrated in Figure 6.5-9. This lateral decrease in lithophysal porosity is most likely related to the lateral thinning of the Topopah Spring Tuff from the central region of the model. (This is illustrated in Figure 6-15 of the Geologic Framework Model report, BSC 2004 [DIRS 170029]). Further this figure shows that the ESF and ECRB are located in a region with a thick consistent deposit of Topopah Spring Tuff. This shows that we should expect higher values of lithophysal porosity in the central regions of the model and the ESF and ECRB and that it should decrease near the margins of the modeled area.

- The mean value of lithophysal porosity for the Topopah Spring Tuff has been determined for the entire welded portion of the formation as shown in Table 6.1-1. Most other determinations of lithophysal porosity have been determined on portions of the welded Topopah Spring Tuff or analyzed based on zones of the Topopah Spring Tuff.

The results of the of lithophysal porosity measurements by Mongano et al., (1999 [DIRS 149850]) are presented in Figure 7-1. The mean value for lithophysal porosity determined from the graphical data has been calculated to be 21.3 percent (BSC 2004 [DIRS 169854], Table 7-2). The range defined by the mean value and standard deviation for lithophysal porosity in DTN: SN0004T0501399.003 [DIRS 155045]) is 7.0 to 22.2 percent. The mean value of the corroborating data set is observed to fall within the validation range for the TSw layer, therefore this validation is determined to be successful. Furthermore, the mean value for lithophysal porosity is higher for the independent corroborative data than the models mean value. Therefore, in terms of its specific use in the Saturated Zone Flow and Transport Model Abstraction, (BSC 2004 [DIRS 170042]) the models mean value is conservative when compared to the independent corroborative value when evaluating SZUZflow. 
Figure 7-2 illustrates the lithophysal porosity measurements from DTN: GS021008314224.002 [DIRS 161910], Table: S03045_001, File Name: Tptpll Litho PMap A-T-Trav L-Litho Graph.pdf. This DTN provides three measurements of lithophysal porosity, tape and angular measurements, and panel maps (DTN: GS021008314224.002 [DIRS 161910], Table Name: S03045_001, File Name: Tptpll Lithop SEP Data File.xls). The mean value for the tape measurements is 19.4 percent with a standard deviation of 10.2 percent. The mean value for the angle measurements is 15.3 percent with a standard deviation of 6.9 percent. The mean value for the panel mapping is 12.9 percent with a standard deviation of 3.6 percent. Based on the results of the angle measurements and panel maps the values for the tape measurements were then "corrected". The mean value and standard deviation for the corrected tape measurements is 13.1 and 5.3 percent, respectively (BSC 2004 [DIRS 166107], Table XV-10).

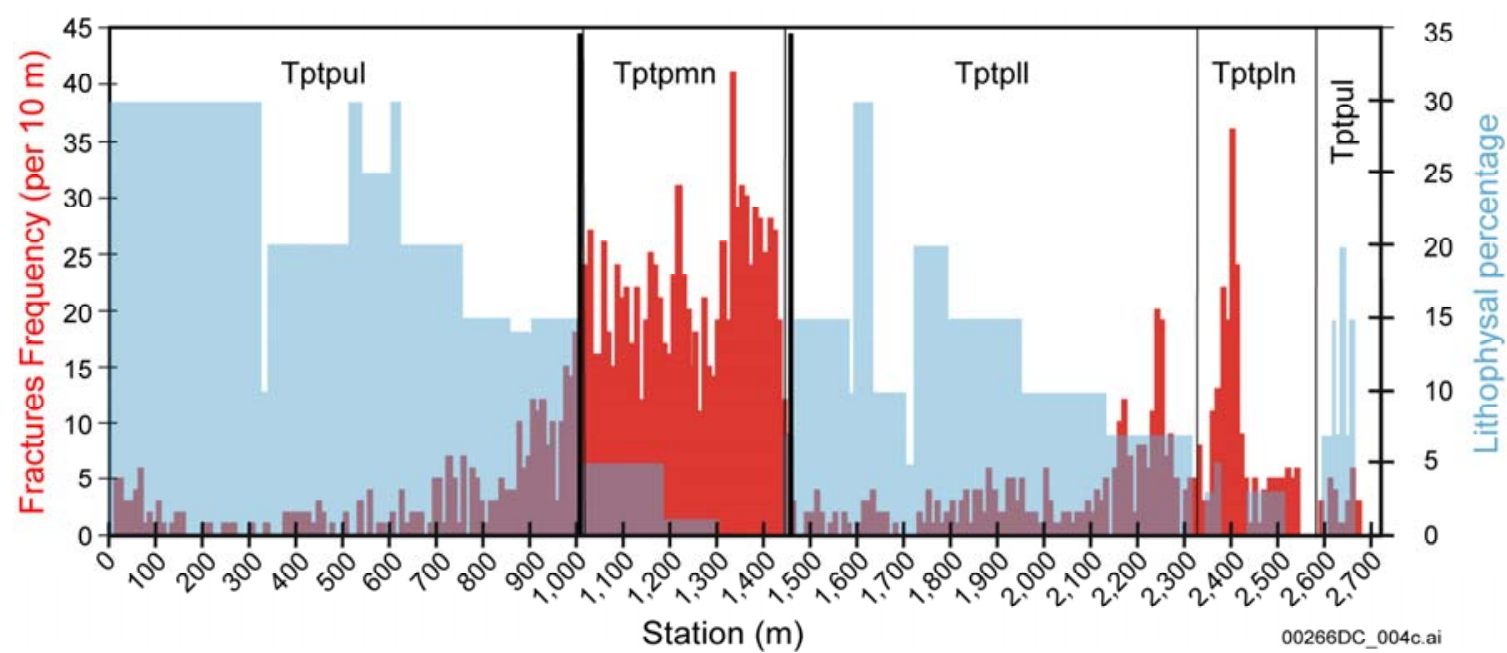

Source: Mongano et al., 1999 [DIRS 149850], Figure 13.

Figure 7-1. ECRB Lithophysal Porosity Versus Stationing

Data from panel maps, tape and angular traverses, and selected large-lithophysae inventory

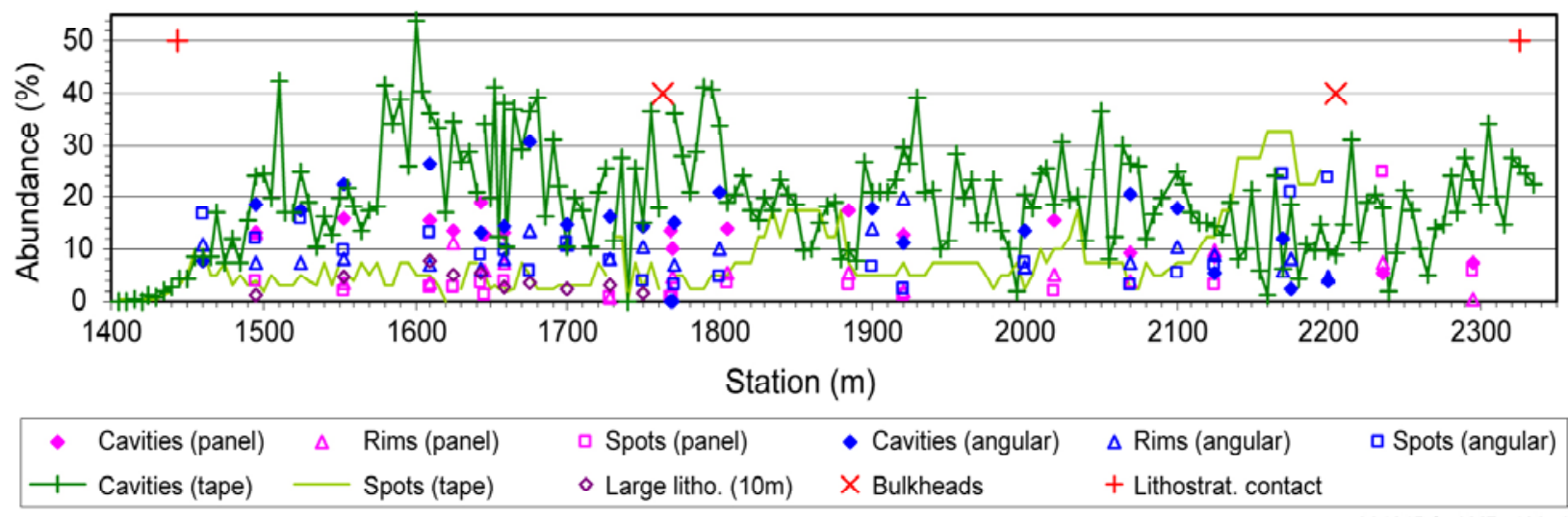

Source: GS021008314224.002 [DIRS 161910], File Name: Tptpll Litho PMap A-T-Trav L-Litho Graph.pdf

Figure 7-2. Calculated Porosity of Lithophysal Cavities Calculated By Tape, Angular, and Panel Map Measurements in the Tptpll Exposed Along the ECRB Cross-Drift 
As illustrated while the tape measurements are available for the entire exposure of the Tptpll zone the mean value of 19.4 percent is high when compared mean value observed for the entire ECRB of 21.3 percent in Mongano et al., (1999 [DIRS 149850]). This is graphically illustrated by examining Figure 7-1. It was felt that the angular traverses and panel map data were of similar resolution (BSC 2004 [DIRS 166107], Attachment XV, Section XV.1) and therefore the results of the tape measurement data were corrected (BSC 2004 [DIRS 166107], Attachment $\mathrm{XV}$, Table XV-10). This correction shifted the mean value for lithophysal porosity from 19.4 to 13.1 percent that appears to be consistent with the results provided by Mongano et al., (1999 [DIRS 149850]).

The range for validation of lithophysal porosity for the TSw layer is 7.0 to 22.2 percent. The mean values for all of the corroborating data sets are observed to fall within the range defined by model layer, therefore this validation is determined to be successful.

Prior to discussing the adequacy and accuracy of this validation the three factors listed earlier will be addressed. While the three factors complicate the corroboration they do not invalidate it. First, while faults are observed in the ECRB they occur towards the end of the tunnel and do not appear to significantly truncate the Topopah Spring Tuff zones. Second, to account for regional and stratigraphic differences in lithophysal porosity, values from the model could be extracted along the ECRB transect for comparison. However, for the purposes of validating the mean lithophysal porosity value for the TSw layer this activity was not warranted. Third, while none of the ECRB derived data samples the entire TSw model layer the data from Mangano et al., (1999 [DIRS 149850]) nearly does. Further, the examination of the Tptpll zone (BSC 2004, [DIRS 166107] and DTN: GS021008314224.002 [DIRS 161910]) provides results, which are consistent with the results of the Mongano et al., (1999 [DIRS 149850]) data.

In addition the mean value for lithophysal porosity provided by this model report is 14.6 percent. This value is used in the Saturated Zone Flow and Transport Model Abstraction, MDL-NBS-HS-000021, REV 02 (BSC 2004 [DIRS 170042]). The mean value from Mongano et al., (1999 [DIRS 149850]) is 21.3 percent. The mean value from the Drift Degradation Analysis Report (BSC 2004 [DIRS 166107]) is 13.1 percent. Therefore, the mean values for the two independent corroborating data sets bracket the value provided by this model report. The bracketing of model reports mean value by the two independent data sets provides further confidence that it is appropriate for its intended use.

This validation is deemed to be adequate and accurate for the following reasons: 1) Comparisons between the data used for corroboration with the model's product output the lithophysal porosity values and overall trends are comparable and consistent. The corroborative data are also consistent with the complicating factors that affect the distribution of lithophysal porosity; borehole versus tunnel data, vertical and lateral heterogeneity, and differing stratigraphic divisions. 2) The method of determining lithophysal porosity values differs for the model and the corroborative data set, and both are equally valid. The model's product output was calculated based on borehole geophysical data, while the corroborative data are based on physical measurements or visual observations. Both techniques are valid methods of determining lithophysal porosity. 


\subsubsection{Validation: Bulk Density}

The purpose of this section is to validate the model by corroborating the correlated relationship between porosity and bulk density illustrated in Figure 6.4-21b (DTN: SN0004T0501399.002) [DIRS 155046] with data not cited as direct input. The linear correlation shown in Figure 7-3 and the model layers average matrix porosity are used to determine the layers average bulk density in the Saturated Zone Flow and Transport Model Abstraction (BSC 2004 [DIRS 170042], Section 4.1]. The planned approach for validation is corroboration with data that were not used as direct input in the development of the product output. The explicit criterion for successful validation is if corroborating data set fall within the field defined by the data used as input or within the boundary defined by analytical uncertainty surrounding the observed field. The analytical uncertainty for porosity is defined as 1 percent porosity (or 1 porosity unit), and the uncertainty associated with bulk density is the measurement error determining its mass and volume (Brodsky 2003 [DIRS 164584]).

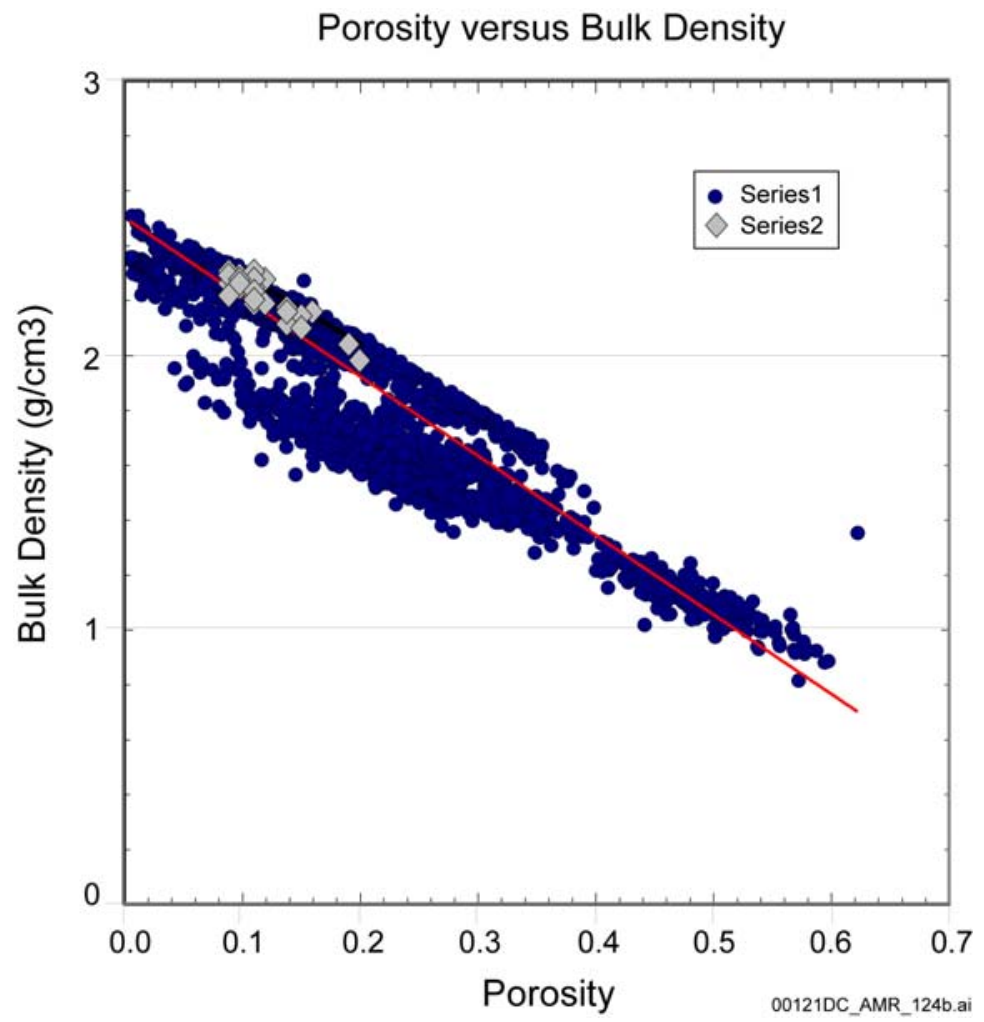

NOTE: Series 1 are data from direct input DTN: SN0004T0501399.002 [DIRS 155046]. Series 2 are corroborative data from DTN: SN0209L01A1202.001 [DIRS 163601].

Figure 7-3. Scatterplot of Bulk Density as a Function of Matrix Porosity for Corroborating and Input Data

The independent corroborative data listed in Table 7-1 (DTN: SN0209L01A1202.001 [DIRS 163601]), are used to validate bulk density and also used to validate matrix porosity. Figure 7-3 shows that the corroborative data (DTN: SN0209L01A1202.001 [DIRS 163601]) fall within the field defined by the data used to construct the model. Therefore, this validation activity is determined to be successful. 
In addition, relative to the linear correlation used to establish the layers bulk density, the corroborative data plot above the linear correlation line with higher values. Bulk density is related to the retardation factor, $R$, of a sorbing constituent as follows (Freeze and Cherry 1979 [DIRS 101173], equation 9.14):

$$
R=\frac{\bar{v}}{\bar{v}_{c}}=1+\frac{\rho_{b}}{n} * K_{d}
$$

where

$\bar{v}$ is the average linear velocity of the ground water

$\bar{v}_{c}$ is the $C / C_{0}=0.5$ point on the concentration profile of the retarded constituent (where

$C$ is the solute concentration and $C_{0}$ is the original solute concentration)

$\rho_{b}$ is the bulk density

$n$ is the porosity

$K_{d}$ is the distribution coefficient.

Equation 7-1 shows that the retardation factor decreases as the bulk density decreases. Comparing the linear correlation used to establish the bulk density for the model layers and the corroborative data, the bulk density values of the corroborative data are generally higher. Therefore, the use of the correlation line conservatively underestimates the retardation of radionuclides in the saturated zone.

While the corroborating data are observed to fall within only a portion of the field defined by the model data this validation is deemed to be adequate and accurate for the following reasons. 1) The corroborating and input data sets are all obtained by direct measurements from core samples. All of these data are qualified and verified and are either supported by a records package or data qualification report that establishes that it is adequate for its intended use. The restricted range observed for the corroborative data is indicative of the relatively low and consistent matrix porosity values observed for the Tptpll zone from which they were collected. 2) As illustrated in Figure 6.4-22b and discussed in Section 6.4.5.2 location of the Tptpll samples in Figure 7-3 are consistent with the highly densely welded TSw model units and therefore consistent with model results. The low-density samples are observed to represent nonwelded ash fall PTn samples (Figure 6.4-22a). Intermediate density nonwelded to partially welded materials are represented by the CHn and Tcp model units (Figures 6.4-22c and 6.4-22d, respectively).

\subsection{MODEL VALIDATION SUMMARY AND CONCLUSIONS}

The model validation of matrix and lithophysal porosity and bulk density met the explicit validation criteria and therefore the validation activities were determined to be successful. The model validation criteria were established in accordance with the procedural requirements based on the required level of confidence. Therefore, by process, the validation criteria met are consistent with the stated level of confidence required for the model. Further, the model product outputs were corroborated with equivalent or comparable data. This permitted a direct 
comparison with the product output that adds additional confidence that the stated validation criteria are consistent with the stated level of confidence. Activities required for confidence building during model development have also been satisfied. The model development activities and the postdevelopment validation activities described establish the scientific bases for the rock properties model. Based on this, the rock properties model is considered to be sufficiently accurate and adequate for the intended purpose and to the level of confidence required by the models relative importance to the potential performance of the repository system.

As stated in the TWP and demonstrated by the successful model validation documented in this report no future or additional validation activities are needed for this model. 


\section{INTENTIONALLY LEFT BLANK}




\section{CONCLUSIONS}

The RPM provides exhaustive, 3-D, discretized, numerical representations of several important hydrologic and thermal rock properties (porosity, bulk density, thermal conductivity, and hydraulic conductivity) that are intended for further use in numerical design and performance assessment analyses. The four composite modeling units defined for this analysis encompass the majority of the rocks within the UZ throughout the immediate vicinity of the repository at Yucca Mountain. The product output from the RPM is provided by the DTNs: SN9910T0501399.001 [DIRS 129717], SN0004T0501399.002 [DIRS 155046], and SN0004T0501399.003 [DIRS 155045]. It should be noted that as discussed in Section 7 the product output parameters matrix and lithophysal porosity and bulk density have been validated. For thermal and hydraulic conductivity the user should refer to the technical products discussed in Section 7.

There are no confirmatory actions, such as compliance runs, additional sensitivity runs, and neutralization runs contained in this model report.

\subsection{SUMMARY OF MODEL ACTIVITIES AND DESCRIPTIVE RESULTS}

Premodeling geostatistical analysis has produced a statistical and spatial continuity description of porosity for each of the four modeling units. Spatial correlation patterns are unit-specific and are relatively complex; nested variogram models were required to fit the observed continuity patterns. Spatial correlation is anisotropic, both vertically and in the stratigraphically horizontal plane. For porosity, a significant fraction of the total variability is reached within a distance of 2,000 to 6,000 feet, although another significant fraction exhibits a maximum range of between 10,000 and 38,000 feet. The spatial correlation of hydrous-phase mineral alteration was also evaluated for the lower two modeling units. Variogram patterns again are unit-specific, and the range of maximum correlation is observed to vary between 7,000 and 15,000 feet. Cross-variable correlations between porosity and the several secondary material properties have been analyzed on a global basis.

The individual model components have been constructed using geostatistical simulation methods, conditioned to drill hole-based measurements of porosity, with the result that the individual stochastic models are heterogeneous, spatially correlated, and essentially indistinguishable statistically from the set of measured values. These simulated models of porosity have been provided as input to a linear coregionalization algorithm, which has been used to generate simulated models of the derivative material properties, such as bulk density, matrix hydraulic conductivity, and thermal conductivity. These derivative property models are also spatially correlated and heterogeneous and are close statistical replicas of the set of measured secondary property data. Cross-variable correlations exist, and the strength of these correlations is approximately that described by the input sample correlation coefficients. Unit-specific postprocessing steps have been used to impart additional desired property attributes such as microfractured hydraulic conductivity associated with very low-porosity (vitrophyric) welded tuffs and different hydraulic conductivities associated with altered and unaltered nonwelded tuffs.

Sets of 50 simulations for each material property in each modeling unit have been postprocessed to provide spatially varying models of the node-by-node standard deviation of the replicate 
individual models. These representations of the spatially heterogeneous inter-simulation variability serve as a first-pass uncertainty model for each material property. The same postprocessing run has also been used to generate a summary expected-value type (E-type) model, defined as the arithmetic mean value of the 50 input replicate simulated models. Although the averaging process distorts the statistical character of the conditioning data and simulated models, these E-type models are useful for visualizing large-scale heterogeneities in material properties across the site area.

Visual examination of block diagrams and cross-sectional views through the various model components indicate that there is substantial, complex internal heterogeneity in all four modeling units, although the E-type models reveal material properties broadly compatible with the conceptual model of layered volcanic stratigraphy at Yucca Mountain. Features such as high-porosity "lithophysal" intervals that correlate approximately with formally named lithophysal zones have been generated based solely on measured porosity values. However, it can be demonstrated that such high porosity intervals exist outside the formally named zones. Matrix porosity is also higher associated with these intervals of high "lithophysal" porosity. Major heterogeneity of matrix saturated hydraulic conductivity, which reflects principally the distribution of hydrous-phase mineral alteration in the CHn and Prow Pass Tuff model units, is internally complex. Some interfingering of altered and unaltered material is indicated.

\subsection{UNCERTAINTY AND RESTRICTIONS}

The concept of "uncertainty" in terms of limitation on the "accuracy" of the RPM does not particularly apply to rock properties models in the usual sense. The intent of the rock properties modeling activities is not to make location-specific predictions, but rather to provide an entire suite of equally plausible, realistic models that collectively describes the total space of uncertainty associated with the relevant material properties. No representation is made that the individual simulated models are "accurate" (except at data locations). However, these same individual models are represented as geologically reasonable and consistent with all known information, and collectively they have been demonstrated (through validation) to be near-perfect replicas of the (geo)statistical character of the data ensemble used in their construction. It is fully intended that the consequences of the geologic uncertainty represented by the suites of models be evaluated through Monte Carlo-style flow-and-transport calculations or other suitable analyses.

Methodological uncertainties involved in the RPM include those inherent in any statistical study, and these relate principally to uncertainties (error or bias) present in the input measurements used to condition the modeling algorithms. Measurement errors are presumed to be small in comparison with spatial heterogeneity. Two instances of measurement bias have been identified, but both have been compensated for to the extent possible. Some increased uncertainty is induced in the models of derivative material properties through the use of coregionalization (the concept of porosity-as-a-surrogate, based solely on the correlation coefficient) as the modeling algorithm (in contrast to conditional cosimulation). However, because of the overall modeling focus on defining spaces of uncertainty rather than on locally "accurate" predictions, the variability across a given suite of coregionalized models will be larger than it would otherwise, and hence that increased uncertainty is already accounted for. The use of stratigraphic coordinates for modeling purposes can act to increase uncertainty in the presence of significant 
erosion within a modeling unit or in the presence of faulted sections. However, instances of these confounding geologic features are known to be relatively few in the specific rocks being modeled, and the increased precision gained by correlating materials formed under similar temperature-pressure conditions afforded by the stratigraphic-coordinate conversion overall appear to be well worth the local distortions caused by erosion and/or faulting.

Restrictions on subsequent use of the rock properties models are minimal and most are completely consistent with the Monte Carlo modeling methodology adopted as the conceptual framework for this activity. It is the individual simulated models (matched by run number across different properties to preserve the joint spatial character) that are intended for subsequent use in various relevant consequence analyses. The summary E-type models are not intended for general use in downstream analyses, except perhaps for individually justified special cases, because of their known distortion of the (geo)statistical character of the measured data.

The models are useful for the stratigraphic intervals considered. Rocks belonging to the welded portion of the Tiva Canyon Tuff, as well as overlying units, were not modeled. Neither were deeper rocks, occurring principally in the SZ at Yucca Mountain, beginning at the stratigraphic level of the Bullfrog Tuff. The models are not valid beyond the defined lateral limits of the RPM, although the (geo)statistical descriptions and relevant measured values could be used to create other models not subject to these lateral limits. However, such extended modeling should be restricted to the outflow facies (in contrast to the caldera-margin or intra-caldera facies) of the several ash-flow tuff units involved in the four modeling units.

A final restriction involves the saturated hydraulic conductivity models of the Topopah Spring welded modeling unit (only). These hydraulic conductivity models represent matrix permeability only, and they do not consider the effect of large lithophysal cavities that may be connected by either matrix porosity or by fractures. Thus, the matrix hydraulic conductivity models are intended more as the upper permeability limit of the unsaturated hydraulic conductivity function at near-full matrix saturation, rather than as representing the permeability of the TSw model unit were it present within the SZ. As the TSw unit is almost invariably high within the SZ in the immediate vicinity of the repository (the modeled area), this restriction is of little practical effect. Note that the substitution of water-filled porosity (volumetric water content) within the upper lithophysal zone (in particular) for drill holes from which no core measurements are available leads to a slight underestimation of the true (fully saturated) matrix hydraulic conductivity in those regions. Again, however, the modeled values are reasonable estimates of the upper permeability limit of the unsaturated hydraulic conductivity function at the ambient matrix saturation.

\subsection{CONCLUSIONS FOR YMRP CRITERIA}

The following information describes how this analysis addresses the acceptance criteria in the Yucca Mountain Review Plan (NRC 2003 [DIRS 163274], Section 2.2.1.3.9.3). Only those acceptance criteria that are applicable to this report (see Section 4.2) are discussed. In most cases, the applicable acceptance criteria are not addressed solely by this report; rather, the acceptance criteria are fully addressed when this report is considered in conjunction with other analysis and model reports that describe radionuclide transport in the SZ. Where a subcriterion 
includes several components, only some of those components may be addressed. How these components are addressed is summarized below.

\section{Acceptance Criteria From Section 2.2.1.3.9.3, Radionuclide Transport in the Saturated Zone.}

Parameters developed in this analysis and used in the SZ radionuclide transport models are matrix and lithophysal porosities and bulk density. This information is provided for use as input to numerical physical-process modeling, such as of ground-water flow and/or radionuclide transport.

\section{Acceptance Criterion 1: System Description and Model Integration Are Adequate.}

Subcriterion (2): The description of the aspects of geology provided by the Rock Properties Model are adequate. This model provides a determination of the matrix and lithophysal porosities and bulk density of the rock types at Yucca Mountain. This information is used to support physical process modeling for radionuclide transport in the SZ (see Section 6.1). The conceptual basis, development, and validation of the model are presented in Sections 6.3, 6.4, and 6.7, respectively.

\section{Acceptance Criterion 2: Data Are Sufficient for Model Justification.}

Subcriterion (3): The matrix and lithophysal porosities and bulk density of the Yucca Mountain rock types provided by the Rock Properties Model were developed based on appropriate techniques. The techniques involved measurements of rock material properties, either in the laboratory or by calculation from geophysical measurements obtained in the field. These processes are discussed and their appropriateness justified in Sections 4.1.1 through 4.1.7 and in the reports referenced by those sections. The techniques for determining the lithophysal porosities from the borehole information are discussed in Sections 6.1, 6.3, and 6.4, and the results are presented in Section 6.5. 


\section{INPUTS AND REFERENCES}

\subsection{DOCUMENTS CITED}

The following is a list of the references cited in this document. Column 2 represents the unique six-digit numerical identifier (the Document Input Reference System [DIRS] number), which is placed in the text following the reference callout (e.g., BSC 2002 [DIRS 155950]). The purpose of these numbers is to assist the reader in locating a specific reference in the DIRS database. Within the reference list, multiple sources by the same author and date (e.g., BSC 2002) are sorted alphabetically by title.

Altman, S.J.; Arnold, B.W.; Barnard, R.W.; Barr, G.E.; Ho, C.K.; McKenna, S.A.; and

100591

Eaton, R.R. 1996. Flow Calculations for Yucca Mountain Groundwater Travel Time (GWTT-95). SAND96-0819. Albuquerque, New Mexico: Sandia National

Laboratories. ACC: MOL.19961209.0152.

Bish, D. 2001. TWS-ESS-1-7/86-35, Brinkman Sample Grinding Logbook.

169750

SN-LANL-SCI-015-V1. ACC: MOL.20010718.0254.

Bish, D.L. 1989. Evaluation of Past and Future Alterations in Tuff at Yucca

101194

Mountain, Nevada, Based on the Clay Mineralogy of Drill Cores USW G-1, G-2, and

G-3. LA-10667-MS. Los Alamos, New Mexico: Los Alamos National Laboratory.

ACC: NNA.19890126.0207.

Bish, D.L. and Chipera, S.J. 1989. Revised Mineralogic Summary of Yucca Mountain, 101195 Nevada. LA-11497-MS. Los Alamos, New Mexico: Los Alamos National

Laboratory. ACC: NNA.19891019.0029.

Bish, D.L. and Vaniman, D.T. 1985. Mineralogic Summary of Yucca Mountain,

101196

Nevada. LA-10543-MS. Los Alamos, New Mexico: Los Alamos National

Laboratory. ACC: MOL.19950412.0041.

Brodsky, N.S. 2003. Uncertainty Estimates - Measurement Error Estimates for

Porosity, Thermal Conductivity, Bulk Density. Fax from N.S. Brodsky (SNL) to N.

Garcia, July 29, 2003. ACC: MOL.20030729.0082.

Broxton, D. 1990. Hurricane Mesa, Absaroka Mts., Wyo., Lathrop Wells Section,

Nev., Sampling of Wt Holes Yucca Mt., Nev., Calico Hills Section in Paintbursh, Cny.

Field Book No. 8152-60. ACC: MOL.19981006.0244.

BSC (Bechtel SAIC Company) 2003. Saturated Zone Flow and Transport Model

167651

Abstraction. MDL-NBS-HS-000021 REV 01. Las Vegas, Nevada: Bechtel SAIC

164584

Company. ACC: DOC.20040128.0001.

BSC (Bechtel SAIC Company) 2004. Analysis of Hydrologic Properties Data.

170038 ANL-NBS-HS-000042, Rev. 00. Las Vegas, Nevada: Bechtel SAIC Company. 
BSC (Bechtel SAIC Company) 2004. Drift Degradation Analysis.

ANL-EBS-MD-000027, Rev. 03. Las Vegas, Nevada: Bechtel SAIC Company.

BSC (Bechtel SAIC Company) 2004. Geologic Framework Model (GFM2000).

170029

MDL-NBS-GS-000002 REV 02. Las Vegas, Nevada: Bechtel SAIC Company.

ACC: DOC.20040827.0008.

BSC (Bechtel SAIC Company) 2004. Mineralogic Model (MM3.0) Report.

170031

MDL-NBS-GS-000003, Rev. 01. Las Vegas, Nevada: Bechtel SAIC Company.

ACC: DOC.20040908.0006.

BSC (Bechtel SAIC Company) 2004. Q-List. 000-30R-MGR0-00500-000-000

168361

REV 00. Las Vegas, Nevada: Bechtel SAIC Company. ACC: ENG.20040721.0007.

BSC (Bechtel SAIC Company) 2004. Saturated Zone Flow and Transport Model

170042

Abstraction. MDL-NBS-HS-000021, Rev. 02. Las Vegas, Nevada: Bechtel SAIC

Company.

BSC (Bechtel SAIC Company) 2004. Technical Work Plan for: The Integrated Site

169635

Model. TWP-NBS-GS-000003 REV 05. Las Vegas, Nevada: Bechtel SAIC

Company. ACC: DOC.20040601.0002.

BSC (Bechtel SAIC Company) 2004. Thermal Conductivity of Non-Repository

Lithostratigraphic Layers. MDL-NBS-GS-000006, Rev. 01. Las Vegas, Nevada:

Bechtel SAIC Company.

BSC (Bechtel SAIC Company) 2004. Thermal Conductivity of the Potential

169854

Repository Horizon. MDL-NBS-GS-000005, Rev. 01. Las Vegas, Nevada: Bechtel

SAIC Company.

Buesch, D.C.; Spengler, R.W.; Moyer, T.C.; and Geslin, J.K. 1996. Proposed Stratigraphic Nomenclature and Macroscopic Identification of Lithostratigraphic Units of the Paintbrush Group Exposed at Yucca Mountain, Nevada. Open-File Report 94-469. Denver, Colorado: U.S. Geological Survey. ACC: MOL.19970205.0061.

Burns \& McDonnell Engineering. 1959. Report on Development of Wells J-11 \& J12, 169662 Jackass Flats, Nye County, Nevada. Kansas City, Missouri: Burns \& McDonnell Engineering. ACC: MOL.19961209.0118.

Byers, F. 1982. “Trip to NTS, February 19-22, RE: Holes H-3, Yucca Mountain, 169663 NTS.” Office memorandum from F. Byers (LANL) to ESS-1 and -2 NNWSI Group, February 23, 1982, TWS-ESS-2-3/82-90. ACC: NNA.19900418.0142.

Byers, F.M. 1983. Thin-Section Data Microprobe Data, UE25-1, Yucca Mtn. Nevada 169692 Test Site. TWS-ESS-1-6/83-20. ACC: NNA.19900404.0108. 
Caporuscio, F.A. 1986. Scientific Notebook. Scientific Notebook Number S-4077.

169644

ACC: NNA.19900404.0106.

Chipera, S.J. 1986. Scientific Notebook. Scientific Notebook Number S-9075.

169680

ACC: NNA.19900605.0236.

Chipera, S.J. 1989. Scientific Notebook. Scientific Notebook Number S-10079.

169683

ACC: MOL.19980727.0642.

Chipera, S.J. and Bish, D.L. 1988. Mineralogy of Drill Hole UE-25p\#1 at Yucca

105080

Mountain, Nevada. LA-11292-MS. Los Alamos, New Mexico: Los Alamos National

Laboratory. ACC: NNA.19880607.0036.

CRWMS M\&O 1996. Determining Porosity, Balanced Water Content, and Other

100632

Rock Properties from Geophysical Logs for the Modern Borehole Data Set at Yucca

Mountain, Nevada, June 1996. BAAA00000-01717-0200-00013 REV 00. Las Vegas,

Nevada: CRWMS M\&O. ACC: MOL.19970210.0171.

CRWMS M\&O 1999. Combined Porosity from Geophysical Logs. BAA000000-

109022

01717-0200-00003 REV 00. Las Vegas, Nevada: CRWMS M\&O.

ACC: MOL.19991208.0437.

Deutsch, C.V. and Journel, A.G. 1992. GSLIB Geostatistical Software Library and

User’s Guide. New York, New York: Oxford University Press. TIC: 224174.

Deutsch, C.V. and Journel, A.G. 1998. GSLIB Geostatistical Software Library and

102895

User's Guide. 2nd Edition. New York, New York: Oxford University Press.

TIC: 240101.

Fenix \& Scisson. 1988. Hole History Data NNWSI, J-12 Water Well.

169661

[Mercury, Nevada]: Fenix \& Scisson. ACC: MOL.19961209.0119.

Flint, L.E. 1998. Characterization of Hydrogeologic Units Using Matrix Properties, 100033 Yucca Mountain, Nevada. Water-Resources Investigations Report 97-4243.

Denver, Colorado: U.S. Geological Survey. ACC: MOL.19980429.0512.

Freeze, R.A. and Cherry, J.A. 1979. Groundwater. Englewood Cliffs,

101173

New Jersey: Prentice-Hall. TIC: 217571.

Horton, D.G. 1990. “U.S. Department of Energy (DOE) Office of Civilian 169954

Radioactive Waste Management (OCRWM) Acceptance of the Los Alamos National Laboratories (Los Alamos) Quality Assurance (QA) Program.” Letter from D.G. Horton (DOE) to D.E. Shelor, December 21, 1990, OQA:NAV-1413, with enclosures. ACC: HQO.19910107.0034; HQO.19910107.0036. 
Journel, A.G. 1983. "Nonparametric Estimation of Spatial Distributions."

102897

Mathematical Geology, 15, (3), 445-468. New York, New York: Plenum Publishing

Corporation. TIC: 224736.

Journel, A.G. and Huijbregts, C.J. 1978. Mining Geostatistics. New York, New York: 102898 Academic Press. TIC: 210128.

LANL (Los Alamos National Laboratory) 1992. SMF Specimen Custody Receipt, 169718 Shipment ID 0052, Shipping Date: January 3, 1992. Los Alamos, New Mexico: Los Alamos National Laboratory. ACC: MOL.19980330.0458.

LANL (Los Alamos National Laboratory) 1997. SMF Speciman Removal Logs for SRR\#: 01000038 and SRR\#: 01000039. [Los Alamos, New Mexico: Los Alamos National Laboratory]. ACC: DRC.19970818.0039.

Levy, S.S. 1984. Petrology of Samples from Drill Holes USW H-3, H-4, and H-5, Yucca Mountain, Nevada. LA-9706-MS. Los Alamos, New Mexico: Los Alamos National Laboratory. ACC: MOL.19970729.0322.

Levy, S.S. 1991. "Mineralogic Alteration History and Paleohydrology at Yucca 100053 Mountain, Nevada.” High Level Radioactive Waste Management, Proceedings of the Second Annual International Conference, Las Vegas, Nevada, April 28-May 3, 1991. 1, 477-485. La Grange Park, Illinois: American Nuclear Society. TIC: 204272.

Levy, S.S. 1996. History of Mineralogic and Geochemical Alteration of Yucca 106676 Mountain. Scientific Notebook TWS-ESS-1-10/82-19. ACC: MOL.19990601.0176.

Luster, G.R. 1985. Raw Materials for Portland Cement: Applications of Conditional 102904 Simulation of Coregionalization. Ph.D. dissertation. Stanford, California: Stanford University. TIC: 226080.

Mongano, G.S.; Singleton, W.L.; Moyer, T.C.; Beason, S.C.; Eatman, G.L.W.; Albin, A.L.; and Lung, R.C. 1999. Geology of the ECRB Cross Drift - Exploratory Studies Facility, Yucca Mountain Project, Yucca Mountain, Nevada. [Deliverable SPG42GM3]. Denver, Colorado: U.S. Geological Survey. ACC: MOL.20000324.0614.

Moyer, T.C. and Geslin, J.K. 1995. Lithostratigraphy of the Calico Hills Formation 101269 and Prow Pass Tuff (Crater Flat Group) at Yucca Mountain, Nevada. Open-File Report 94-460. Denver, Colorado: U.S. Geological Survey. ACC: MOL.19941208.0003.

Nelson, P.H. 1996. Computation of Porosity and Water Content from Geophysical 101270 Logs, Yucca Mountain, Nevada. Open-File Report 96-078. Denver, Colorado: U.S. Geological Survey. ACC: MOL.19980529.0444. 
NRC (U.S. Nuclear Regulatory Commission) 2003. Yucca Mountain Review Plan,

Final Report. NUREG-1804, Rev. 2. Washington, D.C.: U.S. Nuclear Regulatory Commission, Office of Nuclear Material Safety and Safeguards. TIC: 254568.

Rautman, C. 1999. Geostatistical Modeling of Porosity and Derivative Properties (fy

109035 1999). Scientific Notebook SNL-SCI-011. ACC: MOL.19990623.0025.

Rautman, C. and McKenna, S. 1998. Geostatistical Modeling of Porosity and 107442 Derivative Properties for Fiscal Year 1998. Scientific Notebook SNL-SCI-006. ACC: MOL.19981027.0187.

Rautman, C.A. and Engstrom, D.A. 1996. Geology of the USW SD-12 Drill Hole 100642 Yucca Mountain, Nevada. SAND96-1368. Albuquerque, New Mexico: Sandia National Laboratories. ACC: MOL.19970613.0101.

Rautman, C.A. and Engstrom, D.A. 1996. Geology of the USW SD-7 Drill Hole Yucca Mountain, Nevada. SAND96-1474. Albuquerque, New Mexico: Sandia National Laboratories. ACC: MOL.19971218.0442.

Rautman, C.A. and McKenna, S.A. 1997. Three-Dimensional Hydrological and 100643 Thermal Property Models of Yucca Mountain, Nevada. SAND97-1730. Albuquerque, New Mexico: Sandia National Laboratories. ACC: MOL.19980311.0317.

Sawyer, D.A.; Fleck, R.J.; Lanphere, M.A.; Warren, R.G.; Broxton, D.E.; and Hudson, 100075 M.R. 1994. "Episodic Caldera Volcanism in the Miocene Southwestern Nevada Volcanic Field: Revised Stratigraphic Framework, \{superscript 40\} Ar/\{superscript 39\} Ar Geochronology, and Implications for Magmatism and Extension.” Geological Society of America Bulletin, 106, (10), 1304-1318. Boulder, Colorado: Geological Society of America. TIC: 222523.

Schlumberger 1972. Principles. Schlumberger Log Interpretation. Volume I. 129068 New York, New York: Schlumberger Limited. TIC: 240326.

SNL (Sandia National Laboratory) 2002. Software Management Report, Etype Version 171419 2.01. Software Management Report Number: 10731-SMR-2.01-00. Albuquerque, New Mexico: Sandia National Laboratory. ACC: MOL.20020603.0347.

Steinborn, T.L. 2002. Data Qualification Report: Mineralogy Data for Use on the 160702 Yucca Mountain Project. TDR-NBS-HS-000005 REV 00. Las Vegas, Nevada:

Bechtel SAIC Company. ACC: MOL.20020807.0442.

USGS (U.S. Geological Survey) [1995]. Lithologic Log of Drill Hole USW WT-1. 169694 [Denver, Colorado]: U.S. Geological Survey. ACC: MOL.19960110.0344.

Vaniman, D. 1983. Volcanic Hazards Studies Book 2. Notebook Unique 169665 Identification Number: TWS-G6-8/79-50. ACC: MOL.20020826.0192. 
Vaniman, D.; Bish, D.; Broxton, D.; Byers, F.; Heiken, G.; Carlos, B.; Semarge, E.;

101363

Caporuscio, F.; and Gooley, R. 1984. Variations in Authigenic Mineralogy and

Sorptive Zeolite Abundance at Yucca Mountain, Nevada, Based on Studies of Drill

Cores USW GU-3 and G-3. LA-9707-MS. Los Alamos, New Mexico: Los Alamos

National Laboratory. ACC: NNA.19870519.0043.

Whitfield, M.S., Jr.; Thordarson, W.; and Eshom, E.P. 1984. Geohydrologic and

101366

Drill-Hole Data for Test Well USW H-4, Yucca Mountain, Nye County, Nevada. Open-

File Report 84-449. Denver, Colorado: U.S. Geological Survey. ACC:

NNA.19870407.0317.

\subsection{CODES, STANDARDS, REGULATIONS, AND PROCEDURES}

10 CFR 63. Energy: Disposal of High-Level Radioactive Wastes in a Geologic

156605

Repository at Yucca Mountain, Nevada. Readily available.

AP-2.22Q, Rev. 1, ICN 1. Classification Analyses and Maintenance of the Q-List. Washington, D.C.: U.S. Department of Energy, Office of Civilian Radioactive Waste Management. ACC: DOC.20040714.0002.

AP-2.27Q, Rev. 1, ICN 4. Planning for Science Activities. Washington, D.C.: U.S. Department of Energy, Office of Civilian Radioactive Waste Management.

ACC: DOC.20040610.0006.

AP-SI.1Q, Rev. 0, ICN 0. Software Configuration Management. Washington, D.C.: U.S. Department of Energy, Office of Civilian Radioactive Waste Management.

ACC: MOL.19990505.0125.

AP-SIII.2Q, Rev. 1, ICN 2. Qualification of Unqualified Data. Washington, D.C.: U.S. Department of Energy, Office of Civilian Radioactive Waste Management. ACC:

DOC.20040127.0008.

AP-SIII.10Q, Rev. 2, ICN 5. Models. Washington, D.C.: U.S. Department of Energy, Office of Civilian Radioactive Waste Management. ACC: DOC.20040615.0003.

DOE (U.S. Department of Energy) 2004. Quality Assurance Requirements and 171539 Description. DOE/RW-0333P, Rev. 16. Washington, D.C.: U.S. Department of Energy, Office of Civilian Radioactive Waste Management.

ACC: DOC.20040907.0002.

QAIP 19-1, Rev. 4. Software Quality Assurance Requirements. Albuquerque,

New Mexico: Sandia National Laboratories. ACC: MOL.19981103.0547.

QAIP 20-2, Rev. 02. Scientific Notebooks. Albuquerque, New Mexico: Sandia 109474 National Laboratories. ACC: MOL.19990224.0508. 


\subsection{SOURCE DATA, LISTED BY DATA TRACKING NUMBER}

GS000308314211.002. Stratigraphic Contacts for Boreholes UE-25 A\#1, UE-25 A\#4, 158000 USW G-1, USW G-2, USW H-5, USW SD-9, USW SD-12 and USW VH-2. Submittal date: $04 / 28 / 2000$.

GS021008314224.002. Lithophysal Data Study from the Tptpll in the ECRB from

161910 Stations $14+44$ to 23+26. Submittal date: 01/28/2003.

GS960708312132.002. Porosity, Water Content, Mineralogy and Other Data Derived from Geophysical Logs and Cores for 26 Boreholes. Submittal date: 07/09/1996.

GS980708312242.010. Physical Properties of Borehole Core Samples, and Water Potential Measurements Using the Filter Paper Technique, for Borehole Samples from USW WT-24. Submittal date: 07/27/1998.

GS980808312242.014. Physical Properties of Borehole Core Samples and Water Potential Measurements Using the Filter Paper Technique for Borehole Samples from USW SD-6. Submittal date: 08/11/1998.

LA000000000086.002. Mineralogic Variation in Drill Core UE-25 UZ\#16 Yucca Mountain, Nevada. Submittal date: 03/28/1995.

113584

106752 LA9908JC831321.001. Mineralogic Model "MM3.0" Version 3.0. Submittal date: 08/16/1999.

LA9910JC831321.001. Supplementary Mineralogical Data for Mineralogic Model 3.0. Submittal date: 10/29/1999.

LA9910DB831321.001. Mineralogic Variation in Drill Holes. Submittal date:

106748 11/18/1999.

LADB831321AN98.002. Revised Mineralogic Summary of Yucca Mountain, Nevada. 109003 Submittal date: 05/26/1998.

LADV831321AQ97.001. Mineralogic Variation in Drill Holes. Submittal date:

107142 05/28/1997.

LADV831321AQ97.007. Geotechnical Data Report: Hazardous Minerals. Submittal 113499 date: $01 / 27 / 1998$.

LAJC831321AQ98.005. Quantitative XRD Results for Drill Core USW SD-7, USW 109004 SD-9, USW SD-12 and UE-25 UZ\#16. Submittal date: 10/27/1998.

MO0004QGFMPICK.000. Lithostratigraphic Contacts from 152554 MO9811MWDGFM03.000 to be Qualified Under the Data Qualification Plan, TDPNBS-GS-000001. Submittal date: 04/04/2000. 
MO0010CPORGLOG.002. Calculated Porosity from Geophysical Logs Data from "Old 40" Boreholes. Submittal date: 10/16/2000.

MO0010CPORGLOG.003. Calculated Porosity Values at Depth Derived from Qualified Geophysical Log Data from Modern Boreholes. Submittal date: 10/16/2000.

MO0012MWDGFM02.002. Geologic Framework Model (GFM2000). Submittal date: $12 / 18 / 2000$.

MO0109HYMXPROP.001. Matrix Hydrologic Properties Data. Submittal date: 155989 09/17/2001. MO0109HYMXPROP.001. Matrix Hydrologic Properties Data. Submittal date: 09/17/2001.

MO0101XRDMINAB.001. XRD Analyses of Drill Core from Boreholes UE-25B\#1, 163796 USW G-1, USW G-3, USW GU-3, and USW G-4. Submittal date: 01/26/2001. MO0101XRDMINAB.001. XRD Analyses of Drill Core from Boreholes UE-25B\#1, USW G-1, USW G-3, USW GU-3, and USW G-4. Submittal date: 01/26/2001.

MO0101XRDDRILC.001. XRD Analyses of Drill Core from Boreholes UE-25 J-12, 169517 USW WT-1, USW H-3, USW H-4, USW WT-2, UE-25 P\#1, AND USW H-5. Submittal date: 01/26/2001. MO0101XRDDRILC.001. XRD Analyses of Drill Core from Boreholes UE-25 J-12, USW WT-1, USW H-3, USW H-4, USW WT-2, UE-25 P\#1, AND USW H-. Submittal date: 01/26/2001.

MO9510RIB00002.004. RIB Item: Stratigraphic Characteristics: Geologic/Lithologic 103801 Stratigraphy. Submittal date: 06/26/1996. MO9510RIB00002.004. RIB Item:

Stratigraphic Characteristics: Geologic/Lithologic Stratigraphy. Submittal date: 06/26/1996.

MO9804MWDGFM03.001. An Update to GFM 3.0; Corrected Horizon Grids for 109050 Four Fault Blocks. Submittal date: 04/14/1998. MO9804MWDGFM03.001. An Update to GFM 3.0; Corrected Horizon Grids for Four Fault Blocks. Submittal date: 04/14/1998.

MO9901MWDGFM31.000. Geologic Framework Model. Submittal date: 103769 01/06/1999. MO9901MWDGFM31.000. Geologic Framework Model. Submittal date: $01 / 06 / 1999$.

MO9910MWDISMRP.002. ISM3.1 Rock Properties Models. Submittal date: 145731 10/06/1999. MO9910MWDISMRP.002. ISM3.1 Rock Properties Models. Submittal date: $10 / 06 / 1999$.

SNF40060198001.001. Unsaturated Zone Lithostratigraphic Contacts in Borehole 107239 USW WT-24. Submittal date: 10/15/1998. SNF40060198001.001. Unsaturated Zone Lithostratigraphic Contacts in Borehole USW WT-24. Submittal date: 10/15/1998. 
SNF40060298001.001. Unsaturated Zone Lithostratigraphic Contacts in Borehole 107372 USW SD-6. Submittal date: 10/15/1998. SNF40060298001.001. Unsaturated Zone Lithostratigraphic Contacts in Borehole USW SD-6. Submittal Date: 10/15/1998.

SNL01A05059301.005. Laboratory Thermal Conductivity Data for Boreholes UE25

109002 NRG-4, NRG-5; USW NRG-6 and NRG-7/7A. Submittal date: 02/07/1996. SNL01A05059301.005. Laboratory Thermal Conductivity Data for Boreholes UE25 NRG-4, NRG-5; USW NRG-6 and NRG-7/7A. Submittal Date: 02/07/1996.

SNL01A05059301.007. Calculated Porosities for Thermal Conductivity Specimens from Boreholes UE25 NRG-4, UE25 NRG-5, USW NRG-6, and USW NRG-7/7a. Submittal date: 10/14/1998. SNL01A05059301.007. Calculated Porosities for Thermal Conductivity Specimens from Boreholes UE25 NRG-4, UE25 NRG-5, USW NRG-6, and USW NRG-7/7a. Submittal Date: 10/14/1998.

SN0209L01A1202.001. Thermal Conductivity Laboratory Data (Including Densities

163601 and Porosities) Generated in FY02 on the Topopah Springs Lower Lithophysal (Tptpll) Lithostratigraphic Unit. Submittal date: 09/23/2002. SN0209L01A1202.001. Thermal Conductivity Laboratory Data (Including Densities and Porosities) Generated in FY02 on the Topopah Springs Lower Lithophysal (Tptpll) Lithostratigraphic Unit. Submittal date: 09/23/2002.

\subsection{OUTPUT DATA, LISTED BY DATA TRACKING NUMBER}

SN0004T0501399.002. Correlation of RH (Relative Humidity) Porosity and Bulk Density. Submittal date: 04/13/2000.

SN0004T0501399.003. Statistical Summary of Porosity Data. Submittal date: 04/13/2000.

SN9910T0501399.001. Three-Dimensional Rock Property Models for FY99 (RPM3.1). Submittal date: 10/18/1999.

\subsection{SOFTWARE CODES}

BUD. Routine.

COORDS. Routine.

COREGPC. Routine.

EARTHVISION V4.0 Dynamic Graphics. 1997. STN: 30035 V4.0.

113625

ETYPE V2.01, SNL (Sandia National Laboratories) PC Windows 2000 Server. 10731159417 2.01.00. 
GSLIB V1.4 MNSCOREV1.201. STN: 10109-1.4MNSCOREV1.201-00.

GSLIB V1.4 Module BICALIB V2.0.

114227

GSLIB V1.4 Module TRANS V1.3.

114225

GSLIB V1.4 MSGSIMV1.40. STN: 10110-1.4MSGSIMV1.40-00.

113569

GSLIB V2.0 MIK3DV2.0. STN: 10122-2.0MIK3DV2.0-00.

113587

MATCH V 12/05/98. V.12/05/98.

113664

MATCHUP Version 12/05/98. STN: 10196-12/05/98-00.

113660

STRATC4. .

113708

TWOFOOT 6/25/98

113653

VITROPHYRE 9/10/98

113694

ZEOLITE5 9/10/98

113682 
APPENDIX A

SIGMA PLOT TRANSFORM “STRATC4” 


\section{A1. SOFTWARE ROUTINE IDENTIFICATION}

Software Name and Version Number: "stratc4", ver. 4:

NOTE: The software documentation is for information only and to provide completeness and traceability.

Version number was not assigned originally, but was added for documentation to be included in the Rock Properties Model Analysis Model Report. However, the digit " 4 " in the routine name was intended to indicate that this is the fourth iteration of a software routine to perform a similar function.

SRR Document Identification Number: none.

SRR Media Number: none.

\section{A2. DESCRIPTION AND TESTING}

Documentation that the software routine or macro provides correct results for a specified range of input parameters:

- Description and equations of mathematical models, algorithms, and numerical solution techniques, as applicable:

The equation that is implemented in software routine "stratc4" to convert drill hole measured depths to stratigraphic coordinates, more specifically to stratigraphic depths (StratDepth), is as follows (equation 6.4-2 in Section 6.4.3.2, of this report):

$$
\text { StratDepth }=\frac{\text { SampleDepth }- \text { UnitTop }}{\text { UnitBottom }- \text { UnitTop }} . \text { NominalThickness }
$$

where SampleDepth is the depth of the relevant sample measurement in a given drill hole, UnitTop and UnitBottom are the measured or projected top and bottom contacts of relevant model unit at the drill hole location used to determine the thickness of the unit, and NominalThickness is the appropriate unit-specific scaling constant (Table 6.4-1 of this report). The conversion produces a "stratigraphic depth" such that the very top of the geologic unit in question is at a "depth" of zero, the very bottom of the unit is at a "depth" equal to the nominal stratigraphic thickness of the unit, and all depths in between are scaled proportionately to the nominal thickness. Stratigraphic coordinates are dimensionless.

- Description of software routine including the execution environment:

Software routine "stratc4" is a "transform" implemented within the industry-standard, commercial statistical and graphics software package, Sigma Plot (SPSS, Inc.; 233 South Wacker Drive, 11th Floor; Chicago, Illinois 60606-6307). The routine is essentially a "macro" (however, see next paragraph). Sigma Plot transform syntax does not appear to be version specific, but this routine has been used for the current 
application within Sigma Plot, version 5.00, running under Windows NT, version 4. Use of the transform is intimately associated with the spreadsheet mechanics of Sigma Plot.

Note that a "transform" in Sigma Plot parlance is different than a "macro". A Sigma Plot macro consists of a recording of a sequence of mouse-based actions for creating or modifying a graph. In contrast, a transform performs one or more mathematical operations on a set of input data and provides essentially what amounts to an internal programming language for performing those operations.

The Sigma Plot spreadsheets designed for use with software routine "stratc4" are intended to contain various sets of core-based and geophysics-based rock property measurements, and to present those data values graphically as drill hole profiles displaying the selected measurements as a function of depth. Accordingly, the true, measured depths associated with each set of property values are arranged in a columnar manner, with four blank columns to the right of the true-depth column (to be filled in with stratigraphic depths); property values are typically arranged to the right of the four blank columns as a logical grouping. Multiple sets of such depth and property data may be present in a single spreadsheet. Additionally, a column of top and bottom depth values corresponding to the top and bottom of each geologic unit of interest is provided elsewhere in the spreadsheet. The numeric identifiers of the true-depth and "tops" columns are required as manual input to the software routine (involves editing the transform listing within Sigma Plot).

The transform is invoked according to Sigma Plot conventions, whereupon the appropriate unit tops and bottoms are read from the spreadsheet, and the coordinate-conversion equation is computed repeatedly for each depth value present in the specified true-depth column, with the results being inserted into the appropriate output columns (presumably the four blank columns set up for this purpose).

- Description of test cases:

Any arbitrary set of "depth" values can be used to test the stratigraphic depth calculations performed by software routine "stratc4". The only requirement is that some number of "true-depth" values be contained within the "top" and "bottom" depths of the "geologic unit" being considered. As an alternative, the following data set, which consists of the depths associated with selected laboratory core property measurements taken from drill hole USW SD-7 (the property data themselves are irrelevant and are not modified by the transform), may be used to validate the software routine. Note that within Sigma Plot, these data entries are associated with specific cells identified by row and column numbers. 
The column headed "unit designation" is not used by the transform, and it is included only for reader reference.

$\begin{array}{llr}\text { “Tops” Depth } & \text { Unit Designation } & \text { “True-Depth” } \\ 316.0000 & \text { top PTn } & 302.8000 \\ 316.0000 & & 306.1000 \\ & & 308.6000 \\ 384.3000 & \text { base PTn } & 312.1000 \\ 384.3000 & \text { top TSw } & 320.9000 \\ & & 323.7000 \\ 1308.0000 & \text { base TSw } & 330.1000 \\ 1308.0000 & \text { top CH } & 332.9000 \\ 1621.5000 & & 338.9000 \\ 1621.5000 & \text { base CH } & 341.5000 \\ & \text { top PP } & 368.0000 \\ 2183.9000 & & 369.0000 \\ 2183.9000 & \text { base Prow } & 371.9000 \\ & \text { top Bullfrog } & 386.3000 \\ & & 389.7000 \\ & & 392.7000 \\ & & 395.8000 \\ & & 399.1000 \\ & & 401.4000 \\ & & 404.6000\end{array}$

- Description of test results:

The following lines are copied from the Sigma Plot spreadsheet in which the stratigraphic coordinate conversion was computed. In the original, each entry is associated with a particular cell, identified by row and column numbers.

\begin{tabular}{|l|l|l|l|l}
\hline True Depth & PTn StratD & TSw StratD & CHn StratD & Tcp StratD \\
\hline 302.8000 & -38.6530 & -88.2321 & -1282.5518 & -937.9090 \\
\hline 306.1000 & -28.9898 & -84.6595 & -1278.3413 & -935.5619 \\
308.6000 & -21.6691 & -81.9530 & -1275.1515 & -933.7838 \\
312.1000 & -11.4202 & -78.1639 & -1270.6858 & -931.2945 \\
320.9000 & 14.3485 & -68.6370 & -1259.4577 & -925.0356 \\
323.7000 & 22.5476 & -65.6057 & -1255.8852 & -923.0441 \\
330.1000 & 41.2884 & -58.6771 & -1247.7193 & -918.4922 \\
332.9000 & 49.4876 & -55.6458 & -1244.1467 & -916.5007
\end{tabular}




$\begin{array}{|lllll|}\text { True Depth } & \text { PTn StratD } & \text { TSw StratD } & \text { CHn StratD } & \text { Tcp StratD } \\ 338.9000 & 67.0571 & -49.1502 & -1236.4912 & -912.2333 \\ 341.5000 & 74.6706 & -46.3354 & -1233.1738 & -910.3841 \\ 368.0000 & 152.2694 & -17.6464 & -1199.3620 & -891.5363 \\ 369.0000 & 155.1977 & -16.5638 & -1198.0861 & -890.8250 \\ 371.9000 & 163.6896 & -13.4243 & -1194.3860 & -888.7624 \\ 386.3000 & 205.8565 & 2.1652 & -1176.0128 & -878.5206 \\ 389.7000 & 215.8126 & 5.8461 & -1171.6746 & -876.1024 \\ 392.7000 & 224.5974 & 9.0939 & -1167.8469 & -873.9687 \\ 395.8000 & 233.6750 & 12.4499 & -1163.8915 & -871.7639 \\ 399.1000 & 243.3382 & 16.0225 & -1159.6810 & -869.4168 \\ 401.4000 & 250.0732 & 18.5125 & -1156.7464 & -867.7809 \\ 404.6000 & 259.4436 & 21.9768 & -1152.6635 & -865.5050\end{array}$

Several items are of note. First, the input data (first listing, above) represent only a very small portion of the relevant drill hole data set. Specifically, the "true depths" include only those associated with the PTn geologic unit, plus a few extra depths both above and below for illustrative purposes. As expected, true depths higher in the hole than the top of the PTn unit (given above as $316 \mathrm{ft}$ ), are converted to meaningless stratigraphic depths ("PTn StratD") less than zero. Second, depths below the bottom of the PTn unit (given above as $384.3 \mathrm{ft}$ ) are converted to equally meaningless stratigraphic depths in excess of the nominal stratigraphic thickness of the PTn unit, which is 200.0 (dimensionless). Third, using similar logic, almost all stratigraphic depths for the TSw geologic unit ("TSw StratD") are negative (those above the top of the TSw unit at $384.3 \mathrm{ft}$ ), as are all of the indicated stratigraphic depths for the CHn unit and Tcp unit ("CHn StratD" and "Tcp StratD"), as none of the measured depths of with this illustrative data set are associated with those deeper units. Finally, the lowermost valid PTn stratigraphic depth (at a true depth of $371.9 \mathrm{ft}$ ) is immediately succeeded by the first valid TSw stratigraphic depth (at a true depth of $386.3 \mathrm{ft}$ ). Shaded values in the listing indicate numbers that are meaningless (though arithmetically correct) for one or more of the reasons discussed above.

A manual calculation, conducted by calculator (a Hewlett-Packard HP-11C; HewlettPackard Co.; 3000 Hanover Street; Palo Alto, CA 94304), for the first valid PTn "true depth" value (at $320.9 \mathrm{ft}$ ) is as follows:

$$
\text { StratDepth }=\frac{320.9-316.0}{384.3-316.0} \cdot 200.0=14.34846266
$$


which has been rounded up to 14.3485 by the display-format specified in the results presented above (set within Sigma Plot).

- Range of input parameter values for which the results were verified:

There are no input parameter values specified by the user, other than the column identifiers specifying where to look for the unit tops and bottoms and for the true depths that are to be converted. In terms of input data values, any real number recognized by Sigma Plot is a mathematically valid entry for both the unit contacts (top and bottom) and for the true depths. Whether or not specific values are legitimate values for a particular drill hole or sample depth is another issue (discussion above). The user is responsible for providing geologically meaningful input values.

- Identification of any limitations on software routine applications or validity:

There are no particular limitations to the software routine, per se. Any valid real number recognized by Sigma Plot is acceptable as input. However, the routine does not limit the calculation of the stratigraphic depth to the geologic unit of interest. Accordingly, the routine may generate stratigraphic depths that are outside the legitimate range of zero through NominalThickness. Such values, although representing arithmetically correct results, are meaningless. The user is responsible for identifying and dealing properly with such values in later applications.

\section{A3. SUPPORTING INFORMATION}

- Directory listing of executable and data files:

Because software routine "stratc4" is a macro designed to operate inside another software package, there is no "executable", per se. The Sigma Plot transform capability operates in an "interpreter" mode, compiling and executing each line of the transform at runtime. There are also no data files, per se. All input data is contained within the composite Sigma Plot spreadsheet and graphics file.

Computer listing of source code, if available.

The following listing of the transform code has been annotated (in a different font) to illustrate some salient features and required user-input values.

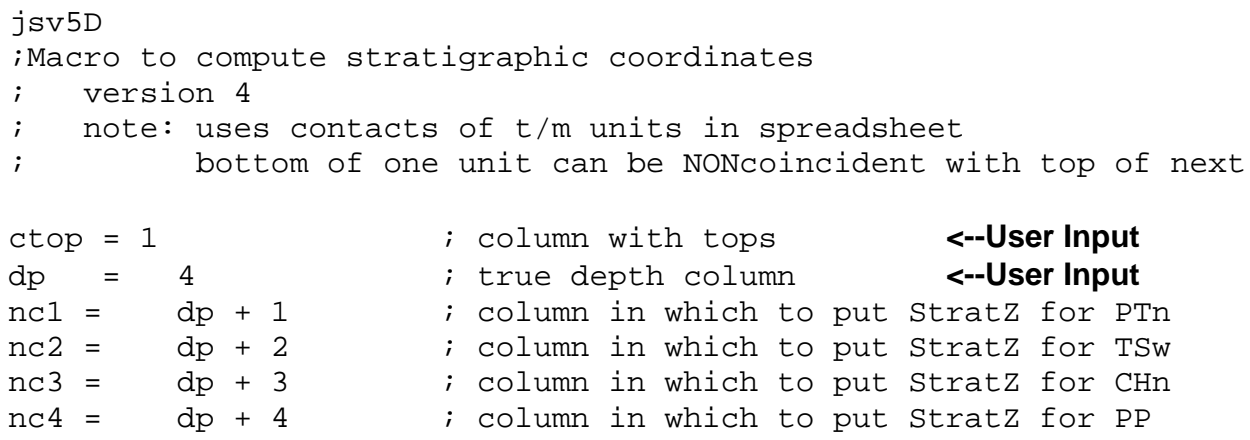




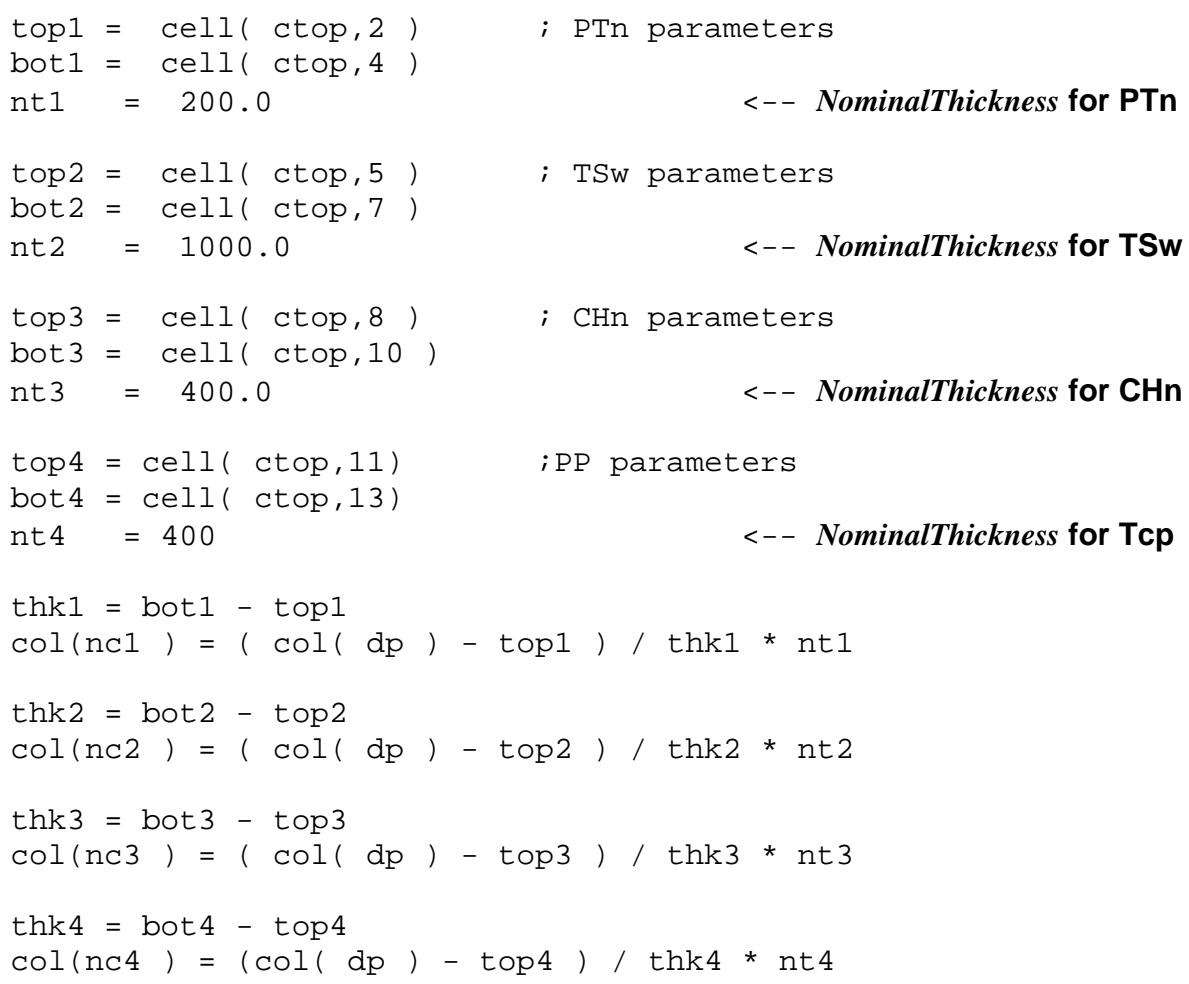

Computer listing of test data input and output, identifying software routine name and version number.

A printout (taken from an Acrobat portable-document-format [.pdf] file) of the relevant parts of the test Sigma Plot spreadsheet is reproduced below in Figure A-1. No "software names" or "version numbers" are associated with the internal appearance of the spreadsheet. 


\begin{tabular}{|c|c|c|c|c|c|c|c|}
\hline & FY97 3DM & 3 & Core Depth & PTn StratC & TSw StratC & $\mathrm{CHn}$ StratC & Tcp StratC \\
\hline 1 & 316.0000 top PTn & & 302.8000 & -38.6530 & -88.2321 & -1282.5518 & -937.9090 \\
\hline 2 & 316.0000 & & 306.1000 & -28.9898 & -84.6595 & -1278.3413 & -935.5619 \\
\hline 3 & \multirow[b]{2}{*}{384.3000 base PTn } & & 308.6000 & -21.6691 & -81.9530 & -1275.1515 & -933.7838 \\
\hline 4 & & & 312.1000 & -11.4202 & -78.1639 & -1270.6858 & -931.2945 \\
\hline 5 & 384.3000 top TSw & & 320.9000 & 14.3485 & -68.6370 & -1259.4577 & -925.0356 \\
\hline 6 & & & 323.7000 & 22.5476 & -65.6057 & -1255.8852 & -923.0441 \\
\hline 7 & 1308.0000 base TSw & & 330.1000 & 41.2884 & -58.6771 & -1247.7193 & -918.4922 \\
\hline 8 & 1308.0000 top $\mathrm{CH}$ & & 332.9000 & 49.4876 & -55.6458 & -1244.1467 & -916.5007 \\
\hline 9 & \multirow[b]{2}{*}{1621.5000 base $\mathrm{CH}$} & & 338.9000 & 67.0571 & -49.1502 & -1236.4912 & -912.2333 \\
\hline 10 & & & 341.5000 & 74.6706 & -46.3354 & -1233.1738 & -910.3841 \\
\hline 11 & 1621.5000 top PP & & 368.0000 & 152.2694 & -17.6464 & -1199.3620 & -891.5363 \\
\hline 12 & \multirow[b]{2}{*}{2183.9000 base Prow } & & 369.0000 & 155.1977 & -16.5638 & -1198.0861 & -890.8250 \\
\hline 13 & & & 371.9000 & 163.6896 & -13.4243 & -1194.3860 & -888.7624 \\
\hline 14 & 2183.9000 top Bullfrog & & 386.3000 & 205.8565 & 2.1652 & -1176.0128 & -878.5206 \\
\hline 15 & & & 389.7000 & 215.8126 & 5.8461 & -1171.6746 & -876.1024 \\
\hline 16 & & & 392.7000 & 224.5974 & 9.0939 & -1167.8469 & -873.9687 \\
\hline 17 & & & 395.8000 & 233.6750 & 12.4499 & -1163.8915 & -871.7639 \\
\hline 18 & & & 399.1000 & 243.3382 & 16.0225 & -1159.6810 & -869.4168 \\
\hline \multirow{2}{*}{$\begin{array}{l}19 \\
20\end{array}$} & & & 401.4000 & 250.0732 & 18.5125 & -1156.7464 & -867.7809 \\
\hline & & & 404.6000 & 259.4436 & 21.9768 & -1152.6635 & -865.5050 \\
\hline
\end{tabular}

00121DC_AMR_122

Source: Reproduced from a .pdf file.

NOTE: Columns are numbered sequentially from the left (see col. "3"), but alphanumeric titles may be entered for user convenience.

Figure A-1. Printed Spreadsheet Cells from Sigma Plot File Containing the Test Case Data and Output 


\section{INTENTIONALLY LEFT BLANK}




\section{APPENDIX B}

\section{GSLIB ROUTINE “TRANS”}


NOTE: The software documentation is for information only and to provide completeness and traceability.

Software routine TRANS, Version 1.3, is used directly from the geostatistical software library, GSLIB (Deutsch and Journel 1992 [DIRS 100567], pp. 213 to 214). The routine is intended to convert any particular univariate distribution of values to match that of a different "reference" distribution. For the rock properties modeling exercise, TRANS was used to transform coregionalized, standard-normal $\left(\mu=0, \sigma^{2}=1\right)$ models to match the target statistics of the desired secondary property in order to create the full-field derivative-property models.

\section{Source Code Listing}

program trans

С\%\%\%\%\%\%\%\%\%\%\%\%\%\%\%\%\%\%\%\%\%\%\%\%\%\%\%\%\%\%\%\%\%\%\%\%\%\%\%\%\%\%\%\%\%\%\%\%\%\%\%\%\%\%\% $\% \% \% \% \% \% \% \% \% \% \% \% \% \% \% \%$

$\mathrm{C}$

\section{$\%$}

C Copyright (C) 1992 Stanford Center for Reservoir Forecasting. All \%

C rights reserved. Distributed with: C.V. Deutsch and A.G. Journel. \%

C 'GSLIB: Geostatistical Software Library and User's Guide,'” Oxford \%

C University Press, New York, 1992.

$\mathrm{C}$ $\%$

C The programs in GSLIB are distributed in the hope that they will be \%

C useful, but WITHOUT ANY WARRANTY. No author or distributor accepts $\%$

$\mathrm{C}$ responsibility to anyone for the consequences of using them or for \%

$\mathrm{C}$ whether they serve any particular purpose or work at all, unless he $\%$

$\mathrm{C}$ says so in writing. Everyone is granted permission to copy, modify $\%$

$\mathrm{C}$ and redistribute the programs in GSLIB, but only under the condition \%

$\mathrm{C}$ that this notice and the above copyright notice remain intact. $\%$

$\mathrm{C}$

$\%$

$\mathrm{C} \% \% \% \% \% \% \% \% \% \% \% \% \% \% \% \% \% \% \% \% \% \% \% \% \% \% \% \% \% \% \% \% \% \% \% \% \% \% \% \% \% \% \% \% \% \% \% \% \% \% \% \% \%$ $\% \% \% \% \% \% \% \% \% \% \% \% \% \% \%$

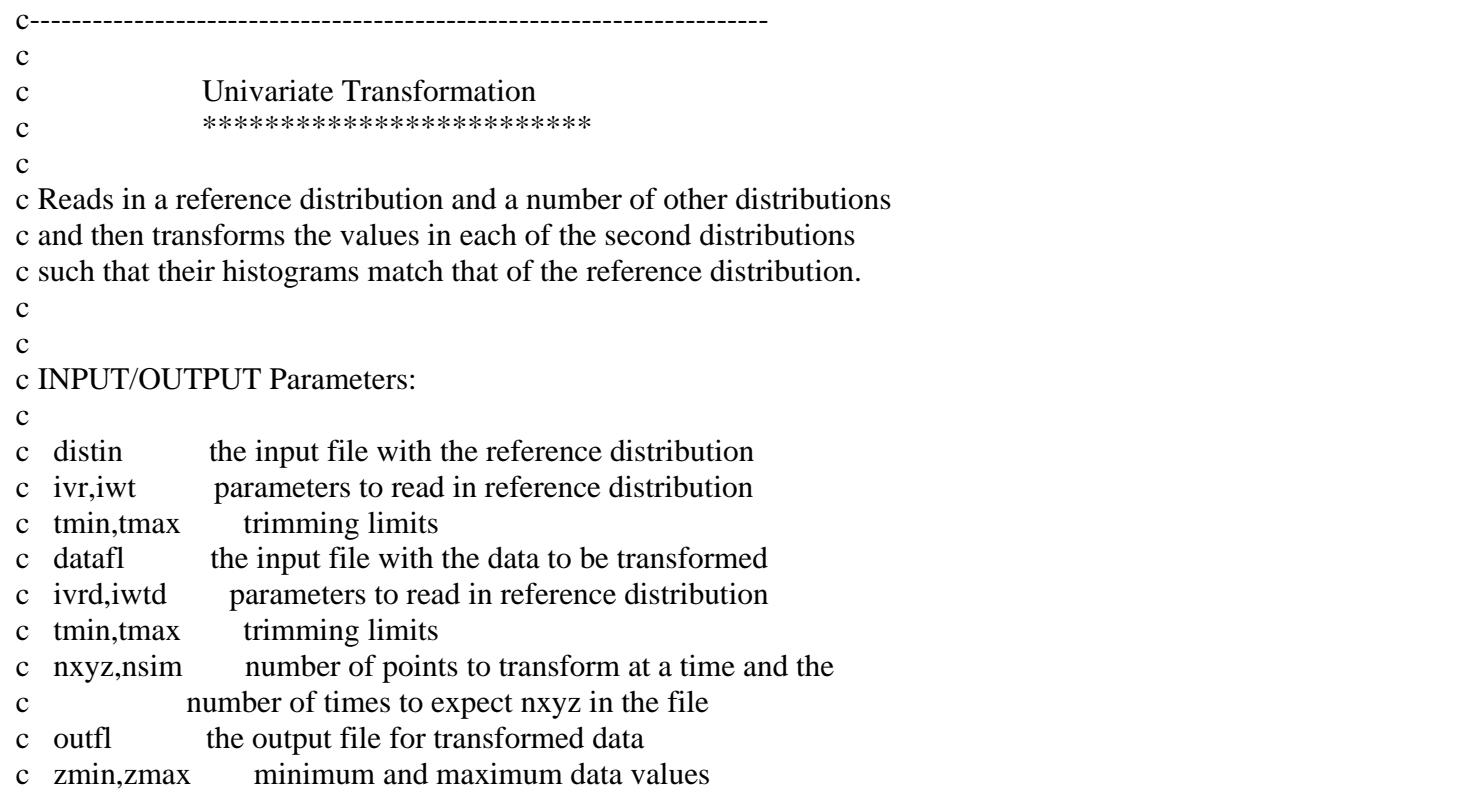




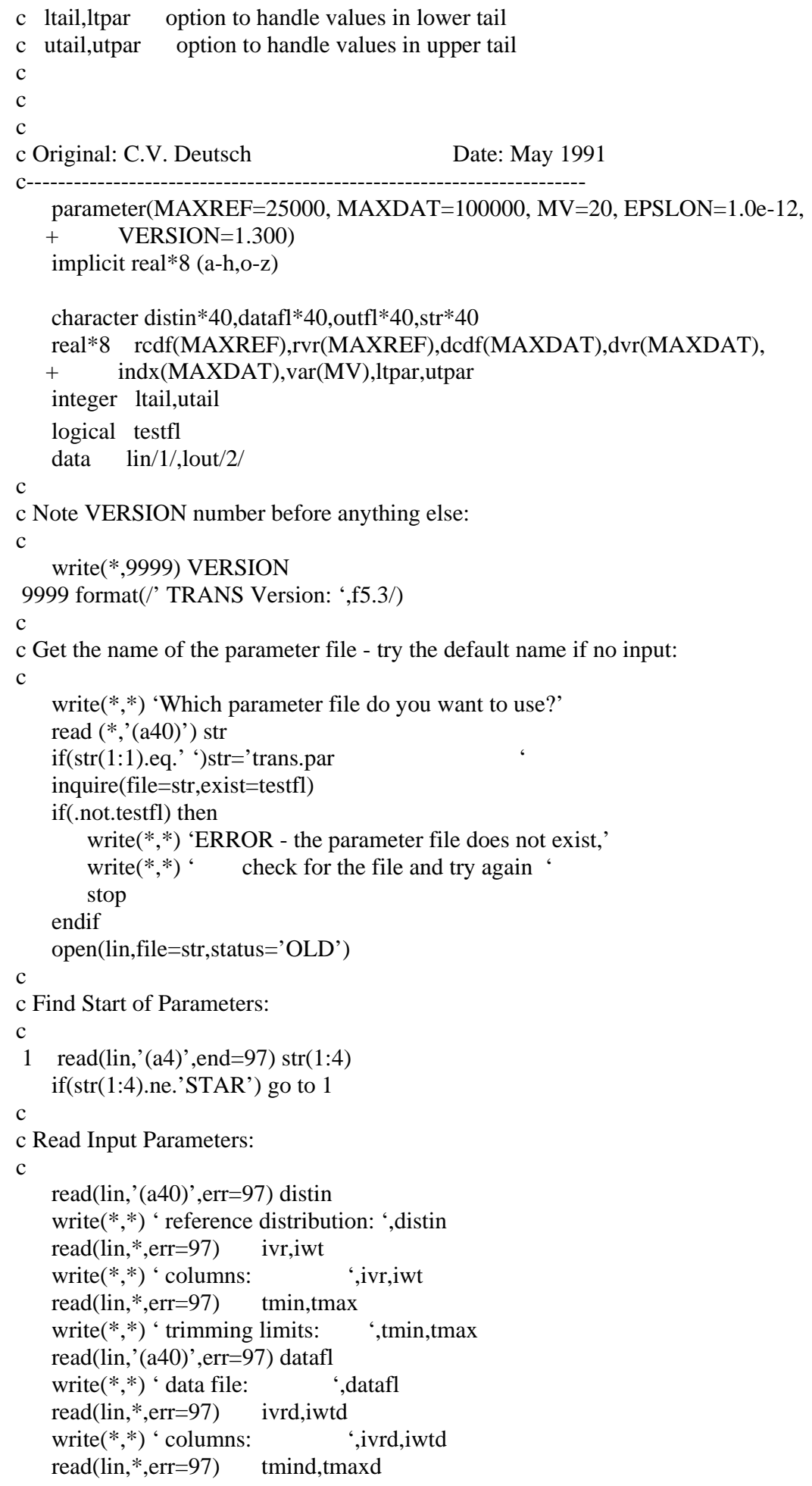




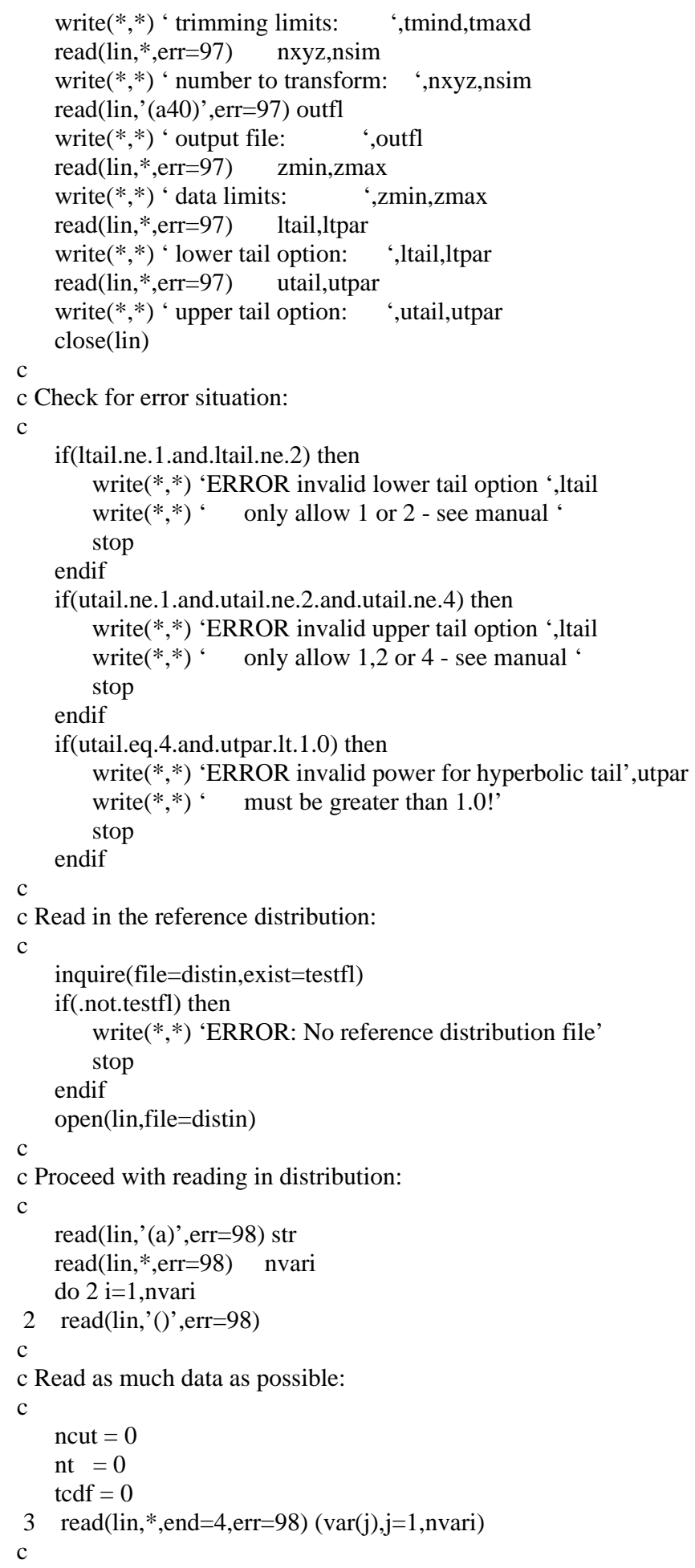


c Trim this data?

c

if(var(ivr).lt.tmin.or.var(ivr).ge.tmax) then

$\mathrm{nt}=\mathrm{nt}+1$

go to 3

endif

if(iwt.ge.1) then

if( $\operatorname{var}(\mathrm{iwt})$. le.EPSLON) then

$\mathrm{nt}=\mathrm{nt}+1$

go to 3

endif

endif

$\mathrm{c}$

c Accept this data:

c

ncut $=$ ncut +1

if(ncut.gt.MAXREF) then

write $(*, *)$ 'ERROR: exceeded available storage for reference'

write $(*, *)$ ' have ',MAXREF,' available'

stop

endif

$\operatorname{rvr}($ ncut $)=\operatorname{var}($ ivr $)$

if(iwt.ge.1) then

$\operatorname{rcdf}($ ncut $)=\operatorname{var}(i w t)$

else

$\operatorname{rcdf}($ ncut $)=1.0$

endif

c

tcdf $=$ tcdf $+\operatorname{rcdf}($ ncut $)$

c Go back for another data:

$\mathrm{c}$

go to 3

4 close(lin)

write $(*, *)$

write $(*, *)$ ' TRANS: there were ',ncut,' reference values'

write $(*, *)$ ' trimmed ',nt,' values'

write $(*, *)$ ' the total weight ',tcdf

c

c Sort the Reference Distribution and Check for error situation:

c

call sortem(1,ncut,rvr, 1, rcdf,c,d,e,f,g,h)

if(ncut.le.1.or.tcdf.le.EPSLON) then

write $(*, *)$ 'ERROR: too few data or too low weight'

stop

endif

if(utail.eq.4.and.rvr(ncut).le.0.0) then

write $(*, *)$ 'ERROR can not use hyperbolic tail with ‘

write $(*, *)$ ' negative values! - see manual ‘

stop

endif

if(zmin.gt.rvr(1)) then

write $(*, *)$ 'ERROR zmin should be no larger than smallest'

write $(*, *)$ ' reference value'

write $(*, *)$ ' $\quad$ zmin = ',zmin,' vr1 ',rvr(1) 


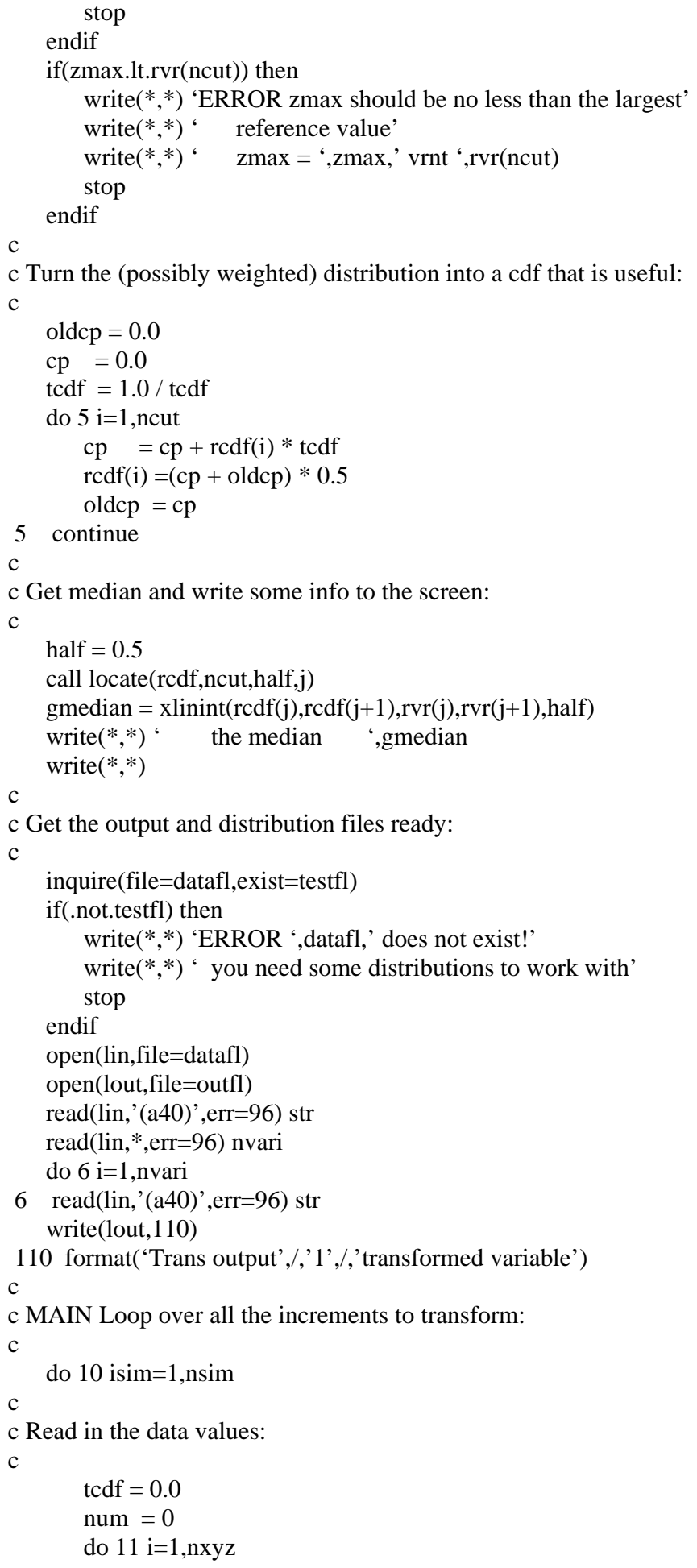




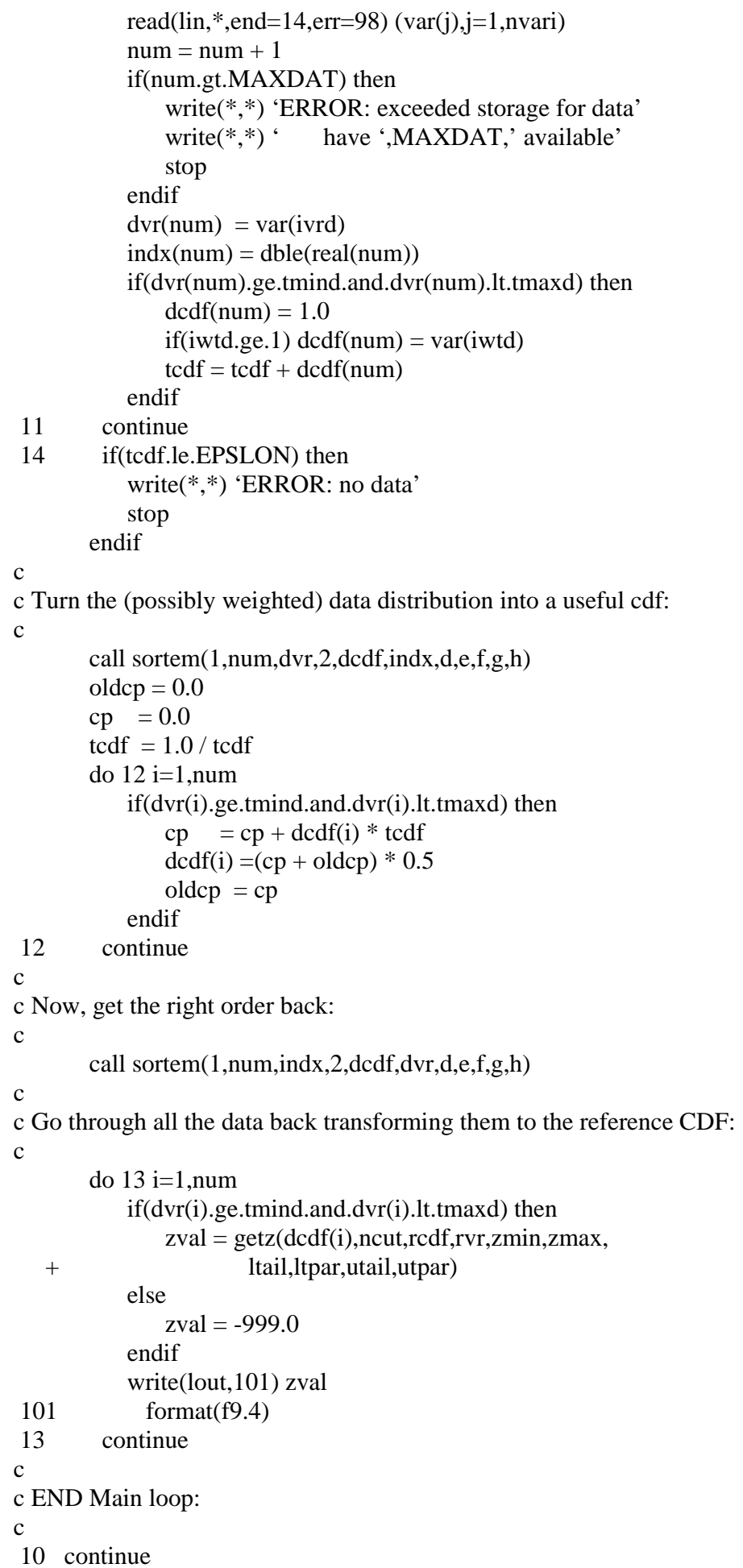




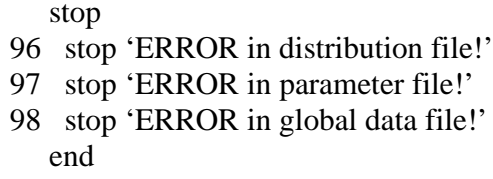




\section{c OR, ARE WE IN THE MIDDLE?}

$\mathrm{c}$

else if(ipart.eq.1) then

call locate(rcdf,ncut,cdfval,cclow)

cchigh $=$ cclow +1

getz $=$ xlinint $(\operatorname{rcdf}($ cclow $), \operatorname{rcdf}($ cchigh $)$,

$+\quad \operatorname{rvr}($ cclow),rvr(cchigh),cdfval)

$\mathrm{c}$

c OR, ARE WE IN THE UPPER TAIL?

c

else if(ipart.eq.2) then

c

Linear interpolation to upper limit zmax?

$\mathrm{c}$

if(utail.eq.1) then getz $=x \operatorname{linint}($ rcdf(ncut),one,rvr(ncut),

$+$

else if(utail.eq.2) then zmax,cdfval)

$$
\text { cpow }=1.0 / \text { utpar }
$$

$\mathrm{c}$

c Fit a Hyperbolic Distribution? Figure out "lambda":

c

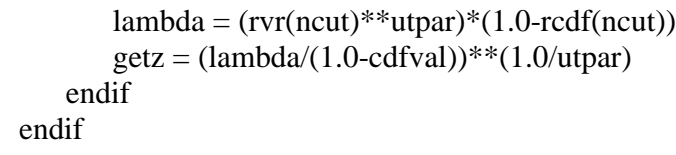


end

double precision function powint(xlow,xhigh,ylow,yhigh,xval,pow)

c-

c Power interpolate the value of y between (xlow,ylow) and (xhigh,yhigh)

c for a value of $\mathrm{x}$ and a power pow.

c

$\mathrm{c}$

parameter(EPSLON=1.0e-20)

implicit real*8 (a-h,o-z)

powint $=$ ylow $+\quad(\text { yhigh-ylow })^{*}$

$+\quad(((\text { xval-xlow)/amax1(EPSLON,(xhigh-xlow })))^{* *}$ pow $)$

return

end

subroutine locate $(\mathrm{xx}, \mathrm{n}, \mathrm{x}, \mathrm{j})$

c

c Given an array "xx" of length " $n$ ", and given a value " $x$ ", this routine

c returns a value " $\mathrm{j}$ " such that " $\mathrm{x}$ " is between $\mathrm{xx}(\mathrm{j})$ and $\mathrm{xx}(\mathrm{j}+1)$. $\mathrm{xx}$

$c$ must be monotonic, either increasing or decreasing. $j=0$ or $j=n$ is

$\mathrm{c}$ returned to indicate that $\mathrm{x}$ is out of range.

$\mathrm{c}$

c Bisection Concept From "Numerical Recipes”, Press et. al. 1986 pp 90.

real $* 8 \times x(n), x$

$\mathrm{c}$

c Initialize lower and upper methods:

$\mathrm{c}$

$\mathrm{jl}=0$

$\mathrm{ju}=\mathrm{n}$

c

c If we are not done then compute a midpoint:

$\mathrm{c}$

10 if(ju-jl.gt.1) then $\mathrm{jm}=(\mathrm{ju}+\mathrm{jl}) / 2$

$\mathrm{c}$

c Replace the lower or upper limit with the midpoint:

$\mathrm{c}$

if $((x x(n) \cdot g t \cdot x x(1)) \cdot e q v \cdot(x \cdot g t \cdot x x(j m)))$ then

$$
\mathrm{jl}=\mathrm{jm}
$$

else

$\mathrm{ju}=\mathrm{jm}$

endif

go to 10

endif

c

c Return with the array index:

$\mathrm{c}$ 


$$
\begin{aligned}
& \mathrm{j}=\mathrm{j} 1 \\
& \text { return } \\
& \text { end }
\end{aligned}
$$

subroutine sortem(ib,ie,a,iperm,b,c,d,e,f,g,h)

$\begin{array}{ll}\mathrm{c} & \\ \mathrm{c} & \text { Quickersort Subroutine } \\ \mathrm{c} & * * * * * * * * * * * * * * * * * * *\end{array}$

c This is a subroutine for sorting a real array in ascending order. This c is a Fortran translation of algorithm 271, quickersort, by R.S. Scowen $\mathrm{c}$ in collected algorithms of the ACM.

c

c The method used is that of continually splitting the array into parts c such that all elements of one part are less than all elements of the c other, with a third part in the middle consisting of one element. An c element with value $t$ is chosen arbitrarily (here we choose the middle c element). $i$ and $j$ give the lower and upper limits of the segment being $\mathrm{c}$ split. After the split a value $\mathrm{q}$ will have been found such that $\mathrm{c} a(\mathrm{q})=\mathrm{t}$ and $\mathrm{a}(\mathrm{l})<=\mathrm{t}<=\mathrm{a}(\mathrm{m})$ for all $\mathrm{i}<=\mathrm{l}<\mathrm{q}<\mathrm{m}<=\mathrm{j}$. The program then c performs operations on the two segments $(\mathrm{i}, \mathrm{q}-1)$ and $(\mathrm{q}+1, \mathrm{j})$ as follows c The smaller segment is split and the position of the larger segment is $\mathrm{c}$ stored in the lt and ut arrays. If the segment to be split contains c two or fewer elements, it is sorted and another segment is obtained $\mathrm{c}$ from the lt and ut arrays. When no more segments remain, the array $\mathrm{c}$ is completely sorted.

c

$\mathrm{c}$

\section{c INPUT PARAMETERS:}

ib,ie start and end index of the array to be sorteda

a array, a portion of which has to be sorted.

c iperm no other array is permuted.

1 array $b$ is permuted according to array $a$

2 arrays b,c are permuted.

3 arrays b,c,d are permuted.

4 arrays b,c,d,e are permuted.

5 arrays b,c,d,e,f are permuted.

6 arrays b,c,d,e,f,g are permuted.

7 arrays b,c,d,e,f,g,h are permuted.

$>7$ no other array is permuted.

b,c,d,e,f,g,h arrays to be permuted according to array a.

c OUTPUT PARAMETERS:

c

c $\mathrm{a}=$ the array, a portion of which has been sorted.

b,c,d,e,f,g,h =arrays permuted according to array a (see iperm)

c NO EXTERNAL ROUTINES REQUIRED: 


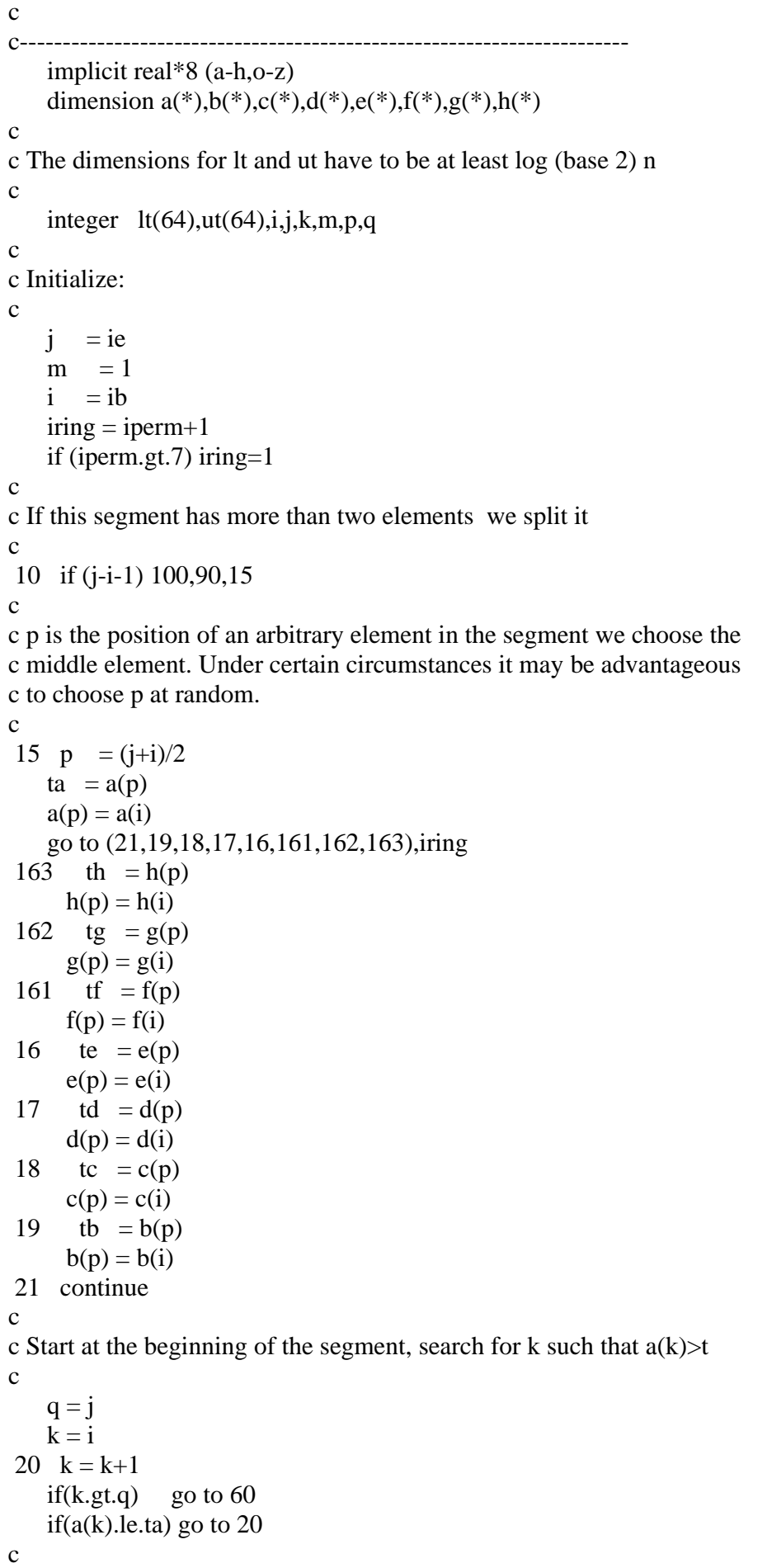

c Such an element has now been found now search for a $q$ such that $a(q)<t$ 
c starting at the end of the segment.

c

30 continue

if(a(q).lt.ta) go to 40

$\mathrm{q}=\mathrm{q}-1$

if(q.gt.k) go to 30

go to 50

$\mathrm{c}$

$\mathrm{c} a(\mathrm{q})$ has now been found. we interchange $\mathrm{a}(\mathrm{q})$ and $\mathrm{a}(\mathrm{k})$

$\mathrm{c}$

$40 \quad \mathrm{xa}=\mathrm{a}(\mathrm{k})$

$\mathrm{a}(\mathrm{k})=\mathrm{a}(\mathrm{q})$

$a(q)=x a$

go to $(45,44,43,42,41,411,412,413)$,iring

$413 \mathrm{xh}=\mathrm{h}(\mathrm{k})$

$\mathrm{h}(\mathrm{k})=\mathrm{h}(\mathrm{q})$

$h(q)=x h$

$412 x g=g(k)$

$\mathrm{g}(\mathrm{k})=\mathrm{g}(\mathrm{q})$

$\mathrm{g}(\mathrm{q})=\mathrm{xg}$

$411 x f=f(k)$

$f(k)=f(q)$

$f(q)=x f$

$41 \quad \mathrm{xe}=\mathrm{e}(\mathrm{k})$

$\mathrm{e}(\mathrm{k})=\mathrm{e}(\mathrm{q})$

$e(q)=x e$

$42 \quad \mathrm{xd}=\mathrm{d}(\mathrm{k})$

$\mathrm{d}(\mathrm{k})=\mathrm{d}(\mathrm{q})$

$\mathrm{d}(\mathrm{q})=\mathrm{xd}$

$43 \quad \mathrm{xc}=\mathrm{c}(\mathrm{k})$

$\mathrm{c}(\mathrm{k})=\mathrm{c}(\mathrm{q})$

$c(q)=x c$

$44 \quad \mathrm{xb}=\mathrm{b}(\mathrm{k})$

$\mathrm{b}(\mathrm{k})=\mathrm{b}(\mathrm{q})$

$b(q)=x b$

45 continue

c

c Update q and search for another pair to interchange:

$\mathrm{c}$

$\mathrm{q}=\mathrm{q}-1$

go to 20

$50 \mathrm{q}=\mathrm{k}-1$

60 continue

$\mathrm{c}$

c The upwards search has now met the downwards search:

c

$\mathrm{a}(\mathrm{i})=\mathrm{a}(\mathrm{q})$

$\mathrm{a}(\mathrm{q})=\mathrm{ta}$

go to $(65,64,63,62,61,611,612,613)$,iring

$613 \mathrm{~h}(\mathrm{i})=\mathrm{h}(\mathrm{q})$

$h(q)=$ th

$612 \mathrm{~g}(\mathrm{i})=\mathrm{g}(\mathrm{q})$

$\mathrm{g}(\mathrm{q})=\operatorname{tg}$

$611 \mathrm{f}(\mathrm{i})=\mathrm{f}(\mathrm{q})$ 


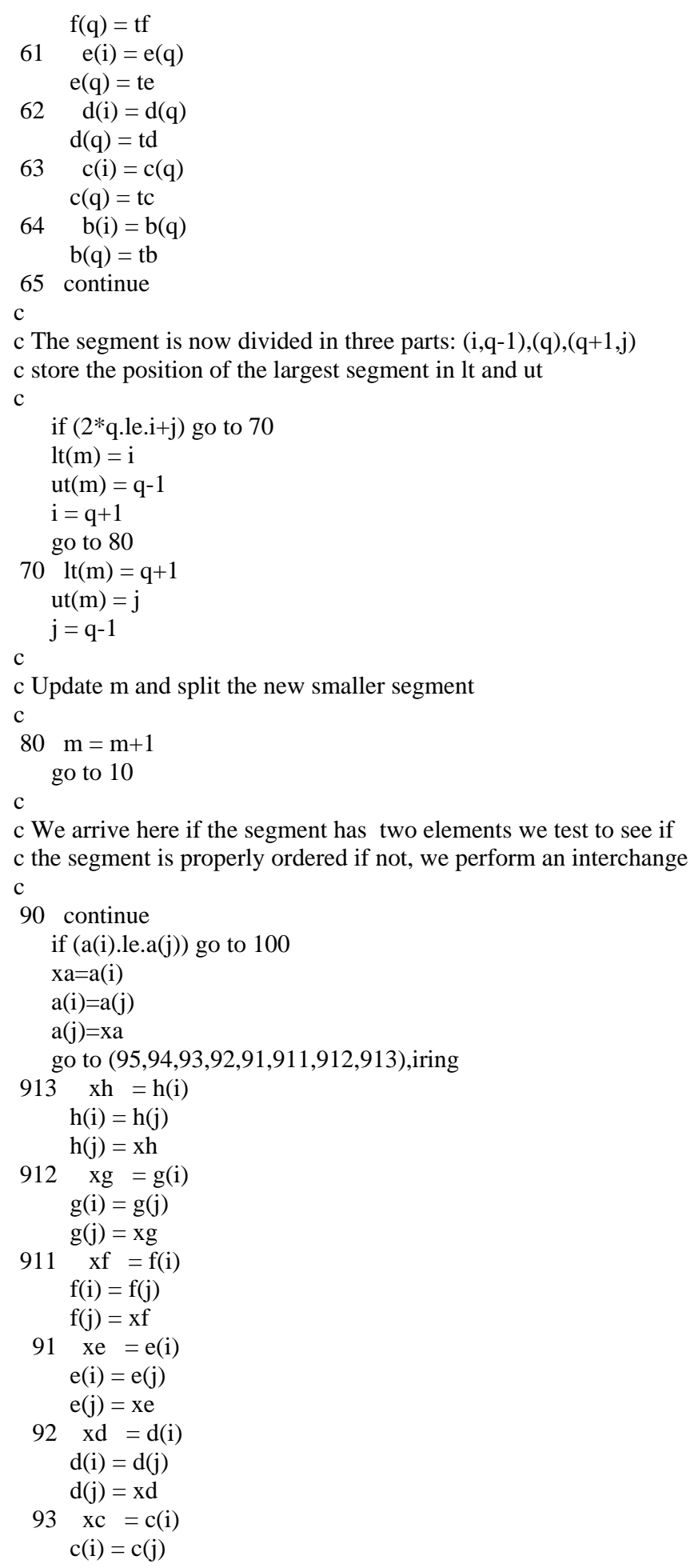




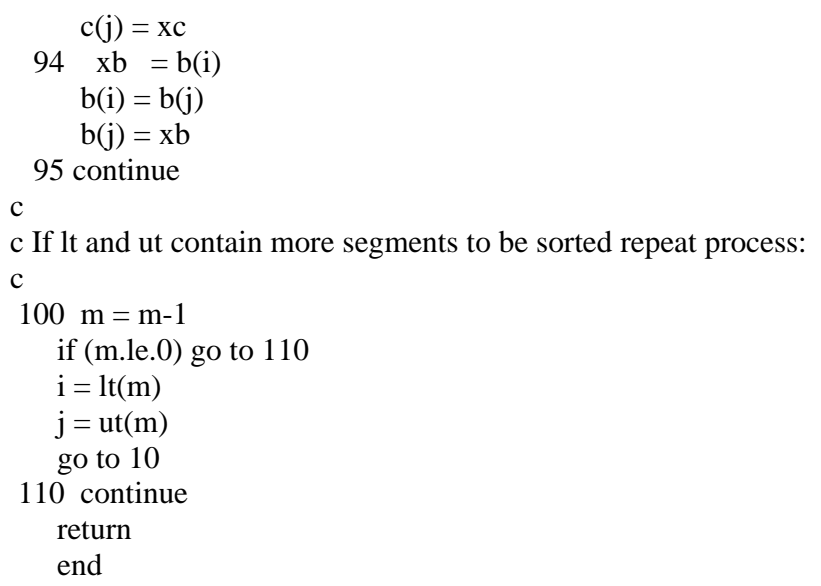

\section{Parameter File for TRANS}

The following lines are the input "parameter" file for TRANS. This file must be edited using a standard ASCII text editor to specify the appropriate quantities for the problem under consideration.

Parameters for TRANS

$* * * * * * * * * * * * * * * * * * * *$

START OF PARAMETERS:

..../data/true.dat

10

$-1.0 \mathrm{e} 21 \quad 1.0 \mathrm{e} 21$

..../data/cluster.dat

30

$-1.0 \mathrm{e} 21 \quad 1.0 \mathrm{e} 21$

$1000 \quad 1$

trans.out

$\begin{array}{ll}0.0 & 250.0\end{array}$

11.0

$\begin{array}{ll}4 & 1.5\end{array}$

\author{
Ifile with ref distribution \\ liv, iwt \\ Itmin, tmax \\ Ifile with uncorrected dists \\ livr, iwt \\ Itmin, tmax \\ Inxyz, nsim \\ Ifile for revised distributions \\ Izmin, zmax \\ lower tail: option, parameter \\ lupper tail: option, parameter
}

\section{Validation Exercise for TRANS}

The following activities were conducted as a validation exercise for software routine TRANS. A distribution of values was selected (the choice of distribution is arbitrary). Specifically, a standard-normal distribution was chosen, coregionalized after matrix porosity in the $\mathrm{CHn}$ model unit (number of values, $N=35,088$ ). Note, however, that the spatial information is never used in the transformation process. This arbitrary univariate distribution was processed through TRANS using the univariate distribution of bulk density values obtained from laboratory measurements on core samples $(N=510)$ as the reference distribution. Again, the specific choice of a reference distribution is arbitrary. At the end of processing, the transformed distribution is virtually identical in form to that of the reference distribution, and the validation exercise is complete.

Note that the maximum and minimum values (and therefore the total range) of the transformed distribution are not limited by the necessarily limited and incomplete set of measured values. 
The following statistical and graphical observations indicate that the transformation has been accomplished properly (Table B-1):

Table B-1. Comparative Statistics for Input, Transformed, and Reference Distributions

\begin{tabular}{|c|c|c|c|}
\hline & Input & Transformed & Reference \\
\hline Mean & 0.0950 & 1.6812 & 1.6814 \\
\hline Std.Dev. & 0.8821 & 0.1534 & 0.1525 \\
\hline Minimum & -3.8911 & 0.8081 & 1.3590 \\
\hline Maximum & 3.4005 & 2.3987 & 2.3110 \\
\hline $\mathrm{N}$ & 35,088 & 35,088 & 510 \\
\hline
\end{tabular}

1. The transformation is one-to-one, with the lowest input value corresponding to the lowest transformed value, the next highest input value corresponding to the next highest transformed value, and so on (monotonically increasing; Figure B-1.)

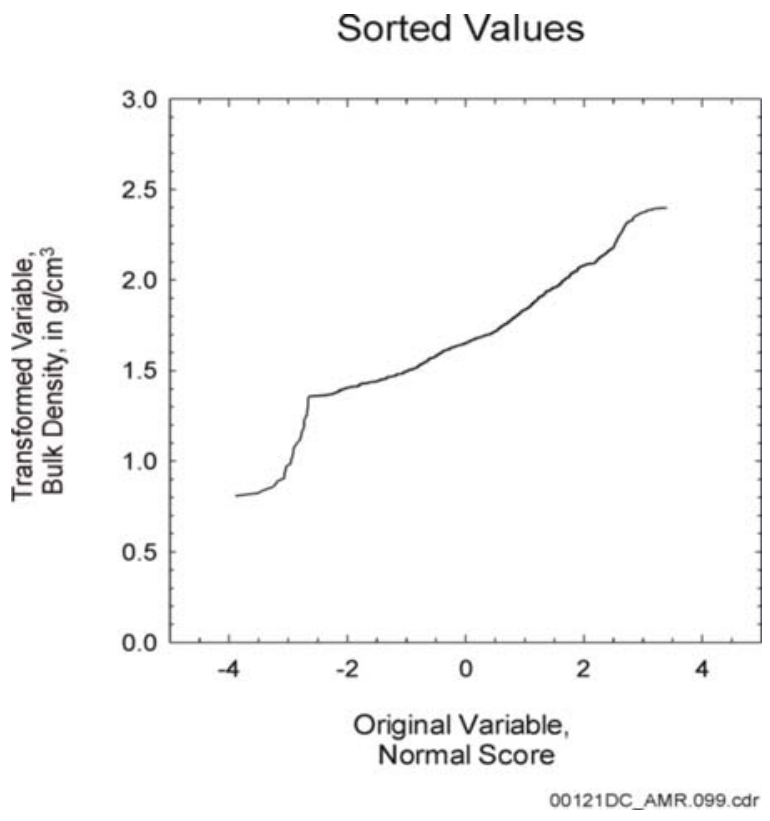

Figure B-1. Cross plot of the Transformed Variable as a Function of the Input Variable Indicating a One-to-One Monotonically Increasing, but Nonlinear, Relationship

2. The initial input and transformed output distributions are, in fact, different (Figure B-2.)

3. The transformed output distribution is essentially identical to the target reference distribution in that the two curves overlie one another exactly (Figure B-3.). 

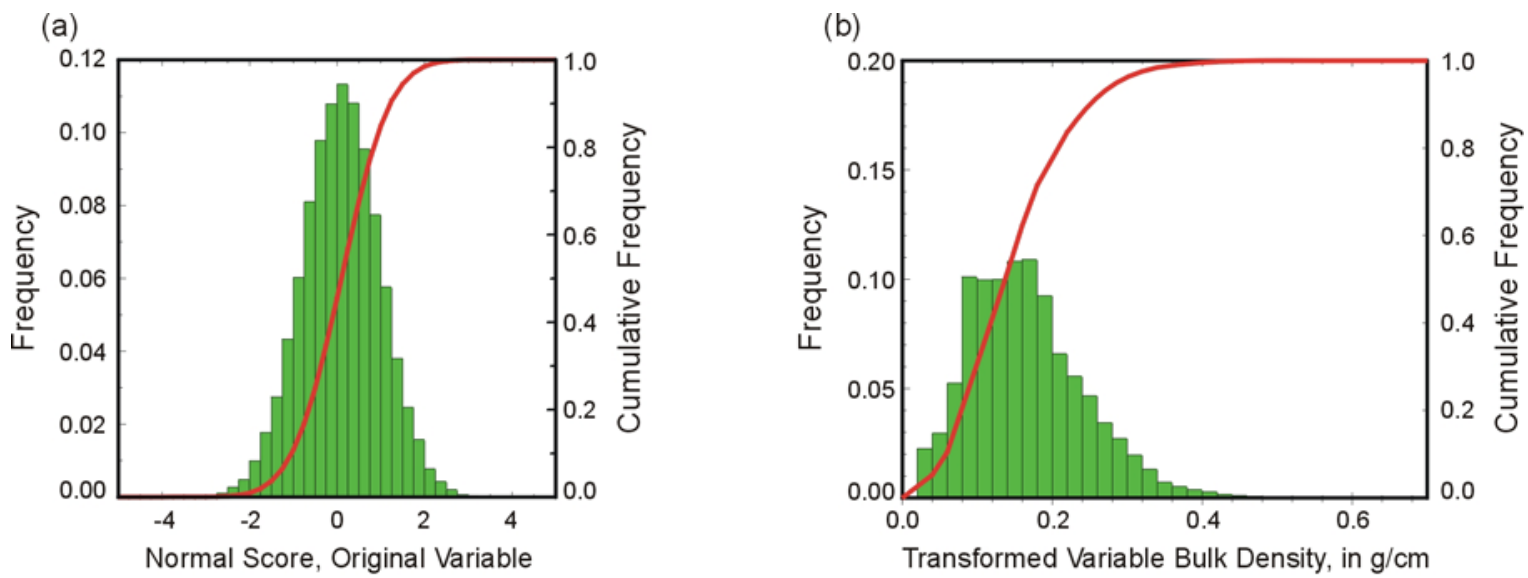

00121DC_AMR_108b.cdr

Figure B-2. Histograms and Cumulative Distribution Functions for (a) Input Standard-Normal Distribution and (b) Transformed Distribution Where $\mathrm{N}=35,088$ (both figures)

(a)

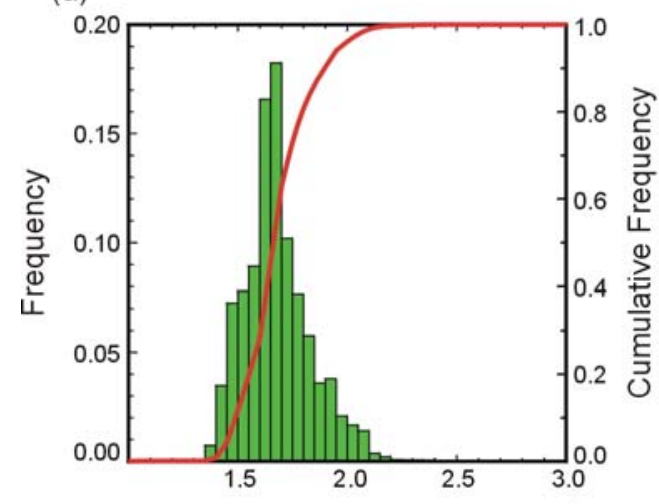

Target Variable Bulk Density, in $\mathrm{g} / \mathrm{cm}^{3}$ (b)

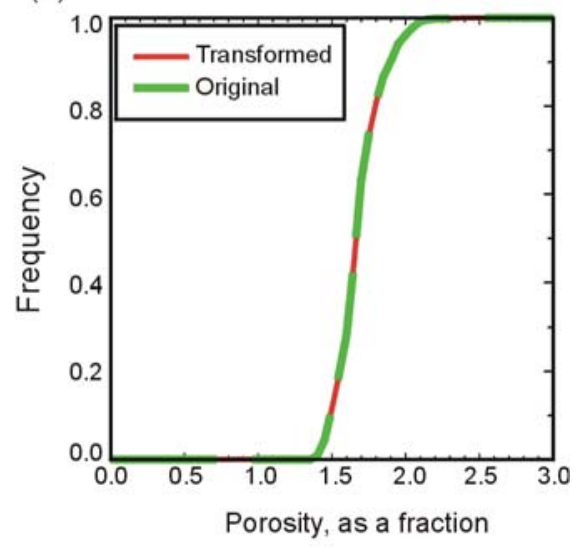

00121DC AMR 121b.cdr

Figure B-3. (a) Histogram and Cumulative Distribution Function for the Target Reference Distribution; Compare with Figure B-2 (b) where $N=510$. (b) Comparison of cumulative distribution functions for the transformed [Figure B-2(b)] and target distributions [Figure B-3(a)] 
APPENDIX C

VALIDATION OF UNCERT PROGRAM “VARIO” 
NOTE: The software documentation is for information only and to provide completeness and traceability.

\section{Background}

Program VARIO, versions 1.16 and 1.20 , which is part of the industry-standard geostatistical software package UNCERT, is intended to compute a simple experimental variogram based on measured data spatially distributed in (up to) three-dimensions. The program was available to the Yucca Mountain Project as a compiled Unix executable. Accordingly, a source listing is not available.

The algebraic formula for computation of the variogram is extremely simple, and is essentially equivalent to that for a variance. The variogram value, gamma $(\gamma)$, is specified simply as one-half the average squared difference of all pairs of points separated by a specified vector distance, $h$ :

$$
\gamma_{h}=\frac{1}{2 N_{h}} \sum_{n=1}^{N_{h}}\left[Z_{(x)}-Z_{(x+h)}\right]^{2}
$$

where $Z_{x}$ is the value at spatial location, $x, Z_{(x+h)}$ is the value at a location a vector $h$ distant, and $N_{h}$ is the number of such pairs that can be identified. The variogram value is computed for a number of different separation values, and the results are plotted as a function of $h$.

In practice, because the input data locations are not generally located on a regular grid, the separation vector is typically taken as a nominal distance plus-or-minus some tolerance value, usually set equal to one-half the "lag" spacing of the nominal values. The actual average separation distance is the $h$ value used in plotting the variogram. Additionally, the orientation of the separation vector is typically specified as some nominal direction plus-or-minus a "half-angle" tolerance value. An "omnidirectional" variogram computed without regard for orientation of the vector, $h$, is specified using a half-angle tolerance of 90 degrees. A "bandwidth" distance value, computed normal to the nominal vector orientation, may be used in conjunction with the angular tolerance value to limit the sample locations selected for inclusion in the computation. The search parameters in VARIO are user specified.

\section{Procedure}

Because of the near-infinite number of lag spacing-angular orientation and tolerance-bandwidth combinations that are possible for all possible pairs of values of a large data set in three dimensions, the trick for validating a variogram program, such as VARIO, is to design a synthetic data set that is computationally tractable for manual calculation. The data set for which the locations are shown in Figure C-1 is specifically designed to test the search capabilities of VARIO and to allow manual reproduction of the variogram value for one lag distance. The calculations are easily conducted in a spreadsheet program, such as EXCEL 97. 

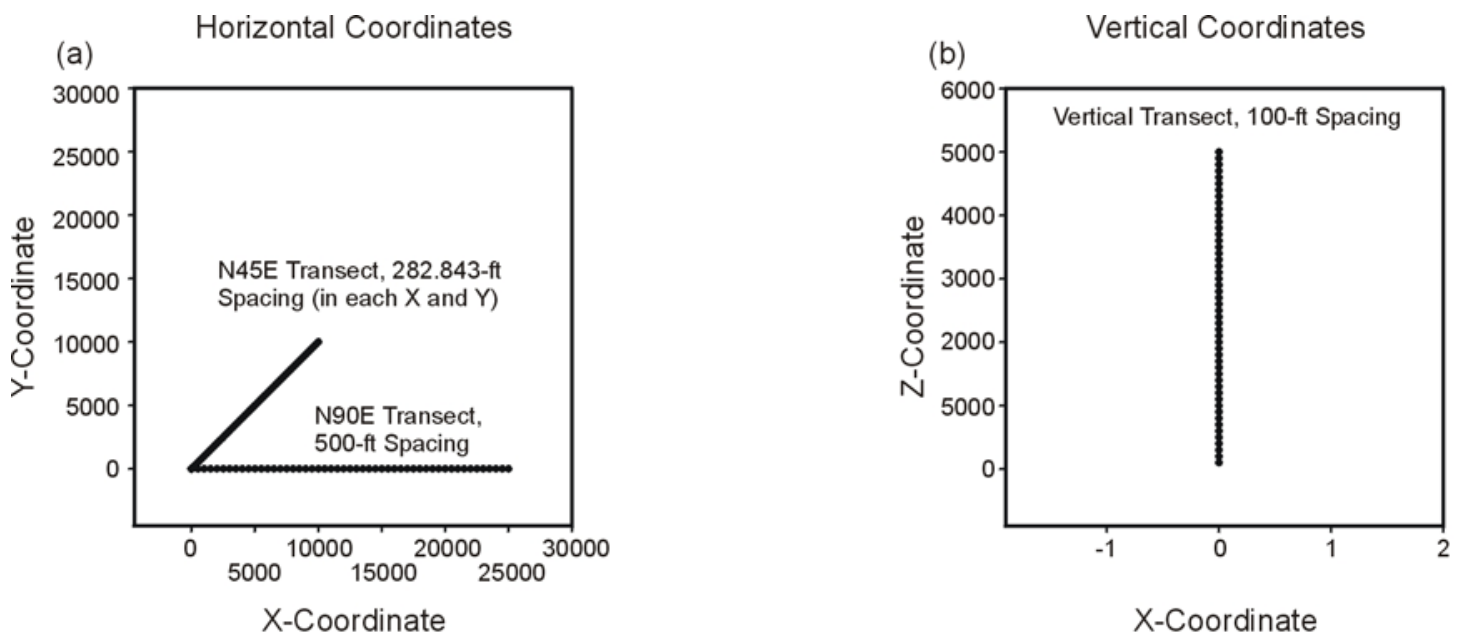

00121DC_AMR_100a.cdr

Source: For illustrative purposes only

NOTE: Individual points may overlap at the scale shown. (a) horizontal plane, (b) vertical plane

Figure C-1. Locations of Sample Values for the Test Case Data Set

One subset of the data set appears as the east-trending series of points shown in Figure C-1(a). These locations consist of 50 randomly generated "data" values located at 500 (arbitrary) grid units apart along a line with the $y$-coordinate equal to zero. The second subset again consists of another 50 randomly generated values located at positions described by $x$ - and $y$-coordinates regularly increasing by 200 arbitrary units. This paired-coordinate scheme produces a 45 -degree line with a sample spacing of $200 \sqrt{2}=282.843$ units. The third subset of data consists of 50 additional randomly generated values equally spaced at 100 -unit intervals in the $z$-coordinate direction.

The object of the validation exercise is to specify the relevant search parameters in each different direction with a very small tolerance (e.g. N45E plus-or-minus 5 degrees or a bandwidth of plus-or-minus 5 units), such that the search routines of VARIO locate only the samples belonging to each subset separately. This is the step that allows manual calculation of the corresponding values in EXCEL. The use of markedly different lag spacings for each subset allows identification of "mixing" of samples from the different subsets, something that would invalidate the simplistic manual computation. For example, if VARIO identify only the 500-unit-spaced values located along the $x$-axis. Because all data spacings are 500 units, the average lag distance, $h$, for the first lag should be precisely equal to 500.0 units. If the search locates pairs of points, one member of which belongs to another data subset, the average lag distance reported will differ from 500. The same logic applies in the other two directions.

As a further (although perhaps less-definitive) check of the search strategy portion of VARIO, the randomly generated "data" values were scaled differently for each subset of data. The 500-unit lag set was scaled between 0 and 1, the 200-unit lag set between 0 and 5, and the 100-unit lag set between 0 and 10. Although this means of checking the search results is less definitive than examination of the average lag spacing, the different magnitudes provide the opportunity for improperly identified pairs to influence the VARIO-computed gamma value disproportionately in 
comparison to the simple manual calculation. Random data values are appropriate, in that there is no particular spatial structure required for the validation exercise. It is sufficient to confirm that the algebraic calculation of Equation $\mathrm{C}-1$ is being carried out correctly.

If the search routine executed internally within VARIO properly identifies the members of each data subset separately, and if the mathematical computation of Equation C-1 is executed properly, then the gamma value returned for the first lag of each directional variogram should essentially be identical to the value of Equation C-1 computed manually for the pairs of the data set considered as the "tines on a comb" (Figure C-2). Such an ordered computation of squared differences is easily implemented using the cell-based arithmetic capabilities of Excel.

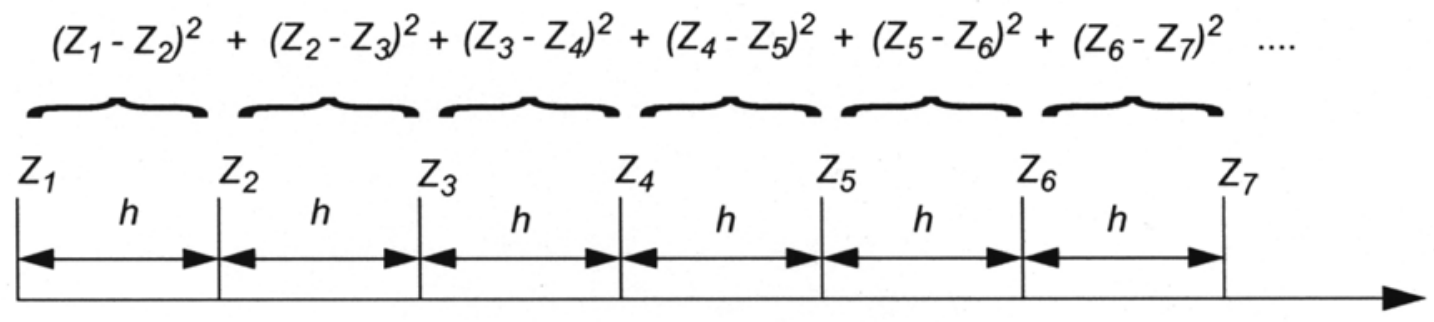

00121DC_AMR_123

Source: For illustrative purposes only.

NOTE: Gamma is computed as one-half the average squared difference.

Figure C-2. "Ordered" Computation of Squared Differences between Sequential Values Implemented in the "Manual" Calculation Using Excel 97

The validation criterion is "essentially identical" results computed by the two methods.

\section{Results}

Table C-1 presents the gamma values calculated by VARIO for the first lag for each directional variogram, as well as the actual average lag spacing, $h$, corresponding to each of the three data subsets. Also presented in the table are the results of the "manual" calculation conducted using the arithmetic capabilities of Excel.

Table C-1. Validation Results

\begin{tabular}{|l|c|r|r|r|}
\hline \multicolumn{2}{|c|}{ Data Subset } & \multicolumn{2}{c|}{ VARIO Results } & Excel Results \\
\hline Orientation & Nominal $\boldsymbol{h}$ & Average $\boldsymbol{h}$ & \multicolumn{1}{c|}{ Gamma } & Gamma \\
\hline NOE & 500 & 500.0000 & 0.0828 & 0.0828 \\
\hline N45E & 282.843 & 282.8427 & 11.1223 & 11.1222 \\
\hline Vertical & 100 & 100.0000 & 1.8289 & 1.8289 \\
\hline
\end{tabular}

Source: For illustrative purposes only. 
Examination of the table indicates two things: (1) The average lag spacing is precisely identical to the nominal spacing of the input data values. This indicates that the search algorithm has restricted the computation of the variogram value to only the pairs involved in each data subset. (2) The gamma values reported by the two calculation methods are effectively identical. Observed differences are limited to the fourth decimal place and are nonmeaningful. Accordingly, the conclusion is that VARIO is computing the experimental variogram values as desired. 
APPENDIX D

VALIDATION OF UNCERT PROGRAM “VARIOFIT" 
NOTE: The software documentation is for information only and to provide completeness and traceability.

\section{Background}

Program VARIOFIT Version 1.16, which is part of the "industry-standard" geostatistical software package UNCERT, is a simple program intended to compute and plot any of a number of algebraically defined variogram models for comparison with an experimental variogram derived from measured data. The program plots the underlying experimental variogram (computed separately with program "vario") to the screen and overlays the theoretical model calculation on that screen image. The program can also create a postscript output file containing the screen image for printing and write a ".out" file containing various information related to the modeled variogram. The program was available for Yucca Mountain Project use as a compiled Unix executable. Accordingly, a source listing is not available.

\section{Procedure}

The validation approach adopted is as follows:

1. A model variogram with arbitrary parameters is created using a dummy input variogram file to initialize the program (plotting of the dummy plot is turned off, and the input file is never used in the variogram model calculations).

2. The model variogram information is written to a ".out" file for plotting in a separate graphics package capable of simple mathematical calculations (SIGMAPLOT, ver. 5).

3. A second model variogram is computed in the second graphics package using the same input parameters.

4. The two models are plotted on the same graph using different symbols/line types and a visual comparison is made.

Validation has been conducted for the spherical variogram model (Deutsch and Journel 1998 [DIRS 102895]), which is the only of current interest. The formula for the spherical model is as follows:

$$
\gamma=\left\{\begin{aligned}
c \cdot\left[1.5 \frac{h}{a}-0.5 \frac{h^{3}}{a^{3}}\right] & \leftarrow h \leq a \\
c & \leftarrow h>a
\end{aligned}\right.
$$

where $c$ is the sill value associated with the model, $h$ is the lag spacing under consideration and $a$ is the range of the variogram model. A nugget component, $c 0$, may. be added to the formula for the spherical model. Spherical models may be "nested" by adding two (or more) functions of this form, each with its own sill and range values. 
The validation criterion is identical results by visual comparison.

\section{Results}

Shown in Figure D-1, a replicate of the screen image from VARIOFIT after entry of the variogram parameters and calculation of the model variogram. The model consists of two nested spherical structures plus a nugget effect. The parameters are indicated on the figure as: $c 0=2, \mathrm{c} 1=10$, $\mathrm{a} 1=1000, \mathrm{c} 2=25$, and $\mathrm{a} 2=5000$. The units for the range are arbitrary.

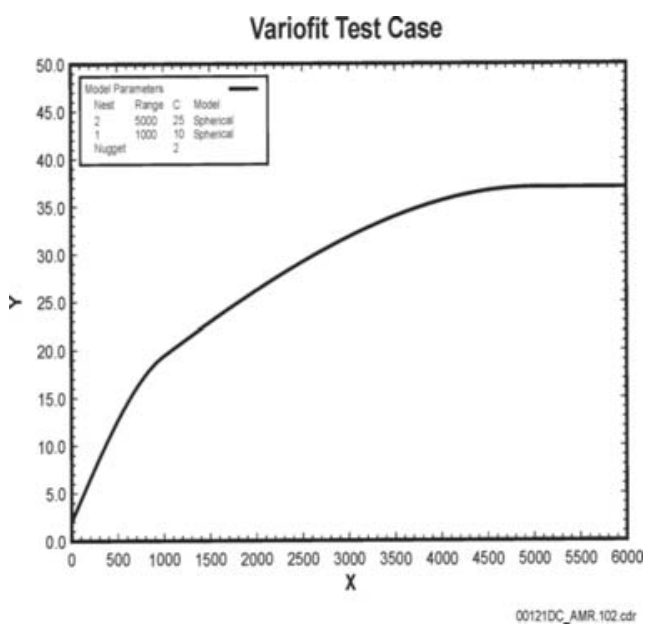

Source: For illustrative purposes only.

Figure D-1. Reproduced Screen Image of an Arbitrary Nested Variogram Model Generated Using the UNCERT Program, Variofit

Shown in Figure D-2, the replotted variogram model from VARIOFIT plus the independently computed model using the same parameters, generated using the graphics/spreadsheet package, SIGMAPLOT. Note that the two models appear to overlie one another precisely.

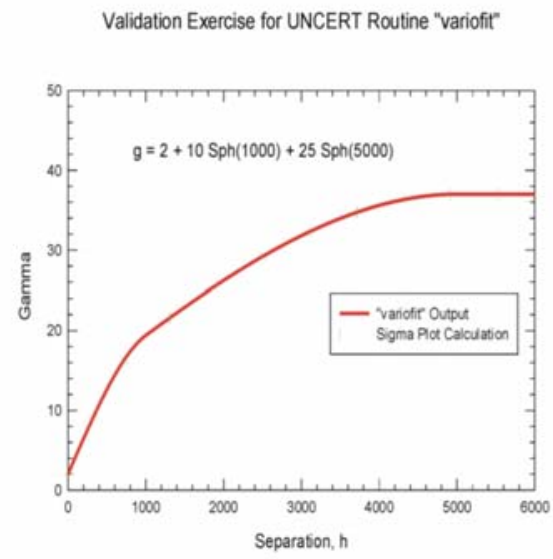

Source: For illustrative purposes only.

Figure D-2. Comparison of Model Variograms Generated by Program Variofit and by an Independent Computation Using Sigmaplot 


\section{Conclusion}

Based on the nearly exact correspondence between the variogram models computed by the two different methods (the maximum difference in gamma is 0.0005 compared to a total sill value of 37.0), we conclude that VARIOFIT is validated for use with the spherical model equation. A similar exercise could be conducted for other variogram model types, if necessary.

\section{Listing of SigmaPlot Transform}

;transform to compute nested spherical variograms

$\mathrm{c} 0=2.0$

$\mathrm{c} 1=10 . \quad \mathrm{a} 1=1000$

$\mathrm{c} 2=25 . \quad \mathrm{a} 2=5000$

$\mathrm{n}=8 \quad$; column in which to start variogram

$\operatorname{col}(\mathrm{n})=\operatorname{data}(0,7000,35) \quad$;lag distances to compute variogram for

; intermediate computational results: first nugget, then nest 1 , then nest 2

$\operatorname{col}(\mathrm{n}+2)=\mathrm{c} 0$

$\operatorname{col}(\mathrm{n}+3)=$ if $\left(\operatorname{col}(\mathrm{n})<\mathrm{a} 1, \mathrm{c} 1^{*}\left(1.5^{*} \operatorname{col}(\mathrm{n}) / \mathrm{a} 1-0.5^{*}\left(\operatorname{col}(\mathrm{n})^{\wedge} 3\right) /\left(\mathrm{a} 1^{\wedge} 3\right)\right), \mathrm{c} 1\right)$

$\operatorname{col}(\mathrm{n}+4)=\operatorname{if}\left(\operatorname{col}(\mathrm{n})<\mathrm{a} 2, \mathrm{c} 2 *\left(1.5^{*} \operatorname{col}(\mathrm{n}) / \mathrm{a} 2-0.5^{*}\left(\operatorname{col}(\mathrm{n})^{\wedge} 3\right) /\left(\mathrm{a} 2^{\wedge} 3\right)\right), \mathrm{c} 2\right)$

; output model and preservation of input parameters Output is sum of 3 cols

$\operatorname{col}(n+1)=\operatorname{col}(n+2)+\operatorname{col}(n+3)+\operatorname{col}(n+4)$

$\operatorname{cell}(18,1)=\mathrm{c} 0$

cell $(18,3)=\mathrm{c} 1$

cell $(18,4)=\mathrm{a} 1$

$\operatorname{cell}(18,6)=\mathrm{c} 2$

$\operatorname{cell}(18,7)=\mathrm{a} 2$

; compute difference between two methods

$\operatorname{col}(7)=\operatorname{col}(6)-\operatorname{col}(9)$

; preserve maximum delta gamma

$\operatorname{cell}(18,9)=\max (\operatorname{col}(7))$ 


\section{INTENTIONALLY LEFT BLANK}


APPENDIX E

DATA QUALIFICATION REPORT: CUTTINGS MINERALOGY DATA 


\section{E1. INTRODUCTION}

\section{E1.1 PURPOSE}

The purpose of this section is to qualify the XRD mineralogic abundance data used as an indicator of hydrous phase mineral alteration as described in Section 4.1.4. This is contrary to the information provided in the TWP (BSC 2004 [DIRS 169635], Section 8.3.3) that states "no data qualification issues affect the RPM report." This statement was made as no specific technical user was citing the product output representation of hydraulic conductivity as direct input. The hydraulic conductivity representation uses the XRD data as direct input. However, for completeness the data qualification report (QRD) prepared for the Mineralogic Model was included in this report as it qualifies all the XRD mineralogic abundance data cited by this report. The user is reminded that while this qualifies the XRD mineralogical data, the representation of hydraulic conductivity provided by this model has not been validated as discussed in Section 7.

This DQR uses the corroboration method according to Attachments 2 and 3 of AP-SIII.2Q, Qualification of Unqualified Data, to evaluate the data in DTN: LA9910DB831321.001 [DIRS 113568]. The qualification of XRD mineral abundance data is documented in Appendices E, F and G. However, DTN: LA9910DB831321.001 [DIRS 113568] has several DTN sources. Further the data contained in these DTNs has been repartitioned because of the qualification report of Steinborn, 2002 [DIRS 160702]. The relationship between the DTN: LA9910DB831321.001 [DIRS 113568] and its DTN sources and the changes caused by the qualification report are illustrated in Appendix H. The QRD of Steinborn, 2002 [DIRS 160702] and the qualification activity documented by Appendices E, F, and G qualifies the XRD mineralogic abundances cited as direct input by this report.

The initial scope of this qualification activity was the qualification of the DTN: MO0101XRDDRILC.001 [DIRS 169517]. The data addressed in this DQR originally were part of DTN: LADV831321AQ97.001 [DIRS 107142] or DTN: LADB831321AN98.002 [DIRS 109003]. These DTNs were evaluated by the technical assessment methods as documented by Steinborn (2002 [DIRS 160702]). The data in these DTNs consisted of mineral abundances determined by quantitative X-ray diffraction analysis of drill core, sidewall core, and drill cuttings. As described by Steinborn, a decision was made to not qualify data for sidewall core or drill cuttings because of the uncertainty in identifying the stratigraphic location from which the samples were obtained. It was recommended that these samples be used only to corroborate assumptions or other data. However, as described in this report further examination of the inputs to mineralogic model input DTNs revealed that DTNs LADV831321AQ97.001 [DIRS 107142], LADV831321AQ97.007 [DIRS 113499], and LA9910JC831321.001 [DIRS 113496] also require inclusion in this qualification activity.

The unqualified data considered in this $\mathrm{DQR}$ are direct inputs to this report. As described in Section 4.1.4 mineral abundance data are used as direct indicators of "hydrous-phase mineral alteration." The unqualified sidewall core and cuttings data provide mineralogic information for parts of the repository block and surrounding areas that otherwise would be unrepresented. In particular, many of these samples are from locations that are optimal to document lateral transitions in mineralogic assemblages. Three-dimensional representations of mineralogy and associated properties would be degraded by the omission of these data. Therefore, a 
qualification activity has been undertaken to assess the status of the specified data from sidewall core and cuttings.

The purpose of this DQR is to recommend data that can be cited as qualified for use in this report. The appropriateness and limitations (if any) of the data with respect to intended use are addressed in this DQR.

\section{E1.2 SCOPE}

This DQR evaluates the data identified in Qualification Plan for Unqualified Mineralogical Model (MDL-NBS-GS-000003) Data, Appendix A of TWP-NBS-GS-000003 REV 05 (BSC 2004 [DIRS 169635]). The data qualification plan identifies one unqualified DTN (MO0101XRDDRILC.001 [DIRS 169517]) containing or using acquired and developed mineral abundance data measured by investigators at Los Alamos National Laboratory (LANL). The DTN: MO0101XRDDRILC.001 [DIRS 169517] was created according to the recommendation of Steinborn (2002 [DIRS 160702]) that data from cuttings, sidewall samples, and intermittent core be segregated in a new, unqualified data package (Table E-1). The predecessor DTN: LADB831321AN98.002 [DIRS 109003] contains data that were originally published in a LANL report (Bish and Chipera 1989 [DIRS 101195]), plus additional data. A subset of the mineral abundance data in this DTN is used directly in mapping the distribution of a selected number of minerals and in correlation with rock properties for specific lithostratigraphic intervals.

These data are generally unqualified because the data and/or the samples were acquired before issuance of the OCRWM Quality Assurance Requirements and Description (DOE 2004 [DIRS 171539]). Some of the data were acquired according to technical procedures that had not, at that time, been approved for Yucca Mountain Project (YMP) work. YMP approval was obtained for LANL in 1991 (Horton 1990 [DIRS 169954]). The current qualification effort relies in part on the review of methods used for the x-ray diffraction (XRD) analyses of core samples qualified by Steinborn (2002 [DIRS 160702]). The methods used to analyze sidewall core and cuttings samples typically were the same as for core samples analyzed during the same time period.

Table E-1. Source DTNs of MO0101XRDDRILC.001 [DIRS 169517] and their Relevant Contents

\begin{tabular}{|l|l|}
\hline LADV831321AQ97.001 [DIRS 107142] & \multicolumn{1}{|c|}{ Mineralogy of USW H-3 sidewall core and cuttings samples } \\
\hline \multirow{5}{*}{ LADB831321AN98.002 [DIRS 109003] } & Mineralogy of UE-25 J-12 cuttings samples \\
\cline { 2 - 2 } & Mineralogy of USW H-3 sidewall core and cuttings samples \\
\cline { 2 - 2 } & Mineralogy of USW H-4 sidewall core and cuttings samples \\
\cline { 2 - 2 } & Mineralogy of USW WT-1 cuttings samples \\
\cline { 2 - 2 } & $\begin{array}{l}\text { Mineralogy of UE-25 p\#1 intermittent core, sidewall core, and } \\
\text { cuttings samples }\end{array}$ \\
\cline { 2 - 2 } & Mineralogy of USW WT-2 intermittent core and cuttings samples \\
\cline { 2 - 2 } & Mineralogy of USW H-5 sidewall core and cuttings samples \\
\hline
\end{tabular}


The current qualification activity also addressed whether the correct data sets were placed into DTN: MO0101XRDDRILC.001 [DIRS 169517]. The criterion was that all XRD data from sidewall core, drill cuttings, and intermittent core used as input to the Mineralogic Model (MM3.0) (BSC 2004 [DIRS 170031]), and excluded from qualification by Steinborn (2002 [DIRS 160702]), should have been placed into the DTN. Identification of data used as input was based on the contents of DTN: LA9908JC831321.001 [DIRS 113495], which contains the input files of mineralogic abundance data for the model. While it is true that the purpose of this qualification activity is to qualify data in MO0101XRDDRILC.001 [DIRS 169517] for any use on the Yucca Mountain Project, the specific data requirements of the mineralogical model must be addressed to provide maximum benefit. Appropriate recommendations will be made to achieve this goal.

In the process of this qualification activity, it was found that DTN: MO0101XRDDRILC.001 [DIRS 169517] and its predecessor DTN: LADB831321AN98.002 [DIRS 109003] do not contain all of the cuttings and sidewall core mineralogical data that were inputs to DTN: LA9908JC831321.001 [DIRS 113495] and the Mineralogic Model (MM3.0) (BSC 2004 [DIRS 170031]). Sources of input to the Mineralogical Model also include DTN: LADV831321AQ97.001 [DIRS 107142] and DTN: LADV831321AQ97.007 [DIRS 113499], both of which are listed in the Technical Data Management System as qualified even though they contain data from unqualified cuttings samples. An additional data source was the unqualified DTN: LA9910JC831321.001 [DIRS 113496].

\section{E1.3 BACKGROUND}

The DTNs in Table E-1 contain XRD data that were collected by LANL investigators beginning in the early 1980s and completed by 1986. Descriptions of the analytical methodologies for these data can be found in published LANL documents (Levy 1984 [DIRS 101392], Bish and Vaniman 1985 [DIRS 101196], Chipera and Bish (1988 [DIRS 105080]), and Bish and Chipera 1989 [DIRS 101195]). Table E-2 is an excerpt from a data set in DTN: MO0101XRDDRILC.001 [DIRS 169517] 
Table E-2. Sample Extraction from DTN: MO0101XRDDRILC.001 [DIRS 169517], SEP Table S01025_003, Illustrating the Data Type and Structure

\begin{tabular}{|c|c|c|c|c|c|c|c|}
\hline \multicolumn{8}{|c|}{$\begin{array}{l}\text { S01025_003 Data Report } \\
\text { Table Description: } \\
\text { Mineral Abundance data from X-Ray Diffraction analyses of sidewall and drill cuttings from } \\
\text { USW } \mathrm{H}-3,01 / 02 / 1981 \text { to } 11 / 01 / 1988 \text {. }\end{array}$} \\
\hline \multicolumn{8}{|c|}{ TDIF : $\quad 311749$} \\
\hline \multicolumn{8}{|c|}{ M00101XRDDRILC. $\odot \odot 1$} \\
\hline \multicolumn{8}{|c|}{$\begin{array}{l}\text { FOOTNOTES: Sample Number indicates depth in feet. Mineral Abundance values are reported in } \\
\text { weight percent. All uncertainty values are valid within two standard deviations. } \\
\text { Clinoptilolite Abundance represents clinoptilolite/heulandite group mineral abundance. Opal-CT } \\
\text { present in zeolitic tuff is reported as cristobalite. (SW) = sidewall core sample from Levy } \\
\text { (1984 [DIRS 101392]). Tr. = trace (less than } 0.5 \%) . \quad-\text { indicates not detected. Blanks are } \\
\text { intended. }\end{array}$} \\
\hline $\begin{array}{r}\text { PARAMETE } \\
\text { SME } \\
\text { MIC } \\
\text { CLI } \\
\text { MORI } \\
\text { TRI } \\
\text { QUA } \\
\text { CRI } \\
\text { FEL } \\
\text { GLA } \\
\text { HEM } \\
\text { HORI }\end{array}$ & 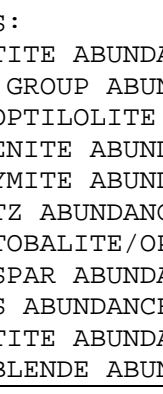 & $\begin{array}{l}\text { E } \\
\text { NCE } \\
\text { UNNDANCE } \\
\text { ICE } \\
\text { ICE } \\
\text { ABUNDANC }\end{array}$ & & & & & \\
\hline $\begin{array}{l}\text { SAMPLE } \\
\text { NUMBER }\end{array}$ & DEPTH $(m)$ & $\begin{array}{l}\text { SMECTITE } \\
\text { ABUNDANC } \\
\text { E (\%) }\end{array}$ & $\begin{array}{l}\text { SMECTITE } \\
\text { UNCER- } \\
\text { TAINTY } \\
(+/-)\end{array}$ & $\begin{array}{l}\text { MICA GROUP } \\
\text { ABUNDANCE } \\
(\%)\end{array}$ & $\begin{array}{l}\text { MICA GROUP } \\
\text { UNCERTAINT } \\
Y(+/-)\end{array}$ & $\begin{array}{l}\text { CLINOPTILO } \\
- \text { LITE } \\
\text { ABUNDANCE } \\
(\%)\end{array}$ & $\begin{array}{l}\text { CLINOPTILO } \\
- \text { LITE } \\
\text { UNCERTAINT } \\
Y(+/-)\end{array}$ \\
\hline $470-480$ & $\begin{array}{l}143.3- \\
146.3\end{array}$ & - & & 2 & 1 & - & \\
\hline $520-530$ & $\begin{array}{l}158.5- \\
161.5\end{array}$ & - & & - & & - & \\
\hline $1550(\mathrm{SW})$ & 472.4 & Tr. & & 1 & 1 & 2 & 3 \\
\hline $1800(\mathrm{SW})$ & 548.6 & 2 & 3 & 1 & 1 & 60 & 10 \\
\hline
\end{tabular}

$\mathrm{DTN}=$ data tracking number; TDIF=technical data information form 


\section{E2. QUALIFICATION METHODS}

The qualification method of corroboration is used in this DQR to determine the degree to which mineralogic data for the sidewall core and cuttings samples are consistent with qualified mineralogic information for the same stratigraphic units in nearby cored boreholes. The corroborating-data method involves comparing different data sets to evaluate the consistency of mineral content within lithostratigraphic units between the existing unqualified data and data that have been qualified under a qualification report or data with verified $Q$ status. In addition, inferences of similar primary texture, mineralogy, or mineralogical alteration between cuttings data and the data from core samples were identified and documented wherever this information aided the corroboration process.

The initial evaluation of data quality and correctness reviewed the uncertainties associated with collection of cuttings and sidewall-core samples. The principal uncertainty is in assigning depths to the cutting samples and sidewall-core samples. The existing data sets of cuttings and sidewall-core samples lack the visible record of continuous core needed to provide the highest level of confidence in the accuracy of recorded sampling depths. Uncertainties may also be associated with the subsampling of cuttings samples. Subsampling can be problematic because the samples commonly have mixed lithologies including rock types from depths shallower than the nominal sample depth. Records supporting the unqualified data and the adequacy of the procedures or methods used were reviewed and addressed in the evaluation of these data. Types of records examined included evidence of procedures in use when the samples were collected, sample collection and description records, XRD analysis records, and additional types of sample analyses that document sample integrity.

\section{E2.1 EVALUATION CRITERIA}

The types of geologic sample materials subject to qualification are identified for each borehole in Table E-3. The criteria of consideration in evaluating the qualification of the unqualified cuttings mineralogical data include the following conditions.

- Do samples from a particular lithostratigraphic unit have mineralogic abundances similar to samples of the same unit from qualified borehole data sets?

- Do samples from a succession of lithostratigraphic units show mineralogic changes between units that are consistent with changes observed in the qualified data sets?

- Does at least some documentation exist for sample collection, sample description, or X-ray diffraction analysis?

- Is the X-ray diffraction methodology used comparable to the methodology used to collect data for qualified data sets? 
Table E-3. List of Boreholes in DTN: MO0101XRDDRILC.001 [DIRS 169517], Material Type Analyzed, and Qualification Status of the Material

\begin{tabular}{|c|l|c|}
\hline Well & \multicolumn{1}{|c|}{ Material Type } & Qualification Status \\
\hline UE-25 J-12 & Cuttings & Unqualified \\
\hline UE-25 p\#1 & Cuttings, Intermittent Core, Sidewall Core & Unqualified \\
\hline USW H-3 & Cuttings, Sidewall Core & Unqualified \\
\hline USW H-4 & Cuttings, Sidewall Core & Unqualified \\
\hline USW H-5 & Cuttings, Sidewall Core & Unqualified \\
\hline USW WT-1 & Cuttings & Unqualified \\
\hline USW WT-2 & Cuttings, Intermittent Core & Unqualified \\
\hline
\end{tabular}

These criteria were selected to incorporate the considerations in procedure AP-SIII.2Q Attachments 2 and 3, plus data-specific considerations.

This evaluation was primarily qualitative in nature because the number of cuttings or sidewall samples from certain drill holes is small and many lithostratigraphic units are represented by only one sample in a data set. The basic statistic for data comparisons is the raw data range representing the upper and lower bounds of mineral abundance in a lithostratigraphic unit.

\section{E3. EVALUATION RESULTS}

The evaluation results are presented on a borehole-by-borehole basis in each of the following sections. Section E3.1 provides a comparison of samples analyzed between DTNs MO0101XRDDRILC.001 [DIRS 169517], LADB831321AN98.002 [DIRS 109003], LADV831321AQ97.001 [DIRS 107142], LADV831321AQ97.007 [DIRS 113499], LA9910JC831321.001 [DIRS 113496], and LA9908JC831321.001 [DIRS 113495]. Section E3.2 reviews the existing records pertinent to sample collection, description, and preparation for XRD analysis. Section E3.3 provides descriptions of the XRD methodologies used to analyze samples from the boreholes. Section E3.4 contains comparisons of mineralogical abundances between the unqualified data sets and qualified data sets from continuously cored boreholes.

\section{E3.1 DTN ANALYSIS CONTENTS}

This section provides comparisons of samples analyzed by quantitative XRD among DTNs MO0101XRDDRILC.001 [DIRS 169517], LADB831321AN98.002 [DIRS 109003], LADV831321AQ97.001 [DIRS 107142], LA9910JC831321.001 [DIRS 113496], and LA9908JC831321.001 [DIRS 113495]. A separate set of comparisons is made for each borehole data set to be evaluated. DTN: LA9908JC831321.001 [DIRS 113495] contains the input files for Mineralogic Model (MM3.0) (BSC 2004 [DIRS 170031]), with sample locations and mineralogical abundances rendered in a form suitable for the model. The purpose of the comparisons is to confirm the identities of DTNs that are sources for the model input and assure that all necessary unqualified source data are included in the qualification effort. 


\section{UE-25 J-12}

As shown in table E-4, the J-12 sample analyses in DTN: MO0101XRDDRILC.001 [DIRS 169517] are derived completely and exclusively from DTN: LADB831321AN98.002 [DIRS 109003]. They are not used as input to the Mineralogic Model and therefore are not in the DTN that provides input files for the model.

Table E-4. Comparison for Equivalence of J-12 Analyzed Samples Included in Data Packages

\begin{tabular}{|c|c|c|}
\hline $\begin{array}{c}\text { MO0101XRDDRILC.001 } \\
\text { [DIRS 169517] } \\
\text { (depth interval in ft) }\end{array}$ & $\begin{array}{c}\text { LADB831321AN98.002 } \\
\text { [DIRS 109003] } \\
\text { (depth interval in ft) }\end{array}$ & \multirow{2}{*}{$\begin{array}{c}\text { LA9908JC831321.001 } \\
\text { [DIRS 113495] }\end{array}$} \\
\hline $620-630$ & $620-630$ & \\
\hline $650-660$ & $650-660$ & \multirow{3}{*}{ No J-12 sample analyses as input } \\
\hline $710-720$ & $710-720$ & \\
\hline $770-780$ & $770-780$ & \\
\hline $860-870$ & $860-870$ & \\
\hline $905-915$ & $905-915$ & \\
\hline $983-992$ & $983-992$ & \\
\hline $1067-1077$ & $1067-1077$ & \\
\hline $1093-1097$ & $1093-1097$ & \\
\hline $1107-1110$ & $1107-1110$ & \\
\hline $1121-1126$ & $1121-1126$ & \\
\hline $1136-1139$ & $1136-1139$ & \\
\hline &
\end{tabular}

\section{UE-25 p\#1}

As shown in table E-5, the UE-25 p\#1 sample analyses in DTN: MO0101XRDDRILC.001 [DIRS 169517] are derived completely from DTN: LADB831321AN98.002 [DIRS 109003]. Inputs to the Mineralogical Model (MM3.0) (BSC 2004 [DIRS 170031]) in DTN: LA9908JC831321.001 [DIRS 113495] are also derived from DTN: LADB831321AN98.002 [DIRS 109003]. Two numbers (shown in bold type, corresponding to parts of the sampling depth intervals in meters) in DTN: LADB831321AN98.002 [DIRS 109003] are incorrect, and the errors also are present in DTN: MO0101XRDDRILC.001 [DIRS 169517]. The errors are traceable to Bish and Chipera (1989 [DIRS 101195], p. 24, 26). These errors were fixed in DTN: LA9908JC831321.001 [DIRS 113495] for the one erroneous sample-depth conversion included in that DTN. However, DTN: LA9908JC831321.001 [DIRS 113495] contains one erroneous entry for this borehole. The entry for elevation $131.0 \mathrm{~m} /$ depth $3,225 \mathrm{ft}$ (shown in bold type) does not correspond to an analyzed sample. The mineralogic data associated with this entry correspond with data for 3,320-3,330-ft depth as listed in Bish and Chipera (1989 [DIRS 101195], p. 25) and in DTNs LADB831321AN98.002 [DIRS 109003] and MO0101XRDDRILC.001 [DIRS 169517]. The correct elevation would be $-(3325 \times 12 \div 39.37)+1114=100.5 \mathrm{~m}$, where $12 \div 39.37$ is the feet-to-meters conversion factor and 1114 is the ground-level elevation in meters of the borehole (DTN: LA9908JC831321.001 [DIRS 113495]). 
Rock Properties Model

Table E-5. Comparison for Equivalence of UE-25 p\#1 Analyzed Samples Included in Data Packages

\begin{tabular}{|c|c|c|}
\hline $\begin{array}{c}\text { MO0101XRDDRILC.001 } \\
\text { [DIRS 169517] } \\
\text { (depth interval in ft/m) }\end{array}$ & $\begin{array}{c}\text { LADB831321AN98.002 } \\
\text { [DIRS 109003] } \\
\text { (depth interval in ft/m) }\end{array}$ & $\begin{array}{c}\text { LA9908JC831321.001 } \\
\text { [DIRS 113495] } \\
\text { (midpoint elevation in m/depth in } \mathrm{ft} \text { ) }\end{array}$ \\
\hline 200-210/61.8-64.0 & 200-210/61.8-64.0 & $1051.5 / 205$ \\
\hline $260-270 / 79.2-82.3$ & $260-270 / 79.2-82.3$ & $1033.2 / 265$ \\
\hline 280-290/85.3-88.4 & 280-290/85.3-88.4 & $1027.1 / 285$ \\
\hline $410-420 / 125.0-128.0$ & $410-420 / 125.0-128.0$ & $987.5 / 415$ \\
\hline $570-580 / 173.7-176.8$ & $570-580 / 173.7-176.8$ & $938.7 / 575$ \\
\hline 810-820/246.9-249.9 & 810-820/246.9-249.9 & $865.6 / 815$ \\
\hline $900-910 / 274.3-277.4$ & $900-910 / 274.3-277.4$ & $838.2 / 905$ \\
\hline $1040-1050 / 317.0-320.0$ & $1040-1050 / 317.0-320.0$ & $795.5 / 1045$ \\
\hline $1240-1250 / 378.0-381.0$ & $1240-1250 / 378.0-381.0$ & reassigned to $730.0 / 1260$ \\
\hline $1260-1270 / 384.0-387.1$ & $1260-1270 / 384.0-387.1$ & $728.4 / 1265$ \\
\hline 1290/393.2 (sidewall core) & 1290/393.2 (sidewall core) & $720.8 / 1290$ \\
\hline $1340-1350 / 408.4-411.5$ & $1340-1350 / 408.4-411.5$ & 704.0/1345 \\
\hline 1400/426.7 (sidewall core) & 1400/426.7 (sidewall core) & $687.3 / 1400$ \\
\hline 1420/432.8 (sidewall core) & 1420/432.8 (sidewall core) & $681.2 / 1420$ \\
\hline 1470/448.1 (sidewall core) & 1470/448.1 (sidewall core) & reassigned to $668.0 / 1463$ \\
\hline 1590-1598/484.6-487.1 & $1590-1598 / 484.6-487.1$ & $627.8 / 1595$ \\
\hline $1640-1650 / 499.9-502.9$ & $1640-1650 / 499.9-502.9$ & $612.6 / 1645$ \\
\hline 1690-1700/515.1-518.2 & $1690-1700 / 515.1-518.2$ & $597.4 / 1695$ \\
\hline $1730-1740 / 527.3-530.4$ & $1730-1740 / 527.3-530.4$ & $585.2 / 1735$ \\
\hline $1790-1800 / 545.6-548.6$ & $1790-1800 / 545.6-548.6$ & $566.9 / 1795$ \\
\hline $1830-1840 / 557.8-560.8$ & $1830-1840 / 557.8-560.8$ & $554.7 / 1835$ \\
\hline $1870-1880 / 570.0-573.0$ & $1870-1880 / 570.0-573.0$ & $542.5 / 1875$ \\
\hline $1920-1930 / 585.2-588.3$ & $1920-1930 / 585.2-588.3$ & $527.3 / 1925$ \\
\hline $1970-1980 / 600.5-603.5$ & $1970-1980 / 600.5-603.5$ & $512.0 / 1975$ \\
\hline 1990-2000/606.6-609.6 & 1990-2000/606.6-609.6 & $505.9 / 1995$ \\
\hline 2030-2040/618.7-621.8 & 2030-2040/618.7-621.8 & 493.7/2035 \\
\hline 2070-2080/630.9/634.0 & 2070-2080/630.9/634.0 & $481.5 / 2075$ \\
\hline $2120-2130 / 646.2-649.2$ & $2120-2130 / 646.2-649.2$ & $466.3 / 2125$ \\
\hline 2150-2160/655.3-658.4 & 2150-2160/655.3-658.4 & $457.2 / 2155$ \\
\hline 2210-2220/673.6-676.7 & $2210-2220 / 673.6-676.7$ & $438.9 / 2215$ \\
\hline $2240-2250 / 682.8-685.8$ & $2240-2250 / 682.8-685.8$ & $429.7 / 2245$ \\
\hline $2280-2290 / 694.9-698.0$ & $2280-2290 / 694.9-698.0$ & $417.5 / 2285$ \\
\hline $2330-2340 / 710.2-713.2$ & $2330-2340 / 710.2-713.2$ & $402.3 / 2335$ \\
\hline $2370-2380 / 722.4-725.4$ & $2370-2380 / 722.4-725.4$ & $390.1 / 2375$ \\
\hline $2410-2420 / 734.6-737.6$ & $2410-2420 / 734.6-737.6$ & $377.9 / 2415$ \\
\hline $2460-2470 / 749.8-752.9$ & $2460-2470 / 749.8-752.9$ & $362.7 / 2465$ \\
\hline 2510-2520/765.0-768.1 & $2510-2520 / 765.0-768.1$ & $347.4 / 2515$ \\
\hline 2570-2580/783.3-786.4 & 2570-2580/783.3-786.4 & $329.1 / 2575$ \\
\hline 2630-2640/801.6-804.7 & 2630-2640/801.6-804.7 & $310.9 / 2635$ \\
\hline 2650-2660/807.7-810.8 & 2650-2660/807.7-810.8 & $304.8 / 2655$ \\
\hline $2690-2700 / 819.9-823.0$ & 2690-2700/819.9-823.0 & $292.6 / 2695$ \\
\hline $2750-2760 / 838.2-841.2$ & $2750-2760 / 838.2-841.2$ & $274.3 / 2755$ \\
\hline
\end{tabular}


Rock Properties Model

Table E-5. Comparison for Equivalence of UE-25 p\#1 Analyzed Samples Included in Data Packages (Continued)

\begin{tabular}{|c|c|c|}
\hline $\begin{array}{l}\text { MO0101XRDDRILC.001 } \\
\text { [DIRS 169517] } \\
\text { (depth interval in ft/m) }\end{array}$ & $\begin{array}{l}\text { LADB831321AN98.002 } \\
\text { [DIRS 109003] } \\
\text { (depth interval in ft/m) }\end{array}$ & $\begin{array}{c}\text { LA9908JC831321.001 } \\
\text { [DIRS 113495] } \\
\text { (midpoint elevation in m/depth in } \mathrm{ft} \text { ) }\end{array}$ \\
\hline 2790-2800/850.4-853.4 & 2790-2800/850.4-853.4 & $262.1 / 2795$ \\
\hline 2840-2850/865.6-868.7 & 2840-2850/865.6-868.7 & $246.8 / 2845$ \\
\hline 2890-2900/880.9-883.9 & 2890-2900/880.9-883.9 & $231.6 / 2895$ \\
\hline 2940-2950/896.1-899.2 & 2940-2950/896.1-899.2 & $216.4 / 2945$ \\
\hline 2980-2990/908.3-911.4 & 2980-2990/908.3-911.4 & $204.2 / 2985$ \\
\hline $3030-3040 / 923.5-926.6$ & $3030-3040 / 923.5-926.6$ & $188.9 / 3035$ \\
\hline 3080-3090/938.8-941.8 & 3080-3090/938.8-941.8 & $173.7 / 3085$ \\
\hline $3130-3140 / 954.0-957.1$ & $3130-3140 / 954.0-957.1$ & $158.5 / 3135$ \\
\hline $3160-3170 / 963.2-966.2$ & $3160-3170 / 963.2-966.2$ & $149.3 / 3165$ \\
\hline $3230-3240 / 984.5-987.6$ & $3230-3240 / 984.5-987.6$ & $128.0 / 3235$ \\
\hline $3270-3280 / 996.7-999.7$ & $3270-3280 / 996.7-999.7$ & $115.8 / 3275$ \\
\hline 3320-3330/1011.9-1015.0 & $3320-3330 / 1011.9-1015.0$ & $131.0 / 3225$ location is in error \\
\hline $3370-3380 / 1027.2-1030.2$ & $3370-3380 / 1027.2-1030.2$ & $85.3 / 3375$ \\
\hline $3410-3420 / 1039.4-1042.4$ & $3410-3420 / 1039.4-1042.4$ & $73.1 / 3415$ \\
\hline $3453 / 1052.5$ (core) & $3453 / 1052.5$ (core) & $61.5 / 3453$ \\
\hline $3480-3490 / 1060.7-1063.8$ & $3480-3490 / 1060.7-1063.8$ & $51.8 / 3485$ \\
\hline $3510-3520 / 1069.8-1072.9$ & $3510-3520 / 1069.8-1072.9$ & $42.6 / 3515$ \\
\hline 3550-3560/1082.0-1085.1 & $3550-3560 / 1082.0-1085.1$ & $30.4 / 3555$ \\
\hline 3560-3570/1085.1-1088.1 & 3560-3570/1085.1-1088.1 & $27.4 / 3565$ \\
\hline $3590-3600 / 1094.2-1097.3$ & $3590-3600 / 1094.2-1097.3$ & $18.2 / 3595$ \\
\hline 3630-3640/1106.4-1109.5 & $3630-3640 / 1106.4-1109.5$ & $6.1 / 3635$ \\
\hline $3650-3660 / 1112.5-1115.6$ & $3650-3660 / 1112.5-1115.6$ & $0.0 / 3655$ \\
\hline 3660-3670/1115.6-1118.6 & 3660-3670/1115.6-1118.6 & $-3.1 / 3665$ \\
\hline $3690-3700 / 1124.7-1127.8$ & $3690-3700 / 1124.7-1127.8$ & $-12.2 / 3695$ \\
\hline 3720-3730/1133.9-1136.9 & $3720-3730 / 1133.9-1136.9$ & $-21.4 / 3725$ \\
\hline $3750-3760 / 1143.0-1146.0$ & $3750-3760 / 1143.0-1146.0$ & $-30.5 / 3755$ \\
\hline $3790-3800 / 1155.2-1158.2$ & $3790-3800 / 1155.2-1158.2$ & $-42.7 / 3795$ \\
\hline 3820-3830/1164.3-1167.4 & $3820-3830 / 1164.3-1167.4$ & $-51.9 / 3825$ \\
\hline $3860-3870 / 1176.5-1179.6$ & 3860-3870/1176.5-1179.6 & $-64.1 / 3865$ \\
\hline 3913/1192.7 (core) & 3913/1192.7 (core) & $-78.7 / 3913$ \\
\hline 3916/1193.6 (core) & 3916/1193.6 (core) & $-79.6 / 3916$ \\
\hline 3928/1197.3 (core) & 3928/1197.3 (core) & $-83.3 / 3928$ \\
\hline $3940-3950 / 1200.9-1204.0$ & $3940-3950 / 1200.9-1204.0$ & $-88.4 / 3945$ \\
\hline 3980-3990/1213.1-1216.2 & 3980-3990/1213.1-1216.2 & $-100.6 / 3985$ \\
\hline 4040-4050/1231.4-1234.4 & 4040-4050/1231.4-1234.4 & $-118.9 / 4045$ \\
\hline $4070-4080 / 1240.5-1243.6$ & $4070-4080 / 1240.5-1243.6$ & $-128.1 / 4075$ \\
\hline 4080-4090/1243.6-1249.1 & 4080-4090/1243.6-1249.1 & Paleozoic unit not in model \\
\hline $4170-4180 / 1271.0-1274.1$ & 4170-4180/1271.0-1274.1 & Paleozoic unit not in model \\
\hline $4313-4318 / 1314.6-1316.1$ & 4313-4318/1314.6-1316.1 & Paleozoic unit not in model \\
\hline
\end{tabular}

NOTE: erroneous information is in bold type. 


\section{USW H-3}

As shown in table E-6, the USW H-3 sample analyses in DTN: MO0101XRDDRILC.001 [DIRS 169517] are derived from DTN: LADB831321AN98.002 DIRS 109003], duplicated by data in LADV831321AQ97.001 [DIRS 107142]. It also shows that some of the data used as input by the Mineralogic Model (MM3.0) (BSC 2004 [DIRS 170031]) were derived only from DTN: LADV831321AQ97.001 [DIRS 107142] and are missing from DTN: MO0101XRDDRILC.001 [DIRS 169517].

Table E-6. Comparison for Equivalence of USW H-3 Analyzed Samples Included in Data Packages

\begin{tabular}{|c|c|c|c|}
\hline $\begin{array}{c}\text { MO0101XRDDRILC.001 } \\
\text { [DIRS 169517] } \\
\text { (depth interval in ft/m) }\end{array}$ & $\begin{array}{l}\text { LADB831321AN98.002 } \\
\text { [DIRS 109003] } \\
\text { (depth interval in } \mathrm{ft} / \mathrm{m} \text { ) }\end{array}$ & $\begin{array}{c}\text { LADV831321AQ97.001 } \\
\text { [DIRS 107142] } \\
\text { (depth interval in ft/m) }\end{array}$ & $\begin{array}{l}\text { LA9908JC831321.001 } \\
\text { [DIRS 113495] } \\
\text { (midpoint elevation in } \\
\text { m/depth in } \mathrm{ft} \text { ) }\end{array}$ \\
\hline $470-480 / 143.3-146.6$ & $470-480 / 143.3-146.6$ & 470-480/143.3-146.6 & $1338.4 / 475$ \\
\hline $520-530 / 158.5-161.5$ & $520-530 / 158.5-161.5$ & $520-530 / 158.5-161.5$ & $1323.2 / 525$ \\
\hline $540-550 / 164.6-167.6$ & $540-550 / 164.6-167.6$ & $540-550 / 164.6-167.6$ & $1317.1 / 545$ \\
\hline 610-620/185.9-189.0 & 610-620/185.9-189.0 & 610-620/185.9-189.0 & $1295.7 / 615$ \\
\hline $740-750 / 225.6-228.6$ & $740-750 / 225.6-228.6$ & $740-750 / 225.6-228.6$ & $1256.1 / 745$ \\
\hline $800-810 / 243.8-246.9$ & $800-810 / 243.8-246.9$ & $800-810 / 243.8-246.9$ & $1237.8 / 805$ \\
\hline $870-880 / 265.2-268.2$ & $870-880 / 265.2-268.2$ & $870-880 / 265.2-268.2$ & $1216.5 / 875$ \\
\hline $930-940 / 283.5-286.5$ & $930-940 / 283.5-286.5$ & $930-940 / 283.5-286.5$ & 1198.2/935 \\
\hline 990-1000/301.8-304.8 & $990-1000 / 301.8-304.8$ & $990-1000 / 301.8-304.8$ & $1179.9 / 995$ \\
\hline $1030-1040 / 313.9-317.0$ & $1030-1040 / 313.9-317.0$ & $1030-1040 / 313.9-317.0$ & $1167.7 / 1035$ \\
\hline $1100-1110 / 335.3-338.3$ & $1100-1110 / 335.3-338.3$ & $1100-1110 / 335.3-338.3$ & $1146.4 / 1105$ \\
\hline $1160-1170 / 353.6-356.6$ & $1160-1170 / 353.6-356.6$ & $1160-1170 / 353.6-356.6$ & $1128.1 / 1165$ \\
\hline $1270-1280 / 387.1-390.1$ & $1270-1280 / 387.1-390.1$ & $1270-1280 / 387.1-390.1$ & $1094.6 / 1275$ \\
\hline \multirow[t]{5}{*}{$1320-1330 / 402.3-405.4$} & $1320-1330 / 402.3-405.4$ & $1320-1330 / 402.3-405.4$ & $1079.3 / 1325$ \\
\hline & & $1360-1370 / 414.5-417.6$ & 1067.1/1365 \\
\hline & & $1440-1450 / 438.9-442.0$ & $1042.8 / 1445$ \\
\hline & & $1480-1490 / 451.1-454.2$ & $1030.6 / 1485$ \\
\hline & & $1500-1510 / 457.2-460.2$ & $1024.5 / 1505$ \\
\hline 1550/472.4 (sidewall core) & 1550/472.4 (sidewall core) & 1550/472.4 (sidewall core) & $1010.8 / 1550$ \\
\hline 1655/504.5 (sidewall core) & 1655/504.5 (sidewall core) & 1655/504.5 (sidewall core) & $978.7 / 1655$ \\
\hline 1700/518.2 (sidewall core) & 1700/518.2 (sidewall core) & 1700/518.2 (sidewall core) & $965.0 / 1700$ \\
\hline 1800/548.6 (sidewall core) & 1800/548.6 (sidewall core) & 1800/548.6 (sidewall core) & $934.6 / 1800$ \\
\hline 1900/579.1 (sidewall core) & 1900/579.1 (sidewall core) & 1900/579.1 (sidewall core) & $904.1 / 1900$ \\
\hline 2400/731.5 (sidewall core) & 2400/731.5 (sidewall core) & 2400/731.5 (sidewall core) & $751.7 / 2400$ \\
\hline 2440/743.7 (sidewall core) & 2440/743.7 (sidewall core) & 2440/743.7 (sidewall core) & $739.5 / 2440$ \\
\hline 2490/759 (sidewall core) & 2490/759 (sidewall core) & 2490/759.0 (sidewall core) & $724.2 / 2490$ \\
\hline
\end{tabular}

NOTE: Blank boxes are intentional. 


\section{USW H-4}

As shown in table E-7, the USW H-4 sample analyses in DTN: MO0101XRDDRILC.001 [DIRS 169517] are derived completely and exclusively from DTN: LADB831321AN98.002 [DIRS 109003]. There is a one-to-one correspondence between the DTN: MO0101XRDDRILC.001 [DIRS 169517] data set and the data set in DTN: LA9908JC831321.001 [DIRS 113495] that is input to the Mineralogic Model (MM3.0) (BSC 2004 [DIRS 170031]).

Table E-7. Comparison for Equivalence of USW H-4 Analyzed Samples Included in Data Packages

\begin{tabular}{|c|c|c|}
\hline $\begin{array}{c}\text { MO0101XRDDRILC.001 } \\
\text { [DIRS 169517] } \\
\text { (depth interval in ft/m) }\end{array}$ & $\begin{array}{l}\text { LADB831321AN98.002 } \\
\text { [DIRS 109003] } \\
\text { (depth interval in ft/m) }\end{array}$ & $\begin{array}{c}\text { LA9908JC831321.001 } \\
\text { [DIRS 113495] } \\
\text { (midpoint elevation in m/depth in } \mathrm{ft} \text { ) }\end{array}$ \\
\hline $310-320 / 94.5-97.5$ & $310-320 / 94.5-97.5$ & $1152.5 / 315$ \\
\hline $390-400 / 118.9-121.9$ & 390-400/118.9-121.9 & $1128.1 / 395$ \\
\hline $440-450 / 134.1-137.2$ & $440-450 / 134.1-137.2$ & $1112.9 / 445$ \\
\hline $490-500 / 149.4-152.4$ & 490-500/149.4-152.4 & $1097.6 / 495$ \\
\hline 640-650/195.1-198.1 & 640-650/195.1-198.1 & $1051.9 / 645$ \\
\hline $830-840 / 253.0-256.0$ & $830-840 / 253.0-256.0$ & 994.0/835 \\
\hline $910-920 / 277.4-280.4$ & $910-920 / 277.4-280.4$ & 969.6/915 \\
\hline $940-950 / 286.5-289.6$ & $940-950 / 286.5-289.6$ & $960.5 / 945$ \\
\hline $1040-1050 / 317.0-320.0$ & $1040-1050 / 317.0-320.0$ & $930.0 / 1045$ \\
\hline $1150-1160 / 350.5-353.6$ & $1150-1160 / 350.5-353.6$ & $896.5 / 1155$ \\
\hline $1190-1200 / 362.7-365.8$ & $1190-1200 / 362.7-365.8$ & $884.3 / 1195$ \\
\hline $1230-1240 / 374.9-378.0$ & $1230-1240 / 374.9-378.0$ & $872.1 / 1235$ \\
\hline 1312/399.9 (sidewall core) & 1312/399.9 (sidewall core) & $848.6 / 1312$ \\
\hline 1320-1330/402.3-405.4 & $1320-1330 / 402.3-405.4$ & $844.6 / 1325$ \\
\hline 1350-1360/411.5-414.5 & $1350-1360 / 411.5-414.5$ & $833.5 / 1355$ \\
\hline $1410-1420 / 429.8-432.8$ & $1410-1420 / 429.8-432.8$ & $817.2 / 1415$ \\
\hline 1420/432.8 (sidewall core) & 1420/432.8 (sidewall core) & $815.7 / 1420$ \\
\hline 1455/443.5 (sidewall core) & 1455/443.5 (sidewall core) & $805.0 / 1455$ \\
\hline $1540-1550 / 469.4-472.4$ & $1540-1550 / 469.4-472.4$ & $777.6 / 1545$ \\
\hline 1550/472.4 (sidewall core) & 1550/472.4 (sidewall core) & $776.1 / 1550$ \\
\hline $1600-1610 / 487.7-490.7$ & $1600-1610 / 487.7-490.7$ & $770.0 / 1570^{*}$ \\
\hline 1640-1650/499.9-502.9 & $1640-1650 / 499.9-502.9$ & $747.1 / 1645$ \\
\hline 1656/504.8 (sidewall core) & 1656/504.8 (sidewall core) & 741.0/1665* \\
\hline $1710-1720 / 521.2-524.3$ & $1710-1720 / 521.2-524.3$ & $725.8 / 1715$ \\
\hline 1790-1800/545.6-548.6 & $1790-1800 / 545.6-548.6$ & 701.4/1795 \\
\hline 1900-1910/579.1-582.2 & 1900-1910/579.1-582.2 & $667.9 / 1905$ \\
\hline 1980-1990/603.5-606.6 & $1980-1990 / 603.5-606.6$ & $643.5 / 1985$ \\
\hline
\end{tabular}

* These samples were reassigned to different depths, as shown here and explained in Table F-3). 


\section{USW H-5}

Comparison of the data contents of DTNs MO0101XRDDRILC.001 [DIRS 169517] and LA9908JC831321.001 [DIRS 113495] indicated that there must be additional sources of input to the Mineralogic Model (MM3.0) (BSC 2004 [DIRS 170031]) beside DTN: LADB831321AN98.002 [DIRS 109003] (the precursor of DTN: MO0101XRDDRILC.001 [DIRS 169517]). Two other DTNs were found to be input sources. DTN: LADV831321AQ97.007 [DIRS 113499] is listed in the Technical Data Management System as a qualified DTN even though it contains unqualified data from the USW H-5 cutting samples. This DTN is identified in the Mineralogic Model (MM3.0) (BSC 2004 [DIRS 170031]) as an input source. DTN: LA9910JC831321.001 [DIRS 113496] is listed as unqualified in the Technical Data Management System and is not identified as an input source in the Mineralogic Model (MM3.0) (BSC 2004 [DIRS 170031]). Table E-8 shows how the three DTNs, with some duplication, comprise the input to the Mineralogical Model.

Table E-8. Comparison for Equivalence of USW H-5 Analyzed Samples Included in Data Packages

\begin{tabular}{|c|c|c|c|}
\hline $\begin{array}{c}\text { MO0101XRDDRILC.001 } \\
\text { [DIRS 169517] } \\
\text { and LADB831321AN98.002 } \\
\text { [DIRS 109003] } \\
\text { (depth interval in ft/m) }\end{array}$ & $\begin{array}{l}\text { LA9910JC831321.001 } \\
\text { [DIRS 113496] } \\
\text { (depth interval in } \\
\text { ft/depth interval } \\
\text { midpoint in m) }\end{array}$ & $\begin{array}{c}\text { LADV831321AQ97.007 } \\
\text { [DIRS 113499] } \\
\text { (depth interval in ft/m) }\end{array}$ & $\begin{array}{l}\text { LA9908JC831321.001 } \\
\text { [DIRS 113495] } \\
\text { (midpoint elevation in } \\
\text { m/depth in } \mathrm{ft} \text { ) }\end{array}$ \\
\hline & $40-50 / 13.7$ & & $1464.9 / 45$ \\
\hline \multirow[t]{3}{*}{$50 / 15.2$} & & & $1463.3 / 50$ \\
\hline & $110-12035.1$ & & $1443.5 / 115$ \\
\hline & $160-170 / 50.3$ & & $1428.3 / 165$ \\
\hline \multirow[t]{4}{*}{$190 / 57.9$} & & & $1420.7 / 190$ \\
\hline & $230-240 / 71.6$ & & $1407.0 / 235$ \\
\hline & 320-33099.1 & & $1379.5 / 325$ \\
\hline & 380-390117.3 & & $1361.2 / 385$ \\
\hline $420 / 128$ & & & $\begin{array}{c}\text { reassigned to } \\
1353.0 / 412\end{array}$ \\
\hline \multirow[t]{3}{*}{$450 / 137.2$} & & & $1341.4 / 450$ \\
\hline & $460-470 / 141.7$ & & $1336.8 / 465$ \\
\hline & & 620-630/189.0-192.0 & $1288.1 / 625$ \\
\hline \multirow[t]{3}{*}{$700 / 213.4$} & & $700 / 213.4$ & $1265.2 / 700$ \\
\hline & & $720-730 / 219.5-222.5$ & $1257.6 / 725$ \\
\hline & & 750-760/228.6-231.6 & $1248.5 / 755$ \\
\hline $800-810 / 243.8-246.9$ & & $800-810 / 243.8-246.9$ & $1233.2 / 805$ \\
\hline \multirow[t]{2}{*}{$830-840 / 253.0-256.0$} & & $830-840 / 253.0-256.0$ & $1224.1 / 835$ \\
\hline & & $860-870 / 262.1-265.2$ & $1214.9 / 865$ \\
\hline $920-930 / 280.4-283.5$ & & $920-930 / 280.4-283.5$ & $1196.6 / 925$ \\
\hline \multirow[t]{2}{*}{$970-980 / 295.7-298.7$} & & $970-980 / 295.7-298.7$ & $1181.4 / 975$ \\
\hline & & 990-1000/301.8-304.8 & $1175.3 / 995$ \\
\hline \multirow[t]{2}{*}{$1050 / 320$} & & $1050 / 320.0$ & $1158.5 / 1050$ \\
\hline & & $1090-1100 / 332.2-335.3$ & $1144.8 / 1095$ \\
\hline \multirow[t]{2}{*}{$1150-1160 / 350.3-353.6$} & & $1150-1160 / 350.5-353.6$ & $1126.5 / 1155$ \\
\hline & & $1200-1210 / 365.8-368.8$ & $1111.3 / 1205$ \\
\hline $1230-1240 / 374.9-378.0$ & & $1230-1240 / 374.9-378.9$ & $1102.2 / 1235$ \\
\hline
\end{tabular}


Table E-8. Comparison for Equivalence of USW H-5 Analyzed Samples Included in Data Packages (Continued)

\begin{tabular}{|c|c|c|c|}
\hline $\begin{array}{c}\text { MO0101XRDDRILC.001 } \\
\text { [DIRS 169517] } \\
\text { and LADB831321AN98.002 } \\
\text { [DIRS 109003] } \\
\text { (depth interval in ft/m) }\end{array}$ & $\begin{array}{l}\text { LA9910JC831321.001 } \\
\text { [DIRS 113496] } \\
\text { (depth interval in } \\
\text { ft/depth interval } \\
\text { midpoint in m) }\end{array}$ & $\begin{array}{c}\text { LADV831321AQ97.007 } \\
\text { [DIRS 113499] } \\
\text { (depth interval in ft/m) }\end{array}$ & $\begin{array}{l}\text { LA9908JC831321.001 } \\
\text { [DIRS 113495] } \\
\text { (midpoint elevation in } \\
\text { m/depth in } \mathrm{ft} \text { ) }\end{array}$ \\
\hline \multirow{2}{*}{$1290-1300 / 393.2-396.2$} & & $1290-1300 / 393.2-396.2$ & $1083.9 / 1295$ \\
\hline & & $1350-1360 / 411.5-414.5$ & $1065.6 / 1355$ \\
\hline $1380-1390 / 420.6-423.7$ & & $1380-1390 / 420.6-423.7$ & $1056.4 / 1385$ \\
\hline $1450-1460 / 442.0-445.0$ & & $1450-1460 / 442.0-445.0$ & $1035.1 / 1455$ \\
\hline \multirow[t]{2}{*}{$1490-1500 / 454.2-457.2$} & & $1490-1500 / 454.2-457.2$ & $1022.9 / 1495$ \\
\hline & & $1530-1540 / 466.3-469.4$ & $1010.7 / 1535$ \\
\hline $1590-1600 / 484.6-487.7$ & & $1590-1600 / 484.6-487.7$ & $992.4 / 1595$ \\
\hline \multirow[t]{3}{*}{$1610 / 490.7$} & & $1610 / 490.7$ & $987.9 / 1610$ \\
\hline & & $1630-1640 / 496.8-499.9$ & $980.2 / 1635$ \\
\hline & & $1650-1660 / 502.9-506.0$ & $974.1 / 1655$ \\
\hline 1666/507.8 (sidewall core) & & & $970.8 / 1666$ \\
\hline $1710-1720 / 521.2-524.3$ & & & $955.8 / 1715$ \\
\hline $1750 / 533.4$ & & & $945.2 / 1750$ \\
\hline \multirow[t]{2}{*}{ 1762/537.1 (sidewall core) } & & & $941.5 / 1762$ \\
\hline & $1760-1770 / 538.0$ & & $940.6 / 1765$ \\
\hline \multirow[t]{2}{*}{ 1800/548.6 (sidewall core) } & & & $929.9 / 1800$ \\
\hline & $1820-1830 / 556.3$ & & $922.3 / 1825$ \\
\hline 1852/564.5 (sidewall core) & & & $914.1 / 1852$ \\
\hline \multirow[t]{4}{*}{ 1875/571.5 (sidewall core) } & & & $907.1 / 1875$ \\
\hline & $1890-1900 / 577.6$ & & $901.0 / 1895$ \\
\hline & $1900-1910 / 580.6$ & & $897.9 / 1905$ \\
\hline & $1910-1920 / 583.7$ & & $894.9 / 1915$ \\
\hline \multirow[t]{2}{*}{ 1917/584.3 (sidewall core) } & & & $894.3 / 1917$ \\
\hline & $1920-1930 / 586.7$ & & $891.8 / 1925$ \\
\hline \multirow[t]{2}{*}{$1930 / 588.3$} & & & $890.3 / 1930$ \\
\hline & $1950-1960 / 595.9$ & & $882.7 / 1955$ \\
\hline \multirow[t]{4}{*}{ 1966/599.2 (sidewall core) } & & & $879.3 / 1966$ \\
\hline & 1990-2000/608.1 & & $\begin{array}{l}\text { reassigned to } \\
879.2 / 1966.5\end{array}$ \\
\hline & $2070-2080 / 632.5$ & & $846.1 / 2075$ \\
\hline & $2140-2150 / 653.8$ & & $\begin{array}{c}\text { Reassigned to } \\
830.0 / 2128\end{array}$ \\
\hline \multirow[t]{3}{*}{$2200 / 670.6$} & & & $808.0 / 2200$ \\
\hline & $2230-2240 / 681.2$ & & $797.4 / 2235$ \\
\hline & $2260-2270 / 690.4$ & & $788.2 / 2265$ \\
\hline
\end{tabular}

NOTE: Blank boxes are intentional.

\section{USW WT-1}

As shown in Table E-9, the USW WT-1 sample analyses in DTN: MO0101XRDDRILC.001 [DIRS 169517] are derived completely and exclusively from DTN: LADB831321AN98.002 
[DIRS 109003]. Inputs to the Mineralogic Model (MM3.0) (BSC 2004 [DIRS 170031]) in DTN: LA9908JC831321.001 [DIRS 113495] also are derived from DTN: DB831321AN98.002 [DIRS 109003].

Table E-9. Comparison for Equivalence of USW WT-1 Analyzed Samples Included in Data Packages

\begin{tabular}{|c|c|c|}
\hline $\begin{array}{c}\text { MO0101XRDDRILC.001 } \\
\text { [DIRS 169517] } \\
\text { (depth interval in ft/m) }\end{array}$ & $\begin{array}{c}\text { LADB831321AN98.002 } \\
\text { [DIRS 109003] } \\
\text { (depth interval in ft) }\end{array}$ & $\begin{array}{c}\text { LA9908JC831321.001 } \\
\text { [DIRS 113495] } \\
\text { (midpoint elevation in m/depth in ft) }\end{array}$ \\
\hline $440-450 / 134.1-137.2$ & $440-450$ & $1065.4 / 445$ \\
\hline $500-510 / 152.4-155.4$ & $500-510$ & $1047.1 / 505$ \\
\hline $550-560 / 167.6 / 170.7$ & $550-560$ & $1031.8 / 555$ \\
\hline $640-650195.1 / 198.1$ & $640-650$ & $1004.4 / 645$ \\
\hline $690-700 / 210.3-213.4$ & $690-700$ & $989.2 / 695$ \\
\hline $780-790 / 237.7-240.8$ & $780-790$ & $961.7 / 785$ \\
\hline $840-850 / 256.0-259.1$ & $840-850$ & $943.4 / 845$ \\
\hline $930-940 / 283.5-286.5$ & $930-940$ & $916.0 / 935$ \\
\hline $1000-1010 / 304.8-307.8$ & $1000-1010$ & $894.7 / 1005$ \\
\hline $1090-1100 / 332.2-335.3$ & $1090-1100$ & $867.2 / 1095$ \\
\hline $1160-1170 / 353.6-356.6$ & $1160-1170$ & $845.9 / 1165$ \\
\hline $1220-1230 / 371.9-374.9$ & $1220-1230$ & $827.6 / 1225$ \\
\hline $1300-1310 / 396.2-399.3$ & $1300-1310$ & $*$ \\
\hline $1320-1330 / 402.3-405.4$ & $1320-1330$ & $*$ \\
\hline $1340-1350 / 408.4-411.5$ & $1340-1350$ & $*$ \\
\hline $1380-1390 / 420.6-423.7$ & $1380-1390$ & $* 78.9 / 1385$ \\
\hline $1410-1420 / 429.8-432.8$ & $1410-1420$ & $769.7 / 1415$ \\
\hline $1470-1480 / 448.1-451.1$ & $1470-1480$ & $*$ \\
\hline $1510-1520 / 460.2-463.3$ & $1510-1520$ & $*$ \\
\hline $1550-1560 / 472.4-475.5$ & $1550-1560$ & $*$ \\
\hline $1570-1580 / 478.5-481.6$ & $1570-1580$ & $*$ \\
\hline
\end{tabular}

*Exclusion of these analyses is documented in Table F-5.

\section{USW WT-2}

As shown in table E-10, the USW WT-2 sample analyses in DTN: MO0101XRDDRILC.001 [DIRS 169517] are derived completely and exclusively from DTN: LADB831321AN98.002 [DIRS 109003]. Inputs to the Mineralogic Model (MM3.0) (BSC 2004 [DIRS 170031]) in DTN: LA9908JC831321.001 [DIRS 113495] are also derived from DTN: LADB831321AN98.002 [DIRS 109003]. One sample number (shown in bold type, corresponding to the sampling depth interval in feet) in DTN: LADB831321AN98.002 [DIRS 109003] is incorrect, and the error is also present in DTN: MO0101XRDDRILC.001 [DIRS 169517]. The sample number, "420-450," does not conform to the typical 10 foot sampling interval for drill cuttings. Notebook entries documenting the collection, description, and receipt of the USW WT-2 samples from the USGS Core Library confirm that the correct footage for the sample is 420-430 ft (Broxton 1990 [DIRS 169640], p. 58; Caporuscio 1986 
[DIRS 169644], p. 128). The substitution of "450" for "430" appears to have been derived from a typographical error in Bish and Vaniman (1985 [DIRS 101196], p. 29) that was repeated in Bish and Chipera (1989 [DIRS 101195], p. 49). The conversion from depth in feet to depth in meters in the source documents and in the DTNs reflects the correct footage. The midpoint elevation for the sample used in DTN: LA9908JC831321.001 [DIRS 113495] also is correct.

Table E-10. Comparison for Equivalence of USW WT-2 Analyzed Samples Included in Data Packages

\begin{tabular}{|c|c|c|}
\hline $\begin{array}{l}\text { MO0101XRDDRILC.001 } \\
\text { [DIRS 169517] } \\
\text { (depth interval in ft/m) }\end{array}$ & $\begin{array}{c}\text { LADB831321AN98.002 } \\
\text { [DIRS 109003] } \\
\text { (depth interval in ft) }\end{array}$ & $\begin{array}{c}\text { LA9908JC831321.001 } \\
\text { [DIRS 113495] } \\
\text { (midpoint elevation in m/depth in } \mathrm{ft} \text { ) }\end{array}$ \\
\hline $250-260 / 76.2-79.2$ & $250-260 / 76.2-79.2$ & $1223.2 / 255$ \\
\hline $260-270 / 79.2-82.3$ & $260-270 / 79.2-82.3$ & $1220.1 / 265$ \\
\hline $290-300 / 88.4-91.4$ & $290-300 / 88.4-91.4$ & $1211.0 / 295$ \\
\hline $370-380 / 112.8-115.8$ & $370-380 / 112.8-115.8$ & $1186.6 / 375$ \\
\hline $420-450^{1} / 128.0-131.0$ & $420-450^{1} / 128.0-131.0$ & $1171.4 / 425$ \\
\hline $510-520 / 155.4-158.5$ & 510-520/155.4-158.5 & $1143.9 / 515$ \\
\hline $570-580 / 173.7-176.8$ & $570-580 / 173.7-176.8$ & $1125.6 / 575$ \\
\hline 650-660/198.1-201.1 & 650-660/198.1-201.1 & $1101.3 / 655$ \\
\hline $720-730 / 219.5-222.5$ & $720-730 / 219.5-222.5$ & $1079.9 / 725$ \\
\hline $780-790 / 237.7-240.8$ & $780-790 / 237.7-240.8$ & $1061.6 / 785$ \\
\hline $850-860 / 259.1-262.1$ & $850-860 / 259.1-262.1$ & $1040.3 / 855$ \\
\hline $930-940 / 283.5-286.5$ & $930-940 / 283.5-286.5$ & $1015.9 / 935$ \\
\hline $990-1000 / 301.8-304.8$ & 990-1000/301.8-304.8 & $997.6 / 995$ \\
\hline 1060-1070/323.1-326.1 & 1060-1070/323.1-326.1 & $976.3 / 1065$ \\
\hline $1130-1140 / 344.4-347.5$ & $1130-1140 / 344.4-347.5$ & $955.0 / 1135$ \\
\hline $1190-1200 / 362.7-365.8$ & $1190-1200 / 362.7-365.8$ & $936.7 / 1196$ \\
\hline $1200-1210 / 365.8-368.8$ & $1200-1210 / 365.8-368.8$ & $933.6 / 1205$ \\
\hline $1250-1260 / 381.0-384.0$ & $1250-1260 / 381.0-384.0$ & $918.4 / 1255$ \\
\hline 1300-1310/396.2-399.3 & $1300-1310 / 396.2-399.3$ & $903.1 / 1305$ \\
\hline $1360-1370 / 414.5-417.6$ & $1360-1370 / 414.5-417.6$ & $884.8 / 1365$ \\
\hline $1420-1430 / 432.8-435.9$ & $1420-1430 / 432.8-435.9$ & $866.6 / 1425$ \\
\hline $1450-1460 / 442.0-445.0$ & $1450-1460 / 442.0-445.0$ & $857.4 / 1455$ \\
\hline $1470-1480 / 448.1-451.1$ & $1470-1480 / 448.1-451.1$ & $851.3 / 1475$ \\
\hline 1520-1530/463.3-466.3 & $1520-1530 / 463.3-466.3$ & $836.1 / 1525$ \\
\hline 1570-1580/478.5-481.6 & $1570-1580 / 478.5-481.6$ & $820.8 / 1575$ \\
\hline 1640-1650/499.9-502.9 & $1640-1650 / 499.9-502.9$ & $799.5 / 1645$ \\
\hline $1710-1720 / 521.2-524.3$ & $1710-1720 / 521.2-524.3$ & $778.2 / 1715$ \\
\hline 1750-1760/533.4-536.4 & $1750-1760 / 533.4-536.4$ & $766.0 / 1755$ \\
\hline 1820-1830/554.7-557.8 & $1820-1830 / 554.7-557.8$ & $744.6 / 1825$ \\
\hline 1910-1920/582.2-585.2 & 1910-1920/582.2-585.2 & $717.2 / 1915$ \\
\hline 2000-2010/609.6-612.6 & 2000-2010/609.6-612.6 & $689.8 / 2005$ \\
\hline $2050.25 / 624.9$ (core) & $2050.25 / 624.9$ (core) & 2 \\
\hline
\end{tabular}


Table E-10. Comparison for Equivalence of USW WT-2 Analyzed Samples Included in Data Packages (Continued)

\begin{tabular}{|c|c|c|}
\hline $\begin{array}{c}\text { MO0101XRDDRILC.001 } \\
\text { [DIRS 169517] } \\
\text { (depth interval in ft/m) }\end{array}$ & $\begin{array}{c}\text { LADB831321AN98.002 } \\
\text { [DIRS 109003] } \\
\text { (depth interval in ft) }\end{array}$ & $\begin{array}{c}\text { LA9908JC831321.001 } \\
\text { [DIRS 113495] } \\
\text { (midpoint elevation in m/depth in ft) }\end{array}$ \\
\hline $2053.7 / 626$ (core) & $2053.7 / 626$ (core) & 2 \\
\hline $2059.3 / 627.7$ (core) & $2059.3 / 627.7$ (core) & 2 \\
\hline
\end{tabular}

${ }^{1}$ The original collection and sample receipt notebook entries identify the footage of this sample as $420-430 \mathrm{ft}$. See text for further explanation.

${ }^{2}$ These analyses from MO0101XRDDRILC.001 [DIRS 169517] were also included in LA9908JC831321.001 [DIRS 113495] but were assigned to slightly different depths, as explained Table F-6).

\section{E3.2 SAMPLE COLLECTION AND PREPARATION FOR XRD ANALYSIS}

\section{E3.2.1 Samples from $\mathbf{J}-12$}

The J-12 water well was spudded on August 4, 1957, and completed to a depth of $887 \mathrm{ft}$ on October 9, 1957 (Fenix and Scisson, Inc., 1988 [DIRS 169661]). Records from Burns \& McDonnell Engineering Company (1959 [DIRS 169662]) indicate that the hole was cased for the full $887 \mathrm{ft}$ depth. The hole was recompleted in August 1968, to a depth of 1,139 ft. Fenix and Scisson, Inc. (1988 [DIRS 169661]) found that drilling records were not available for the deepening of the hole. Of the 12 sample analyses for J-12 samples contained in DTN: MO0101XRDDRILC.001 [DIRS 169517], 5 samples are from depths corresponding to the initial well completion, and the remaining 7 samples are from depths associated with the deepening of the well.

In the course of this qualification activity, no records were found to document LANL sampling of the J-12 cuttings, sample descriptions, or sample preparation for XRD analysis. Based on the lack of documentation and the fact that the J-12 data were not used in the Mineralogic Model (MM3.0) (BSC 2004 [DIRS 170031]), a decision was made to not qualify this data set.

\section{E3.2.2 Samples from Other Drill Holes}

Records of sample collection, sample description, and sample preparation and analysis by XRD are partial to complete for samples from drill holes USW H-3, USW H-4, USW H-5, USW WT-1, USW WT-2, and UE-25 p\#1. Table E-11 summarizes the records that have been identified. As noted by Steinborn (2002 [DIRS 160702]), it is likely that more records exist. 
Table E-11. Summary of Records for Sample Collection and XRD Analysis

\begin{tabular}{|c|c|c|}
\hline Drill Hole & Sample Collection and Description Records & $\begin{array}{c}\text { Sample Preparation and XRD } \\
\text { Analysis Records }\end{array}$ \\
\hline USW H-3 & $\begin{array}{l}\text { Byers 1982 [DIRS 169663]; Vaniman } 1983 \text { [DIRS } \\
\text { 169665], p. 84-85; Levy } 1996 \text { [DIRS 106676], p. } \\
\text { 1,4,21-23; LANL } 1997 \text { [DIRS 169667] }\end{array}$ & $\begin{array}{l}\text { Levy } 1996 \text { [DIRS 106676], p. 4,10,23; Bish } \\
2001 \text { [DIRS 169750], p. } 46\end{array}$ \\
\hline USW H-4 & $\begin{array}{l}\text { Vaniman } 1983 \text { [DIRS 169665], p. 85-87; Levy } \\
1996 \text { [DIRS 106676], p. 23; Caporuscio, } 1986 \\
\text { [DIRS 169644], p. 135 }\end{array}$ & Levy 1996 [DIRS 106676], p. 4,10 \\
\hline USW H-5 & $\begin{array}{l}\text { Vaniman } 1988 \text { [DIRS 169665], p. 67-70,72-75,87- } \\
\text { 88; Levy } 1996 \text { [DIRS 106676], p. 25; Caporuscio } \\
\text { 1986 [DIRS 169644], p. 135; LANL } 1992 \text { [DIRS } \\
\text { 169718] }\end{array}$ & $\begin{array}{l}\text { Levy } 1996 \text { [DIRS 106676], p. 10; Bish } 2001 \\
\text { [DIRS 169750], p. 45-46 }\end{array}$ \\
\hline USW WT-1 & $\begin{array}{l}\text { Broxton } 1990 \text { [DIRS 169640], p.61-63; } \\
\text { Caporuscio } 1986 \text { [DIRS 169644], p. } 127\end{array}$ & no records found \\
\hline USW WT-2 & $\begin{array}{l}\text { Broxton } 1990 \text { [DIRS 169640], p. 58-60; } \\
\text { Caporuscio } 1986 \text { [DIRS 169644], p. } 128\end{array}$ & no records found \\
\hline UE-25 p\#1 & $\begin{array}{l}\text { Caporuscio } 1986 \text { [DIRS 169644], p. 131-133; } \\
\text { Chipera } 1986 \text { [DIRS 169680], p.100 }\end{array}$ & $\begin{array}{l}\text { Chipera } 1986 \text { [DIRS 169680], } \\
\text { p.34,36,37,38,39,40,48,49,50, } \\
52,53,55,56,57,58,59,60,62,63,64,65,66,68,6 \\
9, \\
\text { 101,102; Bish } 2001 \text { [DIRS 169750], p. } 2-5 ; \\
\text { Chipera et al. } 1989 \text { [DIRS 169683], p. 2,3 }\end{array}$ \\
\hline
\end{tabular}

\section{E3.3 X-RAY DIFFRACTION METHODOLOGY}

X-ray diffraction analysis of the cutting samples, sidewall core samples, and intermittent core samples was conducted in the same time period as XRD analysis of samples from the continuously cored boreholes. The same analytical equipment and software were used. Documentation and evaluation of technical procedures found to be acceptable by Steinborn (2002 [DIRS 160702]) for qualification of XRD mineralogic data from core samples apply to the data under consideration here as well. E-12 identifies specific published sources of information about XRD analytical techniques for the borehole data sets considered for qualification.

Table E-12. Published Sources on XRD Mineralogy for Unqualified Data Sets

\begin{tabular}{|l|l|}
\hline \multicolumn{1}{|c|}{ Borehole } & \multicolumn{1}{c|}{ Published Information Source on XRD Methodology } \\
\hline UE-25 p\#1 & Chipera and Bish (1988 [DIRS 105080]) for all samples \\
\hline USW H-3 & Levy (1984 [DIRS 101392]) for samples 1550, 1655, 1700, 1800, 1900, 2400, 2440, 2490; \\
\hline USW H-4 & Levy (1984 [DIRS 101392]) for sidewall core samples \\
\hline USW H-5 & $\begin{array}{l}\text { Levy (1984 [DIRS 101392]) for samples 50, 190, 420, 450, 700, 1050, 1610, 1666, 1750, } \\
\text { 1762, 1800, 1852, 1875, 1917, 1930; }\end{array}$ \\
\hline USW WT-1 & Bish and Chipera (1989 [DIRS 101195]) for all samples \\
\hline USW WT-2 & Bish and Chipera (1989 [DIRS 101195]) for all samples \\
\hline
\end{tabular}




\section{E3.4 DATA CORROBORATION ANALYSIS}

The comparison of mineral abundance data between boreholes with unqualified cuttings and boreholes with qualified core was conducted with restrictions imposed by the nature of mineralogic variation within the study area and by certain characteristics of the data sets. Variations in mineralogy across the Yucca Mountain area reflect primary compositional differences between consecutive ash flows. Lateral and vertical variability in pyroclastic constituents of ash flows and in postdepositional cooling and crystallization history also affects the mineralogy. Superimposed upon the variations in primary pyroclastic and syngenetic (high-temperature postdepositional crystallization) mineralogy are mineralogic changes due to alteration. The most important alteration was zeolitic alteration of originally glassy tuff. Distribution of zeolitic alteration was affected by multiple episodes of tectonic tilting and past variations in the position of the water table. A conceptual model that explains the interrelationship between these factors and the distribution of zeolitization is given by Levy (1991 [DIRS 100053]).

Paired borehole mineralogy data sets of qualified core data and unqualified cuttings (plus sidewall core and intermittent core) data were selected on the basis of physical proximity plus comparable ground-level elevations of boreholes. These criteria were applied to minimize the effects of lateral and vertical mineralogical variability on the comparisons of mineralogy data sets. The comparisons of mineralogical data were made for individual lithostratigraphic units or successions of units, based on unit contacts from DTN MO0004QGFMPICK.000 [DIRS 152554]. This qualified DTN contains unit contacts for both the boreholes with qualified core and those with unqualified cuttings. Unit descriptions and abbreviations are listed in E-13. The locations of unit contacts in boreholes without continuous core were determined more from downhole $\operatorname{logs}$ than from cuttings data. Most of the contacts are located within ten-foot intervals represented by cuttings samples. These samples would therefore contain material from two adjacent lithostratigraphic units. In addition, some cuttings, sidewall, or intermittent core samples located near unit boundaries have mineralogic affinities to an adjacent unit rather than the unit to which they would belong simply on the basis of sample footage location. This phenomenon was recognized by the authors of the BSC report (2004 [DIRS 170031]), who omitted some sample data from their model or adjusted the footage of some samples to avoid placing mineralogic data in an inappropriate lithostratigraphic unit. Unit contacts in cored holes are not free of these potential discrepancies because contacts in cored holes may have been selected more on the basis of rock texture than of mineralogy. In this report, such discrepancies are addressed on an individual basis.

Mineral-abundance data for lithostratigraphic units are presented as ranges bounded by the highest and lowest values. In general, neither the qualified nor the unqualified data sets contain enough analyses from any single lithostratigraphic unit to justify statistical comparisons of mean or standard deviation between borehole data sets. Borehole cuttings data sets typically contain four or fewer analyses for each unit.

The listings of individual samples used for comparison between unqualified and qualified data sets are contained in Appendices F (unqualified data) and G (qualified data). Analyses of cavity fillings, fracture fillings, and inclusions were omitted from the comparisons because these samples do not represent the bulk mineralogy of the lithostratigraphic units in which they were 
collected. Calcite-rich samples in the qualified data sets were omitted from the comparisons. In tables of this section where data are presented as ranges of mineral content, zeroes are substituted for "not detected" symbols present in the original DTN tables and in the appendices of this report. Symbols for approximate mineral content (e.g., $~ 1)$, also present in some of the original DTN tables in this section. In some comparison tables, mineral abundances for feldspar and silica minerals (tridymite, quartz, cristobalite, and opal) from the appendix have been combined to simplify the comparisons.

Lithostratigrahic units and their abbreviations, as used in this report, are listed in Table E-13. The unit names and boundaries are taken from DTN: MO0004QGFMPICK.000 [DIRS 152554]. The units are listed in order from lesser to greater depths and from younger to older ages. The term, "crystallized," as used in the lithostratigraphic unit descriptions, has a meaning equivalent to the term "devitrified," which is in more common usage in the petrographic descriptions of core and cutting samples cited in this report. Devitrification refers here to the high-temperature crystallization of glassy tuffs to mineral assemblages dominated by anhydrous silica minerals and feldspar.

Table E-13. Lithostratigraphic Unit Descriptions and Abbreviations

\begin{tabular}{|c|c|}
\hline $\begin{array}{c}\text { Unit } \\
\text { Abbreviation }\end{array}$ & Lithostratigraphic Unit Description \\
\hline Tpc_un & Tiva Canyon Tuff nondivided \\
\hline Tpcpv3 & Tiva Canyon Tuff, crystal-poor vitric densely welded subzone \\
\hline Tpcpv2 & Tiva Canyon Tuff, crystal-poor vitric moderately welded subzone \\
\hline Tpcpv1 & Tiva Canyon Tuff, crystal-poor vitric nonwelded to partially welded subzones \\
\hline Tpbt4 & Pre-Tiva Canyon Tuff bedded tuff \\
\hline Tpy & Yucca Mountain Tuff nondivided \\
\hline Tpbt3 & Pre-Yucca Mountain Tuff bedded tuff \\
\hline Tpp & Pah Canyon Tuff nondivided \\
\hline Tpbt2 & Pre-Pah Canyon Tuff bedded tuff \\
\hline Tptrv3 & Topopah Spring Tuff crystal-rich vitric nonwelded to partially welded zones \\
\hline Tptrv2 & Topopah Spring Tuff crystal-rich vitric moderately welded zone \\
\hline Tptrv1 & Topopah Spring Tuff crystal-rich vitric densely welded zone \\
\hline Tptrn & Topopah Spring Tuff crystal-rich nonlithophysal zone \\
\hline Tptrl & Topopah Spring Tuff crystal-rich lithophysal zone \\
\hline Tptpul & Topopah Spring Tuff crystal-poor upper lithophysal zone \\
\hline Tptpmn & Topopah Spring Tuff crystal-poor middle nonlithophysal zone \\
\hline Tptpll & Topopah Spring Tuff crystal-poor lower lithophysal zone \\
\hline Tptpln & Topopah Spring Tuff, crystal-poor lower nonlithophysal zone \\
\hline Tptpv3 & Topopah Spring Tuff, crystal-poor vitric densely welded subzone \\
\hline Tptpv2 & Topopah Spring Tuff, crystal-poor vitric moderately welded subzone \\
\hline Tptpv1 & Topopah Spring Tuff, crystal-poor vitric nonwelded to partially welded subzones \\
\hline Tpbt1 & Pre-Topopah Spring Tuff bedded tuff \\
\hline Tac & Calico Hills Formation undifferentiated \\
\hline
\end{tabular}


Table E-13. Lithostratigraphic Unit Descriptions and Abbreviations (Continued)

\begin{tabular}{|l|l|}
\hline \multicolumn{1}{|c|}{$\begin{array}{c}\text { Unit } \\
\text { Abbreviation }\end{array}$} & \\
\hline Tacbt & Pre-Calico Hills Formation bedded tuff \\
\hline Tcpuv & Prow Pass Tuff upper vitric (zeolitic) nonwelded to partially welded zones \\
\hline Tcpuc & Prow Pass Tuff, upper crystallized nonwelded to partially welded zones \\
\hline Tcpm & Prow Pass Tuff, crystallized moderately to densely welded zones \\
\hline Tcplc & Prow Pass Tuff, lower crystallized nonwelded to partially welded zones \\
\hline Tcplv & Prow Pass Tuff, lower vitric (zeolitic) nonwelded to partially welded zones \\
\hline Tcpbt & Pre-Prow Pass Tuff bedded tuff \\
\hline Tcbuv & Bullfrog Tuff upper vitric (zeolitic)nonwelded to partially welded zones \\
\hline Tcbuc & Bullfrog Tuff, upper crystallized nonwelded to partially welded zones \\
\hline Tcbm & Bullfrog Tuff, crystallized moderately to densely welded zones \\
\hline Tcblc & Bullfrog Tuff, lower crystallized nonwelded to partially welded zones \\
\hline Tcblv & Bullfrog Tuff, lower vitric (zeolitic) nonwelded to partially welded zones \\
\hline Tcbbt & Pre-Bullfrog Tuff bedded tuff \\
\hline Tctuv & Tram Tuff, upper vitric (zeolitic) nonwelded to partially welded zones \\
\hline Tctuc & Tram Tuff, upper crystallized nonwelded to partially welded zones \\
\hline Tctm & Tram Tuff, crystallized moderately to densely welded zones \\
\hline Tctlc & Tram Tuff, lower crystallized nonwelded to partially welded zones \\
\hline Tctlv & Tram Tuff, lower vitric (zeolitic) nonwelded to partially welded zones \\
\hline Tctbt & Pre-Tram Tuff bedded tuff \\
\hline Tund & lower Tertiary units undifferentiated \\
\hline Pz & Paleozoic and older units \\
\hline Source:
\end{tabular}

Source: DTN: MO0004QGFMPICK.000 [DIRS 152554].

\section{UE-25 p\#1 Compared with UE-25 UZ\#16, USW SD-12, USW G-4, and USW G-1}

For purposes of corroboration, the mineralogical data from the upper part of $\mathrm{p \# 1}$ were compared with qualified data from UE-25 UZ\#16. This is the borehole closest to p\#1 that has qualified data. The data are compared in Table E-14. Mineralogic data from the lower part of p\#1 are compared with qualified data from USW G-1.

For the devitrified units of the Topopah Spring Tuff, ranges of mineralogic abundance in both boreholes generally overlap. The absence of either glass or major hydrous alteration products (smectite or zeolites) in the devitrified units is a common characteristic of both data sets.

One cutting sample from the 1240-1250 ft depth in p\#1 straddles the boundary between Tptpv2 and Tptpv1 at $1243 \mathrm{ft}$. Data for this sample are listed in Table E-14 as Tptpv2/1. A downward transition from vitric to zeolitic tuff is located within the Tptpv2 + Tptpv1 interval in both boreholes. In UZ\#16, the transition lies within Tptpv2. The transition cannot be specified as lying within Tptpv2 or Tptpv1 in p\#1, but the absence of glass in the sample suggests the transition is within Tptpv2, in agreement with the UZ\#16 data. 
Table E-14. Mineral-Abundance Ranges, UE-25 p\#1 and UE-25 UZ\#16 (Weight Percent)

\begin{tabular}{|c|c|c|c|c|c|c|c|c|c|c|c|c|c|c|}
\hline \multirow[t]{2}{*}{ Unit } & \multicolumn{2}{|c|}{$\begin{array}{c}\text { Smectite } \\
\pm \text { Mordenite }\end{array}$} & \multicolumn{2}{|c|}{ Clinoptilolite } & \multicolumn{2}{|c|}{ Tridymite } & \multicolumn{2}{|c|}{ Quartz } & \multicolumn{2}{|c|}{$\begin{array}{c}\text { Cristobalite } \\
\pm \text { Opal }\end{array}$} & \multicolumn{2}{|c|}{ Feldspar } & \multicolumn{2}{|c|}{ Glass } \\
\hline & $\mathrm{p} \# 1$ & UZ16 & $\mathrm{p} \# 1$ & UZ16 & $\mathrm{p \# 1}$ & UZ16 & $\mathrm{p} \# 1$ & UZ16 & $\mathrm{p \# 1}$ & UZ16 & $\mathrm{p \# 1}$ & UZ16 & $\mathrm{p} \# 1$ & UZ16 \\
\hline Tptrn & 0 & Tr. -5 & 0 & $0-0$ & 14 & $3-22$ & 0 & $0-0$ & 6 & $5-13$ & 76 & $64-81$ & 0 & $0-0$ \\
\hline Tptpul & $2-3$ & $4-6$ & $0-0$ & $0-0$ & Tr. -4 & $1-16$ & 3-9 & $2-11$ & $24-25$ & $17-29$ & $54-71$ & $54-58$ & $0-0$ & $0-0$ \\
\hline Tptpmn & 2 & $3-4$ & 0 & $0-0$ & Tr. & Tr.-4 & 30 & $6-23$ & 3 & $13-27$ & 67 & $54-57$ & 0 & $0-0$ \\
\hline Tptpll & $1-2$ & 1-6 & $0-0$ & $0-0$ & $0-0$ & $1-7$ & $27-36$ & $0-36$ & $1-5$ & $5-26$ & $59-61$ & $50-58$ & $0-0$ & $0-0$ \\
\hline Tptpln & 0 & $2-6$ & 0 & $0-0$ & 0 & $0-5$ & 27 & $14-31$ & 5 & $8-23$ & 67 & $45-57$ & 0 & $0-0$ \\
\hline Tptpv2 & & 2 & & 10 & & 0 & & 2 & & 20 & & 17 & & 49 \\
\hline Tptpv2/1 & 1 & & 54 & & 0 & & Tr. & & 20 & & 24 & & 0 & \\
\hline Tptpv1 & 1 & 1 & 62 & 80 & 0 & 0 & Tr. & 3 & 23 & 13 & 14 & 8 & 0 & 0 \\
\hline Tac & Tr.-10 & $1-19$ & $34-56$ & $38-72$ & $0-0$ & $0-0$ & $2-17$ & $3-9$ & $0-22$ & $10-26$ & $21-39$ & $6-19$ & $0-9$ & $0-0$ \\
\hline Tacbt & 12 & $5-9$ & 0 & $40-42$ & 0 & $0-0$ & 24 & $8-11$ & 0 & $20-27$ & 40 & $18-27$ & 22 & $0-0$ \\
\hline Tсpuc & 39 & $3-8$ & 0 & $0-0$ & 0 & $0-0$ & 25 & $17-41$ & 0 & $0-20$ & 40 & $48-58$ & 0 & $0-0$ \\
\hline Tcpm & 0 & 3-4 & 3 & $0-0$ & 0 & $0-0$ & 39 & 24-39 & 0 & $0-14$ & 60 & $58-62$ & 0 & $0-0$ \\
\hline Tcplc & 5 & $6-7$ & 0 & $0-0$ & 0 & $0-0$ & 37 & $11-20$ & 0 & $15-27$ & 58 & $55-56$ & 0 & $0-0$ \\
\hline Tcplv & 3-7 & 3 & $40-60$ & 42 & $0-0$ & 0 & $4-11$ & 5 & $14-17$ & 28 & $17-25$ & 28 & $0-0$ & 0 \\
\hline
\end{tabular}


A p\#1 sidewall sample from 1,470 ft falls within the devitrified Tcpuc lithostratigraphic unit two feet below the boundary with the overlying vitric Tcpuv unit. This sample contains 39 percent mordenite plus minor smectite and therefore must have been partly vitric prior to the hydrous-mineral alteration. The mineralogy of the sample therefore represents a transition between Tcpuv and Tcpuc. The uppermost Tcpuc sample from UZ\#16 contains 8 percent mordenite, which is the upper end of the smectite + mordenite range for UZ\#16 samples in the Tcpuc and the only sample in that lithostratigraphic unit that contains mordenite. This similarity is corroborative of the location and mineralogy of the p\#1 sample.

The single p\#1 sample analysis from the Tptpmn unit falls outside the range of UZ\#16 values for the major constituents quartz, cristobalite, and feldspar. In Table E-15, this analysis is compared to mineral-abundance ranges for tridymite, quartz, cristobalite, and feldspar in the Tptpmn unit of three qualified borehole data sets in addition to UZ\#16. The feldspar content of the p\#1 sample is similar to values in USW G-4 but the cristobalite content falls far below the ranges of the other boreholes and the quartz content is slightly to substantially higher. Byers (1983 [DIRS 169692]) described a thin section of this sample (570-580 ft depth, identified in his unpaginated notebook as P1-580) as a partially welded, devitrified ash-flow tuff. The Tptpmn unit is described by Buesch et al. (1996 [DIRS 100106]) as densely welded, devitrified tuffs. Based on the welding difference, it appears that the 570-580 ft sample does not represent the lithology of the Tptpmn unit. No documentation or sample remainder was found that could explain the origin of this atypical material. Therefore, it will be recommended that the data for this material be excluded from qualification.

Table E-15. Ranges of Mineral Content in the Tptpmn of p\#1, UZ\#16, SD-12, and G-4 (Weight Percent)

\begin{tabular}{|c|c|c|c|c|}
\hline Borehole & Tridymite & Quartz & Cristobalite/Opal & Feldspar \\
\hline UE-25 p\#1 & Tr. & 30 & 3 & 67 \\
\hline UE-25 UZ\#16 & Tr.-4 & $6-23$ & $13-27$ & $54-57$ \\
\hline USW SD-12 & $2-4$ & $3-11$ & $26-34$ & $52-54$ \\
\hline USW G-4 & $0-17$ & $3-4$ & $13-28$ & $62-68$ \\
\hline
\end{tabular}

There is a substantial difference in the values for quartz and cristobalite/opal between the single p\#1 sample and the UZ\#16 samples in the Tcplc unit. The p\#1 1,640-1,650-ft sample values (Table E-15) fall within the ranges for quartz and cristobalite/opal in the overlying Tcpm unit of both p\#1 and UZ\#16. It is noteworthy that the lowest analyzed sample in the UZ\#16 Tcpm unit has quartz and cristobalite/opal values that are more typical of the underlying Tcplc unit. The larger UZ\#16 data set shows a downward change from quartz much greater than cristobalite/opal to quartz less than or equal to cristobalite/opal that is offset by about $20 \mathrm{ft}$ above the unit boundary between Tcpm and Tcplc. In p\#1, the same mineralogic change is present but is offset by about $10 \mathrm{ft}$ below the unit boundary. Therefore, this particular discrepancy between the two mineralogy data sets exists because the lithostratigraphic unit boundaries were not picked on the basis of the mineralogic change. The p\#1 data for the Tcpm and Tcplc units are corroborated by the UZ\#16 data. 


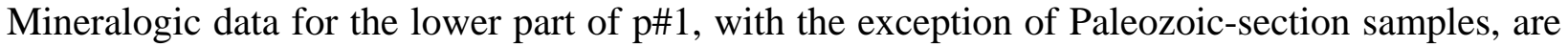
compared with data from USW G-1 in Table E-16. Common aspects of both data sets are the presence of only small amounts of clay and zeolite in the devitrified units Tcbuc, Tcbm, Tcblc (not recognized in USW G-1), Tctuc, and Tctm. The originally vitric units Tcpbt, Tcblv, Tcbbt, Tctuv, and Tctlv have clay and zeolites as major constituents.

Sample p\#1 2030-2040, in the Tcbm unit, is listed as containing seven percent glass. The presence of glass in the middle of approximately equal to $300 \mathrm{ft}$ thick devitrified interval (Tcbuc-Tcbm-Tcblc) is unlikely. No thin section of this sample is available for examination. In the absence of information to support the presence of glass in this sample, it will be recommended that the sample not be qualified.

The lowermost Tertiary unit, Tund, combines multiple pyroclastic deposits. In p\#1, the Tund unit is 1,217 ft thick, whereas in G-1 it is 2,442 ft from the top of the unit to the depth of the lowest analyzed sample. This large difference of thickness precludes the use of a side-by-side mineralogic-abundance comparison between data sets for this unit. Instead, the comparison is based on general mineralogic similarities and on the vertical variations in illite/smectite interstratification in $\mathrm{p} \# 1$ and $\mathrm{G}-1$.

Tund samples in p\#1 and G-1 are similar in the lack of tridymite and cristobalite/opal. The only exception is one sample from near the top of Tund in G-1 that contains 6 percent cristobalite/opal. Chlorite is generally absent from rocks above the Tund and the upper Tund, but is a common constituent in trace to minor quantities in the lower Tund of both borehole data sets.

Investigations of illite/smectite interstratification in p\#1 and G-1 are documented in Chipera and Bish (1988 [DIRS 105080]) and Bish (1989 [DIRS 101194]). These references describe the increasing proportions of illite with depth and its inferred correlation with increasing temperature. Ordering of the interstratifications changes with depth from random to more highly ordered. Chipera and Bish (1988 [DIRS 105080], p. 17) compared the suites of illite/smectite samples for p\#1 and G-1 (also G-2), most of which represent the Tund, and found similar trends with increasing depth. They attributed the similarities to similar alteration histories. In particular, an inferred early higher-temperature alteration event with temperatures increasing with depth was recognized in both data sets. This suggests that the p\#1 sample set reflects good depth control.

No qualified data sets exist for comparison with the three lowermost samples from p\#1 representing the Paleozoic section. Therefore, these samples cannot be qualified by corroboration with qualified data. The Paleozoic section is not part of the Mineralogic Model (3.0) (BSC 2004 [DIRS 170031]) and the data for these three samples are not used as input to the model. 
Table E-16. Mineral-Abundance Ranges, UE-25 p\#1 and USW G-1 (Weight Percent)

\begin{tabular}{|c|c|c|c|c|c|c|c|c|c|c|c|c|c|c|}
\hline \multirow[t]{2}{*}{ Unit } & \multicolumn{2}{|c|}{$\begin{array}{c}\text { Smectite } \\
\pm \text { Mordenite }\end{array}$} & \multicolumn{2}{|c|}{$\begin{array}{c}\text { Clinoptilolite } \\
\pm \text { Analcime }\end{array}$} & \multicolumn{2}{|c|}{ Tridymite } & \multicolumn{2}{|c|}{ Quartz } & \multicolumn{2}{|c|}{$\begin{array}{c}\text { Cristobalite } \pm \\
\text { Opal }\end{array}$} & \multicolumn{2}{|c|}{ Feldspar } & \multicolumn{2}{|c|}{ Glass } \\
\hline & $\mathrm{p} \# 1$ & G-1 & $\mathrm{p} \# 1$ & G-1 & $\mathrm{p} \# 1$ & G-1 & $\mathrm{p} \# 1$ & G-1 & $\mathrm{p} \# 1$ & G-1 & $\mathrm{p \# 1}$ & G-1 & $\mathrm{p} \# 1$ & G-1 \\
\hline Tcpbt & 24 & 9 & 45 & 33 & 0 & 0 & 12 & 2 & 0 & 8 & 18 & 41 & 0 & 0 \\
\hline Tcbuc & Tr. -5 & $1-3$ & $0-9$ & $0-0$ & $0-0$ & $0-0$ & $27-45$ & $32-35$ & $0-0$ & Tr.-1 & $39-64$ & $62-67$ & $0-0$ & $0-0$ \\
\hline Tcbm & Tr.-2 & Tr.-1 & $0-0$ & $0-0$ & $0-0$ & $0-0$ & $31-39$ & $32-36$ & $0-0$ & $0-T r$. & $59-65$ & $63-67$ & $0-7$ & $0-0$ \\
\hline Tcblc & 3 & * & Tr. & * & 0 & * & 29 & * & 0 & * & 61 & * & 0 & * \\
\hline Tcblv & 31 & $27-39$ & 14 & $40-48$ & 0 & $0-0$ & 28 & Tr.-3 & 0 & $2-10$ & 33 & $12-20$ & 0 & $0-0$ \\
\hline Tcbbt & 10 & $14-26$ & 8 & $26-42$ & 0 & $0-0$ & 29 & $12-21$ & 0 & $1-1$ & 52 & $17-30$ & 0 & $0-0$ \\
\hline Tctuv & $6-11$ & $4-15$ & $6-35$ & $15-40$ & $0-0$ & $0-0$ & $22-32$ & $4-18$ & $0-0$ & $4-8$ & $32-45$ & $33-52$ & $0-0$ & $0-0$ \\
\hline Tctuc & 7 & $1-3$ & 0 & $0-0$ & 0 & $0-0$ & 40 & $31-36$ & 0 & $0-1$ & 49 & $62-64$ & 0 & $0-0$ \\
\hline Tctm & $0-2$ & $1-2$ & $0-0$ & $0-2$ & $0-0$ & $0-0$ & $24-43$ & $30-36$ & $0-0$ & $0-T r$. & $51-77$ & 61-67 & $0-0$ & $0-0$ \\
\hline Tctlv & $4-25$ & $4-18$ & $0-13$ & $4-41$ & $0-0$ & $0-0$ & $29-42$ & $18-38$ & $0-0$ & $0-0$ & $34-57$ & $20-43$ & $0-0$ & $0-0$ \\
\hline
\end{tabular}

*Tcblc is not recognized in USW G-1. 


\section{USW H-3 Compared with USW GU-3}

Two samples within two feet or less of a lithostratigraphic unit boundary, one from each borehole, were reassigned to an adjacent unit based on strong mineralogic affinity to that unit. Sample GU-3 1,598.5 falls within the devitrified Tcpuc unit (upper boundary at 1,597 ft depth) but contains 45 percent glass. This sample was moved to the overlying vitric Tcpuv for the purpose of unit-to-unit mineralogic comparison. Sample H-3 1,700 falls within the devitrified Tcplc unit two feet above the boundary with the underlying vitric Tcplv unit. The sample contains 15 percent glass and therefore was moved to the underlying unit Tcplv.

The succession of lithostratigraphic units shown in Table E-17 includes distinctive lithologic-unit transitions that correspond to mineralogic transitions. Mineralogic features common to both USW H-3 and USW GU-3 data sets include:

- Restriction of detectable hornblende to the phenocryst-rich Tacbt.

- Transition from Tcpuv to Tcpuc corresponds to a transition from glass bearing to nonglass-bearing mineral assemblages.

- Transition from Tcplc to Tcplv corresponds to a transition from nonglass-bearing mineral assemblages to assemblages containing either glass or clinoptilolite derived from the alteration of glass.

The raw-value ranges of mineral abundances within lithostratigraphic units are generally similar in USW H-3 and USW-GU-3. One difference is observed in the Tptpln unit. The H-3 samples have cristobalite heavily predominant over quartz, whereas the GU-3 samples show the opposite pattern. Both Tptpln sample sets are small, with two H-3 samples and three GU-3 samples. The cristobalite greater than quartz pattern in the Tptpln unit is uncommon within the qualified data sets, but similar patterns are present in two samples from the lower Tptpln in USW SD-12 where this unit was very well sampled. Nonoverlapping mineral-abundance ranges exist in the Tptpv3 data, but this unit typically shows high variability in mineral abundances. The mineralogic differences between the single $\mathrm{H}-3$ sample and the GU-3 samples are attributable to a higher glass content in the H-3 sample. 
Table E-17. Mineral-Abundance Ranges, USW H-3 and USW GU-3 (Weight Percent)

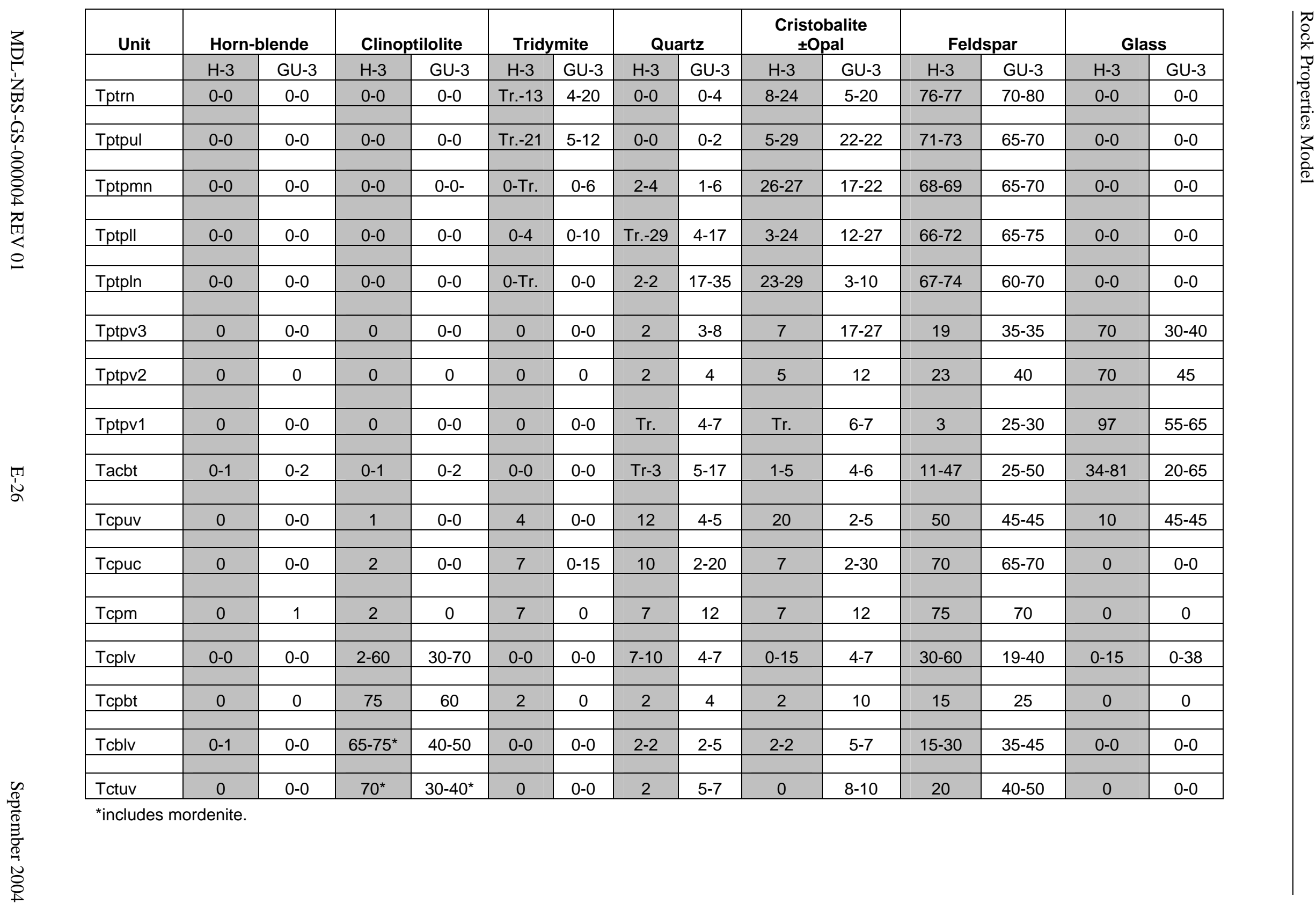




\section{USW H-4 Compared with USW SD-12, UE-25 UZ\#16, and USW G-4}

Examination of the mineralogical data for $\mathrm{H}-4$ and the three closest drill holes with qualified data revealed considerable variability. Because of this variability, it was determined that comparisons of data for the purpose of corroboration would have to include some input from all three qualified data sets.

Preliminary examination of H-4 mineralogical data organized by lithostratigraphic unit identified one potential outlier sample analysis. The XRD analysis of Calico Hills Formation (Tac) sample H-4 1320-1330 indicates that it is composed exclusively of crystalline silica (dominantly quartz) and feldspar. This mineralogic composition closely matches the compositions of devitrified tuffs in the Prow Pass Tuff (e.g., H-4 1710-1720) and other devitrified tuffs. The Calico Hills Formation is not known to contain any fully devitrified intervals at Yucca Mountain, but it typically contains lithic clasts of densely welded, devitrified tuff in a matrix of glassy clasts or zeolitized glassy clasts. Moyer and Geslin (1995 [DIRS 101269]) specify the lithic-clast content of the upper part of the Calico Hills Formation as less than or equal to 5 percent, with presumably higher contents in localized lithic-clast swarms.

At the time the H-4 1320-1330 sample was collected, the variations in lithology and mineralogy of the Calico Hills Formation were poorly known. The USGS drill hole report for USW H-4 describes the Tuffaceous beds of Calico Hills (informal usage) as nonwelded to partly welded, devitrified and zeolitized, with possible silicification of the upper $11 \mathrm{~m}$. The tuff is described as containing abundant rhyolitic lithic fragments (Whitfield et al. 1984 [DIRS 101366], p. 7). The notebook entry for the 1,320-1,330 ft sampling interval made at the time the LANL sample was collected from materials at the USGS Core Library describes it as "silicified tuff of unknown origin" (Vaniman 1983 [DIRS 169665]). The remnant of this sample was examined under the binocular microscope at LANL for the current investigation. It contained subequal portions of lithic clasts (dark densely welded, devitrified tuff) and zeolitic nonwelded tuff plus vitric nonwelded tuff. The aliquot of this sample submitted for XRD apparently contained little or none of the nonwelded tuff because the analysis shows no zeolite or glass content. Existing documentation of the dominant lithology of this rock unit suggests it is very unlikely that the source rock could have been composed only of devitrified tuff. Even a lithic-clast swarm, sampled over a $10 \mathrm{ft}$ interval, would not yield a sample that is exclusively devitrified tuff. Based on the information cited here, H-4 1320-1330 data are omitted from the comparison of $\mathrm{H}-4$ data and qualified mineralogical data and a recommendation will be made that the data for this sample not be qualified.

One sidewall sample, H-4 1656, nominally falls within Tcpuv but was reassigned to a lower unit whose boundary is six feet below the sample collection depth. The boundary separates vitric Prow Pass Tuff (Tcpuv) from underlying devitrified tuff (Tcpuc). Sample H-4 1656 is devitrified, but its cryptocrystalline texture differs from the coarser texture of a sample lower in the Tcpuc (Levy 1984 [DIRS 101392], p. 21) in ways that suggest it must be close to the vitric_-devitrified boundary. 
Table E-18 compares the contents of the most abundant rock-forming minerals in the Tptpln of H-4 and three qualified borehole data sets. This lithostratigraphic unit consists of densely welded, devitrified tuff. The Tptpln intervals in all four boreholes are similar in containing little or no tridymite. The intervals are most notably different in their feldspar contents. H-4 and G-4 have very similar ranges of feldspar content. SD-12 and UZ\#16 also have very similar ranges of feldspar content, but these ranges do not overlap with the ranges for H-4 and G-4. The differences in feldspar content are matched by greater or lesser amounts of quartz or cristobalite/opal, although the abundance ranges for the two silica minerals show substantial overlap among all four data sets. This comparison show that the abundance ranges of tridymite, quartz, and cristobalite/opal in the three qualified borehole data sets are corroborative of the data from H-4. The feldspar data show that genuine variability exists among the qualified data sets but that at least one of the data sets is a good corroborative match to the $\mathrm{H}-4$ data.

Table E-18. Ranges of Mineral Content in the Tptpln of H-4, SD-12, UZ\#16, and G-4 (Weight Percent)

\begin{tabular}{|c|c|c|c|c|}
\hline Borehole & Tridymite & Quartz & Cristobalite/Opal & Feldspar \\
\hline USW H-4 & $0-0$ & $6-15$ & $18-23$ & $64-70$ \\
\hline USW SD-12 & $1-3$ & $7-24$ & $15-30$ & $53-57$ \\
\hline UE-25 UZ\#16 & $0-5$ & $14-31$ & $8-23$ & $45-57$ \\
\hline USW G-4 & $0-0$ & $2-25$ & $13-24$ & $60-69$ \\
\hline
\end{tabular}

Mineralogic changes across unit boundaries are documented and compared in Table E-19. Characteristic mineralogic changes across boundaries, observed in $\mathrm{H}-4$ plus at least one of SD-12 and UZ\#16, include the change from assemblages dominated by feldspar plus silica in the Tptprn-Tptpln to an assemblage with glass plus minor smectite and clinoptilolite in the Tptpv3. The Tpbt1-Tac-Tacbt sequence in the three drill holes consists of originally vitric tuffs in which the glass has been slightly to completely altered to clinoptilolite and smectite, with or without mordenite. The data for SD-12 and UZ\#16 show that there is considerable lateral variability in the degree of alteration within specific units. The $\mathrm{H}-4$ data for Tpbt 1 more closely resemble SD-12 (persistence of glass), whereas the H-4 data are more similar to UZ\#16 data in the Tac (complete alteration of glass). The single Tacbt sample from $\mathrm{H}-4$ has alteration (presence of clinoptilolite, absence of glass) that generally falls within or close to the highly variable ranges of alteration in SD-12 and UZ\#16. The values for feldspar+silica that are generally higher in the Tacbt than in the Tac for all three drill holes reflect the higher phenocryst and lithic-clast content of the Tacbt (Vaniman et al. 1984 [DIRS 101363], p. 24-25).

The mineralogic changes from Tcpuv downward to the devitrified sequence Tcpuc-Tcpm-Tcplc are the disappearance of clinoptilolite and the appearance of a mineral assemblage dominated by feldspar plus silica. For these changes, the H-4 data are consistent with the data from SD-12 and UZ\#16. The downward change from the devitrified units to the Tcplv is marked in all three drill holes by the reappearance of clinoptilolite. 
Table E-19. Mineral-Abundance Ranges, USW H-4, USW SD-12, and UE-25 UZ\#16 (Weight Percent)

\begin{tabular}{|c|c|c|c|c|c|c|c|c|c|c|c|c|}
\hline \multirow[t]{2}{*}{ Unit } & \multicolumn{3}{|c|}{$\begin{array}{c}\text { Smectite } \\
\pm \text { Mordenite }\end{array}$} & \multicolumn{3}{|c|}{ Clinoptilolite } & \multicolumn{3}{|c|}{ Feldspar+Silica } & \multicolumn{3}{|c|}{ Glass } \\
\hline & $\mathrm{H}-4$ & SD-12 & UZ\#16 & $\mathrm{H}-4$ & SD-12 & UZ\#16 & $\mathrm{H}-4$ & SD-12 & UZ\#16 & $\mathrm{H}-4$ & SD-12 & UZ\#16 \\
\hline Tptprn & 0 & $0-2$ & Tr.-5 & 0 & $0-0$ & $0-0$ & 96 & $95-100$ & $94-103$ & 0 & $0-0$ & $0-0$ \\
\hline Tptpul & $2-2$ & 3-5 & $4-6$ & $0-0$ & $0-0$ & $0-0$ & $97-98$ & $92-98$ & $90-96$ & $0-0$ & $0-0$ & $0-0$ \\
\hline Tptpmn & 2 & $3-5$ & $3-4$ & 0 & $0-0$ & $0-0$ & 98 & $93-96$ & $91-99$ & 0 & $0-0-$ & $0-0$ \\
\hline Tptpll & $1-3$ & $2-5$ & $1-6$ & $0-0$ & $0-0$ & $0-11^{2}$ & 95-99 & 93-98 & $88-100$ & $0-0$ & $0-0$ & $0-0$ \\
\hline Tptpln & $1-2$ & $0-4$ & $2-6$ & $0-0$ & $0-1$ & $0-14^{2}$ & 97-99 & $92-98$ & $84-97$ & $0-0$ & $0-0$ & $0-0$ \\
\hline Tptpv3 & $0-20$ & $0-2$ & $0-73$ & $0-5$ & $0-0$ & $0-4$ & $30-49$ & $11-18$ & $8-23$ & $30-70$ & $72-85$ & $0-82$ \\
\hline Tptpv2 & & & & & & sample & in $\mathrm{H}-4 \mathrm{~d}$ & ta set & & & & \\
\hline Tptpv1 & & & & & & sample & in $\mathrm{H}-4 \mathrm{~d}$ & ta set & & & & \\
\hline Tpbt1 & 2 & 2 & $8^{1}$ & 5 & 1 & 83 & 42 & 12 & 11 & 50 & 85 & 0 \\
\hline Tac & $0-25^{1}$ & $0-3$ & $1-19^{1}$ & $29-78$ & $1-10$ & $38-72$ & $18-52$ & $9-35$ & $22-54$ & $0-0$ & $58-89$ & $0-0$ \\
\hline Tacbt & 0 & $3-11^{1}$ & $5-9^{1}$ & 31 & $12-68$ & 40-42 & 61 & $22-78$ & $53-58$ & 0 & $0-62$ & $0-0$ \\
\hline Tcpuv & 0 & 7 & -.--- & 10 & 58 & -..-- & 90 & 39 & -..-- & 0 & 0 & ----- \\
\hline $\begin{array}{l}\text { Tcpuc } \\
\text { Tcpm } \\
\text { Tcplc }\end{array}$ & $0-3$ & Tr.-5 & $3-8^{1}$ & $0-0$ & $0-0$ & $0-0$ & $96-102$ & $89-99$ & $85-100$ & $0-0$ & $0-0$ & $0-0$ \\
\hline Tcplv & $0-23^{1}$ & $2-15^{1}$ & 3 & $11-22$ & $10-65$ & 42 & $63-77$ & $38-84$ & 61 & $0-0$ & $0-0$ & 0 \\
\hline
\end{tabular}

NOTE: $\quad-----=$ no samples analyzed from this unit

Tr. = trace amount present.

Blanks are intentional.

${ }^{1}$ Includes mordenite in at least one sample.

${ }^{2}$ The zeolite present is stellerite. 


\section{USW H-5 Compared with UE-25 UZ\#16 and USW GU-3}

The dominant mineralogy of the Tpc_un unit of the Tiva Canyon Tuff in USW H-5 is compared with the mineralogy of two qualified data sets in Table E-20. For this devitrified-rock interval, there is a very close similarity in the raw-data ranges of mineral abundance between $\mathrm{H}-5$ and GU-3. Comparison of H-5 data with data from UZ\#16 shows a general similarity of mineralogic content, although UZ\#16 has higher cristobalite/opal content and lower feldspar content.

Table E-20. Ranges of Mineral Content in the Tpc_un of H-5, UZ\#16, and GU-3 (Weight Percent)

\begin{tabular}{|c|c|c|c|c|}
\hline Borehole & Tridymite & Quartz & Cristobalite/Opal & Feldspar \\
\hline USW H-5 & $2-31$ & $0-6$ & $0-29$ & $66-80$ \\
\hline UE-25 UZ\#16 & Tr.-7 & Tr.-4 & $25-33$ & $57-62$ \\
\hline USW GU-3 & $0-25$ & $0-2$ & $6-30$ & $70-75$ \\
\hline
\end{tabular}

The H-5 data set contains no samples from Tpcpv3 or Tpcpv2. Mineralogic comparisons of units from the Tpcpv1 downward are complicated by large variations in secondary-mineral alteration, both within and between boreholes. For units affected by variable alteration, the corroboration of H-5 data is based on similarities of primary mineralogic or textural characteristics.

Three samples from H-5 were recognized as having mineralogic compositions similar to the units directly above their nominal unit assignments based on depth. These reassignments are equivalent to changes made in the Mineralogic Model (MM3.0) (BSC 2004 [DIRS 170031]). Sample H-5 1666 falls within the Tptpv2 unit beginning at $1659 \mathrm{ft}$. The published petrographic description of the highly altered sample indicates that it has a relict densely welded texture characteristic of the Tptpv3 (Levy 1984 [DIRS 101392], p. 27). It was reassigned to Tptpv3 for the purpose of this qualification activity. The same reassignment was made by BSC (2004 [DIRS 170031]).

The XRD analysis for sample H-5 1990-2000 contains 59 percent glass even though the recorded sample depth falls within the devitrified Tcpuc unit extending from 1,967-2,085 ft depth. This discrepancy was addressed in the BSC report (2004 [DIRS 170031]) by reassigning the sample to the overlying vitric Tcpuv. Examination of the sample remainder shows it to be composed of vitric tuff and devitrified tuff, with the vitric tuff predominant. Given that the nominal sample depth is more than $20 \mathrm{ft}$ below the top of the devitrified Tcpuc unit, it is likely that this sample contains a very large impurity of vitric tuff from the overlying unit. It will be recommended that this sample and its associated XRD analysis be excluded from qualification.

Sample H-5 2140-2150 was moved from the vitric Tcplv unit to the devitrified Tcplc unit whose lower boundary is located at 2,130 ft depth. The sample remainder contains a very small amount of residual glassy clasts, but the XRD analysis of the sample shows no glass content. Therefore, the sample was moved to Tcplc. 
The comparison of Tpcpv1 mineralogy for H-5 and UZ\#16 shows similar smectitic alteration of still partly glassy tuff (Table E-21). The Tpy samples differ between the two borehole data sets in degree of smectitic alteration, but the samples share high glass content and very low content of feldspar and silica phenocrysts. Data for the Tpbt3 in H-5, UZ\#16, and GU-3 all show smectitic alteration of vitric tuff with highly variable contents of feldspar and silica phenocrysts. The Tptrn, Tptrl, Tptpul, and Tptpmn are all devitrified tuff units with minor smectitic alteration. Samples from the Tptpll and Tptpln units of UZ\#16 are unusual in containing modest amounts of the zeolite stellerite but otherwise are similar to the H-5 and GU-3 samples with slight smectitic alteration of devitrified tuff. Alteration in the Tptpv3 of both H-5 and UZ\#16 is highly variable. In both holes, some samples contain substantial smectite and minor clinoptilolite and other samples contain mostly unaltered glass. The GU-3 samples are less altered but fall within the ranges of alteration for $\mathrm{H}-5$ and UZ\#16.

Samples of Tac from H-5 and GU-3 are predominantly vitric with phenocrysts or lithic inclusions of silica+feldspar composition and minor alteration to smectite and clinoptilolite. Alteration of the Tacbt unit in H-5 is intermediate between UZ\#16 and GU-3, but a higher content of silica+feldspar phenocrysts and lithic inclusions is a common attribute of all three borehole data sets. Mineralogic proportions in the Tcpuv are slightly different between H-5 and GU-3 samples, although both sets are partly vitric. The higher silica+feldspar content of the GU-3 samples reflects their locations lower in the Tcpuv unit, probably transitional to the underlying devitrified tuff.

\section{USW WT-1 Compared with UE-25 UZ\#16 and USW GU-3}

Mineral abundances in WT-1 are compared with UE-25 UZ\#16 and USW GU-3 in Table E-22. For the devitrified units Tptrn, Tptrl, Tptpul, Tptpmn, Tptpll, and Tptpln, the three data sets have very similar ranges of mineral abundances except for the presence of stellerite in the Tptpll and Tptpln of UZ\#16. The vitric tuff of Tpbt3 has minor smectitic alteration and residual glass in all three data sets. The Tptpv3 samples from all three data sets are partly devitrified with variable contents of smectite and clinoptilolite.

Sample WT-1 1570-1580 spans the interval from six to sixteen feet below the base of the Tac, which is the lowest recognized unit in WT-1 (see Table G-5). This makes it unclear which unit from a qualified data set should be used for comparison. The largest cuttings in the sample remainder have the appearance of a densely welded tuff, and the XRD analysis is consistent with this lithology. USGS (1995 [DIRS 169694], p. 6) stated that bit cutting samples from 1560 to $1610 \mathrm{ft}$ are contaminated with densely welded tuff fragments of Tiva Canyon Tuff that are larger than the other cuttings. USGS (1995 [DIRS 169694], p. 6) also proposed that a fault exists from 1540 to $1564 \mathrm{ft}$ and that the unit below the Tac is the Bullfrog Tuff (Tcb). Because of the uncertainties in unit identification and sample integrity, it will be recommended that this sample be excluded from qualification. 
Table E-21. Mineral-Abundance Ranges, USW H-5, UE-25 UZ\#16, and USW GU-3 (Weight Percent)

\begin{tabular}{|c|c|c|c|c|c|c|c|c|c|c|c|c|}
\hline \multirow[t]{2}{*}{ Unit } & \multicolumn{3}{|c|}{$\begin{array}{c}\text { Smectite } \\
\pm \text { Mordenite }\end{array}$} & \multicolumn{3}{|c|}{ Clinoptilolite } & \multicolumn{3}{|c|}{ Feldspar+Silica } & \multicolumn{3}{|c|}{ Glass } \\
\hline & $\mathrm{H}-5$ & UZ\#16 & GU-3 & $\mathrm{H}-5$ & UZ\#16 & GU-3 & $\mathrm{H}-5$ & UZ\#16 & GU-3 & $\mathrm{H}-5$ & UZ\#16 & GU-3 \\
\hline Tpcpv1 & 15 & $8-14$ & ----- & 0 & $0-0$ & ----- & 45 & $4-29$ & ----- & 40 & $63-82$ & ----- \\
\hline Tpy & 0 & $9-12$ & ----- & 0 & $0-0$ & ----- & 3 & $0-3$ & --.-- & 96 & 85-91 & ----- \\
\hline Tpbt3 & 14 & $6-18$ & 4 & 0 & $0-0$ & 0 & 14 & $11-29$ & 58 & 69 & $59-78$ & 40 \\
\hline Tptrn & Tr.-1 & Tr.-5 & $0-1$ & $0-0$ & $0-0$ & $0-0$ & $90-100$ & $94-103$ & $95-99$ & $0-0$ & $0-0$ & $0-0$ \\
\hline Tptrl & 3 & 7 & ----- & 0 & 0 & ------ & 97 & 104 & ----- & 0 & 0 & ----- \\
\hline Tptpul & $0-5$ & $4-6$ & & $0-0$ & $0-0$ & & $94-100$ & $90-96$ & & $0-0$ & $0-0$ & \\
\hline Tptpmn & Tr. -3 & $3-4$ & & $0-0$ & $0-0$ & & $91-97$ & 91-99 & & $0-0$ & $0-0$ & \\
\hline Tptpll & $2-4$ & $1-6$ & $0-1$ & $0-0$ & $0-11^{*}$ & $0-0$ & $95-100$ & $88-100$ & $96-100$ & $0-0$ & $0-0$ & $0-0$ \\
\hline Tptpln & Tr.-2 & $2-6$ & $0-1$ & $0-0$ & $0-14^{*}$ & $0-0$ & $95-99$ & $84-97$ & $97-98$ & $0-0$ & $0-0$ & $0-0$ \\
\hline Tptpv3 & $0-50$ & $0-73$ & $2-2$ & $0-10$ & $0-4$ & $0-0$ & $10-57$ & $17-23$ & $60-65$ & $0-90$ & $0-82$ & $30-40$ \\
\hline Tptpv2 & & & & & & & & & & & & \\
\hline Tptpv1 & & & & & No $s$ & mples it & $\mathrm{H}-5$ data & & & & & \\
\hline Tpbt1 & & & & & & & & & & & & \\
\hline & & & & & & & & & & & & \\
\hline $\mathrm{Tac}$ & $0-3$ & $1-19$ & $0-1$ & $0-6$ & $38-72$ & $0-3$ & $7-30$ & $22-54$ & $36-46$ & $70-95$ & $0-0$ & $55-65$ \\
\hline Tacbt & $0-3$ & $5-9$ & $3-3$ & $10-52$ & $40-42$ & $0-2$ & $12-75$ & $53-58$ & $36-71$ & $0-78$ & $0-0$ & $20-65$ \\
\hline Tcpuv & $3-5$ & ------ & $2-4$ & $0-51$ & -----. & $0-0$ & $15-17$ & -----. & $52-54$ & $31-75$ & ------ & $45-45$ \\
\hline
\end{tabular}


Table E-21. Mineral-Abundance Ranges, USW H-5, UE-25 UZ\#16, and USW GU-3 (Weight Percent) (Continued)

\begin{tabular}{|c|c|c|c|c|c|c|c|c|c|c|c|c|}
\hline Unit & & $\begin{array}{l}\text { necti } \\
\text { order }\end{array}$ & & & optilo & & & sparts & & & Glas & \\
\hline Tсpuc & 1 & 3-8 & $0-1$ & 0 & $0-0$ & $0-0$ & 90 & $85-97$ & 88-97 & 0 & $0-0$ & $0-0$ \\
\hline Tcpm & & & & & & mples in & $-1-5$ data & & & & & \\
\hline Tcplc & 1 & 6-7 & 0 & 0 & $0-0$ & 0 & 103 & $90-94$ & 101 & 0 & $0-0$ & 0 \\
\hline Tcplv & Tr.-10 & 3 & $0-3$ & $60-64$ & 42 & $30-70$ & 28-39 & 61 & $30-52$ & $0-0$ & 0 & $0-38$ \\
\hline Tcpbt & 13 & [----- & 0 & 56 & ------ & 60 & 34 & ---- & 39 & 0 & ----- & 0 \\
\hline
\end{tabular}

NOTE: ------ = no samples analyzed from this unit.

Tr. = trace amount present.

Blanks are intentional.

${ }^{*}$ The zeolite present is stellerite. 
Table E-22. Mineral-Abundance Ranges, USW WT-1, UE-25 UZ\#16, and USW GU-3 (Weight Percent)

\begin{tabular}{|c|c|c|c|c|c|c|c|c|c|c|c|c|}
\hline \multirow[t]{2}{*}{ Unit } & \multicolumn{3}{|c|}{$\begin{array}{c}\text { Smectite } \\
\pm \text { Mordenite }\end{array}$} & \multicolumn{3}{|c|}{ Clinoptilolite } & \multicolumn{3}{|c|}{ Feldspar+Silica } & \multicolumn{3}{|c|}{ Glass } \\
\hline & WT-1 & UZ\#16 & GU-3 & WT-1 & UZ\#16 & GU-3 & WT-1 & UZ\#16 & GU-3 & WT-1 & UZ\#16 & GU-3 \\
\hline Tpbt3 & 5 & $6-18$ & 4 & 0 & $0-0$ & 0 & 24 & $11-29$ & 58 & 70 & $59-78$ & 40 \\
\hline Tptrn & $0-0$ & Tr. -5 & $0-1$ & $0-0$ & $0-0$ & $0-0$ & $95-100$ & $94-103$ & $95-99$ & $0-0$ & $0-0$ & $0-0$ \\
\hline Tptrl & \multicolumn{12}{|c|}{ No samples in WT-1 data set } \\
\hline & & & & & & & & & & & & \\
\hline Tptpul & $1-1$ & $4-6$ & & $0-0$ & $0-0$ & & $98-99$ & $90-96$ & & $0-0$ & $0-0$ & \\
\hline Tptpmn & $1-1$ & $3-4$ & & $0-0$ & $0-0$ & & $98-99$ & 91-99 & & $0-0$ & $0-0$ & \\
\hline & & & & & & & & & & & & \\
\hline Tptpll & $1-3$ & 1-6 & $0-1$ & $0-1$ & $0-11^{*}$ & $0-0$ & $95-98$ & $88-100$ & $96-100$ & $0-0$ & $0-0$ & $0-0$ \\
\hline Tptpln & 0 & $2-6$ & $0-1$ & 0 & $0-14^{*}$ & $0-0$ & 99 & $84-97$ & $97-98$ & 0 & $0-0$ & $0-0$ \\
\hline Tptpv3 & $1-2$ & $0-73$ & $2-2$ & $2-14$ & $0-4$ & $0-0$ & $83-98$ & $17-23$ & $60-65$ & $0-0$ & $0-82$ & $30-40$ \\
\hline Tptpv2 & 1 & 2 & 2 & 29 & 10 & 0 & 70 & 39 & 56 & 0 & 49 & 45 \\
\hline & & & & & & & & & & & & \\
\hline Tptpv1 & \multirow{2}{*}{\multicolumn{12}{|c|}{ No samples in WT-1 data set }} \\
\hline Tpbt1 & & & & & & & & & & & & \\
\hline & & & & & & & & & & & & \\
\hline Tac & $8-18$ & $1-19$ & $0-1$ & $25-40$ & $38-72$ & $0-3$ & $46-56$ & $22-54$ & $36-46$ & $0-0$ & $0-0$ & $55-65$ \\
\hline & & & & & & & & & & & & \\
\hline $\begin{array}{l}\text { Below } \\
\text { Tac }\end{array}$ & 3 & & & 5 & & & 92 & & & 0 & & \\
\hline
\end{tabular}

NOTE: ------ = no samples analyzed from this unit.

Tr. = trace amount present.

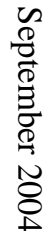

Blanks are intentional.

*The zeolite present is stellerite. 


\section{USW WT-2 compared with USW SD-12 and UE-25 UZ\#16}

The upper boundary of unit Tcplv at $1,794 \mathrm{ft}$ is the lowest recognized unit boundary in WT-2. In SD-12, about half a kilometer away (BSC 2004 [DIRS 170031], p. 27), the Tcplv is $268 \mathrm{ft}$ thick. Therefore, it is likely that the WT-2 samples from 1,820-1,830, 1,910-1,920, and 2,000-2,010 ft belong to the Tcplv unit. The WT-2 Tcplv unit in Table E-23 is represented by the summarized mineralogic data from these three samples. Mineralogic data for three WT-2 core samples from the lowermost ten feet of the borehole are compared to data for Tcb samples in SD-12.

Mineral abundances in the Tptrn, Tptpul, Tptpmn, Tptpll, Tptpln, Tacbt, Tcpuc, Tcpm, Tcplv, and Tcb are similar in all three borehole data sets. Samples from the Tpbt2, Tptpv3, Tptpv2, and Tptpv1 units in WT-2 tend to have higher feldspar+silica and lower glass contents than the SD-12 and UZ\#16 samples from the corresponding units. Some similar higher feldspar+silica values have been measured in qualified borehole data sets. For example, feldspar+silica values in the Tptpv3 of GU-3 are in the 60-65 weight percent range and are comparable to the 48-69 weight percent values for WT-2. The feldspar+silica content of a Tptpv2 sample from GU-3 is 56 weight percent, comparable to 57 weight percent in WT-2. The sample remainders of the questioned analyses were examined for impurities and were estimated to contain less than 5 volume percent of devitrified tuff impurities. Therefore, the differences among data sets are considered acceptable.

\section{E4. CONCLUSIONS}

The data sets for Boreholes UE-25 p\#1, USW H-3, USW H-4, H-5, WT-1, and WT-2 are recommended for qualification with the exceptions noted below. Mineral abundances in these data sets generally show very good correspondence with abundances in the same lithostratigraphic units of qualified data sets. These data are qualified for use the for the Rock Properties Model report.

Data for UE-25 J-12 should remain unqualified because no records were found to document collection, description, or analysis of the samples. These data are not input to the Rock Properties Model (RPM3.1) (BSC 2004 [DIRS 170031]).

The Qualified status of LADV831321AQ97.001 [DIRS 107142] recommended by Steinborn (2002 [DIRS 160702]) is incorrect because the DTN contains cuttings data from Borehole USW H-3 that remained unqualified. The qualification recommendation made by Steinborn (2002 [DIRS 160702]) was based on the qualification of the software POWD10. The qualification activity in this report includes cuttings data from Borehole USW H-3, and the results qualify the DTN for use in this report.

Similarly, the Qualified status of LADV831321AQ97.007 [DIRS 113499] is incorrect because the DTN contains cuttings data from borehole USW H-5 that are still unqualified. The qualification activity in this report includes cuttings data from the borehole USW H-5, and the results qualify the DTN for use in this report. 
Table E-23. Mineral-Abundance Ranges, USW WT-2, USW SD-12, and UE-25 UZ\#16 (Weight Percent)

\begin{tabular}{|c|c|c|c|c|c|c|c|c|c|c|c|c|}
\hline \multirow[t]{2}{*}{ Unit } & \multicolumn{3}{|c|}{$\begin{array}{c}\text { Smectite } \\
\pm \text { Mordenite }\end{array}$} & \multicolumn{3}{|c|}{ Clinoptilolite } & \multicolumn{3}{|c|}{ Feldspar+Silica } & \multicolumn{3}{|c|}{ Glass } \\
\hline & WT-2 & SD-12 & UZ\#16 & WT-2 & SD-12 & UZ\#16 & WT-2 & SD-12 & UZ\#16 & WT-2 & SD-12 & UZ\#16 \\
\hline Tpbt2 & $4-7$ & ----- & $8-16$ & $0-0$ & ----- & $0-0$ & $47-59$ & ----- & $19-22$ & $30-50$ & ----- & $58-71$ \\
\hline Tptrn & $1-1$ & $0-2$ & Tr. -5 & $0-0$ & $0-0$ & $0-0$ & $97-97$ & $95-100$ & $95-99$ & $0-0$ & $0-0$ & $0-0$ \\
\hline Tptpul & $1-3$ & $3-5$ & $4-6$ & $0-0$ & $0-0$ & $0-0$ & $98-99$ & $92-98$ & $90-96$ & $0-0$ & $0-0$ & $0-0$ \\
\hline Tptpmn & $1-2$ & $3-5$ & $3-4$ & $0-0-$ & $0-0$ & $0-0$ & $96-98$ & $93-96$ & $91-99$ & $0-0$ & $0-0$ & $0-0$ \\
\hline Tptpll & $1-2$ & $2-5$ & $1-6$ & $0-0$ & $0-0$ & $0-11^{*}$ & $96-99$ & $93-98$ & $88-100$ & $0-0$ & $0-0$ & $0-0$ \\
\hline Tptpln & $1-3$ & $0-4$ & $2-6$ & $0-0$ & $0-1$ & $0-14^{*}$ & $96-98$ & $92-98$ & $84-97$ & $0-0$ & $0-0$ & $0-0$ \\
\hline Tptpv3 & $1-2$ & $0-2$ & $0-73$ & $1-1$ & $0-0$ & $0-4$ & $48-69$ & $11-18$ & $8-23$ & $30-50$ & $72-85$ & $0-82$ \\
\hline Tptpv2 & 2 & Tr.-2 & 2 & 0 & $0-0$ & 10 & 57 & $18-35$ & 39 & 40 & $65-80$ & 49 \\
\hline Tptpv1 & 1 & $0-8$ & 1 & 1 & $0-3$ & 80 & 58 & $7-22$ & 24 & 40 & $74-93$ & 0 \\
\hline Tpbt1 & No sa & analyze & n WT-2 & & & & & & & & & \\
\hline Tac & $1-1$ & $0-3$ & $1-19$ & $1-5$ & $1-10$ & $38-72$ & $59-66$ & $9-35$ & $22-54$ & $30-40$ & $58-89$ & $0-0$ \\
\hline Tacbt & $0-3$ & 3-11 & $5-9$ & $19-24$ & $12-68$ & $40-42$ & $71-78$ & $22-78$ & $53-58$ & $0-0$ & $0-62$ & $0-0$ \\
\hline
\end{tabular}


Table E-23. Mineral-Abundance Ranges, USW WT-2, USW SD-12, and UE-25 UZ\#16 (Weight Percent) (Continued)

\begin{tabular}{|c|c|c|c|c|c|c|c|c|c|c|c|c|}
\hline \multirow{3}{*}{ 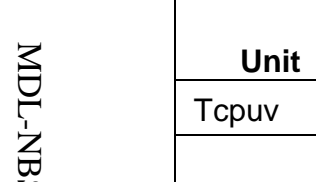 } & \multicolumn{3}{|c|}{$\begin{array}{c}\text { Smectite } \\
\pm \text { Mordenite } \\
\end{array}$} & \multicolumn{3}{|c|}{ Clinoptilolite } & \multicolumn{3}{|c|}{ Feldspar+Silica } & \multicolumn{3}{|c|}{ Glass } \\
\hline & \multicolumn{12}{|c|}{ No samples analyzed in WT-2 } \\
\hline & & & & & & & & & & & & \\
\hline Tсрuс & 1 & $2-3$ & $3-8$ & 2 & $0-0$ & $0-0$ & 96 & 89-96 & $85-97$ & 0 & $0-0$ & $0-0$ \\
\hline & & & & & & & & & & & & \\
\hline Tcpm & $1-1$ & Tr. -5 & $3-4$ & $1-1$ & $0-0$ & $0-0$ & $97-98$ & 91-99 & $97-100$ & $0-0-$ & $0-0$ & $0-0$ \\
\hline & & & & & & & & & & & & \\
\hline Tcplc & \multicolumn{12}{|c|}{ No samples analyzed in WT-2 } \\
\hline & & & & & & & & & & & & \\
\hline Tcplv & $0-4$ & $2-15$ & 3 & $19-42$ & $10-65$ & 42 & $58-78$ & $38-84$ & 61 & $0-0$ & $0-0$ & 0 \\
\hline $\mathrm{Tcb}$ & $1-1$ & $0-2$ & & $0-0$ & $0-0$ & & $96-96$ & $95-98$ & & $0-0$ & $0-0$ & \\
\hline
\end{tabular}

NOTE: $\quad-----=$ no samples analyzed from this unit.

Tr. = trace amount present.

Blanks are intentional.

*The zeolite present is stellerite. 
The following errors were noted in these data in this report:

- Data from sample p\#1 570-580 are excluded from qualification due to the questionable representativeness of the sample material.

- Data for sample p\#1 2030-2040, in the Tcbm unit, are excluded from qualification because the XRD analysis shows the sample containing seven percent glass. The presence of glass in the middle of approximately $300 \mathrm{ft}$ thick devitrified interval (Tcbuc-Tcbm-Tcblc) is unlikely.

- Data from samples p\#1 4080-4090, 4170-4180, and 4313-4318 are excluded from qualification because they represent the Paleozoic section and no qualified data from Paleozoic samples exist for corroboration.

- USW H-4 1320-1330 XRD data are not qualified due to unrepresentative subsampling for XRD analysis.

- USW H-5 1990-2000 XRD data are not qualified due to the likely abundant presence of impurities from an overlying unit

- The XRD data for sample USW WT-1 1570-1580 are not qualified due to the uncertainties in unit identification and sample integrity.

There are several thousand mineralogic abundance analyses used to as input to the Rock Properties Model. The eight errors noted above are a very small portion of the data. The impact of these eight errors to the analysis performed to determine the total hydrous (altered mineralogy) is insignificant. Therefore, there is no significant impact to the model. 


\section{APPENDIX F \\ SELECTED MINERALOGIC-ABUNDANCE DATA \\ FROM DATA SETS TO BE QUALIFIED}


Table F-1. Selected Mineralogic-Abundance Data for Drill Hole UE-25 p\#1 (Weight Percent)

\begin{tabular}{|c|c|c|c|c|c|c|c|}
\hline & $\begin{array}{l}\text { Smectitel } \\
\text { Mordenite }\end{array}$ & $\begin{array}{c}\text { Clinoptilolitel } \\
\text { Analcime }\end{array}$ & Tridymite & Quartz & Cristobalite \pm Opal & Feldspar & Glass \\
\hline \multicolumn{8}{|c|}{ Unit or Sample Depth Range in feet } \\
\hline \multicolumn{8}{|l|}{ p\#1 Tptrn 150-228 } \\
\hline p\#1 200-210 & $-1-$ & $-/-$ & 14 & - & 6 & 76 & - \\
\hline \multicolumn{8}{|l|}{ p\#1 Tptrl 228-248 } \\
\hline \multicolumn{8}{|l|}{ not analyzed } \\
\hline \multicolumn{8}{|l|}{ p\#1 Tptpul 248-493 } \\
\hline p\#1 260-270 & $2 /-$ & $-/-$ & Tr. & 3 & 24 & 71 & - \\
\hline p\#1 280-290 & $2 /-$ & $-/-$ & Tr. & 5 & 25 & 68 & - \\
\hline p\#1 410-420 & $3 /-$ & $-/-$ & 4 & 9 & 24 & 59 & - \\
\hline \multicolumn{8}{|l|}{ p\#1 Tptpmn 493-640 } \\
\hline p\#1 570-580 & $2 /-$ & $-1-$ & Tr. & 30 & 3 & 67 & - \\
\hline \multicolumn{8}{|l|}{ p\#1 Tptpll 640-958 } \\
\hline p\#1 810-820 & $2 /-$ & $-1-$ & - & 27 & 5 & 59 & - \\
\hline p\#1 900-910 & $1 /-$ & $-1-$ & - & 36 & 1 & 61 & - \\
\hline \multicolumn{8}{|l|}{ p\#1 Tptpln 958-1090 } \\
\hline p\#1 1040-1050 & $-/-$ & $-1-$ & - & 27 & 5 & 67 & - \\
\hline \multicolumn{8}{|l|}{ p\#1 Tptpv3 1090-1200 } \\
\hline \multicolumn{8}{|l|}{ not analyzed } \\
\hline \multicolumn{8}{|l|}{ p\#1 Tptpv2 1200-1243 } \\
\hline \multicolumn{8}{|l|}{ partly sampled, see below } \\
\hline \multicolumn{8}{|l|}{ p\#1 Tptpv1 1243-1270 } \\
\hline p\#1 1240-1250 & $1 /-$ & $54 /-$ & - & Tr. & 20 & 24 & - \\
\hline $\mathrm{p} \# 1$ 1260-1270 & $1 /-$ & $62 /-$ & - & Tr. & 23 & 14 & - \\
\hline \multicolumn{8}{|l|}{ p\#1 Tac 1270-1390 } \\
\hline p\#1 1290 (sidewall core) & $2 /-$ & $37 /-$ & - & 3 & 22 & 39 & - \\
\hline p\#1 1340-1350 & Tr./- & $56 /-$ & - & 2 & 20 & 21 & - \\
\hline
\end{tabular}


Table F-1. Selected Mineralogic-Abundance Data for Drill Hole UE-25 p\#1 (Weight Percent) (Continued)

\begin{tabular}{|c|c|c|c|c|c|c|c|}
\hline & $\begin{array}{c}\text { Smectitel } \\
\text { Mordenite }\end{array}$ & $\begin{array}{c}\text { Clinoptilolitel } \\
\text { Analcime }\end{array}$ & Tridymite & Quartz & Cristobalite \pm Opal & Feldspar & Glass \\
\hline p\#1 1400 (sidewall core) & $10 /-$ & $34 /-$ & - & 17 & - & 29 & 9 \\
\hline \multicolumn{8}{|l|}{ p\#1 Tacbt 1390-1441 } \\
\hline p\#1 1420 (sidewall core) & $12 /-$ & $-/-$ & - & 24 & - & 40 & 22 \\
\hline p\#1 Tcpuv 1441-1468 & & & & & & & \\
\hline not analyzed & & & & & & & \\
\hline \multicolumn{8}{|l|}{ p\#1 Тсрис 1468-1535 } \\
\hline p\#1 1470 (sidewall core) & $5 / 34$ & $-/-$ & - & 25 & - & 40 & - \\
\hline \multicolumn{8}{|l|}{ p\#1 Tcpm 1535-1630 } \\
\hline p\#1 1590-1598 & - & $3 /-$ & - & 39 & - & 60 & - \\
\hline \multicolumn{8}{|l|}{ p\#1 Tcplc 1630-1680 } \\
\hline p\#1 1640-1650 & $5 /-$ & $-/-$ & - & 37 & - & 58 & - \\
\hline \multicolumn{8}{|l|}{ p\#1 Tcplv 1680-1790 } \\
\hline p\#1 1690-1700 & $7 /-$ & $40 /-$ & - & 11 & 17 & 25 & - \\
\hline p\#1 1730-1740 & $3 /-$ & $60 /-$ & - & 4 & 14 & 17 & - \\
\hline \multicolumn{8}{|l|}{ p\#1 Tcpbt 1790-1826 } \\
\hline p\#1 1790-1800 & $1 / 23$ & $45 /-$ & - & 12 & - & 18 & - \\
\hline \multicolumn{8}{|l|}{ p\#1 Tcbuv not present } \\
\hline \multicolumn{8}{|l|}{ p\#1 Tcbuc 1826-1953 } \\
\hline p\#1 1830-1840 & Tr./- & $-1-$ & - & 45 & - & 39 & - \\
\hline p\#1 1870-1880 & $3 /-$ & 9/- & - & 27 & - & 55 & - \\
\hline p\#1 1920-1930 & $5 /-$ & $-1-$ & - & 28 & - & 64 & - \\
\hline \multicolumn{8}{|l|}{ p\#1 Tcbm 1953-2130 } \\
\hline p\#1 1970-1980 & Tr./- & $-/-$ & - & 35 & - & 61 & - \\
\hline p\#1 1990-2000 & $1 /-$ & $-/-$ & - & 39 & - & 60 & - \\
\hline p\#1 2030-2040 & $2 /-$ & $-/-$ & - & 31 & - & 59 & 7 \\
\hline p\#1 2070-2080 & Tr./- & $-1-$ & - & 39 & - & 59 & - \\
\hline p\#1 2120-2130 & Tr./- & $-1-$ & - & 36 & - & 65 & - \\
\hline
\end{tabular}


Table F-1. Selected Mineralogic-Abundance Data for Drill Hole UE-25 p\#1 (Weight Percent) (Continued)

\begin{tabular}{|c|c|c|c|c|c|c|c|}
\hline & $\begin{array}{l}\text { Smectitel } \\
\text { Mordenite }\end{array}$ & $\begin{array}{c}\text { Clinoptilolitel } \\
\text { Analcime }\end{array}$ & Tridymite & Quartz & Cristobalite \pm Opal & Feldspar & Glass \\
\hline p\#1 Tcblc 2130-2162 & & & & & & & \\
\hline p\#1 2150-2160 & $3 /-$ & Tr./- & - & 29 & - & 61 & - \\
\hline p\#1 Tcblv 2160-2240 & & & & & & & \\
\hline $\mathrm{p} \# 1$ 2210-2220 & $3 / 28$ & $-/ 14$ & - & 28 & - & 33 & - \\
\hline p\#1 Tcbbt 2240-2262 & & & & & & & \\
\hline p\#1 2240-2250 & $7 / 3$ & $-/ 8$ & - & 29 & - & 52 & - \\
\hline p\#1 Tctuv 2262-2340 & & & & & & & \\
\hline p\#1 2280-2290 & $6 /-$ & $31 / 4$ & - & 22 & - & 32 & - \\
\hline p\#1 2330-2340 & $11 /-$ & $2 / 4$ & - & 32 & - & 45 & - \\
\hline p\#1 Tctuc 2340-2395 & & & & & & & \\
\hline p\#1 2370-2380 & $7 /-$ & $-/-$ & - & 40 & - & 49 & - \\
\hline p\#1 Tctm 2395-2595 & & & & & & & \\
\hline p\#1 2414-2420 & Tr./- & $-/-$ & - & 43 & - & 51 & - \\
\hline p\#1 2460-2470 & $2 /-$ & $-/-$ & - & 32 & - & 61 & - \\
\hline $\mathrm{p} \# 1$ 2510-2520 & - & $-/-$ & - & 24 & - & 77 & - \\
\hline p\#1 2570-2580 & $2 /-$ & $-/-$ & - & 30 & - & 71 & - \\
\hline p\#1 Tctlc 2595-2616 & & & & & & & \\
\hline not analyzed & & & & & & & \\
\hline p\#1 Tctlv 2616-2863 & & & & & & & \\
\hline p\#1 2630-2640 & $7 /-$ & $-/-$ & - & 34 & - & 57 & - \\
\hline p\#1 2650-2660 & $15 /-$ & $-/-$ & - & 31 & - & 51 & - \\
\hline p\#1 2690-2700 & $4 /-$ & $-/-$ & - & 34 & - & 56 & - \\
\hline p\#1 2750-2760 & 13/- & 13/- & - & 32 & - & 35 & - \\
\hline p\#1 2790-2800 & $21 /-$ & $4 /-$ & - & 29 & - & 39 & - \\
\hline p\#1 2840-2850 & $25 /-$ & $-/ T r$. & - & 42 & - & 34 & - \\
\hline p\#1 Tctbt not recognized & & & & & & & \\
\hline & & & & & & & \\
\hline
\end{tabular}


Table F-1. Selected Mineralogic-Abundance Data for Drill Hole UE-25 p\#1 (Weight Percent) (Continued)

\begin{tabular}{|c|c|c|c|c|c|c|c|}
\hline & $\begin{array}{l}\text { Smectitel } \\
\text { Mordenite }\end{array}$ & $\begin{array}{c}\text { Clinoptilolitel } \\
\text { Analcime }\end{array}$ & Tridymite & Quartz & Cristobalite \pm Opal & Feldspar & Glass \\
\hline \multicolumn{8}{|l|}{ p\#1 Tund 2863-4080 } \\
\hline p\#1 2890-2900 & $15 /-$ & $-1-$ & - & 34 & - & 47 & - \\
\hline p\#1 2940-2950 & $4 /-$ & $-/ 2$ & - & 36 & - & 55 & - \\
\hline p\#1 2980-2990 & $6 /-$ & -16 & - & 29 & - & 55 & - \\
\hline p\#1 3030-3040 & $11 /-$ & $-/ 1$ & - & 30 & - & 53 & - \\
\hline p\#1 3080-3090 & $15 /-$ & $-1-$ & - & 44 & - & 34 & - \\
\hline p\#1 3130-3140 & $6 /-$ & $2 / 5$ & - & 34 & - & 50 & - \\
\hline p\#1 3160-3170 & $13 /-$ & $3 / 11$ & - & 37 & - & 39 & - \\
\hline $\mathrm{p \# 1}$ 3230-3240 & $5 /-$ & Tr./19 & - & 38 & - & 37 & - \\
\hline p\#1 3270-3280 & $5 /-$ & $2 / 13$ & - & 36 & - & 43 & - \\
\hline p\#1 3320-3330 & $25 /-$ & $4 /-$ & - & 38 & - & 25 & - \\
\hline p\#1 3370-3380 & $22 /-$ & $2 /-$ & - & 35 & - & 35 & - \\
\hline p\#1 3410-3420 & $7 /-$ & $3 / 6$ & - & 35 & - & 44 & - \\
\hline p\#1 3453 (core) & $6 /-$ & $2 / 13$ & - & 38 & - & 39 & - \\
\hline p\#1 3480-3490 & $7 /-$ & $7 / 4$ & - & 40 & - & 42 & - \\
\hline p\#1 3510-3520 & $11 /-$ & $-1-$ & - & 37 & - & 49 & - \\
\hline p\#1 3550-4560 & $4 /-$ & $-1-$ & - & 43 & - & 45 & - \\
\hline p\#1 3560-3570 & $7 /-$ & $-1-$ & - & 42 & - & 49 & - \\
\hline p\#1 3590-3600 & 9/- & $-/-$ & - & 42 & - & 48 & - \\
\hline p\#1 3630-3640 & $19 /-$ & $-1-$ & - & 32 & - & 41 & 1 \\
\hline p\#1 3650-3660 & $19 /-$ & $-/-$ & - & 29 & - & 42 & 1 \\
\hline p\#1 3660-3670 & $16 /-$ & $-1-$ & - & 30 & - & 51 & 1 \\
\hline p\#1 3690-3700 & $15 /-$ & -13 & - & 36 & - & 38 & 1 \\
\hline p\#1 3720-3730 & $20 /-$ & $-/ 2$ & - & 27 & - & 41 & 1 \\
\hline p\#1 3750-3760 & $15 /-$ & Tr./- & - & 33 & - & 36 & - \\
\hline p\#1 3790-3800 & $14 /-$ & $-1-$ & - & 35 & - & 23 & 1 \\
\hline p\#1 3820-3830 & 9/- & Tr./- & - & 44 & - & 19 & - \\
\hline
\end{tabular}


Table F-1. Selected Mineralogic-Abundance Data for Drill Hole UE-25 p\#1 (Weight Percent) (Continued)

\begin{tabular}{|c|c|c|c|c|c|c|c|}
\hline & $\begin{array}{l}\text { Smectitel } \\
\text { Mordenite }\end{array}$ & $\begin{array}{c}\text { Clinoptilolitel } \\
\text { Analcime }\end{array}$ & Tridymite & Quartz & Cristobalite \pm Opal & Feldspar & Glass \\
\hline $\mathrm{p \# 1}$ 3860-3870 & $10 /-$ & $-1-$ & - & 52 & - & 33 & - \\
\hline p\#1 3913 (core) & $37 /-$ & $-1-$ & - & 53 & - & - & - \\
\hline p\#1 3916 (core) & $45 /-$ & $-1-$ & - & 49 & - & - & Tr. \\
\hline p\#1 3928 (core) & $40 /-$ & $-1-$ & - & 18 & - & - & - \\
\hline p\#1 3940-3950 & 9/- & $-/ T r$. & - & 39 & - & 44 & - \\
\hline p\#1 3980-3990 & $13 /-$ & $2 / 2$ & - & 32 & - & 48 & - \\
\hline $\mathrm{p \# 1}$ 4040-4050 & $16 /-$ & $2 / T r$ & - & 29 & - & 29 & - \\
\hline p\#1 4070-4080 & $29 /-$ & $1 / \operatorname{Tr}$ & - & 30 & - & 38 & - \\
\hline $\mathrm{p} \# 1 \mathrm{Pz} 4080$ to bo & & & & & & & \\
\hline p\#1 4080-4090 & \multirow{3}{*}{\multicolumn{7}{|c|}{ These samples contain 80-93 \% dolomite, 1-9 \% smectite, 4-8 \% quartz, and 3-4 \% calcite. }} \\
\hline p\#1 4170-4180 & & & & & & & \\
\hline p\#1 4313-4318 & & & & & & & \\
\hline
\end{tabular}

Sources: DTNs MO0101XRDDRILC.001 [DIRS 169517], MO0004QGFMPICK.000 [DIRS 152554]

- = not detected;Tr. = trace amount much less than $1 \%$. 
Table F-2. Selected Mineralogic-Abundance Data for Drill Hole USW H-3 (Weight Percent)

\begin{tabular}{|c|c|c|c|c|c|c|c|}
\hline & $\begin{array}{l}\text { Hornblendel } \\
\text { Mordenite }\end{array}$ & Clinoptilolite & Tridymite & Quartz & Cristobalite \pm Opal & Feldspar & Glass \\
\hline \multicolumn{8}{|c|}{$\begin{array}{l}\text { Unit or Sample Depth Range } \\
\text { in feet }\end{array}$} \\
\hline \multicolumn{8}{|l|}{ H-3 Tptrn 449-526.9 } \\
\hline $\mathrm{H}-3470-480$ & $-1-$ & - & 13 & - & 8 & 77 & - \\
\hline H-3 520-530 & $-1-$ & - & Tr. & - & 24 & 76 & - \\
\hline \multicolumn{8}{|l|}{ H-3 Tptpul 540-680.1 } \\
\hline H-3 540-550 & $-1-$ & - & 21 & - & 5 & 73 & - \\
\hline $\mathrm{H}-3$ 610-620 & $-1-$ & - & Tr. & - & 29 & 71 & - \\
\hline \multicolumn{8}{|c|}{ H-3 Tptpmn 680.1-848.1 } \\
\hline $\mathrm{H}-3$ 740-750 & $-1-$ & - & - & 4 & 26 & 68 & - \\
\hline $\mathrm{H}-3800-810$ & $-1-$ & - & Tr. & 2 & 27 & 69 & - \\
\hline \multicolumn{8}{|c|}{ H-3 Tptpll 848.1-1049.9 } \\
\hline H-3 870-880 & $-1-$ & - & - & 29 & 3 & 66 & - \\
\hline H-3 930-940 & $-1-$ & - & - & 14 & 16 & 69 & - \\
\hline H-3 990-1000 & $-1-$ & - & 4 & Tr. & 23 & 72 & - \\
\hline H-3 1030-1040 & $-1-$ & - & Tr. & 3 & 24 & 72 & - \\
\hline \multicolumn{8}{|c|}{ H-3 Tptpln 1049.9-1194 } \\
\hline $\mathrm{H}-3$ 1100-1110 & $-1-$ & - & Tr. & 2 & 23 & 74 & - \\
\hline H-3 1160-1170 & $-1-$ & - & - & 2 & 29 & 67 & - \\
\hline \multicolumn{8}{|l|}{ H-3 Tptpv3 1194-1308 } \\
\hline H-3 1270-1280 & $-1-$ & - & - & 2 & 7 & 19 & 70 \\
\hline \multicolumn{8}{|l|}{ H-3 Tptpv2 1308-1341 } \\
\hline $\mathrm{H}-3$ 1320-1330 & $-1-$ & - & - & 2 & 5 & 23 & 70 \\
\hline \multicolumn{8}{|l|}{ H-3 Tptpv1 1341-1392 } \\
\hline $\mathrm{H}-3$ 1360-1370 & $-1-$ & - & - & Tr. & Tr. & 3 & 97 \\
\hline H-3 Tacbt 1437-1495 & & & & & & & \\
\hline
\end{tabular}


Table F-2. Selected Mineralogic-Abundance Data for Drill Hole USW H-3 (Weight Percent) (Continued)

\begin{tabular}{|c|c|c|c|c|c|c|c|}
\hline & $\begin{array}{c}\text { Hornblendel } \\
\text { Mordenite }\end{array}$ & Clinoptilolite & Tridymite & Quartz & Cristobalite \pm Opal & Feldspar & Glass \\
\hline H-3 1440-1450 & $-1-$ & - & - & Tr. & 5 & 11 & 81 \\
\hline H-3 1480-1490 & $1 /-$ & 1 & - & 3 & 1 & 47 & 34 \\
\hline H-3 Tcpuv 1495-1518 & & & & & & & \\
\hline H-3 1500-1510 & $-/-$ & 1 & 4 & 12 & 20 & 50 & 10 \\
\hline Н-3 Тсрис 1518-1640 & & & & & & & \\
\hline H-3 1550 (sidewall core) & $-1-$ & 2 & 7 & 10 & 7 & 70 & - \\
\hline H-3 Tcpm 1640-1690 & & & & & & & \\
\hline H-3 1655 (sidewall core) & $-/-$ & 2 & 7 & 7 & 7 & 75 & - \\
\hline H-3 Tcplc 1690-1702 & & & & & & & \\
\hline sample moved to Tcplv & & & & & & & \\
\hline H-3 Tcplv 1702-1899.9 & & & & & & & \\
\hline $\begin{array}{l}\text { H-3 } 1700 \text { (sidewall core) } \\
\text { moved to Tcplv }\end{array}$ & $-/-$ & 2 & - & 10 & 15 & 60 & 15 \\
\hline H-3 1800 (sidewall) & $-/-$ & 60 & - & 7 & - & 30 & - \\
\hline H-3 Tcpbt 1899.9-1907.1 & & & & & & & \\
\hline H-3 1900 (sidewall core) & $-/-$ & 75 & 2 & 2 & 2 & 15 & - \\
\hline H-3 Tcblv 2397-2449.1 & & & & & & & \\
\hline H-3 2400 (sidewall core) & 1/- & 75 & - & 2 & 2 & 15 & - \\
\hline H-3 2440 (sidewall core) & $-/ 30$ & 35 & - & 2 & 2 & 30 & - \\
\hline H-3 Tctuv 2477-2567 & & & & & & & \\
\hline H-3 2490 (sidewall core) & $-/ 25$ & 45 & - & 2 & - & 20 & - \\
\hline
\end{tabular}

Sources: DTNs LADV831321AQ97.001 [DIRS 107142], MO0101XRDDRILC.001 [DIRS 169517], MO0004QGFMPICK.000 [DIRS 152554] - = not detected; $\mathrm{Tr} .=$ trace amount much less than $1 \%$. 
Table F-3. Selected Mineralogic-Abundance Data for Drill Hole USW H-4 (Weight Percent)

\begin{tabular}{|c|c|c|c|c|c|c|c|}
\hline & $\begin{array}{l}\text { Smectitel } \\
\text { Mordenite }\end{array}$ & Clinoptilolite & Tridymite & Quartz & Cristobalite \pm Opal & Feldspar & Glass \\
\hline Unit or Sample Depth Range in feet & & & & & & & \\
\hline H-4 Tptrn 254-376 & & & & & & & \\
\hline $\mathrm{H}-4$ 310-320 & $-1-$ & - & 11 & - & 10 & 75 & - \\
\hline H-4 Tptpul 376-576 & & & & & & & \\
\hline $\mathrm{H}-4$ 390-400 & $2 /-$ & - & 14 & 2 & 13 & 68 & - \\
\hline $\mathrm{H}-4$ 440-450 & $2 /-$ & - & 19 & 2 & 13 & 64 & - \\
\hline $\mathrm{H}-4$ 490-500 & $2 /-$ & - & 11 & $\sim 1$ & 18 & 67 & - \\
\hline H-4 Tptpmn 576-703 & & & & & & & \\
\hline $\mathrm{H}-4$ 640-650 & $2 /-$ & - & - & 4 & 26 & 68 & - \\
\hline H-4 Tptpll 703-987 & & & & & & & \\
\hline H-4 830-840 & $3 /-$ & - & 12 & $\sim 1$ & 14 & 68 & - \\
\hline $\mathrm{H}-4$ 910-920 & $\sim 1 /-$ & - & - & 11 & 20 & 67 & - \\
\hline $\mathrm{H}-4$ 940-950 & $\sim 1 /-$ & - & - & 7 & 21 & 71 & - \\
\hline H-4 Tptpln 987-1185 & & & & & & & \\
\hline $\mathrm{H}-4$ 1040-1050 & $\sim 1 /-$ & - & - & 6 & 23 & 70 & - \\
\hline H-4 1150-1160 & $2 /-$ & - & - & 15 & 18 & 64 & - \\
\hline H-4 Tptpv3 1185-1209 & & & & & & & \\
\hline $\mathrm{H}-4$ 1190-1200 & $-/-$ & 5 & - & - & 15 & 15 & 70 \\
\hline H-4 1230-1240 & $20 /-$ & - & - & 4 & 20 & 25 & 30 \\
\hline H-4 Tptpv2-1 1209-1312 & & & & & & & \\
\hline not sampled & & & & & & & \\
\hline H-4 Tpbt1 1312-1317 & & & & & & & \\
\hline H-4 1312 (sidewall core) & $2 /-$ & 5 & - & 10 & 7 & 25 & 50 \\
\hline H-4 Tac $1317-1572$ & & & & & & & \\
\hline $\mathrm{H}-4$ 1350-1360 & - & 78 & - & 3 & 9 & 10 & - \\
\hline H-4 1410-1420 & $-/ 5$ & 52 & - & 7 & 9 & 31 & - \\
\hline
\end{tabular}


Table F-3. Selected Mineralogic-Abundance Data for Drill Hole USW H-4 (Weight Percent) (Continued)

\begin{tabular}{|c|c|c|c|c|c|c|c|}
\hline & $\begin{array}{l}\text { Smectitel } \\
\text { Mordenite }\end{array}$ & Clinoptilolite & Tridymite & Quartz & Cristobalite $\pm O p a l$ & Feldspar & Glass \\
\hline H-4 1420 (sidewall core) & $2 /-$ & 70 & - & 2 & 2 & 25 & - \\
\hline H-4 1455 (sidewall core) & $-/ 25$ & 45 & - & 2 & 2 & 20 & - \\
\hline $\mathrm{H}-4$ 1540-1550 & $3 / 16$ & 29 & - & 11 & 10 & 31 & - \\
\hline H-4 1550 (sidewall core) & $2 /-$ & 75 & - & 1 & 2 & 15 & - \\
\hline H-4 Tacbt 1572-1626.9 & & & & & & & \\
\hline $\mathrm{H}-4$ 1600-1610 & $-1-$ & 31 & - & 17 & 9 & 35 & - \\
\hline H-4 Tcpuv 1626.9-1662 & & & & & & & \\
\hline H-4 1640-1650 & $-1-$ & 10 & - & 6 & 24 & 60 & - \\
\hline Н-4 Тсрис 1662-1746 & & & & & & & \\
\hline $\begin{array}{l}\text { H-4 } 1656 \text { (sidewall core, } \\
\text { moved from Tcpuv) }\end{array}$ & $-1-$ & - & - & 2 & 35 & 65 & - \\
\hline $\mathrm{H}-4$ 1710-1720 & $\sim 1 /-$ & - & - & 33 & 3 & 61 & - \\
\hline H-4 Tcpm 1746-1820 & & & & & & & \\
\hline H-4 1790-1800 & $3 /-$ & - & - & 15 & 17 & 64 & - \\
\hline H-4 Tcplc 1820-1840 & & & & & & & \\
\hline not sampled & & & & & & & \\
\hline H-4 Tcplv 1840-2263.1 & & & & & & & \\
\hline H-4 1900-1910 & $-1-$ & 22 & - & 5 & 16 & 56 & - \\
\hline H-4 1980-1990 & $-/ 23$ & 11 & - & 2 & 6 & 55 & - \\
\hline
\end{tabular}

Sources: DTNs MO0101XRDDRILC.001 [DIRS 169517], MO0004QGFMPICK.000 [DIRS 152554].

- = not detected; $\mathrm{Tr} .=$ trace amount much less than $1 \%$. 
Table F-4. Selected Mineralogic-Abundance Data for Drill Hole USW H-5 (Weight Percent)

\begin{tabular}{|c|c|c|c|c|c|c|c|}
\hline & $\begin{array}{l}\text { Smectitel } \\
\text { Mordenite }\end{array}$ & Clinoptilolite & Tridymite & Quartz & Cristobalite \pm Opal & Feldspar & Glass \\
\hline \multicolumn{8}{|c|}{ Unit or Sample Depth Range in feet } \\
\hline \multicolumn{8}{|l|}{ H-5 Tpc_un 0-404 } \\
\hline $\mathrm{H}-540-50$ & $-/-$ & - & 31 & Tr. & - & 66 & - \\
\hline $\mathrm{H}-550$ & $-/-$ & - & 17 & - & 2 & 80 & - \\
\hline $\mathrm{H}-5$ 110-120 & Tr.l- & - & 17 & - & 13 & 68 & - \\
\hline H-5 160-170 & Tr./- & - & 13 & - & 20 & 70 & - \\
\hline $\mathrm{H}-5190$ & $-/-$ & - & 2 & - & 23 & 75 & \\
\hline $\mathrm{H}-5$ 230-240 & Tr./- & - & 10 & 1 & 22 & 69 & - \\
\hline H-5 320-330 & $1 /-$ & - & 3 & 6 & 22 & 69 & - \\
\hline $\mathrm{H}-5$ 380-390 & $-/-$ & - & 2 & - & 29 & 68 & - \\
\hline \multicolumn{8}{|c|}{ H-5 Tpcpv3 404-404 } \\
\hline \multicolumn{8}{|c|}{ H-5 Tpcpv2 404-420 } \\
\hline \multicolumn{8}{|c|}{ H-5 Tpcpv1 420-437.5 } \\
\hline $\mathrm{H}-5420$ & $15 /-$ & - & - & 1 & 12 & 32 & 40 \\
\hline \multicolumn{8}{|c|}{ H-5 Tpbt4 437.5-438 } \\
\hline \multicolumn{8}{|l|}{ not sampled } \\
\hline \multicolumn{8}{|l|}{ H-5 Tpy $438-457$} \\
\hline $\mathrm{H}-5450$ & - & - & - & 1 & - & 2 & 96 \\
\hline \multicolumn{8}{|c|}{ H-5 Tpbt3 457-471 } \\
\hline $\mathrm{H}-5$ 460-470 & $14 /-$ & - & - & - & 2 & 12 & 69 \\
\hline \multicolumn{8}{|c|}{ H-5 Tpp-Tptrv1 471-564 } \\
\hline \multicolumn{8}{|l|}{ not sampled } \\
\hline \multicolumn{8}{|l|}{ H-5 Tptrn 564-700 } \\
\hline $\mathrm{H}-5$ 620-630 & $1 /-$ & - & 4 & 1 & 9 & 76 & - \\
\hline $\mathrm{H}-5700$ & Tr./- & - & 20 & - & 15 & 65 & - \\
\hline H-5 Tptrl 700-741 & & & & & & & \\
\hline
\end{tabular}


Table F-4. Selected Mineralogic-Abundance Data for Drill Hole USW H-5 (Weight Percent) (Continued)

\begin{tabular}{|c|c|c|c|c|c|c|c|}
\hline & $\begin{array}{c}\text { Smectitel } \\
\text { Mordenite }\end{array}$ & Clinoptilolite & Tridymite & Quartz & Cristobalite $\pm O p a l$ & Feldspar & Glass \\
\hline H-5 720-730 & $3 /-$ & - & 23 & - & 9 & 65 & - \\
\hline H-5 Tptpul 741-988 & & & & & & & \\
\hline $\mathrm{H}-5$ 750-760 & $5 /-$ & - & 17 & 1 & 17 & 62 & - \\
\hline $\mathrm{H}-5$ 800-810 & $3 /-$ & - & Tr. & 2 & 24 & 72 & - \\
\hline $\mathrm{H}-5$ 830-840 & $-/-$ & - & Tr. & - & 24 & 76 & - \\
\hline $\mathrm{H}-5$ 860-870 & $4 /-$ & - & 8 & 4 & 23 & 59 & - \\
\hline $\mathrm{H}-5$ 920-930 & $2 /-$ & - & Tr. & 3 & 24 & 71 & - \\
\hline H-5 970-980 & $2 /-$ & - & Tr. & 2 & 26 & 71 & - \\
\hline H-5 Tptpmn 988-1088 & & & & & & & \\
\hline H-5 990-1000 & $3 /-$ & - & 3 & 1 & 28 & 59 & - \\
\hline H-5 1050 & Tr./- & - & - & 2 & 40 & 55 & - \\
\hline H-5 Tptpll 1088-1450 & & & & & & & \\
\hline H-5 1090-1100 & $4 /-$ & - & 4 & 4 & 26 & 61 & - \\
\hline $\mathrm{H}-5$ 1150-1160 & $2 /-$ & - & - & 26 & 10 & 62 & - \\
\hline H-5 1200-1210 & $3 /-$ & - & 3 & 22 & 11 & 61 & - \\
\hline $\mathrm{H}-5$ 1230-1240 & $2 /-$ & - & - & 7 & 23 & 69 & - \\
\hline $\mathrm{H}-5$ 1290-1300 & $2 /-$ & - & - & 10 & 18 & 71 & - \\
\hline H-5 1350-1360 & $2 /-$ & - & 3 & 15 & 16 & 61 & - \\
\hline H-5 1380-1390 & $2 /-$ & - & - & 15 & 20 & 65 & - \\
\hline H-5 Tptpln 1450-1582 & & & & & & & \\
\hline H-5 1450-1460 & Tr./- & - & - & 20 & 8 & 71 & - \\
\hline H-5 1490-1500 & $2 /-$ & - & - & 9 & 21 & 68 & - \\
\hline H-5 1530-1540 & $1 /-$ & - & - & 21 & 14 & 60 & - \\
\hline H-5 Tptpv3 1582-1659 & & & & & & & \\
\hline H-5 1590-1600 & $35 /-$ & 10 & - & - & 17 & 40 & - \\
\hline H-5 1610 & $-/-$ & - & - & 1 & 2 & 7 & 90 \\
\hline H-5 1630-1640 & Tr./- & - & - & 1 & 2 & 9 & 88 \\
\hline
\end{tabular}


Table F-4. Selected Mineralogic-Abundance Data for Drill Hole USW H-5 (Weight Percent) (Continued)

\begin{tabular}{|c|c|c|c|c|c|c|c|}
\hline & $\begin{array}{l}\text { Smectitel } \\
\text { Mordenite }\end{array}$ & Clinoptilolite & Tridymite & Quartz & Cristobalite \pm Opal & Feldspar & Glass \\
\hline H-5 1650-1660 & $-/-$ & - & - & 2 & 5 & 4 & 89 \\
\hline $\begin{array}{l}\text { H-5 } 1666 \text { (sidewall core) } \\
\text { (moved from Tptpv2) }\end{array}$ & $50 /-$ & 10 & - & 1 & 12 & 25 & - \\
\hline H-5 Tptpv2-Tpbt1 1659-1705 & & & & & & & \\
\hline not sampled & & & & & & & \\
\hline H-5 Тac $1705-1879.9$ & & & & & & & \\
\hline H-5 1710-1720 & $3 /-$ & - & - & 5 & 5 & 20 & 70 \\
\hline H-5 1750 & $-/-$ & Tr.? & - & 2 & 5 & 5 & 85 \\
\hline H-5 1762 (sidewall core) & $-/-$ & - & - & 1 & 1 & 5 & 95 \\
\hline $\mathrm{H}-5$ 1760-1770 & $-/-$ & 6 & - & 3 & 4 & 6 & 81 \\
\hline H-5 1800 & $-/-$ & - & - & 2 & 2 & 10 & 85 \\
\hline $\mathrm{H}-5$ 1820-1830 & Tr./- & 4 & - & 4 & 2 & 10 & 80 \\
\hline H-5 1852 (sidewall core) & $-/-$ & - & - & 2 & - & 7 & 90 \\
\hline H-5 1875 (sidewall core) & $-/-$ & Tr.? & - & 2 & Tr.? & 5 & 92 \\
\hline H-5 Tacbt 1879.9-1944.9 & & & & & & & \\
\hline H-5 1890-1900 & $1 /-$ & 11 & - & 4 & 3 & 6 & 75 \\
\hline H-5 1900-1910 & Tr./- & 10 & - & 3 & 1 & 8 & 78 \\
\hline H-5 1910-1920 & Tr./- & 18 & - & 5 & 5 & 7 & 65 \\
\hline H-5 1917 (sidewall core) & $-/-$ & 25 & - & 30 & 10 & 35 & - \\
\hline H-5 1920-1930 & $3 /-$ & 52 & - & 14 & 7 & 16 & 6 \\
\hline H-5 1930 & $2 /-$ & 50 & - & 15 & - & 30 & - \\
\hline H-5 Tcpuv 1944.9-1967 & & & & & & & \\
\hline H-5 1950-1960 & $3 /-$ & 51 & - & 2 & 5 & 8 & 31 \\
\hline H-5 1966 (sidewall core) & $5 /-$ & - & - & 2 & - & 15 & 75 \\
\hline Н-5 Тсрис 1967-2085 & & & & & & & \\
\hline $\begin{array}{l}\mathrm{H}-5 \text { 1990-2000 excluded from } \\
\text { corroboration }\end{array}$ & $1 /-$ & 10 & - & Tr. & 9 & 21 & 59 \\
\hline H-5 2070-2080 & $1 /-$ & - & - & 29 & 3 & 68 & - \\
\hline
\end{tabular}


Table F-4. Selected Mineralogic-Abundance Data for Drill Hole USW H-5 (Weight Percent) (Continued)

\begin{tabular}{|c|c|c|c|c|c|c|c|}
\hline & $\begin{array}{l}\text { Smectitel } \\
\text { Mordenite }\end{array}$ & Clinoptilolite & Tridymite & Quartz & Cristobalite \pm Opal & Feldspar & Glass \\
\hline H-5 Tcpm 2085-2113 & & & & & & & \\
\hline not sampled & & & & & & & \\
\hline H-5 Tcplc 2113-2130 & & & & & & & \\
\hline H-5 2140-2150 moved from Tcplv & $1 /-$ & - & - & 27 & 7 & 69 & - \\
\hline H-5 Tcplv 2130-2240.1 & & & & & & & \\
\hline $\mathrm{H}-52200$ & Tr./- & 60 & - & 2 & 2 & 35 & - \\
\hline $\mathrm{H}-5$ 2230-2240 & $2 / 8$ & 64 & - & 4 & 16 & 8 & - \\
\hline H-5 Tcpbt 2240.1-2263.1 & & & & & & & \\
\hline $\mathrm{H}-52260-2270$ & $6 / 7$ & 56 & - & 3 & 20 & 11 & - \\
\hline H-5 Tcbuv 2263.1-2310 & & & & & & & \\
\hline not sampled & & & & & & & \\
\hline
\end{tabular}

Sources: DTNs MO0101XRDDRILC.001 [DIRS 169517], LADV831321AQ97.007 [DIRS 113499], LA9910JC831321.001 [DIRS 113496], MO0004QGFMPICK.000 [DIRS 152554]

- = not detected; Tr. = trace amount much less than $1 \%$ 
Table F-5. Selected Mineralogic-Abundance Data for Drill Hole USW WT-1 (Weight Percent)

\begin{tabular}{|c|c|c|c|c|c|c|c|}
\hline & $\begin{array}{l}\text { Smectitel } \\
\text { Mordenite }\end{array}$ & Clinoptilolite & Tridymite & Quartz & Cristobalite \pm Opal & Feldspar & Glass \\
\hline \multicolumn{8}{|c|}{$\begin{array}{l}\text { Unit or Sample Depth Range in } \\
\text { feet }\end{array}$} \\
\hline \multicolumn{8}{|l|}{ WT-1 Tpbt3 435-446 } \\
\hline WT-1 440-450 & $5 /-$ & - & 8 & - & 4 & 12 & 70 \\
\hline \multicolumn{8}{|l|}{ WT-1 Tpbt2 446-477 } \\
\hline \multicolumn{8}{|l|}{ not sampled } \\
\hline \multicolumn{8}{|c|}{ WT-1 Tptrv3-Tptrv1 477-492 } \\
\hline \multicolumn{8}{|l|}{ not sampled } \\
\hline \multicolumn{8}{|l|}{ WT-1 Tptrn 492-575 } \\
\hline WT-1 500-510 & $-/-$ & - & 11 & - & 12 & 72 & - \\
\hline WT-1 550-560 & $-/-$ & - & 19 & - & 10 & 71 & - \\
\hline \multicolumn{8}{|l|}{ WT-1 Tptrl 575-593 } \\
\hline \multicolumn{8}{|l|}{ not sampled } \\
\hline \multicolumn{8}{|l|}{ WT-1 Tptpul 593-733 } \\
\hline WT-1 640-650 & $1 /-$ & - & 11 & 9 & 16 & 62 & - \\
\hline WT-1 690-700 & $1 /-$ & - & - & 19 & 19 & 61 & - \\
\hline \multicolumn{8}{|c|}{ WT-1 Tptpmn 733-888 } \\
\hline WT-1 780-790 & $1 /-$ & - & 3 & 25 & 9 & 61 & - \\
\hline WT-1 840-850 & $1 /-$ & - & 6 & 20 & 16 & 56 & - \\
\hline \multicolumn{8}{|l|}{ WT-1 Tptpll 888-1187 } \\
\hline WT-1 930-940 & $3 /-$ & - & 5 & 26 & 7 & 57 & - \\
\hline WT-1 1000-1010 & $1 /-$ & - & - & 22 & 16 & 60 & - \\
\hline WT-1 1090-1100 & $1 /-$ & - & - & 24 & 15 & 58 & - \\
\hline WT-1 1160-1170 & $1 /-$ & 1 & 11 & 10 & 18 & 58 & - \\
\hline \multicolumn{8}{|c|}{ WT-1 Tptpln 1187-1299 } \\
\hline WT-1 1220-1230 & $-/-$ & - & 5 & 27 & 8 & 59 & - \\
\hline
\end{tabular}


Table F-5. Selected Mineralogic-Abundance Data for Drill Hole USW WT-1 (Weight Percent) (Continued)

\begin{tabular}{|c|c|c|c|c|c|c|c|}
\hline & $\begin{array}{l}\text { Smectitel } \\
\text { Mordenite }\end{array}$ & Clinoptilolite & Tridymite & Quartz & Cristobalite \pm Opal & Feldspar & Glass \\
\hline WT-1 Tptpv3 1299-1337 & & & & & & & \\
\hline WT-1 1300-1310 & $1 /-$ & 2 & - & 35 & 4 & 59 & - \\
\hline WT-1 1320-1330 & $2 /-$ & 14 & - & 20 & 13 & 50 & - \\
\hline WT-1 Tptpv2 1337-1368 & & & & & & & \\
\hline WT-1 1340-1350 & 1/- & 29 & - & 10 & 9 & 51 & - \\
\hline WT-1 Tptpv1 1368-1380 & & & & & & & \\
\hline not sampled & & & & & & & \\
\hline WT-1 Tpbt1 1380-1384 & & & & & & & \\
\hline partly sampled, 1380-1390 & & & & & & & \\
\hline WT-1 Tac 1384-1564 & & & & & & & \\
\hline WT-1 1380-1390 & $-/ 12$ & 40 & - & 8 & 7 & 31 & - \\
\hline WT-1 1410-1420 & -18 & 40 & - & 3 & 8 & 40 & - \\
\hline WT-1 1470-1480 & $-/ 18$ & 25 & - & 10 & 7 & 39 & - \\
\hline WT-1 1510-1520 & $-/ 10$ & 43 & - & 8 & 5 & 33 & - \\
\hline WT-1 1550-1560 & $-/ 12$ & 40 & - & 14 & 7 & 26 & - \\
\hline $\begin{array}{l}\text { WT-1 no units defined below } \\
1564\end{array}$ & & & & & & & \\
\hline WT-1 1570-1580 & -13 & 5 & - & 26 & 9 & 57 & - \\
\hline
\end{tabular}

Sources: DTNs MO0101XRDDRILC.001 [DIRS 169517], MO0004QGFMPICK.000 [DIRS 152554].

- = not detected; Tr. = trace amount much less than $1 \%$ 
Table F-6. Selected Mineralogic-Abundance Data for Drill Hole USW WT-2 (Weight Percent)

\begin{tabular}{|c|c|c|c|c|c|c|c|}
\hline & $\begin{array}{l}\text { Smectitel } \\
\text { Mordenite }\end{array}$ & Clinoptilolite & Tridymite & Quartz & Cristobalite \pm Opal & Feldspar & Glass \\
\hline \multicolumn{8}{|c|}{ Unit or Sample Depth Range in feet } \\
\hline \multicolumn{8}{|l|}{ WT-2 Tpbt2 247-271 } \\
\hline WT-2 250-260 & $4 /-$ & - & - & 2 & 11 & 34 & 50 \\
\hline WT-2 260-270 & $7 /-$ & - & - & 1 & 7 & 51 & 30 \\
\hline \multicolumn{8}{|c|}{ WT-2 Tptrv3-1 271-285 } \\
\hline \multicolumn{8}{|l|}{ not analyzed } \\
\hline \multicolumn{8}{|l|}{ WT-2 Tptrn 285-380 } \\
\hline WT-2 290-300 & $1 /-$ & - & 10 & - & 9 & 78 & - \\
\hline WT-2 370-380 & $<1 /-$ & - & 19 & 1 & 5 & 72 & - \\
\hline \multicolumn{8}{|l|}{ WT-2 Tptpul 421-590 } \\
\hline WT-2 420-450 & $1 /-$ & - & 12 & 2 & 11 & 73 & - \\
\hline WT-2 510-520 & 1/- & - & 13 & 3 & 21 & 62 & - \\
\hline WT-2 570-580 & 3/- & - & 13 & 5 & 21 & 59 & - \\
\hline \multicolumn{8}{|c|}{ WT-2 Tptpmn 590-727 } \\
\hline WT-2 650-660 & $2 /-$ & - & 10 & 6 & 22 & 58 & - \\
\hline WT-2 720-730 & $1 /-$ & - & 10 & 8 & 19 & 61 & - \\
\hline \multicolumn{8}{|c|}{ WT-2 Tptpll 727-1014 } \\
\hline WT-2 780-790 & $1 /-$ & - & 6 & 21 & 10 & 59 & - \\
\hline WT-2 850-860 & 1/- & - & 13 & 14 & 16 & 56 & - \\
\hline WT-2 930-940 & $1 /-$ & - & 13 & 11 & 17 & 57 & - \\
\hline WT-2 990-1000 & $2 /-$ & - & - & 14 & 21 & 62 & - \\
\hline \multicolumn{8}{|c|}{ WT-2 Tptpln 1014-1179 } \\
\hline WT-2 1060-1070 & $3 /-$ & - & - & 16 & 19 & 61 & - \\
\hline WT-2 1130-1140 & $<1 /-$ & - & - & 13 & 15 & 70 & - \\
\hline \multicolumn{8}{|c|}{ WT-2 Tptpv3 1179-1223 } \\
\hline WT-2 1190-1200 & $2 /-$ & 1 & - & 4 & 9 & 56 & 30 \\
\hline
\end{tabular}


Table F-6. Selected Mineralogic-Abundance Data for Drill Hole USW WT-2 (Weight Percent) (Continued)

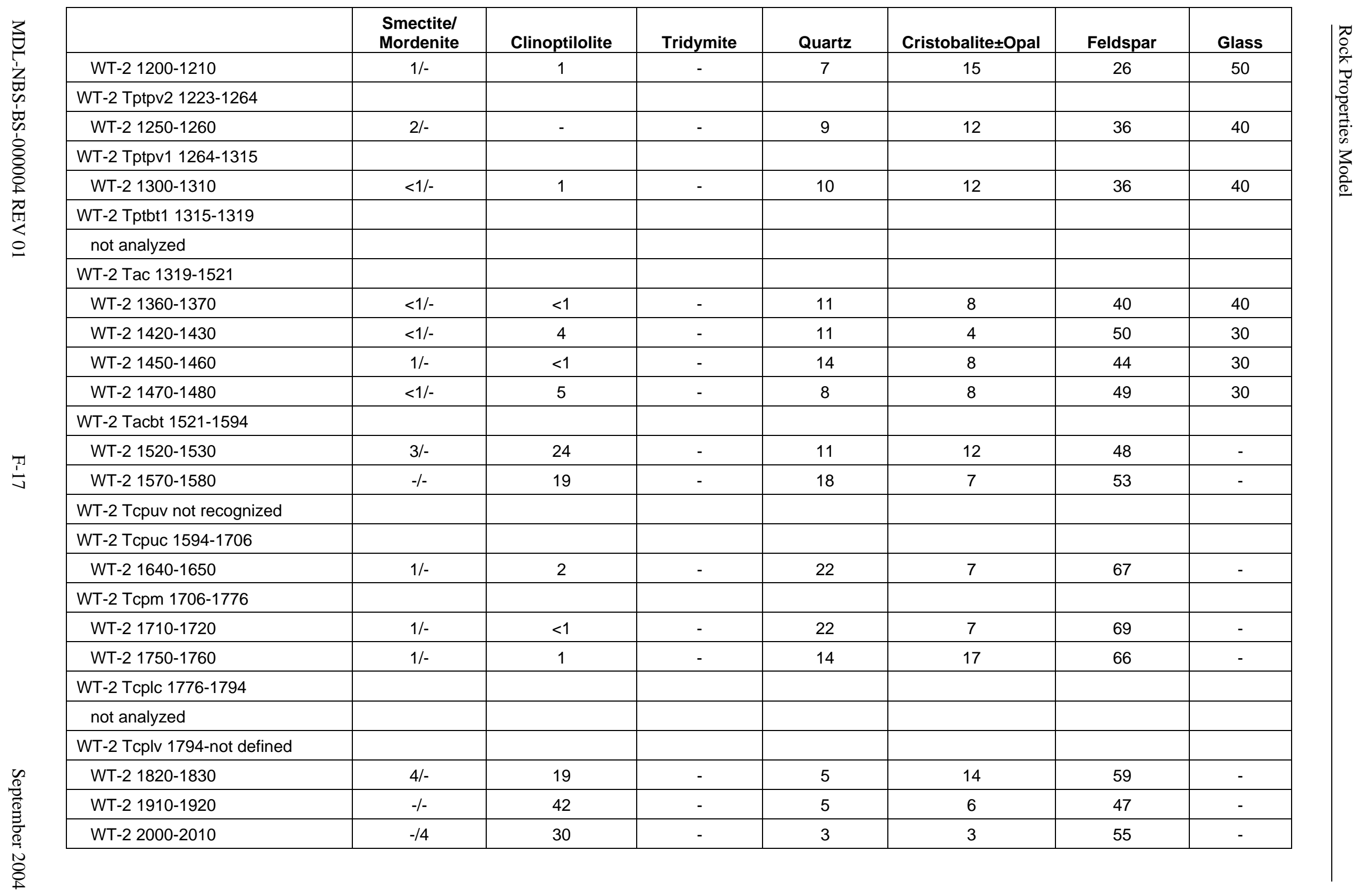


Table F-6. Selected Mineralogic-Abundance Data for Drill Hole USW WT-2 (Weight Percent) (Continued)

\begin{tabular}{|c|c|c|c|c|c|c|c|}
\hline & $\begin{array}{l}\text { Smectitel } \\
\text { Mordenite }\end{array}$ & Clinoptilolite & Tridymite & Quartz & Cristobalite \pm Opal & Feldspar & Glass \\
\hline \multicolumn{8}{|l|}{ WT-2 Tcb? } \\
\hline WT-2 2050.25 (core) & $1 /-$ & - & - & 18 & 9 & 69 & - \\
\hline WT-2 2053.7 (core) & $1 /-$ & - & - & 19 & 10 & 67 & - \\
\hline WT-2 2059.5 (core) & $<1 /-$ & - & - & 21 & 9 & 66 & - \\
\hline
\end{tabular}

Sources: DTNs MO0101XRDDRILC.001 [DIRS 169517], MO0004QGFMPICK.000 [DIRS 152554].

- = not detected; $\mathrm{Tr}$. = trace amount much less than $1 \%$. 
Table G-1. Selected Mineralogic-Abundance Data for Drill Hole UE-25 UZ\#16 (Weight Percent)

\begin{tabular}{|c|c|c|c|c|c|c|c|}
\hline & $\begin{array}{c}\text { Smectitel } \\
\text { Mordenite }\end{array}$ & Clinoptilolite & Tridymite & Quartz & Cristobalite \pm Opal & Feldspar & Glass \\
\hline \multicolumn{8}{|c|}{ Unit or Sample Depth Range in feet } \\
\hline \multicolumn{8}{|c|}{ UZ\#16 Tpc_un 39.5-140.8 } \\
\hline UZ\#16 54.8-55.0 & $2 /-$ & - & 4 & 2 & 28 & 61 & - \\
\hline UZ\#16 64.7-64.9 & $3 /-$ & - & 7 & 4 & 25 & 62 & - \\
\hline UZ\#16 78.6-78.9 & 3/- & - & 3 & 1 & 30 & 59 & - \\
\hline UZ\#16 88.7-88.8 & $2 /-$ & - & 3 & 1 & 31 & 59 & - \\
\hline UZ\#16 102.1-102.2 & 3/- & - & 3 & Tr. & 32 & 57 & - \\
\hline UZ\#16 112.5-112.7 & $3 /-$ & - & 2 & Tr. & 32 & 58 & - \\
\hline UZ\#16 126.0-126.2 & $1 /-$ & 1 & Tr. & Tr. & 33 & 59 & - \\
\hline UZ\#16 140.2-140.3 & $1 /-$ & - & Tr. & 2 & 32 & 58 & - \\
\hline \multicolumn{8}{|l|}{ UZ\#16 Tpcpv2 140.8-153 } \\
\hline \multicolumn{8}{|l|}{ not sampled } \\
\hline \multicolumn{8}{|l|}{ UZ\#16 Tpcpv1 153-160.7 } \\
\hline UZ\#16 154.2-154.5 & 8/- & - & - & - & 12 & 17 & 63 \\
\hline UZ\#16 156.1-156.2 & $14 /-$ & - & - & Tr. & Tr. & 4 & 82 \\
\hline \multicolumn{8}{|l|}{ UZ\#16 Tpbt4 160.7-165.9 } \\
\hline UZ\#16 165.1-165.3 & $6 /-$ & - & - & 5 & 2 & 16 & 71 \\
\hline \multicolumn{8}{|l|}{ UZ\#16 Tpy 165.9-173.4 } \\
\hline UZ\#16 167.4-167.5 & $12 /-$ & - & - & - & - & 3 & 85 \\
\hline UZ\#16 171.3-171.5 & 9/- & - & - & - & - & - & 91 \\
\hline \multicolumn{8}{|l|}{ UZ\#16 Tpbt3 173.4-188.8 } \\
\hline UZ\#16 174.9-175.1 & $11 /-$ & - & - & 1 & 2 & 8 & 78 \\
\hline UZ\#16 179.3-179.4 & $6 /-$ & - & - & 7 & 2 & 20 & 65 \\
\hline UZ\#16 183.9-184.1 & 18/- & - & - & 2 & 1 & 19 & 59 \\
\hline UZ\#16 188.5-188.7 & 7/- & - & - & Tr. & 1 & 20 & 70 \\
\hline UZ\#16 Tpbt2 188.8-217 & & & & & & & \\
\hline
\end{tabular}


Table G-1. Selected Mineralogic-Abundance Data for Drill Hole UE-25 UZ\#16 (Weight Percent) (Continued)

\begin{tabular}{|c|c|c|c|c|c|c|c|}
\hline & $\begin{array}{l}\text { Smectitel } \\
\text { Mordenite }\end{array}$ & Clinoptilolite & Tridymite & Quartz & Cristobalite \pm Opal & Feldspar & Glass \\
\hline UZ\#16 190.4-190.5 & $16 /-$ & - & - & 2 & 1 & 19 & 58 \\
\hline UZ\#16 201.8-202.2 & 9/- & - & - & 3 & Tr. & 19 & 64 \\
\hline UZ\#16 211.4-211.6 & $8 /-$ & - & - & Tr. & Tr. & 19 & 71 \\
\hline UZ\#16 Tptrv3 217-228.1 & & & & & & & \\
\hline UZ\#16 223.7-224.2 & 9/- & 18 & - & - & 15 & 55 & - \\
\hline UZ\#16 224.1-224.7 & $6 /-$ & 18 & - & 2 & 24 & 48 & - \\
\hline UZ\#16 227.0-227.2 & $5 /-$ & 17 & - & 1 & 34 & 41 & - \\
\hline UZ\#16 Tptrv2 228.1-229.4 & & & & & & & \\
\hline not sampled & & & & & & & \\
\hline UZ\#16 Tptrv1 229.4-238.9 & & & & & & & \\
\hline UZ\#16 230.1-230.3 & $1 /-$ & - & - & Tr. & 1 & 21 & 73 \\
\hline UZ\#16 234.1-234.2 & Tr./- & - & - & Tr. & 2 & 38 & 58 \\
\hline UZ\#16 Tptrn 238.9-357.8 & & & & & & & \\
\hline UZ\#16 249.8-250.0 & $1 /-$ & - & 3 & - & 13 & 78 & - \\
\hline UZ\#16 269.2-269.8 & $1 /-$ & - & 7 & - & 11 & 81 & - \\
\hline UZ\#16 290.8-291.2 & $1 /-$ & - & 12 & - & 8 & 77 & - \\
\hline UZ\#16 309.1-309.5 & Tr./- & - & 13 & - & 8 & 77 & - \\
\hline UZ\#16 331.7-332.2 & $1 /-$ & - & 22 & - & 5 & 76 & - \\
\hline UZ\#16 348.7-349.7 & $5 /-$ & - & 22 & - & 8 & 64 & - \\
\hline UZ\#16 Tptrl 357.8-371 & & & & & & & \\
\hline UZ\#16 370.2-370.7 & $7 /-$ & - & 22 & 3 & 8 & 61 & - \\
\hline UZ\#16 Tptpul 371-545 & & & & & & & \\
\hline UZ\#16 391.6-392.0 & $6 /-$ & - & 11 & 4 & 21 & 54 & - \\
\hline UZ\#16 412.7-413.0 & $4 /-$ & - & 16 & 2 & 19 & 56 & - \\
\hline UZ\#16 435.1-435.5 & $4 /-$ & - & 7 & 3 & 28 & 58 & - \\
\hline UZ\#16 458.6-458.9 & $4 /-$ & - & 10 & 11 & 17 & 56 & - \\
\hline UZ\#16 484.4-485.7 & $4 /-$ & - & 4 & 5 & 29 & 55 & - \\
\hline
\end{tabular}


Table G-1. Selected Mineralogic-Abundance Data for Drill Hole UE-25 UZ\#16 (Weight Percent) (Continued)

\begin{tabular}{|c|c|c|c|c|c|c|c|}
\hline & $\begin{array}{c}\text { Smectitel } \\
\text { Mordenite }\end{array}$ & Clinoptilolite & Tridymite & Quartz & Cristobalite \pm Opal & Feldspar & Glass \\
\hline UZ\#16 509.6-510.0 & $4 /-$ & - & 3 & 9 & 28 & 54 & - \\
\hline UZ\#16 533.3-533.6 & $4 /-$ & - & 1 & 11 & 25 & 55 & - \\
\hline \multicolumn{8}{|l|}{ UZ\#16 Tptpmn 545-669 } \\
\hline UZ\#16 552.9-553.3 & $3 /-$ & - & Tr. & 21 & 16 & 57 & - \\
\hline UZ\#16 577.3-577.6 & $3 /-$ & - & 1 & 23 & 13 & 57 & - \\
\hline UZ\#16 602.8-603.4 & $3 /-$ & - & 3 & 12 & 27 & 57 & - \\
\hline UZ\#16 627.9-628.2 & $3 /-$ & - & 1 & 10 & 26 & 56 & - \\
\hline UZ\#16 648.8-649.3 & $4 /-$ & - & 4 & 6 & 27 & 54 & - \\
\hline \multicolumn{8}{|l|}{ UZ\#16 Tptpll 669-935 } \\
\hline UZ\#16 674.2-674.7 & $5 /-$ & - & 1 & 27 & 13 & 58 & - \\
\hline UZ\#16 701.5-701.9 & $3 /-$ & - & 1 & 36 & 5 & 58 & - \\
\hline UZ\#16 726.1-726.4 & $1 /-$ & $2^{*}$ & 7 & 23 & 10 & 57 & - \\
\hline UZ\#16 751.4-751.7 & $3 /-$ & - & 1 & 29 & 10 & 56 & - \\
\hline UZ\#16 773.0-773.4 & $1 /-$ & $3^{*}$ & 3 & 17 & 19 & 56 & - \\
\hline UZ\#16 797.0-797.2 & $1 /-$ & $1^{*}$ & 1 & 14 & 23 & 57 & - \\
\hline UZ\#16 820.6-820.9 & $3 /-$ & $1^{*}$ & 1 & 26 & 11 & 56 & - \\
\hline UZ\#16 843.0-843.5 & $3 /-$ & Tr.* & 6 & 18 & 16 & 55 & - \\
\hline UZ\#16 862.4-862.7 & $2 /-$ & $5^{\star}$ & 5 & 9 & 22 & 55 & - \\
\hline UZ\#16 876.8-877.1 & $3 /-$ & $11^{*}$ & 4 & 10 & 21 & 53 & - \\
\hline UZ\#16 896.2-896.6 & $4 /-$ & - & 6 & 9 & 24 & 54 & - \\
\hline UZ\#16 910.2-910.4 & $6 /-$ & $2^{*}$ & 3 & 18 & 18 & 56 & - \\
\hline UZ\#16 925.4-925.7 & $4 /-$ & $5^{\star}$ & 4 & 12 & 26 & 50 & - \\
\hline \multicolumn{8}{|l|}{ UZ\#16 Tptpln 935-1107.5 } \\
\hline UZ\#16 940.0-940.4 & $4 /-$ & $1^{*}$ & Tr. & 27 & 13 & 57 & - \\
\hline UZ\#16 954.3-954.7 & $3 /-$ & $2^{*}$ & 3 & 18 & 20 & 52 & - \\
\hline UZ\#16 970.9-971.4 & $5 /-$ & $2^{*}$ & 2 & 17 & 21 & 51 & - \\
\hline UZ\#16 984.2-984.8 & $4 /-$ & $4^{*}$ & 2 & 18 & 21 & 52 & - \\
\hline
\end{tabular}


Table G-1. Selected Mineralogic-Abundance Data for Drill Hole UE-25 UZ\#16 (Weight Percent) (Continued)

\begin{tabular}{|c|c|c|c|c|c|c|c|}
\hline & $\begin{array}{l}\text { Smectitel } \\
\text { Mordenite }\end{array}$ & Clinoptilolite & Tridymite & Quartz & Cristobalite \pm Opal & Feldspar & Glass \\
\hline UZ\#16 1001.0-1001.6 & $5 /-$ & $4^{*}$ & 1 & 22 & 16 & 50 & - \\
\hline UZ\#16 1014.9-1015.0 & $6 /-$ & - & 5 & 14 & 21 & 53 & - \\
\hline UZ\#16 1029.2-1029.5 & $5 /-$ & $14^{*}$ & 3 & 15 & 21 & 45 & - \\
\hline UZ\#16 1030.4-1030.6 & $4 /-$ & $8^{*}$ & 2 & 20 & 18 & 50 & - \\
\hline UZ\#16 1047.0-1047.3 & $4 /-$ & $2^{*}$ & 2 & 24 & 13 & 55 & - \\
\hline UZ\#16 1059.6-1059.8 & $5 /-$ & - & 3 & 15 & 23 & 54 & - \\
\hline UZ\#16 1074.8-1075.1 & $4 /-$ & $1^{*}$ & 2 & 21 & 17 & 54 & - \\
\hline UZ\#16 1090.4-1090.6 & $4 /-$ & $2^{\star}$ & 1 & 24 & 15 & 53 & - \\
\hline UZ\#16 1104.1-1104.4 & $2 /-$ & - & - & 31 & 8 & 57 & - \\
\hline \multicolumn{8}{|l|}{ UZ\#16 Tptpv3 1107.5-1165.2 } \\
\hline UZ\#16 1113.1-1113.2a & $73 /-$ & 4 & - & Tr. & 10 & 10 & - \\
\hline UZ\#16 1113.1-1113.2b & $5 /-$ & - & - & 1 & 7 & 14 & 73 \\
\hline UZ\#16 1135.3-1135.6 & $3 /-$ & - & - & 1 & 9 & 7 & 80 \\
\hline UZ\#16 1149.2-1149.5 & $-/-$ & - & - & 1 & 10 & 7 & 82 \\
\hline UZ\#16 1157.4-1157.6 & $1 /-$ & - & - & 1 & 12 & 10 & 75 \\
\hline \multicolumn{8}{|l|}{ UZ\#16 Tptpv2 1165.2-1178 } \\
\hline UZ\#16 1166.5-1167.0 & $2 /-$ & 10 & - & 2 & 20 & 17 & 49 \\
\hline \multicolumn{8}{|l|}{ UZ\#16 Tptpv1 1178-1190 } \\
\hline UZ\#16 1179.8-1180.5 & $1 /-$ & 80 & - & 3 & 13 & 8 & - \\
\hline \multicolumn{8}{|l|}{ UZ\#16 Tpbt1 1190-1197 } \\
\hline UZ\#16 1190.2-1191.2 & $6 / 2$ & 83 & - & 1 & 6 & 4 & - \\
\hline \multicolumn{8}{|l|}{ UZ\#16 Tac 1197-1455.4 } \\
\hline UZ\#16 1202.8-1203.1 & $1 / 12$ & 66 & - & 3 & 14 & 6 & - \\
\hline UZ\#16 1215.7-1216.0 & $1 / 11$ & 72 & - & 3 & 12 & 7 & - \\
\hline UZ\#16 1235.5-1235.7 & $1 / 7$ & 69 & - & 3 & 18 & 7 & - \\
\hline UZ\#16 1256.6-1256.9 & 8/- & 72 & - & 3 & 10 & 12 & - \\
\hline UZ\#16 1261.0-1261.2a & $1 /-$ & 66 & - & 3 & 22 & 11 & - \\
\hline
\end{tabular}


Table G-1. Selected Mineralogic-Abundance Data for Drill Hole UE-25 UZ\#16 (Weight Percent) (Continued)

\begin{tabular}{|c|c|c|c|c|c|c|c|}
\hline & $\begin{array}{l}\text { Smectitel } \\
\text { Mordenite }\end{array}$ & Clinoptilolite & Tridymite & Quartz & Cristobalite \pm Opal & Feldspar & Glass \\
\hline UZ\#16 1275.7-1276.0 & $3 / 8$ & 54 & - & 6 & 18 & 13 & - \\
\hline UZ\#16 1300.2-1300.3 & $9 / 5$ & 58 & - & 5 & 20 & 10 & - \\
\hline UZ\#16 1305.0-1305.3 & $2 / 9$ & 60 & - & 5 & 19 & 11 & - \\
\hline UZ\#16 1312.0-1312.4 & $3 / 12$ & 54 & - & 4 & 18 & 11 & - \\
\hline UZ\#16 1335.4-1336.2 & $1 / 11$ & 38 & - & 9 & 26 & 19 & - \\
\hline UZ\#16 1342.7-1343.0 & $3 / 16$ & 55 & - & 3 & 19 & 10 & - \\
\hline UZ\#16 1362.3-1362.7 & $3 / 13$ & 52 & - & 4 & 17 & 11 & - \\
\hline UZ\#16 1379.3-1379.5 & $3 / 9$ & 60 & - & 4 & 21 & 9 & - \\
\hline UZ\#16 1417.5-1418.0 & $2 / 8$ & 58 & - & 4 & 19 & 11 & - \\
\hline UZ\#16 1441.3-1441.8 & $2 / 12$ & 65 & - & 3 & 17 & 6 & - \\
\hline \multicolumn{8}{|l|}{ UZ\#16 Tacbt 1455.4-1485 } \\
\hline UZ\#16 1460.2-1460.7 & $5 / 4$ & 42 & - & 8 & 27 & 18 & - \\
\hline UZ\#16 1476.7-1477.0 & $5 /-$ & 40 & - & 11 & 20 & 27 & - \\
\hline \multicolumn{8}{|l|}{ UZ\#16 Tcpuv 1485-1497.7 } \\
\hline \multicolumn{8}{|l|}{ not sampled } \\
\hline \multicolumn{8}{|l|}{ UZ\#16 Tсрис 1497.7-1571 } \\
\hline UZ\#16 1498.4-1498.9 & $-/ 8$ & - & - & 17 & 20 & 48 & - \\
\hline UZ\#16 1521.7-1522.2 & $3 /-$ & - & - & 41 & - & 54 & - \\
\hline UZ\#16 1539.3-1539.7 & $4 /-$ & - & - & 41 & - & 56 & - \\
\hline UZ\#16 1561.2-1561.7 & $4 /-$ & - & - & 39 & - & 58 & - \\
\hline \multicolumn{8}{|l|}{ UZ\#16 Tcpm 1571-1638 } \\
\hline UZ\#16 1579.1-1579.9 & $3 /-$ & - & - & 38 & - & 59 & - \\
\hline UZ\#16 1600.2-1600.4 & $4 /-$ & - & - & 39 & - & 58 & - \\
\hline UZ\#16 1618.7-1619.2 & $3 /-$ & - & - & 24 & 14 & 62 & - \\
\hline
\end{tabular}


Table G-1. Selected Mineralogic-Abundance Data for Drill Hole UE-25 UZ\#16 (Weight Percent) (Continued)

\begin{tabular}{|c|c|c|c|c|c|c|c|}
\hline & $\begin{array}{l}\text { Smectitel } \\
\text { Mordenite }\end{array}$ & Clinoptilolite & Tridymite & Quartz & Cristobalite $\pm O$ pal & Feldspar & Glass \\
\hline \multicolumn{8}{|l|}{ UZ\#16 Tcplc 1638-1669.2 } \\
\hline UZ\#16 1638.7-1639.2 & $7 /-$ & - & - & 20 & 15 & 55 & - \\
\hline UZ\#16 1655.5-1656.0 & $6 /-$ & - & - & 11 & 27 & 56 & - \\
\hline \multicolumn{8}{|l|}{ UZ\#16 Tcplv 1669.2-bottom } \\
\hline UZ\#16 1683.5-1684.0 & 3/- & 42 & - & 5 & 28 & 28 & - \\
\hline
\end{tabular}

Sources: LA000000000086.002 [DIRS 107144], MO0004QGFMPICK.000 [DIRS 152554].

- = not detected; $\mathrm{Tr}$. = trace amount much less than $1 \%$.

*Stellerite fracture fillings. 
Table G-2. Selected Mineralogic-Abundance Data for Drill Hole USW G-1 (Weight Percent)

\begin{tabular}{|c|c|c|c|c|c|c|c|}
\hline & $\begin{array}{l}\text { Smectitel } \\
\text { Mordenite }\end{array}$ & $\begin{array}{c}\text { Clinoptilolitel } \\
\text { Analcime }\end{array}$ & Tridymite & Quartz & Cristobalite \pm Opal & Feldspar & Glass \\
\hline \multicolumn{8}{|l|}{ Unit or Sample Depth Range in feet } \\
\hline \multicolumn{8}{|l|}{ G-1 Tcpbt 2154.9-2173.3 } \\
\hline G-1 2173 & $-/ 9$ & $33(\mathrm{c})$ & - & 2 & 8 & 41 & - \\
\hline \multicolumn{8}{|l|}{ G-1 Tcbuv 2173.2-2337 } \\
\hline G-1 2190 & $4 /-$ & $51(c)$ & - & 4 & 23 & 19 & - \\
\hline G-1 2198 & $1 / 2$ & $48(c)$ & - & 4 & 20 & 20 & - \\
\hline G-1 2256 & $-/ 44$ & $\operatorname{Tr}$. (c) & - & 3 & 22 & 26 & - \\
\hline G-1 2279 & Tr./38 & 29 (c) & - & 3 & 8 & 21 & - \\
\hline G-1 2290 & $2 / 43$ & 31 (c) & - & 3 & 2 & 18 & - \\
\hline G-1 2316 & $-/ 23$ & $30(\mathrm{c})$ & - & 19 & - & 27 & - \\
\hline \multicolumn{8}{|l|}{ G-1 Tcbuc 2337-2461 } \\
\hline G-1 2401 & 3/- & - & - & 35 & Tr. & 62 & - \\
\hline G-1 2456 & $1 /-$ & - & - & 32 & 1 & 67 & - \\
\hline \multicolumn{8}{|l|}{ G-1 Tcbm 2461-2547 } \\
\hline G-1 2486 & $1 /-$ & - & - & 33 & - & 67 & - \\
\hline G-1 2499 & Tr./- & - & - & 32 & Tr. & 66 & - \\
\hline G-1 2506 & Tr./- & - & - & 32 & Tr. & 63 & - \\
\hline G-1 2544 & Tr./- & - & - & 36 & Tr. & 64 & - \\
\hline \multicolumn{8}{|l|}{ G-1 Tcblc not recognized } \\
\hline \multicolumn{8}{|l|}{ G-1 Tcblv 2547-2601.6 } \\
\hline G-1 2564 & $\operatorname{Tr} . / 27$ & 40 (c) & - & 3 & 10 & 20 & - \\
\hline G-1 2600 & $-/ 39$ & $48(\mathrm{c})$ & - & Tr. & 2 & 12 & - \\
\hline \multicolumn{8}{|l|}{ G-1 Tcbbt 2601.6-2639.4 } \\
\hline G-1 2606 & Tr./26 & $42(c)$ & - & 12 & 1 & 17 & - \\
\hline G-1 2607 & $-/ 21$ & $26(\mathrm{c})$ & - & 20 & 1 & 29 & - \\
\hline G-1 2622 & Tr./14 & $30(\mathrm{c})$ & - & 21 & 1 & 30 & - \\
\hline
\end{tabular}


Table G-2. Selected Mineralogic-Abundance Data for Drill Hole USW G-1 (Weight Percent) (Continued)

\begin{tabular}{|c|c|c|c|c|c|c|c|}
\hline & $\begin{array}{l}\text { Smectitel } \\
\text { Mordenite }\end{array}$ & $\begin{array}{c}\text { Clinoptilolitel } \\
\text { Analcime }\end{array}$ & Tridymite & Quartz & Cristobalite \pm Opal & Feldspar & Glass \\
\hline \multicolumn{8}{|l|}{ G-1 Tctuv 2639.4-2800 } \\
\hline G-1 2641 & $2 / 6$ & $30 /-$ & - & 4 & 7 & 44 & - \\
\hline G-1 2663 & Tr./15 & $40 /-$ & - & 5 & 4 & 33 & - \\
\hline G-1 2734 & $\operatorname{Tr} . / 4$ & $31 /-$ & - & 16 & 8 & 40 & - \\
\hline G-1 2765 & 4/Tr. & $15 /-$ & - & 18 & 8 & 52 & - \\
\hline \multicolumn{8}{|l|}{ G-1 Tctuc $2800-2840$} \\
\hline G-1 2804 & $1 /-$ & $-1-$ & - & 31 & 1 & 62 & - \\
\hline G-1 2805 & $3 /-$ & $-/-$ & - & 33 & 1 & 62 & - \\
\hline G-1 2820 & $1 /-$ & $-/-$ & - & 36 & Tr. & 65 & - \\
\hline G-1 2838 & $2 /-$ & $-/-$ & - & 31 & - & 64 & - \\
\hline \multicolumn{8}{|l|}{ G-1 Tctm 2840-2956 } \\
\hline G-1 2868 & $1 /-$ & $-/-$ & - & 36 & Tr. & 63 & - \\
\hline G-1 2884 & $2 /-$ & $-/-$ & - & 34 & - & 64 & - \\
\hline G-1 2915 & $2 /-$ & $-/-$ & - & 36 & - & 61 & - \\
\hline G-1 2932 & $1 /-$ & $-/-$ & - & 36 & - & 64 & - \\
\hline G-1 2937 & $2 /-$ & $-/-$ & - & 35 & - & 63 & - \\
\hline G-1 2948 & $2 /-$ & $2 /-$ & - & 30 & - & 67 & - \\
\hline \multicolumn{8}{|l|}{ G-1 Tctlc 2956-3005 } \\
\hline G-1 2966 & $1 /-$ & $-/-$ & - & 36 & - & 67 & - \\
\hline G-1 2981 & $3 /-$ & $-/-$ & - & 37 & - & 58 & - \\
\hline \multicolumn{8}{|l|}{ G-1 Tctlv 3005-3522 } \\
\hline G-1 3018 & 18/- & $-/ 4$ & - & 33 & - & 34 & - \\
\hline G-1 3079 & $11 /-$ & $13 / 5$ & - & 36 & - & 34 & - \\
\hline G-1 3167 & 10/- & $19 / 5$ & - & 31 & - & 31 & - \\
\hline G-1 3288 & $17 /-$ & $40 / 1$ & - & 18 & - & 20 & - \\
\hline G-1 3401 & $4 /-$ & $10 / 2$ & - & 38 & - & 43 & \\
\hline G-1 Tctbt 3522-3558.2 & & & & & & & \\
\hline
\end{tabular}


Table G-2. Selected Mineralogic-Abundance Data for Drill Hole USW G-1 (Weight Percent) (Continued)

\begin{tabular}{|c|c|c|c|c|c|c|c|}
\hline & $\begin{array}{l}\text { Smectitel } \\
\text { Mordenite }\end{array}$ & $\begin{array}{c}\text { Clinoptilolitel } \\
\text { Analcime }\end{array}$ & Tridymite & Quartz & Cristobalite \pm Opal & Feldspar & Glass \\
\hline G-1 3523 & $7 /-$ & $13 / 1$ & - & 32 & - & 46 & - \\
\hline Tund 3558.2-bottom of hole & & & & & & & \\
\hline G-1 3621 & $24 /-$ & $-/-$ & - & 3 & 6 & 59 & - \\
\hline G-1 3810 & $65 /-$ & $-/-$ & - & - & - & 37 & - \\
\hline G-1 3940 & $48 /-$ & $2 / 2$ & - & 19 & - & 23 & 2 \\
\hline G-1 4246 & $17 /-$ & $-/ 6$ & - & 38 & - & 38 & - \\
\hline G-1 4400 & $7 /-$ & $-/ 13$ & - & 39 & - & 42 & - \\
\hline G-1 4503 & $4 /-$ & $-/ 19$ & - & 39 & - & 37 & - \\
\hline G-1 4555 & $21 /-$ & $-/ 2$ & - & 22 & - & 47 & - \\
\hline G-1 4612 & $13 /-$ & -17 & - & 34 & - & 41 & - \\
\hline G-1 4626 & $4 /-$ & $-/-$ & - & 42 & - & 52 & - \\
\hline G-1 4652 & $7 /-$ & $-/ 11$ & - & 40 & - & 38 & - \\
\hline G-1 4700 & $6 /-$ & $-/ 7$ & - & 46 & - & 40 & - \\
\hline G-1 4750 & 8/- & $-/ 10$ & - & 37 & - & 44 & - \\
\hline G-1 4805 & 8/- & $-/ 9$ & - & 38 & - & 43 & - \\
\hline G-1 4848 & $6 /-$ & $-/ 11$ & - & 41 & - & 38 & - \\
\hline G-1 4876 & $4 /-$ & $-/ 4$ & - & 45 & - & 45 & - \\
\hline G-1 4912 & $7 /-$ & $-/ 8$ & - & 43 & - & 37 & - \\
\hline G-1 4941 & $27 /-$ & -17 & - & 27 & - & 25 & - \\
\hline G-1 4958 & 8/- & $-/ 17$ & - & 46 & - & 30 & - \\
\hline G-1 4998 & $30 /-$ & $-/ 3$ & - & 39 & - & 27 & - \\
\hline G-1 5026 & $5 /-$ & $-/ 2$ & - & 45 & - & 51 & - \\
\hline G-1 5049 & $52 /-$ & $-1-$ & - & 5 & - & 28 & - \\
\hline G-1 5093 & $5 /-$ & $-/ 2$ & - & 39 & - & 47 & Tr. \\
\hline G-1 5126 & $2 /-$ & $-/ 15$ & - & 50 & - & 33 & Tr. \\
\hline G-1 5167 & $2 /-$ & $-/ 14$ & - & 46 & - & 40 & Tr. \\
\hline G-1 5212 & $1 /-$ & $-/ 16$ & - & 48 & - & 38 & Tr. \\
\hline
\end{tabular}


Table G-2. Selected Mineralogic-Abundance Data for Drill Hole USW G-1 (Weight Percent) (Continued)

\begin{tabular}{|c|c|c|c|c|c|c|c|}
\hline & $\begin{array}{c}\text { Smectitel } \\
\text { Mordenite }\end{array}$ & $\begin{array}{c}\text { Clinoptilolitel } \\
\text { Analcime }\end{array}$ & Tridymite & Quartz & Cristobalite \pm Opal & Feldspar & Glass \\
\hline G-1 5253 & $1 /-$ & $-/ 27$ & - & 36 & - & 35 & - \\
\hline G-1 5296 & $2 /-$ & $-/ 19$ & - & 37 & - & 39 & Tr. \\
\hline G-1 5310 & 29/- & $-1-$ & - & 23 & - & 52 & - \\
\hline G-1 5311 & $6 /-$ & $1 /-$ & - & 46 & - & 45 & - \\
\hline G-1 5329 & $11 /-$ & $12 /-$ & - & 40 & - & 40 & Tr. \\
\hline G-1 5338 & $41 /-$ & $1 /-$ & - & 28 & - & 26 & - \\
\hline G-1 5348 & 9/- & Tr./- & - & 35 & - & 44 & - \\
\hline G-1 5378 & $46 /-$ & $15 /-$ & - & 17 & - & 24 & - \\
\hline G-1 5412 & $5 /-$ & $12 /-$ & - & 40 & - & 40 & Tr. \\
\hline G-1 5433 & $35 /-$ & $20 /-$ & - & 9 & - & 27 & Tr. \\
\hline G-1 5458 & $26 /-$ & $25 /-$ & - & 18 & - & 28 & - \\
\hline G-1 5477 & $5 /-$ & $-/ 12$ & - & 44 & - & 36 & - \\
\hline G-1 5498 & $5 /-$ & $-/ 17$ & - & 38 & - & 41 & - \\
\hline G-1 5534 & $38 /-$ & $20 / 4$ & - & 8 & - & 24 & - \\
\hline G-1 5560 & $5 / 23$ & $23 /-$ & - & 21 & - & 33 & Tr. \\
\hline G-1 5596 & $2 /-$ & $1 / 7$ & - & 34 & - & 50 & Tr. \\
\hline G-1 5637 & $3 /-$ & $-/ 16$ & - & 38 & - & 42 & 1 \\
\hline G-1 5679 & $20 /-$ & $-/ 13$ & - & 24 & - & 36 & Tr. \\
\hline G-1 5699 & $5 /-$ & -19 & - & 33 & - & 50 & Tr. \\
\hline G-1 5746 & $12 /-$ & $-/ 10$ & - & 32 & - & 46 & 1 \\
\hline G-1 5803 & $10 /-$ & $-1-$ & - & 29 & - & 54 & 1 \\
\hline G-1 5847 & $13 /-$ & $-1-$ & - & 29 & - & 54 & 1 \\
\hline G-1 5898 & $7 /-$ & $-/ 12$ & - & 42 & - & 34 & - \\
\hline G-1 5947 & $12 /-$ & $2 / 15$ & - & 28 & - & 34 & 1 \\
\hline G-1 5980 & $14 /-$ & $4 /-$ & - & 29 & - & 40 & 2 \\
\hline Sources: $N$ & $\begin{array}{l}\text { RS 163796], } \\
\text { amount much }\end{array}$ & $\begin{array}{l}\text { O004QGFMPICF } \\
\text { ss than } 1 \%\end{array}$ & 00 [DIRS 15 & & & & \\
\hline
\end{tabular}


Table G-3. Selected Mineralogic-Abundance Data for Drill Hole USW GU-3 (Weight Percent)

\begin{tabular}{|c|c|c|c|c|c|c|c|}
\hline & $\begin{array}{c}\text { Smectitel } \\
\text { Hornblende }\end{array}$ & Clinoptilolite & Tridymite & Quartz & Cristobalite \pm Opal & Feldspar & Glass \\
\hline \multicolumn{8}{|l|}{ Unit or Sample Depth Range in feet } \\
\hline \multicolumn{8}{|l|}{ GU-3 Tpc_un 0-348.1 } \\
\hline GU-3 45.0 & $-1-$ & - & 6 & - & 17 & 75 & - \\
\hline GU-3 79.0 & $-1-$ & - & 25 & 2 & 6 & 70 & - \\
\hline GU-3 103.1 & $-1-$ & - & 7 & 2 & 20 & 70 & - \\
\hline GU-3 196.3 & $-1-$ & - & - & - & 25 & 75 & - \\
\hline GU-3 245.7 & $2 /-$ & - & 3 & 2 & 25 & 70 & - \\
\hline GU-3 303.6 & $<1 /-$ & - & - & - & 25 & 75 & - \\
\hline GU-3 316.8 & $-1-$ & - & - & - & 22 & 75 & - \\
\hline GU-3 341.5 & $3 /-$ & - & - & - & 30 & 70 & - \\
\hline \multicolumn{8}{|l|}{ GU-3 Tpbt3 375.5-391.7 } \\
\hline GU-3 376.1 & $4 /-$ & - & - & 3 & 5 & 50 & 40 \\
\hline \multicolumn{8}{|l|}{ GU-3 Tptrn 427.8-542 } \\
\hline GU-3 429.0 & $-1-$ & - & 4 & 4 & 20 & 70 & - \\
\hline GU-3 430.5 & $-1-$ & - & 4 & - & 12 & 80 & - \\
\hline GU-3 465.5 & $-1-$ & - & 10 & - & 9 & 80 & - \\
\hline GU-3 482.0 & $-1-$ & - & 20 & - & 7 & 70 & - \\
\hline GU-3 520.3 & $-1-$ & - & 20 & - & 5 & 70 & - \\
\hline GU-3 525.3 & $-1 /-$ & - & 20 & 1 & 6 & 70 & - \\
\hline \multicolumn{8}{|l|}{ GU-3 Tptpul 548-688 } \\
\hline GU-3 579.0 & $\sim 1 /-$ & - & 12 & - & 22 & 65 & - \\
\hline GU-3 633.4 & $\sim 1 /-$ & - & 7 & 2 & 22 & 70 & - \\
\hline GU-3 674.7 & $\sim 1 /-$ & - & 5 & 2 & 22 & 70 & - \\
\hline \multicolumn{8}{|l|}{ GU-3 Tptpmn 688-830 } \\
\hline GU-3 702.5 & $\sim 1 /-$ & - & - & 6 & 17 & 70 & - \\
\hline GU-3 769.1 & $\sim 1 /-$ & - & 6 & -1 & 22 & 65 & - \\
\hline \multicolumn{8}{|l|}{ GU-3 Tptpll 830-1044 } \\
\hline GU-3 849.4 & $\sim 1 /-$ & - & - & 4 & 17 & 75 & - \\
\hline
\end{tabular}


Table G-3. Selected Mineralogic-Abundance Data for Drill Hole USW GU-3 (Weight Percent) (Continued)

\begin{tabular}{|c|c|c|c|c|c|c|c|}
\hline & $\begin{array}{c}\text { Smectitel } \\
\text { Hornblende }\end{array}$ & Clinoptilolite & Tridymite & Quartz & Cristobalite $\pm O p a l$ & Feldspar & Glass \\
\hline GU-3 910.5 & $\sim 1 /-$ & - & - & 4 & 27 & 65 & - \\
\hline GU-3 924.3 & $\sim 1 /-$ & - & 10 & 12 & 12 & 65 & - \\
\hline GU-3 951.1 & $\sim 1 /-$ & - & 5 & 8 & 17 & 70 & - \\
\hline GU-3 954.8 & $\sim 1 /-$ & - & - & 17 & 12 & 70 & - \\
\hline GU-3 1027 & $-/-$ & - & - & 6 & 17 & 75 & - \\
\hline \multicolumn{8}{|l|}{ GU-3 Tptpln 1044-1186.7 } \\
\hline GU-3 1061.0 & $-1-$ & - & - & 20 & 7 & 70 & - \\
\hline GU-3 1130.3 & $-1-$ & - & - & 17 & 10 & 70 & - \\
\hline GU-3 1175.0 & $\sim 1 /-$ & - & - & 35 & 3 & 60 & - \\
\hline \multicolumn{8}{|l|}{ GU-3 Tptpv3 1186.7-1280 } \\
\hline GU-3 1195.7 & 2/- & - & - & 3 & 27 & 35 & 30 \\
\hline GU-3 1227 & 2/- & - & - & 8 & 17 & 35 & 40 \\
\hline \multicolumn{8}{|l|}{ GU-3 Tptpv2 1280-1317 } \\
\hline GU-3 1302.4 & 2/- & - & - & 4 & 12 & 40 & 45 \\
\hline \multicolumn{8}{|l|}{ GU-3 Tptpv1 1317-1406.3 } \\
\hline GU-3 1322.0 & $-1-$ & - & - & 4 & 7 & 30 & 65 \\
\hline GU-3 1344.8 & $-/-$ & - & - & 7 & 7 & 30 & 55 \\
\hline GU-3 1369.6 & $-1-$ & - & - & 4 & 6 & 25 & 65 \\
\hline GU-3 1394.5 & $-1-$ & - & - & 4 & 6 & 30 & 65 \\
\hline GU-3 1394.6 & $-1-$ & - & - & 4 & 6 & 30 & 65 \\
\hline \multicolumn{8}{|l|}{ GU-3 Tac 1412.5-1506.3 } \\
\hline GU-3 1415.5 & $-/-$ & - & - & 5 & 6 & 35 & 55 \\
\hline GU-3 1439.2 & Tr./- & - & - & 20 & 6 & 20 & 55 \\
\hline GU-3 1439.5 & $\sim 1 /-$ & - & - & 5 & 6 & 35 & 55 \\
\hline GU-3 1468.5 & $-/-$ & - & - & 5 & 6 & 35 & 55 \\
\hline GU-3 1493.7 & $\sim 1 /-$ & 2 & - & 5 & 6 & 25 & 65 \\
\hline GU-3 1498.3 & $-/-$ & 3 & - & 7 & 6 & 25 & 65 \\
\hline \multicolumn{8}{|l|}{ GU-3 Tacbt 1506.3-1553.9 } \\
\hline GU-3 1510.7 & 3/- & - & - & 5 & 6 & 25 & 65 \\
\hline
\end{tabular}


Table G-3. Selected Mineralogic-Abundance Data for Drill Hole USW GU-3 (Weight Percent) (Continued)

\begin{tabular}{|c|c|c|c|c|c|c|c|}
\hline & $\begin{array}{c}\text { Smectitel } \\
\text { Hornblende }\end{array}$ & Clinoptilolite & Tridymite & Quartz & Cristobalite \pm Opal & Feldspar & Glass \\
\hline GU-3 1537.5 & $3 / 2$ & 2 & - & 17 & 4 & 50 & 20 \\
\hline GU-3 Tcpuv 1553.9-1597 & & & & & & & \\
\hline GU-3 1571.6 & $2 /-$ & - & - & 4 & 5 & 45 & 45 \\
\hline $\begin{array}{l}\text { GU-3 } 1598.5 \text { moved to } \\
\text { Tcpuv }\end{array}$ & $4 /-$ & - & - & 5 & 2 & 45 & 45 \\
\hline GU-3 Tcpuc 1597-1663 & & & & & & & \\
\hline GU-3 1603.0 & $-1-$ & - & - & 2 & 30 & 65 & - \\
\hline GU-3 1624.2 & $-/-$ & - & 7 & 20 & 2 & 70 & - \\
\hline GU-3 1653.3 & $\sim 1 /-$ & - & 15 & 15 & 3 & 70 & - \\
\hline GU-3 Tcpm 1663-1744 & & & & & & & \\
\hline GU-3 1709.0 & $\sim 1 /-$ & - & - & 12 & 12 & 70 & - \\
\hline GU-3 Tcplc 1744-1755 & & & & & & & \\
\hline GU-3 1744.0 & $-/-$ & - & - & 6 & 25 & 70 & - \\
\hline GU-3 Tcplv 1755-1992.3 & & & & & & & \\
\hline GU-3 1827.2 & $2 /-$ & 30 & - & 4 & 7 & 19 & 38 \\
\hline GU-3 1874 & $-1-$ & 50 & - & 7 & 5 & 40 & - \\
\hline GU-3 1935.8 & $3 /-$ & 60 & - & 4 & 4 & 30 & - \\
\hline GU-3 1986 & $-1-$ & 70 & - & 4 & 6 & 20 & - \\
\hline GU-3 Tcpbt 1992.3-1998.7 & & & & & & & \\
\hline GU-3 1993.1 & $-/-$ & 60 & - & 4 & 10 & 25 & - \\
\hline GU-3 Tcblv 2550.8-2617 & & & & & & & \\
\hline GU-3 2577.4 & $3 /-$ & 50 & - & 2 & 5 & 35 & - \\
\hline GU-3 2615.3 & $2 /-$ & 40 & - & 5 & 7 & 45 & - \\
\hline GU-3 Tctuv 2637-2719 & & & & & & & \\
\hline GU-3 2656.6 & $4 /-$ & 30 & - & 5 & 8 & 50 & - \\
\hline GU-3 2695.7 & $\sim 1 /-$ & 30 & - & 7 & 10 & 40 & - \\
\hline
\end{tabular}

Sources: MO0101XRDMINAB.001 [DIRS 163796], MO0004QGFMPICK.000 [DIRS 152554]

- = not detected; $\mathrm{Tr}$. = trace amount much less than $1 \%$ 
Table G-4. Selected Mineral-Abundance Data for Drill Hole USW G-4 (Weight Percent)

\begin{tabular}{|c|c|c|c|c|c|c|c|}
\hline & Smectite & Clinoptilolite & Tridymite & Quartz & Cristobalite \pm Opal & Feldspar & Glass \\
\hline \multicolumn{8}{|c|}{ Unit or Sample Depth Range in feet } \\
\hline \multicolumn{8}{|l|}{ G-4 Tptpmn 674-774 } \\
\hline G-4 676 & 3 & - & 4 & 4 & 23 & 66 & - \\
\hline G-4 694 & 3 & - & 17 & 4 & 13 & 62 & - \\
\hline G-4 746 & $\sim 1$ & - & - & 3 & 28 & 68 & - \\
\hline \multicolumn{8}{|c|}{ G-4 Tptpln 1127.9-1316.5 } \\
\hline G-4 1163 & - & - & - & 16 & 15 & 69 & - \\
\hline G-4 1190 & 1 & - & - & 25 & 13 & 60 & - \\
\hline G-4 1244 & 1 & - & - & 17 & 15 & 67 & - \\
\hline G-4 1282 & 1 & - & - & 16 & 18 & 65 & - \\
\hline G-4 1283-1293E & 1 & - & - & 6 & 23 & 69 & - \\
\hline G-4 1299 & 2 & 5 & - & 8 & 23 & 62 & - \\
\hline G-4 1301 & 1 & 5 & - & 9 & 20 & 65 & - \\
\hline G-4 1310 & 1 & 3 & - & 5 & 24 & 65 & - \\
\hline G-4 1314* & 45 & 28 & - & 2 & 14 & 11 & \\
\hline
\end{tabular}

Sources: MO0101XRDMINAB.001 [DIRS 163796], MO0004QGFMPICK.000 [DIRS 152554].

*This sample is excluded from the comparison with Tptpln in other drill hole samples because the presence of abundant smectite and clinoptilolite means it is from a localized alteration zone.

- = not detected; Tr. = trace amount much less than $1 \%$ 
Table G-5. Selected Mineral-Abundance Data for Drill Hole USW SD-12 (Weight Percent)

\begin{tabular}{|c|c|c|c|c|c|c|c|}
\hline & $\begin{array}{l}\text { Smectitel } \\
\text { Mordenite }\end{array}$ & Clinoptilolite & Tridymite & Quartz & Cristobalite \pm Opal & Feldspar & Glass \\
\hline \multicolumn{8}{|c|}{ Unit or Sample Depth Range in feet } \\
\hline \multicolumn{8}{|l|}{ SD-12 Tptrn 330.7-436.4 } \\
\hline SD-12 331.1 & Tr./- & - & 4 & 5 & 25 & 63 & - \\
\hline SD-12 337.8 & $1 /-$ & - & 6 & - & 15 & 79 & - \\
\hline SD-12 376.3 & Tr./- & - & 13 & - & 9 & 77 & - \\
\hline SD-12 395.9 & $-/-$ & - & 14 & Tr. & 7 & 74 & - \\
\hline SD-12 419.8 & $2 /-$ & - & 16 & Tr. & 10 & 74 & - \\
\hline \multicolumn{8}{|l|}{ SD-12 Tptpul 470.2-663.7 } \\
\hline SD-12 489.6 & $4 /-$ & - & 14 & 3 & 21 & 55 & - \\
\hline SD-12 517.4 & $3 /-$ & - & 9 & 1 & 27 & 56 & - \\
\hline SD-12 534.7 & $4 /-$ & - & 7 & 3 & 30 & 55 & - \\
\hline SD-12 561.9 & $5 /-$ & - & 7 & 3 & 28 & 54 & - \\
\hline SD-12 580.7 & $5 /-$ & - & 6 & 9 & 25 & 55 & - \\
\hline SD-12 602.6 & $4 /-$ & - & 8 & 12 & 23 & 55 & - \\
\hline SD-12 629.7 & $4 /-$ & - & 5 & 6 & 29 & 54 & - \\
\hline SD-12 654.4 & $3 /-$ & - & 7 & 15 & 19 & 56 & - \\
\hline SD-12 Tptpmn 663.7-786.9 & & & & & 30 & & \\
\hline SD-12 679.5-679.9 & $4 /-$ & - & 2 & 8 & & 53 & - \\
\hline SD-12 706.0-706.1 & $5 /-$ & - & 4 & 11 & 26 & 52 & - \\
\hline SD-12 733.0-733.3 & $5 /-$ & - & 3 & 5 & 34 & 54 & - \\
\hline SD-12 759.8-760.1 & $4 /-$ & - & 4 & 9 & 28 & 54 & - \\
\hline SD-12 785.5-785.8 & $3 /-$ & - & 4 & 3 & 34 & 54 & - \\
\hline \multicolumn{8}{|l|}{ SD-12 Tptpll 786.9-1065.5 } \\
\hline SD-12 807.0 & $4 /-$ & - & 3 & 10 & 27 & 53 & - \\
\hline SD-12 831.4 & $4 /-$ & - & 3 & 33 & 6 & 56 & - \\
\hline SD-12 852.9 & $4 /-$ & - & 14 & 13 & 16 & 55 & - \\
\hline
\end{tabular}


Table G-5. Selected Mineral-Abundance Data for Drill Hole USW SD-12 (Weight Percent) (Continued)

\begin{tabular}{|c|c|c|c|c|c|c|c|}
\hline & $\begin{array}{c}\text { Smectitel } \\
\text { Mordenite }\end{array}$ & Clinoptilolite & Tridymite & Quartz & Cristobalite \pm Opal & Feldspar & Glass \\
\hline SD-12 881.1 & $3 /-$ & - & 3 & 23 & 17 & 54 & - \\
\hline SD-12 903.1 & $5 /-$ & - & 4 & 12 & 25 & 54 & - \\
\hline SD-12 929.9 & 4/- & - & 7 & 24 & 10 & 55 & - \\
\hline SD-12 954.7 & $3 /-$ & - & 4 & 16 & 22 & 54 & - \\
\hline SD-12 979.7 & $2 /-$ & - & 3 & 11 & 26 & 54 & - \\
\hline SD-12 Tptpln 1065.5-1278.1 & & & & & & & \\
\hline SD-12 1160.8-1161.1 & $4 /-$ & - & 1 & 21 & 20 & 55 & - \\
\hline SD-12 1180.9-1181.1 & $4 /-$ & - & 1 & 24 & 15 & 54 & - \\
\hline SD-12 1200.2-1200.6 & $3 /-$ & - & 2 & 17 & 24 & 54 & - \\
\hline SD-12 1219.2-1220.2 & $4 /-$ & - & 2 & 9 & 27 & 54 & - \\
\hline SD-12 1240.4-1240.6 & $2 /-$ & - & 2 & 16 & 23 & 57 & - \\
\hline SD-12 1261.9-1262.1 & $3 /-$ & - & 2 & 19 & 22 & 53 & - \\
\hline SD-12 1271.1-1271.3 & $3 /-$ & - & 3 & 7 & 30 & 53 & - \\
\hline SD-12 1273.4-1273.45 & $-/-$ & 1 & 2 & 7 & 29 & 56 & - \\
\hline SD-12 Tptpv3 1278.1-1308 & & & & & & & \\
\hline SD-12 1278.5-1278.8 & $2 /-$ & - & - & 1 & - & 10 & 72 \\
\hline SD-12 1291.4-1291.8 & $-/-$ & - & - & 1 & 8 & 6 & 85 \\
\hline SD-12 1301.0-1301.4 & Tr./- & - & - & Tr. & 10 & 8 & 82 \\
\hline SD-12 Tptpv2 1308-1337.5 & & & & & & & \\
\hline SD-12 1309.3 & Tr./- & - & - & 1 & 20 & 14 & 65 \\
\hline SD-12 1319.0 & Tr./- & - & - & 1 & 18 & 15 & 66 \\
\hline SD-12 1320.6 & Tr./- & - & - & 1 & 18 & 13 & 68 \\
\hline SD-12 1333.2 & $2 /-$ & - & - & 1 & 8 & 9 & 80 \\
\hline SD-12 Tptpv1 1337.5-1408.1 & & & & & & & \\
\hline SD-12 1342.1 & Tr./- & - & - & 1 & 4 & 4 & 91 \\
\hline SD-12 1351.9 & Tr./- & - & - & 1 & 6 & 5 & 88 \\
\hline SD-12 1361.9 & $-/-$ & - & - & 1 & 3 & 4 & 92 \\
\hline
\end{tabular}


Table G-5. Selected Mineral-Abundance Data for Drill Hole USW SD-12 (Weight Percent) (Continued)

\begin{tabular}{|c|c|c|c|c|c|c|c|}
\hline & $\begin{array}{l}\text { Smectitel } \\
\text { Mordenite }\end{array}$ & Clinoptilolite & Tridymite & Quartz & Cristobalite \pm Opal & Feldspar & Glass \\
\hline SD-12 1371.4 & Tr./- & - & - & 1 & 2 & 4 & 93 \\
\hline SD-12 1381.1 & $1 /-$ & 2 & - & 1 & 4 & 5 & 87 \\
\hline SD-12 1388.0 & Tr./- & 2 & - & 3 & 5 & 8 & 82 \\
\hline SD-12 1399.2 & $1 /-$ & 3 & - & 5 & 5 & 12 & 74 \\
\hline SD-12 1408.0 & 8/- & 1 & - & 2 & 3 & 9 & 77 \\
\hline SD-12 Tpbt1 1408.1-1411.5 & & & & & & & \\
\hline SD-12 1410.5-1410.6 & $2 /-$ & 1 & - & 2 & 3 & 7 & 85 \\
\hline SD-12 Tac 1411.5-1599.5 & & & & & & & \\
\hline SD-12 1439.9-1440.1 & $-/-$ & 1 & - & 2 & 2 & 6 & 89 \\
\hline SD-12 1458.7-1458.9 & Tr./- & 4 & - & 2 & 2 & 5 & 87 \\
\hline SD-12 1480.2-1480.5 & Tr./- & 4 & - & 4 & 4 & 9 & 79 \\
\hline SD-12 1500.8-1501.0 & $1 /-$ & 5 & - & 4 & 4 & 7 & 79 \\
\hline SD-12 1519.8-1520.1 & $2 /-$ & 5 & - & 6 & 12 & 17 & 58 \\
\hline SD-12 1540.9-1541.3 & $2 /-$ & 10 & - & 5 & 9 & 10 & 64 \\
\hline SD-12 1561.1-1561.3 & $3 /-$ & 3 & - & 3 & 5 & 8 & 78 \\
\hline SD-12 1581.3-1581.6 & $2 /-$ & 9 & - & 4 & 5 & 7 & 73 \\
\hline SD-12 Tacbt 1599.5-1648.4 & & & & & & & \\
\hline SD-12 1600.0-1600.3 & $4 /-$ & 12 & - & 7 & 5 & 10 & 62 \\
\hline SD-12 1600.0-1600.3 & $7 / 4$ & 51 & - & 2 & 30 & 8 & - \\
\hline SD-12 1601.5-1601.8 & $5 /-$ & 68 & - & 4 & 15 & 6 & - \\
\hline SD-12 1609.9-1610.4 & 3/- & 30 & - & 11 & 7 & 11 & 34 \\
\hline SD-12 1620.4-1620.6 & $4 /-$ & 59 & - & 8 & 18 & 14 & - \\
\hline SD-12 1641.4-1641.7 & 9/- & 14 & - & 8 & 25 & 45 & - \\
\hline SD-12 Tcpuv 1648.4-1677 & & & & & & & \\
\hline SD-12 1656.3-1656.8 & $7 /-$ & 58 & - & 3 & 23 & 13 & - \\
\hline SD-12 Tсрис 1677-1787 & & & & & & & \\
\hline SD-12 1680.7-1680.9 & $2 /-$ & - & - & 35 & - & 54 & - \\
\hline
\end{tabular}


Table G-5. Selected Mineral-Abundance Data for Drill Hole USW SD-12 (Weight Percent) (Continued)

\begin{tabular}{|c|c|c|c|c|c|c|c|}
\hline & $\begin{array}{c}\text { Smectitel } \\
\text { Mordenite }\end{array}$ & Clinoptilolite & Tridymite & Quartz & Cristobalite \pm Opal & Feldspar & Glass \\
\hline SD-12 1700.3-1700.6 & $3 /-$ & - & 2 & 34 & 4 & 55 & - \\
\hline SD-12 1720.1-1720.4 & $2 /-$ & - & 3 & 32 & 2 & 56 & - \\
\hline SD-12 1739.8-1740.2 & $2 /-$ & - & 3 & 32 & 2 & 58 & - \\
\hline SD-12 1760.0-1760.4 & $3 /-$ & - & 3 & 30 & 2 & 60 & - \\
\hline SD-12 1780.2-1780.4 & $2 /-$ & - & - & 26 & 10 & 60 & - \\
\hline SD-12 Tcpm 1787-1842 & & & & & & & \\
\hline SD-12 1799.4-1800.0 & $2 /-$ & - & 3 & 31 & 4 & 57 & - \\
\hline SD-12 1821.2-1821.6 & Tr./- & - & - & 21 & 18 & 60 & - \\
\hline SD-12 1840.6-1840.8 & $5 /-$ & - & - & 9 & 27 & 55 & - \\
\hline SD-12 Tcplc 1842-1865 & & & & & & & \\
\hline SD-121860.0-1860.3 & $2 /-$ & - & - & 5 & 31 & 57 & - \\
\hline SD-12 Tcplv 1865-2133 & & & & & & & \\
\hline SD-12 1874.4-1874.5 & $6 / 5$ & 10 & - & 4 & 45 & 34 & - \\
\hline SD-12 1891.6-1891.9 & $5 / 10$ & 50 & - & 6 & 11 & 22 & - \\
\hline SD-12 1911.8-1911.9 & $5 / 4$ & 48 & - & 5 & 21 & 19 & - \\
\hline SD-12 1929.7-1929.9 & $3 / 6$ & 51 & - & 4 & 21 & 19 & - \\
\hline SD-12 1950.0-1950.7 & $3 / 5$ & 56 & - & 4 & 16 & 21 & - \\
\hline SD-12 1972.1-1972.4 & $2 /-$ & 65 & - & 4 & 15 & 19 & - \\
\hline SD-12 Tcb 2137.8-bottom & & & & & & & \\
\hline SD-12 2148.6 & $2 /-$ & - & - & 26 & 13 & 56 & - \\
\hline SD-12 2163.0 & $-/-$ & - & - & 33 & 6 & 59 & - \\
\hline
\end{tabular}

Sources: LADV831321AQ97.001 [DIRS 107142], LAJC831321AQ98.005 [DIRS 109004], MO0004QGFMPICK.000 [DIRS 152554]

- = not detected; $T r$. = trace amount much less than $1 \%$. 
APPENDIX H

SOURCE DATA TRACKING NUMBERS FOR LA9910DB831321.001 
The following text illustrates the source relationship for the source or X-Ray diffraction indicators of mineralogical alteration for the RPM, DTN: LA9910DB831321.001. This also demonstrates that all data provided by the source DTNs are qualified by Steinborn, T.L. (2002 [DIRS 160702]), and the qualification activities contained in Appendices E, F, and $G$ of this report.

\section{Rock Properties Model Section 4.1.4 - X-Ray Diffraction Indicators of Mineral Alteration} LA9910DB831321.001 [DIRS 113568] (TBV \#3682)

1. LA000000000086.002 Qualified, Verified using AP-3.15Q Procedure, Developed, TBV \#3074 removed

2. LA9908JC831321.001 Product Output, Mineralogic Model (MM 3.0)

3. LADB831321AN98.002 Unqualified (TBV \#5854)

4. LADV831321AQ97.001 Qualified by TDR-NBS-HS-000005, REV 00

5. LAJC831321AQ98.005 Qualified, Verified using AP-3.15Q Procedure, Acquired, TBV \#3066 removed

6. LASC831321AQ96.002 Qualified, Verified using AP-3.15Q Procedure, Acquired, TBV \#3067 removed

7. LASL831322AQ97.001 Qualified, Verified using AP-3.15Q Procedure, Acquired, TBV \#3071 removed

\section{LA9908JC831321.001 [DIRS 113495]}

Product Output Data Tracking Number from the Mineralogic Model (MM 3.0) REV 00 Listing of DTNs from “Table 4-1. Data Input.”

1. LA000000000086.002 Qualified, Verified using AP-3.15Q Procedure, Developed, TBV 3074 removed

2. LA9910JC831321.001

3. LADB831321AN98.002

4. LADV831321AQ97.001

5. LADV831321AQ97.007

6. LADV831321AQ99.001

7. LAJC831321AQ98.005

8. LASC831321AQ96.002

9. LASC831321AQ98.001

10. LASC831321AQ98.003

11. LASL831322AQ97.001
Unqualified (TBV \#3657)

Unqualified (TBV \#3065)

Unqualified (TBV \#0868)

Qualified, Verified using AP-3.15Q Procedure, Acquired, TBV \#3658 removed

Qualified, Verified using AP-3.15Q Procedure, Acquired, TBV \#3069 removed

Qualified, Verified using AP-3.15Q Procedure, Acquired, TBV \#3066 removed

Qualified, Verified using AP-3.15Q Procedure, Acquired, TBV \#3067 removed

Qualified, Verified using AP-3.15Q Procedure, Acquired, TBV \#3072 removed

Qualified, Verified using AP-3.15Q Procedure, Acquired, TBV \#3068 removed

Qualified, Verified using AP-3.15Q Procedure, Acquired, TBV \#3071 removed 
Steinborn, T.L. 2002 [DIRS 160702], Table 10, Data Qualification Report: Mineralogy Data for Use on the Yucca Mountain Project. TDR-NBS-HS-000005, REV 00

3. LADB831321AN98.002

4. LADV831321AQ97.001 (a) MO0101XRDMINAB.001, Qualified by TDR-NBS-HS-000005, REV 00 Boreholes: UE-25b\#1, USW G-1, USW G-3, USW GU-3, and USW G-4

(b) MO0101XRDDRILC.000, Not qualified by

TDR-NBS-HS-000005, REV 00

Borehole: UE-25 J-13 (not an input to MM3.0)

(c) MO0106XRDDRILC.003, Qualified by

TDR-NBS-HS-000005, REV 00

Borehole: USW H-6

(d) MO0101XRDDRILC.002, Qualified by

TDR-NBS-HS-000005, REV 00

Boreholes: UE-25 a\#1 and USW G-2

(e) MO0101XRDDRILC.001, Not qualified by

TDR-NBS-HS-000005, REV 00

Cuttings samples from boreholes.

Qualified by TDR-NBS-HS-000005, REV 00

The qualification activity contained in this report MDL-NBS-GS-000004, REV 01

(e) MO0101XRDDRILC.001

(I) $\quad$ LADV831321AQ97.001

(II) LADV831321AQ97.007

(III) LA9910JC831321.001
Qualified by the activity documented in this report. Cuttings, sidewall samples, and intermittent core samples. LADV831321AQ97.001 - USW H-3 sidewall core and cuttings samples LADB831321AN98.002 - UE-25 J-12 cuttings samples USW H-3 sidewall core and cuttings samples USW H-4 sidewall core and cuttings samples USW WT-1 cuttings samples UE-25 p\#1 intermittent core, sidewall core, and cuttings samples USW WT-2 intermittent core and cuttings samples USW H-5 sidewall core and cuttings samples. Qualified by the activity documented in this report. TDR-NBS-HS-000005 qualification of software POWD10 did not qualify cuttings samples in DTN.

Qualified by the activity documented in this report Qualified by the activity documented in this report. 


\section{APPENDIX I}

\section{ETYPE}




\section{I1. JUSTIFICATION FOR CHANGE IN ETYPE CITATION}

For this model report the citation of the software code ETYPE has been changed from the routine documented in Geostatistical Modeling of Porosity and Derivative Properties for Fiscal Year 1998 (Rautman and McKenna 1998 [DIRS 107442], pages 1134-1142), to the baselined version (STN: 10731-2-2.01-00 [DIRS 159417]). Justification for this change is that the test case results for the ETYPE routine on page 1138 of Rautman and McKenna were duplicated using the baselined version of the code.

Documentation of this justification is provided in three parts. First, a description of the software code ETYPE is provided in Sections I1.1 and I1.2. The basis of this description is the ETYPE Software Management Report (SNL 2002 [DIRS 171419]). Second, documentation of the ETYPE routine from Rautman and McKenna (1998 [DIRS 107442]) is provided in Section I1.3. Third, the result for the ETYPE routine test case (Rautman and McKenna 1998 [DIRS 107442] p. 1138 and reproduced on page I-7) are provided in Section I1.4.

\section{I1.1 BACKGROUND}

In many instances, multiple data sets (or files) are identically formatted. The position of each data component in the set is usually meaningful. For example, row "i" and column "j" (for each data file) might stand for temperature (parameter $\mathrm{j}$ ) at a certain well at a certain depth (parameter i). Each individual file/data set might represent a particular date. When it is desirable to obtain statistical measures for properties such as these, the analyst must be able to enter all of the data sets or files, then access and develop the data accordingly.

The ETYPE program computes the mean and standard deviation of multiple realizations saved in separate files, along the lines of the above example.

\section{I1.2 FORMULAS AND EQUATIONS}

ETYPE calculates the standard deviation of a set of input numbers and therefore also calculates the mean of those numbers.

The equation for the mean, $\mu$ is:

$$
\mu=\frac{\sum_{i=1}^{N} X_{i}}{N}
$$

where,

$X_{i}=$ the elements or variables for which the mean is being calculated.

$N=$ the number of elements or variables 
The equation of the standard deviation $\sigma$, is:

$$
\sigma=\sqrt{\frac{\sum_{i=1}^{N}\left(\mu-X_{i}\right)^{2}}{N-1}}
$$

where,

$\mu=$ the calculated mean value

\section{I1.3 DOCUMENTATION OF THE ETYPE SOFTWARE ROUTINE}

This section reproduces the documentation of the software routine ETYPE in Geostatistical Modeling of Porosity and Derivative Properties for Fiscal Year 1998. The test case input values and results are documented on page 1138 of the document (Rautman and McKenna 1998 [DIRS 107442], pages 1134-1142). 


\section{$001 / 34 \quad$ wBS: $1 \cdot 2 \cdot 3 \cdot 2 \cdot 2 \cdot 2.2$}

QA: $L$

Brief description of or annotations for 8 pages that follow; added $6 / 30 / 98^{\text {Work Agreement: WA-0344 }}$

Quick cluck of program "etype. for" - routine to read

a specified number of sumilcter files and compute node-by-

node mean + std.dev. (could be notifiet for other statistical mea sunca)

In put: 4 files w/ nominel $3 \times 3 \times 3=27$ test values; select col to to average.

Output: file w/ compated mean (E-type value) + sth.dev. If input numbers

Compare hand calculator results wf test rutput. -OK 
etype.for

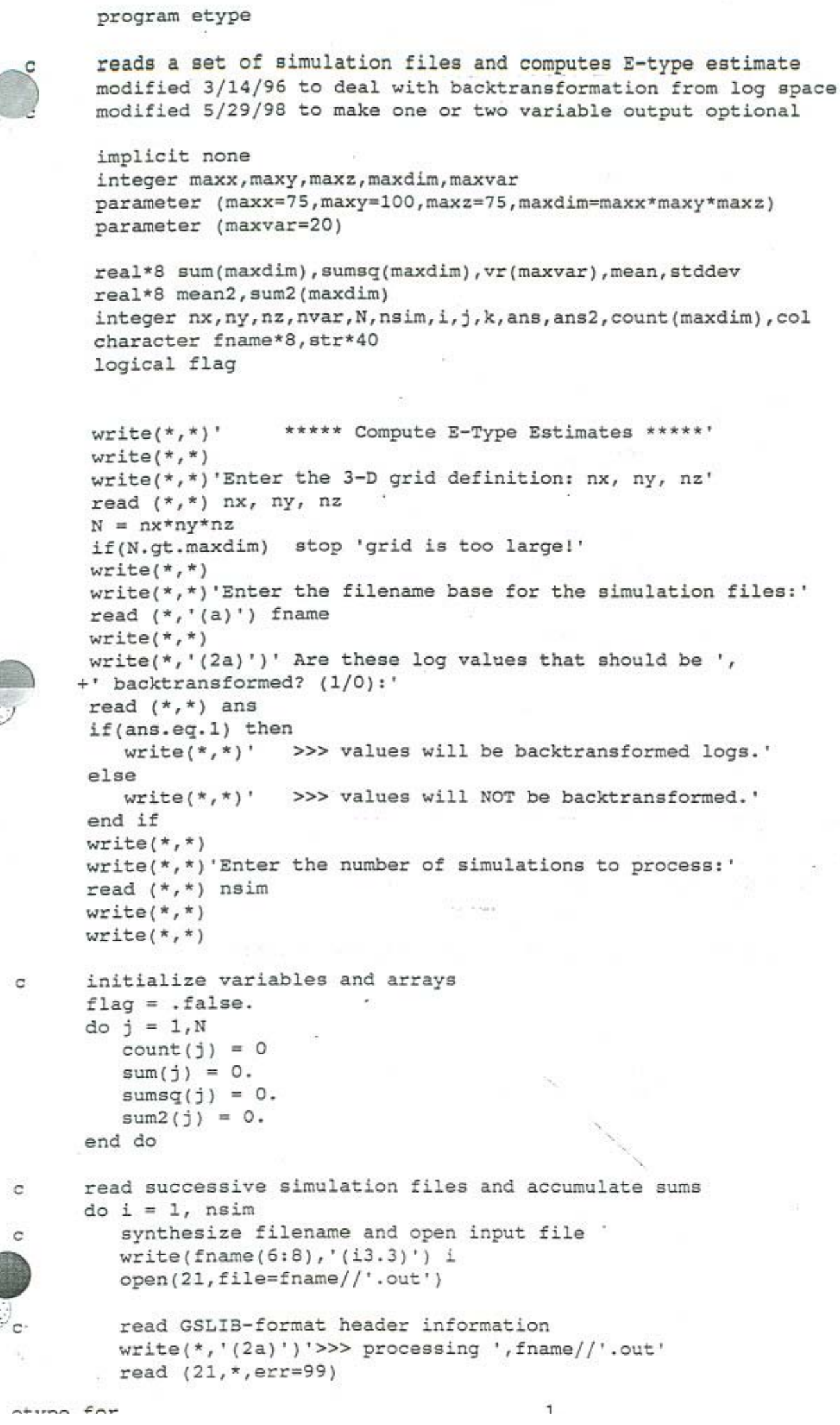


etype.for

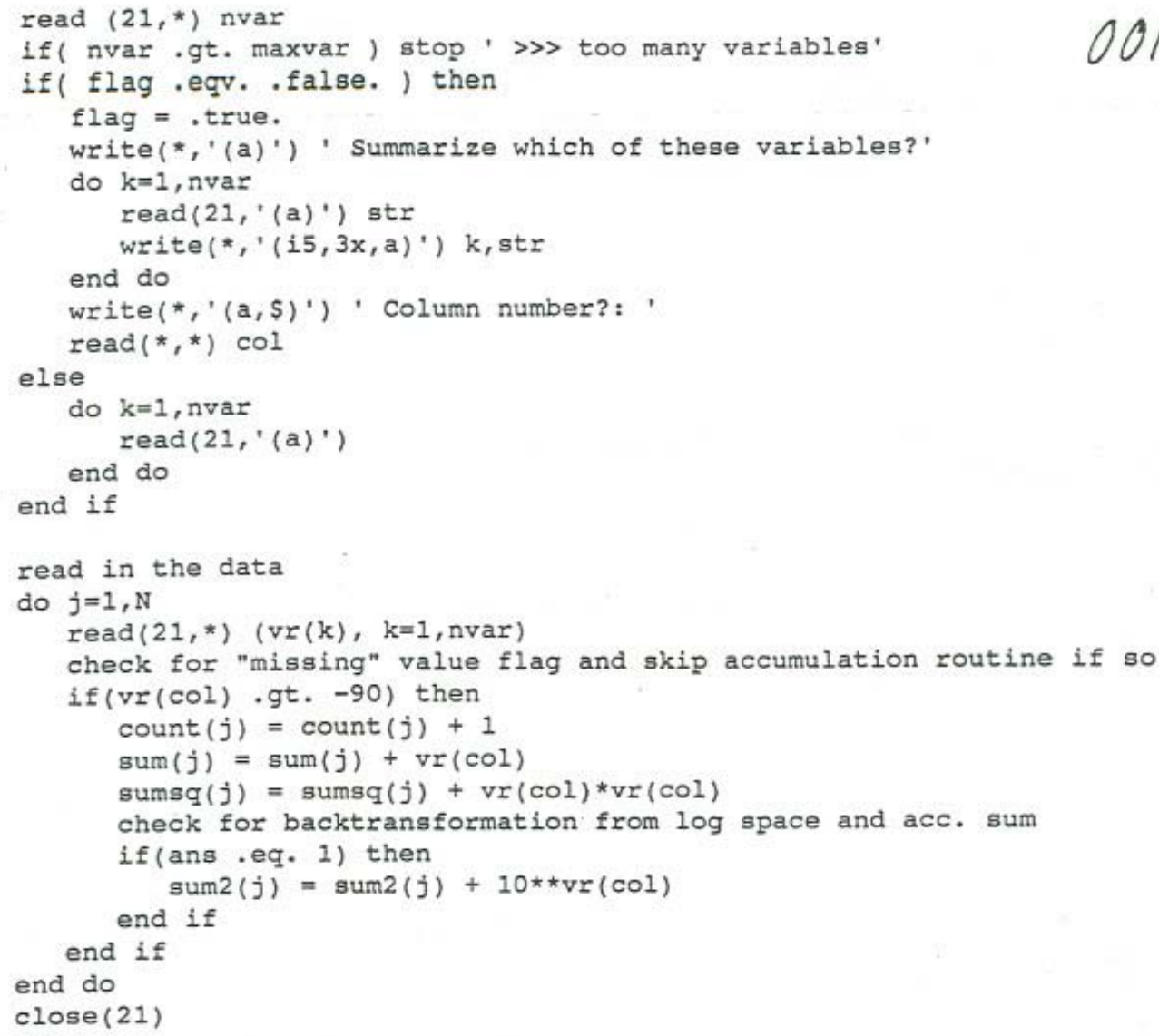




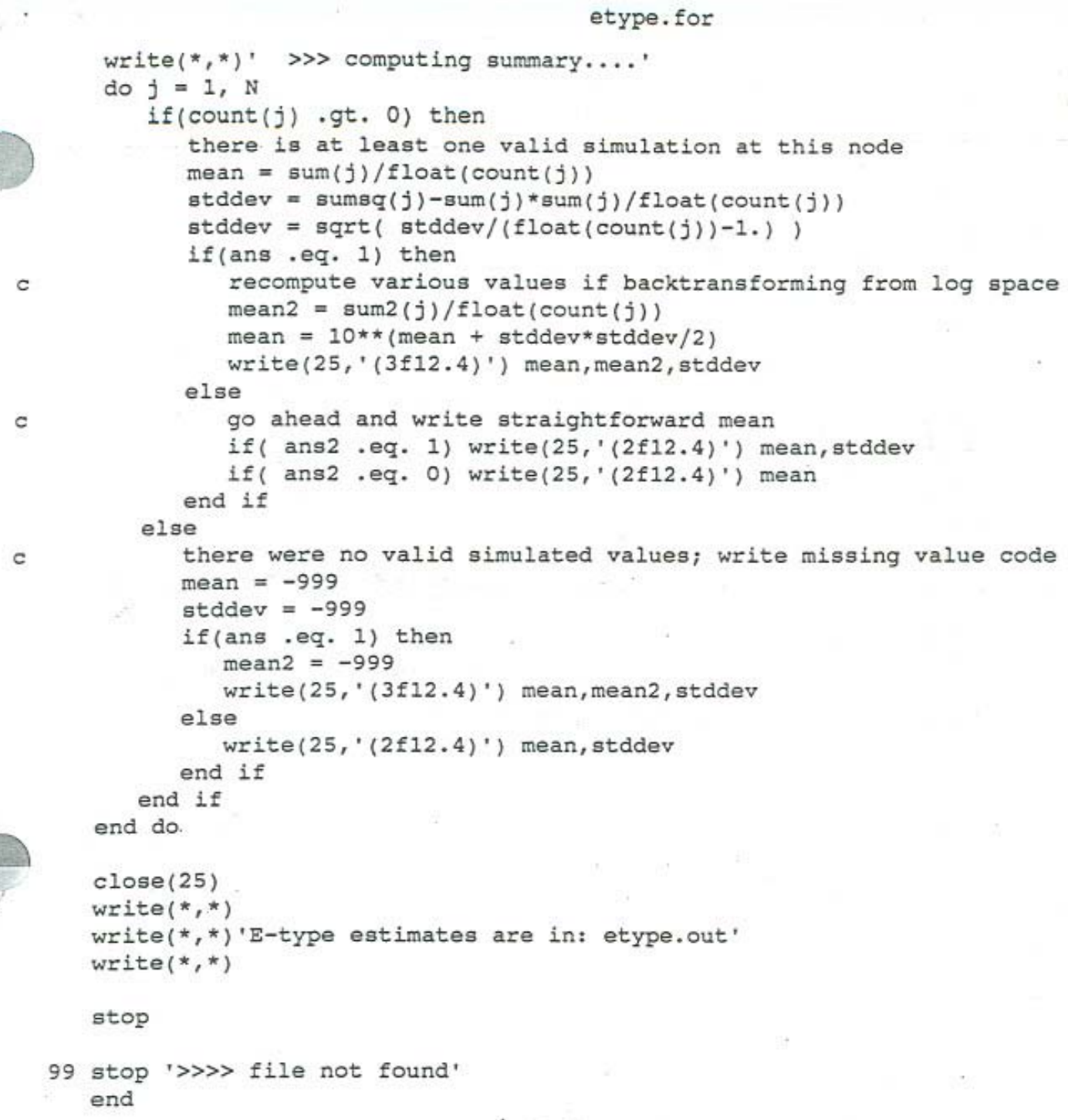




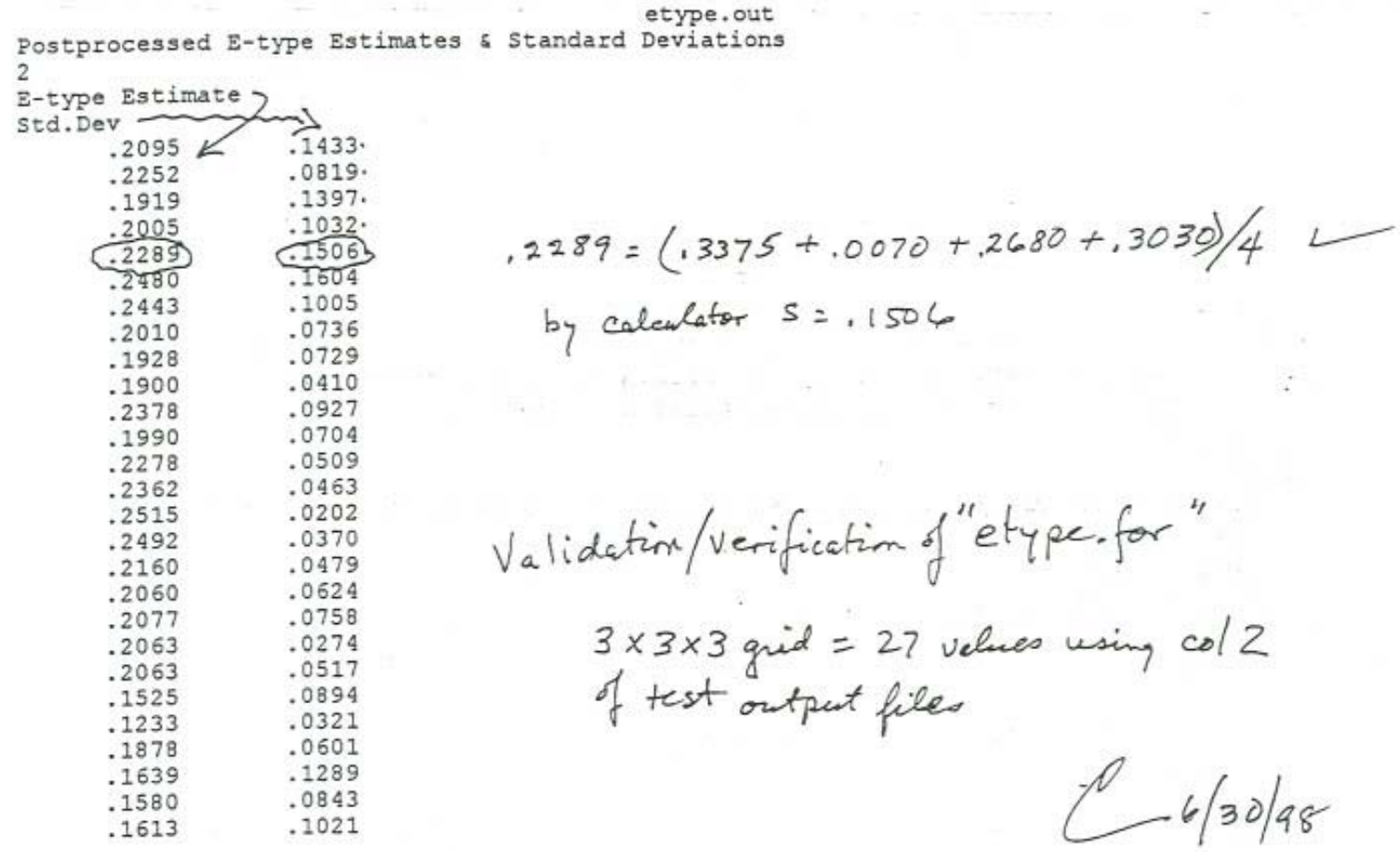




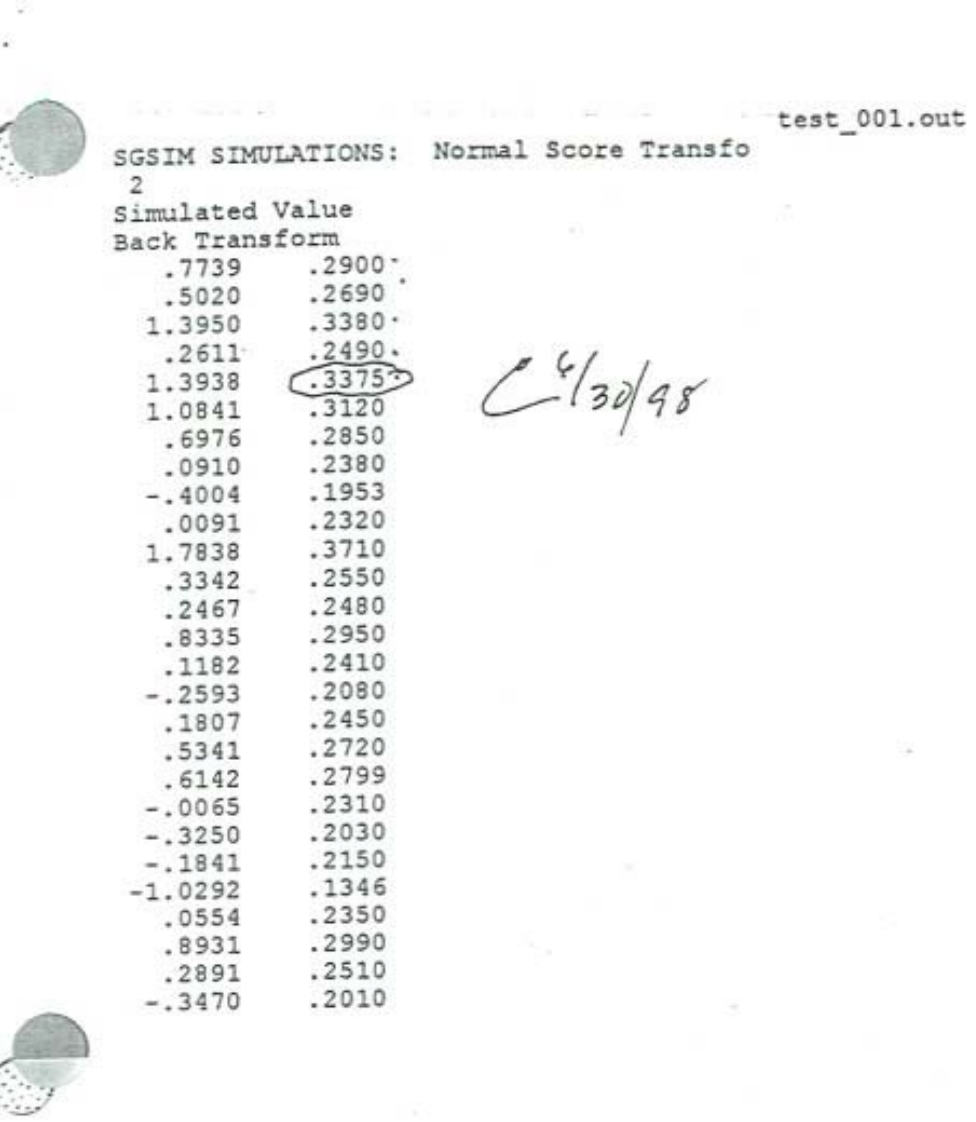




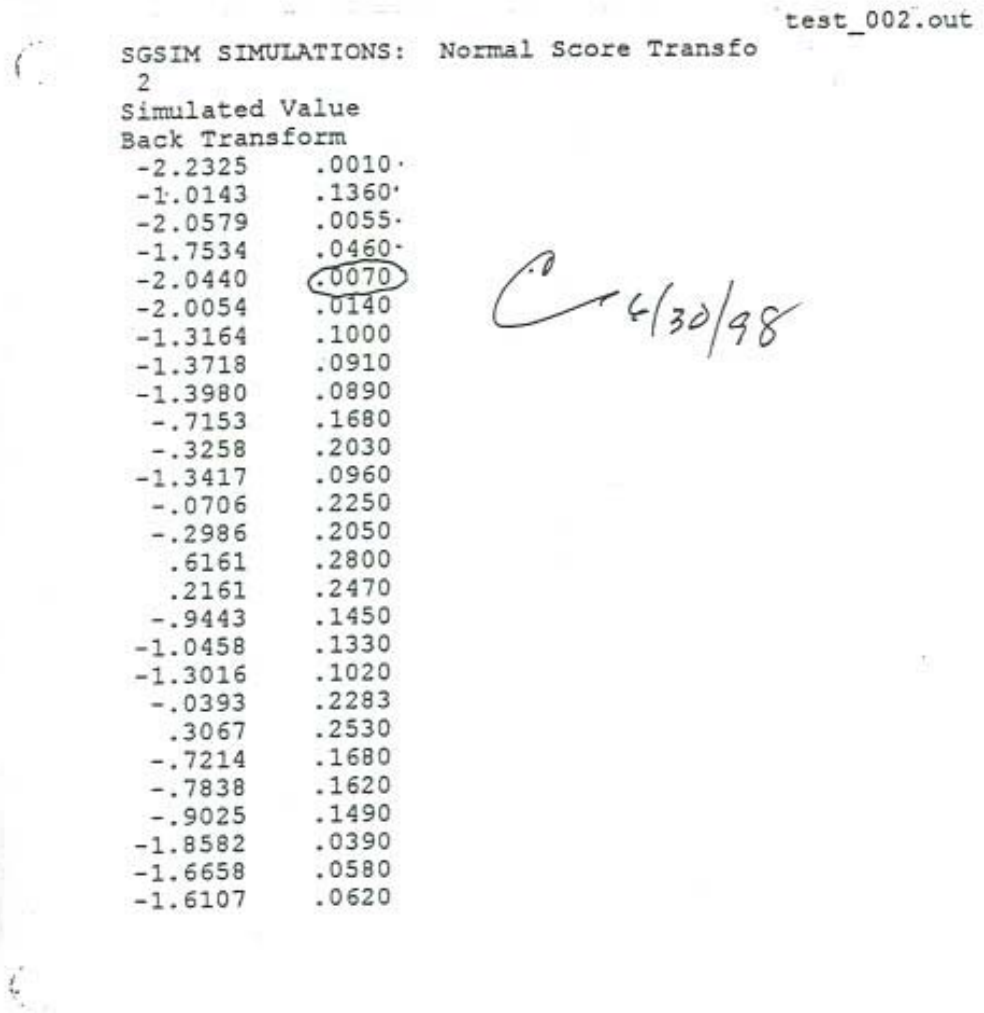




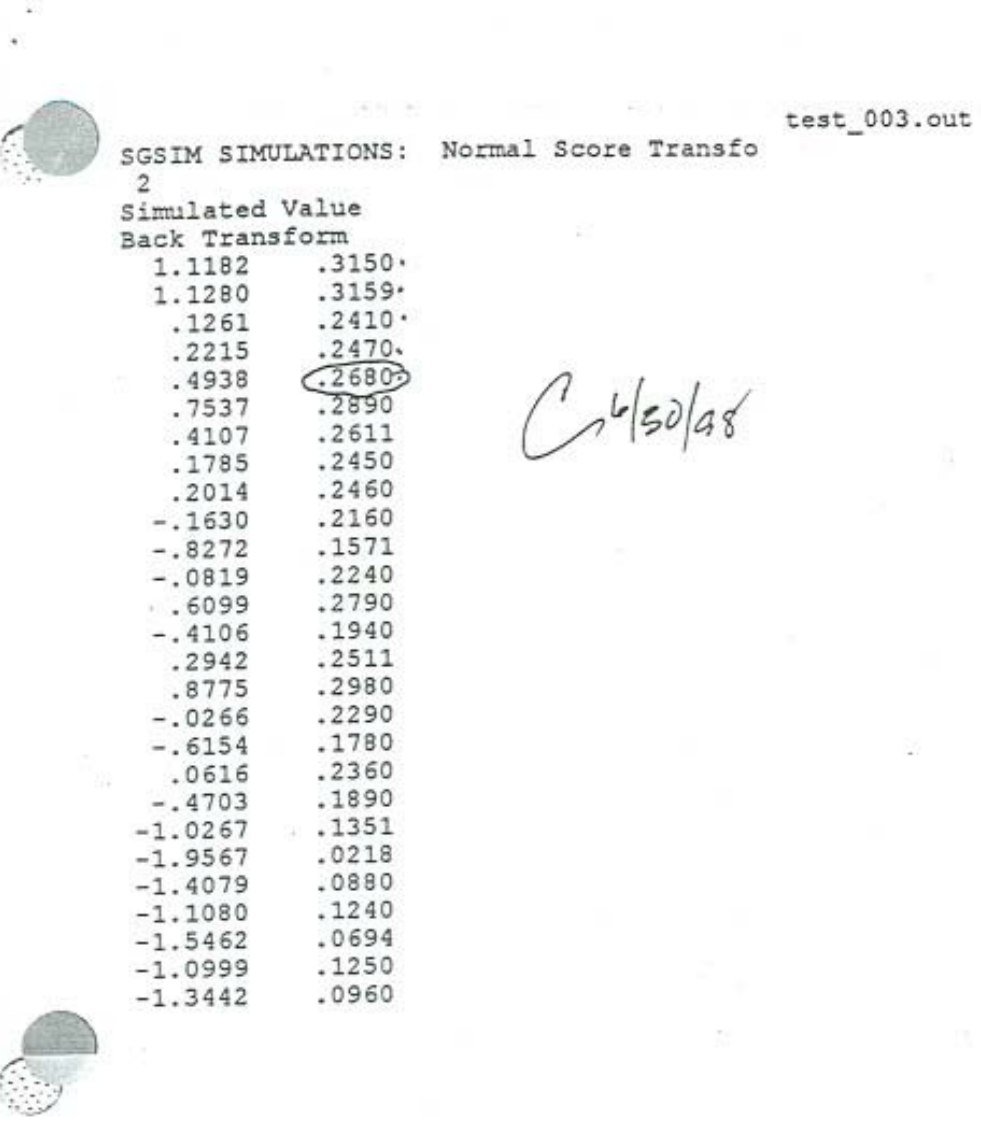




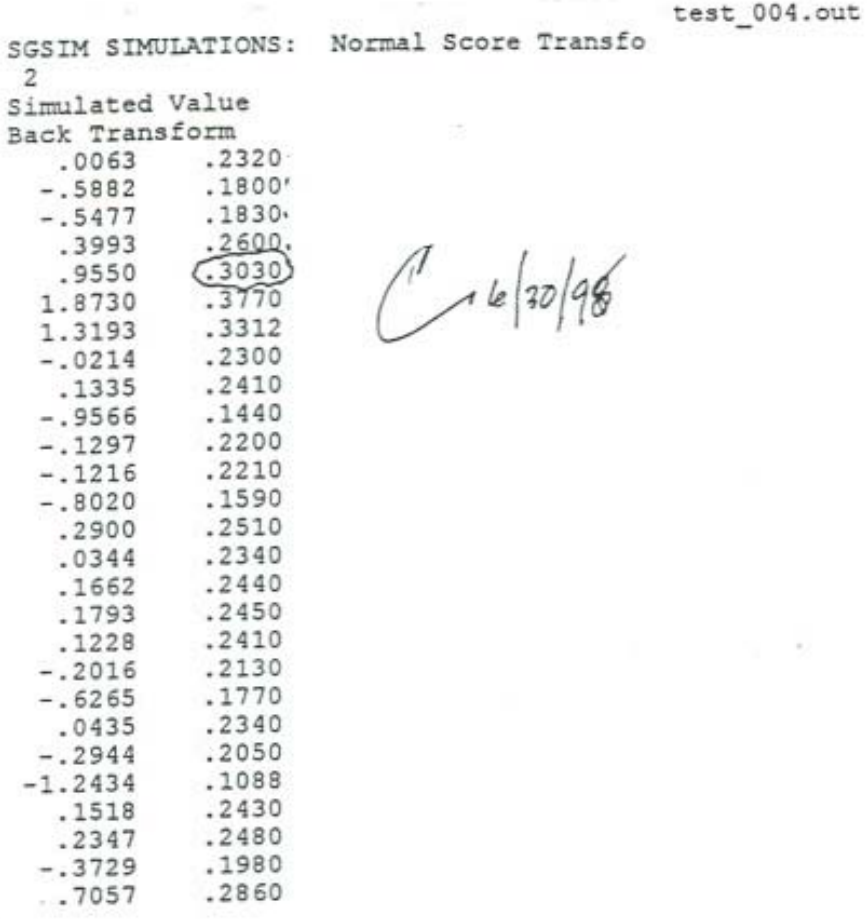




\section{I1.4 DOCUMENTATION OF THE DUPLICATION OF ETYPE ROUTINE TEST CASE RESULTS}

The following is a description of the ETYPE parameter file:

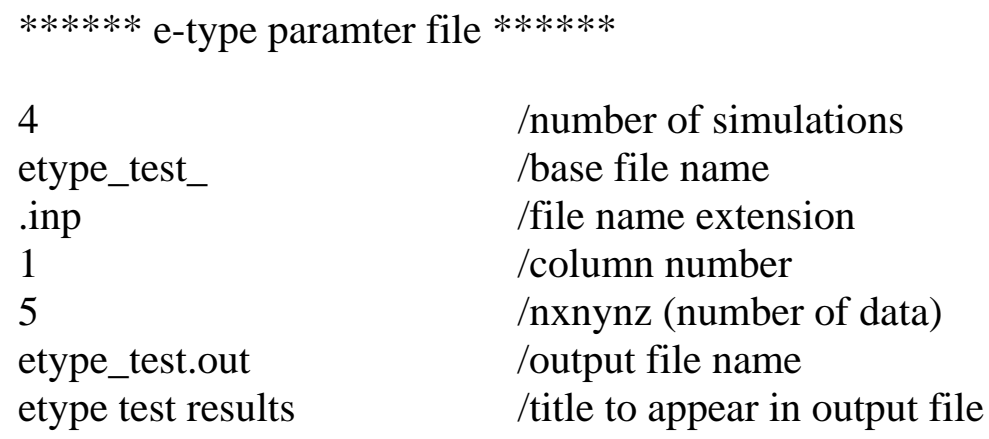

The parameter file was used to create the input test files 1 through 4 that duplicate the test case described on page 1138 of Geostatistical Modeling of Porosity and Derivative Properties for Fiscal Year 1998 (Rautman and McKenna 1998 [DIRS 107442]).

$\begin{array}{llll}\text { e-type test file \#1 } & \text { e-type test file \#2 } & \text { e-type test file \#3 } & \text { e-type test file \#4 } \\ 1 & 1 & 1 & 1 \\ \text { data \#1 } & \text { data \#1 } & \text { data \#1 } & \text { data \#1 } \\ 0.3375 & 0.007 & 0.2680 & 0.3030 \\ 0.3375 & 0.007 & 0.2680 & 0.3030 \\ 0.3375 & 0.007 & 0.2680 & 0.3030 \\ 0.3375 & 0.007 & 0.2680 & 0.3030 \\ 0.3375 & 0.007 & 0.2680 & 0.3030\end{array}$

The ETYPE test results are provided below:

etype test results

2

Mean

Standard Deviation

$0.229 \quad 0.151$

$0.229 \quad 0.151$

$0.229 \quad 0.151$

$0.229 \quad 0.151$

0.151

The test results documented on page 1138 of Geostatistical Modeling of Porosity and Derivative Properties for Fiscal Year 1998 provide a mean value of 0.2289 and a standard deviation of 0.1506 (Rautman and McKenna 1998 [DIRS 107442]). Therefore, the test results from the ETYPE routine documented in Rautman and McKenna and the baselined ETYPE (STN: 10731-2-2.01-00 [DIRS 159417]) are identical, with the exception that the baselined code provides results to three significant figures after the decimal point. 
In conclusion, this change in significant figures between the two versions of the code has no impact on the product output. The input parameters documented in Section 4.1 (porosity, bulk density, thermal conductivity, and mineral alteration indicators) all provide data with two significant figures after the decimal point. Therefore, calculation and ETYPE representation of product outputs as shown throughout the document are similarly restricted to two significant figures after the decimal point. Calculation of the mean value and standard to three rather than four significant figures after the decimal point has no impact on the product output or this comparison of the two versions of the code. 


\section{INTENTIONALLY LEFT BLANK}

